Software \& Systems

Programmnye produkty i sistemy

2018, vol. 31, no. 3
Print ISSN 0236-235X

Online ISSN 2311-2735

Программные продукты и системы

DOI 10.15827/0236-235X

$\begin{array}{llll}\text { / Создание оболочек } & / \text { Разработка } & \text { / Высокоуровневая } & \text { / Один из методов } \\ \text { интеллектуальных } & \text { драйверов } & \text { архитектура } & \text { обнаружения } \\ \text { сервисов } & \text { графической } & \text { тренажерно-обучающих } & \text { вредоносных } \\ & \text { подсистемы } & \text { систем } & \text { программ }\end{array}$

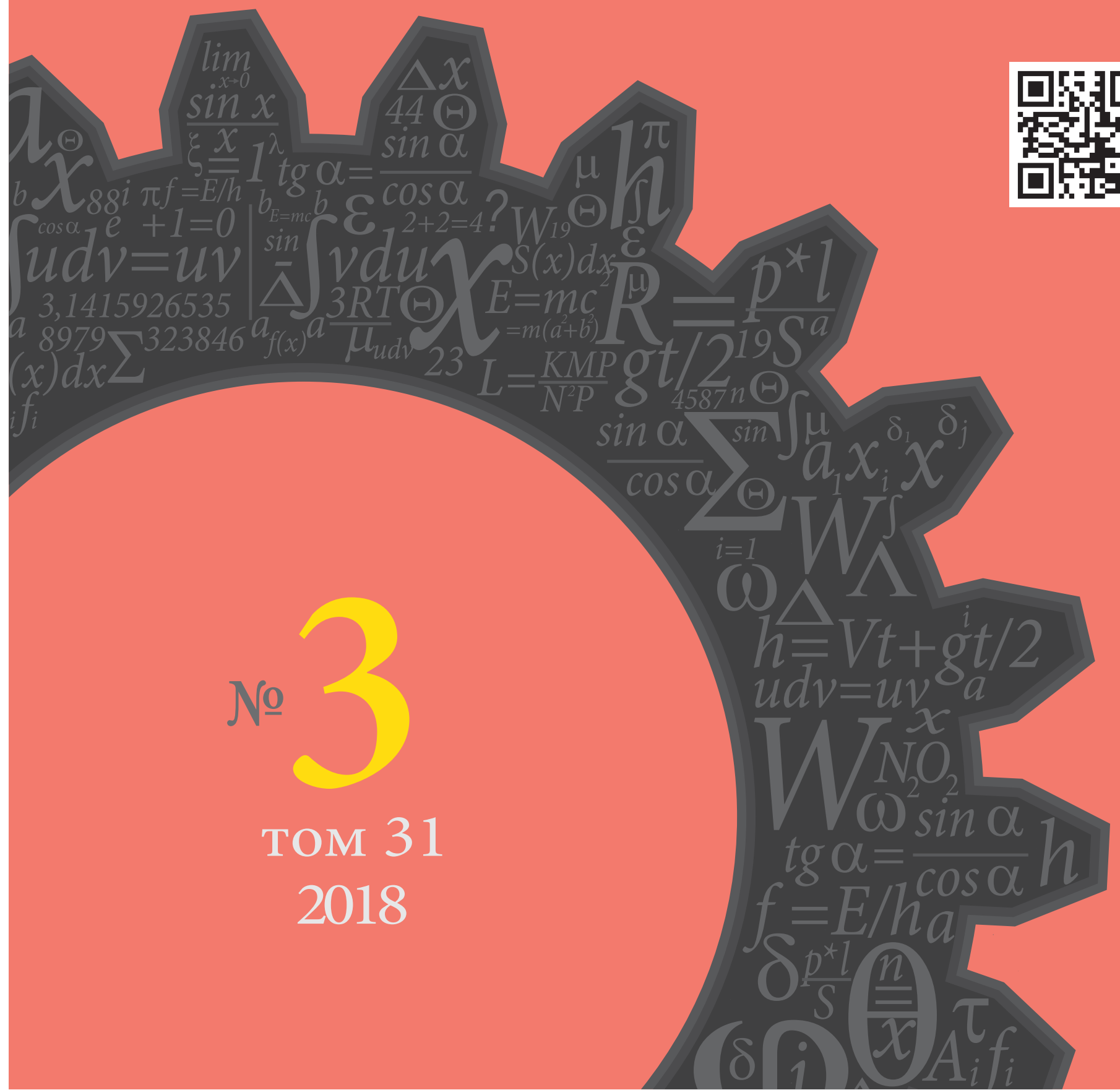




\section{Колонка научного редактора}

\section{Поздравляем с 75-летием}

Решетникова Валерия Николаевича, заместителя главного редактора нашего журнала, доктора физико-математических наук, профессора, заслуженного деятеля науки России, главного научного сотрудника НИИСИ РАН.

Решетников В.Н. является известным специалистом в области информатики, системного анализа, космических телекоммуникаций и связи. К числу главных результатов научной деятельности ученого следует отнести построенную им алгебраическую теорию информационного поиска, которая стала классическим средством и базовым инструментом исследования информационных процессов и систем обработки информации, открыла новые возможности в области построения и анализа поисковых алгоритмов, формирования требований к архитектуре вычислительно-коммуникационных сред. Полученные результаты в значительной степени определили развитие теории информационного поиска и формирование эффективных подходов к построению информационно-поисковых систем для различных приложений.

Одним из важных этапов научно-организационной деятельности Решетникова В.Н. является создание Центра визуализации и спутниковых информационных технологий НИИСИ РАН. Под его руководством и при непосредственном участии выполнены теоретические исследования и практические разработки по развитию методов визуализации и управления отображением информации в научных исследованиях, проведены работы по формированию и развитию концептуальных основ создания современных и перспективных систем космической связи.

Огромный педагогический талант и опыт В.Н. Решетникова успешно реализуются в процессе подготовки научных кадров и специалистов. Умение видеть перспективные направления исследований и разработок, чувствовать потребность в специалистах для этих целей воплотились в созданной им кафедре «Космические телекоммуникации» МАТИ - РГТУ им. К.Э. Циолковского, которая стала авторитетным учебно-методическим центром подготовки уникальных инженерных кадров.

Высокий профессионализм, преданность делу, жизненная мудрость, научная щедрость и доброжелательность снискали В.Н. Решетникову глубокое уважение коллег, признательность и благодарность учеников.

Редколлегия и коллектив редакции журнала искренне благодарят Валерия Николаевича за неоценимую поддержку и помощь и поздравляют с юбилеем. Желаем крепкого здоровья, бодрости духа, энергии, реализации новых идей!

В настоящем номере журнала опубликованы результаты научных исследований коллег и учеников профессора В.Н. Решетникова, развивающих сформированные им научные направления. Кроме того, традиционно представлены другие актуальные работы отечественных и зарубежных ученых и специалистов.

Семенов Н.А., Ә.т.н., профрессор

Сотников А.Н., д.фр.-м.н., профрессор Мамросенко К.А., к.т.н., доцент 


\section{Программные продукты и системы}

МЕЖДУНАРОДНЫЙ НАУЧНО-ПРАКТИЧЕСКИЙ ЖУРНАЛ

2018, том 31, № 3

(год издания тридцать первый)

Главный редактор

С.В. ЕМЕЛЬЯНОВ, академик РАН

Тверь

\section{SOFTWARE \& SYSTEMS}

(PROGRAMMNYE PRODUKTY I SISTEMY)

International research and practice journal

2018, vol. 31 , no. 3

Editor-in-Chief

S.V. EMELYANOV, Academician of the Russian Academy of Sciences 
(С ПРОГРАММНЫЕ ПРОДУКТЫ И СИСТЕМЫ

Международный научно-практический журнал

2018. T. 31. № 3

DOI: 10.15827/0236-235X.123

Главный редактор

С.В. ЕМЕЛЬЯНОВ

академик РАН (г. Москва, Россия)

Научные редакторы:

H.A. CEMEHOB, д.Т.Н., професссор ТвГТУ

(г. Тверь, Россия)

А.Н. СОТНИКОВ, д.ф.-м.Н., професссор МСЦ РАН

(г. Москва, Россия)

К.А. МАМРОСЕНКО, К.Т.Н., ДОцеНТ МАИ

(г. Москва, Россия)
Издатель НИИ «Центрпрограммсистем»

(г. Тверь, Россия)

Учредители: МНИИПУ (г. Москва, Россия),

Главная редакция международного журнала «Проблемы теории и практики управления» (г. Москва, Россия),

АОЗТ НИИ «Центрпрограммсистем» (г. Тверь, Россия)

Журнал зарегистрирован в Комитете Российской Федерации по печати 26 июня 1995 г.

Регистрационное свидетельство № 013831

Подписной индекс в каталоге

Агентства «Роспечать» 70799

ISSN 0236-235X (печатн.) ISSN 2311-2735 (онлайн)

\section{МЕЖДУНАРОДНАЯ РЕДАКЦИОННАЯ КОЛЛЕГИЯ}

Семенов H.A. - д.т.н., профессор Тверского государственного технического университета, заместитель главного редактора (г. Тверь, Россия)

Решетников В.Н. - д.ф.-М.н., профессор Московского авиационного института

(национального исследовательского университета), заместитель главного редактора (г. Москва, Россия)

Арефьев И.Б. - д.т.н., профессор Морской академии Польши (г. Щецин, Польша)

Афанасьев А.П. - д.ф.-М.Н., профессор Московского ффизико-технического института (технического университета),

заведующий Центром распределенных вычислений Института проблем передачи информации РАН (г. Москва, Россия)

Баламетов А.Б. - д.т.н., профессор Азербайджанского научно-исследовательского и проектно-изыскательского института

энергетики (г. Баку, Азербайджан)

Батыршин И.3. - д.Т.н., профессор Мексиканского института нефти (г. Мехико, Мексика)

Вагин В.Н. - д.Т.н., профессор Национального исследовательского университета «МЭИ» (г. Москва, Россия)

Голенков В.В. - д.Т.Н., профессор Белорусского государственного университета информатики и радиоэлектроники

(г. Минск, Беларусь)

Еремеев А.П. - Д.Т.н., профессор Национального исследовательского университета «МЭИ» (г. Москва, Россия)

Котов A.C. - кандидат наук, ассистент профессора университета Уэйна (штат Мичиган) (г. Детройт, США)

Кузнецов О.П. - Д.Т.н., профессор Института проблем управления РАН (г. Москва, Россия)

Курейчик В.М. - д.Т.н., профессор Инженерно-технологической академии Южного федерального университета

(г. Таганрог, Россия)

Лисецкий Ю.М. - к.Т.н., генеральный директор «S\&T Ukraine» (г. Киев, Украина)

Мамросенко К.А. - К.Т.н., доцент Московского авиационного института

(национального исследовательского университета), руководитель Центра визуализации и спутниковых информационных технологий НИИСИ РАН (г. Москва, Россия)

Мейер Б. - доктор наук, профессор, заведующий кафедрой Высшей политехнической школы - ЕТН (г. Цюрих, Швейцария)

Нгуен Тхань Нги - д.ф.-м.н., профессор, проректор Ханойского открытого университета (г. Ханой, Вьетнам)

Николов Р.В. - доктор наук, профессор Университета библиотековедения и информационных технологий Софии

(г. София, Болгария)

Осипов Г.С. - д.ф.-м.н., профессор, заместитель директора Института системного анализа РАН (г. Москва, Россия)

Палюх Б.В. - д.Т.н., профессор Тверского государственного технического университета (г. Тверь, Россия)

Рахманов А.А. - д.т.н., профессор, заместитель генерального директора Концерна «РТИ Системы» (г. Москва, Россия)

Серов В.C. - д.ф.-м.н., профессор Университета прикладных наук Оулу (г. Оулу, Финляндия)

Сотников А.H. - д.ф.-м.н., профессор, Межведомственный суперкомпьютерный центр РАН (г. Москва, Россия)

Сулейманов Д.Ш. - академик АН Республики Татарстан, д.т.н., профессор Казанского государственного

технического университета (г. Казань, Республика Татарстан, Россия)

Тарасов В.Б. - к.Т.н., доцент Московского государственного технического университета им. Н.Э. Баумана (г. Москва, Россия)

Таратухин B.В. - доктор философии, управляющий директор Европейского исследовательского центра

в области информационных систем (ERCIS) Вестфальского университета им. Вильгельма (г. Мюнстер, Германия)

Хорошевский В.Ф. - Д.Т.Н., профессор Московского физико-технического института (технического университета)

(г. Москва, Россия)

Язенин А.В. - д.ф.-М.н., профессор Тверского государственного университета (г. Тверь, Россия)

\section{АССОЦИИРОВАННЫЕ ЧЛЕНЫ РЕДАКЦИИ}

Национальный исследовательский университет «МЭИ», г. Москва, Россия

Технологический институт Южного федерального университета, г. Таганрог, Россия

Тверской государственный технический университет, г. Тверь, Россия

Научно-исследовательский институт «Центрпрограммсистем», г. Тверь, Россия

АДРЕС ИЗДАТЕЛЯ И РЕДАКЦИИ

Россия, 170024, г. Тверь, пр. 50 лет Октября, За

Телефон (482-2) 39-91-49

Факс (482-2) 39-91-00

E-mail: red@cps.tver.ru

Сайт: www.swsys.ru
Дата выхода в свет 28.08.2018 г. Отпечатано ООО ИПП «Фактор и К»

Россия, 170028, г. Тверь, ул. Лукина, д. 4, стр. 1

Выпускается один раз в квартал

Год издания тридцать первый. Формат 60×84 1/8. Объем 228 стр.

Заказ № 21. Тираж 1000 экз. Цена 330,00 руб. Автор статьи отвечает за подбор, оригинальность и точность приводимого фактического материала. Авторские гонорары не выплачиваются. При перепечатке материалов ссылка на журнал обязательна. 
2018, vol. 31, no. 3

DOI: $10.15827 / 0236-235 X .123$

Editor-in-chief

S.V. Emelyanov, Academician of the Russian Academy of Sciences (Moscow, Russian Federation)

Science editors:

N.A. Semenov, Dr.Sc. (Engineering), Professor TvSTU

(Tver, Russian Federation)

A.N. Sotnikov, Dr.Sc. (Physics and Mathematics), Professor JSCC RAS

(Moscow, Russian Federation)

K.A. Mamrosenko, Ph.D. (Engineering), Associate Professor

of Moscow Aviation Institute (National Research University)

(Moscow, Russian Federation)

\section{INTERNATIONAL EDITORIAL BOARD}

Semenov N.A. - Dr.Sc. (Engineering), Professor of Tver State Technical University, Deputy Editor-in-Chief (Tver, Russian Federation)

Reshetnikov V.N. - Dr.Sc. (Physics and Mathematics), Professor of Moscow Aviation Institute (National Research University), Deputy Editor-in-Chief (Moscow, Russian Federation)

Arefev I.B. - Dr.Sc. (Engineering), Professor of Poland Szczecin Maritime Academy (Szczecin, Poland)

Afanasiev A.P. - Dr.Sc. (Physics and Mathematics), Professor of Moscow Institute of Physics and Technology,

Head of Centre for Distributed Computing of Institute for Information Transmission Problems (Moscow, Russian Federation)

Balametov A.B. - Azerbaijan Scientific-Research \& Design-Prospecting Power Engineering Institute (Baku, Azerbaijan)

Batyrshin I.Z. - Dr.Sc. (Engineering), Professor of Mexican Petroleum Institute (Mexico City, Mexico)

Vagin V.N. - Dr.Sc. (Engineering), Professor of National Research University "Moscow Power Engineering Institute" (Moscow, Russian Federation)

Golenkov V.V. - Dr.Sc. (Engineering), Professor of Belarusian State University of Informatics and Radioelectronics (Minsk, Republic of Belarus)

Eremeev A.P. - Dr.Sc. (Engineering), Professor of National Research University "Moscow Power Engineering Institute"

(Moscow, Russian Federation)

Kotov A.S. - Ph.D. (Computer Science), Assistant Professor, Wayne State University (Detroit, MI, USA)

Kuznetsov O.P. - Dr.Sc. (Engineering), Professor of the Institute of Control Sciences of the Russian Academy of Sciences

(Moscow, Russian Federation)

Kureichik V.M. - Dr.Sc. (Engineering), Professor of Academy of Engineering and Technology Southern Federal University

(Taganrog, Russian Federation)

Lisetskiy Yu.M. - Ph.D.Tech.Sc., CEO of "S\&T Ukraine" (Kiev, Ukraine)

Mamrosenko K.A. - Ph.D. (Engineering), Associate Professor of Moscow Aviation Institute (National Research University),

Head of Center of Visualization and Satellite Information Technologies SRISA RAS (Moscow, Russian Federation)

Meyer B. - Dr.Sc., Professor, Head of Department in Swiss Federal Institute of Technology in Zurich, ETH

(Zurich, Switzerland)

Nguyen Thanh Nghi - Dr.Sc. (Physics and Mathematics), Professor, Vice-Principal of Hanoi Open University (Hanoi, Vietnam)

Nikolov R.V. - Full Professor of the University of Library Studies and Information Technology (Sofia, Bulgaria)

Osipov G.S. - Dr.Sc. (Physics and Mathematics), Professor, Deputy of the Principal of Institute of Systems Analysis

of the Russian Academy of Sciences (Moscow, Russian Federation)

Palyukh B.V. - Dr.Sc. (Engineering), Professor of Tver State Technical University (Tver, Russian Federation)

Rakhmanov A.A. - Dr.Sc. (Engineering), Professor, Deputy of the CEO of Concern "RTI Systems"

(Moscow, Russian Federation)

Serov V.S. - Dr.Sc. (Physics and Mathematics), Professor of the Oulu University of Applied Sciences (Oulu, Finland)

Sotnikov A.N. - Dr.Sc. (Physics and Mathematics), Professor, Joint Supercomputer Center of the Russian Academy

of Sciences (Moscow, Russian Federation)

Suleimanov D.Sh. - Academician of TAS, Dr.Sc. (Engineering), Professor of Kazan State Technical University

(Kazan, Republic of Tatarstan, Russian Federation)

Tarassov V.B. - Ph.D. (Engineering), Associate Professor of Bauman Moscow State Technical University

(Moscow, Russian Federation)

Taratoukhine V.V. - Ph.D. (Engineering), Dr.Ph., Managing Director of the Competence Centre ERP and ERCIS Lab

Russia of the ERCIS (Muenster, Germany)

Khoroshevsky V.F. - Dr.Sc. (Engineering), Professor of Moscow Institute of Physics and Technology

(Moscow, Russian Federation)

Yazenin A.V. - Dr.Sc. (Physics and Mathematics), Professor of Tver State University (Tver, Russian Federation)

ASSOCIATED EDITORIAL BOARD MEMBERS

National Research University "Moscow Power Engineering Institute", Moscow, Russian Federation

Technology Institute at Southern Federal University, Taganrog, Russian Federation

Tver State Technical University, Tver, Russian Federation

Research Institute CENTERPROGRAMSYSTEM, Tver, Russian Federation

EDITORIAL BOARD AND PUBLISHER OFFICE ADDRESS

50 let Oktyabrya Ave. 3a, Tver, 170024, Russian Federation

Phone: (482-2) 39-91-49 Fax: (482-2) 39-91-00

E-mail: red@cps.tver.ru

Website: www.swsys.ru
Release date 28.08.2018 Printed in printing-office "Faktor i K" Lukina St. 4/1, Tver, 170028, Russian Federation Published quarterly. 31th year of publication Format $60 \times 841 / 8$. Circulation 1000 copies Prod. order № 21. Wordage 228 pages. Price 330,00 rub. 


\section{Вниманию авторов}

Международный журнал «Программные продукты и системы» публикует материалы научного и научно-практического характера по новым информационным технологиям, результаты академических и отраслевых исследований в области использования средств вычислительной техники. Практикуются выпуски тематических номеров по искусственному интеллекту, системам автоматизированного проектирования, по технологиям разработки программных средств и системам защиты, а также специализированные выпуски, посвященные научным исследованиям и разработкам отдельных вузов, НИИ, научных организаций.

Решением Президиума Высшей аттестационной комиссии (ВАК) Министерства образования и науки РФ международный журнал «Программные продукты и системы» внесен в Перечень ведущих рецензируемых научных журналов и изданий, в которых должны быть опубликованы основные научные результаты диссертаций на соискание ученых степеней кандидата и доктора наук.

Информация об опубликованных статьях по установленной форме регулярно предоставляется в систему Российского индекса научного цитирования (РИНЦ), в CrossRef и в другие базы и электронные библиотеки.

\section{Условия публикации}

К рассмотрению принимаются ранее нигде не опубликованные материалы, соответствующие тематике журнала (специализация 05.13.XX - Информатика, вычислительная техника и управление) и отвечающие редакционным требованиям.

Работа представляется в электронном виде в формате Word. При обилии сложных формул обязательно наличие статьи и в формате PDF. Формулы должны быть набраны в редакторе формул Word (Microsoft Equation или MathTyре). Объем статьи вместе с иллюстрациями - не менее 10000 знаков. Диаграммы, схемы, графики должны быть доступными для редактирования (Word, Visio, Excel). Все иллюстрации для полиграфического воспроизведения представляются в черно-белом варианте. Цветные, тонированные, отсканированные, не подлежащие редактированию средствами Word рисунки и экранные формы следует присылать в хорошем качестве для их дополнительного размещения на сайте журнала в макете статьи с доступом по ссылке. (Публикация материалов с использованием гипертекста, графики, аудио-, видео-, программных средств и др. возможна в электронном издании «Программные продукты, системы и алгоритмы», сайт www.swsys-web.ru.) Заголовок должен быть информативным; сокращения, а также терминологию узкой тематики желательно в нем не использовать. Количество авторов на одну статью - не более 4, количество статей одного автора в номере, включая соавторство, - не более 2. Список литературы, наличие которого обязательно, должен включать не менее 10 пунктов.

Необходимы также содержательная структурированная аннотация (не менее 250 слов), ключевые слова (7-10) и индекс УДК. Название статьи, аннотация и ключевые слова должны быть переведены на английский язык (машинный перевод недопустим), а фамилии авторов, названия и юридические адреса организаций (если нет официального перевода), пристатейные списки литературы - транслитерированы по стандарту BGN/PCGN.

Вместе со статьей следует прислать сопроводительное письмо-рекомендацию в произвольной форме, экспертное заключение, лицензионное соглашение, а также сведения об авторах: фамилия, имя, отчество, название и юридический адрес организации, должность, ученые степень и звание (если есть), контактный телефон, электронный адрес, почтовый адрес для отправки бесплатного авторского экземпляра журнала.

\section{Порядок рецензирования}

Все статьи, поступающие в редакцию (соответствующие тематике и оформленные согласно требованиям к публикации), подлежат обязательному рецензированию в течение месяца с момента поступления.

В редакции есть устоявшийся коллектив рецензентов, среди которых члены международной редколлегии журнала, эксперты из числа крупных специалистов в области информатики и вычислительной техники ведущих вузов страны, а также ученые и специалисты НИИ «Центрпрограммсистем» (г. Тверь).

Рецензирование проводится конфиденциально. Автору статьи предоставляется возможность ознакомиться с текстом рецензии. При необходимости статья отправляется на доработку.

Рецензии обсуждаются на заседаниях рабочей группы, состоящей из членов научного совета журнала. Заседания проводятся раз в месяц в НИИ «Центрпрограммсистем» (г. Тверь), где принимается решение о целесообразности публикации статьи.

Статьи, одобренные редакционным советом, публикуются бесплатно в течение года с момента одобрения, а отправленные на доработку - в течение года с момента поступления после устранения замечаний.

Редакция международного журнала «Программные продукты и системы» в своей работе руководствуется сводом правил Кодекса этики научных публикаций, разработанным и утвержденным Комитетом по этике научных публикаций (Committee on Publication Ethics - COPE). 


\title{
Методы разработки драйверов графической подсистемы
}

\author{
И.A. Eфремов 1, программист, efremov@niisi.ras.ru \\ K.A. Мамросенко 1, к.т.н., руководительЦентра, mamrosenko_k@niisi.ras.ru \\ B.H. Решетников 1, д.фр.-м.н., профессор, главный научный сотрудник, rvn_@mail.ru \\ 1 Центр визуализаиии и спутниковых информаиионных технологий ФНЦ НИИСИ РАН, \\ 2. Москва, 117218, Россия
}

В статье описаны проблемы разработки ПО для задач взаимодействия систем на кристалле и ОC Linux. Архитектурой ОС предусмотрено создание драйвера - компонента, обеспечивающего прием и передачу данных устройства с использованием программного интерфейса. Разработка драйверов для ОС с открытым исходным кодом затрудняется из-за непрерывных изменений функций и структуры ядра.

Описаны структура и составные части графической подсистемы, представляющей собой набор компонентов, находящихся в разных адресных пространствах доступа виртуальной памяти ОС и взаимодействующих между собой, в том числе посредством интерфейса системных вызовов. Программирование графического ядра выполняется при помощи заполнения буфера команд: для каждого приложения создается контекст графического ядра, содержащий свой командный буфер и все необходимые данные, используемые графическим ядром для отрисовки/расчетов, - координаты, векторы нормали, цвета, текстуры.

Существуют несколько подходов к установке графического режима, однако наиболее оправданным решением является применение модуля KMS (Kernel Mode Setting), который используется ключевыми производителями микропроцессоров и графических карт. Для полной реализации возможностей графического ядра необходимо обеспечить взаимодействие модулей ядра ОС и пространства пользователя посредством создания собственных системных вызовов, регламентирующих низкоуровневую работу с устройством.

Применение платформ прототипирования на основе FPGA-матриц позволяет проверить работоспособность ПО, получить некоторые характеристики производительности и выявить ошибки в системе на кристалле на ранних стадиях проектирования. Отладка модулей ядра занимает значительное время в силу ограничений, накладываемых со стороны как платформы для прототипирования, так и ОС. Кроме того, ошибки, возникающие в коде ядра, трудновоспроизводимы, что также затрудняет отладку модулей ядра.

В статье рассмотрены подходы к реализации KMS-модуля и компонентов графической подсистемы OC Linux, которые позволяют обеспечить корректное взаимодействие ОС и контроллера вывода на экран системы на кристалле.

Ключевые слова: графическое ядро, драйвер, Lіпих, СнК, разработка, модуль ядра.

В настоящее время одной из задач микроэлектроники является создание систем на кристалле (СнК) с существенными ограничениями по тепловыделению и энергопотреблению [1]. Проектирование СнК включает в себя разработку ПО для решения задач взаимодействия оборудования и OC [2]. Работа с трехмерной графикой в реальном масштабе времени, как правило, требует наличия графического ядра в СнК.

Архитектурой ОС предусмотрено создание компонента - драйвера, обеспечивающего прием и передачу данных устройства с использованием программного интерфейса [3]. При разработке драйверов для ОС с открытым исходным кодом, например, для ядра OC Linux, возможно возникновение определенных трудностей из-за непрерывных изменений функций и структуры ядра [4]. Кроме того, количество источников информации по данному вопросу, находящихся в открытом доступе, невелико.

В настоящей статье приведены методы разработки драйверов графической подсистемы, обеспечивающих и установку графического режима отображения, рассмотрены проблемы, связанные с отладкой модулей ядра.

\section{Графическая подсистема OC Linux}

Обработку 3D-графики обеспечивает графическая подсистема (или графический стек) OC Linux [5]. Графический стек представляет собой набор компонентов, находящихся в разных адресных пространствах доступа виртуальной памяти ОС и взаимодействующих между собой посредством интерфейса системных вызовов [6] (рис. 1).

В пользовательском пространстве на верхнем уровне набор функций и их поведение описаны спецификацией OpenGL (Open Graphics Library). Свободную реализацию графического API (Application Programming Interface) OpenGL в OC Linux представляет библиотека Mesa 3D, включающая в себя набор драйверов 3D-графики в пользовательском пространстве. Библиотека Mesa реализует независимый от поставщиков драйверов кроссплатформенный стандартный API-интерфейс для взаимодействия с графическими ускорителями различных производителей.

Библиотека libdrm реализует интерфейс DRM в пространстве пользователя, применяя системные вызовы ioctl [7]. Для обеспечения взаимодействия модуля высокого уровня OpenGL и библиотеки 


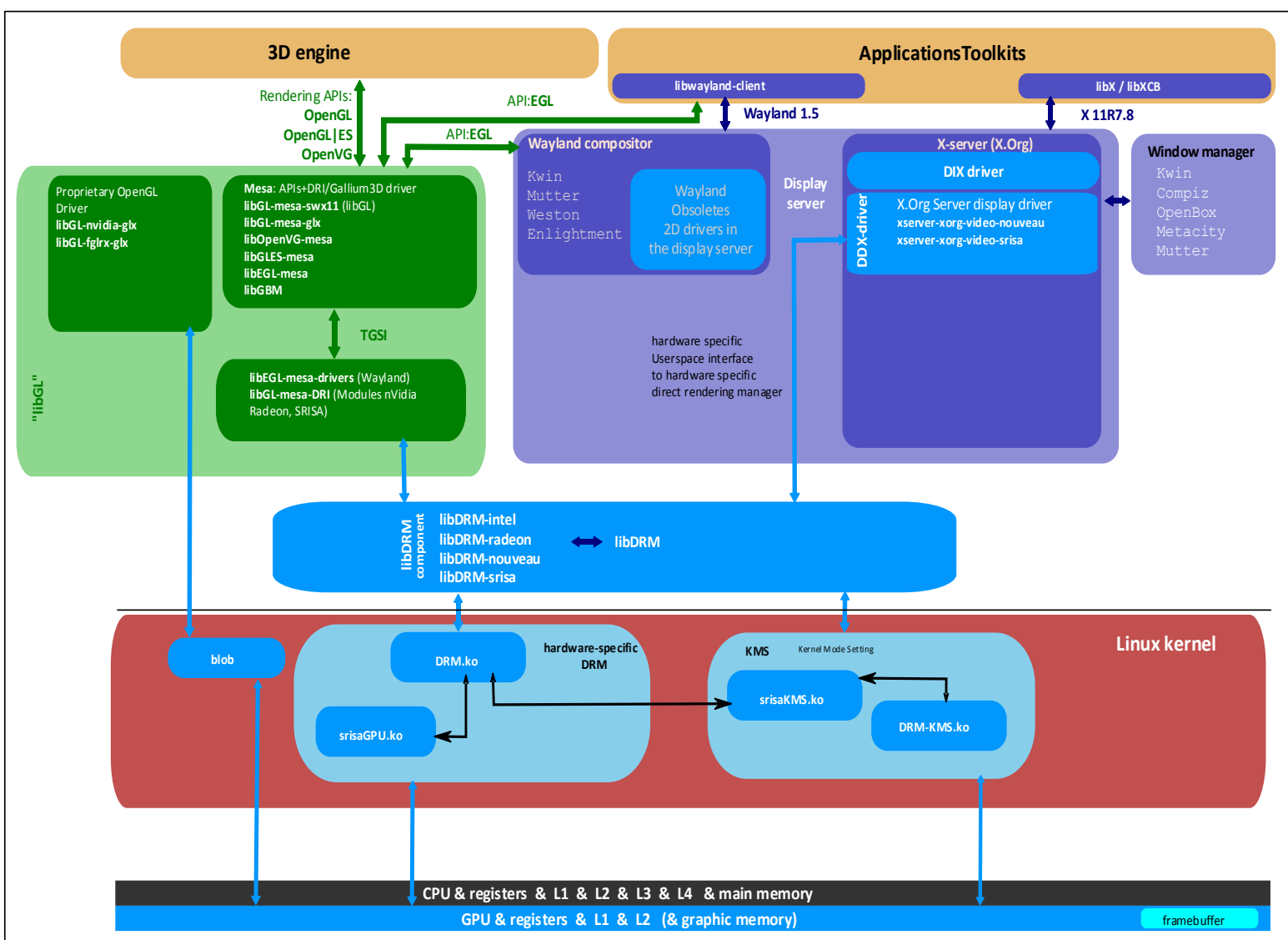

Рис. 1. Компоненты графического стека ОC Linux

Fig. 1. Components of OS Linux graphics stack

libdrm может быть использована библиотека создания драйверов Gallium3D.

Gallium3D является частью Mesa и направлен на упрощение разработки драйверов 3D-графики. Наличие Gallium3D API подразумевает использование TGSI (Tungsten Graphics Shader Infrastructure), являющегося промежуточным представлением описания шейдеров.

После предварительной обработки входящих данных в библиотеке OpenGL, включающих информацию об объектах прорисовки и шейдерных подпрограммах, производится преобразование данных в промежуточный байт-код. На этом этапе также осуществляется оптимизация операций, выполняемых в шейдерных программах, например, разворачивание циклов обработки. Далее сгенерированный байт-код передается в компилятор, преобразующий его в машинные инструкции, предназначенные для конкретного графического процессора, а также формирующий буфер команд. Программирование графического ядра выполняется при помощи заполнения буфера команд: для каждого приложения создается контекст графического ядра, содержащий свой командный буфер и все необходимые данные, используемые графическим ядром для отрисовки/расчетов, - координаты, векторы нормали, цвета, текстуры. Графическое ядро не располагает собственной памятью, поэтому буферы формируются в системной памяти.

Драйвер должен поддерживать многопоточное использование, где на каждый поток выделяются один буфер контекста и один буфер команд. За счет наличия только одного буфера команд синхронизация требуется лишь на момент передачи буфера в графическое ядро. На момент заполнения буфера она не требуется. Правильное выставление контекста в ядре для каждого потока должно гарантироваться драйвером графической подсистемы. Также определяются доступные операции для выполнения на конкретной модели графического процессора, ограничения для входящих данных, например, поддерживаемые форматы сжатия текстур.

В пространстве ядра модуль Direct Rendering Manager (DRM) предоставляет API, который используют программы пользовательского пространства для отправки команд и данных графическому ядру и настройки некоторых параметров режима отображения. DRM предоставляет только базовую функциональность, с которой могут работать различные драйверы, а также снабжает пользовательское пространство неким минимальным набором системных вызовов input output control (ioctl) с общей, независимой от оборудования функциональностью. 
Существуют несколько подходов к установке графического режима. Установка графических режимов из пользовательского пространства (User Mode-Setting) имеет проблемы:

- неоднократная инициализация оборудования (BIOS, framebuffer и X-сервер);

- некорректное отображение при переключениях между виртуальными консолями и экземплярами X-сервера и в процессе загрузки;

- дублирование кода драйвера (fbdev и драйверов графики для X-сервера).

Решением данных проблем является использование модуля KMS (Kernel Mode Setting) [8]. Драйвер контроллера вывода на экран DC (Display Controller) находится в пространстве ядра Linux и также должен включать функционал KMS-модуля.

\section{Kernel Mode Setting}

Ioctl обычно используются для выполнения над устройством некоторых специфических (управляющих) действий, которые не обеспечиваются регулярными POSIX-вызовами $(\operatorname{read}(), w r i t e(), \operatorname{lseek}()$ и др.) [9]. Часто это могут быть действия, зависящие от конкретных аппаратных особенностей реализации устройства. Для использования возможностей графического ядра в полном объеме необходимо обеспечить взаимодействие модулей ядра ОС и пространства пользователя посредством создания собственных системных вызовов, регламентирующих низкоуровневую работу с устройством (ioctl). На данный момент наиболее актуально применение KMS API для установки графического режима на контроллере вывода на экран. Данное АРI используется ключевыми производителями микропроцессоров и графических карт.

При построении KMS-модуля необходимы инициализация структур из KMS API, а также установление связей между блоками модуля. DRM-коннектор представляет собой совокупность структур и функций, которые необходимо реализовать в собственном драйвере. Коннектор обеспечивает получение данных от подключенного дисплея и проверку корректности задаваемых графических режимов.

Кадровый буфер (Frame buffer) служит источником данных для дисплей-контроллера. Он представляет собой объекты памяти (memory objects), которые передаются конвейеру отображения CRTC для вывода на экран (рис. 2).

Плоскость (plane) содержит информацию о параметрах изображения и ссылку на дополнительный кадровый буфер. Плоскость передается в CRTC для объединения изображения основного кадрового буфера с изображением дополнительного буфера. CRTC представляет собой общий конвейер отображения, принимая данные пикселей из плоскостей и смешивая их вместе, а также регла-

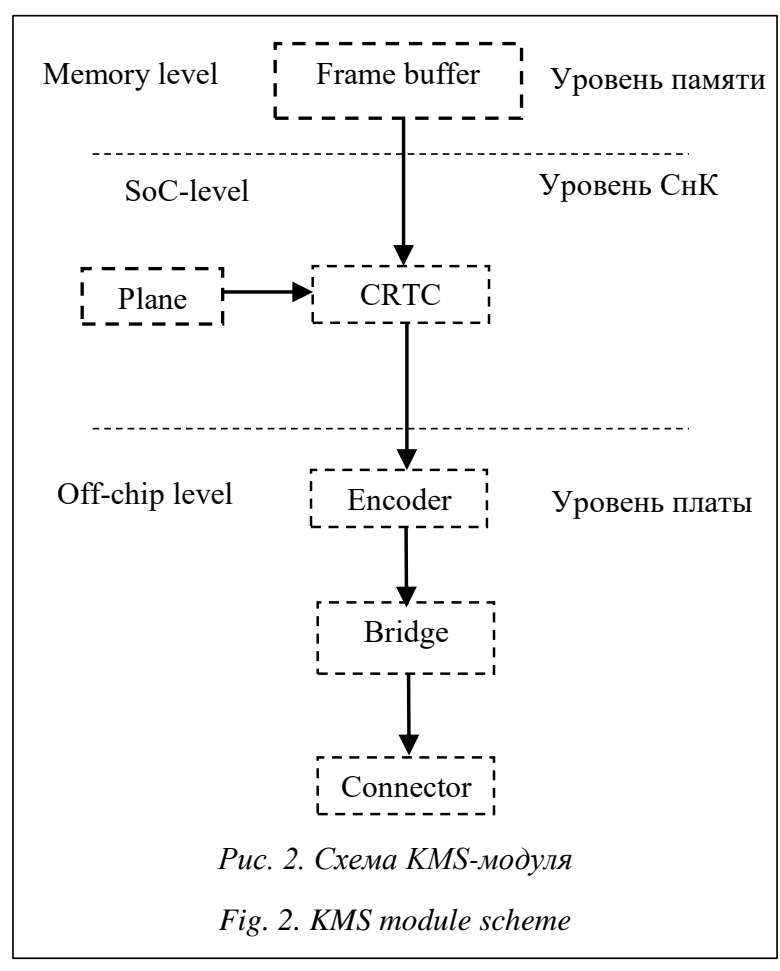

ментируя временные интервалы отображения (display timing).

Графический контроллер не располагает собственной памятью, поэтому буферы формируются в системной памяти. Менеджер графической памяти (GEM) управляет выделением памяти, чтением и записью в буферы. Системные вызовы, являющиеся частью драйвера, обеспечивают создание объектов памяти. Более того, фактически создание буфера для драйверов, использующих GEM, выполняется с помощью специфичного для драйвера ioctl - GEM имеет только общий интерфейс для совместного использования и уничтожения объектов. Для задач, не требующих всей гибкости работы с памятью, например, выделение кадровых буферов для KMS, применяется API для работы с dumb-буферами. Буферы связываются в список, который автоматически опрашивается контроллером на наличие новых буферов.

Энкодер (encoder) является преобразователем изображения в требуемый выходной формат, например, цифровой или аналоговый. На сегодняшний день использование энкодеров считается устаревшим подходом, вместо них рекомендуется применять компоненты bridge. Основное отличие bridge от энкодера - недоступность из пространства пользователя.

В настоящее время рекомендуется применять атомарный подход к установке графического режима. В отличие от применяемого ранее транзакционного подхода атомарный подход обеспечивает возможность проверки корректности режимов работы без изменения состояния аппаратных средств. При атомарном подходе общее состояние драйвера определяется состоянием трех компонентов 
$\mathrm{KMS}$-модуля с использованием структур состояний: drm_plane_state,drm_crtc_state и drm_connector_state. Структура drm_atomic_state - глобальное состояние объекта для атомарных обновлений, включает в себя эти структуры состояний.

\section{Файл описания аппаратной части}

В OC Linux предусмотрена возможность создания .dts-файла (Device Tree Source). Преимущество использования dts-файла в том, что разработчику модулей ядра не требуется перекомпилировать ядро для различных платформ, содержащих СнК. Файл описания используемой архитектуры и блоков СнК dtsi представлен в виде дерева узлов и служит в основном для предоставления информации ядру ОС. Разработчик, предоставляя дерево устройств, делает возможным более широкую поддержку различных конфигураций оборудования в рамках архитектурной линейки СнК.

Файлы дерева устройств могут быть разделены на несколько частей в нескольких файлах. Файлы уровня платы dts включают в себя dtsi-файлы, описывающие уровень СнК. При создании нового дерева устройств для аппаратной платформы необходимо полностью описывать свойства устройства. Файл дерева устройств хранит и данные о свойствах подключения коннектора видеоинтерфейса.

\section{Отладка модулей ядра}

В настоящее время разработка и отладка драйверов зачастую происходят параллельно с разработкой СнК. Как правило, в этих целях используют платформы прототипирования на основе FPGAматриц. Платформы прототипирования позволяют проверить работоспособность ПО, получить некоторые характеристики производительности и выявить ошибки в СнК на ранних стадиях производства [10].

Однако даже при использовании современных программных и аппаратных средств отладка модулей ядра занимает значительное время из-за ограничений, накладываемых и платформой для прототипирования (тактовая частота, длительное время сборки проекта прошивки), и модулями ядра (многие ядерные механизмы принципиально существуют только во временных зависимостях и не могут быть приостановлены). Кроме того, ошибки, возникающие в коде ядра, трудновоспроизводимы, что также затрудняет отладку модулей ядра.

Запуск тестовых приложений с трехмерной графикой происходит с использованием моделирующего комплекса, зачастую не имеющего модуля вывода на экран. В таком случае для проверки корректности визуализации используется сохранение содержимого кадрового буфера в файлы. Для этого на этапе инициализации тестовой программы ис- пользуется флаг EGL_PBUFFER_BIT - он дает возможность установить конфигурацию системы, не требующей использования физического дисплея для вывода изображения и позволяющей прорисовывать изображения в системную память.

\section{Заключение}

При проектировании СнК необходим комплексный подход, учитывающий особенности платформ прототипирования и архитектуру графической подсистемы ОС. Поддержка разрабатываемого ПО в течение всего жизненного цикла СнК является необходимым процессом в условиях изменения архитектуры ядра ОС с открытым исходным кодом. Поддержка трехмерной графики требует от разработчика ПО построения согласованной графической подсистемы с набором компонентов, находящихся в различных адресных пространствах доступа виртуальной памяти ОС. Создание модулей графической подсистемы OC Linux - актуальная и трудоемкая задача, которой в настоящее время посвящается все больше работ в открытой печати. Однако требуются новые инструменты разработки и отладки. В настоящее время отладка модулей ядра занимает значительное время из-за ограничений со стороны ОС и средств прототипирования.

Рассмотренные подходы к реализации KMS-модуля и компонентов графической подсистемы ОС Linux позволяют обеспечить корректное взаимодействие ОС и контроллера вывода на экран СнК. Планируются внедрение новой функциональности KMS-модуля, а также разработка драйверов пользовательского пространства.

\section{Лumepamypa}

1. Бобков С.Г. Высокопроизводительные вычислительные системы. М.: Изд-во НИИСИ РАН, 2014. 296 с.

2. Aryashev S.I., Rogatkin B.Y., Barskikh M.E. Modern methods of functional verification of rtl units of VLSI microprocessor // Проблемы разработки перспективных микро- и наноэлектронных систем МЭС. 2015. № 2. С. 119-122 (англ.).

3. Решетников В.Н. Космические телекоммуникации. Системы спутниковой связи и навигации. СПб: Ленинградское изд-во, 2010. 132 с.

4. Гиацинтов А.М., Баженов П.С. Визуализация виртуальных трехмерных сцен на однокристальных системах // Программные продукты, системы и алгоритмы. 2017. № 3. URL: http://swsys-web.ru/virtual-three-dimensional-scenes-on-singlechip-systems.html (дата обращения: 20.04.18).

5. Лав Р. Разработка ядра Linux. СПб: Вильямс, 2006. $448 \mathrm{c}$.

6. Venkateswaran S. Essential Linux Device Drivers. Prentice Hall, 2008, $714 \mathrm{c}$.

7. The Linux kernel documentation. URL: https://www.kernel.org/doc/html/v4.11/gpu/drm-kms.html (дата обращения: 20.04.2018).

8. Madieu J. Linux device drivers development. Packt Publishing Ltd, 2017, $586 \mathrm{c}$.

9. Bovet D.P., Cesati M. Understanding the Linux Kernel. USA, O’Reilly Media, 2005, 702 p.

10. Богданов А.Ю. Опыт применения платформы прототипирования на ПЛИС «Protium» для верификации микропроцессоров // Тр. НИИСИ РАН. 2017. Т. 7. № 2. С. 46-49. 


\section{Methods of developing graphics subsystem drivers}

I.A.Efremov ${ }^{1}$, Programmer, efremov@niisi.ras.ru

K.A. Mamrosenko ${ }^{1}$, Ph.D. (Engineering), Head of the Center, mamrosenko_k@niisi.ras.ru

V.N. Reshetnikov ${ }^{1}$,Dr.Sc. (Physics and Mathematics), Professor, Chief Researcher, rvn_@mail.ru

${ }^{1}$ Center of Visualization and Satellite Information Technologies SRISA, Moscow, 117218, Russian Federation

Abstract. The paper describes problems of software development for the problems of interaction between systems-on-achip (SoC) and the Linux operating system (OS). The OS architecture provides various instruments for creating a driver that is a component allowing the device data exchange using a software interface. The development of drivers for an open source OS is difficult due to continuous changes in functions and a kernel structure.

The paper describes graphics subsystem structure and components. The subsystem is a component kit located in different address spaces of OS virtual storage. The components interact through a system call interface. Programming of a graphics engine is performed by filling a command buffer. Each application has a graphics engine context that contains its own command buffer and all necessary data used by the graphics engine for rendering/calculations: coordinates, normal vectors, colors, textures.

There are several approaches to setting graphics mode. However, the most reasonable solution is using KMS module (Kernel Mode Setting). Key manufacturers of microprocessors and graphics cards commonly use these modules. It is necessary to ensure the interaction between OS kernel modules and user space through creating own specific system calls. These system calls regulate low-level operations with the device and allow taking full advantage of the graphics unit capabilities.

Using FPGA-based prototyping platforms allows verifying software functionality, getting performance characteristics and finding errors in SoC hardware design at early stages. Debugging kernel modules is time-consuming due to limitations imposed both by a prototyping platform and the OS. In addition, the errors in a kernel code are difficult to reproduce, which also complicates debugging of kernel modules.

The paper considers some approaches to implementation of Linux OS KMS module and graphics subsystem components, which provide correct interaction of the $\mathrm{OS}$ and the SoC display controller.

Keywords: GPU, driver, Linux, SoC, development, kernel module.

\section{References}

1. Bobkov S.G. High Performance Computing Systems. Moscow, 2014, SRISA RAS Publ., 296 p.

2. Aryashev S.I., Rogatkin B.Y., Barskikh M.E. Modern methods of functional verification of rtl units of VLSI microprocessor. Development Problems of Advanced MES Micro- and Nanoelectronic Systems. 2015, no. 2, pp. 119-122 (in Russ.).

3. Reshetnikov V.N. Space Telecommunications. Satellite Communication and Navigation Systems. St. Petersburg, Leningradskoe izdatelstvo Publ., 2010, 132 p.

4. Giatsintov A.M., Bazhenov P.S. Visualization of virtual three-dimensional scenes on single-chip systems. Software, Systems and Algorithms. 2017, no. 3. Available at: http://swsys-web.ru/virtual-three-dimensional-scenes-on-single-chip-systems.html (accessed April 20, 2018).

5. Love R. Linux Kernel Development. Sams Publ., 2003, 332 p

6. Venkateswaran S. Essential Linux Device Drivers. Prentice Hall Publ., 2008, 714 p.

7. The Linux Kernel Documentation. Available at: https://www.kernel.org/doc/html/v4.11/gpu/drm-kms.html (accessed April 20, 2018).

8. Madieu J. Linux Device Drivers Development. Packt Publ. Ltd, 2017, 586 p.

9. Bovet D.P., Cesati M. Understanding the Linux Kernel. 3rd ed., O'Reilly Publ., 2005, 702 p.

10. Bogdanov A.Yu. Using a prototype platform on the FPGA "Protium" for microprocessor verification. SRISA RAS Proc. 2017, vol. 7, no. 2, pp. 46-49 (in Russ.).

\section{Примеры бибциографического описания статьи}

1. Ефремов И.А., Мамросенко К.А., Решетников В.Н. Методы разработки драйверов графической подсистемы // Программные продукты и системы. 2018. Т. 31. № 3. С. 425-429. DOI: $10.15827 / 0236-235 X .123 .425-429$.

2. Efremov I.A., Mamrosenko K.A., Reshetnikov V.N. Methods of developing graphics subsystem drivers. Software \& Systems. 2018, vol. 31, no. 3, pp. 425-429 (in Russ.). DOI: 10.15827/0236-235X.123.425429. 


\title{
нсследование скатия растровых изобразкений с использованием искусственных нейронных сетей
}

\author{
A.A. Генов ${ }^{1}$, д.т.н., профессор, ведуший научный сотрудник, kt-mati@mail.ru \\ К.Д. Русаков 2, младший научный compyдник, rusakov.msk@yandex.ru \\ A.A. Mоисеев 3, студент, moisandry@gmail.com \\ B.B. Осипов 1, к.т.н., доиент, старший научный сотрудник, оvv_42@mail.ru
}

${ }^{1}$ Центр визуализаиии и спутниковых информаиионных технологий ФНЦ НИИСИ РАН,

2. Москва, 117218 , Россия

2 Институт проблем управления им. В.А. Трапезникова РАН, г. Москва, 117997, Россия

3 Московский государственный технический университет им. Н.Э. Баумана,

2. Москва, 105005, Россия

Современные темпы роста объемов информации, хранящихся на жестких дисках, передаваемых по сети Интернет и локальным сетям предприятий, обусловили актуальность задачи сжатия, передачи и хранения данных. Большая часть передаваемых по сети данных представлена в виде мультимедийного контента.

Сегодня все более популярными становятся алгоритмы сжатия визуальной информации, основанные на нейросетевом аппарате. В отличие от классических алгоритмов, основанных на устранении избыточности, данные алгоритмы базируются на искусственных нейронных сетях. Направление актуально в связи с развитием математических алгоритмов обучения сети, что в дальнейшем позволит улучшить существующие методы сжатия.

Проведенный анализ публикаций показал, что в настоящее время конкретная информация о влиянии архитектуры искусственной нейронной сети на процесс обучения и качество их работы на реальном мультимедийном контенте отсутствует. Актуальна задача выбора топологии сети, наиболее подходящей для сжатия визуальной информации.

Целью авторов статьи является описание возможностей одного из типов искусственных нейронных сетей - многослойного персептрона - в области сжатия и восстановления изображений произвольного вида. Рассматриваются топологии искусственных нейронных сетей и алгоритмы их обучения, анализируется эффективность работы этих сетей. Описывается архитектура бутылочного горлышка, наиболее часто используемая при решении задачи сжатия и восстановления изображений. Приводится один из способов кодирования и декодирования данных, полученных при работе сетей. В статье описывается проведенный вычислительный эксперимент, приведены полученные результаты.

Результаты показали, что использование многослойного персептрона с входным вектором свыше восьми значений менее эффективно. В итоге предложена наиболее подходящая архитектура сети, которую можно использовать на практике.

Ключевые слова: нейронная сеть, алгоритм сжатия, изображение, машинное обучение

Сжатие данных широко используется в самых разнообразных областях информационных технологий. Учитывая современные темпы роста объемов информации, хранящихся на жестких дисках, передаваемых по сети Интернет и локальным сетям предприятий, стоит задача сжатия, передачи и хранения данных. Большая часть видеоматериалов и других мультимедийных проектов размещается в Интернете, на различных видеосервисах, в социальных сетях, поэтому передаваемые по сети данные представлены в виде мультимедийного контента. В силу этого возникает задача по созданию более эффективных методов сжатия.

На сегодняшний день набирают популярность алгоритмы сжатия визуальной информации, основанные на нейросетевом аппарате. Данные алгоритмы базируются на искусственных нейронных cетях (ИНС, нейросети) в отличие от классических алгоритмов, основанных на устранении избыточности. Данное направление актуально в связи с развитием математических алгоритмов обучения сети, что в дальнейшем позволит улучшить существующие методы сжатия. Ускорить процесс сжатия и восстановления информации можно также за счет растущей с каждым годом производительности современной вычислительной техники.

Однако существует проблема подбора топологии сети, наиболее подходящей для задачи сжатия. На данный момент нет конкретной информации о влиянии архитектуры сети на процесс обучения и качество работы на реальном мультимедийном контенте. Цель научной работы состоит в анализе возможностей одного из типов ИНС - многослойного персептрона - в области сжатия и восстановления растровых изображений.

Во многих публикациях рассматривается аппарат ИНС. Так, в работах [1-3] описаны механизм функционирования нейросетей, взаимодействие искусственных нейронов, правила смены их состояний, расчет весовых коэффициентов.

В работе [4] рассматриваются методы сжатия геофизических данных с использованием многослойного персептрона в сети с архитектурой бутылочного горлышка. Предлагается комплексный алгоритм по сжатию геофизических данных при помощи ИНС.

В работах [5-8] приведены основные подходы к сжатию изображений на многослойном персеп- 
троне, показан один из методов квантования полученных данных, описаны алгоритмы обучения сетей, такие, как алгоритм градиентного спуска и алгоритм Rprop (Resilent Propogation - упругое pacпространение). Однако в рассмотренных выше публикациях не была найдена информация по воздействию топологии сети на эффективность их работы.

Основная топология сети приведена на рисунке 1. Архитектура бутылочного горлышка предполагает обязательное наличие входного и выходного слоев одинаковой размерности, а также как минимум одного скрытого слоя, размерность которого много меньше размерности входного и выходного слоев.

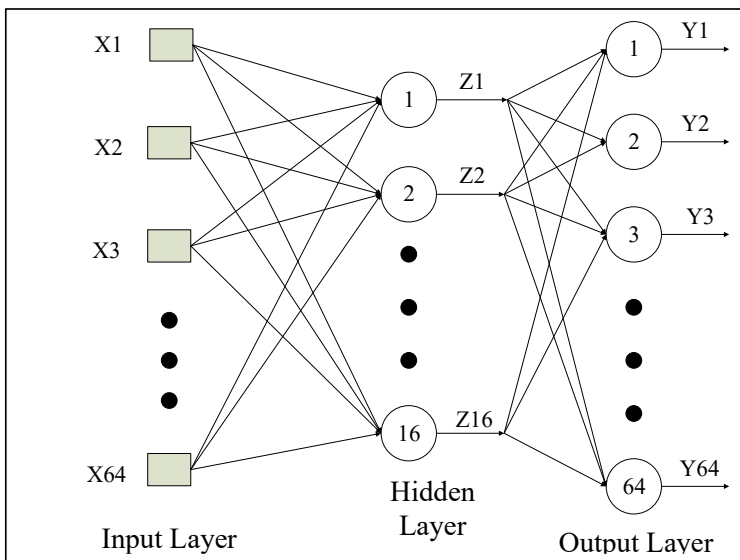

Рис. 1. Архитектура нейронной сети

Fig. 1. A neural network architecture

Изображение представлено в виде вектора пикселей. Каждый вектор состоит из $n$ пикселей, где $n$ - размерность входного слоя сети. Числовые значения каждого пикселя подаются на вход ИНС. Полученные данные на выходах скрытого слоя составляют вектор сжатых данных размерности $m$. Вектор содержит вещественные числа, которые подвергаются кодированию и передаче получателю $[1,7]$. Пример одного из способов кодирования представлен на рисунке 2.

Сжатые данные на скрытом слое подаются на следующий слой, где происходит их декодирование. В результате приведенных выше действий должно получиться исходное изображение.

Особенности описанных нейронных сетей:

- постоянный коэффициент сжатия $K_{c}=\frac{m}{n}$;

- возможность разделения сети на две части: кодирующую и декодирующую.

На рисунке 1 представлена классическая архитектура сети ИНС, $n=64, m=16$. Такая сеть имеет обозначение 64-16-64, где 64 - размерность входного и выходного слоев, 16 - размерность скрытого слоя. Приведенная архитектура обеспечивает коэффициент сжатия $K_{c}=4$. При рассмотрении задачи сжатия изображений данная топология используется в качестве базовой.

В качестве функции активации используется сигмоидальная $[9,10]$, которая обеспечивает диапазон значений $[-1 ; 1]$ и позволяет применить градиентные методы по причине непрерывной дифференцируемости функции.

Так как для изображений числовые значения пикселей могут находиться в широком диапазоне, необходимо выполнить нормализацию вектора входных значений перед подачей на вход нейронной сети.

В реализации используется генератор случайных чисел с диапазоном значений $[-1 ; 1]$ для инициализации весов ИНС. Возможно применение других методов, способствующих уменьшению количества локальных минимумов функции ошибки обучения, что позволяет уменьшить количество циклов обучения.

Для обучения ИНС применяются алгоритм наискорейшего спуска и метод обратного распространения ошибки $[9,11,12]$, имеющие большое количество недостатков, основной из которых длительность поиска минимизации направления весов. Однако другие алгоритмы (алгоритм наискорейшего спуска с адаптируемым шагом, алгоритм сопряженных градиентов) либо потребляют большое количество памяти, либо требуют больших вычислительных ресурсов, что недопустимо при работе с изображениями.

Обучение ИНС проходило на пятидесяти растровых изображениях с разрешением $512 \times 512$ пик-

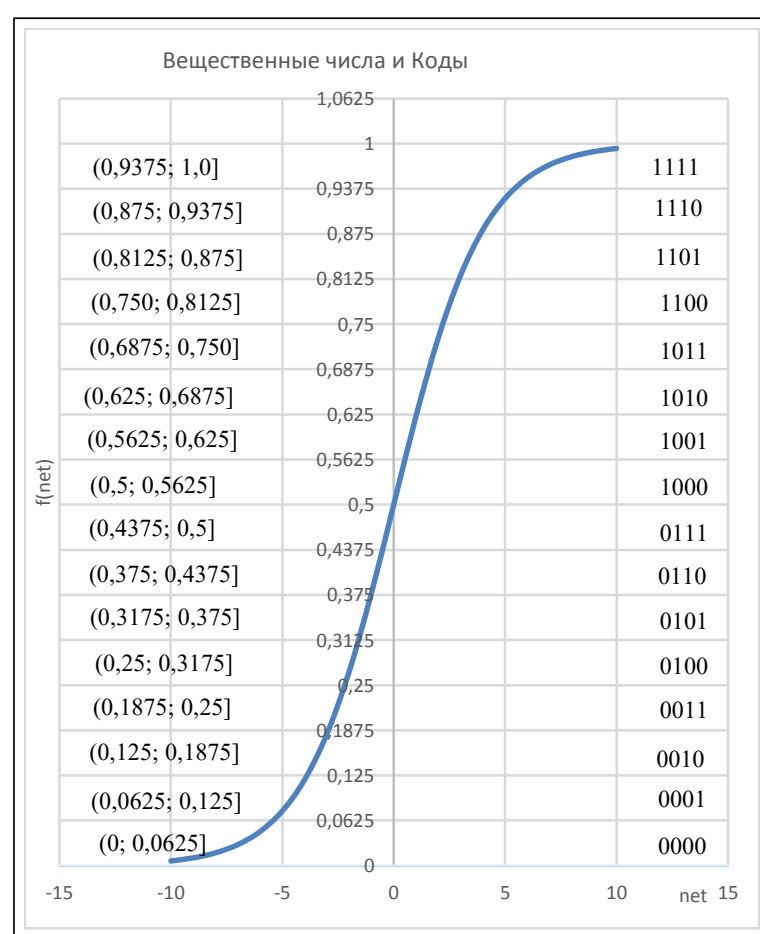

Рис. 2. Кодирование вектора сжатых данных

Fig. 2. Encoding of a compressed data vector 
селей в соответствии с моделью Train/Test/Validation в соотношении 75:15:10 \%, где стадия Train отвечала за обучение, Test - за проверку качества обучения, Validation - за оценку качества работы ИНС.

Результаты обучения сети с архитектурой 6416-64 показали, что количество циклов для каждого изображения сильно зависит от характеристик изображения. Наибольшее количество циклов обучения было на растровых изображених с резкими перепадами интенсивности и большим диапазоном еe значений. Количество циклов на остальных изображениях распределилось в диапазоне примерно от 4 до 450 тыс., в среднем составив 100 тыс. циклов.

На реальных данных архитектура сети 64-16-64 показала себя не лучшим образом, восстановив изображение с достаточно низкой точностью. На рисунке 3 приведен пример исходного и восстановленного изображений.

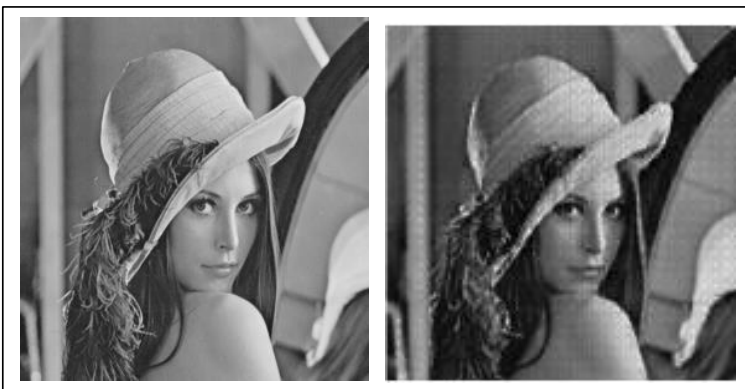

Рис. 3. Конфигураџия сети 64-16-64

Fig. 3. Network configuration 64-16-64

Быстрее обучение проходило на сети с конфигурацией 64-4-64, коэффициент сжатия $K_{c}=16$. Количество циклов - 84 тысячи. Однако стоит отметить, что при уменьшении числа нейронов скрытого слоя уменьшилось число связей, поэтому приведенная архитектура работает хуже, чем 64-16-64. Такая ИНС подвергается эффекту переобучения.

Для примера рассмотрим конфигурацию вида 64-64-64 с коэффициентом сжатия $K_{c}=16$. Среднее количество циклов обучения увеличилось незначительно и составило 120 тысяч. По сравнению с базовой архитектурой данная сеть показала лучшие результаты, изображение стало более контрастным.

Результат работы сети 64-64-64 показан на рисунке 4.

Проведенные исследования позволяют сделать вывод о том, что ИНС с архитектурой бутылочного горлышка, имеющие вектор входных значений размерностью 64 и один скрытый слой, не позволяют восстановить изображение с высокой точностью. Это можно объяснить тем, что при таком размере входного вектора количество возможных значений велико, приблизительно $256^{64}$, и однослойный персептрон просто не в состоянии запомнить всю обу-

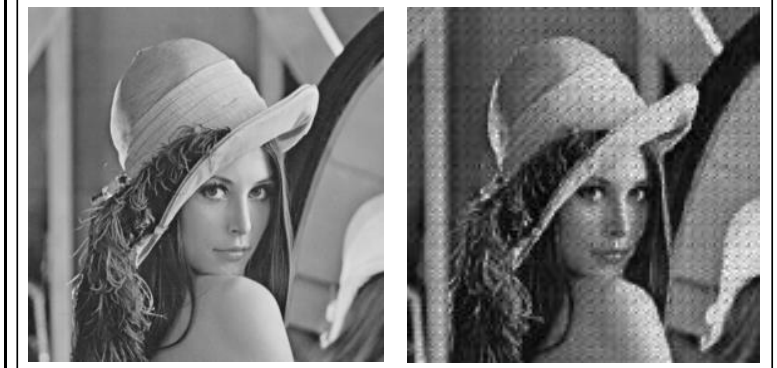

Рис. 4. Конфигуращия сети 64-64-64

Fig. 4. Network Configuration 64-64-64

чающую выборку. Происходит процесс переобучения, что ведет к ошибкам при восстановлении данных.

Для устранения выявленной проблемы было принято решение увеличить количество внутренних слоев и уменьшить количество нейронов на входе и выходе сети.

При выборе архитектуры были приняты во внимание скорость обучения и коэффициент ошибочных ответов.

В результате подобрана архитектура сети, представленная на рисунке 5.

Полученная архитектура ИНС имеет пять слоев, три из которых скрытые. Первый слой - вектор входных значений $\left\{X_{1}, X_{2}, \ldots, X_{n}\right\}$, на который подается битовое представление сжимаемого изображения. Слой состоит из одного нейрона с сигмоидной функцией активации. Значение данного слоя $Z$ подвергается квантованию, в результате чего получается битовая маска $\{1001\}$, которая является сжатым фрагментом изображения. Полученный фрагмент можно сохранить в файл или передать по сети. Для восстановления фрагмента необходимо выполнить обратное преобразование квантования, из битовой маски получить вещественное число, которое подается на третий скрытый слой. Так как пятый слой имеет линейную функцию активации, $Y$ является целочисленным значением в диапазоне $[0,255]$, что соответствует восстановленному байту изображения. Благодаря такой внутренней архитектуре данная ИНС способна запомнить все возможные значения и достаточно точно транслировать входной вектор бит в соответствующее байт-значение. При таком подходе сеть обучается не на наборе изображений, а на векторе бит-значений.

Достаточно сгенерировать набор случайных значений, который охватывал бы весь рассматриваемый диапазон. Благодаря этому была изменена стандартная обучающая выборка, представляющая последовательность байтов изображения, на случайную последовательность значений. Используя данный подход, уменьшаются потери качества изображения на уровне нейронной сети и обеспечивается коэффициент сжатия $K_{c}=2$. Результат работы сети 8-1-16-8-1 показан на рисунке 6. 


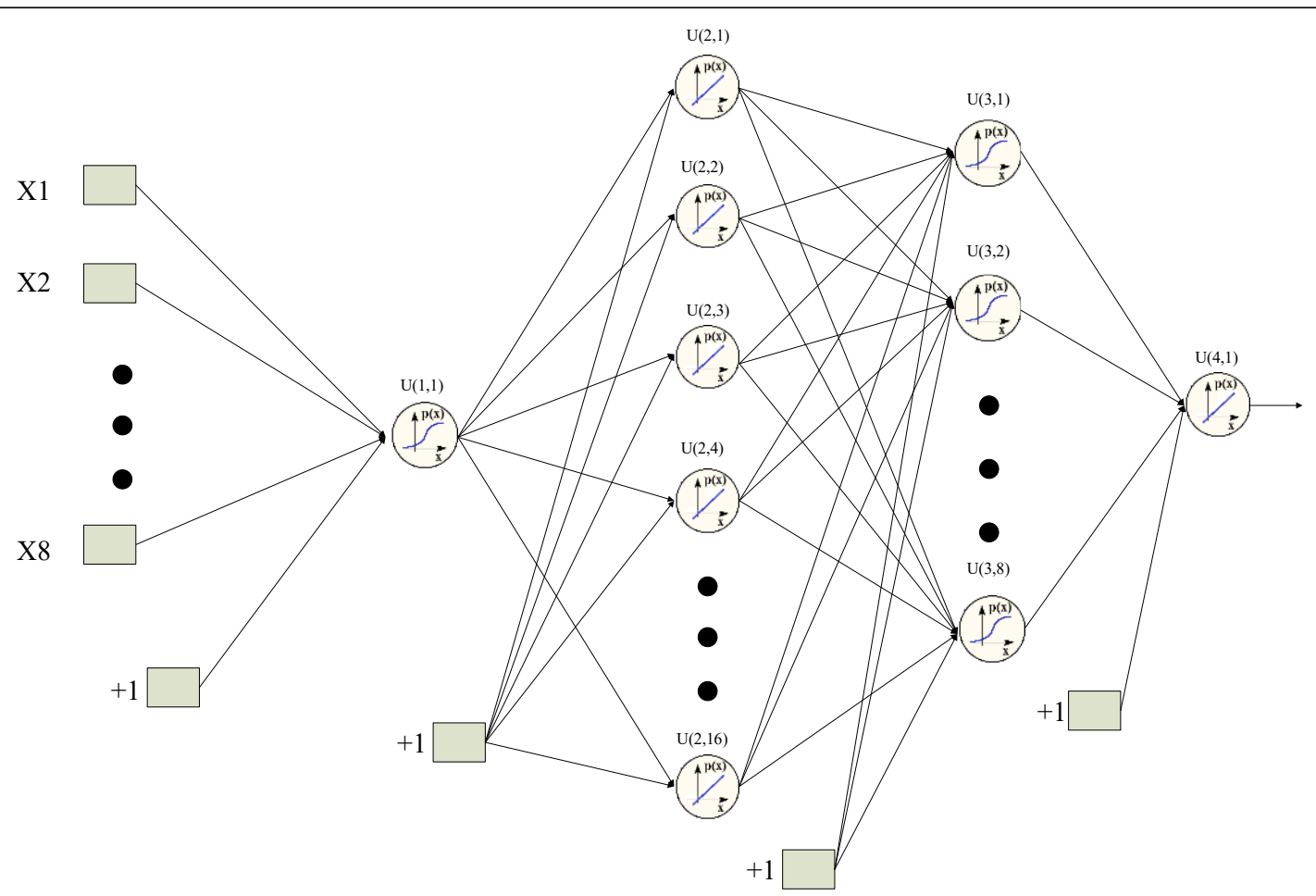

Рис. 5. Архитектура полученной нейронной сети

Fig. 5. The received neural network architecture

Восстановленное изображение не имеет серьезных искажений по сравнению с полученными предыдущими способами. На изображении присутствует плавность цветовых градиентов, отсутствуют точки повышенной резкости.

\section{Заключение}

Таким образом, в работе были рассмотрены и проанализированы несколько базовых архитектур многослойного персептрона. Для оценки качества сжимаемых изображений использовалась метрика $K_{k}=\frac{Y_{\Gamma}}{Y} \cdot 100 \%$, где $Y_{\Gamma}-$ количество верно угадан-

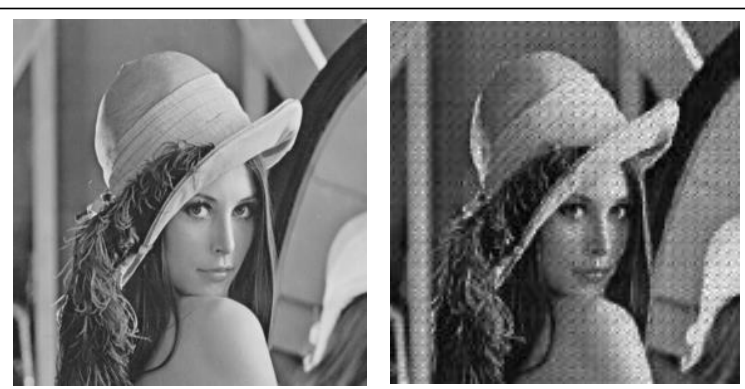

Рис. 6. Улучиение качества изображения с сетью 8-1-16-8-1

Fig. 6. Improving image quality with the network 8-1-16-8-1 ных битовых векторов; $Y$ - полное множество битовых векторов.

Для сети 64-16-64 $K_{k}=64 \%$, для 64-64-64 $K_{k}=70 \%$ и для 8-1-16-8-1 $K_{k}=95 \%$. Полученные результаты свидетельствуют о том, что предложенная структура сети более подходит для решения задач сжатия и восстановления растровых изображений. Для данного класса изображений наиболее приемлемый результат показала ИНС вида 8-1-16-8-1.

\section{Лumepamypa}

1. Хайкин С. Нейронные сети: полный курс. М.: Вильямс, 2006. $1104 \mathrm{c}$

2. Watta P., Desaie B., Dannug N., Hassoun M. Image compression using backprop. Detroit, Wayne State Univ. Publ., 1998, $3 \mathrm{p}$.

3. Круглов В.В. Нечеткая логика и искусственные нейронные сети. М.: Физматлит, 2001.224 с.

4. Булаев В.И., Мунасыпов Р.А. Сжатие геофизических данных с применением вейвлет-преобразования и нейронных сетей // Вестн. УГАТУ. 2008. № 1. С. 200-207.

5. Masalmah Y.M. Image compression using neural networks. Puerto Rico, Univ. of Puerto Rico Publ., 2008. 4 c.

6. Осовский С. Нейронные сети для обработки информации; [пер. с польск. И.Д. Рудинского]. М.: Библио-Глобус, 2016. $448 \mathrm{c}$.

7. Куликов А.И., Михальченко Н.В. Сжатие растровых изображений нейронными сетями Цао Ена // GraphiCon. 2001. C. 231-236.

8. Брюхомицкий Ю.А. Нейросетевые модели для систем информационной безопасности. Таганрог: Изд-во ТРТУ, 2005. $160 \mathrm{c}$.

9. Воронцов К.В. Лекции по искусственным нейронным сетям. Т.: Изд-во ТРТУ, 2007. 29 с. 
10. Севастьянов А.А. Нейросетевая регуляризация решения обратных некорректных задач прикладной спектроскопии. М.: Финансы и статистика, 2003. 195 с.

11. Вороновский Г.К. Генетические алгоритмы, нейронные сети и проблемы виртуальной реальности. Х.: Основа, 1997. $112 \mathrm{c}$.

12. Короткий С. Нейронные сети: алгоритм обратного распространения. Х.: Основа, 2011. 155 с.

\title{
Research on compression of raster images using artificial neural networks
}

\author{
A.A. Genov ${ }^{1}$, Dr.Sc. (Engineering), Professor, Leading Researcher, kt-mati@mail.ru \\ K.D. Rusakov ${ }^{2}$, Junior Researcher, rusakov.msk@yandex.ru \\ A.A. Moiseev ${ }^{3}$, Student, moisandry@ gmail.com \\ V.V. Osipov ${ }^{1}$, Ph.D. (Engineering), Associate Professor, Senior Researcher,ovv_42@mail.ru \\ ${ }^{1}$ Center of Visualization and Satellite Information Technologies SRISA, Moscow, 117218, Russian Federation \\ ${ }^{2}$ A. Trapeznikov Institute of Control Sciences of RAS, 117997, Russian Federation \\ ${ }^{3}$ Bauman Moscow State Technical University, Moscow, 105005, Russian Federation
}

Abstract. Modern rates of information growth stored on hard disks transferred over the Internet and local enterprise networks has made it necessary to solve the problem of compressing, transferring and storing data. Most of the transferred data is in the form of multimedia content.

Nowadays, the algorithms for compressing visual information based on the neural network apparatus are becoming more popular. Unlike classical algorithms, which are based on the elimination of redundancy, these algorithms are based on artificial neural networks. The field is relevant due to the development of mathematical algorithms for network learning, which will improve existing compression methods in the future.

The analysis of publications showed that nowadays there is no particular information about the influence of the artificial neural network architecture on a learning process and the quality of their work in real multimedia content. The important task is to select a network topology, which is most suitable for compressing visual information.

The purpose of the article is to describe the capabilities of one of the types of artificial neural networks called a multi-layer perceptron in the area of compression and recovery of images of an arbitrary type. The paper analyzes topologies of artificial neural networks, algorithms for their learning, and the efficiency of their work. It also describes the architecture of a "bottleneck", which is most often used in solving the problem of image compression and recovery. The authors give one of the ways of encoding and decoding data obtained during network operation. The paper describes a computational experiment and gives its results.

The experiment showed that using a multilayer perceptron with an input vector of more than eight values turned out to be less effective. As a result, the authors propose the most suitable network architecture to use in practice.

Keywords: neural network, compression algorithm, image, machine learning.

\section{References}

1. Haykin S. Neural Networks: Full Course. 2nd ed. Moscow, Vilyams Publ., 2006, 1104 p.

2. Watta P., Desaie B., Dannug N., Hassoun M. Image Compression Using Backprop. Detroit, Wayne State Univ., 1998, $3 \mathrm{p}$.

3. Kruglov V.V. Fuzzy Logic and Artificial Neural Networks. Moscow, Fizmatlit Publ., 2001, 224 p.

4. Bulaev V.I., Munasypov R.A. Compression of geophysical data using wavelet transform and neural networks. Bulletin of USATU. 2008, no. 1, pp. 200-207 (in Russ.).

5. Masalmah Y.M. Image Compression Using Neural Networks. Puerto Rico, Univ. of Puerto Rico, 2008, 4 p.

6. Osovsky S. Neural Networks for Information Processing. Moscow, Biblio-Globus Publ., 2016.

7. Kulikov A.I., Mikhalchenko N.V. Compression of Raster Images by Cao Yen Neural Networks. GraphiCon Publ., 2001, pp. 231-236 (in Russ.).

8. Bryukhomitsky Yu.A. Neural Network Models for Information Security Systems. Taganrog, TRTU, 2005, 160 p.

9. Vorontsov K.V. Lectures on Artificial Neural Networks. Taganrog, TRTU Publ., 2007, 29 p.

10. Sevastyanov A.A. Neural Network Regularization of the Inverse Ill-Posed Problems of Applied Spectroscopy. Moscow, Finansy i statistika Publ., 2003, 195 p. $112 \mathrm{p}$.

11. Voronovsky G.K. Genetic Algorithms, Neural Networks and Virtual Reality Problems. Kharkiv, OSNOVA Publ., 1997,

12. Korotky S. Neural Networks: Back Propagation Algorithm. Kharkiv, OSNOVA Publ., 2011, 155 p. 


\title{
Принципы построения программного комплекса для теплового проектирования электронных систем
}

\author{
А.Г. Мадера 1, д.т.н., профессор, зав. отделом, agmprof@mail.ru \\ П.И. Кандалов 1, зам. зав. отделом, petrki87@gmail.com \\ 1 Центр визуализаиии и спутниковых информаиионных технологий ФНЦ НИИСИ РАН, \\ 2. Москва, 117218, Россия
}

В работе рассматриваются концептуальные вопросы разработки программного комплекса для теплового проектирования сложных электронных систем и проведения многовариантного компьютерного моделирования нестационарных, нелинейных, детерминированных и стохастических тепловых процессов и температурных полей в электронных системах любой сложности и при воздействии дестабилизирующих факторов.

Многофункциональный программный комплекс должен обеспечивать графическое представление исходных данных и результатов вычислений температурных распределений и тепловых характеристик в виде таблиц, графиков, диаграмм и т.п. Вычислительные алгоритмы, реализующие математические модели программного комплекса, должны быть реализованы и оптимизированы как для пользовательских компьютеров, так и для суперкомпьютерных систем путем их распараллеливания с помощью программных интерфейсов Open Multi-Processing (OpenMP) и Message Passing Interface (MPI).

Основным языком программирования разрабатываемого комплекса является язык С\#, обеспечивающий кроссплатформенность, скорость и удобство разработки, поддержку выборочной оптимизации на языках С++ и С. Средой разработки служит Microsoft Visual Studio под управляемой OC Windows, при этом адаптация под другие платформы обеспечивается кроссплатформенной средой исполнения Mono.

Рассмотрена архитектура проектируемого программного комплекса, которая представляет собой трехуровневую модель, включающую уровни представления данных, доменную модель и уровень данных, позволяющих оптимизировать программный комплекс, расширять его функциональные возможности и адаптировать под требуемые платформы.

Ключевые слова: программный комплекс, тепловое проектирование, тепловые прочессы, электронная система, архитектура, температурное распределение.

Возможности современных информационных технологий позволяют создавать многофункичинальные программные комплексы (МФПК) нового поколения, обладающие гибкостью, расширяемостью, возможностью переноса на различные платформы. Такие программные комплексы должны отвечать определенным требованиям, разрабатываться в соответствующей архитектуре и технологиях. Большое внимание при создании МФПК должно уделяться их предварительному моделированию на этапе проектирования [1-7].

МФПК позволяют с высокой эффективностью на этапе проектирования электронных систем (ЭлС) прогнозировать их поведение, эксплуатационные характеристики и параметры. Решение данной проблемы особенно актуально при создании высоконадежных ЭлС, предназначенных для эксплуатации в экстремальных условиях окружающей среды, при тепловых, механических, химических, радиационных и космических воздействиях. Разработка МФПК теплового проектирования (ТП) ЭлС является критически важной для создания новой конкурентоспособной техники.

Существует большое количество зарубежных программных комплексов для тепловых расчетов технических систем, однако присущие им принципиальные недостатки не позволяют рекомендовать их к безусловному применению в практике теплового проектирования ЭлС, что наряду с решением важнейшей проблемы импортозамещения и импортобезопасности ПО делает еще более актуальными разработку и создание отечественных МФПК для теплового проектирования ЭлС (МФПК ТП ЭлС) [8].

\section{Цель и задачи программного комплекса}

Проектируемый МФПК ТП ЭлС предназначен для проведения всестороннего многовариантного математического и компьютерного моделирования тепловых процессов и температурных распределений в ЭлС с конструкцией любой сложности. Исходя из требований $[8,9]$, предъявляемых к функциональным возможностям МФПК ТП ЭлС, можно сформулировать следующие решаемые им основные задачи:

- предоставление пользователю гибкого пользовательского интерфейса для задания исходных данных и эффективных инструментов анализа результатов моделирования температурных распределений и параметров тепловых режимов ЭлС;

- сохранение и загрузка исходных и рассчитанных данных в едином формате их модельного представления;

- экспорт результатов моделирования как интервально-стохастических, так и детерминированных параметров тепловых режимов ЭлС с исполь- 
зованием общепринятых форматов представления данных;

- расчет интервально-стохастических и детерминированных температурных распределений и параметров тепловых режимов ЭлС на различных иерархических уровнях;

- расчет интервально-стохастических и детерминированных параметров тепловых режимов ЭлС [10-12] с учетом влияния тепловой обратной связи $[13,14]$;

- контроль корректности задания исходных данных.

При этом МФПК ТП ЭлС должен обеспечивать возможность моделирования всех конструктивных и физических особенностей элементов ЭлС и всей ЭлС в целом при их изготовлении, установке, монтаже и эксплуатации.

\section{Программные средства}

Основным языком программирования разрабатываемого МФПК ТП ЭлС выбран объектно-ориентированный язык программирования С\# для платформы Microsoft .NET Framework [CLR via C\#] в соответствии с перечисленными далее критериями [15].

- Кроссплатформеность. Современные программные комплексы моделирования должны поддерживать работу на ОC семейства Windows, Linux и Mac OS. Приложение, написанное на С\#, должно иметь возможность компиляции под любую из перечисленных платформ, при этом для компиляции под OC Linux и Mac OS предполагается использовать проект Mono компании Xamarin.

- Скорость и удобство разработки. Высокоуровневые средства программирования С\# и интегрированная среда разработки Microsoft Visual Studio обеспечивают написание эффективного высокопроизводительного кода. Огромное число сторонних программных модулей, оформленных в виде динамически подключаемых библиотек (DLL), позволяет использовать их при разработке в качестве готовых решений. Помимо этого, профилирование кода проводится непосредственно в среде разработки Microsoft Visual Studio, что положительно скажется на времени разработки проекта.

- Поддержка выборочной оптимизации. На определенных стадиях разработки проекта профилирование позволяет выявить критические по времени выполнения участки кода, которые впоследствии можно переписать на $\mathrm{C}$ или $\mathrm{C}++$ в виде отдельных DLL. C\# легко интегрируется с этими языками, что позволяет, кодируя небольшие критические по времени участки кода на $\mathrm{C}$ или $\mathrm{C}++$ и применяя более высокоуровневые абстракции к ним, написанные на С\#, проводить быструю оптимизацию кода.

- Возможность интеграции. Вопрос интеграции может возникнуть, например, при создании отчетности, результаты которой должны быть выгружены в общепринятый формат посредством существующих программ. С\# прекрасно интегрируется с такими существующими программами, как реляционные БД, с текстовыми и табличными редакторами и любыми другими существующими приложениями, которые могут понадобиться для интеграции в МФПК ТП ЭлС в будущем.

- Графический интерфейс пользователя. Графический интерфейс - неотъемлемая часть МФПК ТП ЭлС. Посредством Windows Form, являющегося интерфейсом программирования приложений, отвечающим за графический интерфейс пользователя, и частью Microsoft .NET Framework, предоставляется возможность разработки кроссплатформенного графического пользовательского интерфейса.

Отметим также, что среда разработки Mono поддерживает компиляцию под архитектуру MIPS на OC Linux, что позволяет в будущем запускать МФПК ТП ЭлС на машинах с данной архитектурой.

\section{Архитектура программного комплекса}

Рассмотрим архитектуру МФПК ТП ЭлС. В соответствии с принятой концепцией разработки приложений [16] архитектура МФПК ТП ЭлС разделяется на три уровня: уровень представления, уровень доменной модели, включающий бизнеслогику приложения и уровень доступа к данным, и уровень данных. Такое разделение приложения по уровням повышает производительность, масштабируемость, гибкость, повторное использование кода и обладает рядом других преимуществ. Внутри каждый уровень может разбиваться на целый ряд подуровней, которые обеспечивают более точечную функциональность различных областей приложения (см. рисунок).

Уровень представления - это уровень интерфейса пользователя, который отвечает за представление информации пользователю и отображение пользовательских действий в вызовы функции на уровне бизнес-логики.

Уровень доменной модели - это уровень логики предметной области, реализующий основную функциональность МФПК ТП ЭлС.

Подуровень бизнес-логики состоит из самостоятельных алгоритмических модулей, каждый из которых описывает реализацию алгоритма компьютерного моделирования в виде программного кода. При реализации различных алгоритмов могут выделяться общие процедурные операции, программные коды которых формируются в общую библиотеку алгоритмов. Помимо этого, подуровень бизнес-логики содержит программный код, отвечающий за формирование отчетности, команды действий пользователя, корректность проверки исходных данных для моделирования. 


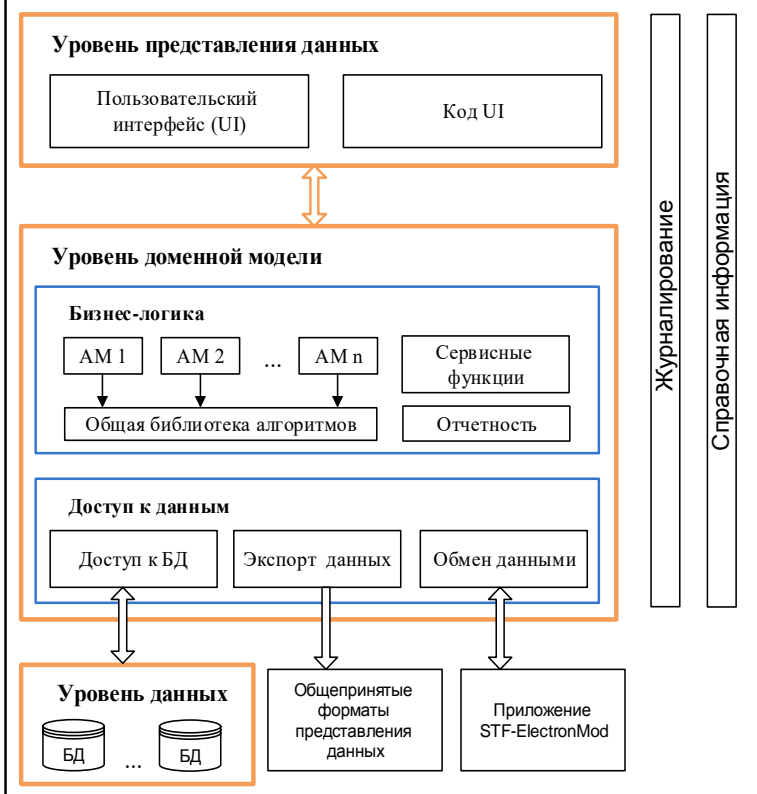

Архитектура МФПК ТП ЭлС:

АМ - алгоритмический модуль

The architecture of a multifunctional software package for electronic system thermal design

Подуровень доступа к данным обеспечивает

- высокоуровневый интерфейс доступа к уровню данных;

- экспорт данных в общепринятые форматы представления данных; например, результаты компьютерного моделирования могут быть выгружены в табличное представление Microsoft Excel;

- обмен результатами моделирования с программным комплексом моделирования интервально-стохастических и детерминированных температурных полей в технических системах STFElectronMod [7].

Уровень данных - это уровень информационного обеспечения МФПК ТП ЭлС, который включает кластер БД тепловых параметров, электрических параметров, характеристик, конфигураций и топологий ЭлС, БД параметров и конструкции теплоотводов и систем охлаждения ЭлС, БД параметров окружающей среды теплоносителей внутри ЭлС.

Журналирование и справочная информация являются общей инфраструктурой для уровней представления данных и доменной модели.

\section{Заключение}

В работе представлена концепция программных средств и архитектуры МФПК ТП ЭлС для проведения всестороннего многовариантного математического и компьютерного моделирования тепловых процессов и температурных распределений в сложных ЭлС. Рассмотренная концепция удовлетворяет всем требованиям [8], предъявляемым к проектируемому МФПК ТП ЭлС, и может быть представлена следующими основными тезисами:

- применение в качестве основного языка программирования для разработки МФПК ТП ЭлС объектно-ориентированного языка С\#, обладающего богатыми средствами визуализации задаваемых пользователем исходных данных и результатов моделирования;

- оптимизация отдельных функциональных возможностей МФПК ТП ЭлС посредством применения языков $\mathrm{C}++$ или $\mathrm{C}$, что особенно актуально при реализации алгоритмов моделирования;

- архитектура программного комплекса представляет многоуровневую систему, состоящую из уровней представления, доменной модели и данных.

Формирование алгоритмических модулей и общих алгоритмических процедур, а также их модификации и новые реализации будут осуществляться на этапе практического использования МФПК ТП ЭлС в режиме сопровождения.

\section{Литература}

1. Конструкторско-технологическое проектирование электронной аппаратуры; [под общ. ред. В.А. Шахнова]. М.: Изд-во МГТУ им. Н.Э. Баумана, 2005. 568 с.

2. Чеканов А.Н. Расчеты и обеспечение надежности электронной аппаратуры. М.: КНОРУС, 2012. 440 с.

3. Ellison G.N. Thermal computations for electronics. Conductive, radiative, and convective air cooling. NY, CRC Press, 2011, $416 \mathrm{p}$.

4. Мадера А.Г. Концепция математического и компьютерного моделирования тепловых процессов в электронных системах // Программные продукты и системы. 2015. № 4. С. 79-86.

5. Мадера А.Г., Кандалов П.И. Моделирование трехмерных температурных полей в электронных модулях // Программные продукты и системы. 2010. № 2. С. 29-33.

6. Мадера А.Г., Кандалов П.И. Анализ интервально-стохастических температурных полей технических систем // Программные продукты и системы. 2014. № 4. С. 41-45.

7. Кандалов П.И. Программный комплекс моделирования стохастических температурных полей в технических системах STF-ElectronMod // Программные продукты и системы. 2016. № 4. C. 171-175.

8. Мадера А.Г., Решетников В.Н. Многофункциональный программный комплекс теплового проектирования электронных систем: требования к архитектуре и функциональным возможностям моделирования // Программные продукты и системы. 2017. № 3. С. 367-372.

9. Решетников В.Н. Космические телекоммуникации. Системы спутниковой связи и навигации. СПб: Ленинградское изд-во, 2010. 132 с

10. Keller C.J., Antonetti V.W. Statistical thermal design for computer electronics. Electronic Packaging and Production, 1979, vol. 19 , no. 3, pp. 55-62.

11. Rinaldi N., D'Alessandro V. Theory of electrothermal behavior of bipolar transistors: part II-two-finger devices. IEEE Transactions Electron Devices, 2005, vol. 52, no. 9, pp. 2022-2033.

12. Mueller O. Internal thermal feedback in four-poles especially in transistors. Proc. IEEE, 1964, vol. 52, pp. 924-930.

13. Kuuse M., Loikkanen M., Bognar Gy. Theoretical investigation of thermal feedback effects in low-power circuits. Proc. Therminic-2005, Belgirate, Italy, 2005, pp. 55-58.

14. Marani R., Perri A. Electrical and thermal characterization of multilayer structure devices for fast PC implementation. Int. J. of Advances in Engineering \& Tchnology, 2013, no. 3, pp. 101-113.

15. Рихтер Дж. CLR via C\#. Программирование на плат- 
форме Microsoft .NET Framework 2.0 на языке C\#. Мастер-класс; [пер. с англ.]. М.: Русская Редакция; СПб: Питер, 2008. 656 с.
16. Martin Robert C. Clean Architecture: A Craftsman's Guide to Software Structure and Design. Prentice Hall Publ., 2017, 432 p.

\title{
Principles of software construction for electronic system thermal design
}

\author{
A.G.Madera ${ }^{1}$, Dr.Sc. (Engineering), Professor, agmprof@mail.ru \\ P.I. Kandalov ${ }^{1}$, Research Associate, petrki87@ gmail.com \\ ${ }^{1}$ Center of Visualization and Satellite Information Technologies SRISA, Moscow, 117218, Russian Federation
}

\begin{abstract}
The paper considers conceptual issues on developing a multifunctional software package for thermal design of complex electronic systems. The software package is intended to carry out mathematical and computer analysis of the nonlinear unsteady-state stochastic and determine thermal processes and temperature distributions in electronic systems of any structural complexity and the impact of destabilizing factors.

A multifunctional software package should provide a graphical representation of both source data and computer modeling results in the form of tables, graphs, diagrams, etc. Computational algorithms that implement mathematical models should be written and optimized both for personal computers and supercomputer systems through their paralleling using Message Passing Interface (MPI) or Open Multi-Processing (OpenMP).

The basic programming language for developing the developed software package is C\#. It provides a cross-platform, development speed and convenience, support for selective optimization in $\mathrm{C}++$ and $\mathrm{C}$. An integrated development environment is Microsoft Visual Studio that runs only Microsoft Windows platform. It is possible to run development programs in Linux or Mac OS X using non-Microsoft .NET implementations like Mono.

The authors consider the architecture of the developed software package divided into three levels. They are: a presentation level, a business logical level, and a database level that allows effective optimizing the software package, extending its functionality and supporting several platforms like Mac OS X or Linux.
\end{abstract}

Keywords: software package, thermal design, thermal processes, electric system, architecture, temperature distribution.

\section{References}

1. Design and Engineering of Electronic Equipment. V.A. Shakhnov (Ed.). Moscow, N.E. Bauman MSTU Publ., 2005, $568 \mathrm{p}$.

2. Chekanov A.N. Calculations and Ensuring Electronic Equipment Reliability. Moscow, KNORUS Publ., 2012,440 p.

3. Ellison G.N. Thermal Computations for Electronics. Conductive, Radiative, and Convective Air Cooling. NY, CRC Press, 2011, $416 \mathrm{p}$.

4. Madera A.G. The concept of mathematical and computer modeling of thermal processes in electronic systems. Software \& Systems. 2015, no. 4, pp. 79-86 (in Russ.).

5. Madera A.G., Kandalov P.I. Modeling three-dimensional temperature fields in electronic modules. Software \& Systems. 2010, no. 2, pp. 29-33 (in Russ.).

6. Madera A.G., Kandalov P.I. Analysis of interval-stochastic temperature fields in technical systems. Software \& Systems. 2014, no. 4, pp. 41-45 (in Russ.)

7. Kandalov P.I. A software complex for simulation of stochastic temperature fields in technical systems STFElectronMod. Software \& Systems. 2016, no. 4, pp. 171-175 (in Russ.).

8. Madera A.G., Reshetnikov V.N. A multifunctional software package for thermal design of electronic systems: requirements for architecture and modeling functionality. Software \& Systems. 2017, no. 3, pp. 367-372 (in Russ.).

9. Reshetnikov V.N. Space Telecommunications. Satellite Communication and Navigation Systems. St. Petersburg, 2010, $132 \mathrm{p}$.

10. Keller C.J., Antonetti V.W. Statistical thermal design for computer electronics. Electronic Packaging and Production. 1979, vol. 19, no. 3, pp. 55-62.

11. Rinaldi N., D'Alessandro V. Theory of electrothermal behavior of bipolar transistors: part II-two-finger devices. IEEE Trans. Electron Devices. 2005, vol. 52, no. 9, pp. 2022-2033.

12. Mueller O. Proc. IEEE Internal thermal feedback in four-poles especially in transistors. 1964, vol. 52, pp. 924-930.

13. Kuuse M., Loikkanen M., Bognar Gy. Theoretical investigation of thermal feedback effects in low power circuits. Therminic-2005. Belgirate, Italy, 2005.

14. Marani R., Perri A. Electrical and thermal characterization of multilayer structure devices for fast PC implementation.

Int. J. of Advances in Engineering \& Technology. 2013, no. 3, pp. 101-113.

15. Richter J. CLR via C\#. 2nd ed., Microsoft Press, 2006, 736 p.

16. Martin R.C. Clean Architecture: A Craftsman's Guide to Software Structure and Design. Prentice Hall Publ., 2017, $432 \mathrm{p}$. 
УДК 004.921

DOI: $10.15827 / 0236-235 X .123 .439-443$

Дата подачи статьи: 25.06 .18

Высокоуровневая архитектура тренакерно-обучаюицих систем слокных технических комплексов

\author{
A.B. Родителев ${ }^{1}$, ведущий программист, avrod_94@mail.ru \\ A.M. Гиаиинтов ${ }^{1}$, старший научный сотрудник, algts@inbox.ru
}

${ }^{1}$ Центр визуализаиии и спутниковых информаиионных технологий ФНЦ НИИСИ РАН, отдел разработки имитаиионных и спутниковых технологий, г. Москва, 117218, Россия

В статье рассмотрена архитектура тренажерно-обучающей системы на примере прототипа авиационного тренажера. Подсистема визуализации тренажерно-обучающей системы обеспечивает отображение результатов моделирования внешней среды и объекта управления с помощью устройств отображения информации. Она должна обеспечивать воспроизведение созданной виртуальной сцены с достаточно подробным содержанием, позволяющим операторам успешно выполнять поставленные задачи.

Приведены требования к тренажерно-обучающей системе сложных технических комплексов, в том числе предъявляемые к ее подсистеме визуализации. Разработанная архитектура обеспечивает унификацию способов сопряжения с оборудованием, использование тренажерно-обучающей системы с различными устройствами ввода информации, а также позволяет избежать высокой связанности компонентов. Каждое устройство, как правило, имеет свои особенности: специализированное ПО, закрытые протоколы обмена информацией, разъемы различных стандартов.

Разработанная система расширений (плагинов) позволяет учитывать особенности устройств без модификации основного модуля и других подсистем. Для работы с плагинами был создан управляющий интерфейс. Плагины не зависят друг от друга и могут быть добавлены или удалены без нарушения целостности работы системы.

В зависимости от вычислительной нагрузки обработку данных тренажерно-обучающей системы можно реализовать на одном аппаратном комплексе или для каждой подсистемы использовать отдельный. Любая подсистема может быть создана независимыми разработчиками и представлена отдельными программными комплексами.

Предусмотрена возможность работы проектируемых подсистем на аппаратных комплексах с различными архитектурами процессоров, способами хранения байтов в памяти (big-endian или little-endian) и на различных операционных системах. Описан алгоритм преобразования координат, полученных от математической модели, в систему координат подсистемы визуализации.

Ключевые слова: ТОС, тренажерно-обучающие системь, система визуализации, трехмерное моделирование, тренажер, имитационные системы.

Под тренажерно-обучающей системой (ТОС) оператора сложной технической системы (СТС) будем понимать техническое средство для подготовки операторов в едином информационном окружении, отвечающее требованиям методик подготовки, создающее условия для получения знаний, навыков и умений, реализующее модель таких систем и обеспечивающее контроль над действиями обучаемого, а также для исследований. Кроме формирования индивидуальных профессиональных навыков и умений, ТОС могут применяться для отработки групповых операций.

В зависимости от объема решаемых задач ТОС можно разделить на комплексные, специализированные, процедурные. Комплексные тренажеры предназначены для решения задач практического обучения и подготовки операторов, в полном объеме охватывающих их профессиональную деятельность, и должны обеспечивать отработку и формирование всех профессиональных навыков. Специализированные тренажеры рассчитаны на подготовку операторов к выполнению определенных проблемно-ориентированных задач. Процедурные тренажеры предназначены для выработки устойчивых навыков в конкретных видах деятельности, отработки отдельных важных процедур управления определенным видом оборудования, выполняемых на конкретных этапах эксплуатации и в определенных условиях [1].

В данной статье рассмотрена система на примере прототипа авиационной ТОС, к которой применяются следующие требования:

- имитация процедур в реальном масштабе времени (латентность тренажера не более $20 \mathrm{Mc}$, для реализации необходимо выполнять вычисления в течение 15 мс, 5 мс запас);

- отсутствие разрывов изображения при многоканальной визуализации;

- исключение привития ложных навыков;

- модульная архитектура построения, позволяющая без глубокой переработки системы удалять, заменять и создавать модули.

\section{Применение модульной архитектуры}

Использование модульной архитектуры построения позволит избежать высокой связанности компонентов, которая может наложить ряд ограничений на функционирование ТОС (например, под каждую новую версию модуля от разных разработчиков необходимо для совместимости изменять функционал всей системы). Была разработана система расширений (плагинов), взаимодействующих с основным модулем. Плагины не зависят друг 
от друга и могут быть добавлены или удалены без нарушения целостности работы системы [2].

Для работы с внешними плагинами был создан управляющий интерфейс. При загрузке системы происходит поиск плагинов по расширению в указанной директории, после чего производится инициализация плагина. Каждый плагин работает в отдельном потоке, так как использование одного потока для всех плагинов может привести к зависанию системы моделирования, если какой-то плагин будет ожидать выполнения определенного условия. Для функционирования загруженного плагина в системе необходимо наличие реализации функции плагина, в которой описываются основные этапы работы плагина. Например, в данной функции могут определяться заранее заданные в конфигурационном файле входящие и исходящие порты и IP-адреса, осуществляться подготовка данных для отправки в соответствующую подсистему и обработка обновленных данных, приходящих из подсистемы с последующей записью в хранилище, а также задаваться частота отправки пакетов.

Если инициализация прошла успешно, плагин добавляется в список загруженных. При неуспешной инициализации он выгружается из памяти. При запросе остановки основного модуля осуществляется выгрузка всех плагинов.

\section{Описание подсистем, входящих в состав ТОС}

В зависимости от вычислительной нагрузки обработку данных ТОС возможно реализовать на одном аппаратном комплексе или для каждой подсистемы использовать отдельный [3]. Любая подсистема может быть создана независимыми разработчиками и представлена отдельными программными комплексами. Необходимо учитывать, что разрабатываемые подсистемы могут работать на аппаратных комплексах с различными архитектурами процессоров, способами хранения байтов в памяти (big-endian или little-endian) и на различных операционных системах. Например, при отправке пакета данных к подсистеме, которая использует иной порядок байт, необходимо производить перестановку байт в плагине после получения пакета от подсистемы и перед отправкой данных. Также следует учесть, что для структур, в которых содержатся вложенные структуры, необходимо производить перестановку порядка байт отдельно для каждого значения. Обмен данными между подсистемой и плагином может осуществляться по технологии Ethernet с использованием протокола UDP либо посредством подключения библиотеки к плагину.

Для указания расположения подсистем в рассматриваемом прототипе ТОС используется конфигурационный файл, в котором указываются IPадреса, входящие и исходящие порты, МАС-адрес сетевой карты аппаратного комплекса основного модуля. Использование МАС-адреса обусловлено возможным наличием нескольких сетевых карт на рабочей станции.

Для подсистем возможен следующий подход к работе с сетью. При получении пакета подсистемой определяется входящий IP-адрес. После расчета новых параметров сформированный пакет будет отправлен по данному IP-адресу на указанный исходящий порт. Входящие и исходящие порты могут задаваться как в конфигурационном файле для конкретной подсистемы, так и в виде входных аргументов приложения. В случае отсутствия заданного IP-адреса или описания входящих или исходящих портов будут использоваться значения, заданные по умолчанию (localhost).

В основной модуль поступают параметры из всех подсистем, значения которых хранятся в едином хранилище (структуре) [4]. Значения параметров могут иметь различный тип, доступ возможен из любого плагина. В данной структуре могут храниться числа, строки, массивы и бинарные данные. Хранение данных реализовано в виде набора пар ключ-значение. Если данные из структуры необходимо извлечь и отправить в нужную подсистему, их преобразуют с помощью соответствующих функций из формата, используемого в этой структуре, в формат, требуемый для нижележащих компонентов.

В ТОС входят подсистемы

- рабочего места инструктора;

- формирования управляющих воздействий;

- математического моделирования объекта, в том числе БД описаний объекта моделирования;

- моделирования электронных и механических средств отображения состояния объекта;

- математического моделирования окружающей обстановки, в том числе физического моделирования, моделирования подстилающей поверхности и БД объектов реального окружения;

- визуализации;

- навигации.

Использование такой архитектуры также может обеспечить унификацию способов сопряжения с оборудованием и позволит использовать ТОС с различными устройствами ввода информации. Каждое аппаратное средство, как правило, имеет свои особенности: специализированное ПО, закрытые протоколы обмена информацией, разъемы различных стандартов [5]. Разработанная система плагинов позволяет учитывать особенности аппаратных средств без модификации основного модуля и других подсистем.

Во время инициализации подсистемы формирования управляющих воздействий производится определение всех подключенных устройств. Этап инициализации состоит в получении индексов устройств в системе, их имен и записи полученных данных в общий массив. Значения параметров 
штурвалов и рычагов управления представляют собой углы отклонения от соответствующих начальных значений осей.

Подсистема математического моделирования объекта в том числе выполняет следующие функции:

- обработка введенных инструктором начальных условий;

- расчет системы автоматического управления (при наличии);

- расчет параметров объекта с учетом управляющих воздействий, в том числе определение пространственного положения объекта в виртуальном окружении и расчет параметров для приборов и рычагов управления.

Для ряда систем поведение в нештатных ситуациях недостаточно изучено. Это может быть связано с тем, что существует недостаток экспериментальных данных или же получение таких данных очень затратно или вовсе опасно.

Подсистема рабочего места инструктора - инструмент для контроля и изменения всех параметров моделирующей системы [6]. С ее помощью можно изменять параметры работы всех систем, входящих в состав ТОС. Инструктор на протяжении всей тренировки может задавать нештатные ситуации, в том числе отказы различных систем и оборудования, задавать параметры окружения, выполнять аварийное отключение тренажера. Система инструкторского контроля обеспечивает сбор, обработку, документирование, анализ и выдачу статистических данных.

\section{Требования, предъявляемые к системе визуализации ТОС}

Рассмотрим требования, которые предъявляются к системе визуализации ТОС. Информация, поступающая путем визуального наблюдения, воспринимается различно в зависимости от отдаленности наблюдаемых объектов. Существует разделение на три зоны: до 1 метра, от 1 до 30 метров и свыше 30 метров от наблюдателя. В зоне более 30 метров, когда бинокулярное зрение ослабевает (оба глаза получают одинаковое изображение), окклюзия и размеры приобретают важность для адекватного восприятия. Если экран размещен на расстоянии порядка 3 метров от обучаемого, а объект по сценарию тренировки удален от наблюдателя менее чем на 3 метра, при использовании проекционных систем отображения информации может происходить рассогласование.

В тренажере передача зрительных сигналов о перемещении основана на том, что мозг человека с трудом различает изменения ситуаций (используя только зрительный канал), когда наблюдатель неподвижен, а окружающие объекты находятся в движении и когда движется наблюдатель, а объекты неподвижны. Поэтому генерируется движу- щаяся окружающая обстановка, создавая иллюзию перемещения наблюдателя (подвижная платформа способствует усилению восприятия движения) [7].

Детализация воспроизведения окружающей обстановки напрямую связана с производительностью имитационной системы. Для повышения эффективности использования ресурсов тренажера необходимо определить наиболее важные для достижения целей тренировки группы объектов и, следовательно, детально воспроизводить именно их.

Для воссоздания окружающей обстановки используются реальные снимки подстилающей поверхности. Формирование подстилающей поверхности может осуществляться в системе для создания и редактирования трехмерной графики или при помощи процедурной генерации [8]. При воссоздании взлетно-посадочной полосы необходимо отобразить места касания шасси воздушного судна при посадке. После создания трехмерной сцены выполняется ее сохранение в промежуточный формат, например COLLADA, который позже преобразуется конвертером графического движка во внутренний формат трехмерных сцен.

\section{Метод преобразования координат математической модели ТОС в систему координат подсистемы визуализации}

В подсистему визуализации через плагин из основного модуля передаются значения идентификации пакета, долготы, широты и высоты (WGS 84), углов (в градусах) крена, рысканья, тангажа. Эти значения используются для изменения позиции и углов наклона виртуальной камеры в трехмерной сцене. Так как подсистема визуализации имеет свою систему координат, необходимо преобразовать полученные значения в систему координат подсистемы визуализации. Расчет расстояния между двумя точками на поверхности Земли происходит по формуле

$$
\begin{aligned}
& d=R \sqrt{\Delta \lambda^{2} \cos \left(\lambda_{1}\right) \cos \left(\lambda_{2}\right) \Delta \varphi^{2}}, \\
& \Delta \lambda=\lambda_{2}-\lambda_{1}, \Delta \varphi=\varphi_{2}-\varphi_{1},
\end{aligned}
$$

где $\lambda_{2}-\lambda_{1}-$ широты двух точек; $\varphi_{2}-\varphi_{1}-$ долгота двух точек; $R$ - радиус Земли; $\Delta \lambda, \Delta \varphi$ - расстояние между точками широты и долготы.

Далее необходимо рассчитать значение азимута, который представляет собой угол между плоскостью меридиана точки наблюдения и вертикальной плоскостью, проходящей через эту точку и наблюдаемый объект [9]. Значение азимута необходимо для расчета итогового положения воздушного судна:

$$
\psi=\tan ^{-1}\left(\left|\frac{\cos \left(\lambda_{2}\right) \sin (\Delta \varphi) \cos \left(\lambda_{1}\right)}{\sin \left(\lambda_{2}\right)-\sin \left(\lambda_{1}\right) \cos (d)}\right|\right) .
$$

Абсолютные значения числителя и знаменателя формулы (2), используемые для вычисления отно- 
сительного азимута, ограничены диапазоном $\pm \pi / 2$. Поэтому, если значение знаменателя формулы (2) меньше нуля, то $\psi=\pi-\psi$, если же значение числителя формулы (2) меньше нуля, то $\psi=-\psi$. После этого вычисляется итоговое значение направления магнитного поля в пределах ВПП в радианах:

$$
q=R Q D M+\text { MagVar, }
$$

где $R Q D M$ - направление магнитного поля; MagVar - магнитная вариация.

Магнитная вариация представляет собой различные изменения во времени геомагнитного поля, обусловленные существованием как внутренних, так и внешних по отношению к поверхности Земли источников магнитного поля [6].

Далее необходимо численное выражение направления магнитного поля преобразовать из градусов относительно магнитного меридиана в градусы относительно истинного меридиана. После этого результат приводится к диапазону \pm 180 градусов по следующему алгоритму.

Если $q>\pi$, значение примет следующий вид: $q=q-2 \pi$

Если $q<-\pi$, значение примет следующий вид: $q=q+2 \pi$.

Вычисление итогового положения воздушного судна внутри виртуальной сцены будет происходить по следующим формулам:

$x=-(-d \sin (\psi) \cos (2 \pi-q)+d \cos (\psi) \sin s(2 \pi-q)) ;$

$z=-(-d \sin (\psi) \cos (2 \pi-q)-d \cos (\psi) \sin s(2 \pi-q))$;

$y=$ altitude,

где $x, y, z$ - преобразованные координаты модели; altitude - высота модели над уровнем моря.

Значения крена (roll), рысканья (yaw), тангажа (pitch) будут преобразованы из радиана в градусы следующим образом:

$$
\begin{aligned}
& r x=\frac{180^{\circ}}{\pi} \text { pitch; } \\
& r y=-\frac{180^{\circ}}{\pi} \text { yaw; } \\
& r z=-\frac{180^{\circ}}{\pi} \text { roll, }
\end{aligned}
$$

где $r x, r y, r z$ - значения отклонения модели в градусах от плоскостей OX, OY, OZ соответственно.

Интервалы во времени между получением новых данных могут накладывать ограничения на плавность движения виртуальной камеры [10]. Это связано с тем, что математическая модель работает с постоянной частотой, а система визуализации на протяжении всего рабочего цикла может изменять частоту обновления кадров. Для сохранения плавности движения необходимо использовать промежуточные значения координат, которые будут рассчитываться с помощью интерполяции.

\section{Заключение}

Для воссоздания ощущений реального мира в процессе тренировочных занятий необходимо воссоздавать сигналы, которые могут быть получены оператором во время выполнения задач. Чтобы повысить эффективность использования ресурсов тренажера, необходимо определить, какие именно группы объектов наиболее важны для достижения целей тренировки, и, следовательно, детально воспроизводить именно эти группы.

Разработанная система расширений (плагинов) позволила в зависимости от вычислительной нагрузки реализовать обработку данных на одном аппаратном комплексе или использовать для каждой подсистемы отдельный комплекс. Плагины не зависят друг от друга и могут быть добавлены или удалены без нарушения целостности работы системы. Описанные в статье подсистемы ТОС могут работать на аппаратных комплексах с различными архитектурами процессоров, способами хранения байтов в памяти (big-endian или little-endian) и на различных операционных системах.

Представлен алгоритм для преобразования географических координат, полученных от математической модели, в систему координат подсистемы визуализации. На следующем этапе развития прототипа ТОС планируется разработать и внедрить систему моделирования атмосферных явлений и систему процедурной генерации земной поверхности.

\section{Литература}

1. Rolfe J.M. and Caro P.W. Determining the training effectiveness of flight simulators: some basic issues and practical development. Appl. Ergon, 1982, no. 13, pp. 243-250.

2. Решетников В.Н. Тригонометрические воспоминания. Сер.: Космические телекоммуникации. СПб, 2015. 138 с.

3. Гиацинтов А.М., Мамросенко К.А., Решетников В.Н. Инструментальные средства предтренажерной и тренажерной подготовки операторов сложных технических систем // Программные продукты, системы и алгоритмы. 2014. № 1. URL: http://swsys-web.ru/simulator-training-operators.html (дата обращения: 22.04.2018).

4. Allerton D. Principles of flight simulation. Chichester, UK, Wiley Publ., 2009, 471 p.

5. Kunc M., Morecroft J.D.W., Brailsford S. Special issue on advances in system dynamics modelling from the perspective of other simulation methods. J. of Simulation, 2018, pp. 87-89.

6. Miloš Ljumović. C ++ Multithreading Cookbook. Packt Publ. Ltd, 2014, 422 p.

7. Горкин А.П. География. Современная иллюстрированная энциклопедия; [под ред. А.П. Горкина]. М.: Росмэн, 2006. $84 \mathrm{c}$.

8. Гиацинтов А.М., Родителев А.В., Агафонов Н.А. Методы визуализации погодных явлений в имитационных системах // Вестн. кибернетики. 2018. № 1. С. 61-65.

9. Акасофу С.И., Чепмен С. Солнечно-земная физика; [пер. с англ.]. М.: Мир, 1975. 512 с.

10. Olsson O., Assarsson U. Tiled Shading. J. Graph. GPU Game Tools, 2011, vol. 15, no. 4, pp. 235-251. 


\title{
High-level architecture of training simulation systems of complex technical systems
}

\author{
A.V. Roditelev ${ }^{1}$, Programmer of ORIST department, avrod_94@mail.ru \\ A.M. Giatsintov ${ }^{1}$, Senior Researcher, giatsintov@niisi.ras.ru \\ ${ }^{1}$ Center of Visualization and Satellite Information Technologies SRISA, Moscow, 117218, Russian Federation
}

\begin{abstract}
The paper provides a detailed description of the training simulation system (TSS) architecture using the example of an air simulator prototype. A TSS visualization subsystem provides visualization of external environment and a control object using display devices. It should provide reproduction of the created virtual scene with a sufficiently detailed content that allows TSS operators to perform the assigned tasks successfully.

The authors give the requirements for TSS subsystems, including those for the TSS visualization subsystem. The developed architecture avoids high coupling of components and provides a unified approach to managing hardware, such as various input devices.

Usually, a device has some peculiar properties: specific control software, closed information exchange protocols, different connector types. The developed plugin management systems allows taking into account various hardware features without modifying the main module and other subsystems. The created control interface works with pluggable modules. Plugins are self-sufficient and can be added or removed without violating the integrity of the system.

Depending on the workload, data processing can be organized on one machine or each subsystem can operate on a separate machine. Each subsystem is a standalone software complex that may be developed by a third-party developer.

The main module and its subsystems can operate on hardware complexes with different processor architectures, endianness (little or big) and operating systems. The paper also describes an algorithm that transforms geographic coordinates received from the modeling subsystem to the coordinate system used by the visualization subsystem.
\end{abstract}

Keywords: TSS, Training simulation systems, visualization system, 3D modeling, trainer, simulation systems.

\section{References}

1. Rolfe J.M., Caro P.W. Determining the training effectiveness of flight simulators: some basic issues and practical development. Appl. Ergon. 1982, no. 13, pp. 243-250.

2. Reshetnikov V.N. Trigonometric Memories. Ser. Space Telecommunications. St. Petersburg, RIP SPB Publ., 2015, $138 \mathrm{p}$.

3. Giatsintov A.M., Mamrosenko K.A., Reshetnikov V.N. Tools for pre-training and simulator training for operators of complex technical systems. Software, Systems and Algorithms. 2014, no. 1. Available at: http://swsys-web.ru/simulator-training-operators.html (accessed April 22, 2018).

4. Allerton D. Principles of Flight Simulation. Chichester, UK, Wiley Publ., 2009, 471 p.

5. Kunc M., Morecroft J.D.W., Brailsford S. Special issue on advances in system dynamics modelling from the perspective of other simulation methods. J. of Simulation. 2018, pp. 87-89.

6. Ljumović M. C++ Multithreading Cookbook. Packt Publ. Ltd, 2014, pp. 422.

7. Gorkin A.P. Geography. Contemporary Illustrated Encyclopedia. Moscow, Rosmen Publ., 2006, 84 p.

8. Giatsintov A.M., Roditelev A.V., Agafonov N.A. Methods of visualizing weather phenomena in imitation systems. Proc. in Cybernetics. 2018, no. 1, pp. 61-65 (in Russ.).

9. Akasofu S.I., Chapman S. Solar-Terrestrial Physics. Oxford, 1972 (Russ. ed.: Moscow, Mir Publ., 1975, 512 p.).

10. Olsson O., Assarsson U. Tiled Shading. J. Graph. GPU Game Tools. 2011, vol. 15, no. 4, pp. 235-251.

\section{Примеры бибциографического описания статьи}

1. Родителев А.В., Гиацинтов А.М. Высокоуровневая архитектура тренажерно-обучающих систем сложных технических комплексов // Программные продукты и системы. 2018. Т. 31 . № 3. C. 439-443. DOI: 10.15827/0236-235X.123.439-443.

2. Roditelev A.V., Giatsintov A.M. High-level architecture of training simulation systems of complex technical systems. Software \& Systems. 2018, vol. 31, no. 3, pp. 439-443 (in Russ.). DOI: 10.15827/0236235X.123.439-443. 


\title{
Адекватные междисииплинарные модели в прогнозировании временных рядов статистических данных
}

\author{
Б.M. Пранов 1, д.m.н., npoфpeccop, boris.pranov@gmail.com \\ ${ }_{1}$ Российская академия народного хозяйства и государственной службы при Президенте \\ Российской Федерайи, г. Москва, 119571, Россия
}

В статистических исследованиях для моделирования и прогнозирования временных рядов обычно используют многофакторные линейные модели. Область их применения весьма обширна.

Они достаточно эффективны в ситуации, когда множество точек, изображающих исследуемые объекты в многомерном пространстве параметров, располагается вблизи некоторого линейного подпространства (или его сдвига относительно начала координат). Этот эффект легко обнаруживается с помощью факторного анализа. Если же такое подпространство (линейное множество) отсутствует, для построения более точных моделей применяют нелинейные зависимости.

В экономике для описания зависимости прибыли предприятия от числа работников и стоимости основных средств используют функцию Кобба-Дугласа. Оказывается, если рассматривать пожары и другие явления социума как своеобразную его «продукцию», то функция Кобба-Дугласа с высокой степенью точности позволяет аппроксимировать соответствующие временные ряды. В результате получается целый ряд интересных моделей в новых предметных областях.

По итогам расчетов выяснилось, что временной ряд общего числа пожаров на территории РФ очень хорошо аппроксимируется функцией Кобба-Дугласа, а прогностические значения, рассчитанные по таким моделям, весьма близки к реальным. Аналогичная адекватная аппроксимация временных рядов общего числа пожаров пригодна для значительного количества европейских стран, а также США.

Такое моделирование применимо, в частности, и в туристической отрасли - в статье рассматриваются модели полного дохода гостиниц в зависимости от числа работников и величины основных фондов.

Ключевые слова: моделирование, прогнозирование, статистические данные, аппроксимация, временной ряд.

Начавшийся в середине прошлого века очередной экономический кризис обусловил появление научных разработок, направленных на оптимизацию деятельности пожарной охраны и полиции, а также других органов. Так как во многих городах мира затраты на содержание охраны и полиции сокращались, возникла необходимость повысить эффективность их деятельности. В результате проведенных исследований был построен ряд моделей для обоснования минимального уровня как пожарной, так и полицейской защиты. Аналогичные исследования продолжаются до сих пор.

Остановимся на необходимом уровне пожарной защиты. Ясно, что обеспечение такого уровня лишь на настоящий момент не является полным решением задачи. Необходимо предвидеть уровень пожарной опасности на некоторое время вперед и обеспечивать соответствующую защиту с упреждением, то есть разработать методы прогнозирования пожарной опасности. Традиционно для прогнозирования временных рядов пожаров используют однофакторные линейные модели вида

$$
y_{i}=a+b x_{i}+\varepsilon_{i}
$$

где $y$ - фактические данные пожарной статистики; $x$ - соответствующий момент времени; $a$ и $b$ - оцениваемые коэффициенты; $b$ - так называемый «тренд» модели; $\varepsilon_{i}-$ ошибка модели; $i$ - номер момента времени (года) [1]. Рассматриваются также линейные многофакторные модели вида

$$
y_{i}=a_{0}+a_{1} x_{1 i}+\ldots+a_{k} x_{k i}+\varepsilon_{I},
$$

где $i$ - номер момента времени; $x_{1}, \ldots, x_{k}$ - пара- метры, с помощью которых оценивается временной ряд $y_{i} ; a_{0}, a_{1}, \ldots, a_{k}$ - оцениваемые коэффициенты. При этом для получения модели вида (2) необходимо иметь временные ряды параметров $x_{1}, \ldots, x_{k}$. Значения этих параметров обычно берутся из официальной статистики (Росстат, МЧС).

К сожалению, для многих объектов и явлений модели (1) и (2) не дают приемлемого описания, так как графики наблюдаемых значений результирующей переменной имеют явно криволинейное строение и не укладываются в достаточно узкую полоску на плоскости для модели (1) или не расположены в достаточной близости к гиперплоскости в модели (2).

Используются также нелинейные математические модели, где в правой части зависимости (1) помещают, помимо первых степеней некоторых параметров $x_{i}$, их вторые степени и, возможно, попарные произведения [2].

Однако при взгляде на график общего числа пожаров, произошедших в какой-либо конкретной стране (в России, США или Европе) на протяжении ряда лет, заметно, что его линия совершает непериодическое волнообразное движение и не может быть удовлетворительно описана линейной зависимостью.

В такой ситуации для более точной аппроксимации статистических данных следует использовать нелинейные зависимости. Одной из самых популярных моделей, используемых в экономике на протяжении уже более 100 лет, является функция 
Кобба-Дугласа, моделирующая величину валового внутреннего продукта (ВВП) в зависимости от двух факторов - численности работников и оценки основных фондов объекта (страны, региона, предприятия) [3]. В экономике довольно успешно используются модели, построенные на основе так называемой производственной функции вида

$$
Y=A \cdot x_{1}^{a_{1}} \cdot x_{2}^{a_{2}} \cdot \ldots \cdot x_{n}^{a_{n}},
$$

где $Y$ - моделируемая величина; $x_{1}, \ldots, x_{n}$ - наблюдаемые параметры объекта [4]. С помощью моделей вида (3) довольно успешно аппроксимируют количество продукции, выпускаемой объектом исследования за определенный период времени.

Оказалось, что та же самая производственная функция (3) может достаточно успешно оценивать количество пожаров в административно-территориальной единице за определенный период времени. В частности, в качестве такой единицы можно взять всю страну. В работах $[5,6]$ построен ряд моделей вида

$$
Y=A \cdot X_{1}^{\alpha} \cdot X_{2}^{\beta},
$$

где $Y$ - общее число пожаров (в Российской Федерации или в какой-либо другой стране); $X_{1}$ - численность населения; $X_{2}$ - величина ВВП.

Отметим любопытное свойство модели (3). Если $Y$ - оцениваемое количество продукции, выпускаемое данным объектом исследования, то в качестве параметров $x_{1}, \ldots, x_{n}$ берутся такие показатели, которые способствуют выпуску продукции. Обычно это численность работников и оценка основных фондов предприятия. Применяя эту метафору как основу для выбора модели (3) при оценке общего числа пожаров, можно считать, что пожары являются своеобразной «продукцией» социума, и для их оценки также можно использовать аналогичные показатели - численность населения (аналог числа работников предприятия) и объем основных фондов (административно-территориальной единицы)

Таким образом, в зависимости (4) под величиной $Y$ понимается продукция объекта - страны, региона, предприятия. Практика почти столетнего моделирования показывает, что это соотношение удовлетворительно описывает зависимость выпускаемой продукции как для макро-, так и для микроэкономического моделирования [6]. Можно сделать предположение, что общее число пожаров, гибель людей на них, получение травм, ущерб от пожаров можно рассматривать как своего рода «продукцию» человеческого сообщества при затратах как материальных, так и человеческих ресурсов. В работе [5] зависимость (2) была применена к аппроксимации общего числа пожаров в России и США. Оказалось, что самым удивительным образом зависимость оказалась неожиданно точной - для России коэффициент корреляции с фактическими данными составляет 0,994, а для США - 0,834. Довольно любопытным оказался тот факт, что зависимость (4) очень точно отражает динамику общего числа пожаров для большинства стран Европы [5].

Попытаемся оценить предикторные возможности как линейной модели (2), так и производственной функции (4). Обычно производственная функция в качестве параметров использует $X_{1}$ - количество населения (млн чел.) и $X_{2}$ - основные фонды РФ (fixed assets - трлн руб.).

Используем статистические данные по населению и основным фондам РФ за 2003-2015 гг. (Росстат). Статистика пожаров приведена на сайте МЧС.

Расчет линейной модели приводит к следующей зависимости:

$Y=-179,868+3,059 \cdot X_{1}-0,772 \cdot X_{2}$.

Коэффициент корреляции статистических данных с оценкой по модели (5) составляет 0,991. Отметим, что коэффициент корреляции общего числа пожаров $Y$ с оценкой основных фондов $X_{2}$ равен -0,986. Этот довольно высокий отрицательный коэффициент корреляции может навести на мысль, что при увеличении основных фондов РФ соответствующее число пожаров уменьшается, а это противоречит здравому смыслу. На рисунке 1 представлена графическая аппроксимация общего числа пожаров с помощью линейной модели (5).

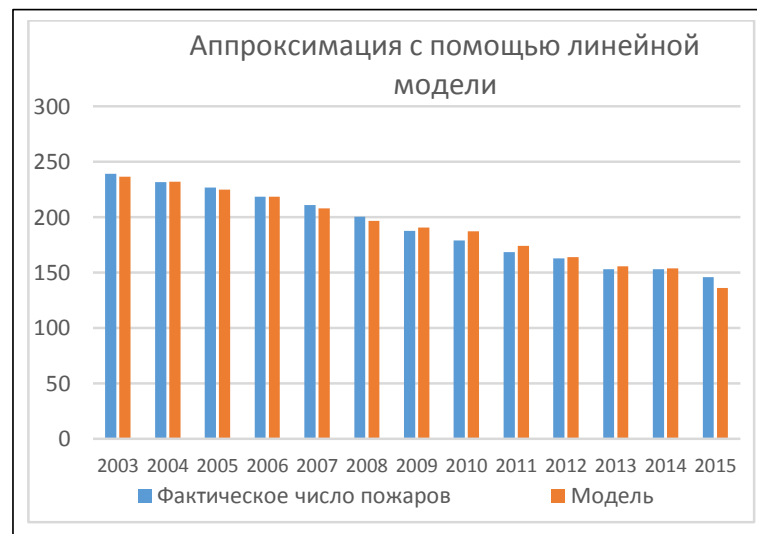

Рис. 1. Графическое представление аппроксимации линейной моделью

Fig. 1. A linear model with graphical representation of approximation

Подставляя в модель (5) сведения о численности населения и объеме основных фондов за 2016 год, получаем прогноз общего числа пожаров на 2016 год:

$Y=-179,868+3,059 \cdot 146,54-0,772 \cdot 181,62=128,19$.

Исходя из того, что в настоящий момент статистика пожаров за 2016 год известна и общее число пожаров составляет 139,70 тыс., получаем, что ошибка прогноза на 2016 год по модели (5) составляет $\eta_{\text {лин. }}=(128,19-139,70) / 139,70 \%=-8,2 \%$.

Из представленного графика видно, что прогностическая прямая (тренд) направлена вниз и уже в 
2015 году дает заниженный результат, а для 2016 года - еще более заниженный.

Рассмотрим реализацию модели (4). Ее расчет можно проводить с помощью как Microsoft Excel (надстройка «Поиск решения») [7], так и статистических пакетов (в данном случае использована программа SPSS) [8]. В результате расчета получена зависимость вида

$$
Y=1317,368 \cdot X_{1}^{(-0,132)} \cdot X_{2}^{(-0,298)}=144,74,
$$

что приводит к ошибке

$\eta_{\text {лин. }}=(144,74-139,70) / 139,70 \%=3,6 \%$.

На рисунке 2 представлена аппроксимация фактических данных с помощью модели (6).

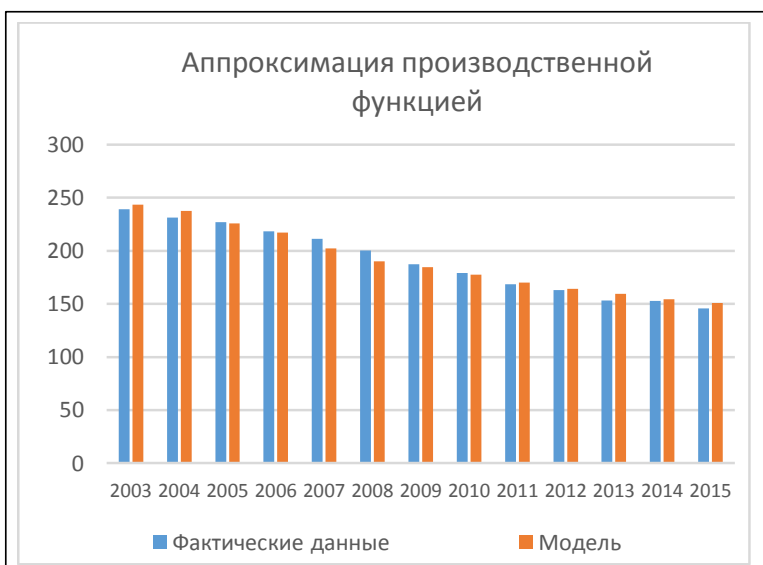

Рис. 2. Аппроксимация общего числа пожаров с помощчью производственной функичии (6)

Fig. 2. Approximation of the total number of fires using the production function (6)

Коэффициент корреляции двух временных рядов на графике рисунка 2 равен 0,988 . Из рисунка 2 и расчета погрешности для нелинейной модели (6) видно, что ее возможности для прогнозирования более обоснованны.

Обратимся теперь к еще одному применению модели (4) производственной функции [9]. Здесь в качестве аппроксимируемой величины $Y$ рассматривается полный доход гостиниц и ресторанов РФ за период с 2005 по 2014 гг. (есть официальная статистика Росстата), $X_{1}$ означает численность работников гостиниц и ресторанов, $X_{2}$ - основных фондов гостиниц и ресторанов. Расчеты показывают, что модель имеет вид

$$
Y=4,110 \cdot X_{1}^{0,836} \cdot X_{2}^{0,785} \text {. }
$$

Сравнение рассчитанных по этой модели данных с фактическими представлено на рисунке 3.

Отметим хорошо наблюдаемый на графике факт - в 2010 году произошло падение выручки, что соответствует кризисному падению экономики в это время. Любопытно, что моделирующая кривая сглаживает этот скачок. Коэффициент корреляции расчетных данных с фактическими составляет 0,971 , что отражает объективную динамику модели.
Поскольку модель (7) очень хорошо аппроксимирует данные в наблюдаемом диапазоне, ее можно использовать и как инструмент прогнозирования, то есть продолжить расчеты по данной формуле уже за пределами этого интервала.

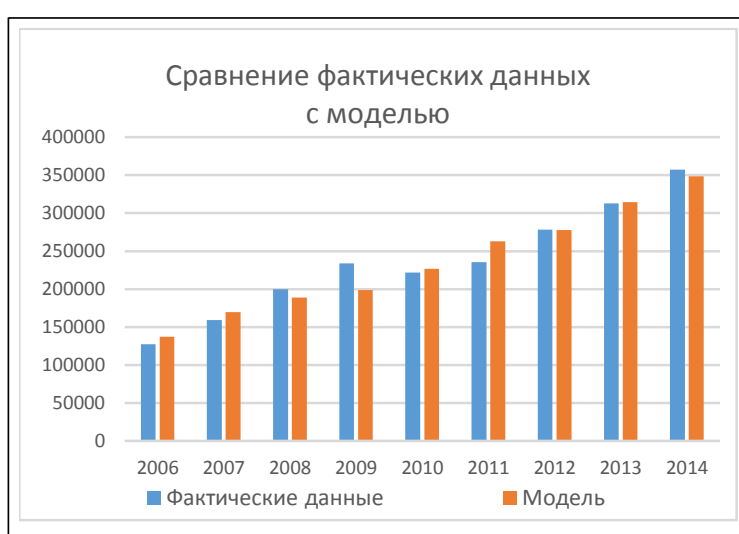

Рис. 3. Сравнение модели с фактическими данными

Fig. 3. Comparing the model and actual data

Описанная в настоящей статье модель основана на статистических данных по Российской Федерации в целом. Аналогичные модели можно строить также и для отдельных регионов, городов, предприятий.

Таким образом, можно сделать следующие выводы.

Аппроксимация отечественной статистики имеет высокое качество (у всех построенных моделей наблюдается высокая корреляция с исходными данными).

Можно строить модели для разных уровней административно-территориальной подчиненности (для городов, их кластеров, сельской местности); при этом в качестве $X_{1}$ и $X_{2}$ следует брать соответствующие показатели (население городское, сельское, ВВП города или сельской местности и т.д.).

Поскольку такое социальное явление, как преступность, также можно рассматривать в качестве своего рода «продукции» населения и ВВП (или соответствующих их разновидностей), аналогичные расчеты следовало бы провести и для аппроксимации, и, возможно, для прогнозирования преступности.

Кроме того, было бы интересно исследовать, имеют ли содержательный смысл коэффициенты модели оценки количества пожаров.

\section{Литература}

1. Смит Г., Дрейпер Н. Прикладной регрессионный анализ. М.: Диалектика, 2016.912 с.

2. Гилл Ф., Мюррей У., Райт М. Практическая оптимизация. М.: Мир, 1985. 509 с.

3. Интрилигатор И. Математические методы оптимизации и экономическая теория. М.: Айрис Пресс, 2002. 553 с.

4. Клейнер Г.Б. Производственные функции: теория, методы, применение. М.: Финансы и статистика, 1986. 354 с.

5. Пранов Б.М. О некоторых подходах к моделированию 
и прогнозированию временных рядов пожарной статистики // Технологии техносферной безопасности. 2014. № 5. URL: http://agps-2006.narod.ru/ttb/2014-5/23-05-14.ttb.pdf (дата обращения: 20.04.2018).

6. Leontief W. Input-output economics. Oxford Univ. Press, $1986,436 \mathrm{p}$.
7. Мадера А.Г. Математические модели в управлении. М.: Изд-во РГГУ, 2007. 564 с.

8. Бюль А., Цефель П. SPSS: искусство обработки информации. СПб: ДиаСофтЮП, 2005. 608 с.

9. Пранов Б.М. Модели динамики и прогнозирования в сфере гостеприимства // Вестн. РМАТ. 2017. № 1. С. 24-27.

\title{
Adequate interdisciplinary models in forecasting time series of statistical data
}

\author{
B.M. Pranov ${ }^{1}$, Dr.Sc. (Engineering), Professor, boris.pranov@gmail.com
}

${ }^{1}$ Russian Presidential Academy of National Economy and Public Administration, 2. Mockвa, 119571, Russian Federation

\begin{abstract}
Statistical studies commonly use multivariate linear models to model and predict time series. Their application area is quite extensive. They are quite effective in a situation when a set of points depicting the objects under investigation in a multidimensional parameter space is located near a certain linear subspace (or its shift relative to the origin). Factor analysis easily reveals this effect. If there is no such subspace (linear set), nonlinear dependencies are used to construct more accurate

In the economy, the Cobb-Douglas function is used to describe the dependence of enterprise profits on the number of employees and the value of fixed assets. It turns out that if we consider fires and other phenomena of society as a kind of its "production", then the Cobb-Douglas function allows approximating a corresponding time series with a high degree of accuracy. As a result, we get a number of interesting models in the new subject areas.

The results of calculations showed that the Cobb-Douglas function is good at approximating the time series of the total number of fires in the territory of the Russian Federation. The prognostic values calculated by such models are very close to the real ones. A significant number of European countries, as well as the United States use a similarly adequate approximation of the time series of the total number of fires.

Such modeling is also appropriate for a tourism industry. The paper considers the models of total hotel income depending on the number of employees and the size of fixed assets.
\end{abstract} models.

Keywords: modeling, forecasting, statistical data, approximation, time series.

\section{References}

1. Smith G., Draper N. Applied Regression Analysis. Moscow, Dialectics Publ., 2016, 912 p.

2. Gill F., Murray W., Wright M. Practical Optimization. Moscow, Mir Publ., 1985, 509 p.

3. Intraligator I. Mathematical Methods of Optimization and Economic Theory. Moscow, Iris Press, 2002, $576 \mathrm{p}$.

4. Kleiner G.B. Production Functions: Theory, Methods, Application. Moscow, Finansy i statistika Publ., 1986, 354 p.

5. Pranov B.M. Some new approach to modeling and forecasting of time series of fire statistics. Technology of Technosphere Safety. 2014, iss. 5. Available at: http://agps-2006.narod.ru/ttb/2014-5/23-05-14.ttb.pdf (accessed April 20, 2018).

6. Leontief W. Input-Output Economics. Oxford, Univ. Press, 1986.

7. Madera A.G. Mathematical Models in Management. Moscow, RGGU Publ., 2007, 564 p.

8. Bühl A., Zöfel P. SPSS Version 10. Einfuhrung in die moderne Datenanalyse unter Windows. Pearson Studium Publ., 744 p. (Russ. ed.: St. Petersburg, DiSoftTU Publ., 2005, 608 p.).

9. Pranov B.M. Dynamics and Forecasting Models in Hospitality. Vestn. RIAT. 2017, no. 1, pp. $24-27$ (in Russ.). 
УДК 519.24

Дата подачи статьи: 23.04.18

DOI: $10.15827 / 0236-235 X .123 .448-454$ 2018. Т. 31. № 3. С. 448-454

\title{
Моделирование восприятия мозгом анаграмино искалкеного текста
}

\author{
З.Д. Усманов 1, д.ф.-м.н., профессор кафедры информатики и информационных систем, \\ zafar-usmanov@rambler.ru
}

${ }_{1}$ Российско-Таджикский (Славянский) университет, г. Душанбе, 734025, Таджикистан

Объектом исследования являются тексты естественных языков, слова которых обессмыслены случайными перестановками букв. Рассматривается способность человеческого мозга безошибочно распознавать смысл непривычной продукции.

В статье предлагается математическая модель объяснения того, каким образом мозг справляется с решением этой задачи в случаях, когда а) первая, б) последняя, в) первая и последняя буквы слова остаются на своих местах, а все прочие переставляются произвольным образом, и, наконец, в самом общем случае г), когда ни одна буква слова не фиксируется и все они в пределах слова могут располагаться в любом порядке. Объяснение основывается на понятии в широком смысле анаграммы слова как совокупности его букв, расставленных в какой-либо последовательности, а также на понятии прообраза анаграммы, в роли которой выступает само слово.

В упрощенной математической модели предполагается, что мозг воспринимает каждую анаграмму изолированно; распознает ее правильно, если ей соответствует единственный прообраз, а если таких прообразов несколько, то автоматически останавливает свой выбор на том из них, который имеет наибольшую частоту встречаемости в текстах. Приемлемость такой модели проверялась на английском, литовском, русском и таджикском языках, а также на искусственном языке эсперанто. Для всех языков эффективность безошибочного распознавания искаженного текста оказывалась приблизительно одинаковой, на уровне 97-98 \%. При необходимости достижения более высоких показателей можно обратиться к расширенной модели, в которой мозг учитывает пары, а возможно, и тройки соседствующих буквенных совокупностей.

Ключевые слова: текст, анаграмма, мозг, восприятие, математическая модель.

Поводом для данного исследования послужило привлекшее внимание сообщение в Интернете. Прочтите его не по буквам и не по слогам, а как обычно читаете тексты.

По рзелульаттам илссеовадний одонго анлигйсокго унвиертисета, не иеемт занчнеия, в кокам пряоддке рсапожплень бкувы в солве. Осатьлыне бкувы мгоут селдовтаь в плоонм бсепордяке, все рвано ткест чтаитсея без побрелм. Пичрионй эгото ялвятеся то, что мы не чиатем кдаужю бкуву по отдльенотси, а все солво иликеом.

Составив на английском, литовском, русском, таджикском языках и на языке эсперанто разнообразные тексты, делая во всех словах случайные перестановки букв и выставив такое творчество на обозрение, можно убедиться в том, что респонденты без затруднений понимают содержание полученного «произведения».

\section{Постановка задачи}

Примем, что текст какого-либо естественного языка является анаграммно искаженным, если каждому его слову сопоставлен набор из тех же самых букв, но расставленных в произвольном порядке. Фрагмент из Интернета как раз является примером такого текста. Каким же образом человеческий мозг легко справляется с его прочтением, восприятием и пониманием?

Предлагаемая далее математическая модель распознавания мозгом содержания искаженного текста основывается на гипотезе (упрощенной), состоящей из трех пунктов:

- мозг воспринимает текст пословно;

- мозг распознает слово правильно, если из заданного набора букв может быть составлено одно и только одно слово;

- мозг допускает ошибку, если из заданного набора букв может быть составлено несколько слов.

В двух последних пунктах в неявном виде просматривается понятие анаграммы. Поскольку в настоящей статье оно будет использоваться в несколько нетрадиционном смысле, приведем вначале два общеизвестных определения.

В энциклопедии анаграмма означает слово или словосочетание, образованное перестановкой букв другого слова или словосочетания.

В толковом словаре русского языка анаграммa - это перестановка букв, посредством которой из одного слова составляется другое.

Из первого определения следует, что анаграмма - слово, а из второго - процедура (перестановка букв). В дальнейшем будем пользоваться обоими определениями, а также и следующим: анаграмма - это конечное множество (по крайней мере, пара) слов естественного языка, составленных из одного и того же набора букв.

Анаграмму естественно называть тривиальной, если она состоит из одного элемента-слова. Рассмотрим, как обстоит дело с нетривиальными анаграммами в некоторых языках. 


\section{Инструмент для формирования подмножеств словоформных анаграмм}

Пусть $L-$ естественный язык с алфавитом $A$ и $W={ }^{\prime \prime} \alpha_{1} \alpha_{2} \ldots \alpha_{n}$ " - некоторое слово длины $n$, состоящее из букв $\alpha_{k} \in A$. Рассмотрим цепочку $C W=$ $=" \alpha_{s 1} \alpha_{s 2} \ldots \alpha_{s n} "$, составленную из тех же самых букв, что и слово $W$, но упорядоченных по алфавиту.

Определение 1. Отображение $F: W \rightarrow C W$ назовем упорядоченным алфавитным кодированием ( $\alpha \beta$-кодированием) слова $W$, а цепочку букв $C W-$ его $\alpha \beta$-кодом [1].

Для пояснения определения укажем, что $\alpha \beta$-кодирование, например, слова $W=$ “реферат” приводит к цепочке $C W=$ "аеерртф $\phi$ ", а слова $W=$ = “агент" - к той же самой цепочке $C W=$ “агент", поскольку в этом слове буквы уже расположены в алфавитном порядке.

Кодирующее отображение $F: W \rightarrow C W$ является однозначным, декодирующее $F^{-1}: C W \rightarrow W$, вообще говоря, является многозначным, поскольку коду могут соответствовать несколько словоформ. Нарушение однозначности происходит на образах анаграмм. Например, цепочке букв $C W=$ = “иикопрт" соответствует анаграмма из двух прообразов (тропики - киприот).

Всякой анаграмме соответствует единственный образ, соответствующий $\alpha \beta$-код. Этот факт подсказывает простой способ извлечения множества словоформных анаграмм из какого-либо текста. Вначале следует построить частотный словарь словоформ, затем каждой словоформе сопоставить ее $\alpha \beta$-код и, наконец, скомпоновать в подмножества словоформы с одинаковыми $\alpha \beta$-кодами.

\section{Исследование декодирующего отображения $F^{-1}$}

Обратимся к таблице 1. В ней в 1-м столбце представлен список языков, во 2-м - размеры (в словах) коллекций текстов. Результаты обработки исходных данных приведены в последующих столбцах: в 3-м указывается число различных словоформ, обнаруженных в коллекциях; в 4-м - число различных $\alpha \beta$-кодов словоформ; в 5-м и 6-м из общего числа кодов выделяются однозначные и многозначные, а в 7-м и 8-м столбцах данные 5-го и 6-го столбцов показаны в процентах.

Из столбцов 5-6 и 7-8 таблицы 1 видно, что для рассматриваемых языков количество однозначно декодируемых кодов на порядок больше суммарного количества кодов анаграмм. Полученный результат, отдавая приоритет однозначно декодируемым кодам, создает искаженную картину об обратном отображении $F^{-1}$, ибо не принимает в расчет частотности кодов и тех, и других.
Уточненные свойства $F^{-1}$ выявляются в столбцах 4 и 6 таблицы 2. Действительно, в этих столбцах приводятся данные о суммарных частотах встречаемости однозначно декодируемых и двусмысленных (многозначных) кодов для соответствующих коллекций. Эти данные, пересчитанные в столбцах 4 и 6 в процентах, показывают недостаточно приемлемый для практических целей уровень декодирования слов, реализуемый отображением $F^{-1}$ : относительные частоты встречаемости элементов анаграмм для отмеченных языков группируются вокруг значения 0,5. Иначе говоря, почти каждое второе слово из корпуса текстов принадлежит множеству анаграмм.

\section{Определение модифицированного отображения $\boldsymbol{F}^{(*)}$}

Итак, $\alpha \beta$-кодирование, будучи удобным средством для выявления всевозможных элементов анаграмм, оказывается неэффективным для декодирования. В связи с этим обратимся к отображению $F^{(*)}$, которое наделим следующими свойствами [1]:

- как и $F$, оно определено на множестве $\{W\}$ слов естественного языка $L$;

- как и $F$, оно ставит в соответствие слову $W$ его $\alpha \beta$-код, то есть $F^{(*)}: W \rightarrow C W$;

- обратное отображение $F^{(*)-1}$ на множестве однозначно декодируемых кодов совпадает с $F^{-1}$, а на множестве многозначных кодов (образов анаграмм) каждому образу $C W$ ставит в соответствие единственное слово $W^{*}$, которое имеет максимальную частоту встречаемости в текстах в сравнении с другими словами из набора слов рассматриваемой анаграммы.

Последнее свойство назовем $F^{(*)}$-схемой декодирования. Очевидно, что принятие решений по этой схеме имеет вероятностный характер и предполагает возможность допущения ошибки в случаях, когда при правильном декодировании на выходе должно появиться слово не с максимальной частотой.

Практическое использование отображения $F^{(*)}$ предполагает наличие развитой БД $\{W \Leftrightarrow C W\}$, peализующей взаимно однозначное соответствие между элементами множеств $\{W\}$ и $\{C W\}$. Поскольку установление такого соответствия основывается на отмеченных свойствах функции $F^{(*)}$, ее априорную эффективность естественно определять суммарной частотой слов, $\alpha \beta$-коды которых декодируются по $F^{(*)}$-схеме. Соответствующие данные, приведенные в столбцах 7 и 8 таблицы 2, указывают на высокий уровень такого декодирования (не менее 94 \% для эсперанто и 97 \% для других языков).

Итак, $F^{(*)}$-отображение можно трактовать как математическую модель работы распознающего 
The statistical properties of displaying $F: W \rightarrow C W$

\begin{tabular}{|c|c|c|c|c|c|c|c|}
\hline Язык & $\begin{array}{c}\text { Размер } \\
\text { коллекции } \\
\text { текстов } \\
\end{array}$ & $\begin{array}{c}\text { Число } \\
\text { словоформ }\end{array}$ & 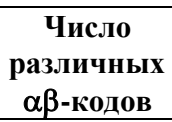 & \begin{tabular}{|c|} 
Число одно- \\
значных \\
кодов \\
\end{tabular} & $\begin{array}{c}\text { Число мно- } \\
\text { гозначных } \\
\text { кодов } \\
\end{array}$ & $(5) /(4), \%$ & $(6) /(4), \%$ \\
\hline 1 & 2 & 3 & 4 & 5 & 6 & 7 & 8 \\
\hline Английский & 11252496 & 137732 & 119055 & 106841 & 12214 & 89,7 & 10,3 \\
\hline Литовский & 34165084 & 693995 & 605039 & 546254 & 58785 & 90,3 & 9,7 \\
\hline Русский & 19175074 & 509031 & 462886 & 430517 & 32369 & 93,0 & 7,0 \\
\hline Эсперанто & 5080195 & 165570 & 147220 & 133851 & 13369 & 90,9 & 9,1 \\
\hline
\end{tabular}

Таблица 2

Частотности кодов

Table 2

Code frequencies

\begin{tabular}{|l|c|c|c|c|c|c|c|}
\hline Язык & $\begin{array}{c}\text { Размер кол- } \\
\text { лекции }\end{array}$ & $\begin{array}{c}\text { Частоты } \\
\text { однозначных } \\
\text { кодов }\end{array}$ & $\begin{array}{c}\text { Отноше- } \\
\text { ние } \\
\mathbf{( 3 ) / ( 2 ) , \%}\end{array}$ & $\begin{array}{c}\text { Частоты } \\
\text { многозначных } \\
\text { кодов }\end{array}$ & $\begin{array}{c}\text { Отноше- } \\
\text { ние } \\
\mathbf{( 5 ) / ( 2 ) , ~ \% ~}\end{array}$ & $\begin{array}{c}\text { Частоты слов, } \\
\text { декодируемых } \\
\text { по } \boldsymbol{F}^{*} \text {-схеме }\end{array}$ & $\begin{array}{c}\text { Отноше- } \\
\text { ние } \\
\mathbf{( 7 ) / ( 2 ) , \%}\end{array}$ \\
\hline $\mathrm{E}$ & 2 & 3 & 4 & 5 & 6 & 7 & 8 \\
\hline $\mathrm{En}$ & 11252496 & 4738825 & 42,1 & 6513671 & 57,9 & 10961792 & 97,4 \\
\hline $\mathrm{Lt}$ & 34165084 & 15637702 & 45,8 & 18527382 & 54,2 & 33199335 & 97,2 \\
\hline $\mathrm{Tj}$ & 19175074 & 10413280 & 54,3 & 8761794 & 45,7 & 18724384 & 97,7 \\
\hline $\mathrm{Eg}$ & 2323965 & 1152420 & 49,6 & 1171545 & 50,4 & 2280334 & 98,1 \\
\hline
\end{tabular}

мозга. Действительно, всякий раз, когда приходится иметь дело с очередным «сумбурным» словом, мозг интуитивно сопоставляет ему то единственное слово (с той же самой совокупностью букв), которое встречалось в его практике чаще других слов из их общей анаграммы. Именно такое свойство мозга заключено в $F^{(*)}$-схеме.

Обратим внимание еще на одну важную сторону $F^{(*)}$-отображения. Оно указывает, что исследование (а фактически заключение) «...одного английского университета», представленное во введении настоящей статьи, является неточным: для понимания анаграммно испорченного текста нет никакой необходимости фиксировать неподвижными первую и последнюю буквы слова (остальные перемешивать произвольно).

Далее рассмотрим другие модели понимания текста, которые в сравнении с $F^{(*)}$-моделью подчиняются дополнительным ограничениям. Априори очевидно, что такие модели будут иметь более высокий процент безошибочного восприятия текстов, однако, как будет показано далее, повышение точности не будет столь принципиальным.

$\boldsymbol{F}^{(*)}$-модель распознавания текста (фиксируются неизменными первые буквы слов).

Функция $F^{(f)}$ задается на множестве $\{W\}$ слов естественного языка $L$.

Определение 2. Отображение $F^{(f)}$ слову W cmaвит в соответствие цепочку $\alpha_{1} C\left(W / \alpha_{1}\right)$, в которой

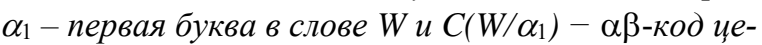
почки $W / \alpha_{1}$, по есть слова $W$ без первой буквы.
В отличие от $F$ это отображение оставляет в слове $W$ неизменной первую букву, то есть $\alpha_{1}$, и упорядочивает по алфавиту прочие буквы. Из общих соображений ясно, что декодирование $\alpha_{1} C\left(W / \alpha_{1}\right) \rightarrow W$ в определенном смысле обладает лучшими свойствами, чем $C W \rightarrow W$.

Пример. Обратимся к анаграмме $\{W: W=a b-$ тор, втора, отвар, рвота, тавро, товар $\}$. Отображение $F^{(f)}$ первые четыре элемента кодирует следующим образом: аворт, ваорт, оаврт, равот, оставляя неизменными первые буквы элементов анаграммы (отмечены жирным шрифтом) и располагая в алфавитном порядке прочие буквы. Этим кодам однозначно соответствуют первые четыре элемента анаграммы. Пятый и шестой элементы анаграммы кодируются одинаково - тавро.

$\boldsymbol{F}^{(f, l)}$-модель распознавания текста (не изменены первые и последние буквы слов).

Как и $F^{(f)}$, функция $F^{(f, l)}$ задается на множестве $\{W\}$ слов естественного языка $L$.

определение 3. $F^{(f, l)}: W \rightarrow \alpha_{1} C\left(W /\left\{\alpha_{1}, \alpha_{n}\right\}\right) \alpha_{n}$.

В нем $\alpha_{1}-$ первая и $\alpha_{n}-$ последняя буквы слова $W$ остаются неподвижными, а цепочка букв между ними, то есть $W /\left\{\alpha_{1}, \alpha_{n}\right\}$, подвергается $\alpha \beta$-кодированию.

Теперь рассмотрим применение отображения $F^{(f, l)}$ к той же анаграмме, что и в примере для $F^{(f)}$. В этом случае первая и последняя буквы (далее показаны жирным шрифтом) элементов анаграмм должны оставаться неизменными, а все другие буквы упорядочиваются по алфавиту. Результаты 
кодирования записываются в виде: авотр, ворта, оавтр, рвота, тавро, тавор, то есть все шесть слов рассматриваемой анаграммы получили собственные коды. Декодирование с помощью обратной функции также однозначно.

Итак, в сравнении с $F$ отображения $F^{(f)}$ и $F^{(f, l)}$ несколько сложнее, зато наверняка успешнее в вопросах декодирования (см. табл. 3). Отметим также, что $F^{(f, l)}$ - именно то отображение, о котором шла речь в начале статьи.

Отметим, что для отображения $F$ речь идет об анаграммах в смысле приведенного определения, а для отображений $F^{(f)}$ и $F^{(f, l)}-$ о соответствующим образом модернизированных анаграммах.

\section{Замечание относительно отображений $\boldsymbol{F}^{(f)}$ и $\boldsymbol{F}^{(f, l)}$}

Из данных столбцов 8 и 9 видно, что для рассматриваемых языков количество различных однозначно декодируемых кодов на порядок больше суммарного количества различных кодов анаграмм. Отметим, что здесь имеется в виду список слов частотных словарей, причем без учета частот их встречаемости. Полученный результат, отмечающий высокий процент однозначно декодируемых кодов, создает, однако, искаженную картину мощности множества слов, входящих в состав анаграмм. Сделанный вывод подтверждает дальнейшее исследование, результаты которого представлены в таблице 4.
Прежде чем переходить к рассмотрению этой таблицы, объясним смысл обозначений $\bar{F}=F^{(*)}$, $\bar{F}^{(f)}$ и $\bar{F}^{(f, l)}$. Как отмечалось ранее, отображения $F, F^{(f)}$ и $F^{(f, l)}$ каждому слову приписывают единственный код, однако обратные отображения в общем случае не обеспечивают однозначного декодирования. Использование отображений $\bar{F}=F^{(*)}$, $\bar{F}^{(f)}$ и $\bar{F}^{(f, l)}-$ это по существу попытка устранения неоднозначности при декодировании анаграмм и распознавании порождающих их прообразов за счет использования дополнительных атрибутов, присоединяемых к $\alpha \beta$-кодированию.

Определения отображений $\bar{F}, \bar{F}^{(f)}$ и $\bar{F}^{(f, l)}$

Определение 4. Отображения $\bar{F}, \bar{F}^{(f)}$ и $\bar{F}^{(f, l)}$ обладают следующими свойствами:

- задаются на множестве слов $\{W\}$ языка L;

- совпадают, соответственно, с $F, F^{(f)}$ и $F^{(f, l)}$ при кодировании слов;

- их обратные отображения $(\bar{F})^{-1},\left(\bar{F}^{(f)}\right)^{-1} u$ $\left(\bar{F}^{(f, l)}\right)^{-1}$ на кодах, однозначно декодируемых, совпадают, соответственно, с $F^{-1},\left(F^{(f)}\right)^{-1},\left(F^{(f, l)}\right)^{-1}$, а на кодах анаграмм каждому из них ставят в соответствие единственное слово $W^{*}$, которое имеет максимальную частоту встречаемости в текстах в сравнении с другими словами с одинаковым кодом.

Таблича 3

Свойства отображений $\boldsymbol{F}^{(f)}$ и $\boldsymbol{F}^{(f, l)}$

Table 3

The properties of displaying $\boldsymbol{F}^{(f)}$ and $\boldsymbol{F}^{(f, l)}$

\begin{tabular}{|c|c|c|c|c|c|c|c|c|}
\hline Язык & $\begin{array}{c}\text { Размер } \\
\text { коллек- } \\
\text { ции }\end{array}$ & $\begin{array}{c}\text { Число } \\
\text { слово- } \\
\text { форм }\end{array}$ & $\begin{array}{r}\text { Тип } \\
\text { кода }\end{array}$ & $\begin{array}{c}\text { Число различ- } \\
\text { ных кодов }\end{array}$ & $\begin{array}{c}\text { Число одно- } \\
\text { значных кодов }\end{array}$ & $\begin{array}{c}\text { Число много- } \\
\text { значных кодов }\end{array}$ & $\begin{array}{c}\text { Отношение } \\
(6) /(5), \%\end{array}$ & $\begin{array}{c}\text { Отношение } \\
(7) /(5), \%\end{array}$ \\
\hline 1 & 2 & 3 & 4 & 5 & 6 & 7 & 8 & 9 \\
\hline \multirow{3}{*}{ En } & \multirow{3}{*}{11252496} & \multirow{3}{*}{137732} & \multirow{3}{*}{$\begin{array}{l}F \\
F^{(f)} \\
F^{(f, l)}\end{array}$} & 119055 & 106841 & 12214 & 89.74 & 10.26 \\
\hline & & & & 130644 & 124366 & 6278 & 95.19 & 4.81 \\
\hline & & & & 135618 & 133570 & 2048 & 98.49 & 1.51 \\
\hline \multirow{3}{*}{$\mathrm{Lt}$} & \multirow{3}{*}{34165084} & \multirow{3}{*}{693995} & \multirow{3}{*}{$\begin{array}{l}F \\
F^{(f)} \\
F^{(f, l)}\end{array}$} & 605039 & 546254 & 58785 & 90.28 & 9.72 \\
\hline & & & & 654475 & 621487 & 32988 & 94.96 & 5.04 \\
\hline & & & & 675208 & 657925 & 17283 & 97.44 & 2.56 \\
\hline \multirow{3}{*}{$\mathrm{Ru}$} & \multirow{3}{*}{19175074} & \multirow{3}{*}{509031} & \multirow{3}{*}{$\begin{array}{l}F \\
F^{(f)} \\
F^{(f, l)}\end{array}$} & 462886 & 430517 & 32369 & 93.01 & 6.99 \\
\hline & & & & 488286 & 470336 & 17950 & 96.32 & 3.68 \\
\hline & & & & 500433 & 492360 & 8073 & 98.39 & 1.61 \\
\hline \multirow{3}{*}{$\mathrm{Tj}$} & \multirow{3}{*}{2323965} & \multirow{3}{*}{87181} & \multirow{3}{*}{$\begin{array}{l}F \\
F^{(f)} \\
F^{(f, l)}\end{array}$} & 80080 & 74512 & 5568 & 93.05 & 6.95 \\
\hline & & & & 84220 & 81501 & 2719 & 96.77 & 3.23 \\
\hline & & & & 85805 & 84499 & 1306 & 98.48 & 1.52 \\
\hline \multirow{3}{*}{ Eo } & \multirow{3}{*}{5080195} & \multirow{3}{*}{165570} & \multirow{3}{*}{$\begin{array}{l}F \\
F^{(f)} \\
F^{(f, l)}\end{array}$} & 147220 & 133851 & 13369 & 90.92 & 9.08 \\
\hline & & & & 158310 & 151885 & 6425 & 95.94 & 4.06 \\
\hline & & & & 162940 & 160407 & 2533 & 98.45 & 1.55 \\
\hline
\end{tabular}


Пример. Положим, что в анаграмме $\{W: W=\kappa a$ зан, казна, наказ $\}$ наибольшую частоту в корпусе текстов имеют слово наказ, затем казна. При отображении $F(=\bar{F})$ рассматриваемой анаграмме будет соответствовать код аазкн, которому отображение $(\bar{F})^{-1}$ поставит в соответствие слово наказ.

Если же применить отображение $\bar{F}^{(f)}\left(=F^{(f)}\right)$, то первые два слова анаграммы получат одинаковый код каазн, а третье слово - код наазк (напомним, что при кодировании первые буквы в словах анаграмм фиксируются). Коду каазн будет сопоставляться слово казна, у которого частота больше, чем у слова казан.

Замечание. Предлагаемый в определении 4 метод выбора единственного прообраза того или иного кода анаграммы носит вероятностный характер. Он не исключает возможности принятия ошибочного решения в случаях, когда при правильном декодировании на выходе должно появиться слово не с максимальной частотой.

В таблице 4 приводятся результаты статистической обработки данных коллекций текстов с учетом определений трех типов кодирования словоформ.
Поясним эту таблицу. В ней первые два столбца - те же, что и в таблице 3 . Столбец 3 отмечает три типа используемых способов кодирования слов. Столбцы 4-7 по существу продолжают таблицу 3. С учетом того, что, согласно определению 4 , при кодировании слов отображения $F$ и $\bar{F}, F^{(f)}$ и $\bar{F}^{(f)}, F^{(f, l)}$ и $\bar{F}^{(f, l)}$ совпадают, эти столбцы представляют информацию о частотах встречаемости однозначно декодируемых кодов и элементов анаграмм (многозначных кодов), причем столбцы 4 и 6 информируют об абсолютных, а 5 и 7 - об относительных значениях частот, выраженных в процентах по отношению к общему количеству слов (словоупотреблений) текстовых коллекций.

Из данных столбцов 4-7 и пяти строк, привязанных к отображению $\bar{F}$, видно, что для всех языков, за исключением русского, слова, являющиеся элементами анаграмм, составляют более половины общего числа слов (словоупотреблений) текстовых коллекций (для русского языка - 45,69 \%). По этой причине при перемешивании всех букв в слове читающий мозг будет допускать много ошибок.

Таблица 4

Свойства отображений $\bar{F}, \bar{F}^{(f)}$ и $\bar{F}^{(f, l)}$

Table 4

The properties of displaying $\bar{F}, \bar{F}^{(f)}$ and $\bar{F}^{(f, l)}$

\begin{tabular}{|c|c|c|c|c|c|c|c|c|}
\hline Язык & $\begin{array}{c}\text { Размер } \\
\text { коллек- } \\
\text { ции }\end{array}$ & $\begin{array}{r}\text { Тип } \\
\text { кода }\end{array}$ & $\begin{array}{c}\text { Частота од- } \\
\text { нозначных } \\
\text { кодов }\end{array}$ & $\begin{array}{c}\text { Отноше- } \\
\text { ние }(4) /(2), \\
\%\end{array}$ & \begin{tabular}{|c|} 
Частота \\
многознач- \\
ных кодов \\
\end{tabular} & $\begin{array}{c}\text { Отношение } \\
\text { (6)/(2), \% }\end{array}$ & \begin{tabular}{|c|} 
Частота слов, \\
декодируемых \\
по опр. 4 \\
\end{tabular} & $\begin{array}{l}\text { Отношение } \\
(\mathbf{8}) /(2), \%\end{array}$ \\
\hline 1 & 2 & 3 & 4 & 5 & 6 & 7 & 8 & 9 \\
\hline \multirow{3}{*}{ Eng } & \multirow{3}{*}{11252496} & $\bar{F}$ & 4738825 & 42.11 & 6513671 & 57.89 & 10961792 & 97.42 \\
\hline & & $\bar{F}^{(f)}$ & 8282101 & 73.60 & 2970395 & 26.40 & 11179579 & 99.35 \\
\hline & & $\bar{F}^{(f, l)}$ & 10830821 & 96.25 & 421675 & 3.75 & 11224361 & 99.75 \\
\hline \multirow{3}{*}{$\mathrm{Lt}$} & \multirow{3}{*}{34165084} & $\bar{F}$ & 15637702 & 45.77 & 18527382 & 54.23 & 33199335 & 97.17 \\
\hline & & $\bar{F}^{(f)}$ & 23737620 & 69.48 & 10427464 & 30.52 & 33834328 & 99.03 \\
\hline & & $\bar{F}^{(f, l)}$ & 28999545 & 84.88 & 5165539 & 15.12 & 34028900 & 99.60 \\
\hline \multirow{3}{*}{$\mathrm{Ru}$} & \multirow{3}{*}{19175074} & $\bar{F}$ & 10413280 & 54.31 & 8761794 & 45.69 & 18724384 & 97.65 \\
\hline & & $\bar{F}^{(f)}$ & 14490319 & 75.57 & 4684755 & 24.43 & 19063618 & 99.42 \\
\hline & & $\bar{F}^{(f, l)}$ & 16449834 & 85.79 & 2725240 & 14.21 & 19145587 & 99.85 \\
\hline \multirow{3}{*}{$\mathrm{Tj}$} & \multirow{3}{*}{2323965} & $\bar{F}$ & 1152420 & 49.59 & 1171545 & 50.41 & 2280334 & 98.12 \\
\hline & & $\bar{F}^{(f)}$ & 1759262 & 75.70 & 564703 & 24.30 & 2309336 & 99.37 \\
\hline & & $\bar{F}^{(f, l)}$ & 2021532 & 86.99 & 302433 & 13.01 & 2316348 & 99.67 \\
\hline \multirow{3}{*}{ Eo } & \multirow{3}{*}{5080195} & $\bar{F}$ & 1788681 & 35.21 & 3291514 & 64.79 & 4782380 & 94.14 \\
\hline & & $\bar{F}^{(f)}$ & 4185715 & 82.39 & 894480 & 17.61 & 5033967 & 99.09 \\
\hline & & $\bar{F}^{(f, l)}$ & 4834326 & 95.16 & 245869 & 4.84 & 5068691 & 99.77 \\
\hline
\end{tabular}


Из пяти ячеек, стоящих на пересечении столбца 7, и пяти строк, привязанных к отображению $\bar{F}^{(f)}$, видно, что относительная частотность многозначных кодов располагается между значениями $17,61 \%$ (эсперанто) и 30,52 \% (литовский язык). Это и предопределяет невозможность достаточно успешного восприятия смысла слов с фиксированной первой буквой.

Из пяти ячеек, стоящих на пересечении столбца 7, и пяти строк, привязанных к отображению $\bar{F}^{(f, l)}$, видно, что частотности многозначных кодов среди общего числа словоупотреблений равны 4,84 \% и $3,75 \%$ соответственно для эсперанто и английского языка, то есть являются относительно малыми величинами, вследствие чего читающий мозг в большинстве случаев правильно справляется с пониманием слов искаженного текста. Наряду с этим в трех других языках частотность многозначных кодов примерно на 10 \% выше, поэтому ошибочность в понимании искаженных слов будет недопустимой для практического применения $\bar{F}^{(f, l)}$-модели.

Итак, несмотря на то, что количество различных однозначно декодируемых слов (словоформ) оказалось на порядок больше количества различных слов, входящих в состав анаграмм (см. данные столбцов 8 и 9 для строк $F$-отображения), частоты встречаемости рассматриваемых элементов в тестовых коллекциях пяти языков оказались одного порядка.

Последние два столбца, 8-й и 9-й, таблицы 4 выдают количественные показатели эффективности декодирования в соответствии с определением 4. Для всех пяти языков ошибки принятия неверных решений заключаются в пределах $1 \%$ при декодировании посредством $\left(F^{(f)}\right)^{-1}$ и $\left(\bar{F}^{(f, l)}\right)^{-1}$ и не превосходят $3 \%$ при декодировании с помощью $(\bar{F})^{-1}$ (для эсперанто - не более 6 \%).

\section{Обсуждение результатов}

Итак, отображения $\bar{F}=F^{(*)}, \quad \bar{F}^{(f)}$ и $\bar{F}^{(f, l)}$ можно рассматривать в качестве математических моделей функционирования мозга, распознающего смысл анаграммно искаженного текста. В согласии с этим процесс понимания мозгом произвольного набора букв происходит следующим образом:

- если набору букв соответствует однозначный $\alpha \beta$-код, мозг сопоставляет ему единственную словоформу;

- если набору букв соответствует многозначный $\alpha \beta$-код, мозг сопоставляет ему ту словоформу из анаграммы, которая имеет максимальную частоту встречаемости.
Математическая модель, описываемая отображением $\bar{F}$, охватывает более общую ситуацию в сравнении с $\bar{F}^{(f)}$ и $\bar{F}^{(f, l)}$. В ней нет по существу каких-либо ограничений на характер перестановок букв в слове. Вместе с тем она обеспечивает достаточно высокий уровень (не менее 97 \%) распознавания смысла искаженных слов, уступая двум другим моделям в точности результата не более чем на $2 \%$ (см. столбец 9). Если сравнивать эффективность моделей по этим двум факторам, предпочтение следовало бы отдать $\bar{F}$-отображению.

\section{Гипотеза (расширенная) распознавания искаженного текста}

Предложенные в настоящей статье математические модели основывались на гипотезе восприятия каждого искаженного слова в отдельности. Даже в этом случае удалось добиться почти безошибочного понимания их смысла в искаженном тексте. При необходимости достижения более точных результатов можно обратиться к цепям Маркова $[2,3]$, привлекая для анализа пары соседствующих слов (так называемые словоформные биграммы), которые привнесут дополнительную информацию о семантической связи слов. Последние должны быть предварительно распознаны с помощью, например, $\bar{F}$-модели.

\section{Заключение}

Настоящая статья по содержанию созвучна работам [4] и [5], в которых обсуждается утверждение Г. Роулинсона о том, что случайное расположение букв в середине слов либо слабо влияет, либо совсем не влияет на способность квалифицированного читателя понимать текст. При этом авторы проходят мимо того факта, что если искаженному слову соответствует многозначный код, то для его правильного восприятия мозг интуитивно использует накопленную в регулярных чтениях информацию о частотности слов, входящих в анаграмму, и извлекает из памяти то слово, которое имеет максимальную частоту.

\section{Литература}

1. Усманов 3.Д. Об упорядоченном алфавитном кодировании слов естественных языков // ДАН РТ. 2012. Т. 55. № 7. C. $545-548$.

2. Марков А.А. Исчисление вероятностей. М.: ГИЗ, 1924. $589 \mathrm{c}$.

3. Гнеденко Б.В. Курс теории вероятностей. М.: Физматгиз, $1961.408 \mathrm{c}$.

4. Rawlinson G.E. The significance of letter position in word recognition: PhD Thesis. Univ. of Nottingham Publ., UK, 1976.

5. MRC Cognition and Brain Sciences Unit. URL: http://www.mrc-cbu.cam.ac.uk/people/matt.davis/Cmabrigde (дата обращения: 20.02.2018). 


\section{Modeling brain activity recognizing anagrammatically distorted words}

\section{Z.D. Usmanov ${ }^{1}$, Dr.Sc. (Physics and Mathematics), Professor, zafar-usmanov@ rambler.ru}

${ }^{1}$ The Russian-Tajik (Slavonic) University (RTSU), Dushanbe, 734025, Tajikistan

Abstract. The object of research are natural language texts the words in which were corrupted by random letter transpositions. The authors analyze the ability of a human brain to accurately recognize the meaning of distorted texts. offer mathematical models how the brain decides the problem.

The paper describes a mathematical model that explains how the brain solves the problem in cases when a) the first, b) the last, c) the first and last letters of words remain in their places, and all others are reset arbitrarily and, finally, in the most general case, d) when no letter is fixed and all letters within a word can be placed in any order. The explanation is based on the concept of a word anagram (in the broad sense, the set of its letters arranged in any sequence) as well as on the concept of an anagram prototype.

A simplified mathematical model assumes that the brain perceives each anagram separately; recognizes it correctly if it has a single prototype. In the case when there are several such prototypes, the brain automatically selects the one that has the highest frequency of occurrence in texts. The acceptability of this model was tested in English, Lithuanian, Russian and Tajik, as well as in the artificial language such as Esperanto. For all languages, efficiency of the correct recognition of distorted text was at the level of $97-98 \%$. If it is necessary to achieve higher indicators, one can refer to an extended idea in which the brain takes into account couples, and maybe triples of neighboring letter sets.

Keywords: text, anagram, brain, perception, mathematical model.

\section{References}

1. Usmanov Z.D. On the Ordered Alphabetic Coding of Natural Language Words. Reports of the Academy of Sciences of the Republic of Tajikistan. 2012, vol. 55, no 7, pp. 545-548 (in Russ.).

2. Markov A.A. Calculus of Probabilities. Moscow, GIZ, 1924, 589 p.

3. Gnedenko B.V. Course of the Probability Theory. Moscow, Fizmatgiz Publ., 1961, 408 p.

4. Rawlinson G.E. The Significance of Letter Position in the Word Recognition: Unpublished. Univ. of Nottingham Publ., UK, 1976.

5. MRC Cognition and Brain Sciences Unit. Available at: http://www.mrc-cbu.cam.ac.uk/people/matt.davis/Cmabrigde (accessed February 20, 2018).

\section{Примеры библиографического описания статьи}

1. Усманов 3.Д. Моделирование восприятия мозгом анаграммно искаженного текста // Программные продукты и системы. 2018. Т. 31. № 3. С. 448-454. DOI: 10.15827/0236-235X.123.448-454.

2. Usmanov Z.D. Modeling brain activity recognizing anagrammatically distorted words. Software \& Systems. 2018, vol. 31, no. 3, pp. 448-454 (in Russ.). DOI: 10.15827/0236-235X.123.448-454. 


\title{
Модели сопровождения информаиионных систем предприятия
} по этапам жизненного иикла

\author{
Ю.М. Аисеикий 1, д.т.н., генеральный директор, Yurii.Lisetskyi@snt.ua \\ 1 ДП «ЭС ЭНД ТИ УКРАИНА", г. Киев, 03680, Украина
}

В статье рассмотрено предприятие как сложная организационная система, для эффективного функционирования которой необходима современная информационная система управления, позволяющая осуществлять сбор, хранение и обработку информации для повышения степени обоснованности и своевременности принимаемых решений. Решение этой задачи возможно на основе комплексной автоматизации управления всеми производственными и технологическими процессами предприятия, а также необходимыми ресурсами.

Показано, что формирование описания информационной системы предприятия осуществляется с помощью модели жизненного цикла, которая определяет порядок выполнения этапов разработки, а также критерии перехода от этапа к этапу. Под моделью жизненного цикла информационной системы понимается структура, определяющая последовательность выполнения и взаимосвязь процессов, действий и задач в течение жизненного цикла. Структура жизненного цикла информационной системы базируется на трех группах процессов: основных (приобретение, поставка, разработка, эксплуатация, сопровождение), вспомогательных (документирование, управление конфигурацией, обеспечение качества, верификация, аттестация, оценка, аудит, решение проблем) и организационных (создание инфраструктуры проекта, управление проектом, определение, оценка и улучшение самого жизненного цикла, обучение).

Приведены наиболее распространенные модели жизненного цикла: каскадная (водопадная), модель итеративной и инкрементальной разработки (поэтапная модель с промежуточным контролем) и спиральная. Показано, что в процессе исследований и проектирования информационная система предприятия выступает пассивной категорией, процесс функционирования которой может быть описан моделями сопровождения по этапам жизненного цикла: моделью строения, моделью функционирования и моделью развития. Разработка этой тройки моделей является также дополнительным информационным фактором, позволяющим осуществлять структуризацию процесса создания и функционирования информационной системы предприятия.

Ключевые слова: предприятие, сложная организационная система, информационная система, структура, жизненный цикл, модель.

Современные предприятия - это сложные организационные системы с постоянно изменяющимися структурными составляющими, которые находятся в непрерывном взаимодействии друг с другом. Для эффективного функционирования предприятий в современных условиях необходима соответствующая система управления, позволяющая осуществлять сбор, хранение и обработку информации и за счет этого повышать степень обоснованности и своевременность принимаемых решений [1].

Решение этой задачи возможно на основе комплексной автоматизации управления всеми производственными и технологическими процессами предприятия, а также необходимыми ресурсами [2]. Именно для этого на предприятиях внедряют информационные системы [3].

Информационной системой называют систему обработки информации и соответствующие организационные ресурсы: человеческие, технические, финансовые и другие, которые обеспечивают и распространяют информацию [4]. Ее неотъемлемыми компонентами являются данные, техническое, программное, информационное, лингвистическое и организационное обеспечение.

Для формирования описания информационных систем предприятия, как правило, используются модели жизненного цикла в соответствии с международными стандартами.

\section{Модели жизненного цикла информационных систем предприятия}

Под моделью жизненного цикла информационной системы понимается структура, которая определяет последовательность выполнения и взаимосвязь процессов, действий и задач в течение жизненного цикла. Структура жизненного цикла информационной системы базируется на трех группах процессов:

- основные (приобретение, поставка, разработка, эксплуатация, сопровождение);

- вспомогательные, обеспечивающие выполнение основных процессов (документирование, управление конфигурацией, обеспечение качества, верификация, аттестация, оценка, аудит, решение проблем);

- организационные (создание инфраструктуры проекта, управление проектом, определение, оценка и улучшение самого жизненного цикла, обучение).

Разработка включает все работы по созданию информационной системы и ее компонент согласно заданным требованиям, в том числе оформление проектной и эксплуатационной документации, подготовку материалов, необходимых для проверки трудоспособности и соответствующего качества программных продуктов, материалов для организации обучения персонала и т.п. в соответ- 
ствии с РД 50-34.698-90. Разработка информационной системы предусматривает, как правило, анализ, проектирование и реализацию.

Эксплуатация подразумевает цикл работ по внедрению компонентов жизненного цикла информационной системы в эксплуатацию, в том числе конфигурирование БД и рабочих мест пользователей, обеспечение эксплуатационной документацией, обучение персонала, эксплуатацию, локализацию проблем и устранение причин их возникновения, модификацию жизненного цикла информационной системы в рамках установленного регламента, подготовку предложений относительно усовершенствования, развития и модернизации системы.

Управление проектом связано с планированием и организацией работ, созданием коллективов разработчиков, контролем за сроками и качеством выполняемых работ.

Техническое и организационное обеспечение проекта заключается в выборе методов и инструментальных средств для реализации проекта, в определении методов описания промежуточных стадий разработки, в разработке методов и средств испытаний информационной системы, обучении персонала и т.п.

Обеспечение качества проекта связано с проблемами верификации, проверки и тестирования информационной системы.

В процессе реализации проекта важное место занимают вопросы идентификации, описания, контроля конфигурации отдельных компонентов и всей системы в целом. Управление конфигурацией является одним из вспомогательных процессов, который поддерживает основные процессы жизненного цикла информационной системы, прежде всего разработку и сопровождение информационной системы. При создании проектов сложных информационных систем, состоящих из многих компонентов, каждый из которых может иметь разновидности, возникает проблема учета их связей и функций, создания унифицированной структуры и обеспечения развития всей системы.

Управление конфигурацией позволяет организовать, систематически учитывать и контролировать внесение изменений в информационную систему на всех стадиях жизненного цикла. Каждый процесс характеризуется определенными задачами и методами их решения, исходными данными, полученными на предыдущем этапе, и результатами. Результатами анализа, в частности, могут быть функциональные модели, информационные модели и соответствующие им диаграммы.

Жизненный цикл информационной системы носит итерационный характер: результаты очередного этапа часто вызывают изменения в проектных решениях, принятых на предыдущих этапах.

Как правило, существующие стандарты не предлагают конкретную модель жизненного цикла, а их положения являются общими для любых моделей жизненного цикла, методов и технологий создания информационной системы. Они описывают структуру процессов жизненного цикла, не конкретизируя, как реализовать или выполнить действия и задачи, включенные в эти процессы.

Во всех работах, так или иначе освещающих жизненный цикл информационной системы, приводятся примеры каскадной модели жизненного цикла и для сравнения на ее фоне спиральной модели, имеющей более совершенные свойства для моделирования процессов жизненного цикла. Но если для каскадной модели жизненный цикл включает стадию эксплуатации и сопровождения, то для спиральной модели (ее графического изображения) жизненный цикл заканчивается стадией тестирования. То есть такая спиральная модель отображает жизненный цикл не информационной системы, а ее разработки.

Жизненный цикл является моделью создания и использования информационной системы, которая отображает ее различные состояния, начиная с момента возникновения необходимости в данной системе и заканчивая ее полным выводом из эксплуатации.

Модель жизненного цикла информационной системы включает в себя стадии, результаты выполнения работ на каждой стадии, ключевые события - точки завершения работ и принятие решений.

Стадия - это часть процесса создания информационной системы, ограниченная определенными временными рамками и заканчивающаяся выпуском конкретного продукта (моделей, программных компонентов, документации), что определяется заданными для данной стадии требованиями.

На каждой стадии могут выполняться несколько процессов, и, наоборот, один и тот же процесс может выполняться на разных стадиях. Соотношение между процессами и стадиями также определяется используемой моделью жизненного цикла информационной системы.

Жизненный цикл образовывается согласно принципу ниспадающего проектирования и, как правило, имеет итерационный характер: реализованные этапы, начиная с первейших, циклически повторяются согласно изменениям требований и внешних условий, введению ограничений и т.п. На каждом этапе жизненного цикла порождается определенный набор документов и технических решений. При этом для каждого этапа начальными являются документы и решения, полученные на предыдущем этапе. Каждый этап завершается верификацией рожденных документов и решений с целью проверки соответствия их исходным.

Существующие модели жизненного цикла определяют порядок выполнения этапов в ходе разработки, а также критерии перехода от этапа к этапу. Наибольшее распространение получили модели жизненного цикла, перечисленные далее. 
1. Каскадная модель [5] предусматривает переход к следующему этапу после полного завершения работ на предыдущем этапе, характеризуется четким делением данных, процессов и их обработкой (рис. 1).

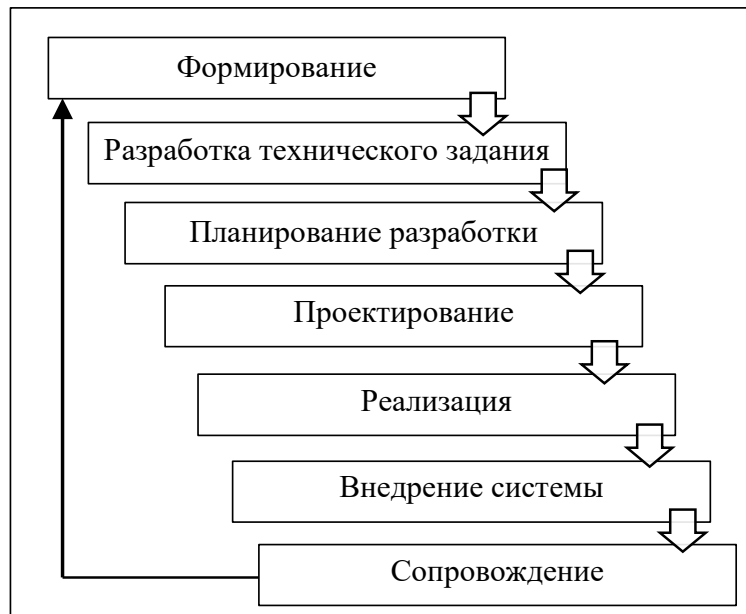

Рис. 1. Каскадная модель жизненного ичикла информачионной системь

Fig. 1. A waterfall model of an information system lifecycle

Преимущества каскадной модели: полная и согласованная документация на каждом этапе, легкость определения сроков и затрат на проект.

Недостатки: у каскадной модели переход от одной фазы проекта к другой предусматривает полную корректность результата (выхода) предыдущей фазы, однако неточность требования или его некорректная интерпретация в результате приводит к тому, что приходится возвращаться к ранней фазе проекта, а необходимая переработка не только выбивает проектную команду из графика, но и влечет за собой существенный рост затрат и, возможно, прекращение проекта в той форме, в которой он сначала задумывался.

Основное заблуждение авторов данной модели - предположение, что проект проходит через процесс один раз. Эта модель исходит из того, что все ошибки будут касаться реализации, а потому их устранение происходит равномерно во время тестирования компонентов и системы. Итак, каскадная модель для больших проектов малореалистична и может эффективно использоваться только для создания небольших систем.

2. Поэтапная модель с промежуточным контролем - итерационная модель разработки с циклами обратной связи между этапами (англ. iterative and incremental development - IID), модель итеративной и инкрементальной разработки, эволюционная модель - является альтернативой последовательной модели [6].

Модель IID предусматривает разбивку жизненного цикла проекта на последовательность итера- ций, каждая из которых напоминает мини-проект, включая все процессы разработки от применения до создания меньших фрагментов функциональности (сравнительно с проектом в целом). Цель каждой итерации - получение работающей версии информационной системы, которая включает функциональность, определенную интегрированным содержанием всех предыдущих и текущей итераций. Результат финальной итерации содержит всю необходимую функциональность информационной системы.

Итак, с завершением каждой итерации система получает прирост - инкремент к ее возможностям, которые развиваются эволюционно.

Преимущество такой модели в том, что межэтапное корректирование обеспечивает меньшую трудоемкость по сравнению с каскадной моделью. С другой стороны, время жизни каждого этапа растягивается на весь период разработки.

Подход IID имеет и свои негативные стороны, в сущности являющиеся обратной стороной достоинств: во-первых, продолжительное время отсутствует целостное понимание возможностей и ограничений проекта; во-вторых, при итерациях приходится отбрасывать часть предварительно сделанной работы.

Разные варианты итерационного подхода реализованы в большинстве современных методологий разработки (RUP, MSF, XP).

3. Спиральная модель (англ. spiral model) была разработана в 1986 г. Барри Боэмом [7]. Она основана на классическом цикле Деминга PDCA (plando-check-act). При использовании этой модели информационная система создается в несколько итераций (витков спирали) методом прототипирования (рис. 2). Спиральная модель заостряет внимание на начальных этапах жизненного цикла: ана-

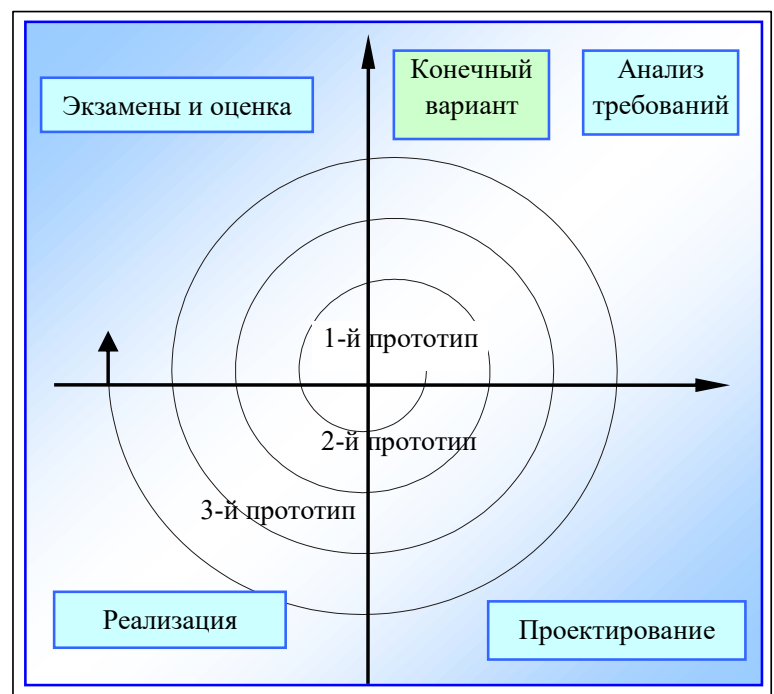

Рис. 2. Спиральная модель жизненного цчикла информационной системы

Fig. 2. A spiral model of an information system lifecycle 
лизе требований, проектировании спецификаций, предыдущем и детальном проектировании. На этих этапах проверяется и обосновывается реализуемость технических решений созданием прототипов. Каждый виток спирали отвечает поэтапной модели создания фрагмента или версии системы, на нем уточняются цели и характеристики проекта, определяется его качество, планируются работы следующего витка спирали. Таким образом, углубляются и последовательно конкретизируются детали проекта и, как следствие, выбирается обоснованный вариант, который приводится к реализации.

Отличительная особенность спиральной модели - особое внимание, которое уделяется рискам, влияющим на организацию жизненного цикла и контрольные точки. Б. Боем сформулировал десять наиболее распространенных (по приоритетности) рисков:

- дефицит специалистов;

- нереальные сроки и бюджет;

- реализация несоответствующей функциональности;

- разработка неправильного пользовательского интерфейса;

- перфекционизм, ненужная оптимизация и оттачивание деталей;

- беспрерывный поток изменений;

- недостаток информации о внешних компонентах, определяющих окружение системы или вовлеченных в интеграцию;

- недостатки в работах, выполняемых внешними (по отношению к проекту) ресурсами;

- недостаточная производительность получаемой системы;

- разрыв в квалификации специалистов разных областей.

В современной спиральной модели определяется такой общий набор контрольных точек:

- concept of operations (COO) - концепция (использование) системы;

- life cycle objectives (LCO) - цели и содержание жизненного цикла;

- life cycle architecture (LCA) - архитектура жизненного цикла; здесь же можно говорить о готовности концептуальной архитектуры целевой программной системы;

- initial operational capability (IOC) - первая версия создаваемой системы, пригодная для исследовательской эксплуатации;

- final operational capability (FOC) - готовая система, развернутая для реальной эксплуатации.

Проведенный анализ наиболее распространенных моделей жизненного цикла информационных систем показал, что они являются достаточно эффективным средством описания всех процессов разработки и создания информационных систем предприятия.

\section{Модели сопровождения информационных систем по этапам жизненного цикла}

Как в процессе исследований, так и в процессе проектирования информационная система предприятия выступает пассивной категорией, функционирование которой описывается моделями. Рассматривая информационную систему предприятия как сложную, ее можно представить следующими основными моделями: строения, функционирования и развития [8].

Модель строения $\left(M_{c}\right)$ является теоретико-множественной моделью, реализующей отношение «часть-целое» и представляемой теоретико-множественной операцией объединения $A=\bigcup A^{i}$, где $I-$ индексное множество; $A^{i}$ - составляющие элементы $A, A^{i}=<A_{1}^{i}, A_{2}^{i}, \ldots A_{n}^{i} ; A_{11}^{i}, A_{12}^{i}, \ldots A_{1 m}^{i} ; \ldots A_{n l}^{i}>$.

Модель функционирования $\left(M_{f}\right)$ определяет процессы достижения целей системой, которые осуществляются его составляющими и представляются отображениями

$$
\begin{aligned}
& F_{1}:<P, C_{c}^{t}, C_{s}^{t}, X^{t-1}>\rightarrow X^{t}, \\
& F_{2}:<P, C_{c}^{t}, C_{s}^{t}, X^{t-1}>\rightarrow Y^{t},
\end{aligned}
$$

где $t$ - момент времени функционирования ИС; $P$ вектор прикладных задач, которые система должна решать; $C_{c}^{t}$ - структура системы в момент времени $t ; C_{s}^{t}-$ стратегия управления; $X^{t}-$ состояние ИС; $Y^{t}$ - выход системы в момент времени $t$.

Модель развития $\left(M_{p}\right)$ описывает адаптивные процессы информационной системы во внешней среде посредством отображения

$$
F_{3}:<E_{z}^{n}, P_{r}^{n}>\rightarrow<E_{e}^{n}, E_{f}^{n}, E_{a}^{n}, R>,
$$

где $E_{Z}^{n}$ и $P_{r}^{n}$ - новые цели и процессы целедостижения, предполагающие существование в структуре ИС таких элементов $E_{e}^{n}$, которые способны взять на себя новые функции $E_{f}^{n}$ и посредством новых операций $E_{a}^{n}$ привести к выработке новых нестандартных решений $R$. Множества $E_{Z}^{n}$ и $P_{r}^{n}$-нечеткие категории, что следует из неопределенности их на этапе проектирования, а также из нечеткости временного интервала между предположением о возможности реализации и реализацией $E_{Z}^{n}$, определяемой функцией $\xi(Z)$. Оценка такой возможности и ее характеристики определяются на этапе исследования разрешимости задачи $\Omega$. Рассматривая предполагаемое функционирование информационной системы аналогично существованию системы исследования в базисе системных свойств [9], обозначим $Q^{0}$ пространство состояний информационной системы. Тогда можно установить существование отображения $<E_{z}^{n}, P_{r}^{n}>\rightarrow Q^{0}$.

Пространство $Q^{0}$ имеет три составляющие: $Q_{c}^{0}, Q_{p}^{0}, Q_{n}^{0}$, где $Q_{c}^{0}$ - компоненты состояния, точно 
известные априори; $Q_{p}^{0}$ - компоненты, распределение вероятностей которых известно; $Q_{n}^{0}-$ компоненты, значения которых могут быть предположены экспертами.

Следовательно, $Q_{c}^{0}$ не зависит от $\xi(Z)$, для $Q_{p}^{0}$ функцию $\xi(Z)$ можно формально рассматривать как плотность вероятности состояния $Q_{p}^{0}$ информационной системы [10]. Учитывая, что составляющие $Q_{n}^{0}$ - нечеткие множества, $\xi(Z)$ - многомерная функция принадлежности [11], устанавливается соответствие $Q_{n}^{0} \leftrightarrow \operatorname{Kern}(\xi(Z))$, где $\operatorname{Kern}(\xi(Z))=$ $=\left\{q_{n}^{m} \in Q_{n}^{0} \mid \xi\left(q_{n}^{m}\right)=\max _{q_{n} \in Q_{n}^{0}} \xi\left(q_{n}\right)\right\}$.

Формально модель развития имеет следующий вид: $F_{3}^{0}:<E_{z}^{n}, P_{r}^{n}>\rightarrow Q^{0}=Q^{0}(C, M \xi(Z), \operatorname{Kern}(\xi(Z)))$, где $C$ - компоненты состояния системы, являющиеся константами.

Разработка тройки моделей $<M_{c}, M_{\phi}, M_{p}>$ является дополнительным информационным фактором, позволяющим осуществлять структуризацию процесса создания и функционирования информационной системы предприятия. Предложенные модели также образуют базис для формирования критериев, которые будут использованы при принятии решений по выбору оптимального варианта при построении информационной системы [12].

\section{Заключение}

Рассмотрено предприятие как сложная организационная система, для эффективного функционирования которой необходима современная информационная система управления, позволяющая осуществлять сбор, хранение и обработку информации для повышения степени обоснованности и своевременности принимаемых решений. Проведен анализ наиболее распространенных моделей жизненного цикла информационных систем, который показал, что они являются достаточно эффективным средством описания всех процессов разработки и создания информационных систем предприятия. Показано, что в процессе исследований и проектирования информационная система предприятия

Software \& Systems

DOI: $10.15827 / 0236-235 X .123 .455-460$ выступает пассивной категорией, процесс функционирования которой может быть описан моделями строения, функционирования и развития. Разработка этих трех моделей является также дополнительным информационным фактором, позволяющим осуществлять структуризацию процесса создания и функционирования информационной системы предприятия.

Таким образом, процесс исследования построения информационной системы предприятия базируется на моделях, сопровождающих ее по всем этапам жизненного цикла. При этом учитывается, что информационная система предприятия представляет собой сложный комплекс взаимосвязанных элементов, характеризуется целостностью, противостоит внешней среде и обеспечивает работу всех своих компонент для выполнения общего предназначения системы.

\section{Лumepamypa}

1. Аганбегян А.Г. Управление и эффективность. М.: Экономика, $1981.71 \mathrm{c}$

2. Баронов В.В., Калянов Г.Н., Попов Ю.И. Автоматизация управления предприятием. М.: ИНФРА-М, 2000. 239 с

3. Берсуцкий Я.Г. Информационная система управления предприятием. К.: Наук. думка, 1986. 167 с.

4. ISO/IEC 2382-1:1993. Information technology. Vocabulary. Part 1. Fundamental terms. Berlin, Springer-Verlag, 2004, $323 \mathrm{p}$.

5. Royce W. Managing the Development of Large Software Systems. Proc. IEEE WESCON, 1970, pp. 328-338.

6. Ларман К., Базили В. Итеративная и инкрементальная разработка: краткая история // Открытые системы. 2003. Вып. 9. C. $43-53$

7. Selby R.W. Software Engineering: Barry W. Boehm's Lifetime Contributions to Software Development, Management and Research. NJ: John Wiley \& Sons, 2007, 834 p.

8. Снитюк В.Е. Эволюционные технологии принятия решений в условиях неопределенности: монографія. К.: МП Леся, $2015.347 \mathrm{c}$.

9. Матвеевский С.Ф. Основы системного проектирования комплексов летательных аппаратов. М.: Машиностроение, 1987. $240 \mathrm{c}$.

10. Дюбуа Д., Прад. А. Теория возможностей. М.: Радио и связь, 1990.286 с.

11. Barlett E.B. Dynamic node architecture learning: An information theoretic approach. Neural Networks, 1994, vol. 3, pp. $129-140$

12. Лисецкий Ю.М., Снитюк В.Е. Формальное представление корпоративной интегрированной информационной системы как совокупности математических моделей. Proc. 17 Intern. Conf. System Analysis and Information Technologies SAIT 2015. Kyiv, 2015, pp. 80-81 (pyc.)

\section{Models of enterprise information system support in lifecycle stages}

Yu.M. Lisetskiy ${ }^{1}$, Ph.D. (Information Technologies), Managing Director, Yurii.Lisetskyi@snt.ua

${ }^{1}$ S\&T Ukraine, Kiev, 03680, Ukraine

Abstract The article considers an enterprise as a complex organizational system, which requires a modern management information system for effective functioning. Such system enables information collection, storage, and procession to increase 
relevance and timeliness of made decisions. The problem might be solved based on complex automation of all industrial and technological processes and required resources management.

The paper shows that the information system description is formed based on a lifecycle model, which defines the order of development stages and criteria of stage transition. An information system lifecycle model is a structure that defines a sequence of completion and interconnection of processes, actions and tasks throughout a life cycle. The structure of the information system life cycle is based on three groups of processes: primary (acquisition, supply, development, operation, maintenance), supplementary (documenting, configuration management, quality assurance, verification, attestation, assessment, audit, problem resolution) and organizational (project infrastructure building, project management, definition, life cycle assessment and improvement, training).

The paper describes the most widely spread life cycle models such as waterfall, iterative and incremental (stage-by-stage model with intermediate control) and spiral. It demonstrates that the enterprise information system appears to be a passive category in the processes of study and design. This category functioning can be described using support life cycle models including composition, functioning and development models. Development of these three models appears to be an additional informational factor that enables structuring of the process of enterprise information system creation and functioning.

Keywords: enterprise, complex organizational system, information system, structure, lifecycle, model.

\section{References}

1. Aganbegyan A.G. Management and Efficency. Moscow, Ekonomika Publ., 1981, 71 p.

2. Baronov V.V., Kalyanov G.N., Popov Yu.I. Enterprise Management Automation. Moscow, INFRA-M Publ., 2000, $239 \mathrm{p}$.

3. Bersutsky Ya.G. Enterprise Management Information System. Kyiv, Naukova dumka Publ., 1986, 167 p.

4. ISO/IEC 2382-1:1993. Information technology. Vocabulary. Part 1: Fundamental terms. Berlin, Springer-Verlag Publ., 2004, 323 p.

5. Royce W. Managing the Development of Large Software Systems. Proc. IEEE WESCON. 1970, pp. 328-338.

6. Larman K., Bazili V. Iterative and incremental development: short history. Open Systems. Moscow, 2003, vol. 9, pp. 43-53.

7. Selby R.W. Software Engineering: Barry W. Boehm's Lifetime Contributions to Software Development, Management and Research. NJ, Wiley \& Sons Publ., 2007, 834 p.

8. Snityuk V.E. Evolutionary Technologies of Decision Making under Ambiguity. Kyiv, MP Lesya Publ., 2015, 347 p.

9. Matveevsky S.F. Basics of Systemic Design of Aircraft Complexes. Moscow, Mashinostroenie Publ., 1987, 240 p.

10. Dyubua D., Prad. A. Possibility Theory. Moscow, Radio i svyaz Publ., 1990, 286 p.

11. Barlett E.B. Dynamic node architecture learning: An information theoretic approach. Neural Networks. 1994, no. 3, pp. 129-140.

12. Lisetskiy Yu.M., Snityuk V.E. Formal Representation of the Corporate Integrated Information System as a Complex of Mathematical Models. Proc. 17th Intern. Conf. "System Analysis and Information Technologies SAIT 2015". Kyiv, 2015, pp. $80-81$.

\section{Примеры бибциографического описания статьи}

1. Аисецкий Ю.М. Модели сопровождения информационных систем предприятия по этапам жизненного цикла // Программные продукты и системы. 2018. Т. 31. № 3. С. 455-460. DOI: $10.15827 / 0236-235 X .123 .455-460$.

2. Lisetskyi Yu.M. Models of enterprise information system support in lifecycle stages. Software \& Systems. 2018, vol. 31, no. 4, pp. 455-460 (in Russ.). DOI: 10.15827/0236-235X.123.455-46. 


\title{
Применение метода английского аукииона при планировании заданий с абсолютными приоритетами в распределенной вычислительной системе
}

\author{
A.В. Баранов 1, к.т.н., доиент, ведущий научный сотрудник, antbar@mail.ru, abaranov@jscc.ru \\ B.B. Молоканов 2, студент, molocan@bk.ru \\ П.Н. Телегин 1, к.т.н., ведуший научный сотрудник, pnt@јscс.ru \\ A.И. Тихомиров 1, младший научный сотрудник, tema4277@rambler.ru \\ ${ }_{1}^{1}$ Межведомственный суперкомпьютерный иентр РАН, г. Москва, 119991, Россия \\ 2 Московский физико-технический институт (государственный университет), \\ 2. Москва, 117303, Россия
}

В статье рассматривается задача планирования заданий с абсолютными приоритетами в территориально распределенной вычислительной среде, для решения которой могут быть эффективно применены аукционные методы. В большинстве современных работ по этой тематике используется рыночная модель, в которой предметом аукционных торгов (товаром) выступают вычислительные ресурсы, а продавцами - их владельцы. Покупателями являются пользователи, участвующие в аукционе с целью приобретения вычислительных ресурсов для выполнения своих заданий. Продавцы стремятся получить максимальную прибыль, покупатели выполнить свои задания с наименьшими затратами. Подобная модель предполагает наличие у пользователей-покупателей определенных бюджетов в условных или реальных деньгах, при этом приоритет задания фактически определяется той ценой, которую пользователь готов заплатить за выполнение задания к определенному сроку на выставленных на торги вычислительных ресурсах.

Исследуемая авторами модель территориально распределенной вычислительной среды отличается от известных тем, что приоритеты заданий являются абсолютными и назначаются по единым правилам. Главная цель - скорейшее выполнение высокоприоритетных заданий. В этом случае теряет смысл понятие бюджета пользователя, и классические аукционные модели перестают работать. Авторы предлагают новый подход, при котором предметом аукционных торгов становятся задания, а владельцы ресурсов выступают в роли покупателей, расплачивающихся за задания имеющимися в наличии свободными вычислительными ресурсами. При таком подходе авторы рассматривают английский аукцион как наиболее предпочтительный метод планирования в территориально распределенной вычислительной среде заданий с абсолютными приоритетами

Главной характеристикой алгоритма планирования, основанного на методе английского аукциона, становится длительность проведения торгов (продолжительность аукциона). В статье приведены результаты экспериментов по определению оптимальной продолжительности английского аукциона по отношению к среднему времени обработки задания

Ключевые слова: высокопроизводительные вычисления, распределенные вычислительные системы, планирование параллельных заданий, абсолютные приоритеты, экономические модели планирования, английский аукиион, продолжительность аукиииона.

Стратегия научно-технологического развития Российской Федерации предусматривает развитие и поддержку функционирования цеентров коллективного пользования (ЦКП) научно-технологическим оборудованием, к которым относятся суперкомпьютерные научные центры (СКЦ). Одной из устойчивых тенденций развития последних является объединение их вычислительных ресурсов в единую территориально распределенную систему (ТРС) с целью повышения эффективности использования вычислительных ресурсов СКЦ и увеличения значений индикаторных показателей (http:// government.ru/docs/23110/). Активные работы над проектом единой распределенной сети научных суперкомпьютерных центров в настоящее время ведутся в Межведомственном суперкомпьютерном центре РАН [1]. В качестве единицы ресурса, подключаемой к ТРС, в проекте рассматривается $6 b l$ числительная установка (ВУ), представляющая собой, как правило, отдельный высокопроизводительный вычислительный кластер (суперкомпью- тер). Важно отметить, что обычно в состав ТРС входят ВУ различной вычислительной мощности, объединенные коммуникационными каналами различной пропускной способности.

Единицей обработки информации в ТРС служит вычислительное задание, под которым понимается набор, включающий входные данные, программу их обработки и ресурсные требования: количество процессоров (ядер), объем оперативной памяти и дискового пространства, заказанное время выполнения задания и др.

Каждая ВУ из состава ТРС находится под управлением локальной системы управления ресурсами (ЛСУР), в качестве которой могут выступать такие распространенные системы, как PBS [2], SLURM [3], Мoab [4], или отечественная Система управления прохождением параллельных заданий (СУППЗ) [5]. Основными функциями ЛСУР являются ведение очереди вычислительных заданий, их планирование, запуск и контроль процесса выполнения на вычислительных ресурсах отдельной ВУ. 
Важнейшей отличительной характеристикой рассматриваемой модели ТРС является наличие единой для всех ВУ системы абсолютных приоритетов, предполагающей немедленное вытеснение с выполнения низкоприоритетных заданий при поступлении в очередь заданий с более высоким приоритетом. Приостановленное задание сохраняет промежуточные результаты выполнения и вытесняется в очередь. Все прерванные задания продолжают свое выполнение после того, как вычислительные ресурсы вновь станут свободными.

Различные задания от разных пользователей образуют один или несколько потоков. В каждой ВУ присутствует как минимум один локальный поток заданий, которые допускают обработку только на локальных вычислительных ресурсах и не могут быть переданы на другие ВУ ТРС (рис. 1).

Задания глобального потока, напротив, могут быть переданы для обработки в любую из ВУ ТРС. Управлением на этом уровне занимается глобальная система управления ресурсами (ГСУР). В предшествующих работах авторы остановили выбор на децентрализованной схеме управления, предполагающей отсутствие единого центра управления и планирования вычислительных заданий. Децентрализованное управление основано на совместной согласованной работе коллектива равноправных диспетчеров (рис. 2), располагающихся локально на всех ВУ ТРС. В работе [6] авторы рассмотрели варианты организации глобальной очереди заданий ГСУР и остановили свой выбор на документо-ориентированной распределенной СУБД Elasticsearch [7] - логически централизованном хранилище информации, обеспечивающим, с одной стороны, симметричный доступ к глобальной очереди от всех диспетчеров ТРС, с другой - надежное распределенное хранение информации в условиях динамически изменяющегося состава ТРС (ВУ мо- гут отключаться или подключаться к ТРС в произвольные моменты времени).

В процессе функционирования диспетчеры вычислительных установок независимо друг от друга обращаются к распределенной СУБД с запросами о состоянии глобальной очереди. Просматривая глобальную очередь, диспетчеры производят выборку заданий для своей ВУ, причем выборка производится в соответствии с критериями, определяемыми дисциплиной и алгоритмами планирования заданий. Выбранное диспетчером из глобальной очереди задание помещается им в ЛСУР своей ВУ, после чего на эту ВУ осуществляется копирование исходных данных задания.

Обратим внимание на тот факт, что в условиях абсолютных приоритетов заданий в глобальную очередь имеет смысл помещать задания с высоким приоритетом. В этом случае выбранные диспетчерами задания глобальной очереди, попадая в ЛСУР, должны либо сразу поступать на выполнение, либо занимать места в начале очереди. В такой постановке в качестве основного показателя качества планирования заданий глобальной очереди целесообразно рассматривать среднее время $T$ обработки задания в соответствии с уровнем приоритета [8]. В этом контексте основными задачами, решаемыми авторами, являются исследование и разработка методов и алгоритмов планирования заданий глобальной очереди, обеспечивающих минимальное среднее время обработки высокоприоритетных заданий.

\section{Применение метода английского аукциона при планировании заданий с абсолютными приоритетами в ТРС}

Известно, что при планировании вычислительных заданий в грид-средах и ТРС могут быть эф-

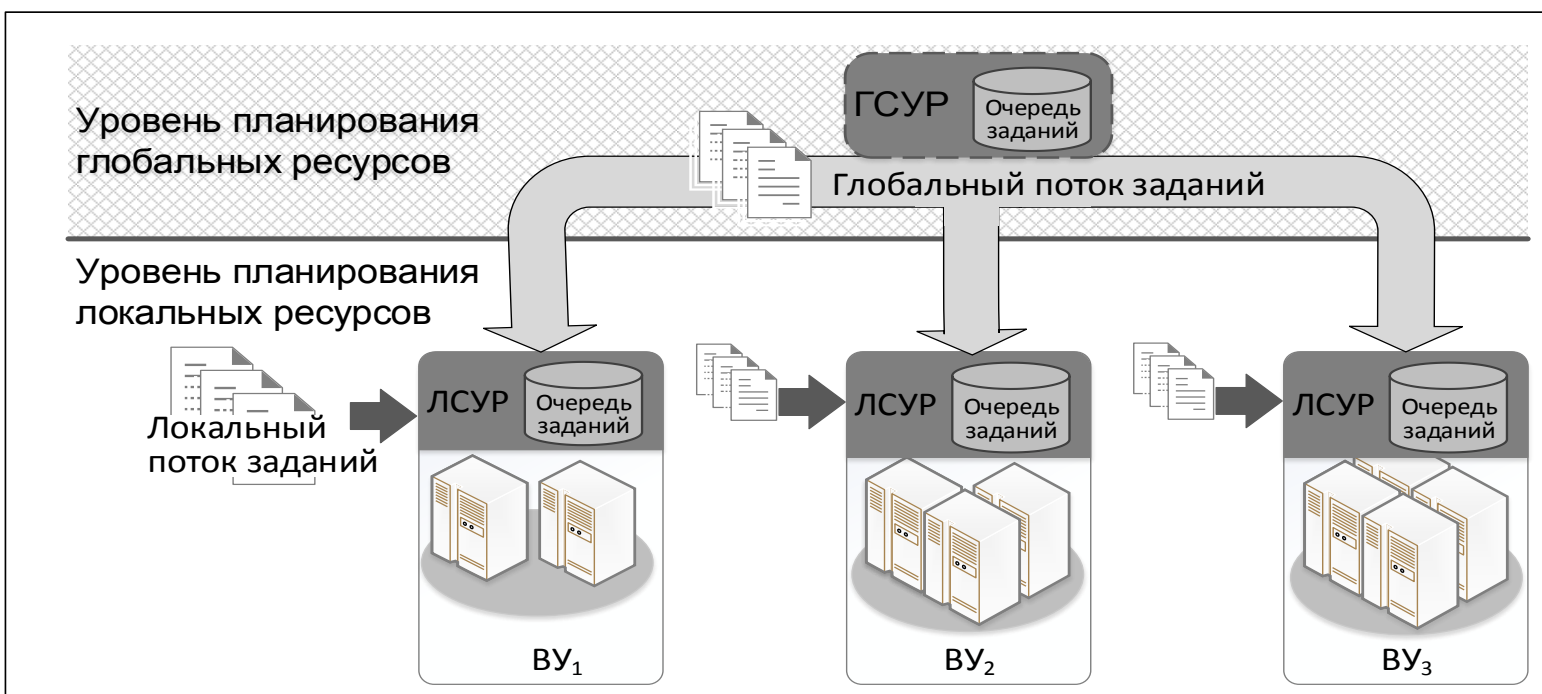

Рис. 1. Модель территориально распределенной вычислительной системы

Fig. 1. Model of a geographically distributed computing system 


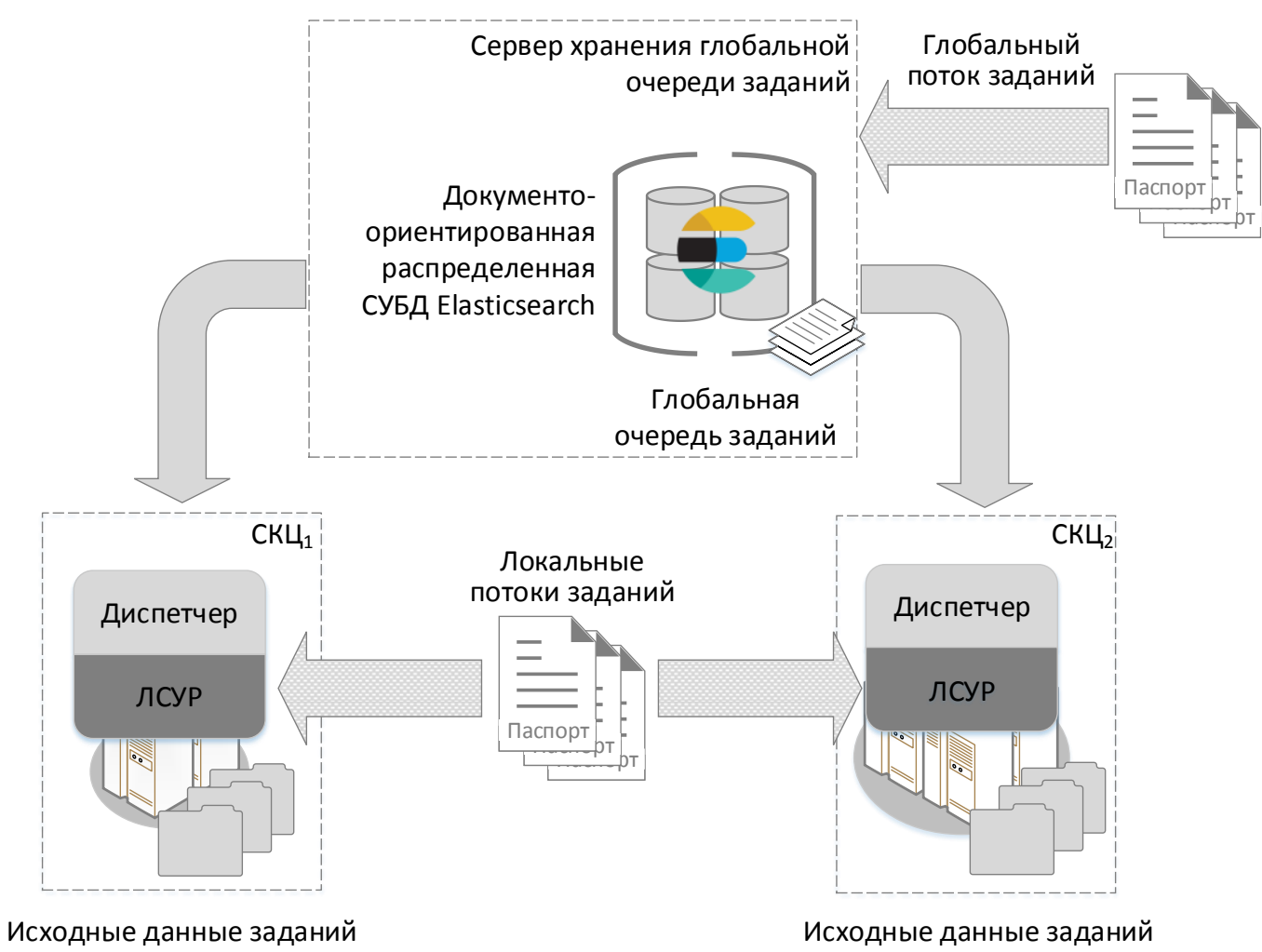

Рис. 2. Схема взаимодействия диспетчеров ТРС

Fig. 2. Interaction scheme of GDS dispatchers

фективно применены аукционные методы [9, 10]. Обязательным требованием любого аукционного метода является наличие в системе предмета торгов (товара) и нескольких ролей: продавца и покупателя. В классическом случае продавцами выступают владельцы вычислительных ресурсов, а покупателями - пользователи, участвующие в аукционе с целью приобретения вычислительных ресурсов для выполнения своих заданий.

Выставляя вычислительные ресурсы на аукцион, каждый продавец стремится, с одной стороны, минимизировать простой вычислительных ресурсов, с другой стороны, извлечь максимальную прибыль от их продажи.

Все покупатели преследуют сложную цель: с одной стороны, они хотят минимизировать затраты на приобретение вычислительных ресурсов, с другой - обработать свои вычислительные задания как можно быстрее [11]. Стремясь найти компромиссное решение из этих двух противоречивых требований, пользователь может как повышать свою ставку (цену, которую он готов заплатить за вычислительные ресурсы), так и понижать ее. Выгода пользователя определяется следующим образом. Для каждого вычислительного задания пользователь заранее определяет бюджет - максимальную цену, которую он готов заплатить за обработку задания. Увеличивая цену, пользователь может разместить задание на ВУ с более производительными вычислительными ресурсами или на менее производительной ВУ, но при этом продвинуть задание в очереди. Один и тот же вычислительный ресурс может представлять интерес для нескольких покупателей, поэтому между ними возникает конкуренция, которая позволяет обеспечить максимальную прибыль продавцу.

Аукционные методы эффективны, когда товар уникален, имеется в ограниченном количестве (всего несколько штук) или когда точно неизвестно число участников (потенциальных покупателей), готовых купить его. В этом случае допускается, что цена товара заранее может быть не установлена и будет определена в процессе проведения аукциона на основе ставок участников. Ставка - это цена, которую готов заплатить участник за товар. В процессе проведения аукциона ставки всех участников поступают аукционисту, который ранжирует их и выявляет победителя аукциона. Победитель определяется в зависимости от используемой модели аукциона. В рассматриваемой авторами децентрализованной схеме управления ТРС в роли покупателей, продавцов и аукционистов выступают диспетчеры ВУ, причем каждый диспетчер в зависимости от текущей ситуации может выступать в любой из ролей.

В исследуемой модели ТРС задания обладают абсолютными приоритетами, которые задаются владельцами заданий по установленным в ТРС еди- 
ным правилам [6]. Соблюдение единых правил назначения приоритетов позволяет определить общую для всей ТРС цель - скорейшее выполнение высокоприоритетных заданий. В такой модели классические аукционные методы теряют свою эффективность, так как пропадает конкуренция между покупателями (покупатель не может изменять свою ставку из-за наличия единых правил), и понятие бюджета пользовательского задания теряет смысл.

Авторы предлагают новый подход, в котором предметом аукционных торгов становятся задания, а участники меняются ролями: владельцы ресурсов становятся покупателями, расплачивающимися за задания имеющимися в наличии свободными вычислительными ресурсами, а продавцы - пользователями, продающими свои задания. Так как в один и тот же момент времени в разных ВУ доступно разное число вычислительных ресурсов (ВУ различаются по производительности и интенсивности локального потока заданий), между покупателями вновь возникает конкуренция.

Важно заметить, что в исследуемой авторами модели у покупателей заранее не определен бюджет, в пределах которого они могут варьировать цену за покупку товара. Авторы предполагают, что такой бюджет мог бы быть определен в случае, когда возможно составление расписания запусков заданий на некоторый интервал времени. Однако в системе с абсолютными приоритетами составленное расписание придется перестраивать каждый раз при поступлении в систему более приоритетного задания. Более того, невозможность составить расписание запусков заданий приводит к тому, что покупатель будет готов принять участие в проведении аукциона только в момент появления у него свободных вычислительных ресурсов. Это обусловливает следующие особенности рассматриваемого подхода:

- продолжительность аукциона должна быть достаточной для того, чтобы в нем успели принять участие не менее двух покупателей;

- ставка покупателя должна отражать реальную загруженность вычислительных ресурсов в течение всей продолжительности аукциона.

При этом загруженность вычислительных ресурсов ВУ в процессе проведения аукциона может измениться в силу следующих причин:

- помимо глобального потока, на вычислительные ресурсы ВУ поступает локальный поток заданий;

- часть заданий успевает завершиться;

- диспетчер ВУ может одновременно участвовать в проведении нескольких аукционов, при этом одни и те же ресурсы могут быть предложены для разных заданий.

Действительность ставки в течение длительного периода времени позволяют обеспечить многораундовые аукционы. В этом случае каждый участник поддерживает актуальность сделанной ставки, изменяя ее каждый раз, когда меняется загруженность вычислительных ресурсов ВУ. Авторами была выбрана модель английского аукциона как наиболее предпочтительная для планирования заданий в ТРС с абсолютными приоритетами [12]. Английский аукцион - это открытый многораундовый аукцион с повышением ставок, который начинается с установления минимальной цены.

Вопрос назначения ставки рассмотрен авторами в работе [12], в которой ставку за задание предлагается формировать из нескольких составляющих: цены за занимаемые вычислительные ресурсы, цены за прерывание низкоприоритетных заданий и цены за передачу исходных данных по коммуникационным каналам. Аукцион выигрывает диспетчер-покупатель, предложивший максимальную ставку. Для того чтобы выиграть, диспетчер должен предложить для задания как можно больше вычислительных ресурсов, время на пересылку исходных данных должно быть минимальным, при этом предлагаемые вычислительные ресурсы должны быть либо свободными, либо занятыми наименее приоритетными заданиями.

В работе [12] рассмотрен разработанный авторами алгоритм проведения английского аукциона в ТРС с абсолютными приоритетами заданий. Последовательность шагов алгоритма повторяется до тех пор, пока все задания глобальной очереди не будут распределены по ВУ. В начале торгов диспетчераукционист устанавливает за это задание минимальную ставку, после чего начинает принимать ставки от других диспетчеров. Прием ставок может многократно повторяться в течение времени проведения аукциона, при этом диспетчеры-участники могут корректировать свои ставки, повышая цену задания. Предполагается, что в течение времени проведения аукциона ставка диспетчера может измениться при изменении доступного объема вычислительных ресурсов. По окончании аукциона задание получает диспетчер, предложивший максимальную цену.

\section{Продолжительность английского аукциона}

Важнейшей характеристикой рассматриваемого алгоритма является длительность проведения (продолжительность) аукциона. Важность этой характеристики обусловливается тем, что, с одной стороны, возможность пересчета ранее предложенной ставки позволяет участникам аукциона поддерживать действительность ставки в течение всего времени проведения аукциона, а с другой увеличение продолжительности аукциона приводит к длительным простоям вычислительных ресурсов и увеличению времени получения результатов выполнения заданий каждого приоритета.

На продолжительность аукциона оказывают влияние характеристики входного потока заданий 
(интенсивность, закон распределения), а также продолжительность выполнения заданий.

Авторы предполагают, что продолжительность аукциона может быть определена как доля относительно среднего времени обработки задания.

Для определения продолжительности английского аукциона авторы провели серию экспериментов с использованием специально подготовленного на базе вычислительных ресурсов МСЦ РАН макета ТРС. В экспериментах моделировалась работа двух суперкомпьютерных центров (СКЦ 1 и СКЦ2), каждый из которых содержал в своем составе две высокопроизводительные вычислительные установки. ВУ моделировались отдельными сегментами суперкомпьютера МВC-100К (см. рис. 3).

На каждом сегменте был развернут следующий набор программных компонентов:

- сервер хранения глобальной очереди (ГО), организованной в соответствии с [6] на базе распределенной СУБД Elasticsearch;

- диспетчер заданий, разработанный авторами на языке программирования Python;

- ЛСУР (СУППЗ и SLURM).

В ходе эксперимента моделировалась работа ВУ с различной вычислительной мощностью от 4 до 8 вычислительных модулей МВС-100К. При этом на все ВУ поступали потоки заданий от локальных пользователей.

В качестве тестовых задач использовались МРIпрограммы из известного пакета NAS Parallel Benchmarks (NPB). Моделирование входного потока заданий проводилось следующим образом. В глобальную очередь поступал стационарный поток из $M=400$ вычислительных заданий. В потоке заданий были выделены четыре уровня приорите- тов заданий, число заданий каждого уровня задавалось равномерным распределением. При этом исходные данные задания были равномерно распределены по всем ВУ ТРС. Интенсивность поступления вычислительных заданий в глобальную очередь задавалась пуассоновским распределением исходя из следующих соображений [13].

Во-первых, даже при потоке заданий, отличающемся от пуассоновского, можно получить удовлетворительные по точности результаты, заменив поток любого распределения пуассоновским с той же плотностью.

Во-вторых, в теории массового обслуживания показано, что при суммировании (взаимном наложении) нескольких потоков, поступающих от независимых источников и обладающих свойствами ординарности и стационарности, получается суммарный поток, сколь угодно близкий к простейшему. При этом должно соблюдаться условие, что складываемые потоки оказывают на сумму приблизительно равномерное малое влияние. На практике достаточно сложить 3-4 потока, чтобы получить поток, с которым можно оперировать как с простейшим [14].

Для выполнения условия стационарности вероятностные характеристики входного потока заданий не должны зависеть от времени. На практике поступающий в ТРС поток заданий может считаться стационарным только на непродолжительном интервале времени, например, с 13 до 18 часов, но этот же поток в течение суток уже не может считаться стационарным (ночью плотность поступления заданий значительно меньше, чем днем, то же относится к выходным и будним дням). Однако во многих задачах теории массового обслуживания

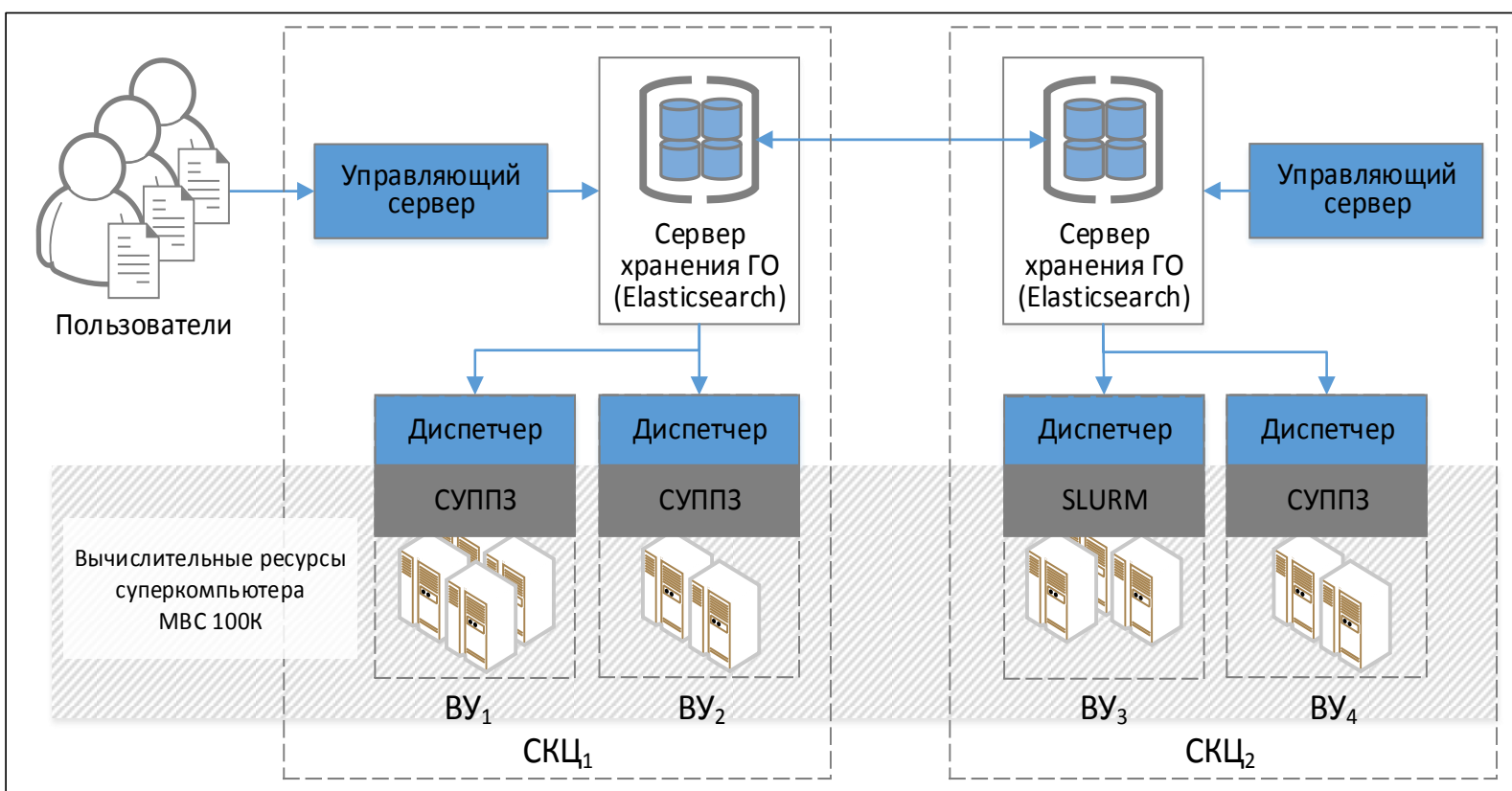

Рис. 3. Схема экспериментального стенда для определения продолжстельности английского аукииона

Fig. 3. Scheme of the test bed for determining English auction duration 
представляет интерес анализ работы системы при постоянных условиях; тогда задача решается для стационарного потока заявок [13].

Соблюдение условия ординарности требует, чтобы задания поступали в систему по одному, а не парами, тройками и т.д. Поступающий в ТРС поток зданий считается ординарным, так как задания поступают друг за другом, а каждое задание не может быть поделено на более мелкие задания. Если задания поступают только парами, тройками и т.д., то такой поток легко свести к ординарному; для этого достаточно вместо потока отдельных заданий рассмотреть поток пар, троек заданий и т.д.

В качестве показателя эффективности алгоритма проведения аукциона рассматривалось среднее время $T$ обработки задания в соответствии с уровнем приоритета [8].

В результате многочисленных запусков авторами было установлено, что результаты зависят не от абсолютных значений времен, а от соотношения продолжительности аукциона и среднего времени выполнения задания. По этой причине среднее время выполнения задания может быть представлено в некоторых условных единицах (у.е.). В этом контексте продолжительность аукциона, например в 0,5 у.е., означает, что аукцион проводится в течение времени, равного половине среднего времени выполнения задания. Для экспериментального определения зависимости среднего времени обработки задания от продолжительности аукциона последняя изменялась с шагом 0,1 у.е. Полученные результаты показаны на рисунке 4 .

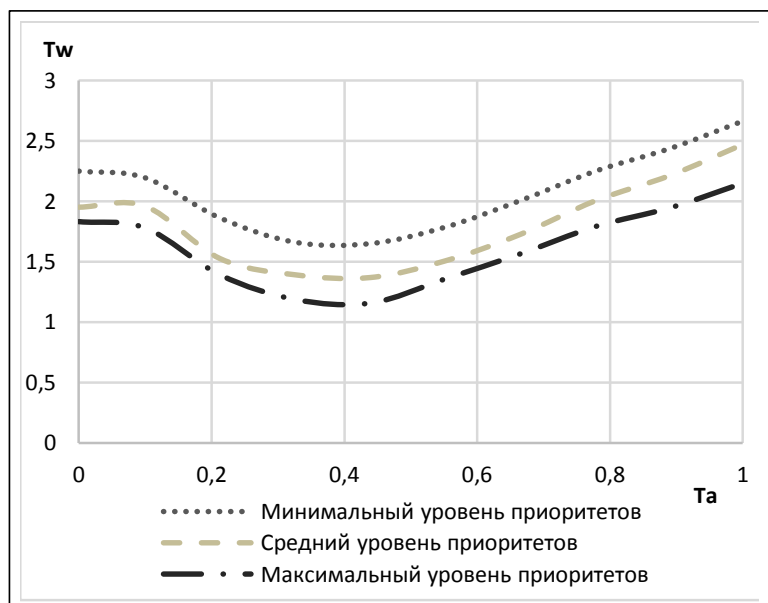

Рис. 4. Среднее время обработки заданий в зависимости от продолжительности английского аукииона для соответствующих уровней приоритетов: $T_{a}$ - продолжительность аукциона в условных единицах задания, $T_{w}$ - среднее время обработки заданий в условных единииах

Fig. 4. Average job processing time depending on the English auction duration for corresponding priority levels, $T_{a}$ is auction duration in conventional units, $T_{w}$ is the average job processing time in conventional units

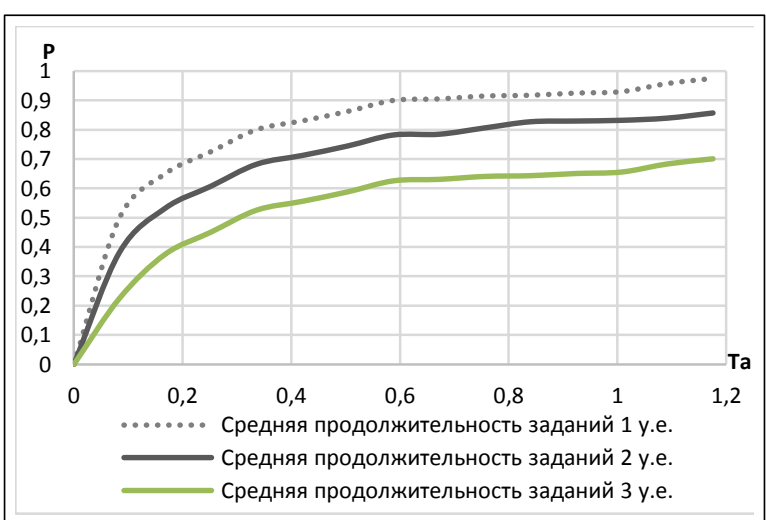

Рис. 5. Зависимость доли участников аукциона от общего числа участников ТРС (P) и от продолжительности аукииона в условных единицах $\left(T_{a}\right)$

Fig. 5. Dependence of auction participants share on the total number of GDS $(P)$ participants and on auction duration in conventional units (Ta)

Из представленных результатов видно, что наибольшая эффективность планирования заданий обеспечивается при продолжительности английского аукциона от 0,3 до 0,4 от среднего времени обработки задания. Еще раз заметим, что это соотношение не зависит от абсолютных значений времен.

Особый интерес представляет определение зависимости числа участников аукциона от его продолжительности. Для исследования этой зависимости авторами была проведена серия экспериментов, результаты которых представлены на графике (см. рис. 5). График демонстрирует следующую зависимость: увеличение средней продолжительности выполнения заданий снижает интенсивность участия диспетчеров в аукционе. При оптимальной продолжительности аукциона в 0,3-0,4 у.е. число участников аукциона в среднем достигает $70 \%$ от общего числа диспетчеров ГСУР.

\section{Заключение}

Для ТРС с абсолютными приоритетами заданий авторами предложен подход к планированию заданий на основе английского аукциона. В отличие от классических аукционных методов в предлагаемом подходе в качестве предмета торгов рассматриваются не вычислительные ресурсы, а задания пользователей. В качестве покупателей выступают владельцы вычислительных ресурсов, конкурирующие друг с другом за задания, предлагая в качестве платы вычислительные ресурсы. Задания выставляются на английский аукцион, в ходе которого покупатели имеют возможность итеративно повышать ставки за задания, при этом на размер ставки могут оказывать влияние динамически освобождающиеся ресурсы. В этом случае важнейшей характеристикой алгоритма планирования выступает 
длительность проведения (продолжительность) аукциона.

Для определения оптимальной продолжительности аукциона авторами проведена серия экспериментов на макете ТРС, построенном на базе нескольких сегментов суперкомпьютера МВС-100К. Анализ результатов экспериментов позволяет сделать два основных вывода.

Во-первых, для продолжительности аукциона и числа его участников важное значение имеет соотношение продолжительности аукциона и среднего времени выполнения задания, при одинаковых соотношениях получаются одинаковые результаты вне зависимости от абсолютных значений времен.

Во-вторых, наибольшая эффективность планирования заданий обеспечивается при продолжительности английского аукциона от 0,3 до 0,4 от среднего времени обработки задания. При такой продолжительности число участников аукциона в среднем достигает $70 \%$.

Работа выполнена в МСЦ РАН в рамках государственного задания по теме 0065-2018-0409. При проведении исследований использовался суперкомпьютер МВС-100К, находящийся в МСЦ РАН.

\section{Литература}

1. Шабанов Б.М., Овсянников А.П., Баранов А.В., Лещев С.А., Долгов Б.В., Дербышев Д.Ю. Проект распределенной сети суперкомпьютерных центров коллективного пользования // Программные системы: теория и приложения. 2017. № 4. C. 245-262. DOI: 10.25209/2079-3316-2017-8-4-245-262.

2. Henderson R.L. Job scheduling under the Portable Batch System. In: Job scheduling strategies for parallel processing, Feitelson D.G., Rudolph L. (Eds.), LNCS, Springer, 1995, vol. 949, pp. 279-294. DOI: 10.1007/3-540-60153-8 34.

3. Yoo A.B., Jette M.A., Grondona M. SLURM: simple linux utility for resource management. In: Job scheduling strategies for parallel processing, Feitelson D., Rudolph L., Schwiegelshohn U. (Eds.), LNCS, Springer, 2003, vol. 2862, pp. 44-60. DOI: $10.1007 / 109689873$

4. Moab HPC Suite Enterprise Edition. URL: http://www. adaptivecomputing.com/products/hpc-products/moab-hpc-suite-enterprise-edition (дата обращения: 12.07.2018).

5. СУПП3. URL: http://suppz.jscc.ru/ (дата обращения: 03.07.2018)

6. Баранов А.В., Тихомиров А.И. Методы и средства организации глобальной очереди заданий в территориально распределенной вычислительной системе // Вестн. Южно-Уральского гос. ун-та. Вычислительная математика и информатика. 2017. T. 6. № 4. C. 28-42. DOI: 10.14529/cmse170403.

7. Singh K.K., Kumar M., Singhal M., Dubey A. Elasticsearch. IJMTER, 2018, vol. 5, iss. 05. DOI: 10.21884/ijmter.2018. 5137.2jz19.

8. Климов Г.П. Теория массового обслуживания. М.: Издво МГУ, 2011. 312 с

9. Buyya R., Abramson D., Giddy J., Stockinger H. Economic models for resource allocation and scheduling in grid computing. Concurrency Comput. Pract. Exp., 2002, vol. 14, pp. 1507-1542. DOI: $10.1002 /$ cpe. 690 .

10. Wolski R., Plank J.S., and Brevik J. Analyzing marketbased resource allocation strategies for the computational grid. J. of High Performance Computing Applications, 2001, vol. 15, iss. 3, pp. 258-281. DOI: 10.1177/109434200101500305.

11. Kale L.V., Kumar S., Potnuru M., DeSouza J., and Bandhakavi S. Faucets: efficient resource allocation on the computational grid. Proc. Intern. Conf. on Parallel Processing (ICPP 2004), 2004, pp. 396-405. DOI: 10.1109/ICPP.2004.1327948.

12. Baranov A., Telegin P., Tikhomirov A. Comparison of auction methods for job scheduling with absolute priorities. LNCS, 2017, vol. 10421 , pp. 387-395. DOI: 10.1007/978-3-319-62932237

13. Вентцель Е.С. Теория вероятностей. М.: Юстиция, 2018. $658 \mathrm{c}$

14. Петухов О.А., Морозов А.В., Петухова Е.О. Моделирование: системное, имитационное, аналитическое. СПб: Изд-во СЗТУ, 2008. $288 \mathrm{c}$.

\section{The English auction method for job scheduling with absolute priorities in a distributed computing system}

A.V. Baranov ${ }^{1}$, Ph.D. (Engineering), Associate Professor, Leading Researcher, antbar@mail.ru, abaranov@jscc.ru

V.V.Molokanov ${ }^{2}$, Student, molocan@bk.ru

P.N. Telegin 1, Ph.D. (Engineering), Leading Researcher, pnt@jscc.ru

A.I. Tikhomirov ${ }^{1}$, Junior Researcher, tema4277@ rambler.ru

${ }^{1}$ Joint Supercomputer Center of RAS, Moscow, 119991, Russian Federation

${ }^{2}$ Moscow Institute of Physics and Technology, Dolgoprudniy, 141700, Russian Federation

Abstract. The article considers the problem of job scheduling with absolute priorities in a geographically distributed computing system (GDS) when auction methods can be efficiently applied. Most latest papers use a market model where the subject of auction trades (goods) are computational resources, and their owners act as sellers. Buyers are users who participate in the auction to purchase computing resources for of their jobs execution. Such model assumes that customers have certain budgets in nominal or real money. Job priority is determined by the price that the user can pay to finish the job by certain time. The investigated GDS model differs from the known ones by thy fact that job priorities are absolute and assigned according to uniform rules. The main goal is the earliest execution of high-priority jobs. In this case, the concept of the user's budget becomes meaningless, and the classic auction models do not work. The authors propose a new approach when the subject of auction 
trades are jobs, and resource owners act as buyers paying for jobs with available free computing resources. Within this approach, the authors consider the English auction as the most preferred method for job scheduling with absolute priorities in GDS.

The main characteristic of the scheduling algorithm, which is based on this method, is the duration of an auction. The paper presents experimental evaluation of the optimal duration of the English auction in reference to the average job processing time.

Keywords: high performance computing, grid, absolute priorities, English auction, duration of the auction, economic scheduling methods.

Acknowledgements. The work has been done in the Joint Supercomputer Center of the Russian Academy of Sciences within the framework of a state assignment 0065-2018-0409. The research included using a supercomputer MVS-100K located in the JSCC RAS.

\section{References}

1. Shabanov B.M., Ovsyannikov A.P., Baranov A.V., Leshchev S.A., Dolgov B.V., Derbyshev D.Yu. A project of a supercomputer center distributed network for collaborative research. Program Systems: Theory and Applications. 2017, vol. 8, no. 4, pp. 245-262 (in Russ.).

2. Henderson R.L. Job scheduling under the Portable Batch System. Feitelson D.G., Rudolph L. (Eds.) JSSPP 2015. Lecture Notes in Computer Science. Springer Publ., Berlin, Heidelberg, 1995, vol. 949, pp. 279-294.

3. Yoo A.B., Jette M.A., Grondona M. SLURM: simple linux utility for resource management. Feitelson D., Rudolph L., Schwiegelshohn U. (Eds.). JSSPP 2003. Lecture Notes in Computer Science. Springer Publ., Berlin, Heidelberg, 2003, vol. 2862, pp. 44-60.

4. Moab HPC Suite Enterprise Edition. Available at: http://www.adaptivecomputing.com/products/hpc-products/moabhpc-suite-enterprise-edition (accessed July 12, 2018).

5. SUPPZ. Available at: http://suppz.jscc.ru/ (accessed July 3, 2018).

6. Baranov A.V., Tikhomirov A.I. Methods and tools for organizing the global job queue in the geographically distributed computing system. Bulletin of the South Ural State Univ. Ser. Computational Mathematics and Software Engineering. 2017, vol. 6 , no. 4, pp. 28-42 (in Russ.).

7. Singh K.K., Kumar M., Singhal M., Dubey A. Elasticsearch. IJMTER. 2018, vol. 5, iss. 05, pp. 23-28.

8. Klimov G.P. Queuing Theory. Moscow, Lomonosov MSU Publ., 2011, 312 p.

9. Buyya R., Abramson D., Giddy J., Stockinger H. Economic models for resource allocation and scheduling in grid computing. Concurrency Comput. Pract. Exp. 2002, vol. 14, pp. 1507-1542.

10. Wolski R., Plank J.S., Brevik J. Analyzing market-based resource allocation strategies for the computational grid. J. of High Performance Computing Applications. 2001, vol. 15, iss. 3, pp. 258-281.

11. Kale L.V., Kumar S., Potnuru M., DeSouza J., and Bandhakavi S. Faucets: efficient resource allocation on the computational grid. Proc. Int. Conf. on Parallel Processing (ICPP 2004). 2004, pp. 396-405.

12. Baranov A., Telegin P., Tikhomirov A. Comparison of Auction Methods for Job Scheduling with Absolute Priorities. Lecture Notes in Computer Science. 2017, vol. 10421, pp. 387-395.

13. Ventsel E.S. Probability Theory. 12th ed. Moscow, Yustitsiya Publ., 2018, 658 p.

14. Petukhov O.A., Morozov A.V., Petukhova E.O. Modeling: System, Simulation, Analytical. St. Petersburg, SZTU Publ., 2008,288 p.

\section{Примеры бибциографического описания статьи}

1. Баранов А.В., Молоканов В.В., Телегин П.Н., Тихомиров А.И. Применение метода английского аукциона при планировании заданий с абсолютными приоритетами в распределенной вычислительной системе // Программные продукты и системы. 2018. Т. 31. № 3. С. 461-468. DOI: 10.15827/0236-235X.123.461-468.

2. Baranov A.V., Molokanov V.V., Telegin P.N., Tikhomirov A.I. The English auction method for job scheduling with absolute priorities in a distributed computing system. Software \& Systems. 2018, vol. 31, no. 3, pp. 461-468 (in Russ.). DOI: 10.15827/0236-235X.123.461-468. 
УДК 004.457

DOI: $10.15827 / 0236-235 X .123 .469-474$

Дата подачи статьи: 04.04.18

Выбор пакетного менеджера для многоверсионнъх приложений

В.А. Галатенко 1, д.ф.-м.н., зав. сектором автоматизаиии программирования, galat@niisi.ras.ru М.Д. Дзабраев 1, инженер, mdzabraev@niisi.ras.ru

K.A. Костюхин 1, к.фр.-м.н., старший научный compyдник, kost@niisi.ras.ru

1 Федеральный научный иентр Научно-исследовательский институт системных исследований PAH, г. Москва, 117218, Россия

Все разработчики ПО рано или поздно сталкиваются с проблемой создания и распространения дистрибутивов их программных продуктов. При этом необходимо учитывать возможности по поддержке уже существующих изделий, то есть замене старых дистрибутивов новыми. Используя качественное средство для создания дистрибутивов, разработчики получают возможность распространять свои изделия на более широкий спектр инструментальных платформ, а также осуществлять необходимую и своевременную поддержку этих изделий.

Авторы статьи ограничиваются рассмотрением UNIX-подобных систем, в большинстве которых в настоящий момент распространены такие средства создания дистрибутивов (пакетные менеджеры), как dpkg, yum. Эти пакетные менеджеры функционируют в соответствии со стандартной концепцией установки программ в UNIX. Cтандартная концепция подразумевает, что программы будут устанавливаться в стандартные каталоги, такие как /usr/bin, /usr/local/bin и так далее. При обновлении программы (пакета) обычной практикой является замещение старых файлов новыми. Стратегия замещения такого рода может носить деструктивный характер. Имеется в виду ситуация, при которой после обновления ПО некоторые программы или библиотеки перестают работать. Не исключено, например, что после обновления может перестать работать и сам пакетный менеджер. Часто пользователь оказывается в ситуации, когда для поддержки совместимости ему необходимы старые версии ПО. В этом случае приходится прибегать к практике сборки программ и библиотек из исходных текстов и ручной установки, такой как make install. Установка такого рода является необратимой и очень опасной, поскольку в этом случае велика вероятность удаления или замещения файлов, находящихся под контролем пакетного менеджера.

В качестве решения описанных проблем предлагается пакетный менеджер NIX [1]. Основным достоинством этого менеджера является то, что полностью исключается деструктивное воздействие с его стороны. Это достигается путем установки каждого пакета в изолированную локацию, при этом всю ответственность за область видимости того, что было установлено, берет на себя пакетный менеджер.

Ключевые слова: пакетный менеджер, NIX, установка программ, дистрибутив, версионность

В настоящее время мир программно-аппаратного обеспечения (как специального, так и общего назначения) стремительно изменяется. Несколько раз в год выходят обновления, зачастую критические, заставляющие разработчиков ПО своевременно реагировать на них. Кроме того, гибкая (agile) методика разработки ПО стала по сути стандартом de facto.

Все это привело к тому, что многие разработчики вынуждены создавать и поддерживать одновременно несколько версий своих продуктов как для соответствия новым требованиям пользователей, так и для обеспечения обратной совместимости со старыми версиями других приложений и/или библиотек, также используемых в проекте.

В OC типа Unix традиционная схема развертывания новой версии приложения состоит в замене старых файлов приложения, расположенных по стандартным путям, на новые. При этом старые файлы можно сохранить в другом месте, чтобы восстановить предыдущую версию приложения в случае, если новая не будет работать. Добиться одновременной работы старой и новой версий приложения бывает очень сложно, необходимо вручную осуществлять множество административных действий по конфигурированию системы.

Соответственно, классические пакетные менеджеры, такие как уum, не предоставляют удобных путей решения проблемы одновременной доступности нескольких версий одного и того же приложения. В то же время сравнительно недавно появились пакетные менеджеры, ориентированные на решение указанной проблемы. Наиболее известным из них и стремительно набирающим популярность является пакетный менеджер NIX.

NIX предназначен для создания дистрибутивов, не конфликтующих друг с другом (и с другими версиями одного и того же дистрибутива) по зависимостям в инструментальной файловой системе. Это означает, что устраняется риск потери работоспособности старых версий приложения, а также других приложений, работающих в указанной инструментальной системе и зависящих от устанавливаемого приложения.

Далее пакетный менеджер NIX и технология создания в нем дистрибутивов рассматриваются более подробно.

\section{Язык программирования NIX}

Для пакетного менеджера NIX [1] разработан одноименный функциональный язык программирования. Он не является языком общего назначения и предназначен именно для создания пакетов.

B рамках NIX каждый пакет - это функция. Тело функции описывает процедуру сборки и уста- 
новки пакета. На вход функция получает свои зависимости. Вычисление функции равнозначно конфигурации, сборке и установке пакета.

Язык NIX обладает очень важным свойством прозрачностью ссылок (referential transparency [2]). Оно означает, что выражение языка всегда вычисляется с одним и тем же результатом. Из этого следует, что вычисление функции с фиксированными аргументами всегда будет приводить к одному и тому же результату. Таким образом, если функция вызывалась с одними и теми же аргументами на разных платформах, результат установки будет одинаковым.

Иногда создателям пакетов приходится прикладывать большие усилия, чтобы сборка пакета при одинаковых зависимостях давала один и тот же результат. Для этого приходится снабжать пакет так называемыми заплатами (патчами, от англ. patch).

C подробным описанием языка NIX можно ознакомиться в [3, 4], эффективным с точки зрения изучения языка может оказаться интерактивный курс [5].

Как и во многих функциональных языках, в языке NIX отсутствуют декларации, а есть только выражения (expressions). Выражением называется единица языка, которая может быть упрощена до конкретного значения. Например, $x+5$ можно упростить до одного числа, а $x=5$ нет, конструкция if $(y)\{/ /$ ветвление с одной ветвью

// что-то вычисляется

тоже не выражение.

Функции в языке NIX являются лямбда-выражениями и могут принимать только один аргумент на свой вход. Функция состоит из названия единственного аргумента, тела и двоеточия, которое разделяет аргумент и тело, например, $x: x * x+1$. Чтобы вычислить функцию на значении $y$, необходимо записать его справа от функции: $(x: x * x+1) y$.

Чтобы ветвление на основе if являлось выражением, оно должно содержать как true-ветвь, так и false-ветвь. Например, функция, возвращающая абсолютное значение $x$ : if $(x>0)$ then $x$ else $-x$.

В языке NIX отсутствует оператор присваивания, однако существует конструкция языка, позволяющая назначить выражение на имя переменной, но сделать это можно только один раз. Например, выражение

let

$y=5$;

$f=x: x^{*} x$

in

ffy

В языке NIX есть следующие типы данных: строка, целое число, список, множество (пары ключ-значение/словарь/хэш-таблица), пути (например /home/user1), булевы значения, null, функция. Множества записываются в таком формате:

\{ $x=1$;

$$
\begin{aligned}
& y=2 ; \\
& \quad g=u: v: u+v ;
\end{aligned}
$$

Множество состоит из записей. После каждой записи должна стоять точка с запятой. Каждая запись состоит из имени, значения и знака =, отделяющего имя от значения. Значением элемента списка может являться функция. Таким образом получается конструкция, похожая на объект. Для обращения к значению элемента множества используется точка:

$$
\begin{array}{ll}
\text { let } & \\
\text { in } & \\
& \text { s. } x+\text { s. } y
\end{array}
$$

Если предполагается, что функция должна принимать множество, ее можно записать в следующем виде: $\{x, y\}: x+y$.

Таким образом, выражение $(\{x, y\}: x+y)\{x=1$; $y=2$; будет вычислено с целочисленным результатом, равным трем.

Множества могут быть обычными и рекурсивными. В рекурсивных множествах допускается, чтобы один элемент множества вычислялся на основе его другого элемента. Для создания рекурсивного множества необходимо поместить ключевое слово rec перед определением множества, например rec $\{x=1 ; y=x+1 ;\}$.

Определение списка состоит из открывающей квадратной скобки, элементов списка, разделенных пробелами, и закрывающей квадратной скобки, например [1 “123” true].

Строки заключаются либо в двойные кавычки “123”, либо в пару одинарных " 456 ”.

Внутри строки можно использовать конструкцию “\$\{expr\}", где ехpr является произвольным выражением языка, которое вычисляется к строковому значению, например:

$$
\begin{aligned}
& \text { rec }\{ \\
& \quad \text { version }=" 8.1 " ; \\
& \text { name }=" g d b-\$\{\text { version }\} " ;
\end{aligned}
$$

Приведенных сведений о языке NIX достаточно для понимания того, что такое пакет в NIX и как его написать самому.

\section{Пакет в NIX}

Пакетом в NIX можно назвать произвольное выражение, которое вычисляется к деривации (derivation). Деривация, с точки зрения языка NIX, является множеством с некоторым набором атрибутов. Для пользователя важно понимать, как писать выражения, которые будут вычисляться к деривациям. B NIX пакеты принято оформлять в виде функций в формате $\{\operatorname{dep} 1, \operatorname{dep} 2, \ldots\}$ : body. body является выражением, которое на основе аргументов $\operatorname{dep} 1, \operatorname{dep} 2, \ldots$ формирует деривацию. Для формирования дериваций, как правило, используются вспомогательные инструменты (generic builders). 
Среда NIX предоставляет такие инструменты для GNU Autotools, для пакетов языка Python, пакетов NodeJS и многих других.

Приведем пример NIX-пакета для программы Midnight Commander:

\{stdenv, fetchurl, pkgconfig, glib, gpm, file, e2fsprogs,

libX11, libICE, perl, zip, unzip, gettext, slang,

libssh2, openssl\}:

stdenv.mkDerivation rec \{

name $=$ "mc- $\$\{$ version $\} " ;$

version = "4.8.19";

$\mathrm{src}=$ fetchurl \{

url = "http://www.midnight-commander.org/downloads/

\$ $\{$ name\}.tar.xz";

sha256 = "1pzjq4nfx12aakxipdjs5hq9n14374ly1100s40

kd2djnnxmd7pb";

\}

nativeBuildInputs $=[$ pkgconfig $]$

buildInputs $=[$ perl glib slang zip unzip file gettext libX11 libICE

libssh2 openssl ] ++

stdenv.lib.optionals (!stdenv.isDarwin) [ e2fsprogs gpm ];

configureFlags $=[$ "--enable-vfs-smb" ];

postFixup $="$

\# remove unwanted build-dependency references

sed $-\mathrm{i}$-e "s!PKG_CONFIG PATH=

"\$\{PKG_CONFIG_PATH $\} !$ PKG_CONFIG_PATH=\$(echo "\$PKG_CONFIG_PATH" | sed -e 's/./0/g')!" \$out/bin/mc

Приведенное выражение является функцией. Она получает на вход свои зависимости. Тело функции - выражение, которое формируется из вызова функции stdenv.mkDerivation, в качестве аргумента вызываемой функции выступает рекурсивное множество гес $\{\ldots\}$.

Внутри этого рекурсивного множества содержится вся необходимая для сборки информация. Атрибут пате является обязательным при работе с функцией stdenv.mkDerivation.

Далее идет атрибут version, который используется для формирования атрибута пате.

Затем обязательный аргумент src. Значение данного атрибута вычисляется при помощи функции fetchurl. Значение атрибута src - это путь до архива с исходными текстами для Midnight Commander.

Функция fetchurl получает на вход множество с двумя атрибутами. Первый атрибут определяет адрес, откуда будет скачан архив. Атрибут sha256 представляет контрольную сумму, которая должна соответствовать скачанному архиву.

Атрибут nativeBuildInputs является списком зависимостей пакета, которые будут использоваться при сборке пакета и не будут использоваться во время выполнения

buildInputs определяет зависимости, которые будут использоваться во время выполнения. Операцией ++ обозначается конкатенация списков.
Выражение stdenv.lib.optionals (!stdenv.isDarwin) [ e2fsprogs gpm ] вернет список [ e2fsprogs gpm ], если инструментальная платформа [6] будет принадлежать семейству Darwin, в противном случае будет возвращен пустой список.

configureFlags представляет список строк, каждая из которых будет передана как аргумент скрипту ./configure.

Перед описанием атрибута postFixup опишем фазы установки пакета. Существует стандартный набор фаз, через которые проходит пакет перед установкой. Имена стандартных фаз [7] следующие: unpack, patch, configure, build, check, install, fixup, installCheck, distribution.

На стадии unpack осуществляется распаковка архива с исходными текстами, на стадии patch к исходным кодам применяются патчи, если они были перечислены в атрибуте patches множества-аргумента функции stdenv.mkDerivation. Каждую из фаз по необходимости можно переопределить, также имеется возможность выполнения произвольного кода на языке shellscript перед/после каждой фазы. Для этого применяются специальные обработчики. В приведенном пакете выполняется обработчик postFixup, некоторым образом корректирующий бинарный файл.

\section{Репозиторий nixpkgs}

Все выражения, представляющие собой пакеты, хранятся в репозитории nixpkgs [8] на github. Bce пакеты хранятся в виде одного большого выражения. nixpkgs не представляется одним файлом: части большого выражения разнесены по файлам и каталогам. Точкой входа в выражение является файл default.nix, который находится в корневом каталоге репозитория.

Когда пользователь инициирует установку пакета, запускается процесс первичного вычисления nixpkgs, после чего nixpkgs преобразуется в иерархическую структуру, состоящую из множеств. На первом уровне оказываются обычные пакеты типа nixpkgs.gcс и nixpkgs.mc. На второй уровень попадают пакеты, имеющие некоторую общность, например, nixpkgs.python27Packages является множеством, которое содержит пакеты для версии Python 2.7. В частности, это множество содержит пакет nixpkgs.python27Packages.django.

После установки пакетного менеджера NIX на машину каждого пользователя сохраняется выражение nixpkgs, по сути являющееся не более чем набором рецептов того, как собрать то или иное ПО. Никто не мешает сделать копию репозитория nixpkgs, внести в нее свои правки и работать с ней. Более того, можно написать полностью свое выражение со своим набором рецептов сборки и работать с этим выражением. Единственное условие на первом уровне выражения должно оказаться множество. 
Репозиторий nixpkgs представляет нестабильные выражения. Нестабильность означает, что какой-либо пакет может не собраться или для него может не оказаться заранее откомпилированных бинарных файлов. После тестирования нестабильного репозитория nixpkgs его текущее состояние перемещают в nixpkgs-channels.

Один из самых важных вопросов заключается в том, как много пакетов сейчас в nixpkgs и сопоставимо ли их количество с репозиториями для fedora и ubuntu. Ответ на этот вопрос дает таблица (значения взяты на 7.02.2017 г.):

\begin{tabular}{|l|l|l|l|}
\hline \multirow{2}{*}{ Пакет } & \multicolumn{3}{|c|}{ Репозиторий } \\
\cline { 2 - 4 } & \multicolumn{1}{|c|}{ nixpkgs } & ubuntu(16.04) & fedora(27) \\
\hline total & 13960 & 45688 & 46697 \\
\hline python2 & 1730 & 2716 & 1529 \\
\hline python3 & 1569 & 1373 & 1873 \\
\hline
\end{tabular}

В строке с пометкой total отображается общее количество пакетов. Из этой строки видно, что количество пакетов в nixpkgs отстает от своих конкурентов примерно в 3,5 раза, тем не менее стоит отметить, что все наиболее важные и часто используемые пакеты уже попали в nixpkgs. По мнению авторов, на сегодняшний день имеется достаточное количество пакетов в nixpkgs, чтобы этот пакетный менеджер можно было использовать и не сталкиваться с проблемой отсутствия в репозитории какого-либо пакета.

Динамика активности репозитория nixpkgs относительно количества измененных строк кода за день представлена на рисунке.

Из приведенного рисунка можно заключить, что репозиторий набирает популярность. Вокруг него существует сообщество людей, пишущих NIX-выражения. Каждое предложение с изменением (merge request) проходит строгое рецензирование кода и процедуру автоматической сборки.

\section{Структура хранилища /nix/store}

Пакетный менеджер NIX производит установку программ не в корневой каталог (например /usr/bin), а в каталог /nix/store. Каждый пакет устанавливается в индивидуальный каталог с именем /nix/store/ $<$ hash $>-<$ name $>$, где $<$ hash $>-$ значение хэш-функции $[9,10]$, вычисленное от входных параметров деривации (пакета). Входные параметры - это все атрибуты множества, которые передаются сборщику (derivation, stdenv.mkDerivation и им подобные). Параметр $<$ name $>$ - атрибут деривации name. Этот подкаталог будет иметь стандартную структуру с каталогами $/$ nix $/$ store $/<$ hash $>$ - $<$ na$\mathrm{me}>/\{$ bin, usr/bin, ... $\}$.

Пакетный менеджер NIX работает с файлами из /nix/store в следующем режиме. Все, что попало в /nix/store, больше никогда не будет изменено пакетным менеджером. Если та или иная деривация больше не используется, ее можно удалить при помощи сборщика мусора.

Программы, установленные пакетным менеджером NIX, имеют зависимости только из /nix/ store. Стоит отметить, что к числу таких зависимостей относятся динамический загрузчик и bash. Для достижения изоляции такого рода создатели деривации иногда модифицируют исходный код программы. Для использования динамического загрузчика из /nix/store все .elf-файлы в автоматическом режиме модифицируются утилитой patchelf, которая корректным образом изменяет путь до динамического загрузчика. Помимо изменения пути до динамического загрузчика, изменяются специальные комментарии, содержащие строки запуска интерпретаторов, вместо \#! /bin/bash подставляется \#! $/$ nix/store $/<$ hash $>$-bash- $<$ version $>$.

\section{Управление областью видимости}

Пакетный менеджер NIX устанавливает ПО в нестандартные локации. При запуске программы исполняемый файл ищется в путях, перечисленных в переменной окружения РАТН. Поэтому для нахождения установленной программы необходимо, чтобы она оказалась в одном из каталогов, перечисленных в РАТН. За то, какие исполняемые файлы будут найдены в /nix/store, отвечает пакетный менеджер NIX.

Пакетный менеджер NIX позволяет делать разные профили для каждого пользователя. Под профилем имеется в виду набор программ, видных пользователю. Наличие разных профилей для раз-

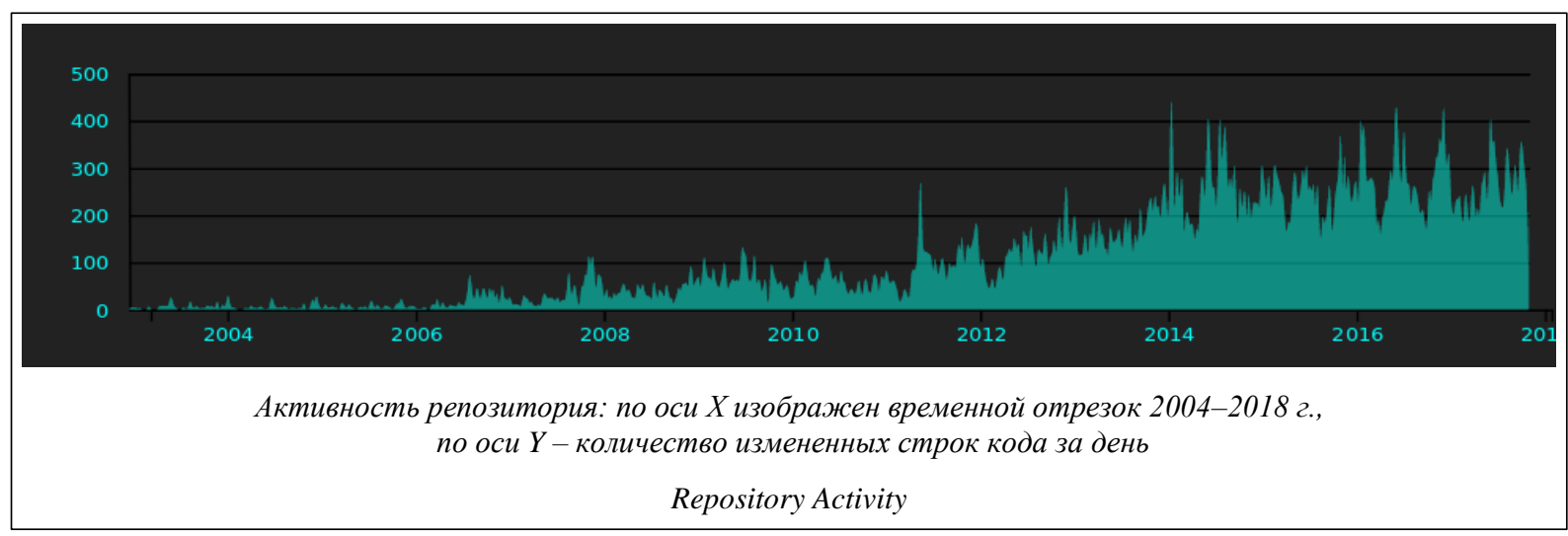


ных пользователей означает, что если из двух существующих пользователей А и В пользователь А поставит в свое окружение программу Р, а пользователь В не установит программу Р, то пользователю А программа будет видна, а пользователю В нет. Отметим, что традиционно в UNIX-подобных операционных системах установка производится глобально и установленная программа видна всем.

Вдобавок к множественным профилям NIX позволяет вести версионный контроль профилей. После каждой операции установки/удаления/обновления создается новая генерация профиля. Если по каким-либо причинам установленная программа не удовлетворяет пользователя, имеется возможность переключения к предыдущей генерации одной командой.

Каждый из каталогов /nix/store/<hash $>$-userenvironment имеет структуру, схожую со структурой корневого каталога, и подкаталоги bin, etc и им подобные. Файлы, находящиеся в подкаталогах, являются символическими ссылками на реальные файлы.

\section{Бинарный кэш}

Пакеты в NIX описывают процесс сборки программы из исходных текстов. Если каждый пользователь будет собирать каждую программу из исходных текстов, это отнимет у него очень много времени на ожидание сборки, а иногда и вовсе окажется невозможным из-за того, что сборка некоторых пакетов требует большого количества оперативной памяти.

Для решения этой проблемы существуют хранилища, содержащие заранее скомпилированные программы. Поэтому алгоритм установки следующий. Сначала пакетный менеджер проверит существование заранее откомпилированных бинарных файлов в бинарном кэше. Если такие файлы существуют, они будут получены от удаленного сервера. Если удаленный сервер не располагает откомпилированными файлами, будет запущена сборка из исходных текстов.

Репозиторий NIX содержит стабильную и нестабильную версии бинарного кэша. Нестабильная версия представляет прекомпилированные файлы для репозитория github.com/NixOS/nixpkgs. После того, как репозиторий nixpkgs пройдет тщательное тестирование, он перемещается в репозиторий github.com/NixOS/nixpkgs-channels. Стабильная версия репозитория гарантирует, что для каждого пакета, для которого необходима сборка, в бинарном кэше будут содержаться прекомпилированные бинарные файлы.

\section{Заключение}

В статье был рассмотрен пакетный менеджер, который принципиальным образом отличается от стандартных пакетных менеджеров. В архитектуре пакетного менеджера NIX отвергается стандартная концепция глобальной установки программ, при этом новая концепция учитывает особенности стандартных систем сборки, что практически всегда позволяет без модификации системы сборки программы использовать ее в пакетном менеджере NIX. Пакетный менеджер NIX управляет файлами таким образом, что всякая операция установки/удаления/обновления гарантированно не будет деструктивно воздействовать на систему.

\section{Лuтература}

1. Getting NIX. URL: https://nixos.org/nix/download.html (дата обращения: 03.04.2018).

2. Referential transparency. URL: https://wiki.haskell.org/ Referential transparency (дата обращения: 03.04.2018).

3. NIX by example. URL: https://medium.com/@MrJames Fisher/nix-by-example-a0063a1a4c55 (дата обращения: 03.04.2018).

4. Learn NIX. URL: https://learnxinyminutes.com/docs/nix/ (дата обращения: 03.04.2018).

5. A tour of NIX. URL: https://nixcloud.io/tour/?id=1 (дата обращения: 03.04.2018).

6. Configure terms and history. URL: https://gcc.gnu.org/ onlinedocs/gccint/Configure-Terms.html (дата обращения: 03.04.2018).

7. NIX phases. URL: https://nixos.org/nixpkgs/manual/\#secstdenv-phases (дата обращения: 03.04.2018).

8. NIX repository. URL: https://github.com/NixOS/nixpkgs (дата обращения: 03.04.2018).

9. NIX pills. Derivation. URL: https://nixos.org/nixos/nixpills/our-first-derivation.html (дата обращения: 03.04.2018).

10. NIX pills. Store paths. URL: https://nixos.org/nixos/nixpills/nix-store-paths.html (дата обращения: 03.04.2018).

\section{A package manager for multiversion applications}

V.A. Galatenko ${ }^{1}$, Dr.Sc. (Physics and Mathematics), Head of Programming Automation Department, galat@niisi.ras.ru M.D.Dzabraev ${ }^{1}$, Engineer, mdzabraev@niisi.ras.ru

K.A. Kostyukhin ${ }^{1}$, Ph.D. (Physics and Mathematics), Senior Researcher, kost@niisi.ras.ru

${ }^{1}$ Federal State Institution "Scientific Research Institute for System Analysis of the Russian Academy of Sciences" (SRISA RAS), Moscow, 117218, Russian Federation

Abstract. All software developers eventually face the problem of creating and distributing their software products. At the same time, it is necessary to take into account possibilities of supporting existing products, i.e. replacing old distributions with 
new ones. When using a quality distribution tool, developers are able to distribute their products to a wider range of platforms, as well as provide the necessary and timely support for these products.

The authors of the article consider only UNIX-like systems, most of which include package managers as dpkg, yum. These package managers operate according to a standard concept of software installation in UNIX. The standard concept implies that programs are installed in standard directories such as /usr/bin, /usr/local/bin, and so on. When updating a program (package), it is common practice to replace old files with new ones. Such substitution strategy can be destructive. This means that after software update, some programs or libraries stop working. It is possible, for example, that a package manager itself may stop working after updating. A user is often in a situation when old versions of software are required to support compatibility. In this case, it is necessary to use the practice of building programs and libraries from source code and manual installation, such as "make install". This kind of installation is irreversible and very dangerous, since in this case the files under control of a package manager may be deleted or replaced.

The authors propose a package manager NIX [1] as a solution for the described problems. The most important advantage of this manager is that it completely excludes destructive impact on its part. This is achieved by installing each package in an isolated location controlled by a package manager.

Keywords: package manager, NIX, program installation, distribution, versioning.

\section{References}

1. Getting NIX. Available at: https://nixos.org/nix/download.html (accessed April 3, 2018).

2. Referential transparency. Available at: https://wiki.haskell.org/Referential_transparency (accessed April 3, 2018).

3. NIX by example. Available at: https://medium.com/@MrJamesFisher/nix-by-example-a0063a1a4c55 (accessed April $3,2018)$.

4. Learn NIX. Available at: https://learnxinyminutes.com/docs/nix/ (accessed April 3, 2018).

5. A tour of NIX. Available at: https://nixcloud.io/tour/?id=1 (accessed April 3, 2018).

6. Configure terms and history. Available at: https://gcc.gnu.org/onlinedocs/gccint/Configure-Terms.html (accessed April 3, 2018).

7. NIX phases. Available at: https://nixos.org/nixpkgs/manual/\#sec-stdenv-phases (accessed April 3, 2018).

8. NIX repository. Available at: https://github.com/NixOS/nixpkgs (accessed April 3, 2018).

9. NIX pills. Derivation. Available at: https://nixos.org/nixos/nix-pills/our-first-derivation.html (accessed April 3, 2018).

10. NIX pills. Store paths. Available at: https://nixos.org/nixos/nix-pills/nix-store-paths.html (accessed April 3, 2018).

\section{Примеры бибциографического описания статьи}

1. Галатенко В.А., Дзабраев М.Д., Костюхин К.А. Выбор пакетного менеджера дмя многоверсионных приможений // Программные продукты и системы. 2018. Т. 31. № 3. С. 469-474. DOI: 10.15827/0236-235X.123.469-474.

2. Galatenko V.A., Dzabraev M.D., Kostyukhin K.A. A package manager for multiversion applications. Software \& Systems. 2018, vol. 31, no. 3, pp. 469-474 (in Russ.). DOI: 10.15827/0236-235X.123. 469-474. 


\title{
температурная модель распределения потенциала в неравномерно легированных нанотранзисторах со структурой кремний на изоляторе
}

\author{
H.В. Масальский 1, к.фp.-м.н., зав. сектором, volkov@niisi.ras.ru \\ 1 Федеральный научный иентр Научно-исследовательский институт системных исследований \\ РАН, ФНЦ НИИСИ РАН, г. Москва, 117218, Россия
}

Обсуждается разработка 2D-аналитической температурной модели распределения потенциала в рабочей области двухзатворного тонкопленочного полевого нанотранзистора со структурой кремний на изоляторе с вертикальной неравномерно легированной рабочей областью в виде функции Гаусса. Двухзатворные полевые транзисторы со структурой кремний на изоляторе являются ведущими представителями элементной базы нового научного направления высокотемпературная микроэлектроника, потому что это идеальные высокотемпературные устройства.

Для случая стационарной температуры в параболическом приближении с использованием специальной функции получено аналитическое решение 2D-уравнения Пуассона. Численно исследованы температурные зависимости распределения поверхностного потенциала от параметров профиля легирования в диапазоне температур от 200 до $500 \mathrm{~K}$.

Для выбранных топологических норм варьирование параметров профиля легирования предоставляет дополнительную возможность управления ключевыми характеристиками нанотранзистора наряду с толщиной рабочей области и подзатворного окисла фронтального затвора, что важно при анализе применимости нанотранзисторных структур. Показано, что структуры с крутыми профилями легирования являются более термостойкими по сравнению с однородно легированными. Для повышения верхней границы температурного диапазона на 100 К необходимо увеличивать уровень легирования рабочей области на порядок. Применение перспективной транзисторной архитектуры для двухзатворных полевых нанотранзисторов со структурой кремний на изоляторе позволяет повысить термическую стойкость их ключевых электрофизических характеристик по сравнению с двухзатворными полевыми транзисторами с однородно легированной рабочей областью и с их объемными аналогами. Результаты моделирования находятся в хорошем соответствии с данными моделирования, полученными при помощи коммерчески доступного для 2D-моделирования транзисторных структур программного пакета ATLAS ${ }^{\mathrm{TM}}$.

Ключевые слова: структура кремний на изоляторе, двухзатворный полевой нанотранзистор, неравномерно легированная рабочая область, аналитическая модель, 2D-распределение потенциала.

Высокотемпературная микроэлектроника - новое научное направление, которое объединяет передовые физико-технологические и конструктивно-схемотехнические принципы организации нового класса электронных устройств, предназначенных для специальных приложений, где условия эксплуатации отличаются от нормальных. Одними из таких устройств являются микросхемы на структурах кремний на изоляторе (КНИ) - идеальные высокотемпературные устройства, широко применяемые в Вооруженных силах, нефтегазовой, ядерной и других отраслях, где необходимо функционирование в высокотемпературной среде [1].

Значимыми представителями элементной базы КНИ микросхем являются двухзатворные КНИ КМОП-транзисторы [2-4]. Они, как известно, обладают практически значимыми возможностями масштабирования параметров в наноразмерной области [5]. Однако проведение макетных исследований наноэлектронных устройств в высокотемпературной области - очень дорогостоящая опция. Следовательно, возникает необходимость разработки высокотемпературных моделей и методов схемотехнического моделирования для прогнозирования, руководствуясь которыми, можно проектировать электронные устройства [6].

Важным условием развития методов моделирования КНИ КМОП-транзисторов является учет современных требований технологии их изготовления. На современном этапе реальные КНИ КМОПтранзисторы характеризуются наличием вертикального гауссового профиля распределения легирующей примеси в рабочей области из-за требования ряда операций имплантации и диффузии во время процесса изготовления $[4,6]$. Таким образом, моделирование основных характеристик транзистора, в частности, распределение потенциала в рабочей области, с учетом гауссова профиля легирования может обеспечить более адекватные физические характеристики реальных КМОП-транзисторов [7-9]. К тому же искусственно созданный гауссовый профиль легирующей примеси, как известно, компенсирует проявление нежелательных короткоканальных эффектов в транзисторе, что положительным образом отражается на всех его характеристиках, что определяет актуальность и востребованность такого направления развития моделей и методов моделирования.

Цель данной работы заключается в разработке температурной аналитической модели распределения потенциала неравномерно легированного двухзатворного КНИ КМОП-нанотранзистора. Модель базируется на аналитическом решении 2Dуравнения Пуассона с соответствующими граничными условиями для случая постоянной температуры тела транзистора [10]. Для проверки адекват- 
ности предложенной модели результаты моделирования сопоставляются с данными, полученными при помощи программного пакета $\operatorname{ATLAS}^{\mathrm{TM}}$ [11] для диапазона температур 200-500 K.

\section{Постановка обобщенной задачи}

Для случая стационарной температуры в рамках концепции зарядового разделения рассмотрим квазиклассическую задачу определения 2D-распределения потенциала в тонкопленочной двухзатворной неравномерно легированной КНИ-транзисторной структуре. Данная структура схематично представлена на рисунке 1.

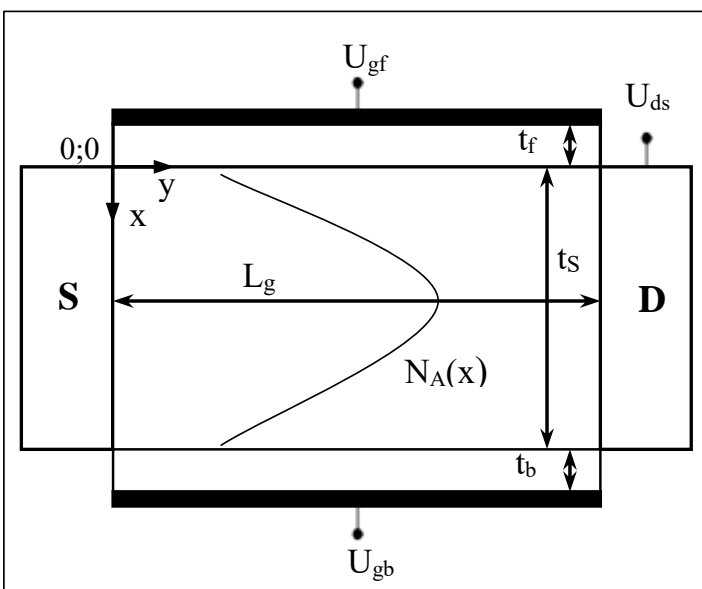

Рис. 1. Схема двухзатворного КНИ КМОПнанотранзистора с неравномерно легированной рабочей областью

Fig. 1. The diagram of a double gate SOI CMOS nanotransistor with non-uniform doping work area

В данном случае необходимо решать самосогласованную задачу нахождения распределения $2 \mathrm{D}$-потенциала в рабочей области $\varphi(x, y, T)$, которая связана уравнением Пуассона, записанным в виде:

$$
\frac{\partial^{2} \varphi(x, y, T)}{\partial x^{2}}+\frac{\partial^{2} \varphi(x, y, T)}{\partial y^{2}}=-\frac{q N_{A}(x, T)}{\varepsilon_{S}(T)},
$$

где $q$ - заряд электрона; $\varphi(x, y, T)$ - температурная зависимость распределения потенциала в рабочей области транзистора; $\varepsilon_{S}(T)$ - температурная зависимость диэлектрической проницаемости материала рабочей области; $N_{A}(x, T)$ - температурная зависимость концентрации легирования рабочей области.

Тепловые процессы в кремниевых транзисторных устройствах можно с некой долей условности разделить на быстрые и медленные. Быстрые процессы оказывают влияние на полупроводниковые свойства тела транзистора (например, ширина запрещенной зоны, собственная концентрация носителей [12]), быстрый отклик, высокий температурный градиент, широкий диапазон воздействия, сравнительно узкий температурный диапазон, вне которого полупроводниковые свойства материала практически исчезают. Медленные процессы связаны с фундаментальными физическими законами. В рассматриваемом случае (1) учитываются температурная зависимость диэлектрической проницаемости кремния и его окисла и процесс термодиффузии примеси в рабочей области транзистора. Данные механизмы характерны для области сверхвысоких температур выше 500 К. Однако при таких высоких температурах даже при принятии специальных мер кремневые устройства перестают функционировать [6]. Поэтому в данной работе рассматривается диапазон температур 200-500 К, который представляет практический интерес.

В рамках указанных приближений правая часть уравнения (1) запишется в виде функции Гаусса: $N_{A}(x)=N_{p i c k} \exp \left(-\left(\frac{x-R_{d}}{\sqrt{2} \sigma_{d}}\right)^{2}\right)$, где $N_{p i c k}-$ максимальная концентрация легирующей примеси; $R_{d}-$ положение пиковой концентрации легирования; $\sigma_{d}$ - крутизна профиля легирующей примеси. А граничные условия для него можно записать так: $\left.\varphi(x, y, T)\right|_{x=0}=\varphi_{f}(y, T)$; $\frac{\varepsilon_{o x}}{t_{f}}\left(U_{g f}-U_{F B}(T)-\varphi(0, y, T)\right)=-\left.\varepsilon_{S} \frac{\partial \varphi(x, y, T)}{\partial x}\right|_{x=0}$ $\frac{\varepsilon_{o x}}{t_{b}}\left(U_{g b}-U_{F B}(T)-\varphi\left(t_{S}, y, T\right)\right)=-\left.\varepsilon_{S} \frac{\partial \varphi(x, y, T)}{\partial x}\right|_{x=t_{S}}$ $\varphi(x, 0, T)=U_{b i}(T) ;$ $\varphi\left(x, L_{g}, T\right)=U_{b i}(T)+U_{d s}$,

где $\varphi_{f}(y, T)$ - поверхностный потенциал; $\varepsilon_{o x}-$ диэлектрическая проницаемость подзатворного окисла; $t_{f}$ и $t_{b}$ - толщина подзатворного окисла фронтального и обратного затворов соответственно; $U_{g f}$ и $U_{g b}$ - напряжение на фронтальном и обратном затворах соответственно; $U_{F B}(T)$ - температурная зависимость напряжения плоских зон; $U_{b i}(T)$ - температурная зависимость контактной разности потенциалов; $L_{g}, t_{S}$ - длина и толщина рабочей области транзистора соответственно; $U_{d s}-$ напряжение сток-исток.

Известно, что напряжение плоских зон для фронтального и обратного затворов

$$
U_{F B}(T)=\Phi_{M S}-\left(\chi_{f}+\frac{E_{g}(T)}{2 q}+U_{F}(T)\right),
$$

где $\Phi_{M S}$ - работа выхода; $\chi_{f}$ - сродство электрона; $E_{g}(T)$ - ширина запрещенной зоны; $U_{F}(T)$ - уровень Ферми. Температурная зависимость ширины запрещенной зоны $E_{g}(T)=E_{g}(0)-g_{E_{g}}\left(\frac{T^{2}}{T+T_{0}}\right)$, где $E_{g}(0)$ - ширина запрещенной зоны при $0 \mathrm{~K} ; g_{E_{g}}-$ температурный градиент ширины запрещенной зоны; $T_{0}$ - начальная температура (оба последних параметра являются по сути подгоночными и определяются экспериментально). Температурная зави- 
симость уровня Ферми $U_{F}(T)=U_{t} \ln \frac{N_{A}}{n_{i}(T)}$, где $U_{t}=\frac{k T}{q}-$ тепловой потенциал; $k-$ константа Больцмана;

$n_{i}(T)=\sqrt{N_{c}(300) N_{v}(300)}\left(\frac{T}{300}\right)^{3 / 2} \exp \left(-\frac{E_{g}(T)}{2 k T}\right)$

собственная концентрация носителей; $N_{c}(300)$ и $N_{v}(300)$ - плотность поверхностных состояний в зоне проводимости и валентной зоне при температуре 300 К соответственно;

$u_{b i}(T)=U_{t} \ln \left(\frac{\left.N_{A} N_{d s}\right)}{n_{i}^{2}(T)}\right)$ - контактная разность потенциалов; $U_{d s}-$ напряжение сток-исток; $N_{d s}$ - максимальная концентрация легирования областей стока и истока.

\section{Свойства гауссова профиля легирования}

На рисунке 2 приведены характерные распределения профиля легирования (функция Гаусса) по глубине рабочей области (в ортогональной плоскости) при ее фиксированной толщине.

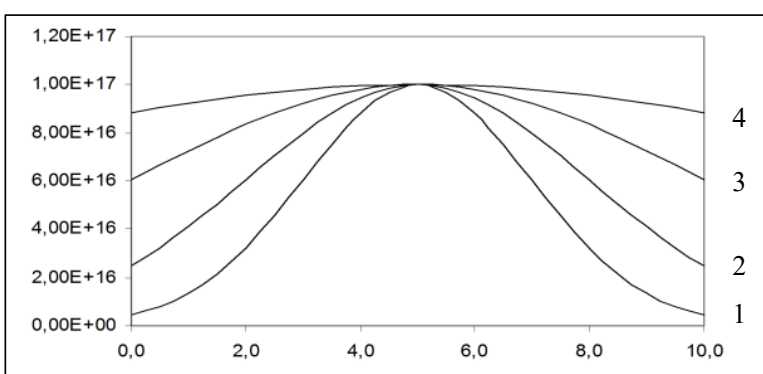

Рис. 2. Распределение профиля легирования по глубине рабочей области транзистора $\mathrm{npu} t_{S}=10 \mathrm{HM}$ для разной крутизны профиля, где $1-\sigma_{d}=3 н$ н, $2-\sigma_{d}=5 \mathrm{H \mu}, 3-\sigma_{d}=8 \mathrm{\mu м}, 4-\sigma_{d}=10 \mathrm{\mu м}$

Fig. 2. Distribution of a doping profile on the depth of a transistor work area when $t \mathrm{~s}=10 \mathrm{~nm}$ for different profile steepness, where $1-\sigma_{d}=3 \mathrm{~nm}, 2-\sigma_{d}=5 \mathrm{~nm}$, $3-\sigma_{d}=8 \mathrm{~nm}, 4-\sigma_{d}=10 \mathrm{~nm}$

Следует отметить, что уровень приповерхностной концентрация легирования (например $N_{A}(0)$ ) существенно зависит от величины параметра $\sigma_{d}$. В области малых значений $\sigma_{d}$ приповерхностная концентрация может отличаться от максимальной более чем на порядок. При этом протяженность этих областей (у верхнего и нижнего затворов) вдоль оси х (по глубине рабочей области) является конечной. Например, при $\sigma_{d}=1$ нм протяженность этих областей составляет примерно 1,9 нм, а приповерхностная концентрация отличается на три порядка от максимальной. Следует отметить, что при уменьшении толщины $t_{S}$ спад параметра $N_{A}(0)$ замедляется. Для получения тех же концентраций необходимо уменьшать $\sigma_{d}$ пропорционально отно- шению толщин. В области больших значений $\sigma_{d}$ отношение $N_{A}(0) / N_{\text {puck }} \rightarrow 1$. Поэтому с некоторого значения $t_{S}$ можно считать рабочую область равномерно легированной.

\section{Распределение потенциала}

В рабочей области рассматриваемой структуры 2D-уравнение Пуассона при переходе к новой координате при помощи новой переменной $\rho=\frac{x-R_{d}}{\sqrt{2} \sigma_{d}}$ и с учетом вышеизложенных допущений имеет следующий вид:

$$
\begin{aligned}
& \frac{1}{2 \sigma_{d}^{2}} \frac{\partial^{2} \varphi(\rho, y, T)}{\partial \rho^{2}}+\frac{\partial^{2} \varphi(\rho, y, T)}{\partial y^{2}}= \\
& =-\frac{q N_{p i c k}}{\varepsilon_{S}} \exp \left(-\rho^{2}\right) .
\end{aligned}
$$

Аналитическое решение уравнения (2) аппроксимируется полиномом с коэффициентами в виде функций, зависящих от $y$ :

$\varphi(\rho, y, T)=a_{1}(y, T)+a_{2}(y, T) \rho+a_{3}(y, T) g(\rho)$,

где вспомогательная функция $g(\rho)$ представлена в виде $g(\rho)=\rho \operatorname{erf}(\rho)+\frac{\exp \left(-\rho^{2}\right)}{\sqrt{\pi}} ;$ специальная функция $\operatorname{erf}(\rho)=\frac{2}{\sqrt{\pi}} \int_{0}^{\rho} \exp \left(-t^{2}\right) d t-$ интеграл вероятности, является, как известно, одной из наиболее используемых в теории и практике специальных функций [13].

При таком выборе решения уравнения (1) функции $a_{m}(y, T)(m=0,1,2)$ определяются исходя из граничных условий, в которых учитываются температурные зависимости:

$$
\begin{aligned}
& \left.\varphi(\rho, y, T)\right|_{\rho=x_{f}}=\varphi_{f}(y, T) ; \\
& \frac{\varepsilon_{o x}}{t_{f}}\left(U_{f}-U_{F B}(T)-\varphi_{f}(y, T)\right)= \\
& =-\left.\frac{\varepsilon_{S}}{\sqrt{2} \sigma_{d}} \frac{\partial \varphi(\rho, y, T)}{\partial \rho}\right|_{\rho=x_{f}} ; \\
& \frac{\varepsilon_{o x}}{t_{b}}\left[U_{b}-U_{F B}(T)-\varphi_{b}(y, T)\right]= \\
& =-\left.\frac{\varepsilon_{S}}{\sqrt{2} \sigma_{d}} \frac{\partial \varphi(\rho, y, T)}{\partial \rho}\right|_{\rho=x_{b}} ; \\
& \varphi(\rho, 0, T)=U_{b i}(T)-U_{F}(T) ; \\
& \varphi\left(\rho, L_{g}, T\right)=U_{b i}(T)-U_{F}(T)+U_{d s},
\end{aligned}
$$

где $\varphi_{b}(y, T)$ - распределение потенциала вдоль обратной поверхности; $x_{f}=\frac{-R_{d}}{\sqrt{2} \sigma_{d}}$ и $x_{b}=\frac{t_{S}-R_{d}}{\sqrt{2} \sigma_{d}}-$ новые координаты фронтальной и обратной поверхностей соответственно; $\varepsilon_{r}=\frac{\varepsilon_{S}}{\varepsilon_{o x}}$. 
Выражение для функций $a_{1}(y), a_{2}(y), a_{2}(y)$, входящих в (3), можно записать в виде

$a_{1}(y, T)=\varphi_{f}(y, T)+$

$+a_{0}\left(\frac{x_{f} e r f\left(x_{b}\right)-g_{f}}{t_{f}}\left(U_{g f}-U_{F B}-\varphi_{f}(y, T)\right)+\right.$

$\left.+\left(g_{f}-x_{f} \operatorname{erf}\left(x_{f}\right)\right) E_{b}(y, T)\right)$;

$a_{2}(y, T)=a_{0}\left(-\frac{\operatorname{erf}\left(x_{b}\right)}{t_{f}}\left(U_{g f}-U_{F B}(T)-\right.\right.$

$\left.\left.-\varphi_{f}(y, T)\right)+\operatorname{erf}\left(x_{f}\right) E_{b}(y, T)\right)$

$a_{3}(y, T)=a_{0}\left(\frac{\operatorname{erf}\left(x_{b}\right)}{t_{f}}\left(U_{g f}-U_{F B}(T)-\varphi_{f}(y, T)\right)-\right.$

$\left.-\operatorname{erf}\left(x_{f}\right) E_{b}(y, T)\right)$

где $g_{b}=g\left(x_{b}\right), g_{f}=g\left(x_{f}\right), a_{0}=\frac{\sqrt{2} \sigma_{d}}{\varepsilon_{r}\left(\operatorname{erf}\left(x_{b}\right)-\operatorname{erf}\left(x_{f}\right)\right)}-$

коэффициент нормировки функций $a_{m}(y, T)$.

После несложных, но громоздких вычислений заключительное выражение для 2D-потенциала $\varphi(\rho, y, T)$ можно представить в виде

$\varphi(\rho, y, T)=U_{g f}-U_{F B}(T)-$

$-\frac{\sqrt{2} \sigma_{d}}{\alpha_{\phi}}\left\{\left(U_{g f}-U_{F B}(T)-\right.\right.$

$\left.-\varphi_{b}(y, T)\right)\left(\xi_{1}+\rho \operatorname{erf}\left(x_{b}\right)-g(\rho)\right)+$

$\left.+\frac{E_{b}(y, T)}{\varepsilon_{r}}\left(\xi_{2}+\xi_{3} \rho-\left(t_{S}+\varepsilon_{r} t_{f}\right) g(\rho)\right)\right\}$,

где $\alpha_{\varphi}-$ коэффициент нормировки потенциала и $\xi_{m}-$ вспомогательные функции. Их выражения приведены в [10]. Связь поля $E_{b}$ с напряжением на обратном затворе $U_{g b}$ можно, например, представить так [4]:

$E_{b}(y, T)=\frac{1}{t_{b}}\left(-\left(U_{g b}-U_{F B}(T)\right)+\varphi_{b}(y, T)\right)$.

Выражение для температурной зависимости фронтального поверхностного потенциала $\varphi_{f}(y, T)$ можно записать в виде

$\varphi_{f}(y, T)=B_{1}(T) \exp \left(y / l_{f}\right)+B_{2}(T) \exp \left(-y / l_{f}\right)+$

$+l_{f}^{2}\left(A_{f}\left(-k_{1}\left(U_{g f}-U_{F B}(T)\right)+\right.\right.$

$\left.+U_{g b}-U_{F B}(T)\right)+\frac{1-k_{1}}{\sigma_{d} a_{\phi}} \exp \left(x_{f}^{2}\right)\left(U_{g f}-U_{F B}(T)\right)-$

$\left.-\frac{q N_{p i c k}}{\varepsilon_{S}} \exp \left(-x_{f}^{2}\right)\right)$

где $B_{1}(T)$ и $B_{2}(T)$ - произвольные коэффициенты; $l_{f}^{2}=\frac{\varepsilon_{r} \sigma_{d} \alpha_{\varphi}\left(t_{b}-k_{2}\right)}{\left(1-k_{1}\right)\left(t_{S}+\varepsilon_{r}\left(t_{b}+t_{f}\right) \exp \left(x_{f}{ }^{2}\right)\right)}-$ характери-

стическая длина для фронтальной поверхности; $A_{f}=\frac{\exp \left(x_{f}{ }^{2}\right)}{\sigma_{d}} \frac{t_{S}+\varepsilon_{r}\left(k_{2}+t_{f}\right)}{\varepsilon_{r} \alpha_{\varphi}}-$ масштабирующий коэффициент потенциала на фронтальной поверх- ности, $k_{1}=\frac{a_{0}}{t_{f}}\left(\Delta g-\Delta \operatorname{xerf}\left(x_{b}\right)\right), k_{2}=a_{0}\left(\Delta \operatorname{xerf}\left(x_{f}\right)+\Delta g\right)$, $\Delta g=g_{b}-g_{f}$

Выражения для температурной зависимости $\varphi_{b}(y, T)$ можно записать в виде $\varphi_{b}(y, T)=B_{3}(T) \exp \left(y / l_{b}\right)+B_{4}(T) \exp \left(-y / l_{b}\right)+$ $+l_{b}^{2}\left(A_{b}\left(U_{g f}-U_{F B}(T)+\frac{t_{S}+\varepsilon_{r} t_{f}}{\varepsilon_{r} t_{b}}\left(U_{g b}-U_{F B}(T)\right)\right)-\right.$ $\left.-\frac{q N_{p i c k}}{\varepsilon_{S}} \exp \left(-x_{b}^{2}\right)\right)$

где $B_{3}(T)$ и $B_{4}(T)$ - произвольные коэффициенты; $l_{b}^{2}=\frac{\varepsilon_{r} \sigma_{d} t_{b} \alpha_{\phi}}{\left(t_{S}+\varepsilon_{r}\left(t_{f}+t_{b}\right)\right) \exp \left(x_{b}^{2}\right)}-$ характеристическая длина для обратной поверхности; $A_{b}=\frac{\exp \left(x_{b}{ }^{2}\right)}{\sigma_{d} \alpha_{\phi}}-$ масштабирующий коэффициент потенциала на обратной поверхности.

Используя граничные условия (4), можно получить выражения для функций $B_{m}(T)$ :

$$
\begin{aligned}
& B_{1}(T)=u_{1}(T)-r_{1} U_{f} ; \\
& B_{2}(T)=u_{2}(T)-r_{2} U_{f} ; \\
& B_{3}(T)=u_{3}(T)-r_{3} U_{b} ; \\
& B_{4}(T)=u_{4}(T)-r_{4} U_{b},
\end{aligned}
$$

где выражения для функций $u_{i}(T)$ и $r_{i}$ приведены в [10]. Необходимо только соотношения $U_{b i}^{\prime}(T)$ и $U_{b i}^{\prime \prime}(T)$ заменить на следующие:

$$
\begin{aligned}
& U_{b i}^{\prime}(T)=U_{b i}(T)+\Phi_{F}(T)-l_{f}^{2}\left(A _ { f } \left(-U_{g f}-\right.\right. \\
& \left.-k_{1} U_{F B}(T)+U_{F B}(T)\right)+ \\
& +U_{F B}(T) \frac{1-k_{1}}{\sigma_{d} k_{2}} \exp \left(x_{f}{ }^{2}\right)+\frac{q N_{p i c k}}{\varepsilon_{S}} \exp \left(-x_{f}{ }^{2}\right), \\
& U_{b i}^{\prime \prime}(T)=U_{b i}(T)+\Phi_{F}(T)-l_{b}^{2}\left(A _ { b } \left(U_{F B}(T)+\right.\right. \\
& \left.\left.+\frac{t_{S}+\varepsilon_{r} t_{f}}{\varepsilon_{r} t_{b}} U_{F B}(T)-U_{g b}\right)+\frac{q N_{p i c k}}{\varepsilon_{S}} \exp \left(-x_{b}{ }^{2}\right)\right) .
\end{aligned}
$$

\section{Температурные зависимости основных физических величин}

Температурная зависимость распределения потенциала в основном определяется температурными зависимостями таких физических величин, как ширина запрещенной зоны, собственная концентрация, встроенная разность потенциалов и напряжение плоских зон [12].

Температурная зависимость ширины запрещенной зоны для КНИ структуры показана на рисунке 3.

Такой вид близкой к линейной зависимости в исследуемом диапазоне температур обусловливается температурным изменением взаимодействия 


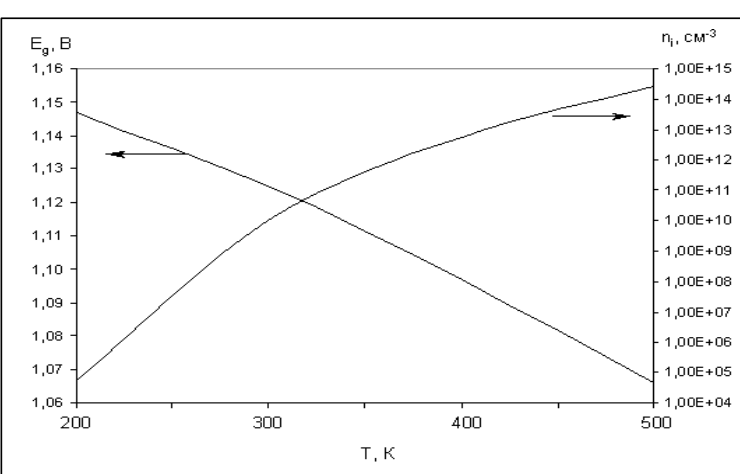

Рис. 3. Температурная зависимость запрещенной зоны $(E g)$ и собственной концентрацчии $\left(n_{i}\right)$

Fig. 3. Temperature dependence of the forbidden band $(E g)$ and own concentration $\left(n_{i}\right)$

носителей с решеткой и температурной зависимостью распределения фононов вследствие линейных колебаний решетки [10].

Температурная зависимость собственной концентрации, приведенная на рисунке 1, имеет выраженный нелинейный характер. Следует отметить, что с ростом температуры величина собственной концентрации резко возрастает. Она каждый раз удваивается при повышении температуры примерно на 10 К. Поэтому при высоких температурах процесс термогенерации становится определяющим для концентрации носителей [12].

Положение уровня Ферми определяется уровнем собственной концентрации носителей. Поскольку при повышении температуры уровень собственной концентрации растет быстрее, чем тепловой потенциал, уровень Ферми будет приближаться к нижней границе запрещенной зоны, что иллюстрируется результатами расчетов, приведенными на рисунке 4. Аналогичным поведением характеризуется и контактная разность потенциалов, показанная на рисунке 4 .

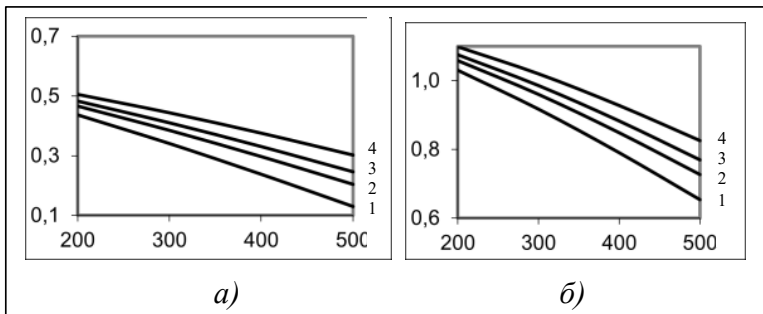

Рис. 4. Температурные зависимости уровня Ферми (а) и контактной разности потенцииалов (б) при разной кониентрачии легирования рабочей области, где $1-N_{A}=5,5 \times 10^{15} \mathrm{~cm}^{3}$,

$2-N_{A}=3,0 \times 10^{16} \mathrm{~cm}^{3}, 3-N_{A}=8,0 \times 10^{16} \mathrm{~cm}^{3}$, $4-3-N_{A}=1,0 \times 10^{17} \mathrm{~cm}^{3}$

Fig. 4. Temperature dependences of the Fermi level (a) and contact potential difference (б) in case of different doping concentration of work area, where

$1-N_{A}=5,5 \times 10^{15} \mathrm{~cm}^{3}, 2-N_{A}=3,0 \times 10^{16} \mathrm{~cm}^{3}$,

$3-N_{A}=8,0 \times 10^{16} \mathrm{~cm}^{3}, 4-3-N_{A}=1,0 \times 10^{17} \mathrm{~cm}^{3}$
Важно отметить, что характер поведения температурных зависимостей основных физических величин анализируемых структур одинаков.

\section{Результаты моделирования распределения потенциала}

Для модельных расчетов был выбран прототип двухзатворного КНИ КМОП-нанотранзистора $n$-типа с гауссовым вертикальным профилем легирования. Параметры устройства, отвечающие современным требованиям, таковы: $L_{g}=45 \mathrm{HM}, t_{S}=$ $=10 \mathrm{HM}, t_{f}=1,8 \mathrm{HM}, t_{b}=50 \mathrm{HM}, N_{\text {pick }}=1 \times 10^{16} \mathrm{~cm}^{-3}$. На рисунке 5 приведены численно рассчитанные распределения фронтального поверхностного потенциала вдоль рабочей области при разных значениях $\sigma_{d}$ при фиксированных напряжениях на контактах транзистора.

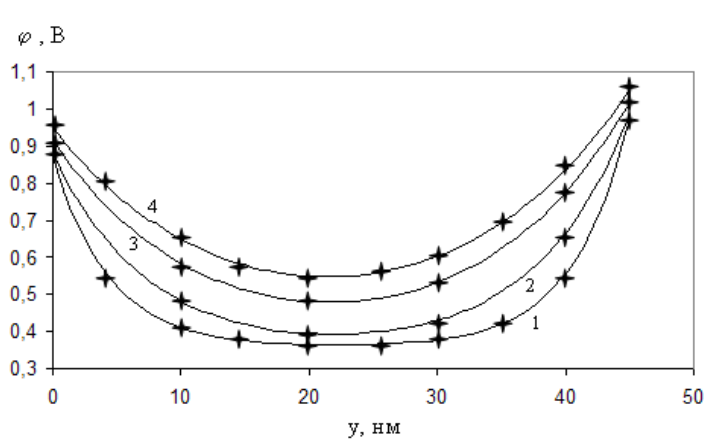

Рис. 5. Распределение фронтального поверхностного потенциала по длине рабочей области при разных значениях крутизны $\sigma_{d}$, где $1-\sigma_{d}=3 \mu \mathrm{\mu}, 2-\sigma_{d}=$ $=5 \mathrm{H \mu}, 3-\sigma_{d}=8 \mathrm{\mu M}, 4-\sigma_{d}=10 \mathrm{\mu м} \mathrm{при} \mathrm{Uds=0.1} \mathrm{B,}$ $U f=0.1 B, U b=0$

Fig. 5. Distribution of front surface potential on the length of work area in case of different steepness values, where $1-\sigma_{d}=3 \mathrm{~nm}, 2-\sigma_{d}=5 \mathrm{~nm}, 3-\sigma_{d}=8 \mathrm{~nm}$, $4-\sigma_{d}=10 \mathrm{~nm}$ at $U d s=0.1 \mathrm{~V}, U f=0.1 \mathrm{~V}, U b=0$

При помощи соотношений (6-8) для малосигнального случая $U_{d s}=U_{g f}=0.1$ В и $U_{g b}=0$ В вычислены значения фронтального поверхностного потенциала для разных значений температур. На рисунке 6 показано распределение данного потенциала для значений крутизны профиля легирования 3 и 10 нм в диапазоне температур от 200 до $500 \mathrm{~K}$.

Такой вид распределения фронтального потенциала обусловлен температурной зависимостью физических величин, рассмотренных выше. В результате абсолютное значение фронтального поверхностного потенциала снижается с повышением температуры. Однако его нормированная величина возрастает с ростом температуры во всех точках канала [14]. Это связано с тем, что с повышением температуры увеличивается собственная концентрация носителей, а уровень 


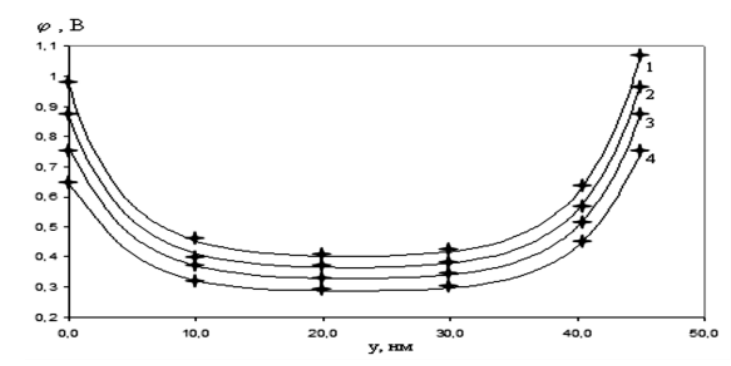

a)

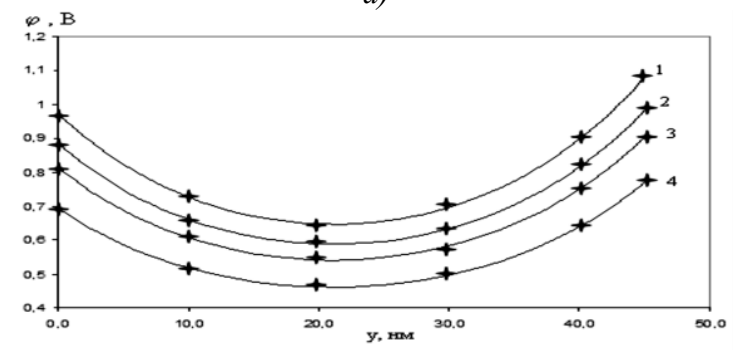

б)

Рис. 6. Температурная зависимость распределения фронтального поверхностного потенциала, где $1-200$ K, $2-300 \mathrm{~K}, 3-400 \mathrm{~K}, 4-500$ К для разных значений крутизны $\sigma_{d}$, где а) $\sigma_{d}=3 \mathrm{\mu м}$, б) $\sigma_{d}=10 \mathrm{Hм}$

Fig. 6. Temperature dependence of front surface potential distribution, where $1-200 \mathrm{~K}, 2-300 \mathrm{~K}, 3-400 \mathrm{~K}$,

4-500 K for different steepness values $\sigma_{d}$ a) $\sigma_{d}=3 \mathrm{~nm}$, б) $\sigma_{d}=10 \mathrm{~nm}$

Ферми понижается. Из результатов моделирования следует, что в исследуемом диапазоне температур зависимость величины изменения потенциала от температуры в любой точке канала носит нелинейный характер.

Этот вывод касается и поведения температурной зависимости минимума поверхностного потенциала $\varphi_{f \min }$. Функция $\varphi_{f \min }$, как известно, используется для моделирования ключевых характеристик КНИ-нанотранзисторов [15]. Полезным результатом для практических приложений является также температурный градиент минимума поверхностного потенциала для разных значений крутизны профиля легирования. Результаты расчетов для исследуемого прототипа отражены на рисунке 7.

Из представленных данных следует, что изменение температурных свойств транзисторной структуры зависит от $\sigma_{d}$. При небольших значениях $\sigma_{d}$ температурный градиент $\operatorname{grad}\left(\varphi_{f \min }\right)$ практически постоянен во всем исследуемом диапазоне температур, что и определяет линейный характер зависимости $\varphi_{f \min }$ и остальных ключевых парамет-

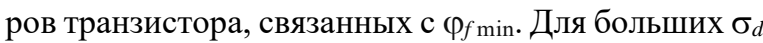
температурный градиент нелинейный. В данном случае это проявляется начиная с температуры примерно 350 К. Поэтому в области высоких температур будет проявляться существенная деградация зависимости $\varphi_{f \min }$ и остальных ключевых параметров транзистора, связанных с ним. Для ни-

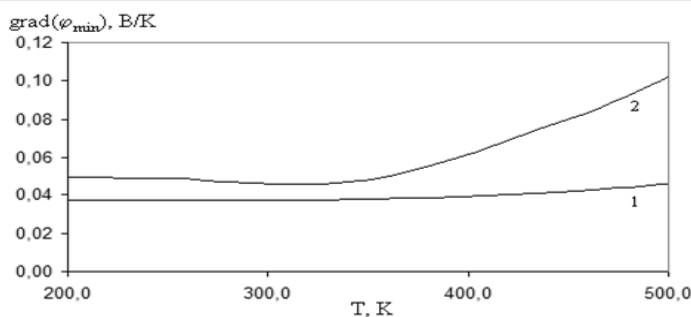

Рис. 7. Температурный градиент минимума поверхностного потенциала для разных значений крутизны $\sigma_{d}$, где $1-\sigma_{d}=3 н м, 2-\sigma_{d}=10 н м$

Fig. 7. Temperature gradient of a surface potential minimum for different steepness values $\sigma_{d}$, where

$$
1-\sigma_{d}=3 \mathrm{~nm}, 2-\sigma_{d}=10 \mathrm{~nm}
$$

велирования этого эффекта и повышения верхней границы температурного диапазона на 100 К необходимо увеличивать уровень легирования рабочей области на порядок.

\section{Заключение}

Разработана 2D-аналитическая температурная модель распределения потенциала в рабочей области двухзатворного тонкопленочного полевого нанотранзистора со структурой кремний на изоляторе с неоднородно легированной рабочей областью в виде функции Гаусса. Модель построена на основе аналитического решения 2D-уравнения Пуассона, полученного в параболическом приближении о виде распределения потенциала, с использованием специальной функции - интеграл ошибок.

В диапазоне температур 200-500 К численно исследованы температурные зависимости распределения основных физических характеристик транзисторной структуры и поверхностного потенциала от крутизны профиля легирования. Результаты моделирования находятся в хорошем соответствии с данными моделирования, полученными при помощи коммерчески доступного программного пакета ATLAS ${ }^{\mathrm{TM}}$, предназначенного для 2D-моделирования транзисторных структур.

Работа выполнена при поддержке Программы фундаментальных исследований РАН№ 43.35 НИР № 0065-2018-0006.

\section{Литература}

1. Colinge J.P. Multiple-gate SOI MOSFETs. Solid-State Electronics, 2004, vol. 48, no. 3, pp. 897-909.

2. Kranti A., Armstrong G.A. Engineering source/drain extension regions in nanoscale double gate (DG) SOI MOSFETs: Analytical model and design considerations. Solid-State Electronics, 2006, vol. 50, no. 2, pp. 437-447.

3. Nikolic B. Design in the power-limited scaling regime. IEEE Trans. Electron Devices, 2008, vol. 55, no. 1, pp. 71-83.

4. Suzuki K., Yuji K., Susumu N., Charles W.M., Temel H.B., Tsutomu N. Analytical model for redistribution profile of ion-implanted impurities during solid-phase epitaxy. IEEE Trans. Electron Devices, 2007, vol. 54, no. 2, pp. 262-271.

5. Масальский Н.В. Характеристики двухзатворных КНИ 
КМОП-нанотранзисторов для перспективных технологий с низким уровнем потребляемой мощности // Микроэлектроника. 2012. T. 41. № 6. C. 436-444.

6. International technology roadmap for semiconductor 2015. URL: http://public.itrs.net/ (дата обращения: 17.03.2018).

7. Reyboz M., Rozeau O., Poiroux T., Martin P., Jomaah J. An explicit analytical charge based model of undoped independent Double-Gate MOSFET. Solid-State Electronics, 2006, vol. 50, no. 8, pp. $1276-1285$

8. Moldovan O., Cerdeira A., Jiménez D., Raskin J.-P., Kilchytska V., Flandre D., Collaert N., Iñiguez B. Compact model for highly-doped double-gate SOI MOSFETs targeting baseband analog applications. Solid-State Electronics, 2007, vol. 51, no. 5, pp. 655-661.

9. Cerdeira A., Iñiguez B., Estrada M. Compact model for short channel symmetric doped double-gate MOSFETs. Solid-State Electronics, 2008, vol. 52, no. 4, pp. 1064-1070.

10. Масальский Н.В. Моделирование распределения потен- циала в неоднородно легированной рабочей области двухзатворного КНИ КМОП-нанотранзистора // Микроэлектроника. 2017. T. 46. № 2. С. 151-160.

11. Silvaco Int. 2004: ATLAS User's Manual A 2D numerical device simulator. URL: https://www.silvaco.com/products/tcad/ device simulation/atlas/atlas.html (дата обращения: 21.03.2018).

12. Зи С. Физика полупроводниковых приборов: В 2 кн. М.: Мир, 1984. Кн. 1. 456 с.

13. Корн Г., Корн Т. Справочник по математике для научных работников и инженеров. М.: Физматгиз, 1978. 720 с.

14. Han J.W., Kim C.J., Choi Y.K. Universal potential model in tied and separated double-gate MOSFETs with consideration of symmetric and separated asymmetric structure. IEEE Trans. Electron Devices, 2008, vol. 55, no. 5, pp. 1472-1480.

15. Масальский Н.В. Проблемы схемотехнического моделирования нанотранзисторов со структурой кремний на изоляторе // Программные продукты и системы. 2013. № 4. С. 60-67.

Software \& Systems

DOI: $10.15827 / 0236-235 X .123 .475-481$

Received 03.05.18

Temperature model of potential distribution for non-uniform doping nanotransistors with the silicon-on-insulator structure

\section{N.V.Masalsky ${ }^{1}$, Ph.D. (Phisics and Mathematics), Head of Sector,volkov@niisi.ras.ru}

${ }^{1}$ Federal State Institution "Scientific Research Institute for System Analysis of the Russian Academy of Sciences" (SRISA RAS), Moscow, 117218, Russian Federation

Abstract. The paper discusses development of a 2D analytical temperature model of potential distribution in a work area of a double gate thin-film field nanotransistor with the silicon-on-the-insulator structure with a vertically non-uniform doping work area in the form of the Gaussian function. Double-gate field transistors with the silicon-on-the-insulator structure are the leading representatives of an element basis for a new scientific direction that is high-temperature microelectronics since they are ideal high-temperature devices.

For a stationary temperature case, in parabolic approximation using a special function the authors have received an analytical solution for a 2D Poisson equation. They also numerically investigated temperature dependences of surface potential distribution on doping profile parameters in the range of temperatures from $200 \mathrm{~K}$ to $500 \mathrm{~K}$.

For the selected layout rules, variation of doping profile parameters gives an additional opportunity of controlling the key nanotransistor characteristics along with thickness of work area and gate oxide of a front lock, which is important when analyzing applicability of nanotransistor structures. The authors show that structures with steep doping profiles are more heat-resistant in comparison with homogeneously doping ones. In order to increase the upper bound of a temperature range by $100 \mathrm{~K}$, it is necessary to increase the work area doping level by times. Using a perspective transistor architecture for double gate field nanotransistors with the structure silicon-on-the-insulator allows increasing thermal firmness of their key electrophysical characteristics in comparison with double-gate field transistors with homogeneously doping work area and with their volume analogs. The results of simulation are in close agreement with simulation data received using the ATLAS ${ }^{\mathrm{TM}}$ software package, which is commercially available for $2 \mathrm{D}$ simulation of transistor structures.

Keywords: structure silicon on insulator, double gate MOSFET nanotransistor, non-uniform doping work area, analytic model, 2D potential distribution.

Acknowledgements. The work has been supported by the Fundamental Research Program of RAS no. 43.35 NIR no. 0065-2018-0006.

\section{References}

1. Colinge J.P. Multiple-gate SOI MOSFETs. Solid-State Electronics. 2004, vol. 48, no. 3, pp. 897-909.

2. Kranti A., Armstrong G.A. Engineering source/drain extension regions in nanoscale double gate (DG) SOI MOSFETs: Analytical model and design considerations. Solid-State Electronics. 2006, vol. 50, no. 2, pp. 437-447.

3. Nikolic B. Design in the power-limited scaling regime. IEEE Trans. Electron Devices. 2008, vol. 55, no. 1, pp. 71-83.

4. Suzuki K., Yuji K., Susumu N., Charles W.M., Temel H.B., Tsutomu N. Analytical model for redistribution profile of ion-implanted impurities during solid-phase epitaxy. IEEE Trans. Electron Devices. 2007, vol. 54, no. 2, pp. 262-271.

5. Masalsky N.V. Characteristics of double gate SOI CMOS nanotransistors for perspective technologies with the low supply power. Microelectronics. 2012, vol. 41, no. 6, pp. 436-444 (in Russ.).

6. International technology roadmap for semiconductor. Available at: http://public.itrs.net/ (accessed March 17, 2018).

7. Reyboz M., Rozeau O., Poiroux T., Martin P., Jomaah J. An explicit analytical charge based model of undoped independent DoubleGate MOSFET. Solid-State Electronics. 2006, vol. 50, no. 8, pp. 1276-1285.

8. Moldovan O., Cerdeira A., Jiménez D., Raskin J.-P., Kilchytska V., Flandre D., Collaert N., Iñiguez B. Compact model for highlydoped double-gate SOI MOSFETs targeting baseband analog applications. Solid-State Electronics. 2007, vol. 51, no. 5, pp. 655-661.

9. Cerdeira A., Iñiguez B., Estrada M. Compact model for short channel symmetric doped double-gate MOSFETs. Solid-State Electronics. 2008, vol. 52, no. 4, pp. 1064-1070.

10. Masalsky N.V. Simulation of the potential distribution in an inhomogeneously doped workspace of a double-gate SOI CMOS nanotransistor. Russian Microelectronics, 2017, vol. 46, no. 2, pp. 139-148 (in Russ.).

11. ATLAS User's Manual A 2D Numerical Device Simulator. Available at: https://www.silvaco.com/products/tcad/device_simulation/ atlas/atlas.html Silvaco Int. 2004 (accessed March 21, 2018).

12. Sze S.M. Physics of Semiconductor Devices. Wiley-Interscience Publ. NY, Chichester, Brisbane, Toronto, Singapore, 1981.

13. Korn G., Korn T. Mathematical Handbook for Scientists and Engineers. McGraw-Hill Book Comp., NY, Sun Francisco, Toronto, London, Sidney, 1981.

14. Han J.W., Kim C.J., Choi Y.K. Universal potential model in tied and separated double-gate MOSFETs with consideration of symmetric and separated asymmetric structure. IEEE Trans. Electron Devices. 2008, vol. 55, no. 5, pp. 1472-1480.

15. Masalsky N.V. Nanotransitors circuitry simulation problems with silicon-on-insulator structure. Software \& Systems, 2013, no. 3, pp. 60-67 (in Russ.) 


\title{
нспользование метода математического моделирования для оиенки влияния смачиваемости пород на нефтеотдачу на примере внутрипластового горения
}

\author{
И.В. Афранаскин ${ }^{1}$, к.т.н., ведущий научный compyдник, ivan@afanaskin.ru \\ A.B. Королев 1, к.т.н., старший научный сотрудник, alexandre.korolev@mail.ru \\ B.A. Юдин 1, к.ф.-м.н., старший научный сотрудник, yudinval@yandex.ru
}

1 Федеральный научный иентр Научно-исследовательский институт системных исследований РАН, г. Москва, 117218 , Россия

В статье рассмотрена значимость одной из проблем корректного численного моделирования тепловых методов добычи нефти - изменение смачиваемости пород при нагреве. При тепловых воздействиях температура пласта может на $100-500^{\circ} \mathrm{C}$ превосходить начальную, и за счет создания такого искусственного поля температур смачиваемость пласта изменяется как в пространстве, так и во времени. Это может кардинально изменить характер фильтрации флюидов и результативность теплового воздействия.

Для изучения температурного изменения смачиваемости необходимы достаточно сложные эксперименты, осуществляемые с учетом температурного изменения большого числа влияющих на смачиваемость процессов. До постановки таких сложных работ необходимо оценить значимость этого фактора для прогноза добычи при использовании тепловых методов разработки.

Влияние температурного изменения смачиваемости учитывали через изменение характерных точек на кривых относительных фазовых проницаемостей.

Авторами была рассмотрена задача многофазной многокомпонентной неизотермической фильтрации с химическими реакциями, в которой учитывается зависимость относительных фазовых проницаемостей от температуры. Для решения возникающей системы уравнений предложена оригинальная, неявная по давлению и явная по температуре и концентрациям конечно-разностная схема. Показано, что при моделировании внутрипластового горения пренебрежение изменениями смачиваемости, которые обусловлены созданием в пласте поля температур, переменного по пространству и времени, может приводить к значительным погрешностям в прогнозе накопленной добычи нефти (до 20 \% относ.) и времени прорыва кислорода к добывающей скважине (до 10 \% относ.). Для учета этого эффекта необходимо экспериментальное изучение изменений смачиваемости (и относительных фазовых проницаемостей) при повышении температуры породы.

Ключевые слова: смачиваемость, зависимость относительных фазовых пронииаемостей от температуры, математическое моделирование фильтрации, внутрипластовое горение.

Известно, что от общего объема разведанных в России запасов нефти около $11 \%$ приходится на высоковязкие нефти [1]. Основная трудность в их разработке - низкие дебиты скважин. Применение традиционных методов, например заводнения, не позволяет достичь высокого значения коэффициента извлечения нефти ввиду вязкостной неустойчивости фронта вытеснения нефти вытесняющими агентами. Основными методами разработки таких месторождений являются тепловые [2-7], в которых обеспечиваются повышение температуры пласта и снижение вязкости нефти, в том числе и путем внутрипластового горения нефти [3-7].

Один из тепловых методов - с закачкой в пласт воздуха и созданием в нефтенасыщенном пласте подвижного очага низкотемпературного окисления, известный как термогазовое воздействие (ТГВ) [2, 6], считается перспективным для разработки нетрадиционных запасов нефти месторождений баженовской свиты.

Особое внимание в связи с этим необходимо уделять вопросам корректного численного моделирования тепловых методов и точности прогноза технологических показателей их применения [6].
Одна из проблем при моделировании - изменение смачиваемости пород при нагреве, поскольку при тепловых воздействиях температура пласта может на $100-500{ }^{\circ} \mathrm{C}$ превосходить начальную [8-11]. При этом за счет создания искусственного поля температур смачиваемость изменяется как в пространстве, так и во времени. Все это может кардинально изменить характер фильтрации флюидов и результативность теплового воздействия.

Пока этот вопрос мало изучен. Более того, полученные разными авторами экспериментальные данные весьма противоречивы $[8,11]$, что определяется рядом объективных факторов [9]. Во-первых, эксперименты проводились по различным методикам, с различными нефтями и в разных условиях. Влияние смачиваемости оценивалось также по-разному: по измерениям краевого угла смачивания, по капиллярному впитыванию, по виду кривых относительных фазовых проницаемостей и т.п. Во-вторых, смачиваемость зависит от многих физических факторов, по-разному реагирующих на повышение температуры [11].

Для изучения температурного изменения смачиваемости необходимы достаточно сложные экс- 
перименты, осуществляемые с учетом большого числа факторов: начальных и текущих термобарических условий в пласте; состава, плотности и вязкости фильтрующихся углеводородных смесей (нефти, а в случае баженовской свиты - дополнительно и природных битумоидов, продуктов искусственного термолиза, окисления нефти и керогена, газов горения т.п.); наличия многофазного насыщения [9].

Разумеется, до постановки таких сложных работ необходимо оценить значимость этого фактора для результата теплового метода разработки.

Упрощенное исследование подобного рода предпринято в работе [10]. Рассматривался вариант, когда за счет нагрева смачиваемость всего пласта скачком менялась на противоположную - с гидрофильной на гидрофобную или наоборот. Показано, что такое резкое изменение смачиваемости существенно меняет результат теплового воздействия при разработке. В ряде случаев это может быть сопоставимо с эффектом уменьшения вязкости нефтей с ростом температуры [10]. Однако равномерный прогрев всего пласта может иметь место лишь в немногих методиках, например, при некоторых способах термолиза in-situ (внутри пласта) горючих сланцев [12], что для России в настоящее время неактуально. По этой причине в данной работе предпринята попытка оценить влияние смачиваемости - переменной и по пространству, и во времени.

\section{Подходы к описанию неизотермической фильтрации}

При численном моделировании фильтрации учет переменной смачиваемости, строго говоря, требует учета капиллярных сил, то есть отказа от простой схемы Бакли-Леверетта (БЛ-модель [13]) и перехода к усложненной модели Маскета-Леверетта (МЛ-модель [10]), в изотермическом случае приводящей к уравнению Рапопорта-Лиса $[8,14]$. Более сложная модель, названная тепловой моделью Маскета-Леверетта (МЛТ-модель [13]), учитывает явно зависимость капиллярных сил от температуры (коэффициента поверхностного натяжения и краевого угла смачивания).

Соответствующие уравнения в общем виде давно выписаны [8]. Однако для классических коллекторов и изотермического случая капиллярные силы обычно считаются пренебрежимо малыми и рассматривается только схема Бакли-Леверетта. То же предположение делается обычно и при неизотермической фильтрации [8, 13-19]. Если неизотермический характер фильтрации и учитывается, то чаще всего только введением температурной зависимости вязкости [8] и фазовых проницаемостей $[8,17]$. Если же капиллярное давление учитывается, то для упрощения считается не зависящим явно от температуры [8, 14], а определяется только величиной насыщенности, как и в уравнении Рапопорта-Лиса.

Если учитывать зависимость капиллярных сил от температуры, то в развернутой записи уравнения Рапопорта-Лиса появляются новые члены, содержащие градиент температуры. Это потребует корректировки системы аппроксимации и схемы численного решения, которое может быть получено лишь после экспериментального исследования зависимости от температуры угла смачивания и коэффициента поверхностного натяжения [9, 11$]$.

Полное описание процесса переноса должно включать также учет диффузии, теплопроводности, растворения газов в жидкостях, фазовые переходы, сжимаемость фаз и т.д. [18]. Однако учет этих процессов существенно усложняет задачу гидродинамического моделирования, а главное затрудняет оценку влияния основных эффектов. Поэтому, следуя большинству работ по многофазной неизотермической фильтрации (обзор таких исследований дается в работе [18]), целесообразно пренебречь диффузионными, капиллярными и неравновесными эффектами (так называемое крупномасштабное приближение). Иными словами, учесть влияние температурного изменения смачиваемости только через изменение фазовых проницаемостей при нагреве. Более того, обычно изменением самого вида кривых пренебрегают; влияние температуры учитывается только через изменение характерных точек на кривых фазовых проницаемостей. Такой подход принят и в данной работе.

\section{Температурная зависимость фазовых проницаемостей}

Фазовые проницаемости, в первую очередь, определяются значениями остаточной нефтенасыщенности и водонасыщенности. С ростом температуры коэффициент поверхностного натяжения на границе вода-нефть уменьшается [8, 18]. Во многих экспериментах при температуре $45-50^{\circ} \mathrm{C}$ начинается и уменьшение угла смачивания [8]: темп убывания составляет $3^{\circ}$ на $10^{\circ} \mathrm{C}$. По этим причинам с ростом температуры уменьшается и остаточная нефтенасыщенность (рис. 1) [12].

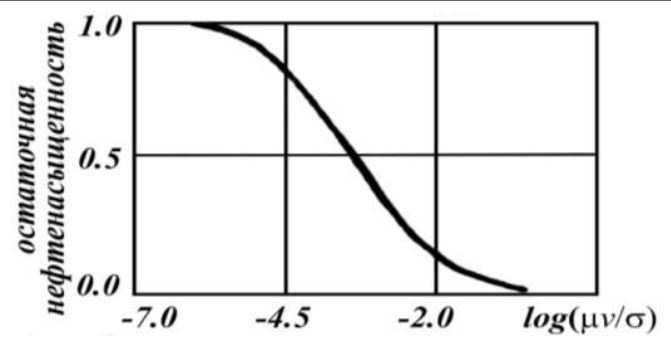

Рис. 1. Влияние коэффициента поверхностного натяжения на степень извлечения нефти

Fig. 1. The influence of the surface tension coefficient on oil recovery ratio 


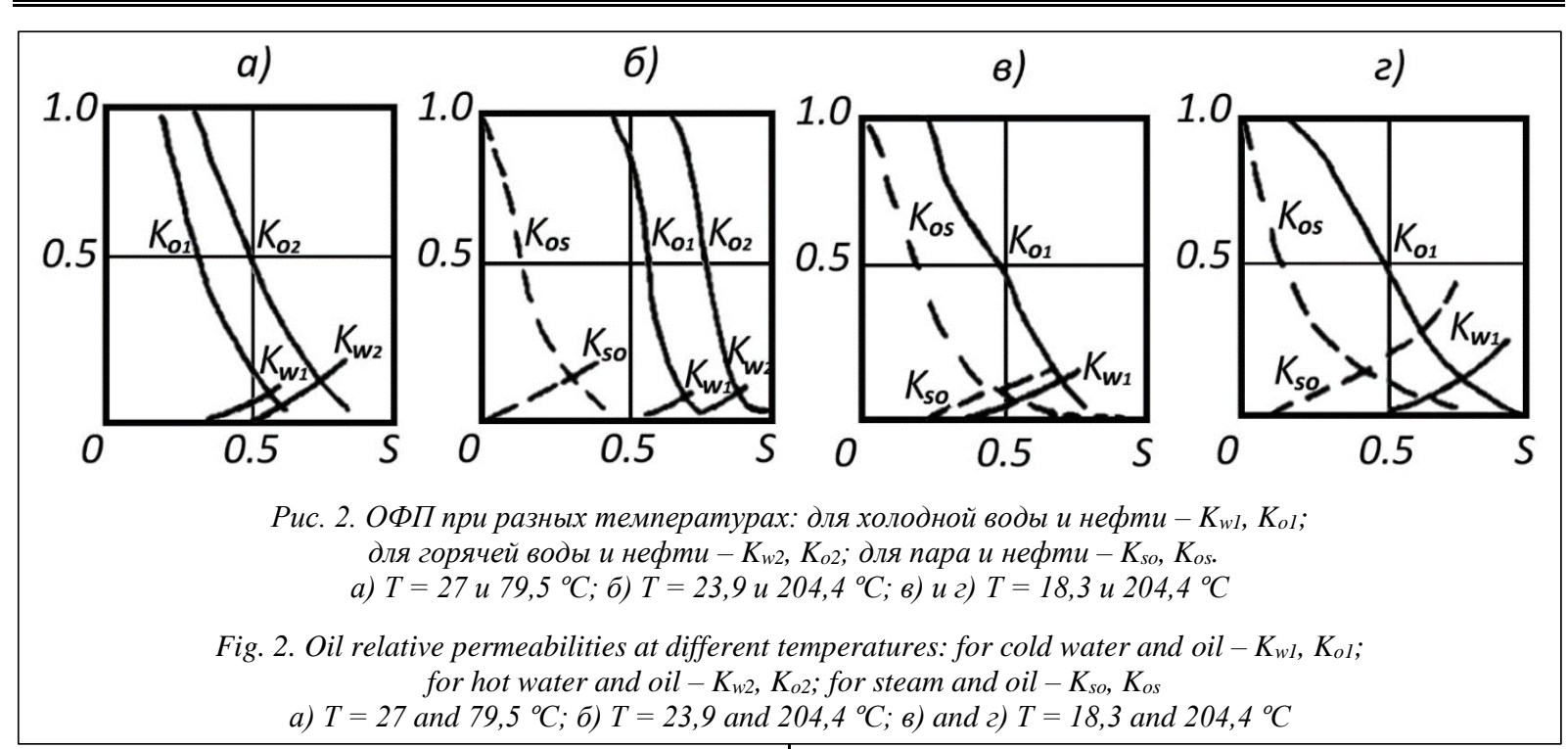

Аналогичные данные приведены в [8]: остаточная нефтенасыщенность для нефти и пород Арланского месторождения составляет 46, 40, 32, 28 \% для температур 10, 24, 50 и $150{ }^{\circ} \mathrm{C}$. В целом темп снижения остаточной нефтенасыщенности по ряду экспериментов составляет примерно $1 \%$ абс. на $10{ }^{\circ} \mathrm{C}$.

Соответственно, по данным значительного числа исследований (см. обзор работ 1970-80-х гг. в [18]), фазовая проницаемость нефти до перехода воды в парообразное состояние с ростом температуры возрастает (рис. 2, 3), а согласно данным работ $[8,20]$, с увеличением температуры рост относительной фазовой проницаемости (ОФП) для нефти сопровождается одновременным снижением ОФП для воды, то есть увеличением остаточной водонасыщенности, темп этого увеличения составляет примерно $1 \%$ абс. на $11^{\circ} \mathrm{C}$ [8].

В работе [8] при разных вариантах численного моделирования неизотермической фильтрации

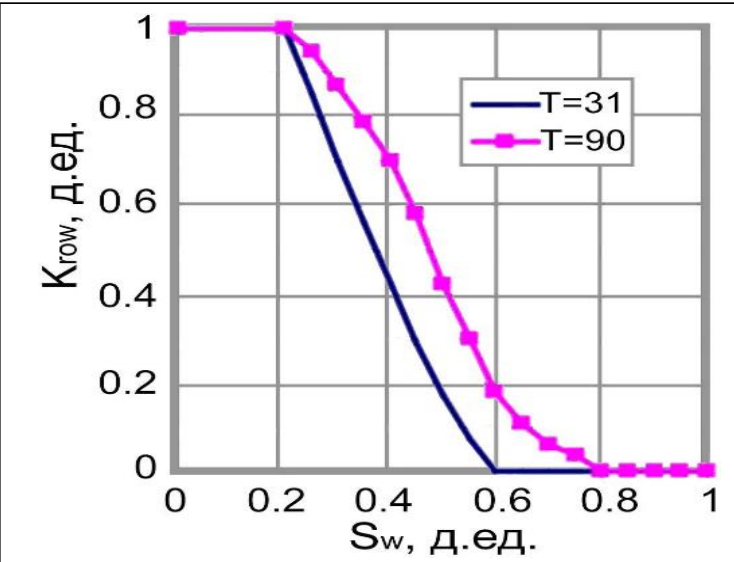

Рис. 3. ОФП нефти при различных температурах пласта

Fig. 3. Oil relative permeabilities at different reservoir temperatures принят линейный закон изменения остаточной нефтенасыщенности $\left(S_{н}\right.$ ост) от температуры $(T)$ :

$$
\begin{aligned}
& S_{\text {н. ост. }}(T)=S_{\text {н. ост. }}\left(T_{0}\right)-0,0015\left(T-T_{0}\right), \\
& S_{\text {н. ост. }}(T)=0,28-0,0015\left(T-T_{0}\right), \\
& S_{\text {н. ост. }}(T)=0,20-0,0020\left(T-T_{0}\right),
\end{aligned}
$$

где $T_{0}$ - начальная температура.

Линейный характер зависимости от температуры [8] принят также и для остаточной водонасыщенности:

$$
S_{\text {в. ост. }}(T)=0,2+0,001\left(T-T_{0}\right) .
$$

После перехода воды в пар фазовые проницаемости испытывают скачок, поскольку пар является несмачивающей фазой, а нефть - смачивающей; после такого фазового перехода фазовая проницаемость нефти снижается, а остаточная нефтенасыщенность растет [18].

На основании литературных данных были сконструированы модельные кривые ОФП, представленные на рисунке (см. http://www.swsys.ru/uploaded/image/2018-3/2018-3-dop/1.jpg) и зависимости от температуры характерных точек на этих кривых (рис. 4).

\section{Математическая модель неизотермической многофазной многокомпонентной фильтрации с химическими реакциями с учетом зависимости ОФП от температуры}

Композиционная термохимическая модель фильтрации представляет собой систему уравнений и дополнительных соотношений многокомпонентной трехфазной фильтрации нефти, газа и воды при переменной температуре с неподвижной твердой четвертой фазой и химическими реакциями $[21,22]$. Эта модель является одной из самых сложных моделей нефтегазовой подземной гидромеханики [21] и обычно используется для моделирования различных тепловых методов добычи нефти $[3,7]$, в том числе внутрипластового горения [22] и термогазового воздействия. 


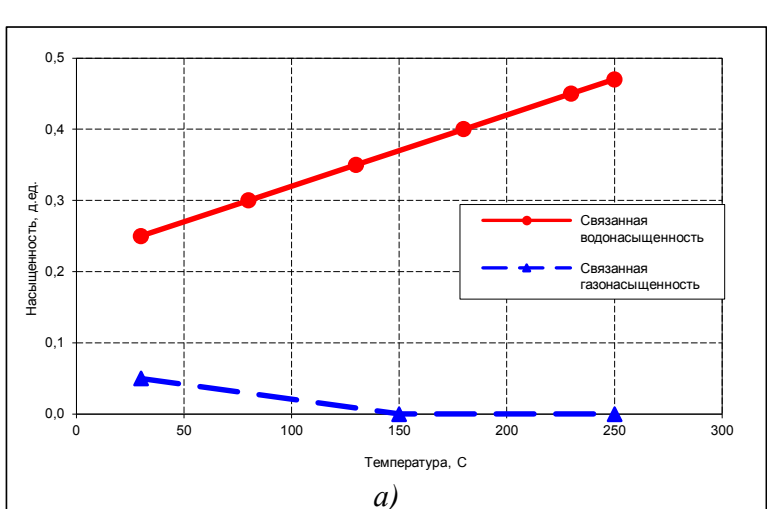

a)

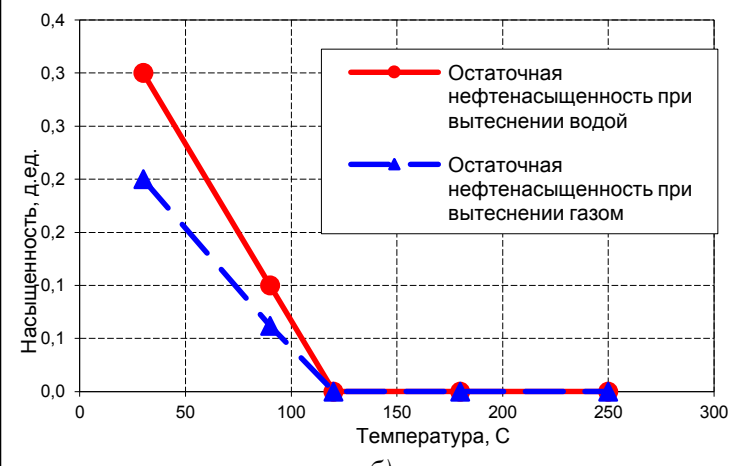

б)

Рис. 4. Использованные модельные зависимости от температуры характерных точек на кривых

относительных фазовых проницаемостей. остаточных насыщенностей вытесняющего (а) и вытесняемого (б) флюидов

Fig. 4. Used temperature dependencies on the temperature of critical points on relative phase permeability curves: residual displacing $(a)$ and displaced (б) fluid saturations

Данная модель специально разработана для моделирования таких методов добычи нефти, как закачка пара, закачка горячих жидкостей и газов, внутрипластовое горение, закачка химически активных реагентов.

В композиционной термохимической модели фильтрации обычно выделяют до четырех фаз [22], при использовании четырех фаз можно выделить от четырех и более компонентов:

- водная фаза (вода); не смешивается с углеводородными фазами, состоит из одного компонента - воды;

- жидкая углеводородная фаза (нефть); состоит из смеси углеводородных компонентов, находящихся при данном давлении, температуре и концентрациях других компонентов в жидком состоянии;

- газообразная углеводородная фаза (газ); состоит из смеси углеводородных компонентов, компонента-кислорода, компонента-воды и других газообразных компонентов, находящихся при данном давлении, температуре и концентрациях других компонентов в жидком состоянии;
- твердая фаза (кокс); состоит из одного твердого компонента, например кокса или парафина.

Элементарный объем $V_{b}$ может быть представлен в виде $V_{b}=V_{r}+V_{p}, V_{p}=V_{s}+V_{f}, V_{f}=V_{w}+V_{o}+V_{g}$, где $V_{r}$ - объем породы (участвует в описании тепловых процессов); $V_{p}$ - поровый объем; $V_{f}$ - подвижный объем; $V_{s}$ - объем твердой фазы; $V_{\alpha}$, $\alpha=w, o, g-$ объемы нефтяной, водной и газовой фаз.

Пористость $\phi$ - доля объема, доступная для заполнения фазами:

$$
\phi=\frac{V_{p}}{V_{b}}=\frac{V_{s}+V_{f}}{V_{b}}=\frac{V_{s}+V_{f}}{V_{r}+V_{s}+V_{f}} .
$$

Подвижная пористость $\phi_{f}$ - доля объема, доступная для заполнения подвижными фазами:

$$
\begin{aligned}
& \phi_{f}=\frac{V_{f}}{V_{b}}=\frac{V_{f}+V_{s}-V_{s}}{V_{b}}=\phi-\frac{V_{s}}{V_{b}}= \\
& =\phi\left(1-\frac{V_{s}}{V_{f}+V_{s}}\right)=\phi\left(1-\frac{V_{s}}{V_{p}}\right) .
\end{aligned}
$$

Насыщенность $S_{\alpha}$ фазой $\alpha(\alpha=w, o, g)-$ доля объема пористой среды, доступного для подвижных фаз, занимаемая этой фазой:

$$
\begin{aligned}
& S_{\alpha}=\frac{V_{\alpha}}{V_{f}}=\frac{V_{\alpha}}{V_{w}+V_{o}+V_{g}}, \alpha=w, o, g, \\
& S_{w}+S_{o}+S_{g}=1 .
\end{aligned}
$$

Насыщенность твердой фазой вводится как $\bar{S}_{s}=\frac{V_{s}}{V_{p}}$, так что, $\phi_{f}=\phi\left(1-\bar{S}_{s}\right)$ и приведенные насыщенности флюидами (подвижными фазами) $\bar{S}_{\alpha}(\alpha=w, o, g): \bar{S}_{\alpha}=\left(1-\bar{S}_{s}\right) S_{\alpha}, \alpha=w, o, g$, так что, $\bar{S}_{s}+\bar{S}_{w}+\bar{S}_{o}+\bar{S}_{g}=1$.

Состояние каждой фазы $\alpha(\alpha=w, o, g)$ задается следующими величинами (неизвестными, определяемыми в процессе расчета):

- $T=T(t, x, y, z)$ - температура среды (предполагается, что фазы находятся в термодинамическом равновесии, поэтому температуры всех фаз и породы в точке среды совпадают);

- $P_{\alpha}=P_{\alpha}(t, x, y, z)$ - давление в фазе $\alpha(\alpha=w$, $o, g)$, в данной работе капиллярным давлением пренебрегается, считается, что давление во всех фазах в элементарном объеме одинаково и равно $P=P(t$, $x, y, z)$;

$-S_{\alpha}=S_{\alpha}(t, x, y, z), \alpha=w, o, g, \bar{S}_{s}=\bar{S}_{s}(t, x$, $y, z)$ - насыщенности фазами.

Разделим фазы $\alpha, \alpha=w, o, g, s=1, \ldots, n_{\alpha}$, на две группы: подвижные (вода, нефть, газ) $\alpha=w, o$, $g=1, \ldots, n_{\alpha}^{\prime}, n_{\alpha}^{\prime}=n_{\alpha}-1$, и твердую $\alpha=s=n_{\alpha}$. Также разделим компоненты $c, c=1, \ldots, n_{c}$, на две группы:

- $c=1, \ldots, n_{c}^{\prime}-$ компоненты, которые могут быть только в подвижных фазах;

- $c=n_{c}^{\prime}+1, \ldots, n_{c}-$ компоненты, которые могут быть только в твердой фазе. 
Обозначим:

$N_{c}=N_{c}(t, x, y, z)$ - молярная плотность компонента $c, c=1, \ldots, n_{c}^{\prime}$, в подвижном объеме, так что, $N_{c} V_{f}=N_{c} \phi V_{b}-$ количество компонента $c$ в объеме $V_{b}$;

$N_{c}=N_{c}(t, x, y, z)$ - молярная плотность компонента $c, c=n^{\prime}{ }_{c}+1, \ldots, n_{c}$, в поровом объеме, так что, $N_{c} V_{p}=N_{c} \phi V_{b}$ - количество компонента $c$ в объемe $V_{b}$.

Распределение компонентов по фазам задается $n_{c} \times n_{\alpha}$ матрицей концентраций $x_{c, \alpha}=x_{c, \alpha}\left(P_{\alpha}, N\right)$, $N=\left(N_{1}, \ldots, N_{n_{c}}\right)$.

Рассмотрим прямолинейно-параллельное течение в горизонтальной плоскости. Капиллярным давлением (как сказано выше) и гравитационными силами будем пренебрегать.

Система уравнений сохранения количества компонентов примет вид

$$
\begin{aligned}
& \frac{\partial}{\partial t}\left[\phi\left(1-\bar{S}_{s}\right) N_{c}\right]= \\
& =-\frac{\partial}{\partial x}\left[\sum_{\alpha=w, o, g}\left(x_{c, \alpha} \xi_{\alpha} w_{\alpha}\right)\right]- \\
& -\bar{q}_{c}+\bar{q}_{R i, c}, c=1, \ldots, n_{c}^{\prime}, \\
& \frac{\partial}{\partial t}\left(\phi N_{c}\right)=\bar{q}_{R i, c}, c=n^{\prime}{ }_{c}+1, \ldots, n_{c},
\end{aligned}
$$

где $\xi_{\alpha}$ - молярная плотность фазы $\alpha ; \bar{q}_{c}$ - отток (в молях) компонента $c$ за счет работы скважин; $\bar{q}_{R i, c}$ - приток (в молях) компонента $c$ за счет химических реакций; $w_{\alpha}-$ скорость фильтрации фазы $\alpha$.

Скорость фильтрации для фазы $\alpha$ определяется с помощью закона Дарси:

$$
w_{\alpha}=-\frac{k k_{r \alpha}}{\mu_{\alpha}} \frac{\partial P}{\partial x},
$$

где $k$ - абсолютная проницаемость пласта; $k_{r \alpha}\left(S_{w}, S_{g}\right)$ - относительная проницаемость для фазы $\alpha ; \mu_{\alpha}$ - динамическая вязкость $\alpha$.

Предполагая выполнение условий локального термодинамического равновесия во всех точках пласта, запишем уравнение сохранения энергии:

$$
\begin{aligned}
& \frac{\partial}{\partial t}\left(U_{b}\right)=-\frac{\partial}{\partial x} \sum_{\alpha=w, o, g}\left[H_{\alpha} \xi_{\alpha} w_{\alpha}\right]+\frac{\partial}{\partial x}\left(K_{b} \frac{\partial T}{\partial x}\right)+ \\
& +\bar{q}_{\mathrm{Re}}-\bar{q}_{e}^{w}-\bar{q}_{L},
\end{aligned}
$$

где $U_{b}-$ внутренняя энергия элементарного объема; $H_{\alpha}$ - энтальпия фазы $\alpha ; K_{b}$ - теплопроводность элементарного объема; $\bar{q}_{\mathrm{Re}}-$ плотность потока энергии за счет химических реакций; $\bar{q}_{e}^{w}-$ плотность потока энергии за счет работы скважин, $\bar{q}_{L}-$ плотность оттока энергии за счет потерь тепла через кровлю и подошву.

Внутренняя энергия элементарного объема вычисляется из внутренних энергий подвижных фаз, твердой фазы и породы:

$$
\begin{aligned}
& U_{b}(P, T)= \\
& =V_{b} \phi\left[\left(1-\bar{S}_{s}\right)\left\{\sum_{\alpha=1}^{n_{\alpha}^{\prime}}\left[\xi_{\alpha}(P, T) H_{\alpha}(T)-P\right]\right\}+\bar{S}_{s} \xi_{s}(P, T) H_{s}(T)\right]+ \\
& +V_{b}(1-\phi) H_{r}(T) .
\end{aligned}
$$

Энтальпия компонентов в твердой и жидких фазах определяется через их удельную теплоемкость и изменение температуры. Аналогично определяется энтальпия породы. Для определения энтальпии компонентов в газовой фазе добавляется еще теплота парообразования. Энтальпия фазы определяется через концентрацию компонентов в фазе, энтальпию компонентов и их молекулярный вес. Энтальпия воды как функция давления и температуры берется из стандартных таблиц.

Теплопроводность элементарного объема определим как

$$
\begin{aligned}
& K_{b}=\phi\left(1-\bar{S}_{s}\right)\left(K_{w} S_{w}+K_{o} S_{o}+K_{g} S_{g}\right)+ \\
& +\phi K_{s} \bar{S}_{s}+(1-\varphi) K_{r},
\end{aligned}
$$

где $K_{\alpha}$ - теплопроводность фазы; $K_{r}$ - теплопроводность породы.

Стехиометрическое уравнение для химической реакции $r$ записываем как

$$
\sum_{i}\left(S_{R r i} C_{i}\right) \rightarrow \sum_{j}\left(S_{\operatorname{Pr} j} C_{j}\right),
$$

где $S_{R r}=\left(S_{R r i}\right)_{i=1, \ldots, n_{c}}-$ вектор стехиометрических коэффициентов для реагентов $C_{i}$ в реакции $r$; $S_{P r}=\left(S_{\operatorname{Pr} j}\right)_{j=1, \ldots, n_{c}}-$ вектор стехиометрических коэффициентов для продуктов $C_{j}$ в реакции $r$.

Скорость реакции $r$ зададим как

$$
\begin{aligned}
& R_{r}=V_{p} \cdot \phi^{n_{r p}} \cdot\left(1-\bar{S}_{s}\right)^{n_{r s}} \cdot A_{r} \times \\
& \times \exp \left[-E_{r} /(R \cdot T)\right] \cdot \prod_{i \in F_{r}}\left(c_{r i}^{\prime}\right)^{n_{r i}},
\end{aligned}
$$

где $A_{r}-$ константа скорости реакции $r ; E_{r}-$ энергия активации реакции $r ;\left(n_{r i}\right)_{i=1, \ldots, n_{c}}-$ веса компонентов, влияющих на реакцию $r$ (для нереагентов $n_{r i}>0$ в случае катализатора и $n_{r i}<0$ в случае ингибитора); $R$ - газовая постоянная; $c_{r i}^{\prime}=\phi \cdot c_{r i}, c_{r i}-$ концентрация компонента в фазе, участвующей в реакции; $n_{r p}, n_{r s}$ - показатели степени для учета влияния пористости и доли подвижных фаз на скорость реакции (должны быть неотрицательными), $F_{r}=\left\{1, \ldots, n_{c}\right\}$.

Приток компонентов $q_{r i, \mathrm{c}}$ за счет химических реакций и приток энергии $q_{R e}$, возникающий в силу химических реакций, определяем как

$$
q_{R i, c}=\sum_{r=1}^{n_{r}}\left(S_{\operatorname{Pr} c}-S_{R r c}\right) R_{r}, \quad q_{\mathrm{Re}}=\sum_{r=1}^{n_{r}} H_{r} R_{r},
$$

где $H_{r}$ - энтальпия реакции $r ; i$ - номер реагента.

Для приведенной системы дифференциальных уравнений в частных производных, описывающей многофазную многокомпонентную неизотермическую фильтрацию с химическими реакциями, в 
данной работе предложена оригинальная неявная по давлению и явная по температуре и концентрациям конечно-разностная схема, что позволило использовать достаточно простой вычислительный алгоритм для решения задачи, отличающейся большим количеством неизвестных и физических процессов, в том числе и зависимостью относительных фазовых проницаемостей от температуры.

Просуммируем уравнения (1) по компонентам $c=1, \ldots, n_{c}^{\prime}$ и перепишем в следующем виде:

$$
\frac{\partial}{\partial t}\left(\phi N_{\xi}\right)=-\frac{\partial}{\partial x}\left(w_{\xi}\right)-\sum_{\alpha=w, o, g} \bar{q}_{\alpha}+\sum_{c=1}^{n_{c}^{\prime}} \bar{q}_{R i, c},
$$

где $N_{\xi}=\left(1-\bar{S}_{s}\right)\left(\xi_{o} S_{o}+\xi_{w} S_{w}+\xi_{g} S_{g}\right)$ и

$$
w_{\xi}=\xi_{o} w_{o}+\xi_{w} w_{w}+\xi_{g} w_{g} \text {. }
$$

Поскольку

$$
\phi=\phi_{0}\left[1+C_{r}\left(P-P_{0}\right)\right],
$$

$\frac{\partial \phi}{\partial t}=\phi_{0} C_{r} \frac{\partial P}{\partial t}$.

Так как $C_{r}<<1$, то $1+C_{r}\left(P-P_{0}\right) \approx 1$, следовательно, $\phi \approx \phi_{0}$.

Тогда, пользуясь формулой для производной произведения и переходя к дискретному аналогу, получаем

$\frac{\partial}{\partial t}\left(\phi N_{\xi}\right) \approx \phi_{0} \frac{1}{\Delta t}\left(N_{\xi}^{n+1}-N_{\xi}^{n}\right)+N_{\xi}^{n} \phi_{0} C_{r} \frac{1}{\Delta t}\left(P^{n+1}-P^{n}\right)$, где $\Delta t$ - размер шага по времени, а верхний индекс $n$ - номер шага по времени.

Запишем дискретный аналог уравнения (5) для прямоугольной блочно-центрированной сетки:

$$
\begin{aligned}
& \Delta x \Delta y \Delta z\left(\phi_{0}\right)_{i} \frac{1}{\Delta t^{n+1}}\left\{\left[\left(N_{\xi}\right)_{i}^{n+1}-\left(N_{\xi}\right)_{i}^{n}\right]+C_{r}\left(N_{\xi}\right)_{i}^{n}\left(P_{i}^{n+1}-P_{i}^{n}\right)\right\}= \\
& =-\Delta y \Delta z\left[\left(w_{\xi}\right)_{i+0.5}^{n+1}-\left(w_{\xi}\right)_{i-0.5}^{n+1}\right]- \\
& -\sum_{\alpha=w, o, g}\left\{\left(\xi_{\alpha}\right)_{i}^{n}\left(P I_{\alpha}\right)_{i}^{n}\left[P_{i}^{n+1}-\left(P_{w}\right)_{i}^{n+1}\right]\right\}+\sum_{c=1}^{n_{c}^{\prime}}\left(q_{R i, c}\right)_{i}^{n},
\end{aligned}
$$

где $\Delta x, \Delta y, \Delta z-$ размеры ячейки в соответствующих направлениях; $\Delta t^{n+1}-$ переменный шаг по времени (определяется в соответствии с рекомендациями [21]), нижний индекс $i-$ номер ячейки вдоль оси $\mathrm{X} ; P I_{\alpha}-$ коэффициент продуктивности скважины по фазе $\alpha ; P_{w}-$ забойное давление. В (6) скорость фильтрации аппроксимируется как

$$
\left(w_{\xi}\right)_{i+0.5}^{n+1}=\sum_{\alpha=w, o, g}\left[\left(\xi_{\alpha}\right)_{i+0.5}^{n}\left(w_{\alpha}\right)_{i+0.5}^{n+1}\right],
$$

где с учетом (3)

$$
\begin{gathered}
\left(w_{\alpha}\right)_{i+0.5}^{n+1}=-\frac{k_{i+0.5}\left(k_{r \alpha}\right)_{i+0.5}^{n}}{\left(\mu_{\alpha}\right)_{i+0.5}^{n}} \frac{P_{i+1}^{n+1}-P_{i}^{n+1}}{\Delta x}, \alpha=w, o, g ; \\
k_{i+0.5}=\frac{2 k_{i+1} k_{i}}{k_{i+1}+k_{i}} ; \frac{1}{\left(\mu_{\alpha}\right)_{i+0.5}^{n}}=\sum_{c=1}^{n_{c}^{\prime}}\left(\frac{x_{c, \alpha}}{\mu_{c, \alpha}}\right)_{i+0.5}^{n} ; \\
\left(k_{r \alpha}\right)_{i+0.5}^{n}=\left\{\begin{array}{l}
\left(k_{r \alpha}\right)_{i+1}^{n}, P_{i+1}^{n} \geq P_{i}^{n}, \\
\left(k_{r \alpha}\right)_{i}^{n}, P_{i+1}^{n}<P_{i}^{n} .
\end{array}\right.
\end{gathered}
$$

$\left(\xi_{\alpha}\right)_{i+0.5}^{n}, \quad\left(x_{c, \alpha}\right)_{i+0.5}^{n}$ и $\left(\mu_{\alpha}\right)_{i+0.5}^{n}$ в3вешиваются вверх по потоку аналогично (7). Для вычисления $\left(w_{\alpha}\right)_{i-0.5}^{n+1}$ используется подход, аналогичный описанному подходу для $\left(w_{\alpha}\right)_{i+0.5}^{n+1}$.

Линеаризуя в уравнении (6) слагаемое $\left(N_{\xi}\right)_{i}^{n+1}$ методом Ньютона (пренебрегая при этом производными по температуре и концентрации):

$$
\left(N_{\xi}\right)_{i}^{n+1} \approx\left(\frac{\partial N_{\xi}}{\partial P}\right)_{i}^{n}\left(P_{i}^{n+1}-P_{i}^{n}\right)+\left(N_{\xi}\right)_{i}^{n},
$$

получаем неявное уравнение для давления.

Чтобы получить уравнение для определения насыщенности твердой фазой $\bar{S}_{s}$, перепишем уравнение (2) с учетом того, что $x_{c, s} \xi_{s} \bar{S}_{s}=N_{c}$, $c \in\left\{n_{c}^{\prime}+1, \ldots, n_{c}\right\}$, и просуммируем его по $c$ :

$$
\frac{\partial}{\partial t}\left(\phi \xi_{s} \bar{S}_{s}\right)=\sum_{c=n_{c}^{\prime}+1}^{n_{c}} \bar{q}_{R i, c}, c=n_{c}^{\prime}+1, \ldots, n_{c} .
$$

Учитывая правило дифференцирования произведения, получим:

$$
\begin{aligned}
& \frac{\partial}{\partial t}\left(\phi \xi_{s} \bar{S}_{s}\right) \approx \phi_{0}\left(\bar{S}_{s} \frac{\partial \xi_{s}}{\partial t}+\xi_{s} \frac{\partial \bar{S}_{s}}{\partial t}\right)+ \\
& +\bar{S}_{s} \xi_{s} \phi_{0} C_{r} \frac{\partial P}{\partial t} .
\end{aligned}
$$

Запишем дискретный аналог уравнения (8) с учетом соотношения (9):

$$
\begin{aligned}
& \Delta x \Delta y \Delta z\left(\phi_{0}\right)_{i} \frac{1}{\Delta t^{n+1}}\left\{\left(\bar{S}_{s}\right)_{i}^{n}\left[\left(\xi_{s}\right)_{i}^{n+1}-\left(\xi_{s}\right)_{i}^{n}\right]+\right. \\
& \left.+\left(\xi_{s}\right)_{i}^{n}\left[\left(\bar{S}_{s}\right)_{i}^{n+1}-\left(\bar{S}_{s}\right)_{i}^{n}\right]+C_{r}\left(\bar{S}_{s}\right)_{i}^{n}\left(\xi_{s}\right)_{i}^{n}\left(P_{i}^{n+1}-P_{i}^{n}\right)\right\}= \\
& =\sum_{c=n_{c}^{\prime}+1}^{n_{c}}\left(q_{R i, c}\right)_{i}^{n} .
\end{aligned}
$$

Линеаризуя в уравнении (10) слагаемое $\left(\xi_{s}\right)_{i}^{n+1}$ методом Ньютона (пренебрегая при этом производными по температуре и концентрации):

$$
\left(\xi_{s}\right)_{i}^{n+1} \approx\left(\frac{\partial \xi_{s}}{\partial P}\right)_{i}^{n}\left(P_{i}^{n+1}-P_{i}^{n}\right)+\left(\xi_{s}\right)_{i}^{n},
$$

получаем явное уравнение для насыщенности твердой фазой.

Перепишем уравнение (1) в качестве уравнения сохранения количества подвижных компонентов в подвижных фазах следующим образом:

$$
\begin{aligned}
& \quad \frac{\partial}{\partial t}\left[\phi_{f} z_{c}\left(\xi_{o} S_{o}+\xi_{g} S_{g}+\xi_{w} S_{w}\right)\right]= \\
& =-\frac{\partial}{\partial x}\left[x_{c, o} \xi_{o} w_{o}+x_{c, g} \xi_{g} w_{g}+x_{c, w} \xi_{w} w_{w}\right]-\bar{q}_{c}+\bar{q}_{R i, c}, \\
& \quad c=1, \ldots, n_{c}^{\prime}, \\
& \text { где } \phi_{f}=\phi\left(1-\bar{S}_{s}\right) .
\end{aligned}
$$


Перепишем уравнение (11) в следующем виде:

$\frac{\partial}{\partial t}\left[\phi_{f} N_{c, w o g}\right]=-\frac{\partial}{\partial x}\left[w_{w o g}\right]-\bar{q}_{c}+\bar{q}_{R i, c}$,

$c=1, \ldots, n_{c}^{\prime}$,

где $N_{c, w o g}=z_{c}\left(\xi_{o} S_{o}+\xi_{g} S_{g}+\xi_{w} S_{w}\right)$,

$w_{w o g}=x_{c, o} \xi_{o} w_{o}+x_{c, g} \xi_{g} w_{g}+x_{c, w} \xi_{w} w_{w}$.

Тогда, согласно правилам дифференцирования,

$$
\begin{aligned}
& \frac{\partial}{\partial t}\left(\phi_{f} N_{c, w o g}\right) \approx \phi_{0}\left(1-\bar{S}_{s}\right) \frac{\partial N_{c, w o g}}{\partial t}+ \\
& +N_{c, w o g}\left[\left(1-\bar{S}_{s}\right) \phi_{0} C_{r} \frac{\partial P}{\partial t}-\phi_{0} \frac{\partial \bar{S}_{s}}{\partial t}\right] .
\end{aligned}
$$

Запишем дискретный аналог уравнения (12) с учетом соотношения (13):

$$
\begin{aligned}
& \Delta x \Delta y \Delta z\left(\phi_{0}\right)_{i} \frac{1}{\Delta t^{n+1}}\left\{\left[1-\left(\bar{S}_{s}\right)_{i}^{n}\right]\left[\left(N_{c, w o g}\right)_{i}^{n+1}-\left(N_{c, w o g}\right)_{i}^{n}\right]+\right. \\
& +\left(N_{c, w o g}\right)_{i}^{n}\left[1-\left(\bar{S}_{s}\right)_{i}^{n}\right] C_{r}\left(P_{i}^{n+1}-P_{i}^{n}\right)-\left(N_{c, w o g}\right)_{i}^{n} \times \\
& \left.\times\left[\left(\bar{S}_{s}\right)_{i}^{n+1}-\left(\bar{S}_{s}\right)_{i}^{n}\right]\right\}=-\Delta y \Delta z\left[\left(w_{w o g}\right)_{i+0.5}^{n+1}-\left(w_{w o g}\right)_{i-0.5}^{n+1}\right]- \\
& -\sum_{\alpha=w, o, g}\left\{\left(x_{c, \alpha} \xi_{\alpha} P I_{\alpha}\right)_{i}^{n}\left[P_{i}^{n+1}-\left(P_{w}\right)_{i}^{n+1}\right]\right\}+\left(q_{R i, c}\right)_{i}^{n},
\end{aligned}
$$$$
\text { где }\left(w_{\text {wog }}\right)_{i+0.5}^{n+1}=\sum_{\alpha=w, o, g}\left[\left(x_{c, \alpha}\right)_{i+0.5}^{n}\left(\xi_{\alpha}\right)_{i+0.5}^{n}\left(w_{\alpha}\right)_{i+0.5}^{n+1}\right] \text {. }
$$

Уравнение (14) является явным уравнением для числа молей компонента $c$ в подвижных фазах $N_{c, \text { wog. }}$.

Мольная доля компонента $c$ в подвижных фазах при этом определяется как

$$
\left(z_{c}\right)_{i}^{n+1}=\left(N_{c, \text { wog }}\right)_{i}^{n+1} / \sum_{c=1}^{n_{c}^{\prime}}\left(N_{c, w o g}\right)_{i}^{n+1} .
$$

Рассмотрим уравнение сохранения энергии (4). Воспользуемся правилом вычисления производной функции многих переменных для кумулятивного члена в левой части уравнения (4) (пренебрегая при этом производными по концентрации):

$$
\frac{\partial U_{b}}{\partial t}=\frac{\partial U_{b}}{\partial P} \frac{\partial P}{\partial t}+\frac{\partial U_{b}}{\partial T} \frac{\partial T}{\partial t} .
$$

Запишем дискретный аналог уравнения (4) с учетом (15):

$$
\begin{aligned}
& \Delta x \Delta y \Delta z \frac{1}{\Delta t^{n+1}}\left\lfloor\left(\frac{\partial U_{b}}{\partial P}\right)_{i}^{n}\left(P_{i}^{n+1}-P_{i}^{n}\right)+\left(\frac{\partial U_{b}}{\partial T}\right)_{i}^{n}\left(T_{i}^{n+1}-T_{i}^{n}\right)\right\rfloor= \\
& =-\Delta y \Delta z \sum_{\alpha=w, o, g}\left[\left(H_{\alpha}\right)_{i+0.5}^{n}\left(\xi_{\alpha}\right)_{i+0.5}^{n}\left(w_{\alpha}\right)_{i+0.5}^{n+1}-\left(H_{\alpha}\right)_{i-0.5}^{n}\left(\xi_{\alpha}\right)_{i-0.5}^{n}\left(w_{\alpha}\right)_{i-0.5}^{n+1}\right]+ \\
& +\frac{\Delta y \Delta z}{\Delta x}\left[\left(K_{b}\right)_{i+0.5}^{n}\left(T_{i+1}^{n+1}-T_{i}^{n+1}\right)-\right. \\
& \left.-\left(K_{b}\right)_{i-0.5}^{n}\left(T_{i}^{n+1}-T_{i-1}^{n+1}\right)\right\rfloor+\left(q_{\mathrm{Re}}\right)_{i}^{n}- \\
& -\sum_{\alpha=w, o, g}\left\{\left(H_{\alpha} \xi_{\alpha} P I_{\alpha}\right)_{i}^{n}\left[P_{i}^{n+1}-\left(P_{w}\right)_{i}^{n+1}\right]\right\}-\left(q_{L}\right)_{i}^{n}
\end{aligned}
$$

где $\left(H_{\alpha}\right)_{i+0.5}^{n}=\left\{\begin{array}{l}\left(H_{\alpha}\right)_{i+1}^{n}, P_{i+1}^{n} \geq P_{i}^{n}, \\ \left(H_{\alpha}\right)_{i}^{n}, P_{i+1}^{n}<P_{i}^{n},\end{array}\right.$ аналогично для $\left(H_{\alpha}\right)_{i-0.5}^{n}$ определяется $\left(K_{b}\right)_{i+0.5}^{n}$ как среднее гармоническое между ячейками $i$ и $i+1$, потеря тепла через кровлю и подошву $\left(q_{L}\right)_{i}^{n}$ рассчитывается по схеме Винсома и Вестервельда.

Уравнение (16) является неявным уравнением для температуры.

Будем считать $c=1$ водным компонентом. Поскольку водный компонент не присутствует в нефтяной фазе и углеводородных компонентов нет в водной фазе, то $x_{1, o} \equiv x_{w, o}=0 ; x_{c, w}=0, c \in\{2, \ldots$, $\left.n_{c}^{\prime}\right\} ; x_{w, w}=1$.

Значение $R_{g} \in[0,1]$ (мольная доля газовой фазы в подвижном флюиде) определяется из уравнения

$$
F\left(R_{g}\right)=\sum_{c=2}^{n_{c}^{\prime}} \frac{z_{c}\left(K_{c}+K_{w}-1\right)}{1-z_{w}+R_{g}\left(K_{c}+K_{w}-1\right)}=0,
$$

где значения констант равновесия компонентов $K_{c}=K_{c}(P, T)$ заданы корреляционной формулой $K_{c}(P, T)=\left(A_{c}+B_{c} / P+C_{c} P\right) \cdot \exp \left[-D_{c} /\left(T-E_{c}\right)\right]$, коэффициенты которой $A_{c}, B_{c}, C_{c}, D_{c}$ и $E_{c}$ являются постоянными для каждого компонента.

Значения $R_{w}$ (мольная доля воды в подвижном флюиде) и $R_{o}$ (мольная доля нефтяной фазы в подвижном флюиде) определяются из соотношений $R_{w}=z_{w}-R_{g} K_{w}, R_{o}=1-z_{w}-R_{g}\left(1-K_{w}\right), x_{w, g}=K_{w}$ при заданной зависимости константы равновесия воды от давления и температуры $K_{w}(P, T)$. Так как $x_{w, g} / x_{w, w}=K_{w}(P, T)$ и $x_{w, w}=1$, значит, $x_{w, g}=K_{w}$. Для расчета содержания компонента $c$ в нефтяной и газовой фазах $x_{c, o}$ и $x_{c, g}$ воспользуемся соотношениями

$$
\begin{aligned}
& x_{c, o}=\frac{z_{c}}{1-z_{w}+R_{g}\left(K_{c}+K_{w}-1\right)}, \\
& x_{c, g}=\frac{z_{c} K_{c}}{1-z_{w}+R_{g}\left(K_{c}+K_{w}-1\right)} . \\
& \text { Поскольку } \quad S_{\alpha}=\frac{N_{t o t} R_{\alpha}}{\xi_{\alpha}}, \quad N_{t o t}=\sum_{c=1}^{n_{c}^{\prime}}\left(N_{c, w o g}\right),
\end{aligned}
$$
$\alpha=1, \ldots, n_{\alpha}^{\prime}$, определим насыщенности жидкими фазами следующим образом:

$$
\begin{gathered}
S_{w}=\frac{R_{w} N_{w, w o g}}{\xi_{w}}, S_{o}=\frac{R_{o} \sum_{c=1}^{n_{c}^{\prime}} N_{c, w o g}}{\xi_{o}} \text { и } S_{g}=1-S_{o}-S_{w} . \\
\begin{array}{c}
\text { Учет зависимости ОФП от температуры } \\
\text { при математическом моделировании }
\end{array}
\end{gathered}
$$

\section{Учет зависимости ОФП от температуры при математическом моделировании}

При задании ОФП в двухфазных системах задаются приведенные далее функциональные зависимости [21, 22]. 
ОФП в системе нефть-вода:

$$
\begin{aligned}
& k_{r w}\left(S_{w}\right)=A\left[\frac{S_{w}-S_{w c r}}{1-S_{w c r}}\right]^{\alpha}, \\
& k_{\text {row }}\left(S_{w}\right)=B\left[\frac{1-S_{\text {owcr }}-S_{w}}{1-S_{\text {owcr }}-S_{w c r}}\right]^{\beta},
\end{aligned}
$$

где $S_{w c r}$ - насыщенность связанной водой; $S_{o w c r}-$ насыщенность остаточной нефтью при вытеснении водой; коэффициенты $A, B, \alpha, \beta$ определяются по результатам интерпретации исследований керна и могут зависеть от пористости или проницаемости.

Аналогично ОФП в системе нефть-газ:

$$
\begin{aligned}
& k_{r g}\left(S_{g}\right)=C\left[\frac{S_{g}-S_{g c r}}{1-S_{g c r}}\right]^{\gamma}, \\
& k_{r o g}\left(S_{g}\right)=D\left[\frac{1-S_{o g c r}-S_{g}}{1-S_{o g c r}-S_{g c r}}\right]^{\delta},
\end{aligned}
$$

где $S_{g c r}-$ насыщенность связанным газом; $S_{\text {ogcr }}-$ насыщенность остаточной нефтью при вытеснении газом; коэффициенты $C, D, \gamma, \delta$ определяются по результатам интерпретации исследований керна и могут зависеть от пористости или проницаемости.

Однако часто эффективнее задавать значения ОФП в двухфазных системах в виде двух таблиц от водо- и газонасыщенности.

ОФП нефти при трехфазной фильтрации определяется по второму методу Стоуна:

$$
\begin{aligned}
& k_{\text {ro }}\left(S_{w}, S_{g}\right)=k_{\text {rocw }}\left\{[ \frac { k _ { \text { row } } ( S _ { w } ) } { k _ { \text { rocw } } } + k _ { r w } ( S _ { w } ) ] \left[\frac{k_{\text {rog }}\left(S_{g}\right)}{k_{\text {rocw }}}+\right.\right. \\
& \left.\left.+k_{r g}\left(S_{g}\right)\right]-k_{r w}\left(S_{w}\right)-k_{r g}\left(S_{g}\right)\right\},
\end{aligned}
$$

где $k_{\text {rocw }}=k_{\text {row }}\left(S_{w c r}\right)=k_{\text {rog }}\left(S_{g}=0\right)-$ ОФП по нефти при насыщенности связанной водой в отсутствие газа.

При задании ОФП так или иначе (с помощью таблиц или функциональных зависимостей) должны быть указаны константы, приведенные в таблице 1.

Перечисленные в таблице константы можно изменить, задав зависимость от температуры.

Вычисленные масштабированные значения ОФП (со штрихом) должны удовлетворять следующим условиям:

$$
\begin{aligned}
& S_{g u}^{\prime} \leq 1-S_{w l}^{\prime} ; S_{g l}^{\prime} \leq 1-S_{w u}^{\prime} ; \\
& S_{o w c r}^{\prime}+S_{w c r}^{\prime}<1 ; S_{o g c r}^{\prime}+S_{g c r}^{\prime}+S_{w l}^{\prime}<1 .
\end{aligned}
$$

В литературе существуют два варианта масштабирования ОФП - двухточечное и трехточечное. Рассмотрим двухточечное масштабирование ОФП, которое сохраняет значения проницаемостей, заданных в таблицах ОФП, в двух точках (табл. 2) в варианте, изложенном в руководстве [23].

\section{Константы ОФП}

Таблича 1

\section{Table 1}

Constants of relative phase permeabilities

\begin{tabular}{|l|l|}
\hline Величина & \multicolumn{1}{|c|}{ Описание величины } \\
\hline$S_{w l}$ & $\begin{array}{l}\text { Наименьшее значение } S_{w} \text { в таблице } \\
\text { для воды }\end{array}$ \\
\hline$S_{w c r}$ & $\begin{array}{l}\text { Наибольшее значение } S_{w} \text { в таблице } \\
\text { для воды, при котором } k_{r w}\left(S_{w}\right)=0\end{array}$ \\
\hline$S_{w u}$ & $\begin{array}{l}\text { Наибольшее значение } S_{w} \text { в таблице } \\
\text { для воды }\end{array}$ \\
\hline$S_{g l}$ & $\begin{array}{l}\text { Наименьшее значение } S_{g} \text { в таблице } \\
\text { для газа }\end{array}$ \\
\hline$S_{g c r}$ & $\begin{array}{l}\text { Наибольшее значение } S_{g} \text { в таблице } \\
\text { для газа, при котором } k_{r g}\left(S_{g}\right)=0\end{array}$ \\
\hline$S_{g u}$ & $\begin{array}{l}\text { Наибольшее значение } S_{g} \text { в таблице } \\
\text { для газа }\end{array}$ \\
\hline$S_{o w c r}$ & $\begin{array}{l}\text { Наибольшее значение } S_{o}=1-S_{w}-S_{g l} \text { в } \\
\text { таблице для воды, при котором } k_{r o w}\left(S_{w}\right)=0\end{array}$ \\
\hline$S_{o g c r}$ & $\begin{array}{l}\text { Наибольшее значение } S_{o}=1-S_{g}-S_{w l} \text { в } \\
\text { таблице для газа, при котором } k_{r o g}\left(S_{g}\right)=0\end{array}$ \\
\hline$k_{r w, \max }$ & Максимальное значение функции $k_{r w}\left(S_{w}\right)$ \\
\hline$k_{r g, \text { mах }}$ & Максимальное значение функции $k_{r g}\left(S_{g}\right)$ \\
\hline$k_{r o, \text { max }}$ & $\begin{array}{l}\text { Максимальное значение функции } \\
k_{\text {row }}\left(S_{w}\right)=0 \text { и } k_{r o g}\left(S_{g}\right)=0\end{array}$ \\
\hline$k_{r w r}$ & $k_{r w}\left(1-S_{\text {owcr }}-S_{g l}\right)$ \\
\hline$k_{r g r}$ & $k_{r g}\left(1-S_{\text {ogcr }}-S_{w l}\right)$ \\
\hline$k_{r o r g}$ & $k_{r o g}\left(S_{g c r}\right)$ \\
\hline$k_{r o r w}$ & $k_{r o w}\left(S_{w c r}\right)$ \\
\hline & \\
\hline
\end{tabular}

Таблица 2

Сохранение значений табличных ОФП при двухточечном масштабировании

Table 2

Preserving relative phase permeabilities table values during two-point rescaling

\begin{tabular}{|c|c|c|}
\hline ОФП & Точка 1 & Точка 2 \\
\hline$k_{r w}$ & $S_{w c r}^{\prime}$ & $S_{w u}^{\prime}$ \\
\hline$k_{r g}$ & $S_{g c r}^{\prime}$ & $S_{g u}^{\prime}$ \\
\hline$k_{\text {row }}$ & $S_{w l}^{\prime}$ & $1-S_{o w c r}^{\prime}-S_{g l}^{\prime}$ \\
\hline$k_{\text {rog }}$ & $S_{g l}^{\prime}$ & $1-S_{o g c r}^{\prime}-S_{w l}^{\prime}$ \\
\hline
\end{tabular}

Для заданных значений немасштабированной насыщенности водой $S_{w}$ и температуры $T$ масштабированная водонасыщенность в таблице ОФП и значение ОФП для воды вычисляются следующим образом:

$$
\begin{aligned}
& S_{w}^{\prime}\left(S_{w}, T\right)= \begin{cases}S_{w}, & S_{w c r}^{\prime}(T) \geq S_{w u}^{\prime}(T) ; \\
S_{w c r}, & S_{w}<S_{w c r}^{\prime}(T) ; \\
S_{w u}, & S_{w}>S_{w u}^{\prime}(T) ; \\
S_{w c r}+\left[S_{w}-S_{w c r}^{\prime}(T)\right] \frac{S_{w u}-S_{w c r}}{S_{w u}^{\prime}(T)-S_{w c r}^{\prime}(T)} \text { иначе; }\end{cases} \\
& k_{r w}^{\prime}\left(S_{w}, T\right)=\frac{k_{r w, \max }^{\prime}(T)}{k_{r w, \max }} k_{r w}\left(S_{w}^{\prime}\left(S_{w}, T\right)\right) .
\end{aligned}
$$


Для нефти в присутствии воды вычисляются

$S_{o w}^{\prime}\left(S_{w}, T\right)=\left\{\begin{array}{l}S_{w}, \quad S_{w l}^{\prime}(T) \geq 1-S_{\text {owcr }}^{\prime}(T)-S_{g l}^{\prime}(T) ; \\ S_{w l}, \quad S_{w}<S_{w l}^{\prime}(T) ; \\ 1-S_{\text {owcr }}-S_{g l}, \quad S_{w}>1-S_{\text {owcr }}^{\prime}(T)-S_{g l}^{\prime}(T) ; \\ S_{w l}+\left[S_{w}-S_{w l}^{\prime}(T)\right] \frac{1-S_{\text {owcr }}-S_{g l}-S_{w l}}{1-S_{\text {owcr }}^{\prime}(T)-S_{g l}^{\prime}(T)-S_{w l}^{\prime}(T)} \quad \text { иначе; }\end{array}\right.$

$k_{\text {row }}^{\prime}\left(S_{w}, T\right)=\frac{k_{r o, \max }^{\prime}(T)}{k_{r o, \max }} k_{\text {row }}\left(S_{o w}^{\prime}\left(S_{w}, T\right)\right)$;

$S_{c o w}^{\prime}\left(S_{w}, T\right)= \begin{cases}S_{w}, & S_{w l}^{\prime}(T) \geq S_{w u}^{\prime}(T) ; \\ S_{w l}, & S_{w}<S_{w l}^{\prime}(T) ; \\ S_{w u}, & S_{w}>S_{w u}^{\prime}(T) ; \\ S_{w l}+\left[S_{w}-S_{w l}^{\prime}(T)\right] \frac{S_{w u}-S_{w l}}{S_{w u}^{\prime}(T)-S_{w l}^{\prime}(T)} \text { иначе. }\end{cases}$

Для заданных значений немасштабированной насыщенности газом $S_{g}$ и температуры $T$ масштабированная газонасыщенность в таблице ОФП и значение ОФП для газа вычисляются следующим образом:

$$
\begin{aligned}
& k_{r g}^{\prime}\left(S_{g}, T\right)= \frac{k_{r g, \max }^{\prime}(T)}{k_{r g, \max }} k_{r g}\left(S_{g}^{\prime}\left(S_{g}, T\right)\right) ; \\
& S_{g}^{\prime}\left(S_{g}, T\right)= \begin{cases}S_{g}, & S_{g c r}^{\prime}(T) \geq S_{g u}^{\prime}(T) ; \\
S_{g c r}, & S_{g}<S_{g c r}^{\prime}(T) ; \\
S_{g u}, & S_{g}>S_{g u}^{\prime}(T) ; \\
S_{g c r}+\left[S_{g}-S_{g c r}^{\prime}(T)\right] \frac{S_{g u}-S_{g c r}}{S_{g u}^{\prime}(T)-S_{g c r}^{\prime}(T)} \quad \text { иначе. }\end{cases}
\end{aligned}
$$

Для нефти в присутствии газа вычисляются

$$
S_{o g}^{\prime}\left(S_{g}, T\right)=\left\{\begin{array}{l}
S_{g}, \quad S_{g l}^{\prime}(T) \geq 1-S_{o g c r}^{\prime}(T)-S_{w l}^{\prime}(T) ; \\
S_{g l}, \quad S_{g}<S_{g l}^{\prime}(T) \\
1-S_{o g c r}-S_{w l}, \quad S_{g}>1-S_{o g c r}^{\prime}(T)-S_{w l}^{\prime}(T) ; \\
S_{g l}+\left[S_{g}-S_{g l}^{\prime}(T)\right] \frac{1-S_{o g c r}-S_{g l}-S_{w l}}{1-S_{o g c r}^{\prime}(T)-S_{g l}^{\prime}(T)-S_{w l}^{\prime}(T)} \quad \text { иначе; }
\end{array}\right.
$$$$
k_{r o g}^{\prime}\left(S_{g}, T\right)=\frac{k_{r o, \max }^{\prime}(T)}{k_{r o, \max }} k_{\text {rog }}\left(S_{o g}^{\prime}\left(S_{g}, T\right)\right) \text {; }
$$$$
S_{c o g}^{\prime}\left(S_{g}, T\right)= \begin{cases}S_{g}, & S_{g l}^{\prime}(T) \geq S_{g u}^{\prime}(T) \\ S_{g l}, & S_{g}<S_{g l}^{\prime}(T) \\ S_{g u}, & S_{g}>S_{g u}^{\prime}(T) \\ S_{g l}+ & {\left[S_{g}-S_{g l}^{\prime}(T)\right] \frac{S_{g u}-S_{g l}}{S_{g u}^{\prime}(T)-S_{g l}^{\prime}(T)} \text { иначе. }}\end{cases}
$$

Рассмотрим масштабирование ОФП при использовании для расчета ОФП по нефти в случае трехфазного течения второй модели Стоуна (как указано выше). Введем следующие функции:

$$
\alpha(T)= \begin{cases}\frac{k_{r g, \max }^{\prime}(T)}{k_{r w, \max }^{\prime}(T)}, & \text { если заданы } k_{r g}(T) \text { и } k_{r w}(T) ; \\ \frac{k_{r w, \max }}{k_{r v, \max }^{\prime}(T)}, & \text { если задано только } k_{r w}(T) ; \\ \frac{k_{r g, \max }^{\prime}(T)}{k_{r w, \max }}, & \text { если задано только } k_{r g}(T) ; \\ 1 \quad \text { иначе; }\end{cases}
$$

$$
\beta(T)= \begin{cases}\frac{k_{r w, \max }^{\prime}(T)}{k_{r g, \max }^{\prime}(T)}, & \text { если заданы } k_{r g}(T) \text { и } k_{r w}(T) ; \\ \frac{k_{r w, \max }^{\prime}(T)}{k_{r g, \max }}, & \text { если задано только } k_{r w}(T) ; \\ \frac{k_{r g, \max }}{k_{r g, \max }^{\prime}(T)}, & \text { если задано только } k_{r g}(T) ; \\ 1 \quad \text { иначе. } & \end{cases}
$$

Тогда ОФП для нефти в трехфазной системе можно записать как

$$
\begin{aligned}
& k_{\text {ro }}^{\prime}\left(S_{w}, S_{g}, T\right)=k_{\text {row }}^{\prime}\left(S_{w l}^{\prime}(T), T\right) \times \\
& \times\left\{\left[\frac{k_{\text {row }}^{\prime}\left(S_{w}, T\right)}{k_{\text {row }}^{\prime}\left(S_{w l}^{\prime}(T), T\right)}+\alpha(T) k_{r w}^{\prime}\left(S_{w}, T\right)\right] \times\right. \\
& \times\left[\frac{k_{\text {rog }}^{\prime}\left(S_{g}, T\right)}{k_{\text {rog }}^{\prime}\left(S_{g l}^{\prime}(T), T\right)}+\beta(T) k_{r g}^{\prime}\left(S_{g}, T\right)\right]- \\
& \left.-\left[\alpha(T) k_{r w}^{\prime}\left(S_{w}, T\right)+\beta(T) k_{r g}^{\prime}\left(S_{g}, T\right)\right]\right\} .
\end{aligned}
$$

Если при расчете ОФП по нефти в трехфазной системе по формуле (17) получается, что $k_{r o}\left(S_{w}, S_{g}\right.$, $T)<0$, то полагают $k_{\text {ro }}\left(S_{w}, S_{g}, T\right)=0$. Так как $k_{r o w}\left(S_{w l}\right.$, $T)=k_{\text {rog }}\left(S_{g l}, T\right)$ - максимальное значение в таблице ОФП, формула (17) обеспечивает выполнение условий $k_{r o}\left(S_{w l}, S_{g}, T\right)=k_{r o g}\left(S_{g}, T\right)$ и $k_{r o}\left(S_{w}, S_{g l}, T\right)=$ $=k_{\text {row }}\left(S_{w}, T\right)$.

\section{Оценка влияния на нефтеотдачу переменной смачиваемости породы пласта-коллектора на примере внутрипластового горения}

Для такой оценки была построена одномерная фильтрационная модель со следующими параметрами: число ячеек по осям $\mathrm{X} \times \mathrm{Y} \times \mathrm{Z}-30 \times 1 \times 1$; размеры ячеек по осям $\mathrm{X} \times \mathrm{Y} \times \mathrm{Z}-6,6666 \times 80 \times 20$ м; общие размеры пласта $200 \times 80 \times 20$ м; пористость 25 \%; горизонтальная проницаемость 700 мД; объемная теплоемкость пласта 2216 кДж/ ${ }^{3} /{ }^{\circ} \mathrm{C}$; коэффициент теплопроводности 10,13 кДж/м/час $/{ }^{\circ} \mathrm{C}$. Начальные параметры пласта: пластовая температура $30^{\circ} \mathrm{C}$; пластовое давление 100 атм.; водонасыщенность $20 \%$; газа нет. При расчете использованы следующие компоненты: $\mathrm{O}_{2}, \mathrm{CO}_{2}, \mathrm{~N}_{2}$, вода и псевдокомпоненты: фракция тяжелой нефти, фракция легкой нефти, кокс. Наличием растворенного в нефти природного газа можно пренебречь, так как высоковязкие нефти обычно содержат небольшое количество растворенного газа. На начальный момент времени углеводородный компонент в пласте представлен только фракцией тяжелой нефти. На рисунке 5 показана зависимость вязкости фракции тяжелой нефти в жидкой фазе от температуры. Вязкость тяжелой нефти несколько завышена, как и в работе [22]. Зависимостью вязкости от дав- 


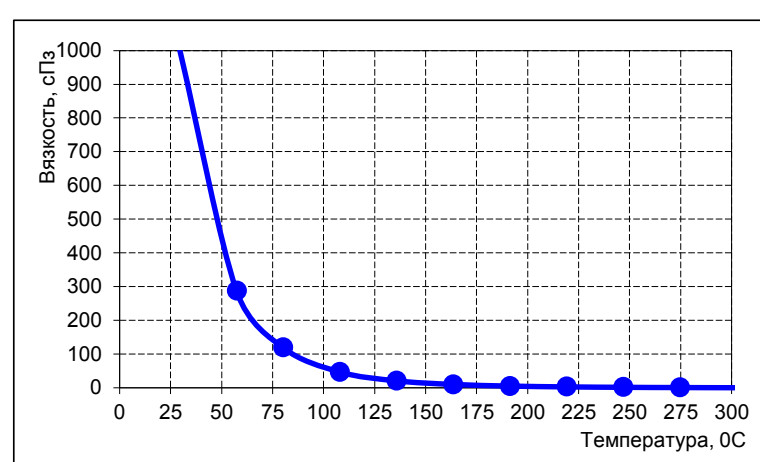

Рис. 5. Зависимость вязкости фракичи тяжелой нефти в жидкой фазе от температуры

Fig. 5. Temperature dependence of heavy fraction viscosity in a liquid phase

ления пренебрегается. Вязкость нефти в начальных пластовых условиях (30 ${ }^{\circ} \mathrm{C}$ и 100 атм.) составляет $1000 \mathrm{cПз.}$

Модель химических реакций была взята из работы [22] со следующими реакциями:

- горение тяжелой нефтяной фракции $\mathrm{HEAVY}+18,5 \mathrm{O}_{2} \rightarrow 12 \mathrm{CO}_{2}+13 \mathrm{H}_{2} \mathrm{O}$;

- горение легкой нефтяной фракции $\mathrm{LIGHT}+5 \mathrm{O}_{2} \rightarrow 3 \mathrm{CO}_{2}+4 \mathrm{H}_{2} \mathrm{O}$;

- пиролиз тяжелой нефтяной фракции $\mathrm{HEAVY} \rightarrow 2 \mathrm{LIGHT}+4,67 \mathrm{COKE}$;

- горение кокса COKE $+1,25 \mathrm{O}_{2} \rightarrow \mathrm{CO}_{2}+0,5 \mathrm{H}_{2} \mathrm{O}$, где HEAVY - фракция тяжелой нефти; LIGHT фракция легкой нефти; COKЕ - кокс.

Параметры химических реакций отражены в таблице 3.

Таблица 3

Параметры химических реакций

Table 3

Chemical reaction parameters

\begin{tabular}{|c|c|c|c|}
\hline Реакция & $\begin{array}{c}\text { Скорость } \\
\text { реакции, } \\
\text { кг-моль/сут }\end{array}$ & $\begin{array}{c}\text { Константа } \\
\text { энергии } \\
\text { активации, } \\
\text { кДж/кг-моль }\end{array}$ & $\begin{array}{c}\text { Энтальпия } \\
\text { реакции, } \\
\text { кДж/кг- } \\
\text { моль }\end{array}$ \\
\hline 1 & $0,45 \mathrm{E}+06$ & 33300 & $8,18 \mathrm{E}+06$ \\
\hline 2 & $0,45 \mathrm{E}+06$ & 33300 & $2,22 \mathrm{E}+06$ \\
\hline 3 & $0,135 \mathrm{E}+06$ & 28800 & $4,69 \mathrm{E}+04$ \\
\hline 4 & $0,45 \mathrm{E}+06$ & 23400 & $0,54 \mathrm{E}+06$ \\
\hline
\end{tabular}

Свойства флюидов взяты из работы [22]. Свойства фракций нефти представлены в таблице 4.

Молекулярная масса кокса принята 13 а.е.м. Плотность кокса при температуре $15^{\circ} \mathrm{C}$ и давлении

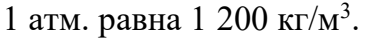

Моделировалось сухое внутрипластовое горение. В ячейке с координатами $1 \times 1 \times 1$ расположена нагнетательная скважина, а в ячейке с координатами $30 \times 1 \times 1$ - добывающая. В нагнетательную скважину закачивается воздух, обогащенный кислородом до 40 \% по массе. Температура закачиваемого воздуха на забое нагнетательной скважины $100{ }^{\circ} \mathrm{C}$. Закачка рабочего агента - 56 тыс. нм$^{3} /$ сут., забойное давление в нагнетательной скважи- не - 150 атм., забойное давление в добывающей скважине - 70 атм. В качестве ограничения на добывающей скважине принята обводненность 98 \%, мольная доля кислорода в продукции скважины выше $1 \%$ и газонефтяной фактор более 5 тыс. $\mathrm{HM}^{3} / \mathrm{M}^{3}$

Свойства фракций нефти

Таблица 4

Properties of oil fractions

Table 4

\begin{tabular}{|l|c|c|}
\hline \multicolumn{1}{|c|}{ Параметр } & $\begin{array}{c}\text { Фракция тяже- } \\
\text { лой нефти }\end{array}$ & $\begin{array}{c}\text { Фракция легкой } \\
\text { нефти }\end{array}$ \\
\hline $\begin{array}{l}\text { Молекулярная } \\
\text { масса, а.ем. }\end{array}$ & 170 & 44 \\
\hline $\begin{array}{l}\text { Критическое } \\
\text { давление, атм. }\end{array}$ & 18,5 & 43,1 \\
\hline $\begin{array}{l}\text { Критическая } \\
\text { температура, }{ }^{\circ} \mathrm{C}\end{array}$ & 897 & 735 \\
\hline Плотность, кг/м ${ }^{3}$ & $\begin{array}{c}\text { при } 1 \text { атм. и } 0{ }^{\circ} \mathrm{C} \\
\text { равна } 853\end{array}$ & $\begin{array}{c}\text { при } 70 \text { атм. и } 0{ }^{\circ} \mathrm{C} \\
\text { равна } 747\end{array}$ \\
\hline $\begin{array}{l}\text { Сжимаемость, } \\
\text { 1/атм. }\end{array}$ & $1,0 \cdot 10^{-5}$ & $2,2 \cdot 10^{-4}$ \\
\hline $\begin{array}{l}\text { Коэффициент } \\
\text { температурного } \\
\text { расширения, } 1 / \mathrm{K}\end{array}$ & $3,0 \cdot 10^{-4}$ & $6,2 \cdot 10^{-4}$ \\
\hline $\begin{array}{l}\text { Теплота парооб- } \\
\text { разования, кДж/кг }\end{array}$ & 615 & 213 \\
\hline
\end{tabular}

Рассмотрены два варианта расчетов - без учета зависимости ОФП от температуры и с учетом такой зависимости.

На рисунке 6 приведен полученный в результате моделирования профиль распределения температуры в пласте через 25 лет после начала разработки, на отметке 0 м находится нагнетательная скважина, 200 м - добывающая. Видно, что наличие зависимости ОФП от температуры в расчетах приводит к смещению теплового фронта на 50 метров в сторону добывающей скважины, что составляет $25 \%$ расстояния между скважинами, а следо-

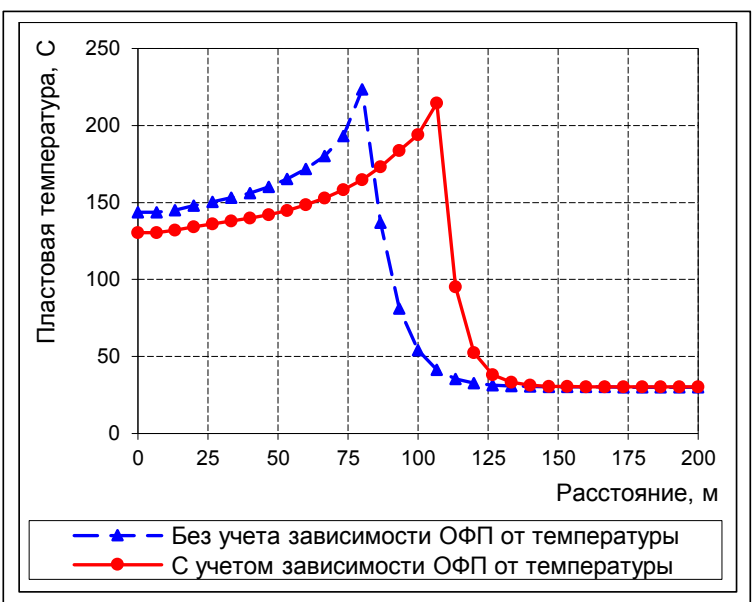

Рис. 6. Профиль распределения температуры в пласте через 25 лет после начала разработки

Fig. 6. Reservoir temperature profile after 25 years of production 
вательно, существенно влияет на показатели разработки, в том числе на нефтеотдачу.

На рисунке 7 приведена полученная зависимость накопленной добычи нефти от времени. Добыча прекращена из-за приближения фронта горения к добывающей скважине и прорыва кислорода. Увеличение скорости роста накопленной добычи нефти к концу разработки по обоим вариантам связано с подходом к добывающей скважине так называемого нефтяного вала (области повышенной нефтенасыщенности), расположенного перед фронтом горения. При наличии зависимости ОФП от температуры в процессе разработки добывается 52,79 тыс. т нефти за 34,83 года. При наличии этой зависимости добыча нефти падает до 48,44 тыс. т, а время разработки - до 29,25 года. Таким образом, не учитывая зависимость ОФП от температуры, накопленная добыча нефти завышена на 19,1 \% относ., а срок разработки - на 10,0\% относ.

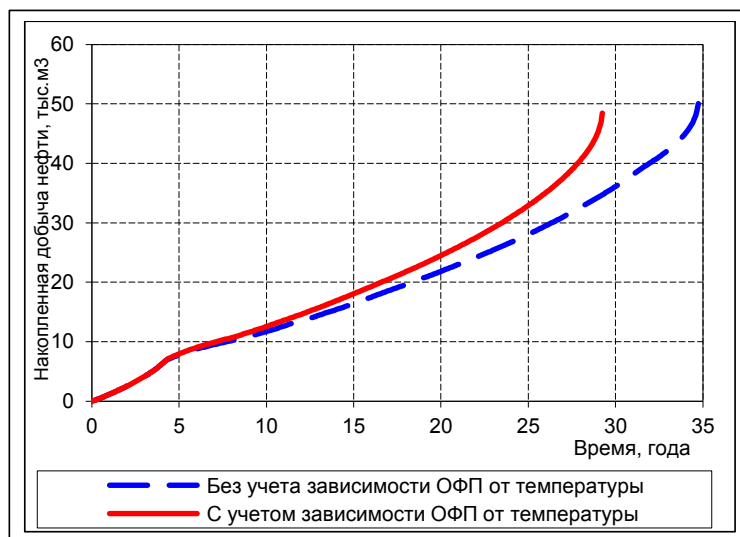

Рис. 7. Зависимость накопленной добычи нефти от времени

Fig. 7. Time dependence of accumulated oil production

\section{Заключение}

Для системы дифференциальных уравнений в частных производных, описывающей многофазную многокомпонентную неизотермическую фильтрацию с химическими реакциями, предложена оригинальная, неявная по давлению и явная по температуре и концентрациям конечно-разностная схема. Это позволяет использовать достаточно простой вычислительный алгоритм для решения задачи с большим количеством неизвестных и физических процессов. Кроме обычно учитываемых при решении такого рода задач явлений и процессов, рассматриваемая модель также учитывает зависимость относительных фазовых проницаемостей от температуры. Для обеспечения устойчивости численной схемы необходимо следить, чтобы изменения неизвестных (давление, температура, концентрации) за временной шаг не превышали заранее заданных предельных значений.
При моделировании внутрипластового горения пренебрежение изменениями смачиваемости, обусловленными созданием в пласте поля температур, переменного по пространству и времени, может приводить к значительным погрешностям в прогнозе накопленной добычи нефти (до 20 \% относ.) и времени разработки (до $10 \%$ относ.). Учет этого эффекта может быть осуществлен только на основании результатов экспериментального изучения изменений смачиваемости (и относительной фазовой проницаемости) при повышении температуры.

Работа выполнена при поддержке Программы фундаментальных научных исследований государственных академий наук № I.2.П27, заказ № 18-0110 П, НИР № 0065-2018-0110.

\section{Лumepamypa}

1. Якуцени В.П., Петрова Ю.Э., Суханов А.А. Нетрадиционные ресурсы углеводородов - резерв для восполнения сырьевой базы нефти и газа в России // Нефтегазовая геология. Теория и практика. 2009. № 4. С. 11-31.

2. Боксерман А.А., Цуканов А.А., Гришин П.А. Термогазовый метод увеличения нефтеотдачи: состояние и перспективы применения // Эффективные технологии разработки залежей углеводородов: матер. науч.-практич. конф. 2013. Речица, Беларусь. С. 41-44.

3. Бурже Ж., Сурио П., Комбарну М. Термические методы повышения нефтеотдачи пластов. М.: Недра, 1988. 424 с.

4. Антониади Д.Г., Гарушев А.Р., Ишханов Б.Г. Настольная книга по термическим методам добычи нефти. Краснодар: Советская Кубань, 2000. 464 с.

5. Боксерман А.А. Востребованность современных МУН - обязательное условие преодоления падения нефтеотдачи // Нефтяное хозяйство. 2004. № 10. С. 41-46.

6. Бетелин В.Б., Юдин В.А., Афанаскин И.В., Вольпин С.Г., Кац Р.М., Королев А.В. Создание отечественного термогидросимулятора - необходимый этап освоения нетрадиционных залежей углеводородов России. М.: Изд-во НИИСИ РАН, 2015. 206 c.

7. Partha S. Sarathi. In-situ combustion hand book - principles and practices. Final Report. 1998. URL: http://repository.icse.utah. edu/dspace/bitstream/123456789/5336/2/DOE-PC-91008-0374OSTI ID-3175-.pdf (дата обращения: 22.04.2018).

8. Алишаев М.Г., Розенберг М.Д., Теслюк Е.В. Неизотермическая фильтрация при разработке нефтяных месторождений. М.: Недра, 1985. 271 с.

9. Юдин В.А., Вольпин С.Г. Возможные изменения смачиваемости пород баженовской свиты при термогазовом воздействии // Вестн. кибернетики. 2017. № 2. С. 73-79.

10. Юдин В.А., Афанаскин И.В. Необходимость учета изменения смачиваемости пород при моделировании тепловых методов добычи нефти // Тр. НИИСИ РАН. 2018. Т. 8. № 1. C. $56-64$.

11. Punase A., Zou A., Elputranto R. How do thermal recovery methods affect wettability alteration? IJPE, 2014, vol. 2014, Art. ID 538021, 9 p.

12. Brandt A.R. Converting Oil Shale to Liquid Fuels: Energy Inputs and Greenhouse Gas Emissions of the Shell in Situ Conversion Process. Environmental Science \& Technology, 2008, vol. 42, no. 19 , pp. 7489-7494.

13. Осокин А.Е. Автомодельные задачи неизотермической двухфазной фильтрации и теплового пограничного слоя: дис. ... к.ф.-м.н. Горно-Алтайск, Новосибирск, 1998. 112 с.

14. Алексеева К.О., Аксаков А.В. Моделирование задач двухфазной неизотермической фильтрации на основе уравнения Рапопорта-Лиса // Вестн. УГАТУ. 2014. Т. 18. № 1. С. 174-179.

15. Байгереев Д.Р. Экономичные разностные схемы для за- 
дачи трехфазной неизотермической фильтрации в переменных глобальное давление, насыщенность, температура: дис. ... PhD. Республика Казахстан. Усть-Каменогорск, 2017. 126 с.

16. Титов А.П. Повышение нефтеотдачи неоднородных по проницаемости пластов в условиях неизотермической фильтрации: дис. ... к.т.н. Уфа, 2008. 172 с.

17. Бочаров О.Б., Осокин А.Е. Численное исследование автомодельных задач неизотермической двухфазной фильтрации // Сибирский журнал индустриальной математики. 2002. Т. 5. № 1. С. $8-19$.

18. Шарафутдинов Р.Ф. Исследование процессов неизотермической фильтрации жидкости и газа с фазовыми переходами: дис. ... к.т.н. Уфа, 1990. 168 с.

19. Владимиров И.В., Валиев Э.М. Изучение процессов не- изотермической фильтрации в поровых коллекторах при применении тепловых методов в разработке залежей высоковязкой нефти // Проблемы сбора, подготовки и транспорта нефти и нефтепродуктов. 2014. № 2. С. 27-40.

20. Ермилов О.М., Ремизов В.В., Ширковский А.И., Чугунов Л.С. Физика пласта, добыча и подземное хранение газа. М. Наука, 1996. 541 с

21. Азиз Х., Сеттари Э. Математическое моделирование пластовых систем. М.-Ижевск: Изд-во ИКИ, 2004. 416 с.

22. Coats K.H. In-situ combustion model. SPE of AIM, 1980, no. 8394 , pp. $533-554$

23. Программа для моделирования процессов разработки нефтегазовых месторождений $t$ Navigator версия 3.0. Технич. pyководство. М.: Rock Flow Dynamics, 2009. 782 c.

\section{A mathematical model approach for evaluation of oil recovery changes caused by wettability during in-situ combustion}

I.V. Afanaskin ${ }^{1}$, Ph.D. (Engineering), Leading Researcher, ivan@afanaskin.ru

A.V. Korolev ${ }^{1}$, Ph.D. (Engineering), Senior Researcher, alexandre.korolev@mail.ru

V.A. Yudin ${ }^{1}$, Ph.D. (Physics and Mathematics), Senior Researcher, yudinval@yandex.ru

${ }^{1}$ Federal State Institution "Scientific Research Institute for System Analysis of the Russian Academy of Sciences" (SRISA RAS), Moscow, 117218, Russian Federation

Abstract. The paper considers a problem arising in simulation of EOR thermal methods that is wettability changes influenced by formation heating. EOR thermal methods may make a formation temperature rise up to $100-500{ }^{\circ} \mathrm{C}$ above the initial value. Wettability may change in time and space as a result of such artificial temperature distribution. Thus, the fluid flow in formation and the result of applying EOR thermal methods may change dramatically.

Investigation of wettability temperature changes requires complicated experiments that take into account temperature changes of a big number of physical processes effecting wettability. Before conducting such experiments, it is mandatory to estimate the importance of such factor in forecasting EOR thermal methods result using computer simulation.

The article took into account wettability temperature changes by implementing temperature dependence of critical points on phase relative permeability curves, both for oil and water.

The authors consider the problem of multi-phase multi-component non-isothermal filtration through with chemical reactions that took into account a temperature dependence of relative phase permeabilities. They proposed an original finite-difference scheme that is implicit on pressure and explicit on temperature and concentrations. The calculations showed that if wettability changes due to temperature profile variability in formation space and time are neglected, considerable errors may occur in estimates of cumulative production and time of oxygen breakthrough in predicting in-situ combustion results by computer simulation. These errors may be as much as $20 \%$ in cumulative production and $10 \%$ in breakthrough time. To take into account this effect, it is necessary to study the changes in wettability (and relative permeability) experimentally with increasing formation temperature.

Keywords: wettability, temperature dependence of relative phase permeabilities, simulation of flow through porous media, in-situ combustion.

Acknowledgements. The article has been supported by the Program of Fundamental Scientific Research of State Academies of Sciences no. I.2.P27, order no. 18-0110_P, Research no. 0065-2018-0110. 


\section{References}

1. Yakutseni V.P., Petrova Yu.E., Sukhanov A.A. Unconventional hydrocarbon resources - a reserve for replenishing the resource base of oil and gas in Russia. Petroleum Geology. Theoretical and Applied Studies. 2009, no. 4, pp. 11-31 (in Russ.).

2. Bokserman A.A., Tsukanov A.A., Grishin P.A. Thermogas method of increasing oil recovery: state and prospects of application. Proc. Sci.-pract. Conf. "Effective Technologies for the Development of Hydrocarbon Deposits". 2013, Rechitsa, Belarus, pp. 41-44 (in Russ.).

3. Burzhe Zh., Surio P., Kombarnu M. Thermal Methods for Enhanced Oil Recovery. Moscow, Nedra Publ., 1988, $424 \mathrm{p}$.

4. Antoniadi D.G., Garushev A.R., Ishkhanov B.G. Handbook on Thermal Methods of Oil Production. Krasnodar, Sovetskaya Kuban Publ., 2000.

5. Bokserman A.A. Demand for Modern EOR is a Prerequisite for Overcoming the Decline in Oil Recovery. Oil Industry. 2004, no. 10, pp. 41-46 (in Russ.).

6. Betelin V.B., Yudin V.A., Afanaskin I.V., Volpin S.G., Kats R.M., Korolev A.V. Creation of a Domestic Thermohydrosimulator is an Indispensible Stage in the Development of Non-Traditional Hydrocarbon Deposits in Russia. Moscow, FGU FNTs NIISI RAN Publ., 2015, 206 p.

7. Partha S. Sarathi. In-situ Combustion Handbook - Principles and Practices. Final Report. BDM Petroleum Technologies. BDM-Oklahoma Inc. Bartlesville. Oklahoma, National Petroleum Technology Office U.S. DEPARTMENT OF ENERGY. Tulsa. Oklahoma. 1998. Available at: http://repository.icse.utah.edu/dspace/bitstream/123456789/5336/2/DOEPC-91008-0374-OSTI_ID-3175-.pdf/ (accessed April 22, 2018).

8. Alishaev M.G., Rozenberg M.D., Teslyuk E.V. Non-Isothermal Flow in Oil Fields Production. Moscow, Nedra Publ., $1985,271 \mathrm{p}$.

9. Yudin V.A., Volpin S.G. Possible changes in the wettability of the rocks of the bazhenov formation during thermogas effects. Proc. in Cybernetics. 2017, no. 2, pp. 73-79 (in Russ.).

10. Yudin V.A., Afanaskin I.V. The need to take into account changes in rock wettability in the modeling of thermal methods of oil production. SRISA RAS Proc. 2018, vol. 8, no. 1, pp. 56-64 (in Russ.).

11. Punase A., Zou A., Elputranto R. How do thermal recovery methods affect wettability alteration? IJPE, 2014, vol. 2014, Art. ID 538021, 9 p.

12. Brandt A.R. Converting Oil Shale to Liquid Fuels: Energy Inputs and Greenhouse Gas Emissions of the Shell in Situ Conversion Process. Environmental Science \& Technology. 2008, vol. 42, no. 19, pp. 7489-7494.

13. Osokin A.E. Self-Similar Problems of Non-Isothermal Two-Phase Flow and Thermal Boundary Layer. PhD Thesis. Gorno-Altaysk, Novosibirsk, 1998.

14. Alekseeva K.O., Aksakov A.V. Simulation of Two-Phase Non-Isothermal Flow Problems Based on the Rapoport-Lis Equation. Bulletin of USATU. 2014, vol. 18, no. 1, pp. 174-179 (in Russ.).

15. Baygereev D.R. Economical Difference Schemes for the Problem of Three-Phase Non-Isothermal Filtration in Variables Global Pressure, Saturation, Temperature. PhD Thesis. Republic of Kazakhstan. Ust-Kamenogorsk, 2017.

16. Titov A.P. Increase in Oil Recovery of Reservoir Heterogeneous Permeability in Conditions of Nonisothermal Flow. PhD Thesis. Ufa, 2008.

17. Bocharov O.B., Osokin A.E. Numerical Investigation of Self-Similar Problems of Non-Isothermal Two-Phase Flow. J. of Applied and Industrial Mathematics. 2002, vol. 5, no. 1, pp. 8-19 (in Russ.).

18. Sharafutdinov R.F. Investigation of Processes of Liquid and Gas Nonisothermal Flow with Phase Transitions. PhD Thesis. Ufa, 1990

19. Vladimirov I.V., Valiev E.M. Studying nonisothermal flow processes in porous reservoirs when applying thermal methods in the development of high-viscosity oil deposits. Problems of Collecting, Preparing and Transporting Oil and Oil Products. 2014, no. 2, pp. 27-40 (in Russ.).

20. Ermilov O.M., Remizov V.V., Shirkovskiy A.I., Chugunov L.S. Reservoir Physics, Gas Production and Underground Storage. Moscow, Nauka Publ., 1996, 541 p.

21. Aziz Kh., Settari E. Mathematical Modeling of Reservoir Systems. Moscow-Izhevsk, IKI Publ., 2004, 416 p.

22. Coats K.H. In-situ combustion model. SPE of AIM. 1980, no. 8394, pp. 533-554.

23. The Program for Modeling Processes of Development of Oil and gas Deposits tNavigator 3.0. Technical Manual. Moscow, Rock Flow Dynamics, 2009, 782 p. 


\title{
Развитие алгоритма спонтанного структурирования иифровых изображений природных комплексов
}

\author{
Э.Я. Островский 1, д.т.н., научный руководитель \\ C.B. Румяниев ${ }^{2}$, к.фр.-м.н., руководитель группы, Sergey_Rumyancev@srisa.ru \\ B.A. Фадеев 1, генеральный директор, cs-tehno@таil.ru
}

1 Компания Форес, 109518, г. Москва, Россия

2 Федеральный научный иентр Научно-исследовательский институт системных исследований РАH, 123182, г. Москва, Россия

Рассматривается совершенствование алгоритма спонтанного формирования непротиворечивой структуры на объектах цифровой матрицы с данными наблюдения параметров (магнитных, гравиметрических, радиоактивных и др.) исследуемого природного комплекса.

Приводится постановка задачи, рассматривается технология спонтанного структурирования, альтернативная традиционным технологиям, которая, выявляя стабильные свойства-признаки, создает непротиворечивую уникальную (единственно возможную) структуру.

Рассматривается алгоритм как последовательность ключевых этапов, составляющих основу технологии спонтанного формирования непротиворечивой структуры. Дается краткий обзор применения технологии.

Авторы подчеркивают роль человека как эксперта в использовании технологии спонтанного формирования непротиворечивой структуры. В заключении перечисляются возможные приложения технологии.

Таким образом, дано развитие технологии (концепция, алгоритм, ПО) формирования непротиворечивой структуры в виде совокупности непересекающихся устойчивых многомерных однородностей - ассоциаций по смежности. Последние - области адекватной экстраполяции (прогнозирования) для образующих их объектов.

Ключевые слова: прогноз, структуры, технология.

В трудах академика Дородницина А.А. при сравнении точных и описательных наук утверждается, что точность или описательность не являются свойствами тех или иных явлений природы, это лишь характеристика этапа развития наук, их изучающих [1]. Развитие вычислительной техники дало возможность многим наукам перейти из раздела описательных в точные. Геологоразведка в свое время основывалась именно на рецептах, выработанных практикой, на мнении экспертов [2-4]. В настоящей работе рассматривается развитие технологии анализа цифровых изображений. Начало этой технологии было положено именно в геологоразведке, которая, благодаря развитию вычислительной техники, получила оформление как точная наука [2-5].

Авторы статьи рассматривают дальнейшее развитие техники спонтанного структурирования применительно к матрицам цифровых изображений [6-8].

\section{Концепция спонтанного структурирования: самоорганизация хаоса в устойчивые однородности - части структуры}

Структура произвольной цифровой матрицы событий (digital matrix event, DME) - это совокупность непересекающихся множеств однородных объектов (однородностей), инструмент превращения DME в информацию об исследуемой реальности и прогнозирования ее объектов. В рамках данного определения очевидно существование струк- тур двух типов, обусловленных двумя типами однородностей.

1. Наделенные только им присущими свойствами-признаками (иифровое изображение - 2D3D-матрица событий, объектам (быть может, не всем) которой поставлены в соответствие циифровые значения (дискретные отсчеты)).

2. Наделенные только им присущими стабильными свойствами-признаками.

Традиционные технологии формируют на объектах DME первый тип однородностей и сколь угодно много разнообразных (противоречивых) структур в зависимости от той или иной субъективной предустановки конкретного эксперта (его знаний, опыта, интуиции, ожиданий, предпочтений и т.п.) $[9,10]$. В терминах зрительного восприятия такой предустановочный подход к структурированию означает: видеть известное или желаемое в неизвестном.

Подход в духе известного принципа дополнительности, постулирующего существование неустранимой множественности точек зрения на одну и ту же реальность (приниип дополнительности рассматривается как впервые введеное в квантовую физику Н. Бором обобщение соотношений неопределенности Гейзенберга). Однако он же становится причиной неадекватных структур - фантомов, артефактов типа слуховых или зрительных галлюцинаций. Разработанная технология спонтанного структурирования, альтернативная традиционным, выявляя однородности второго типа, создает непротиворечивую уникальную (един- 
ственно возможную) структуру. Если в качестве основного информационного признака любого изображения принять однородность, сообщество эквивалентно идентифицированных объектов, то любую DME можно представить хаосом однородностей, которые стохастически образуются на ней и ее функционально разнообразных проекциях $[11,12]$. Такие неравновесные изолированные системы спонтанно эволюционируют к стационарному состоянию, совместимому с наложенными граничными условиями (числом объектов, сетью наблюдений, наблюдаемыми параметрами и т.д.).

Индикаторами этого состояния являются скрытые в стохастическом шуме последовательности высококогерентных (взаимовложенных) однородностей, где каждая последующая вложена в предыдущую (является ее подмножеством с числом объектов $\geq 0.5$ числа объектов предыдущей). Эти высококогерентные однородности характеризуются минимальным производством энтропии и, следовательно, наиболее устойчивы, поэтому они могут использоваться в качестве стабильных признаков DME, ее специфичных многомерных идентификаторов. Эквивалентно идентифицированные ими объекты образуют ассоциации по смежности, поскольку для них справедливо утверждение: появление одного из объектов ассоциации в составе того или иного идентификатора означает появление в нем остальных объектов ассоциации. То есть объект DME может принадлежать одной и только одной ассоциации по смежности, которая в силу этого является областью адекватной пространственной экстраполяции (прогнозирования) для составляющих ее объектов.

\section{Алгоритм спонтанного формирования уникальной высокоинформативной структуры}

Спонтанное структурирование осуществляется приведенной далее последовательностью операций, названных авторами «р-алгоритм».

- Приведение исходных данных к формату цифровой матрицы. Отличия могут быть в машинном представлении значения элементов матрицы - integer*2, integer*4, real*4, real*8. Например, сейсмические данные формата SGY (формат чисел - плавающая запятая), аэро- или космоснимки формата цифрового изображения.

- Формирование матриц изображения в единый проект, определяемый размерами и заданием маски. Маска определяет точки измерений и формируется как двоичный файл. Использование маски позволяет проводить анализ на одних и тех же исходных данных, но отличающихся областью, выделенной посредством маски. Маска может также испоьзоваться для фильтрации исходных данных. Типичный пример - маскирование облаков на космоснимках.
- Увеличение степени разнообразия - добавление в проект матриц, зависящих от исходных данных. Необходимость этой операции возникает при проведении анализа по ограниченному количеству исходных данных. Практика применения алгоритма указывает на необходимость этого этапа. Примером могут служить сейсмические данные, радиолокационные и черно-белые изображения.

На этом этапе, как правило, используется алгоритм скользящего окна для расчета заданных пользователем функций. При этом необходимо учитывать неполное заполнение скользящего окна на границе отсуствия данных. В то же время настоящая технология использует скользящее окно как меру близости на пространстве точек наблюдения. На практике данные типа геохимического опробования, которые могут быть заданы на ограниченном множестве случайно раположенных точек, не дают использовать эту меру близости. Однако использование сегментации только исходных данных позволяет применять технологию и в этом случае.

- Формирование двоичных фильтров (сегментация изображения) - разделение цифровой матрицы на области (фрагменты), однородные по критерию, для которого сформирована цифровая матрица, в соответствии с условием $2 N<K<2 N+1$, где $K$ - число объектов цифровой матрицы; $N$ - число отбираемых для структурирования двоичных фильтров (рис. 1). В идеальном случае двоичный фильтр цифровой матрицы делит ее на равные по площади фрагменты.

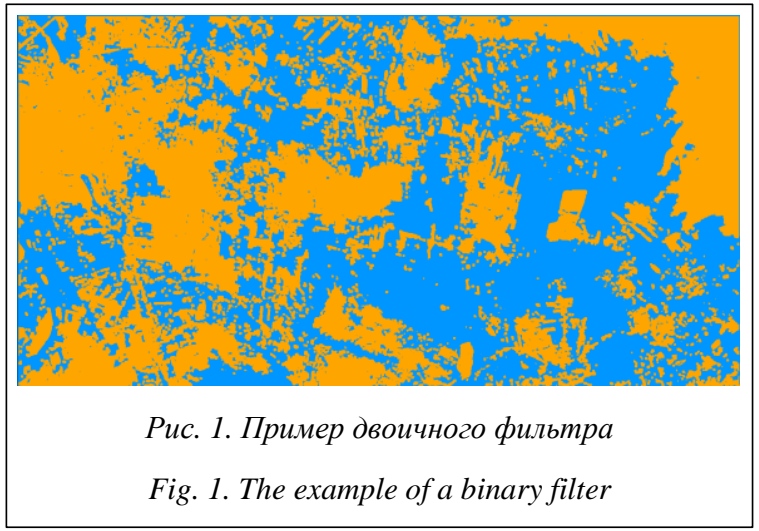

Пересечение всех цифровых фильтров дает пространство элементарных множеств (событий), объединение которых дает всю область анализа.

- Отбор двоичных фильтров. Количество цифровых фильтров определяется желаемой подробностью классификации анализируемой области. Необходимо иметь в виду, что найдутся такие пересечения двоичных фильтров, в которых нет ни одной точки данных. Отбор фильтров должен быть выполнен по сходству. Применение основного принципа (максимальная площадь и минимальная длина границы) имеет своей целью получить наиболее плотные по заполнению фильтры и избежать ситуаций типа шахматной доски. 
- Построение первичной классификации многообразий элементарных однородностей как пересечения выбранных двоичных фильтров. При программной реализации удобнее представить классификацию как кодовый файл, определяющий первичную классификацию.

- Выделение устойчивых однородностей для первичной классификации. Проводится на основе анализа последовательностей вложенных однородностей. Результаты такого анализа позволяют выделить последовательности, обладающие свойством устойчивости. Примечательно, что, несмотря на большое количество точек, устойчивых последовательностей оказывается несколько десятков. Этот примечательный факт и послужил основой технологии спонтанного структурирования.

- Идентификация объектов DME устойчивыми однородностями - построение ассоциации по смежности.

- Визуализация результатов - возможность графического представления объектов спонтанного структурирования:

- примитивная визуализация - раскраска цифровых матриц по цветовой шкале, пропорциональной значению или площади, занимаемой данным признаком, двухцветная раскраска области по двоичному фильтру или по пространству элементарных множеств, заданных пересечением нескольких двоичных фильтров;

- визуализация уникальной (непротиворечивой) высокоинформативной структуры DME - coвокупности непересекающихся ассоциаций по смежности;

- визуализация отдельных ассоциаций по смежности, содержащих объекты, заданные экспертом для прогнозирования.

\section{Опыт применения технологии спонтанного структурирования}

Опыт применения основан на развитии алгоритма для возможности применения к исходным данным различной природы. Изначально алгоритм строился применительно к анализу аэрогеофизических данных. В настоящее время допустим анализ сейсмических данных как 2D-формата, так и $3 \mathrm{D}$. Сложностью в трехмерном случае остается визуализация, но эта проблема не связана с алгоритмом и решается преобразованием результатов прогноза в формат программы 3D-визуализации (например, использование элементов типа voxel в VoxelGeo системе объемной визуализации и детальной интерпретации 3D-данных) (рис. 2) [13].

Для геофизических исследований эксплуатационных нефтегазовых скважин и для данных геофизического опробования необходим модифицированный алгоритм, не использующий меры близости точек исходных данных.

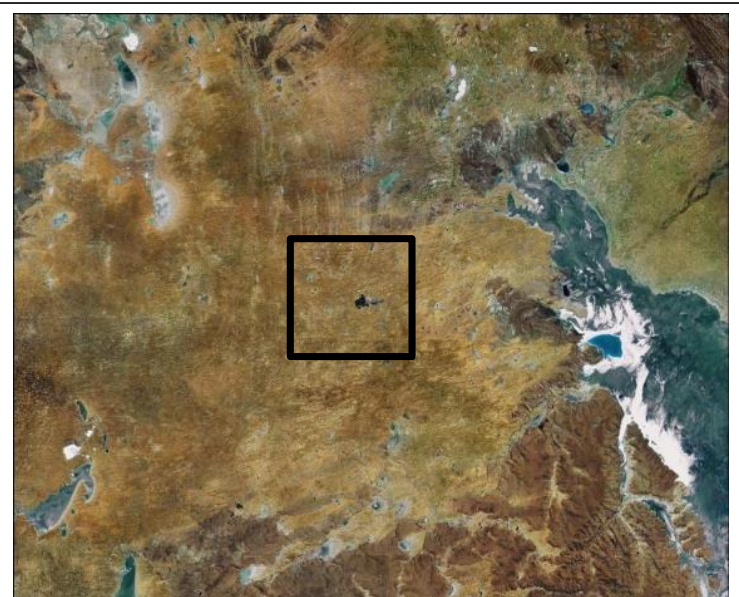

Pис. 2. Исходные данные - GoogleMap. В иентре снимка Olympic Dam Mine Cu-Au-U depositизвестное месторождение в Австралии

Fig. 2. Input data is GoogleMap. In the center of the picture is Olympic Dam Mine Cu-Au-U deposit, a well-known deposit in Australia

Отметим, что стремительное развитие вычислительной техники позволяет анализировать аэрокосмоснимки предельных размеров, но в то же время обеспечивает получение исходных данных с труднопредставимыми скоростями. Американская статистика свидетельствует о 9,5 млрд фотографий в день, сделанных только американцами, больше трети фотографий при этом снимается телефоном.

Ограничения на время для обработки одного снимка приводят, как следствие, к ограничению на размер исходных данных, которые могут возникнуть при анализе аэрокосмоснимков в режиме реального времени (рис. 3).

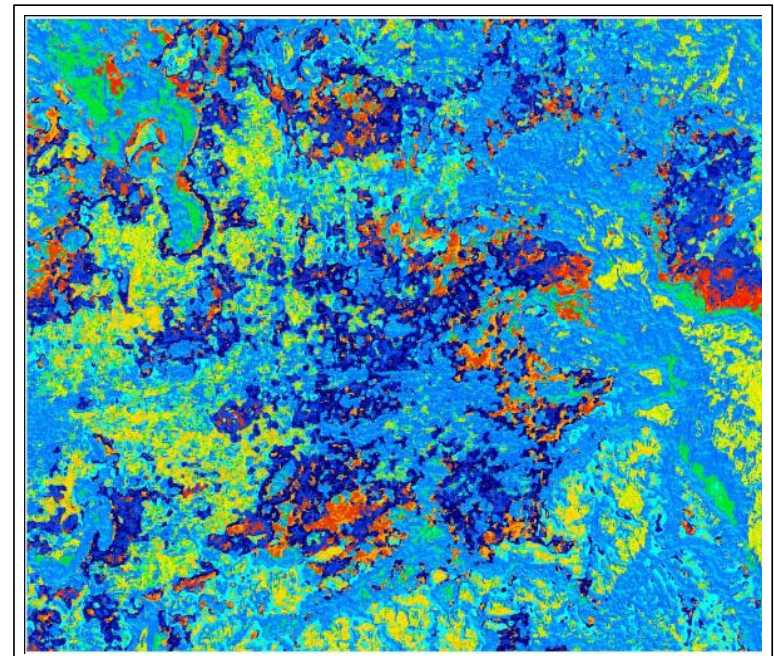

Рис. 3. Результат обработки - консистентная структура изображения на рисунке 1

Fig. 3. A result of processing. The consistent structure of the image in Figure 1 


\section{Человеческий фактор, или роль эксперта в использовании технологии}

Использование технологии, вообще говоря, не зависит от использования вычислительной техники, которая определяет только время, необходимое для анализа, или размеры анализируемой цифровой матрицы. Однако принципиальным является участие в проведении анализа эксперта, то есть развитие технологии рассматривается как создание инструмента, который используется экспертом для решающего заключения.

\section{Заключение}

В работе представлено развитие созданной ранее технологии (концепции, алгоритма) спонтанного структурирования произвольной цифровой матрицы, которая может эффективно использоваться для прогнозирования объектов, заданных в качестве целевых (поиск полезных ископаемых, участков развития болезнетворных процессов в тканях живого организма и др.), оценки природных ресурсов, мониторинга изменений во времени консистентной структуры (экологический мониторинг последствий хозяйственной деятельности и т.п.) и для усиления контрастности выявляемых однородностей.

Кроме того, технология применима при поиске следов упорядоченности (устойчивых однородностей) в шумовых средах (обнаружение и контроль загрязнений водной или воздушной среды, выявление слабоконтрастных структурных «ловушек» в земной коре и т.д.) и в атрибуции уникальных произведений искусства, в частности, на основе оценки сходства разных объектов.

\section{Литература}

1. Дородницын А.А., Каспшицкая М.Ф., Сергиенко И.В. Об одном подходе к формализации классификации // Кибернетика. 1976. № 6. С. 132.

2. Островский Э.Я. Радиоактивные аномалии как индикаторы рудного процесса // Докл. АН СССР. 1975. Т. 221. № 1. C. 201-204.

3. Портнов А.М. О геохимической связи калия и тория в изверженных породах и околорудных метасоматитах // Докл. АН СССР. 1978. Т. 239. № 6. С. 1441-1444.

4. Островский Э.Я., Портнов А.М. Индикаторные свойства геохимической связи калия и тория // Геохимия. 1979. № 5. C. $767-774$.

5. Портнов А.М. Радиогеохимический поиск руды // Природа. 1984. № 5. С. $99-105$.

6. Островский Э.Я., Румянцев С.В. Спонтанное структурирование цифровых геофизических изображений природных комплексов; прогнозирование полезных ископаемых // ДАН. Геофизика. 2004. Т. 398. № 3. С. 396-399.

7. Островский Э.Я., Румянцев С.В., Фадеев В.А. Новый структурный анализ цифровых изображений природных комплексов // Геопрофи. 2005. № 2. С. 49-51.

8. Островский Э.Я. Асимптотическое прогнозирование на основе дистанционных геофизических исследований // Докл. AH CCCP. 1986. T. 289. № 4. C. 827-836.

9. Гонсалес Р., Вудс Р. Цифровая обработка изображений. M.: Техносфера, 2005. $1072 \mathrm{c}$.

10. Гонсалес Р., Вудс Р., Эддинс С. Цифровая обработка изображений в среде MATLAB. М.: Техносфера, 2006. 621 с.

11. Гленсдорф П., Пригожин И. Термодинамическая теория структуры, устойчивости и флуктуации. М.: Мир, 1973. $280 \mathrm{c}$.

12. Федер Е. Фракталы. М.: Мир, 1991. 254 с.

13. VoxelGeo. Объемная интерпретация и выделение тел. URL: http://www.pdgm.com/products/voxelgeo/ (дата обращения: 02.04.18)

\section{Development of the spontaneous structuring algorithm of natural complex digital images}

E.Ya. Ostrovsky ${ }^{1}$, Dr.Sc. (Engineering), Scientific Supervisor

S.V.Rumyantsev ${ }^{2}$, Ph.D. (Physics and Mathematics), Head of Group, Sergey_Rumyancev@srisa.ru

V.A. Fadeev ${ }^{1}$, Director General, cs-tehno@mail.ru

${ }^{1}$ Fores Ltd., 109518, Moscow, Russian Federation

${ }^{2}$ Scientific Research Institute for System Analysis of the Russian Academy of Sciences, Moscow, 123182, Russian Federation

Abstract. The paper considers the way of improving the algorithm of spontaneous formation of a consistent structure on digital matrix objects with observation data of parameters (magnetic, gravimetric, radioactive etc.) of the natural complex under investigation.

In the section "A Spontaneous Structuring Concept: Chaos Self-Organization in Stable Homogeneities - Structure Parts" the authors state the problem. They consider a spontaneous structuring technique that is alternative to traditional technologies and reveals stable properties (signs), creates a unique (only possible) consistent structure.

In the section "The Algorithm of Spontaneous Formation of a Unique Highly Informative Structure" the authors consider the algorithm as a sequence of key stages that form the basis of the technique of the spontaneous formation of a consistent structure. 
The section "Experience in Applying Spontaneous Structuring Technique" gives brief overview of technology application.

In section "Human Factor or the Role of an Expert in Using the Technology" the authors emphasize the role of a man as an expert when using the spontaneous formation technology of a consistent structure. The conclusion contains possible applications of the technology.

Thus, technology development (conception, algorithm and software) for consistent structure formation in the form of a set of the non-crossing stable multidimensional homogeneities (contiguity associations) that represents regions of adequate extrapolation (forecasting) of objects in them.

Keywords: forecast, structure, technique.

\section{References}

1. Dorodnitsyn A.A., Kaspshitskaya M.F., Sergienko I.V. On an approach to the formalization of classification. Cybernetics. 1976, no. 6, pp. 132-140 (in Russ.).

2. Ostrovsky E.Ya. Radioactive anomalies as indicators of the ore process. Reports of the USSR Academy of Sciences. 1975, vol. 221, no. 1, pp. 201-204 (in Russ.).

3. Portnov A.M. On the geochemical connection of potassium and thorium in igneous rocks and near-ore metasomatites. Reports of the USSR Academy of Sciences. 1978, vol. 239, no. 6, pp. 1441-1444 (in Russ.).

4. Ostrovsky E.Ya., Portnov A.M. Indicator properties of potassium and thorium geochemical connection. Geochemistry. 1979, no. 5, pp. 767-774 (in Russ.).

5. Portnov A.M. Radiogeochemical ore search. Nature. 1984, no. 5, pp. 99-105 (in Russ.).

6. Ostrovsky E.Ya., Rumyantsev S.V. Spontaneous structuring of digital geophysical images of natural complexes; forecasting of minerals. DAN. Geophysics. 2004, vol. 398, no. 3, pp. 396-399 (in Russ.).

7. Ostrovsky E.Ya., Rumyantsev S.V., Fadeev V.A. New structural analysis of digital images of natural complexes. Geoprofi. 2005, no. 2, pp. 49-51 (in Russ.).

8. Ostrovsky E.Ya. Asymptotic prediction based on remote geophysical studies. Reports of the USSR Academy of Sciences. 1986, vol. 289, no. 4, pp. 827-836 (in Russ.)

9. Gonzalez R., Woods R. Digital Image Processing. Moscow, Technosphere Publ., 2005, 1072 p.

10. Gonzalez R., Woods R., Eddins C. Digital Image Processing in the MATLAB Environment. Moscow, Technosphere Publ., 2006, 621 p. $280 \mathrm{p}$

11. Glensdorf P., Prigogine I. Thermodynamic Theory of Structure, Stability and Fluctuations. Moscow, Mir Publ., 1973,

12. Feder E. Fractals. Moscow, Mir Publ., 1991, 254 p.

13. VoxelGeo. Volumetric Interpretation and Allocation of Bodies. Available at: http://www.pdgm.com/products/voxelgeo/ (accessed April 2, 2018).

\section{Примеры бибциографического описания статьи}

1. Островский Э.Я., Румянцев С.В., Фадеев В.А. Развитие алгоритма спонтанного структурирования цифровых изображений природных комплексов // Программные продукты и системы. 2018. T. 31. № 3. C. 495-499. DOI: 10.15827/0236-235X.123.495-499.

2. Ostrovsky E.Ya., Rumyantsev S.V., Fadeev V.A. Development of the spontaneous structuring algorithm of natural complex digital images. Software \& Systems. 2018, vol. 31, no. 3, pp. 495-499 (in Russ.). DOI: 10.15827/0236-235X.123.495-499. 


\title{
Интерпретаиия межскважинных исследований карбонатных коллекторов методом дөух режимов с помоцию численных моделей
}

\author{
И.В. Афранаскин 1, к.т.н., ведущий научный сотрудник, ivan@afanaskin.ru \\ С.Г. Вольпин 1, к.т.н., зав. отделом, sergvolpin@gmail.com \\ O.B. Аомакина 1, научный сотрудник, ovllom@mail.ru \\ Ю.M. Штейнберг 1, зав. группой, yurash22@gmail.com
}

1 Федеральный научный иентр Научно-исследовательский институт системных исследований РАН, г. Москва, 117218 , Россия

Рассматривается метод двух режимов, используемый в числе прочих для исследования скважин при неустановившемся течении. Благодаря своему развитию в последние годы он позволяет определять тот же набор параметров, что и распространенный метод восстановления давления. Установлено, что при этом изучаются десятки метров вокруг скважины, редко - более глубокие зоны. Этот метод не требует остановки добывающих скважин, таким образом, потери в добыче нефти в результате проведения исследований уменьшаются. Недостатком метода является меньшая точность определения параметров.

Показано, что при существенной разнице дебитов между двумя режимами и достаточной длительности второго режима работы возмущающей скважины метод двух режимов можно рассматривать как альтернативу гидропрослушиванию. Тогда можно исследовать и межскважинную зону - сотни метров. В работе рассмотрена математическая модель двойной пористости для интерпретации гидродинамических исследований межскважинного пространства трещиновато-пористых карбонатных коллекторов. Эту модель можно использовать для интерпретации межскважинных исследований методом двух режимов.

Приведена оригинальная конечно-разностная схема типа «классики» для такой модели. Описано решение обратной задачи подземной гидродинамики методом Ньютона. На примере синтетической кривой забойного давления проиллюстрировано использование предлагаемого подхода и даны рекомендации по его применению. Рассмотрено несколько вариантов интерпретации для различных наборов уточняемых параметров пласта. Подтверждено, что относительная емкость трещин и параметр перетока матрица-трещины мало влияют на показания давления в реагирующей скважине в дальнейшем. Рекомендуется в качестве определяемых параметров выбирать проницаемость трещин, пористость матрицы и анизотропию проницаемости трещин по площади.

Ключевые слова: гидродинамические исследования скважин, метод двух режимов, гидропрослушивание, модель двойной пористости.

Важным источником информации о свойствах и строении нефте-, газо- и водонасыщенных пластов являются гидродинамические исследования скважин на неустановившихся режимах течения. Они позволяют определять энергетические и фильтрационно-емкостные параметры, изучать геометрию пласта и особенности его строения, вести контроль за разработкой. Для исследования околоскважинных зон пласта (десятки метров, иногда - первые сотни) используется метод восстановления давления, а межскважинного пространства - метод гидропрослушивания [1-9].

Особый интерес с точки зрения исследовательских работ и подробного изучения геологического строения представляют трещиновато-пористые коллекторы, поскольку они характеризуются высокой неоднородностью свойств и содержат сразу две системы емкостей - трещины и поры. Эти системы существенно различаются по своим свойствам, что усложняет разработку таких коллекторов. В силу некоторых особенностей трещиновато-пористых коллекторов многие стандартные методы изучения нефтяных и газовых пластов малоэффективны.

Метод двух режимов, используемый для исследования скважин [3, 10-14], обычно применяется и для исследования околоскважинных зон пласта (десятки метров, иногда - первые сотни). Поскольку данный метод не требует остановки скважины (значит, нет потерь в добыче нефти), может быть исследовано большое количество добывающих скважин, что существенно повышает охват пласта исследованиями. Если при исследовании методом двух режимов разница дебитов значительна и длительность второго режима достаточна для существенного возмущения пласта, исследование можно рассматривать как аналог гидропрослушивания и, регистрируя давление на забое соседних скважин, исследовать межскважинную зону.

В связи с этим представляет интерес изучение способов интерпретации гидродинамических исследований межскважинного пространства трещиновато-пористых коллекторов методом двух режимов, в том числе с помощью численных моделей.

\section{Математическая модель. Решение прямой задачи}

Для решения прямой задачи запишем математическую модель, описывающую фильтрацию флюида при гидродинамических исследованиях меж- 
скважинного пространства для любой геометрии пласта, расстановки и количества скважин, распределения свойств пласта по площади. Такая модель может быть только численной. Рассмотрим границы применимости описываемой математической модели фильтрации флюида в продуктивном пласте:

- фильтрация однофазная;

- жидкость слабосжимаемая;

- пласт упругий;

- гравитационными силами можно пренебречь;

- продуктивный пласт содержит поры и трещины;

- проницаемость трещин значительно больше проницаемости пор;

- пористость трещин значительно меньше пористости пор;

- участки пористой матрицы не обмениваются между собой флюидом;

- к скважине приток происходит только по трещинам;

- при снижении давления поры матрицы отдают флюид в трещины;

- в начальный момент времени матрица и трещины находятся в равновесии, перетоки отсутствуют;

- поток из матрицы в трещину установившийся, поэтому матрицу можно рассматривать как одну ячейку в одном блоке сетки.

Тогда уравнения сохранения объема флюида в поверхностных условиях отдельно для трещин и пор можно записать соответственно как

$$
\begin{aligned}
& \frac{\partial}{\partial t}\left(\frac{\phi_{f}}{B}\right)+\operatorname{div}\left(\frac{\vec{W}}{B}\right)=-\bar{q}_{\text {well }}+\bar{q}_{m f}, \\
& \frac{\partial}{\partial t}\left(\frac{\phi_{m}}{B}\right)=-\bar{q}_{m f},
\end{aligned}
$$

где нижние индексы $f$ и $m$ означают трещины и пористую матрицу соответственно; $\phi-$ пористость; $B$ - объемный коэффициент флюида; $\vec{W}$ - вектор скорости фильтрации; $\bar{q}_{\text {well }}-$ плотность потока в скважину; $\bar{q}_{m f}$ - плотность перетока из пор матрицы в трещины $[1,2,4,15-17]$.

Скорость фильтрации определяется через закон Дарси:

$$
\vec{W}=-\frac{k_{f}}{\mu} \operatorname{grad}\left(P_{f}\right),
$$

где $k_{f}$ - проницаемость трещин; $\mu$ - вязкость флюида; $P_{f}-$ давление в трещинах.

Уравнения (1)-(3) дополняются начальными условиями, граничными условиями и замыкающими соотношениями:

$$
\phi_{f}=\phi_{f 0}\left[1+C_{r f}\left(P_{f}-P_{0}\right)\right],
$$

$$
\begin{gathered}
\phi_{m}=\phi_{m 0}\left[1+C_{r m}\left(P_{m}-P_{0}\right)\right], \\
B=B_{0}\left[1-C_{l}\left(P_{f}-P_{0}\right)\right],
\end{gathered}
$$

где $\phi_{f 0}, \phi_{m 0}$ и $B_{0}-$ пористость трещин, пористость матрицы и объемный коэффициент флюида соответственно при начальном давлении $P_{0} ; C_{r f}, C_{r m}$ и $C_{l}$ - сжимаемость трещин, пор и флюида соответственно.

Кроме замыкающих соотношений (4)-(6), необходимо задать источниковые члены в уравнениях (1) и (2). Поскольку поток из матрицы в трещину установившийся, его можно задать как

$$
q_{m f}=T_{m f}\left(P_{m}-P_{f}\right),
$$

где $T_{m f}=\frac{k_{m f}}{\mu B_{m f}} \sigma V_{b}$,

$$
\begin{aligned}
& k_{m f}=\frac{2}{3}\left(\frac{k_{m x} k_{f x}}{k_{m x}+k_{f x}}+\frac{k_{m y} k_{f y}}{k_{m y}+k_{f y}}+\frac{k_{m z} k_{f z}}{k_{m z}+k_{f z}}\right), \\
& \sigma=\frac{4 n(n+2)}{x_{m}^{2}}, B_{m f}=\frac{1}{2}\left[B\left(P_{f}\right)+B\left(P_{m}\right)\right],
\end{aligned}
$$

$T_{m f}-$ коэффициент трещинно-поровой проводимости; $\sigma$ - фактор формы (шейп-фактор); $V_{b}$ - элементарный объем пласта; $k_{m x}, k_{m y}, k_{m z}$ и $k_{f x}, k_{f y}, k_{f z}-$ проницаемость пор и трещин вдоль осей $\mathrm{X}, \mathrm{Y}, \mathrm{Z}$ декартовой системы координат; $n$ - параметр формы элемента (блока) пористой матрицы ( $n=1-$ плита, $n=2$ - призма или цилиндр, $n=3$ - куб или сфера); $x_{m}^{2}-$ характерный размер блоков матрицы $[1,2,4,15-17]$.

Приток флюида (источниковое слагаемое) к вертикальной скважине в псевдоустановившемся приближении [18] запишется как

$$
q_{\text {well }}=P I\left(P_{f}-P_{\text {well }}\right),
$$

где $P I=\frac{2 \pi k_{e f f} h_{e f f}}{\mu B\left(P_{f}\right)} \cdot \frac{1}{\ln \left(\frac{R_{c}}{r_{\text {well }}}\right)+S k i n}, k_{e f f}=\sqrt{k_{f x} k_{f y}}$,

$h_{e f f}$ - эффективная толщина пласта; $R_{c}-$ радиус контура питания; $r_{w e l l}$ - радиус скважины; Skin - скинфактор скважины.

Вычислим радиус контура питания для прямоугольной конечно-разностной вычислительной сетки:

$$
\left(R_{c}\right)_{i j}=0,28 \frac{\sqrt{\sqrt{\left(\frac{k_{f y}}{k_{f x}}\right)} \Delta x_{i j}^{2}+\sqrt{\left(\frac{k_{f x}}{k_{f y}}\right)_{i j}} \Delta y_{i j}^{2}}}{\sqrt{\left(\frac{k_{f y}}{k_{f x}}\right)_{i j}}+\sqrt{\left(\frac{k_{f x}}{k_{f y}}\right)_{i j}}},
$$

где $i$ и $j-$ индексы ячейки сетки вдоль осей $\mathrm{X}$ и $\mathrm{Y}$ соответственно; $\Delta x$ и $\Delta y-$ размеры ячейки вдоль осей $\mathrm{X}$ и $\mathrm{Y}$ соответственно.

Уравнения (1) и (2) с учетом (4)-(6) можно переписать в виде 
$\phi_{f 0}\left(C_{r f}+C_{l}\right) \frac{\partial P_{f}}{\partial t}=-B_{0}\left\lfloor\bar{q}_{\text {well }}-\bar{q}_{m f}+\operatorname{div}\left(\frac{\vec{W}}{B}\right)\right\rfloor$,

$\phi_{m 0}\left(C_{r m}+C_{l}\right) \frac{\partial P_{m}}{\partial t}=-B_{0} \bar{q}_{m f}$.

Запишем конечно-разностный аналог уравнения (9) для трещиноватой среды. Фильтрация двумерная, в горизонтальной плоскости. Численная схема - «классики». Неявное уравнение для давления в трещинах:

$$
\begin{aligned}
& \Delta x_{i j} \Delta y_{i j} \Delta z_{i j}\left(\phi_{f 0}\right)_{i j}\left(C_{r f}+C_{l}\right)\left[\left(P_{f}\right)_{i j}^{n+1}-\left(P_{f}\right)_{i j}^{n}\right]= \\
& =\Delta t^{n+1} B_{0}\left\{P I_{i j}^{n}\left[\left(P_{f}\right)_{i j}^{n+1}-\left(P_{w e l l}\right)_{i j}^{n+1}\right]-\right. \\
& -\left(T_{m f}\right)_{i j}^{n}\left[\left(P_{m}\right)_{i j}^{n+1}-\left(P_{f}\right)_{i j}^{n+1}\right]+ \\
& +\lambda_{i+0,5 j}^{n}\left(P_{i+1 j}^{n+1}-P_{i j}^{n+1}\right)-\lambda_{i-0,5 j}^{n}\left(P_{i j}^{n+1}-P_{i-1 j}^{n+1}\right)+ \\
& \left.+\lambda_{i j+0,5}^{n}\left(P_{i j+1}^{n+1}-P_{i j}^{n+1}\right)-\lambda_{i j-0,5}^{n}\left(P_{i j}^{n+1}-P_{i j-1}^{n+1}\right)\right\},
\end{aligned}
$$

где $\Delta t^{n+1}-$ переменный шаг по времени, определяемый в соответствии с рекомендациями [18] так, чтобы максимальное по всем блокам сетки изменение давления не превышало заданного значения (при расчетах отдельно задавалось предельное изменение давления в матрице и в трещинах),

$$
\begin{aligned}
& \lambda_{i+0,5 j}^{n}=\frac{\left(k_{f x}\right)_{i+0,5 j}}{\mu B_{i+0,5 j}^{n}} \cdot \frac{\Delta y_{i j} \Delta z_{i j}}{\Delta x_{i+0,5 j}}, \\
& \left(k_{f x}\right)_{i+0,5 j}=\frac{2\left(k_{f x}\right)_{i+1 j}\left(k_{f x}\right)_{i j}}{\left(k_{f x}\right)_{i+1 j}+\left(k_{f x}\right)_{i j}}, \\
& B_{i+0,5 j}^{n}=\frac{1}{2}\left\{B\left[\left(P_{f}\right)_{i+1 j}^{n}\right]+B\left[\left(P_{f}\right)_{i j}^{n}\right]\right\}, \\
& x_{i+0,5 j}=\frac{1}{2}\left(x_{i+1 j}+x_{i j}\right),
\end{aligned}
$$

аналогично для $\lambda_{i-0,5 j}^{n}, \lambda_{i j+0,5}^{n}$ и $\lambda_{i j-0,5}^{n}$.

Явное уравнение для давления в трещинах:

$$
\begin{aligned}
& \Delta x_{i j} \Delta y_{i j} \Delta z_{i j}\left(\phi_{f 0}\right)_{i j}\left(C_{r f}+C_{l}\right)\left[\left(P_{f}\right)_{i j}^{n+1}-\left(P_{f}\right)_{i j}^{n}\right]= \\
& =\Delta t^{n+1} B_{0}\left\{P I_{i j}^{n}\left[\left(P_{f}\right)_{i j}^{n+1}-\left(P_{w e l l}\right)_{i j}^{n+1}\right]-\right. \\
& -\left(T_{m f}\right)_{i j}^{n}\left[\left(P_{m}\right)_{i j}^{n+1}-\left(P_{f}\right)_{i j}^{n+1}\right]+ \\
& +\lambda_{i+0,5 j}^{n}\left(P_{i+1 j}^{n}-P_{i j}^{n}\right)-\lambda_{i-0,5 j}^{n}\left(P_{i j}^{n}-P_{i-1 j}^{n}\right)+ \\
& \left.+\lambda_{i j+0,5}^{n}\left(P_{i j+1}^{n}-P_{i j}^{n}\right)-\lambda_{i j-0,5}^{n}\left(P_{i j}^{n}-P_{i j-1}^{n}\right)\right\} .
\end{aligned}
$$

Название «классики» для разностной схемы связано со способом обхода расчетных точек [19]. На каждом шаге по времени $n+1$ обход точек пространственной сетки в одной (в нашем случае горизонтальной) плоскости совершается дважды. На первом и последующих шагах по времени с нечетным $n+1$ вычисляются значения давления в ячейках с нечетной суммой $i+j$. Этот первый обход осу- ществляется с помощью явной по давлению схемы. При втором обходе на том же шаге по времени вычисляют значения давления в ячейках с четной суммой $i+j$ с помощью неявной по давлению схемы, в соседних ячейках берутся значения давления, полученные на том же шаге по времени при первом обходе. На втором и последующих шагах по времени с четными $n+1$ роли узлов с четной и нечетной суммой $i+j$ меняются. Кратко это можно резюмировать так: при $i+j+n+1$ четном берется уравнение (12), а при нечетном - уравнение (11).

Запишем конечно-разностный аналог уравнения (10) для давления в пористой матрице:

$$
\begin{aligned}
& \Delta x_{i j} \Delta y_{i j} \Delta z_{i j}\left(\phi_{m 0}\right)_{i j}\left(C_{r m}+C_{l}\right)\left[\left(P_{m}\right)_{i j}^{n+1}-\left(P_{m}\right)_{i j}^{n}\right]= \\
& =-\Delta t^{n+1} B_{0}\left(T_{m f}\right)_{i j}^{n}\left[\left(P_{m}\right)_{i j}^{n+1}-\left(P_{f}\right)_{i j}^{n+1}\right] .
\end{aligned}
$$

Из (13) можно легко выразить давление в матрице на новом временном шаге $\left(P_{m}\right)_{i j}^{n+1}$ через давление в трещинах $\left(P_{f}\right)_{i j}^{n+1}$ :

$$
\begin{aligned}
& \left(P_{m}\right)_{i j}^{n+1}=\frac{\Delta x_{i j} \Delta y_{i j} \Delta z_{i j}\left(\phi_{m 0}\right)_{i j}\left(C_{r m}+C_{l}\right)\left(P_{m}\right)_{i j}^{n}}{\Delta x_{i j} \Delta y_{i j} \Delta z_{i j}\left(\phi_{m 0}\right)_{i j}\left(C_{r m}+C_{l}\right)+\Delta t^{n+1} B_{0}\left(T_{m f}\right)_{i j}^{n}}+ \\
& +\frac{\Delta t^{n+1} B_{0}\left(T_{m f}\right)_{i j}^{n}\left(P_{f}\right)_{i j}^{n+1}}{\Delta x_{i j} \Delta y_{i j} \Delta z_{i j}\left(\phi_{m 0}\right)_{i j}\left(C_{r m}+C_{l}\right)+\Delta t^{n+1} B_{0}\left(T_{m f}\right)_{i j}^{n}} \cdot(14)
\end{aligned}
$$

Подставляя (14) в (11) и (12), исключаем из них неизвестное давление в матрице на новом шаге по времени $\left(P_{m}\right)_{i j}^{n+1}$.

При расчете перетоков (7) для плоского случая 2D-геометрии будем считать $k_{f z}=\max \left\{k_{f x}, k_{f x}\right\}$, $k_{m z}=\alpha_{m z} \sqrt{k_{m x} k_{m x}}$, где $\alpha_{m z}-$ коэффициент вертикальной анизотропии проницаемости пористой матрицы.

\section{Решение обратной задачи}

Интерпретация гидродинамических исследований скважин сводится к совмещению расчетной и фактической кривых давления (или дебита) путем изменения параметров модели. Цель - получение наилучшего совмещения и определение параметров модели: фильтрационно-емкостных и (если такие есть) геометрических характеристик пласта. Таким образом, интерпретация гидродинамических исследований скважин сводится к обратной задаче, решаемой методами теории оптимизации. Рассмотрим один из методов решения такой задачи - метод Ньютона.

Пусть необходимо найти минимум функции многих переменных $f(X)$, где $X=\left(x_{1}, x_{2}, \ldots, x_{n}\right)$. В данном случае функция $f(X)$ - это невязка между расчетными и фактическими точками давления, замеренного на забое скважины. Эта задача эквива- 
лентна задаче нахождения значений $X$, при которых градиент функции $f(X)$ равен нулю:

$$
\operatorname{grad}(f(X))=0 .
$$

Применим к (15) метод Ньютона:

$$
\operatorname{grad}\left(f\left(X^{j}\right)\right)+H\left(X^{j}\right)\left(X^{j+1}-X^{j}\right)=0
$$

где $j=1,2,3, \ldots, m$ - номер итерации; $H(X)$ - гессиан функции $f(X)$.

Напомним, что гессиан функции - это симметричная квадратичная форма, описывающая поведение функции во втором порядке:

$$
H(X)=\sum_{i=1}^{n} \sum_{j=1}^{n} a_{i j} x_{i} x_{j}
$$

где $a_{i j}=\partial^{2} f / \partial x_{i} \partial x_{j}$; функция $f(X)$ задана на $n$-мерном пространстве вещественных чисел.

В более удобном для вычислений виде формулу (16) можно представить как

$$
X^{j+1}=X^{j}-H^{-1}\left(X^{j}\right) \operatorname{grad}\left(f\left(X^{j}\right)\right) .
$$

Метод Ньютона прост в реализации, но нахождение матрицы Гессе сопряжено с большими вычислительными затратами из-за необходимости нахождения большого количества частных производных. Однако ввиду некоторой простоты модели, принятой для решения прямой задачи, использование метода Ньютона вполне оправдано и дает приемлемое время счета.

\section{Пример интерпретации гидродинамических исследований межскважинного пространства трещиновато-пористого коллектора методом двух режимов с помощью описанной модели}

Для проверки описанной модели в качестве фактических данных будем использовать значения давления, полученные путем численного моделирования на сетке Вороного с помощью коммерческой программы для интерпретации гидродинамических исследований скважин и пластов Saphir компании Kappa Engineering [5].

Геометрия рассматриваемой модели и расстановка скважин приведены на рисунке 1. Модель содержит три скважины. Две добывающие (возмущающие) скважины по очереди исследуются методом двух режимов (путем однократного изменения режима работы, то есть дебита [3, 10-14]). В третьей (реагирующей) скважине фиксируется изменение забойного давления в результате работы первых двух скважин. Все время исследования составляет 30 суток. Одна возмущающая скважина эксплуатируется 10 суток с дебитом $300 \mathrm{~m}^{3} /$ сут., затем 20 суток с дебитом $100 \mathrm{~m}^{3} /$ сут. Другая возмущающая скважина эксплуатируется 20 суток с дебитом $300 \mathrm{~m}^{3} /$ сут., затем 10 суток с дебитом $100 \mathrm{~m}^{3} /$ сут.

Основные исходные данные для расчетов следующие:

- радиус скважины - 0,1 м;

- толщина пласта - 10 м;

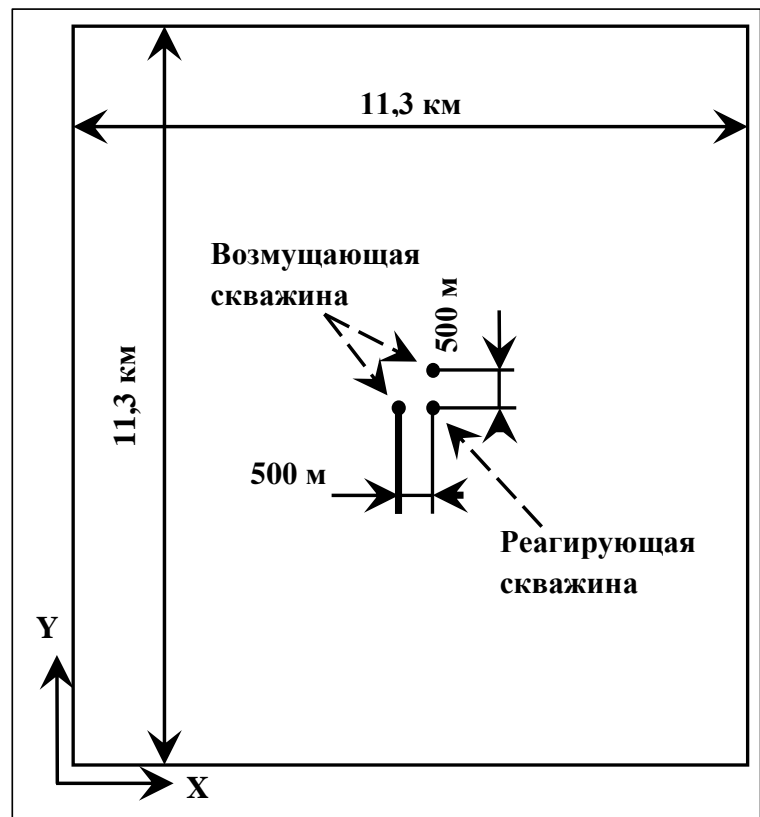

Рис. 1. Геометрия рассматриваемой модели и расстановка скважин

Fig. 1. Considered model geometry and well array

- расстояние между возмущающими и реагирующей скважинами - 500 м;

- объемный коэффициент - 1,1 м ${ }^{3} / \mathrm{M}^{3}$;

- вязкость - 1,3 мПа·с;

- общая сжимаемость - 4,3 $10^{-5} \mathrm{~cm}^{2} /$ кгс;

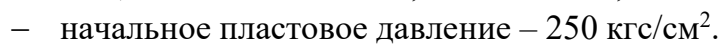

Тензор проницаемости трещиноватой породы диагональный. Проницаемость трещинной части пласта зависит от направления фильтрации. Оси расчетной сетки сориентированы по осям тензора проницаемости. Сетка неравномерная, размеры ячеек по оси X приведены на рисунке 2. По оси Y размеры ячеек аналогичны. Реагирующая скважина находится в ячейке с координатами $120-120$, которая имеет размеры $0,1 \times 0,1$ м. Поскольку по формуле (8) невозможно определить забойное давление при нулевом дебите, в качестве забойного давления в реагирующей скважине принято давление в ячейке, которую она занимает. Поэтому приняты столь малые размеры ячейки.

При интерпретации гидродинамических исследований трещиновато-пористых пластов используются следующие специфические параметры: $\lambda=\sigma r_{w}^{2} \frac{k_{m}}{k_{f}}, \omega=\frac{\left(h \phi C_{t}\right)_{f}}{\left(h \phi C_{t}\right)_{f}+\left(h \phi C_{t}\right)_{m}}$, где $\lambda$ - параметр, характеризующий перетоки между матрицей и трещинами; $\omega$ - отношение емкости трещин к общей емкости системы; $h$ - толщина пласта; $C_{t}-$ суммарная сжимаемость пласта и флюида $[1,2,4$, 15-17].

При этом из параметра перетоков $\lambda$ обычно определяют проницаемость матрицы $k_{m}$ либо фак- 


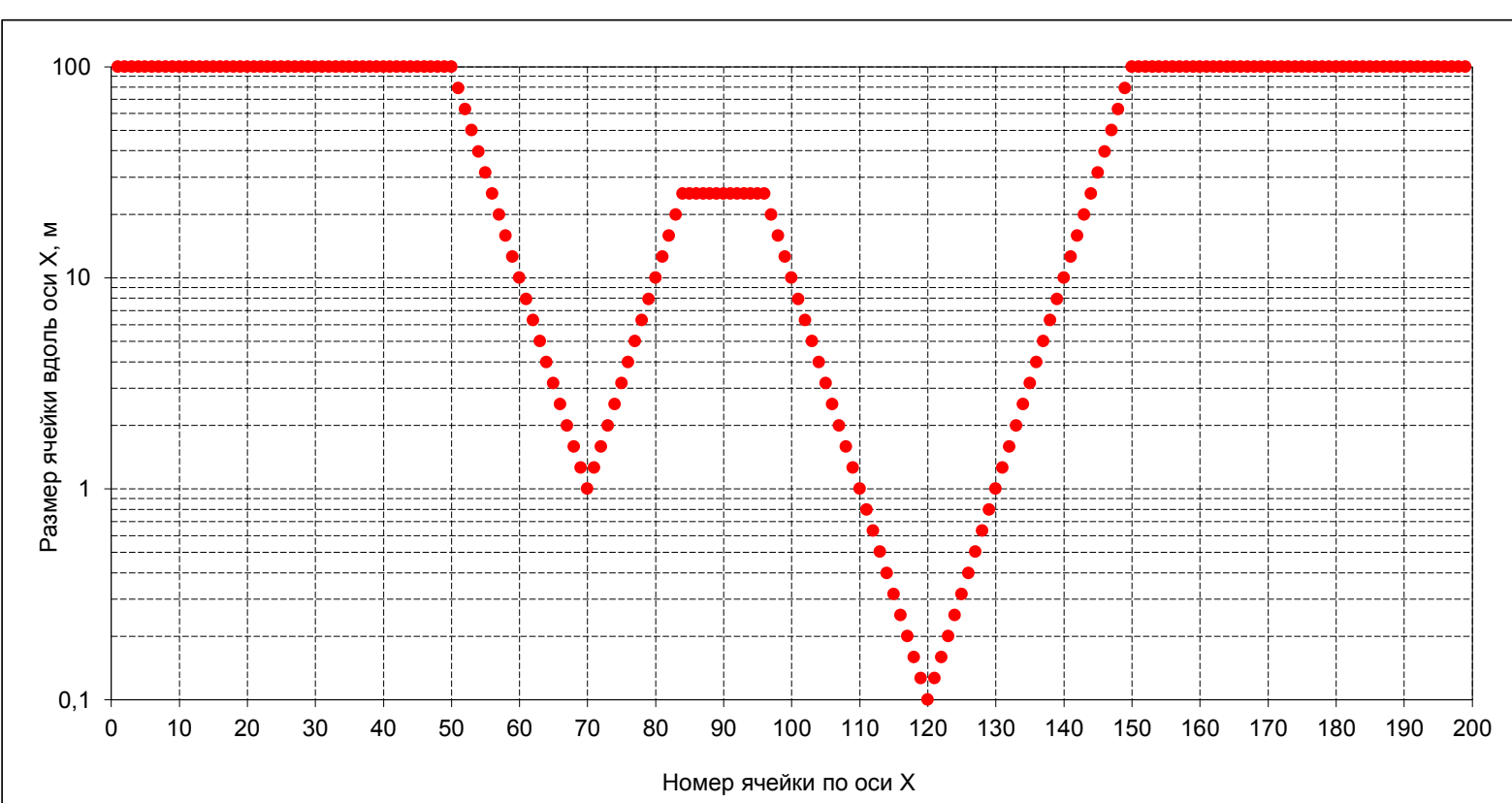

Рис. 2. Размеры ячеек вдоль оси X

Fig. 2. Cells dimensions along the $X$ axis

тор формы $\sigma$ (по которому судят о размерах блоков матрицы), а из отношения емкостей $\omega$ - пористость трещин $\phi_{f}$. Как правило, эти параметры имеют наибольшую степень неопределенности.

Рассмотрены три варианта интерпретации исследования с различным количеством уточняемых параметров.

1. Проницаемость трещин $k_{f}$, пористость матрицы $\phi_{m}$, отношение емкостей $\omega$, параметр перетоков $\lambda$, анизотропия проницаемости трещин по площади $\left(k_{x} / k_{y}\right)_{f}$.

2. Отношение емкостей $\omega$, параметр перетоков $\lambda$.

3. Проницаемость трещин $k_{f}$, пористость матрицы $\phi_{m}$, анизотропия проницаемости трещин по площади $\left(k_{x} / k_{y}\right)_{f}$.

Выбор уточняемых параметров обусловлен наибольшей неопределенностью в указанных параметрах, возникающей при анализе промысловых данных.

Результаты интерпретации приведены в таблице. Видно, что наилучшее качество уточнения дает третья группа параметров, а наихудшее - первая, чего и следовало ожидать, так как параметры $\omega$ и $\lambda$ незначительно влияют на показания давления в реагирующей скважине при больших временах $[1,16,17]$, а большое количество параметров (первая группа) почти всегда плохо поддается уточнению при решении обратных задач методами теории оптимизации.

В качестве примера на рисунке 3 приведены результаты интерпретации для первого начального приближения.

\section{Заключение}

Рассмотрен подход к интерпретации гидродинамических исследований межскважинного пространства трещиновато-пористых коллекторов методом двух режимов с помощью численных моделей. Приведена оригинальная конечно-разностная схема.

Рассмотрено несколько вариантов интерпретации для различных наборов уточняемых пара-

Начальное приближение и результаты интерпретации (уточненное приближение)

Initial guess and interpretation results (refined value)

\begin{tabular}{|l|l|l|l|l|l|l|l|}
\hline Параметр & Факт & Нач. прибл. 1 & $\begin{array}{c}\text { Уточн. нач. } \\
\text { прибл. 1 }\end{array}$ & $\begin{array}{c}\text { Нач. } \\
\text { прибл. 2 }\end{array}$ & $\begin{array}{c}\text { Уточн. нач. } \\
\text { прибл. 2 }\end{array}$ & $\begin{array}{c}\text { Нач. } \\
\text { прибл. 3 }\end{array}$ & $\begin{array}{c}\text { Уточн. нач. } \\
\text { прибл. 3 }\end{array}$ \\
\hline$k_{f}$ м мД & 350 & $\underline{\mathbf{1 5 0}}$ & $\underline{\mathbf{2 1 1}}$ & 350 & 350 & $\underline{\mathbf{1 5 0}}$ & $\underline{\mathbf{3 7 5}}$ \\
\hline$\phi_{m}$, д.ед. & 0,1 & $\underline{\mathbf{0 , 2}}$ & $\underline{\mathbf{0 , 0 8}}$ & 0,1 & 0,1 & $\underline{\mathbf{0 , 2}}$ & $\underline{\mathbf{0 , 0 9}}$ \\
\hline$\omega$, д.ед. & 0,1 & $\underline{\mathbf{0 , 3}}$ & $\underline{\mathbf{0 , 2 5}}$ & $\underline{\mathbf{0 , 3}}$ & $\underline{\mathbf{0 , 0 9}}$ & 0,1 & 0,1 \\
\hline$\lambda$, б/p & $1 \cdot 10^{-6}$ & $\underline{\mathbf{1 \cdot 1 0 ^ { - 5 }}}$ & $\underline{\underline{\mathbf{1 . 1 0}}}$ & $\underline{\mathbf{1 \cdot 1 0 ^ { - 5 }}}$ & $\underline{\mathbf{1 , 3 \cdot 1 0 ^ { - 6 }}}$ & $1 \cdot 10^{-6}$ & $1 \cdot 10^{-6}$ \\
\hline$\left(k_{x} / k_{y}\right)_{f}$, д.ед. & 0,1 & $\underline{\mathbf{0 , 5}}$ & $\underline{\mathbf{0 , 4 6}}$ & 0,1 & 0,1 & $\underline{\mathbf{0 , 5}}$ & $\underline{\mathbf{0 , 1 6}}$ \\
\hline
\end{tabular}

Примечание: подчеркиванием выделены уточняемые параметры. 


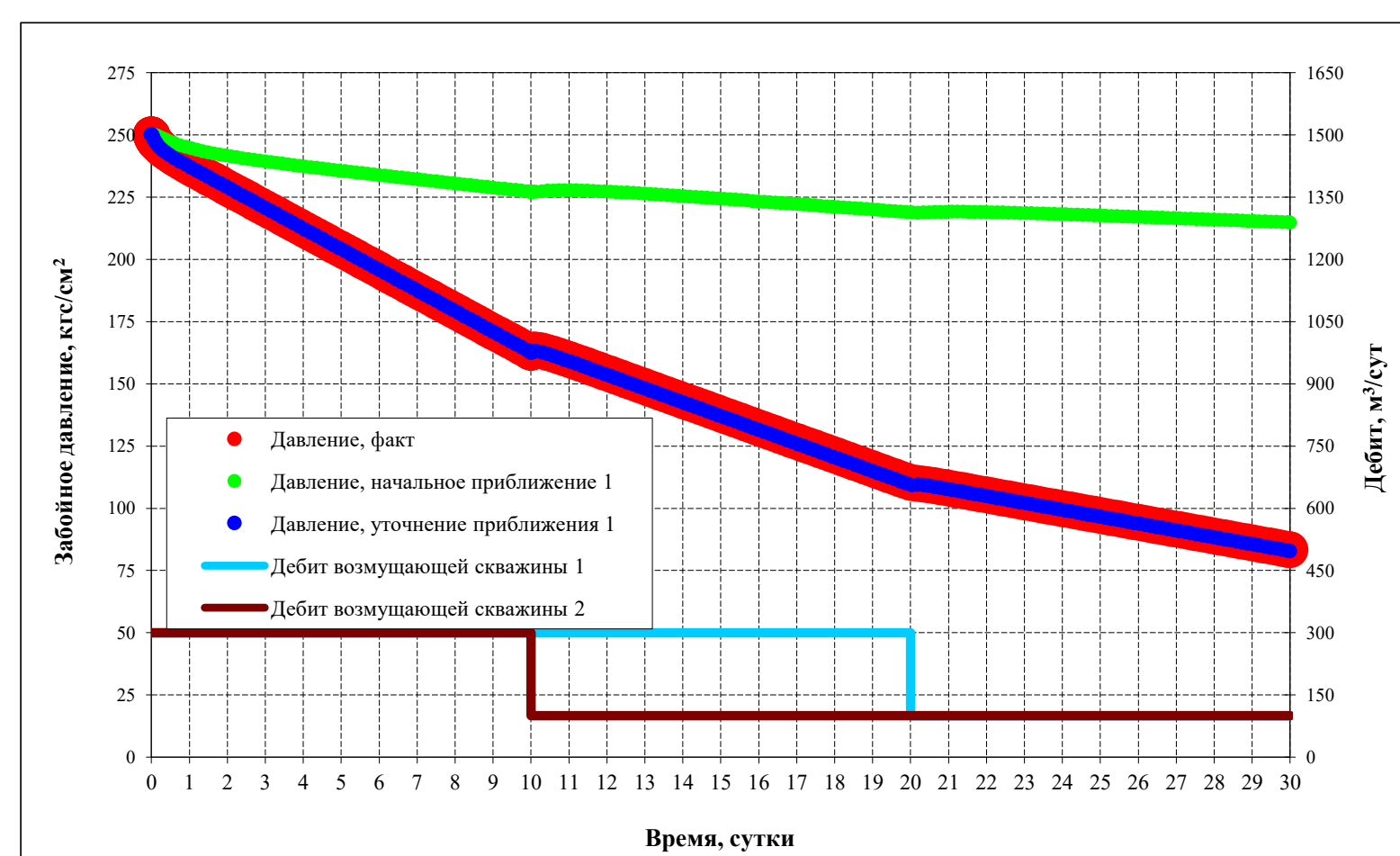

Рис. 3. Результаты интерпретациии для первого начального приближения

Fig. 3. Interpretation results for the first initial guess

метров. Подтверждено, что параметры $\omega$ (относительная емкость трещин) и $\lambda$ (параметр перетока матрица-трещины) мало влияют на показания давления в реагирующей скважине при больших временах.

Поэтому в качестве определяемых параметров рекомендуется выбирать проницаемость трещин, пористость матрицы и анизотропию проницаемости трещин по площади. Использовать в качестве определяемых параметров сразу все пять не рекомендуется.

Работа выполнена при поддержке Программы фундаментальных научных исследований государственных академий наук № I.2.П27, заказ № 18-0111 П, НИР № 0065-2018-0111.

\section{Лumepamypa}

1. Деева Т.А., Камартдинов М.Р., Кулагина Т.Е., Мангазеев П.В. Гидродинамические исследования скважин: анализ и интерпретация данных. Томск: Изд-во ЦППС НД ТПУ, 2009. $243 \mathrm{c}$.

2. Кульпин Л.Г., Мясников Ю.А. Гидродинамические методы исследования нефтегазоводоносных пластов. М.: Недра, 1974. $200 \mathrm{c}$

3. Эрлогер Р. мл. Гидродинамические методы исследования скважин. М.-Ижевск: Изд-во ИКИ, 2007. 512 с.

4. Bourdet D. Well Test analysis: the use of advanced interpretation models. Amsterdam: Elsevier Sc. B.V., 2002, 425 p.

5. Houze O., Viturat D., Fjaere O.S. Dynamic data analysis. V 5.12. Kappa Engineering, 2017, 743 p.

6. Vela S., McKinley R.M. How areal heterogeneities affects pulse-test results. Soc. Pet. Eng. J., 1970, no. 2, pp. 181-191.

7. Jahns Hans O. Rapid method for obtaining a two-dimen- sional reservoir description from well pressure response data. Soc. Pet. Eng. J., 1966, no. 4, pp. 315-327.

8. McKinley R.M., Vela S., Carlton L.A. A field application of pulse-testing for detailed reservoir description. JPT, 1968, vol. 20, no. 3 , pp. $313-321$.

9. Woods E.G. Pulse-test response of a two-zone reservoir. Soc. Pet. Eng. J., 1970, vol. 10, no. 3, pp. 245-256.

10. Афанаскин И.В., Вольпин С.Г., Ломакина О.В., Штейнберг Ю.М. Гидродинамические исследования вертикальных скважин в пластах с двумя границами методом двух режимов // Вестн. кибернетики. 2017. № 4. С. 45-54.

11. Афанаскин И.В., Вольпин С.Г., Штейнберг Ю.М., Ломакина О.В. Гидродинамические исследования горизонтальных скважин методом двух режимов // Вестн. кибернетики. 2017. № 2. C. $108-113$.

12. Афанаскин И.В., Крыганов П.В., Вольпин С.Г., Штейнберг Ю.М., Вольпин И.А. Изучение свойств нефтяных пластов с помощью гидродинамических исследований скважин методом двух режимов - теория, моделирование и практика // Вестн. кибернетики. 2015. № 3. С. 86-107.

13. Афанаскин И.В., Крыганов П.В., Вольпин С.Г., Штейнберг Ю.М., Вольпин И.А. Оценка фильтрационных и энергетических параметров нефтяных пластов с помощью гидродинамических исследований скважин на двух режимах: теория, моделирование и практика // Тр. НИИСИ РАН. 2015. Т. 5. № 1. C. $41-55$.

14. Russell D.G. Determination of formation characteristics from two rate flow test. JPT, 1963, vol. 15, pp. 1317-1355.

15. Бурде Д. Интерпретация результатов исследований скважин // Petroleum Engineering and Related Management Traning Gubkin Academy: матер. лекций. М., 1994. 109 с. (рус.).

16. Гольф-Рахт Т.Д. Основы нефтепромысловой геологии и разработки трещиноватых коллекторов. М.: Недра, 1986. 608 с.

17. Райс Л. Основы разработки трещиноватых коллекторов. М.-Ижевск: Из-во ИКИ, 2012. 118 с.

18. Азиз Х., Сеттари Э. Математическое моделирование пластовых систем. М.-Ижевск: Изд-во ИКИ, 2004. 416 с.

19. Роуч П. Вычислительная гидродинамика. М.: Мир, $1980.616 \mathrm{c}$. 


\title{
Carbonate reservoirs crosswell survey interpretation by a two-rate test using numerical models
}

\author{
I.V. Afanaskin ${ }^{1}$, Ph.D., Leading Researcher, ivan@afanaskin.ru \\ S.G.Volpin ${ }^{1}$, Ph.D., Head of Department, sergvolpin@gmail.com \\ O.V. Lomakina ${ }^{1}$, Researcher, ovllom@mail.ru \\ Yu.M. Shteynberg ${ }^{1}$, Head of Group, yurash22@gmail.com
}

${ }^{1}$ Federal State Institution "Scientific Research Institute for System Analysis of the Russian Academy of Sciences" (SRISA RAS), Moscow, 117218, Russian Federation

Abstract. The paper describes a two-rate well test method that is applied at transient flow. Due to recent development this method allows defining a set of parameters that is the as wide-spread pressure build up test. It is established that the method investigates few dozen meters area, rarely hundreds. The two-rate method doesn't require well shut-in, so oil output loss reduce during the research. A disadvantage of the method is that parameter calculation is not so precise.

The paper shows that at significant rate difference between two modes and sufficient second-rate longevity the two-rate method is a reasonable alternative to interference test. In this case, test area between wells increases to a hundreds of meters. The paper describes a dual-porosity mathematic model for crosswell carbonate fractured reservoir well test interpretation. This model is applicable for crosswell reservoir two-rate test data interpretation.

There is a "classic" original finite-difference calculation scheme for this model. The authors describe a reverse-problem subsurface hydrodynamic solution by Newton method. The method has been applied to synthetic downhole pressure curve with corresponding recommendations. Few interpretation variants presented for different reservoir parameters refinement. A relative fractured volume and matrix-fractures diffusivity coefficient have low influence on a tested well at late time pressure value. It is recommended to include fractures permeability, matrix porosity and area fractures anisotropy as defined parameters.

Keywords: well test, two-rate test, interference-test, dual-porosity model.

Acknowledgements. The article has been supported by the Program of Fundamental Scientific Research of State Academies of Sciences no. I.2.P27, Order no. 18-0111_P, Research no. 0065-2018-0111.

\section{References}

1. Deeva T.A., Kamartdinov M.R., Kulagina T.E., Mangazeev P.V. Well Test: Data Analysis and Interpretation. Tomsk, TsPPS ND TPU Publ., 2009, 243 p.

2. Kulpin L.G., Myasnikov Yu.A. Investigation of Oil and Gas Reservoirs by Hydrodynamic Methods. Moscow, Nedra Publ., 1974, $200 \mathrm{p}$

3. Erloger R. jr. Advances in Well Test Analysis. Moscow-Izhevsk, IKI Publ., 2007, 512 p.

4. Bourdet D. Well Test Analysis: The Use of Advanced Interpretation Models. Amsterdam, Elsevier Science B.V. Publ., 2002,425 p.

5. Houze O., Viturat D., Fjaere O.S. Dynamic Data Analysis. V 5.12. Kappa Engineering Publ., 2017, 743 p.

6. Vela Saul, McKinley R.M. How areal heterogeneities affects pulse-test results. Soc. Pet. Eng. J. 1970, pp. $181-191$.

7. Jahns Hans O. Rapid method for obtaining a two-dimensional reservoir description from well pressure response data. Soc. Pet. Eng. J. 1966, pp. 315-327.

8. McKinley R.M., Vela Saul, Carlton L.A. A field application of pulse-testing for detailed reservoir description. J. Pet. Tech. 1968, pp. 313-321.

9. Woods E.G. Pulse-test response of a two-zone reservoir. Soc. Pet. Eng. J. 1970, pp. 245-256.

10. Afanaskin I.V., Volpin S.G., Lomakina O.V., Shteynberg Yu.M. Two-rate tests of vertical wells in formations with two boundaries. Proc. in Cybernetics. 2017, no. 4, pp. 45-54 (in Russ.)

11. Afanaskin I.V., Volpin S.G., Shteynberg Yu.M., Lomakina O.V. Two-rate tests of horizontal wells. Proc. in Cybernetics. 2017, no. 2, pp. 108-113 (in Russ.).

12. Afanaskin I.V., Kryganov P.V., Volpin S.G., Shteynberg Yu.M., Volpin I.A. Oil-bearing formations characterization by two-rate well tests results - theory, modeling and practice. Proc. in Cybernetics. 2015, no. 3, pp. 86-107 (in Russ.).

13. Afanaskin I.V., Kryganov P.V., Volpin S.G., Shteynberg Yu.M., Volpin I.A. Evaluation of oil-bearing formation flow and energy parameters by two-rate well tests results - theory, modeling and practice. SRISA RAS Proc. 2015, vol. 5, no. 1, pp. 41-55 (in Russ.).

14. Russell D.G. Determination of formation characteristics from two rate flow test. J. Pet. Tech. 963, pp. 1347-1355.

15. Burde D. Interpretation of well test. Proc. Petroleum Engineering and Related Management Traning Gubkin Academy. Moscow, 1994, 109 p.

16. Golf-Rakht T.D. Fundamental of Fractured Reservoir Engineering. Moscow, Nedra Publ., 1986, 608 p

17. Rays L. Fundamentals of the Fractured Reservoirs Development. Moscow-Izhevsk, IKI Publ., 2012, 118 p.

18. Aziz Kh., Settari E. Petroleum Reservoir Simulation. Moscow-Izhevsk, IKI Publ., 2004, 416 p.

19. Rouch P. Computational Fluid Dynamics. Moscow, Mir Publ., 1980, 616 p. 


\title{
Подходы к идентификаиии сетевъх потоков и организаиии марирутов трафика в виртуальном иентре обработки данных на базе нейронной сети
}

\author{
И.П. Болодурина 1, д.т.н., профессор, зав.кафедрой, prmat@mail.osu.ru \\ Д.И. Парфенов ${ }^{1}$, к.т.н., начальник отдела, fdot_it@таil.osu.ru
}

1 Оренбургский государственный университет, г. Оренбург, 460018, Россия

Ежегодно растет трафик, циркулирующий в сетях передачи данных, и на сегодняшний день его основу составляет трафик Big Data. Целью данного исследования является разработка новых методов маршрутизации трафика в наложенных сетях виртуальных центров обработки данных. Эффективное построение маршрутов в современных компьютерных сетях, обрабатывающих большие потоки данных, является одним из важнейших показателей работы центров обработки данных.

Для решения данной задачи авторами разработан ансамбль моделей, описывающий подход к построению адаптивных маршрутов в наложенных сетях виртуального центра обработки данных. Новизна предлагаемого решения заключается в разработке гибридного подхода, позволяющего на основе методов интеллектуального анализа данных осуществлять управление маршрутизацией в сети виртуального центра обработки данных с учетом данных о состоянии сетевых узлов, наложенных каналов связи и требований QoS, предъявляемых потоками трафика.

Предложенная в работе модель идентификации маршрутов позволяет решать такие задачи, как определение порядка использования цепочек наложенных каналов связи в сети виртуального центра обработки данных и установление правил для обеспечения качества обслуживания для критически важного трафика. На базе построенных моделей реализовано программно-алгоритмическое решение, представляющее собой модуль для контроллера программноконфигурируемой сети.

Описанный в данной статье алгоритм позволяет получать наборы квазиоптимальных и оптимальных правил маршрутизации за полиномиальное время. Эффективность предложенного решения доказана путем экспериментального исследования с использованием реальной сетевой инфраструктуры виртуального центра обработки данных. Сопоставление результатов экспериментального исследования, проводившегося с использованием известных алгоритмов маршрутизации, показало не только сокращение времени отклика в сети, но и снижение нагрузки на сетевые узлы, обрабатывающие трафик.

Ключевые слова: маршрутизация трафика, нейронные сети, виртуальный ЦОД, Big Data, QoS.

В последние годы объем данных, которые требуется обрабатывать и анализировать, растет экспоненциально. Это обусловлено тем, что информация, раньше считавшаяся бесполезной, долго не хранилась и не обрабатывалась в автоматизированном режиме, в настоящий момент приобретает высокую ценность. Одним из примеров таких данных являются журналы доступа к информационным системам, события безопасности, возникающие в сегментах сети, и другие неструктурированные данные. На современном этапе развития информационных технологий появились средства, позволяющие хранить, обрабатывать и анализировать большие объемы данных в режиме реального времени. При этом с увеличением объема данных растет и интенсивность циркуляции трафика в инфокоммуникационных сетях. Таким образом, сегодня можно говорить о том, что основу современных конвергентных сетей составляет трафик Big Data.

Для эффективной работы с трафиком Big Data крупные коммерческие и государственные организации, в том числе промышленные предприятия, переносят свою ИТ-инфраструктуру в виртуальные центры обработки данных (ЦОД). При этом виртуализация компонентов ЦОД применяется как на прикладном уровне, так и на уровне сети. Важные бизнес-приложения и сервисы, а также обрабаты- ваемые ими данные размещаются на базе мультиоблачных платформ, а в качестве базового компонента для передачи данных в виртуальном ЦОД применяется программно-конфигурируемая сеть $[1,2]$. Такой подход позволяет обеспечить гибкое управление сетевыми ресурсами, а также дает возможность поддерживать необходимое качество обслуживания $(\mathrm{QoS})$ в соответствии с решаемыми конечными пользователями задачами. Однако, кроме трафика Big Data, в конвергентных сетях, как правило, присутствуют и другие типы потоков данных. При этом каждый поток данных обладает индивидуальными характеристиками, на базе которых определяются требования QoS [3]. Принимая во внимание перечисленные особенности мультисервисных сетей ЦОД, проблема обеспечения качества обслуживания для трафика Big Data становится особенно актуальной [4]. Одним из подходов, позволяющих решить данную задачу, является организация адаптивной маршрутизации трафика [5-7]. В контексте виртуальной инфраструктуры он означает управление потоками данных, циркулирующими в сети ЦОД, на уровне каналов связи.

Проблема организации эффективной маршрутизации в виртуальной сети, как правило, заключается в том, что на базе традиционного ЦОД развернуто несколько облачных платформ [8]. Каждая из 
таких платформ может использовать разные среды виртуализации с различными уровнями абстракции. В связи с этим потоки данных внутри ЦОД проходят через различные виртуальные интерфейсы, имеющие собственную задержку, что не позволяет оптимальным образом согласовывать потоки данных. Поэтому для эффективной маршрутизации трафика в виртуальном ЦОД необходимо разработать единую стратегию планирования маршрутов, которая не зависит от среды виртуализации и в то же время может обеспечить гарантированное качество обслуживания для циркулирующих потоков данных.

В рамках исследования сформулированы следующие требования в области маршрутизации трафика в программно-управляемой инфраструктуре виртуального ЦОД:

- поддержка многопутевой маршрутизации для обеспечения сбалансированного использования сети и повышения общего качества обслуживания;

- переход к моделям трафика, основанным на потоках и методах его маршрутизации;

- использование составных параметров, характеризующих каналы связи и позволяющих максимально учитывать требования к QoS в зависимости от класса идентифицированного трафика.

В настоящее время нет достаточно эффективных методов маршрутизации, адаптированных к потокам трафика Big Data в сети виртуального ЦОД [9]. Прежде всего это связано с проблемой идентификации конкретных приложений и сервисов в общем потоке трафика ЦОД. Существующие решения для идентификации потоков используют в качестве анализируемых параметров лишь незначительный ряд характеристик, например таких, как длина и заголовки сетевого пакета, IP-адрес источника и назначения, а также другие [10]. Это не позволяет достаточно точно идентифицировать приложения и сервисы, а значит, снижает эффективность решений, организующих управление маршрутизацией в сети.

Подобные проблемы наблюдаются также и у методов, используемых для организации традиционной маршрутизации. Существующие подходы не учитывают всю собираемую информацию о каналах связи. Так, важным фактором, влияющим на задержку, является время обработки трафика на сетевых узлах. Этот параметр напрямую зависит от загруженности интерфейсов и самого сетевого узла, обрабатывающего трафик, но при выборе маршрута он не учитывается.

Таким образом, в рамках исследования установлено, что существующие подходы к маршрутизации не учитывают состояние сетевых объектов, требования QoS, а также их коммуникационные схемы взаимодействия облачных приложений и сервисов, возникающие в процессе наложения виртуальных маршрутов на физические каналы связи.

\section{Методы и подходы}

При решении поставленной задачи по организации адаптивной маршрутизации трафика в сети виртуального ЦОД в настоящем исследовании предлагается использовать методы интеллектуального анализа данных и машинного обучения. Выбор методов обусловлен высокой эффективностью их работы с неструктурированными и динамически изменяющимися и непрерывно поступающими от различных источников (сетевого оборудования, виртуальных и физических вычислительных узлов) потоками данных. Кроме этого, предлагаемые методы способны осуществлять быстрый анализ данных в режиме реального времени. Такой подход позволяет с минимальной задержкой принимать управленческие решения по организации маршрутов трафика в программно-конфигурируемой сети, что, в свою очередь, напрямую влияет на эффективность работы всей инфраструктуры виртуального ЦОД.

Одним из основных аспектов в рамках предлагаемого подхода является решение задачи идентификации маршрутов в наложенной сети виртуального ЦОД. В процессе исследования осуществлена декомпозиция задачи идентификации маршрутов на две последовательно связанные между собой подзадачи. Первая направлена на классификацию каналов связи в виртуальном ЦОД по ряду признаков, характерных для всех наложенных сетей. На втором этапе на основе полученных данных выполняется кластеризация маршрутов в соответствии с требованиями к QoS, предъявляемыми текущими потоками трафика. Агрегированные данные объединяются с информацией о текущих потоках трафика и подаются на вход нейронной сети для принятия решения о выборе подходящего маршрута. Таким образом, решение поставленной задачи по организации адаптивной маршрутизации позволяет определять приоритеты при формировании полосы пропускания потоков трафика, а также устанавливать правила по управлению сетью ЦОД.

С технической и программной сторон для организации эффективного сбора данных о состоянии физических и наложенных каналов связи в сети виртуального ЦОД и анализа их использования в рамках исследования предложен гибридный подход, основанный на совместном применении технологии самоорганизующихся интеллектуальных программных агентов и виртуализации сетевых функций. Это позволяет не только эффективно собирать данные о состоянии каналов, но и предварительно обрабатывать данные непосредственно на сетевых узлах. В рамках предложенного подхода программные агенты обмениваются данными внутри группы о состоянии каналов и доступных маршрутах, а управляющий агент передает обработанную и проанализированную информацию в сжатом виде на контроллер сети. 
Такой подход сокращает накладные расходы на интеллектуальную инфраструктуру управления адаптивной маршрутизацией за счет двух ключевых факторов: объединение источников информации и узлов анализа в рамках одного объекта, что оптимизирует количество используемых вычислительных ресурсов; передача на контроллер сети уже обработанных данных, что сокращает объем технической информации, циркулирующей по сети ЦОД.

Таким образом, научная новизна предлагаемого решения заключается в разработке гибридного подхода, позволяющего на основе методов интеллектуального анализа данных управлять маршрутизацией в сети виртуального ЦОД с учетом данных о состоянии сетевых узлов, каналов связи, в том числе наложенных сетей, и требований QoS, предъявляемых потоками трафика.

\section{Модель идентификации каналов связи в наложенной сети виртуального ЦОД}

Модель идентификации каналов связи в наложенной сети является основой для организации адаптивной маршрутизации для облачных приложений и сервисов, расположенных в виртуальном ЦОД. Разработанная модель поэтапно идентифицирует все каналы связи путем решения задач классификации и кластеризации. Опишем каждый из перечисленных элементов.

Так, на этапе классификации наложенных каналов связи в рамках настоящего исследования предлагается использовать метод обучения без учителя. Это позволяет не только идентифицировать новые каналы, возникающие динамически в сети виртуального ЦОД, но и изменять принятую ранее классификацию в зависимости от текущей загруженности сетевых узлов и топологии наложенной сети. Кроме того, использование метода обучения без учителя не нуждается в начальной ручной разметке входных данных, он основывается только на подобии между классифицируемыми каналами связи.

Формально задача классификации наложенных каналов связи определяется следующим образом. Пусть дано множество каналов связи $N v=\left\{n v_{1}, \ldots\right.$, $\left.n v_{n}\right\}$, в котором каждый канал передачи данных $n v_{i}$ характеризуется множеством атрибутов $A=\left\{a_{1,1}\right.$, $\left.\ldots, a_{i, p}\right\}$, где $p$ - количество атрибутов. Прежде чем классифицировать каналы связи, важно установить их атрибуты. Количество атрибутов определим по результатам анализа свойств, влияющих на качество обслуживания, что также играет ключевую роль при выборе маршрута. В качестве атрибутов будем использовать следующий набор характеристик, позволяющих однозначно идентифицировать наложенный канал связи в виртуальном ЦОД: задержка канала, jitter, процент потери пакетов, пропускная способность, узлы агрегации канала (для каждого канала связи предусмотрены два узла агрегации: источник и назначение), текущая интенсивность потока передаваемых данных, используемые правила QoS. Для более точной идентификации каналов с целью построения оптимальных маршрутов можно использовать и другие статистические характеристики, определенные в Service Level Agreement (SLA), на базе которого в виртуальном ЦОД формируются требования к качеству обслуживания в сети. Определим также множество классов каналов связи $C=\left\{c_{1}, \ldots, c_{k}\right\}$. Тогда для решения задачи классификации необходимо определить такое отображение $f: N v \rightarrow C$, чтобы наложенный канал сети ЦОД $n v_{i}$ соответствовал только одному классу $c_{i}$. Количество классов может быть чрезмерно большим, поэтому осуществляется переход ко второму этапу задачи идентификации каналов связи - к кластеризации.

Цель кластеризации - построение оптимального разбиения объектов на группы, то есть разбиение $n$ классов на $C n$ кластеров. При этом для кластеризации объектов выбирается метрика подобия $d\left(k_{j}, k_{p}\right)$.

Формально задачу кластеризации каналов связи в сети ЦОД можно сформулировать следующим образом. Пусть даны множества наложенных каналов связи $N v=\left\{n v_{1}, \ldots, n v_{n}\right\}$ и желаемое количество кластеров $C n$. Требуется определить отображение $f: N v \rightarrow\left\{k_{1}, \ldots, k_{C n}\right\}$, такое, чтобы каждый из каналов связи был отнесен только к одному кластеру $k_{i}$, $1 \leq i \leq C n$, при условии, что $D=\bigcup_{j=1}^{C n} k_{j}$ и $k_{i} \cap k_{j}=$ $=\varnothing, \forall i \neq j$. Оптимальность проведенной кластеризации определим как требование минимизации среднеквадратичной ошибки разбиения.

\section{Модель организации маршрутов трафика}

Следующий этап решения задачи после идентификации каналов связи - определение оптимального маршрута для каждого класса трафика и генерация соответствующих правил на контроллер сети. Полученные из модели идентификации данные о каналах связи представим в виде графа, иллюстрирующего топологию наложенных сетей и позволяющего определить возможные маршруты для каждого класса согласно коммуникационной схеме взаимодействия облачных приложений и сервисов. В данном графе каждый узел представляет собой элемент сети, отвечающий за маршрутизацию и передачу данных, а ребра описывают сетевые соединения между ними. При этом веса ребер рассчитываются с использованием интегральной оценки на базе введенных ранее показателей, характеризующих каналы связи в сети ЦОД. Таким образом, на базе данного описания мы получаем полное представление о состоянии сети в виртуальном ЦОД. Сам граф можно представить в сле- 
дующем виде: $R D C=(V, E)$, где $V=N c \cup N d \cup N r$ обозначает множество вершин, включающих три типа сетевых объектов виртуального ЦОД, а именно $N c$ - множество вершин, задействованных при текущей маршрутизации трафика, $N d$ - множество сетевых объектов, задействованных при перестроении маршрутов трафика, $N r$ - узлы, не входящие в маршрут, достигающий заданного узла.

Для определения оптимальных маршрутов в рамках построенной модели будем использовать нейронные сети. Они легко работают в распределенных системах и позволяют распараллеливать процессы на множество узлов, снижая тем самым вычислительную нагрузку, а также подстраивать весовые коэффициенты, основываясь на исходных данных. Это помогает сделать выбор ключевых характеристик менее субъективным. Для поиска оптимального маршрута в настоящем исследовании предлагается использовать гибридную нейронную сеть, состоящую из самоорганизующейся сети Кохонена и многослойного персептрона. Преимуществом сети Кохонена является способность идентифицировать новые кластеры. Обученная сеть распознает кластеры в данных обучения и назначает все данные тому или иному из них. Если сеть затем встречает набор данных, который отличается от любого из известных образцов, он будет независимо определять новый кластер элементов. Струк- турная схема логики работы модели адаптивной маршрутизации показана на рисунке 1 .

В качестве исходных данных для построения карты Кохонена в части разбиения каналов связи на множества используются данные, полученные из модели идентификации каналов связи виртуального ЦОД. Каждый кластер формирует числовые показатели интенсивности потоков, проходящих через канал данного типа. Фактически отдельные элементы карты Кохонена представляют собой группу наложенных каналов связи, идентичных по своим характеристикам. Входной вектор для самоорганизующейся сети Кохонена содержит следующие компоненты: $x_{1}-$ узел назначения, $x_{2}-$ узел источника, $x_{3}-$ jitter, $x_{4}-$ пропускная способность канала, $x_{5}$ - процент потери пакетов, $x_{6}-$ загрузка источника, $x_{7}-$ количество переданных байтов по каналу, $x_{8}-$ загрузка узла назначения.

После кластеризации с использованием на самоорганизующейся сети Кохонена данные о потоке трафика, для которого необходимо осуществить поиск подходящего маршрута, и наложенных каналах связи ЦОД подаются на вход многослойного персептрона. Обученная поиску маршрутов нейронная сеть анализирует данные о состоянии сети виртуального ЦОД с учетом требований поступившего потока трафика. На выходе нейронной сети формируются два вектора. Первый вектор

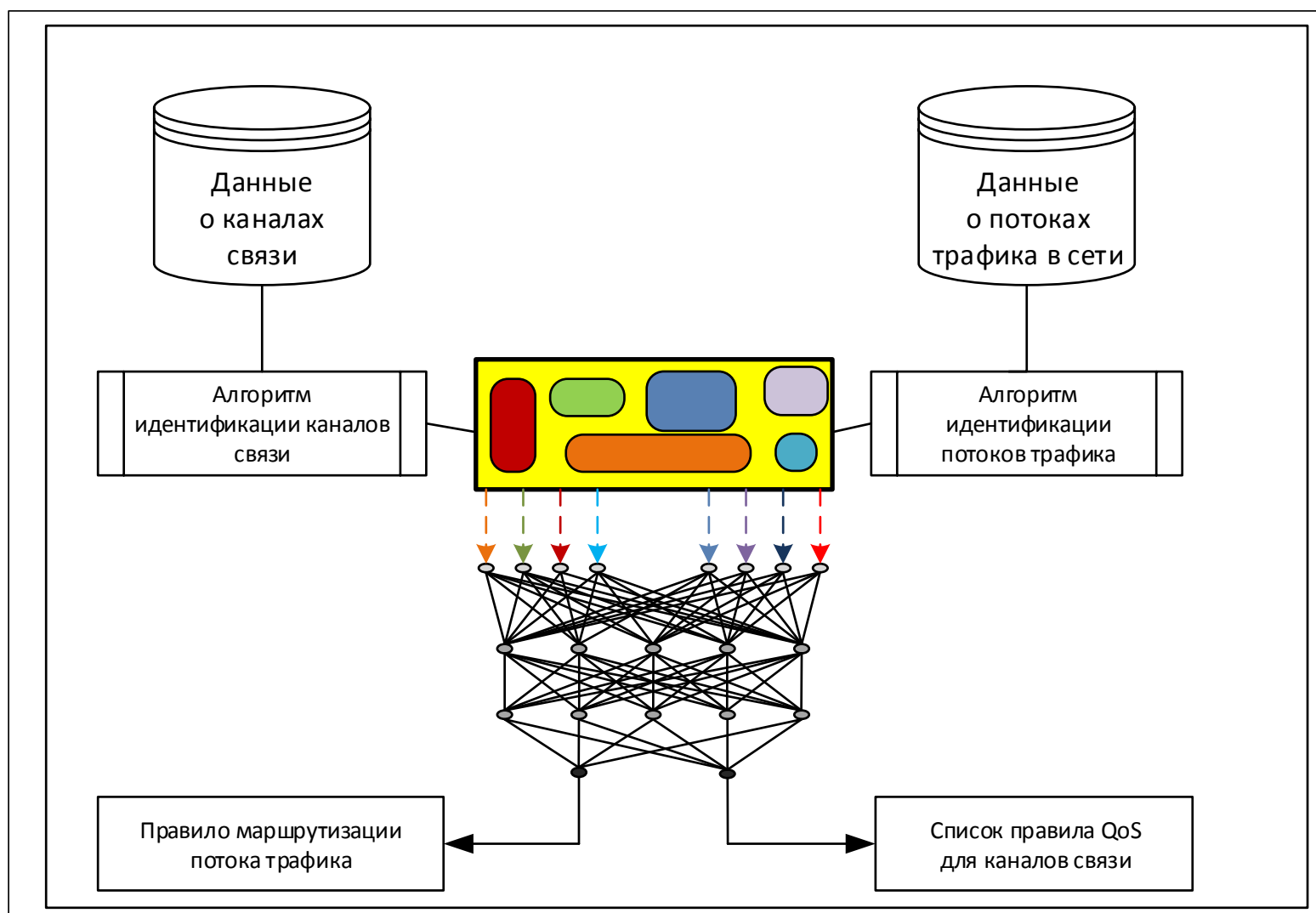

Рис. 1. Структурная схема логики работы модели адаптивной маршрутизации

Fig. 1. Structural diagram of the adaptive routing model logic 
формирует правила для маршрутизации трафика, передаваемые на контроллер, второй - список правил QoS для каналов связи, попавших в маршрут для текущего потока трафика.

\section{Программно-алгоритмическая реализация адаптивной маршрутизации}

На базе разработанных моделей спроектирован модуль адаптивной маршрутизации, позволяющий оптимизировать потоки трафика в сети виртуального ЦОД. Схема логики взаимодействия функциональных элементов модуля представлена на рисунке 2.

Разработанный модуль в своей работе использует приведенный далее обобщенный алгоритм выбора маршрутов для потоков трафика, циркулирующих по наложенным сетям внутри виртуального ЦОД

Шаг 1. Идентификация наложенных сетей виртуального ЦОД путем классификации по характерным признакам, представленным в модели канала связи.

Шаг 2. На основе полученных данных кластеризация каналов по признакам QoS с использованием самоорганизующейся карты Кохонена.

Шаг 3. На основе данных о текущем потоке трафика поиск оптимального маршрута, удовлетворяющего требованиям QoS и SLA, с использованием нейронной сети.

Шаг 4. Если найдены подходящие маршруты, ранжирование по признаку загруженности каналов и сетевых устройств.
Шаг 4.1. Для наименее нагруженного маршрута внесение правил через контроллер программноконфигурируемой сети для текущего потока трафика.

Шаг 5. Если маршрут не найден, поиск наименее нагруженной цепочки каналов среди всех имеющихся наложенных каналов до узла назначения.

Шаг 5.1. Оценка возможностей принятия трафика найденной цепочкой наложенных каналов.

Шаг 5.2. Если канал не удовлетворяет одному из условий, полное освобождение его от другого трафика, используя шаги 1-4.

Шаг 6. Применение к цепочке каналов политики QoS на контроллере программно-конфигурируемой сети и маршрутизация текущего потока через него.

Таким образом, основной задачей разработанного программно-алгоритмического решения является поиск оптимальных маршрутов, проходящих через наименее нагруженные узлы, позволяющие максимизировать производительность работы сети с учетом существующих потоков приложений и сервисов и их требований к задержкам, возникающим в процессе работы в виртуальном ЦОД.

\section{Экспериментальное исследование}

Исследование работы модуля адаптивной маршрутизации для контроллера сети виртуального ЦОД выполнялось на базе лаборатории облачных вычислений Оренбургского государственного университета. В качестве экспериментального

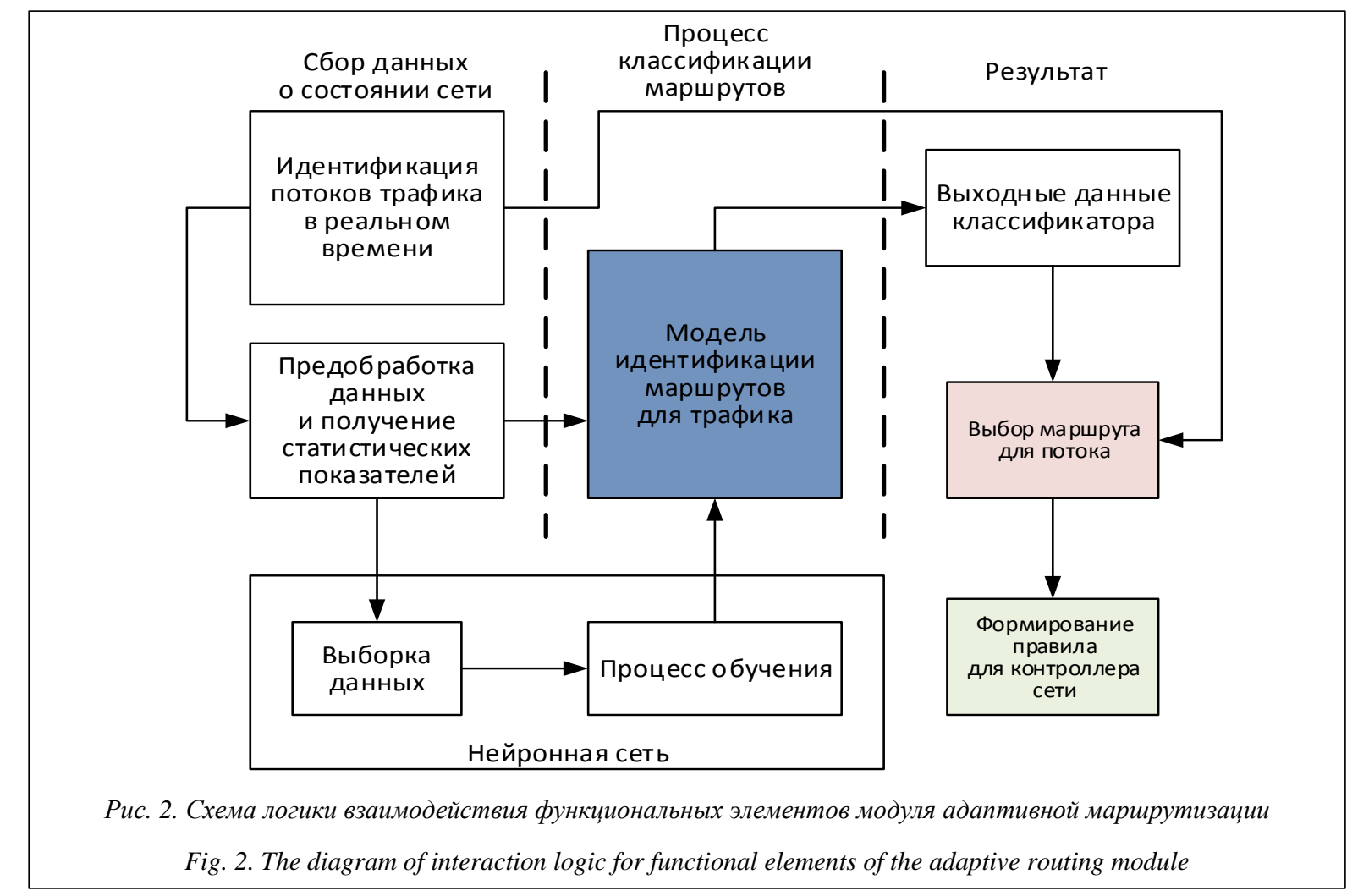




\section{Результаты экспериментального исследования}

The results of the experimental study

\begin{tabular}{|l|l|l|l|l|l|l|l|l|}
\hline \multirow{2}{*}{$\begin{array}{c}\text { Алгоритм } \\
\text { сетевой маршрутизации }\end{array}$} & \multicolumn{1}{|c|}{ Измеряемый параметр } & \multicolumn{5}{|c|}{ Число сетевых объектов ЦОД } \\
\cline { 3 - 9 } & & $\mathbf{1 0}$ & $\mathbf{2 5}$ & $\mathbf{5 0}$ & $\mathbf{1 0 0}$ & $\mathbf{2 5 0}$ & $\mathbf{5 0 0}$ & $\mathbf{1 0 0 0}$ \\
\hline \multirow{2}{*}{ Алгоритм Дейкстры } & Ресурсоемкость & 75 & 680 & 2160 & 8450 & 13250 & 17850 & 340500 \\
\cline { 2 - 9 } & Время отклика сети, мс & 0.129 & 0.193 & 0.250 & 3.579 & 5.629 & 23.378 & 46.507 \\
\hline \multirow{2}{*}{ Алгоритм Йена } & Ресурсоемкость & 146 & 1104 & 1802 & 7230 & 12119 & 15214 & 113815 \\
\cline { 2 - 9 } & Время отклика сети, мс & 0.033 & 0.120 & 0.237 & 0.592 & 1.784 & 6.105 & 25.542 \\
\hline \multirow{2}{*}{$\begin{array}{l}\text { Алгоритм адаптивной } \\
\text { маршрутизации }\end{array}$} & Ресурсоемкость & 25 & 90 & 450 & 680 & 890 & 1250 & 3400 \\
\cline { 2 - 9 } & Время отклика сети, мс & 0.016 & 0.046 & 0.078 & 0.260 & 0.355 & 4.503 & 15.538 \\
\hline
\end{tabular}

стенда использовалась сеть, состоящая из аппаратных OpenFlow-коммутаторов, виртуальных машин под управлением Linux с головным контроллером NOX. Для оценки устойчивости работы с потоками трафика, ориентированными на Big Data, проведен ряд экспериментальных исследований с последовательным увеличением числа сетевых объектов ЦОД от 10 до 1 000. Для создания наложенных сетей с таким количеством устройств использовались функциональные возможности виртуальных сетевых функций, позволяющих на базе среды виртуализации запускать программные аналоги физических узлов. Для этого на экспериментальном стенде использовались десять вычислительных узлов, на каждом из которых создавались от 10 до 100 сетевых объектов с использованием технологии виртуализации сетевых функций и среды эмуляции Mininet. В таблице представлены результаты исследования в сравнении с двумя наиболее известными алгоритмами маршрутизации трафика классическим алгоритм Дейкстры и алгоритмом, применяемым для многопутевой маршрутизации (алгоритм Йена).

Исследования показали, что предлагаемое программно-алгоритмическое решение позволяет не только снизить ресурсоемкость маршрутизации при значительном количестве устройств, но и сократить время отклика в сети по сравнению с традиционно используемыми алгоритмами.

\section{Заключение}

Таким образом, в настоящем исследовании предложено решение, основанное на ансамбле моделей, включающем в себя модель идентификации каналов связи в наложенной сети виртуального ЦОД и модель организации маршрутов трафика. Представленные решения оформлены в виде алгоритма и реализованы в виде модуля адаптивной маршрутизации для программно конфигурируемой сети. Разработанное в рамках исследования программное средство позволяет улучшить время отклика на $25 \%$ - один из ключевых показателей, влияющих на качество обслуживания в сети ЦОД. В сравнении с известными алгоритмами маршрути- зации предлагаемое программно-алгоритмическое решение обладает меньшей ресурсоемкостью, что также снижает накладные расходы на сетевую инфраструктуру.

Работа выполнена при поддержке РФФИ (научные проекты №№ 16-07-01004 и 16-37-60086) и гранта Президента Российской Федерации для государственной поддержки молодых российских ученых - кандидатов наук (МК-1624.2017.9).

\section{Литература}

1. Решетников В.Н., Болодурина И.П., Парфенов Д.И. Моделирование размещения сервис-ориентированных приложений в программно-управляемой инфраструктуре виртуального центра обработки данных // Программные продукты и системы. 2016. № 4. C. 15-22.

2. Herguner K., Kalan R.S., Cetinkaya C., Sayit M. Towards QoS-aware routing for DASH utilizing MPTCP over SDN. Proc. IEEE Conf. NFV-SDN, 2017, pp. 1-6.

3. Kim T.H., Kim S., Lee K.Y., Park S.Y. A QoS assured network service chaining algorithm in network function virtualization architecture. Proc. 15th IEEE/ACM Intern. Sympos. on Cluster, Cloud and Grid Computing, 2015, pp. 1221-1224.

4. Yisheng L., Yanjie D.,Wenwen K., Zhengxi L., Fei-Yue W. Traffic flow prediction with big data: a deep learning approach. Proc. IEEE Transactions on Intelligent Transportation Systems, 2015, vol. 16 , no. 2, pp. 865-873.

5. Chemeritsky E., Smelansky R. On QoS management in SDN by multipath routing. Proc. 1st Intern. Sc. and Tech. Conf. (Modern Networking Technologies), 2014, pp. 1-6.

6. Tomovic S., Radusinovic I., Prasad N. Performance comparison of QoS routing algorithms applicable to large-scale SDN networks. Proc. Intern. Conf. on Computer as a Tool, EUROCON-2015, 2015, pp. 1-6.

7. Layuan L., Chunlin L. A QoS multicast routing protocol for dynamic group topology. Information Sciences, 2005, vol. 169, no. $1-2$, pp. $113-130$.

8. Носков А.Н., Манов И.А. Разработка механизма адаптивной маршрутизации трафика в программно-конфигурируемых сетях // Моделирование и анализ информационных систем. 2015. Вып. 22. С. 521-532.

9. Bolodurina I.P., Parfenov D.I. Dynamic routing algorithms and methods for controlling traffic flows of cloud applications and services. Bulletin of the South Ural State Univ. Series: Computational Mathematics and Software Engineering. 2017. vol. 6, no. 2. pp. 84-98.

10. Шелухин О.И., Симонян А.Г., Ванюшина А.В. Влияние структуры обучающей выборки на эффективность классификации приложений трафика методами машинного обучения // T-СОММ: Телекоммуникации и транспорт. 2017. Вып. 11. C. $25-31$. 


\title{
The approaches to identification of network flows and organization of traffic routes in a virtual data center based on a neural network
}

I.P. Bolodurina ${ }^{1}$, Dr.Sc. (Engineering), Professor, Head of Chair, prmat@mail.osu.ru D.I.Parfenov ${ }^{1}$, Ph.D. (Engineering),Head of Department,fdot_it@mail.osu.ru

${ }^{1}$ Orenburg State University, Orenburg, 460018, Russian Federation

\begin{abstract}
Every year traffic in data transmission networks grows. Currently, their basis is Big Data traffic. The purpose of this study is to develop new methods for routing traffic in superimposed networks of virtual data centers. The effective construction of routes in modern computer networks that process Big Data flows is one of the most important indicators of the operation of data centers.

In order to solve this problem, the authors developed an ensemble of models describing the approach to constructing adaptive routes in superimposed networks of a virtual data center. The novelty of the proposed solution is to develop a hybrid approach that allows (based on methods of data mining) managing routing in a virtual data center network, taking into account data on the status of network nodes, superimposed communication channels and QoS requirements imposed by traffic flows.

The proposed route identification model allows solving such problems as determining the order of using chains of superimposed communication channels in a virtual data center network and establishing rules for providing quality of service for mission-critical traffic. A software-algorithmic solution is implemented based on the built models. It is a module for a controller of a software-configurable network.

The algorithm described in the paper allows obtaining sets of quasi-optimal and optimal routing rules in polynomial time. The effectiveness of the proposed solution is proved by experimental research using a real network infrastructure of a virtual data center. Comparison of the results of an experimental study carried out using known routing algorithms showed a reduction in response time in the network, as well as a reduction in the load on network nodes processing traffic.
\end{abstract}

Keywords: traffic routing, neural networks, virtual data center, Big Data, QoS.

Acknowledgements. The work has been supported by the Russian Fondation for Basic Research (scientific projects no. 16-07-01004 and 16-37-60086) and a grant of the President of the Russian Federation for state support of young Russian scientists who are candidates of science (MK-1624.2017.9).

\section{References}

1. Reshetnikov V.N., Bolodurina I.P., Parfenov D.I. Modeling of placing service-oriented applications in a softwaredefined infrastructure of the virtual data center. Software \& Systems. 2016, vol. 4, pp. 15-22 (in Russ.).

2. Herguner K., Kalan R.S., Cetinkaya C., Sayit M. Towards QoS-aware Routing for DASH Utilizing MPTCP over SDN. IEEE Conf. on NFV-SDN. 2017, pp. 1-6.

3. Kim T.H., Kim S., Lee K.Y., Park S.Y. A QoS assured network service chaining algorithm in network function virtualization architecture. Proc. 15th IEEE/ACM Intern. Symp. on Cluster, Cloud and Grid Computing. 2015, pp. 1221-1224.

4. Yisheng L., Yanjie D.,Wenwen K., Zhengxi L., Fei-Yue W. Traffic flow prediction with big data: a deep learning approach. IEEE Trans. on Intelligent Transportation Systems. 2015, vol. 16, no. 2, pp. 865-873.

5. Chemeritsky E., Smelansky R. On QoS management in SDN by multipath routing. Proc. 1st Intern. Sci. and Tech. Conf. (Modern Networking Technologies). 2014, pp. 1-6.

6. Tomovic S., Radusinovic I., Prasad N. Performance comparison of QoS routing algorithms applicable to large-scale SDN networks. Intern. Conf. on Computer as a Tool (EUROCON). 2015, pp. 1-6.

7. Layuan L., Chunlin L. A QoS multicast routing protocol for dynamic group topology. Information Sciences. 2005, vol. 169 , no. 1-2, pp. 113-130.

8. Noskov A.N., Manov I.A. Development of an adaptive routing mechanism in software-defined networks. Modeling and Analysis of Information Systems. 2015, vol. 22, no. 4, pp. 521-532 (in Russ.).

9. Bolodurina I.P., Parfenov D.I. Dynamic Routing Algorithms and Methods for Controlling traffic Flows of Cloud Applications and Services. Bulletin of the South Ural State Univ. Ser. Computational Mathematics and Software Engineering. 2017, vol. 6, no. 2, pp. 84-98.

10. Shelukhin O.I., Simonyan A.G., Vanyushina A.V. Influence of training sample structure on traffic application efficiency classification using machine-learning methods. T-Comm. 2017, vol. 11, no. 2, pp. 25-31 (in Russ.). 


\title{
Алгоритмическое обеспечение обработки даннъх проиесса структурирования эластомерного композита с иелью решения задачи управления
}

\author{
A.C. Кузнеиов 1, к.т.н., старший преподаватель, askuznetsov@mitht.ru \\ В.Ф. Корнюшко 1, д.m.н., nрофессор,vfk256@mail.ru
}

${ }_{1}^{1}$ Московский технологический университет (МИРЭА), г. Москва, 119454, Россия

Структурирование является важнейшим этапом переработки многокомпонентного эластомерного материала в готовый продукт - изделие с заданным на этапе рецептуростроения комплексом эксплуатационных свойств. Оно представляет собой сочетание двух процессов - химического взаимодействия различных компонентов, входящих в его состав, а также технологического процесса закрепления требуемых свойств и функций будущего изделия. Для успешного протекания данной финальной технологической процедуры необходим строгий контроль за соблюдением заданной последовательности всех технологических стадий и подготовительных операций, в процессе которых получается полуфабрикат - промежуточный продукт. Повышению качества готового продукта в значительной степени способствует применение методов экспресс-контроля на основе виброреометрии для оценки характеристик исходного сырья, а также параметров полуфабриката и готовой продукции.

В работе рассматриваются химико-технологические процессы смешения и структурирования многокомпонентных эластомерных композитов как составляющие химико-технологической системы. Предложено алгоритмическое обеспечение обработки данных виброреометрии с целью повышения эффективности управления сложными химико-технологическими процессами смешения и структурирования многокомпонентных эластомерных композитов.

Построена процессная модель управления структурированием эластомерных композиционных систем. Выделены четыре группы процессов, отвечающих за показатели качества структурирования. Построены блок-схемы алгоритмов управления сложными химико-технологическими процессами смешения и структурирования эластомерных систем. Приведены приемы обработки основной реометрической информации с использованием современных программных продуктов. Показаны приемы визуализации реометрических данных в программах Table curve $2 \mathrm{~d}$ и Table curve $3 \mathrm{~d}$.

Построены пространственные изображения в виде поверхностей отклика для основных рецептурно-технологических факторов и показателей качества процесса, приведен алгоритм расчета коэффициентов математических моделей. Построен набор диаграмм состав-свойство, наглядно характеризующих влияние изменения уровней рецептурно-технологических факторов на кинетику процесса структурирования.

Показано, что визуализация реометрических данных с применением современных программных продуктов предоставляет возможности для более гибкого и адаптивного управления процессом структурирования многокомпонентных эластомерных композитов.

Ключевые слова: алгоритмическое обеспечение, процесс структурирования, управление процессом структурирования, эластомерный композит, визуализация реометрических данных.

Получению готового продукта - изделия из многокомпонентного эластомерного композита с комплексом заданных свойств - предшествует большое количество подготовительных операций и технологических стадий, наиболее сложными из которых с точки зрения организации управления являются смешение и структурирование эластомерных систем [1].

Известно, что возмущения, приводящие к отклонению параметров качества, являются рецептурно-технологическим фактором [2, 3].

Цель данной работы - разработка алгоритмов обработки данных виброреометрии для построения математических моделей и визуализации результатов, что позволяет повысить эффективность и качество управления сложными химико-технологическими процессами структурирования многокомпонентных эластомерных композитов.

Для описания основных процессов производства продукции из эластомерных композитов была построена процессная модель управления структурированием эластомерных систем (рис. 1).
Для операций смешения и структурирования многокомпонентных эластомерных композитов предложены алгоритмы управления, которые в виде блок-схем представлены на рисунках 2 и 3.

На стадии смешения контролируются следующие параметры: пластичность каучука и смеси, температура смеси, время смешения, порядок введения ингредиентов. Данные параметры установлены в паспортах смеси и каучука. Для накопления статистической информации по работе со смесью предусмотрено занесение всех параметров и характеристик в информационную БД. При несовпадении показателей полуфабриката с заданными осуществляется доработка смеси до заданных величин или снижение ее класса вплоть до забраковки [4].

На стадию структурирования попадает только полуфабрикат, отвечающий всем показателям качества. Параметрами переработки смеси в изделие являются температура процесса структурирования, время обработки и давление среды.

После получения готового изделия осуществляются испытания на уровень оценки физико-меха- 


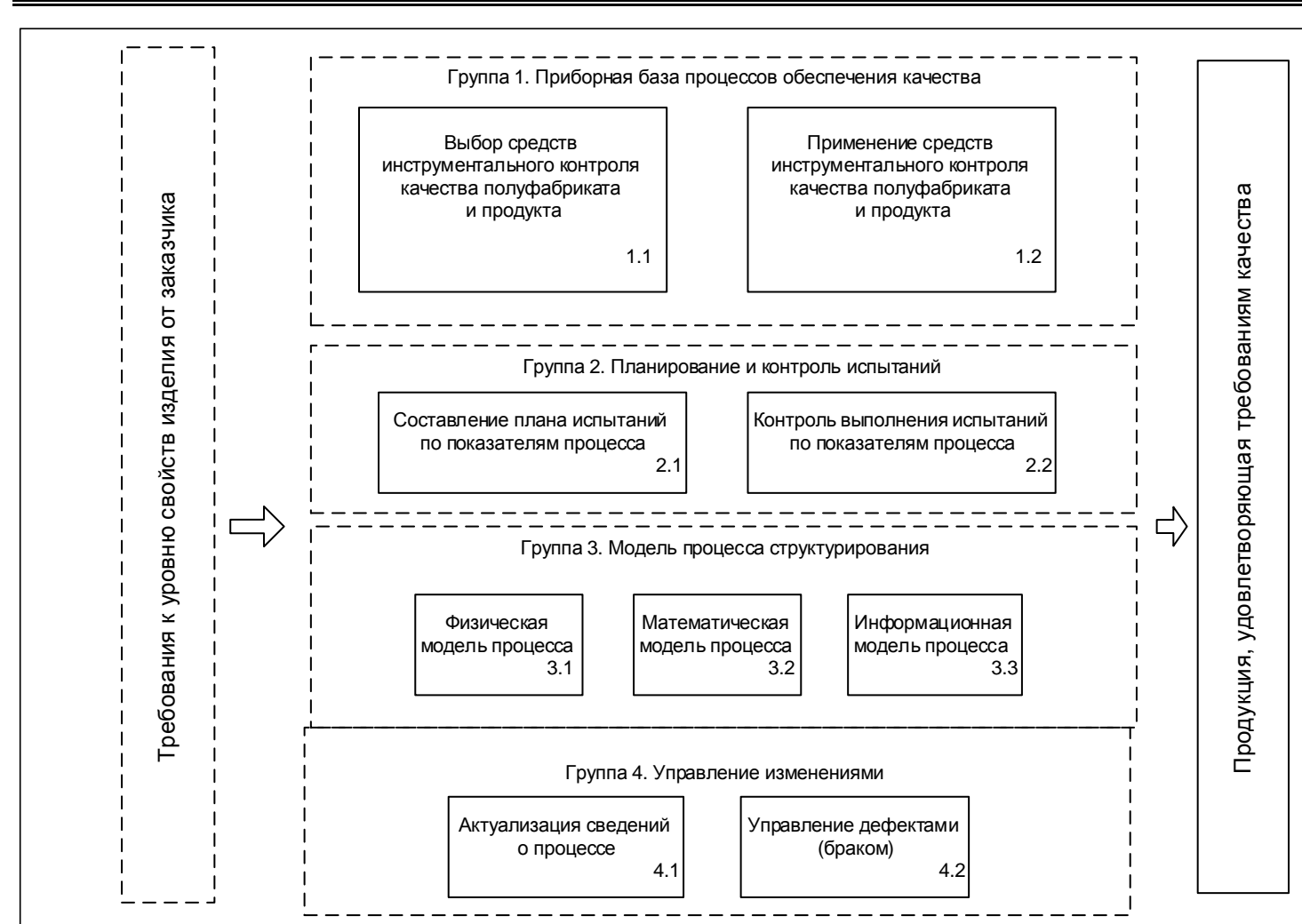

Рис. 1. Процессная модель управления структурированием эластомерных систем

Fig. 1. A process control model for structuring elastomeric systems

нических эластических свойств, а также таких эксплуатационных свойств, как твердость и истираемость.

В результате выполнения алгоритма текущие показатели процесса сравниваются со стандартными, в случае отклонения происходит их корректировка путем доработки смеси или рецептуры.

Путем контроля и управления качеством проведения промежуточных стадий и стадий получения готовой продукции можно добиться более строгого соответствия показателей полуфабриката и готового продукта нормам, установленным в паспорте изделия и карте смеси.

В ходе процессов смешения и структурирования многокомпонентных эластомерных композитов, кроме контроля основных параметров управления процессом, целесообразно анализировать графические зависимости, отражающие основные характеристики процесса [2, 5]. Использование приемов визуализации основных данных процесса структурирования позволяет более наглядно рассмотреть зависимости между данными величинами и организовать оперативное управление процессом. Для визуализации данных реометрии предложено использовать современные программные продукты - комплексы программ Table curve $2 \mathrm{~d}$ и 3d, а также Matlab 2010.

Программа Table curve 2d предназначена для построения двухмерных графиков. Ввод данных осуществляется в двух режимах: импорт из файла с использованием стандартной кодировки ASCII и ручной ввод в режиме Editor (cм. http://www.swsys. ru/uploaded/image/2018-3/2018-3-dop/22.jpg).

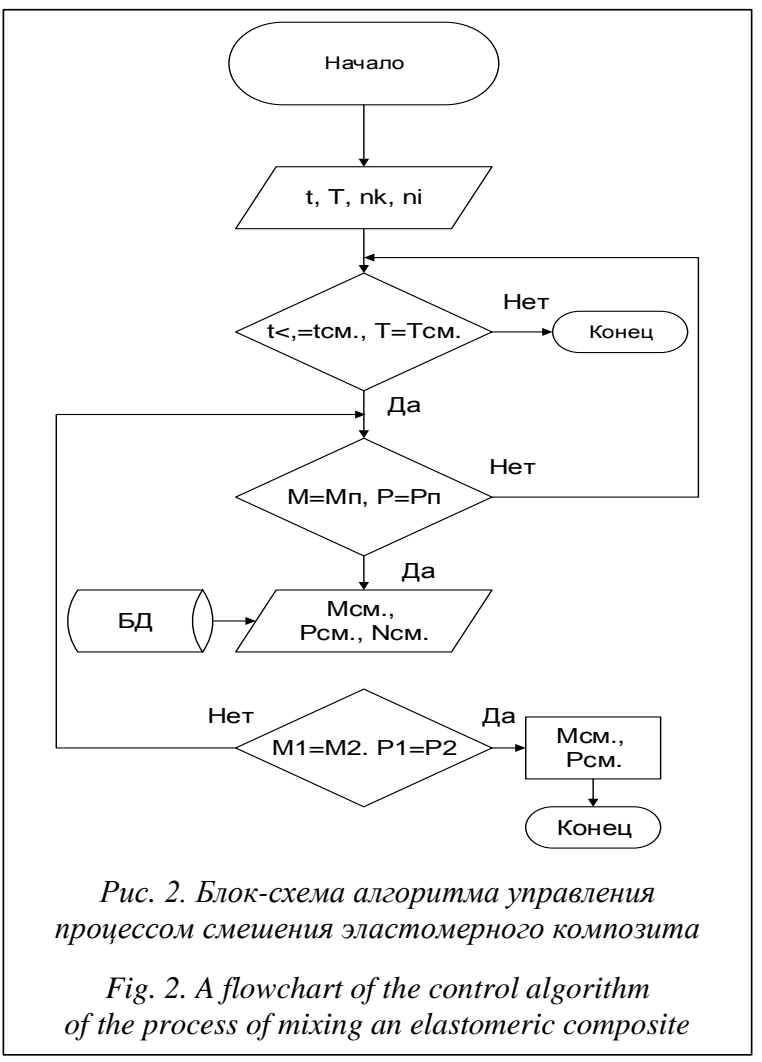




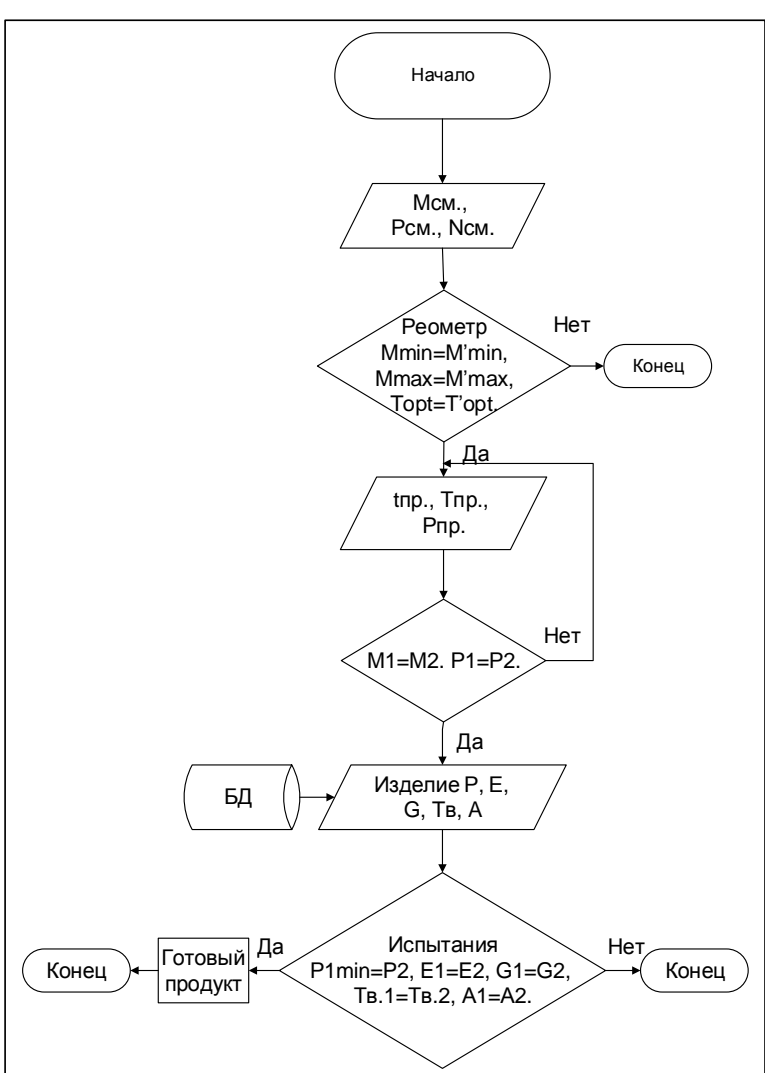

Рис. 3. Блок-схема управления процеессом структурирования эластомерного композита

Fig. 3. A flowchart for controlling the process of structuring an elastomeric composite

Программа позволяет подобрать уравнение, наилучшим образом описывающее данную зависимость с расчетом основных критериев качества, проводить структурную и параметрическую идентификацию, а также ранжировать различные математические модели по разным критериям качества (рис. 4) [2]. Такими критериями могут выступать

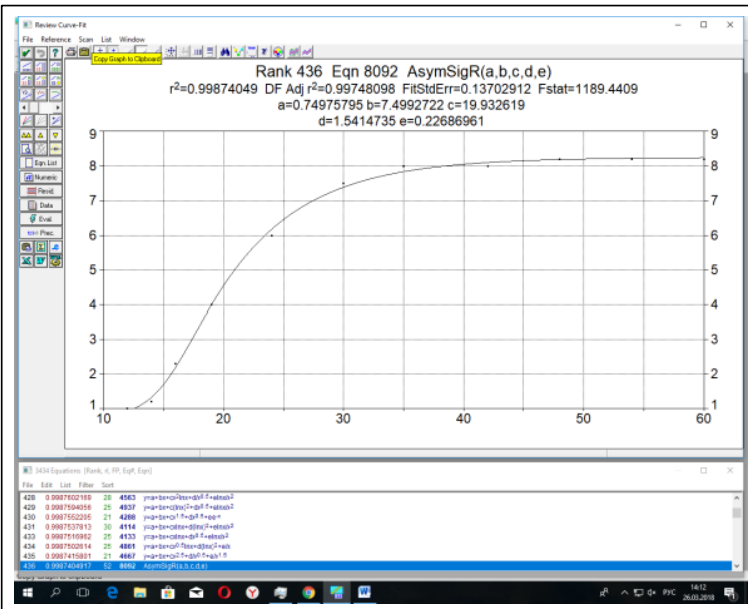

Рис. 4. Поиск и ранжирование моделей в программе Table curve $2 d$

Fig. 4. Search and ranking models in Table curve $2 d$ величины стандартной ошибки, критерия Фишера, коэффициента детерминации.

Модель 8092 по каталогу программы Table curve $2 \mathrm{~d}$ имеет следующий вид:

$$
M=a+b \cdot\left(1-\left(1+\exp \left(\frac{t+d \cdot \ln \left(2^{1 / e}-1\right)-c}{d}\right)\right)^{-e}\right) .
$$

Эта модель представляет собой аналитическое выражение функции распределения случайных величин. Параметр $a$ с учетом воспроизводимости реограмм можно рассматривать как минимальный крутящий момент $M_{\min }$. Параметр $b$ соответствует приращению крутящего момента $\Delta M=M_{\max }-M_{\min }$. Параметр $c$ равен вулканизационной характеристике $t_{C(50)}$. Параметры $d$ и $e$ характеризуют форму реометрической кривой.

Критерии качества и параметры модели 8092: коэффициент детерминации - 0.9987404917, скорректированный коэффициент детерминации 0.9974809834 , стандартная ошибка - 0.1370291176, критерий Фишера - 1189.4409199.

Программный продукт Table curve $2 \mathrm{~d}$ позволяет сразу изобразить на графике производную от исходной зависимости и совместить это в одном окне. В данном случае (см. http://www.swsys.ru/uploaded/image/2018-3/2018-3-dop/23.jpg) была получена графическая характеристика скорости процесса структурирования, имеющая важное значение при анализе и контролировании процесса, так как зачастую оказывается более чувствительной к изменению уровней рецептурно-технологических факторов [5].

Программа Table curve 3d была использована для построения трехмерных пространственных изображений, описывающих зависимости функции-отклика от двух факторов (рис. 5, 6). Данный программный продукт позволяет аппроксимировать поверхность отклика произвольной физической природы различными математическими моделями, в том числе включающими в себя эффекты взаимодействия. Данный подход позволяет количественно охарактеризовать совместное влияние двух и более факторов на отклик материала, а также учитывает вклад каждого из факторов в формирование функции-отклика.

Критерии качества и параметры модели 514 вида $z=a+b x+c y+d y^{2}$ : коэффициент детерминации - 0.9800641228, скорректированный коэффициент детерминации - 0.9667735379, стандартная ошибка - 0.5047270969, критерий Фишера 114.70858582.

Для принятий решений по контролю и управлению процессами структурирования многокомпонентных эластомерных композитов зачастую необходимо принимать во внимание влияние нескольких факторов разного характера. Для визуализации зависимости отклика от трех факторов применяются диаграммы состав-свойство. Блок визуализа- 


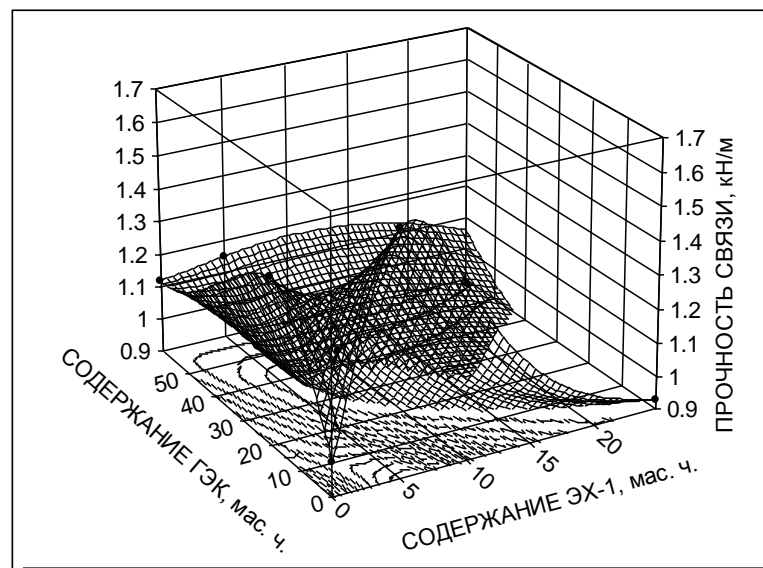

2.prn, $X, Y, Z$

Rank 514 Eqn $2 z=a+b x+c y+d y^{2}$

$r^{2}=0.98006412$ DF Adj $r^{2}=0.96677354$ FitStdE $r r=0.5047271$ Fstat $=114.70859$

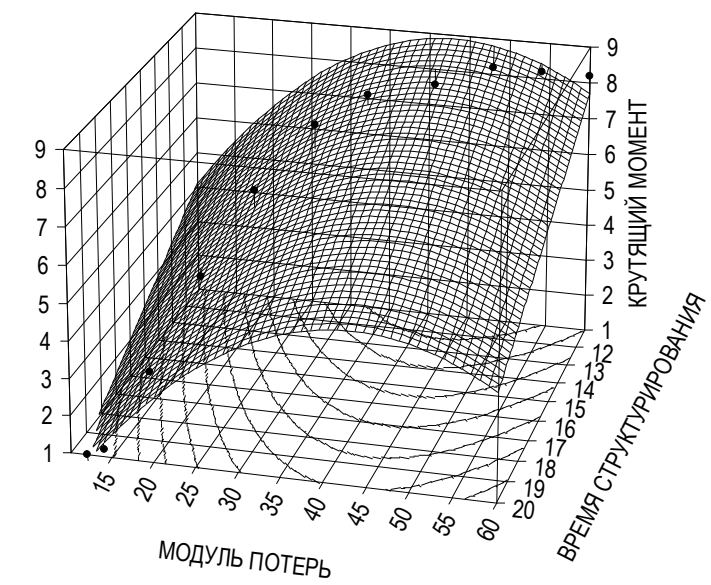

Рис. 6. Обработка реометрических данных в системе Table curve $3 d$

Fig. 6. Processing of rheometric data in Table curve $3 d$

ции реометрических данных является неотъемлемой частью интеллектуальной информационной системы управления сложными химико-технологическими процессами структурирования многокомпонентных эластомерных композитов [6, 7].

Частным случаем решения задачи описания почти стационарной области является построение регрессионных моделей для систем, представляющих собой смеси трех компонентов. Переменные $x_{i}$ в такой системе являются пропорциями (относительным содержанием) трех компонентов и удовлетворяют условию нормировки: $\Sigma x_{i}=x_{1}+x_{2}+x_{3}=1$.

Геометрическое место сумм переменных представляет собой двумерный симплекс (треугольник). Любой комбинации в содержании компонентов соответствует определенная точка симплекса.

В рассматриваемой ситуации вершины симплекса соответствуют 100 \%-му содержанию каждого компонента, лежащие напротив этих вершин стороны треугольника соответствуют нулевому содержанию данного компонента, а относительное содержание каждого компонента откладывается вдоль соответствующей стороны треугольника состава [8-10].

Для построения диаграммы состав-свойство на симплексе была использована модель $y=y\left(x_{1}, x_{2}, x_{3}\right)$ $(y$ - отклик) в форме приведенного полинома. Полином для неполной кубической модели, описывающей почти стационарную область по 7 значениям отклика (рис. 7), будет следующим: $y=\beta_{1} x_{1}+$ $+\beta_{2} x_{2}+\beta_{3} x_{3}+\beta_{12} x_{1} x_{2}+\beta_{13} x_{1} x_{3}+\beta_{23} x_{2} x_{3}+\beta_{123} x_{1} x_{2} x_{3}$.

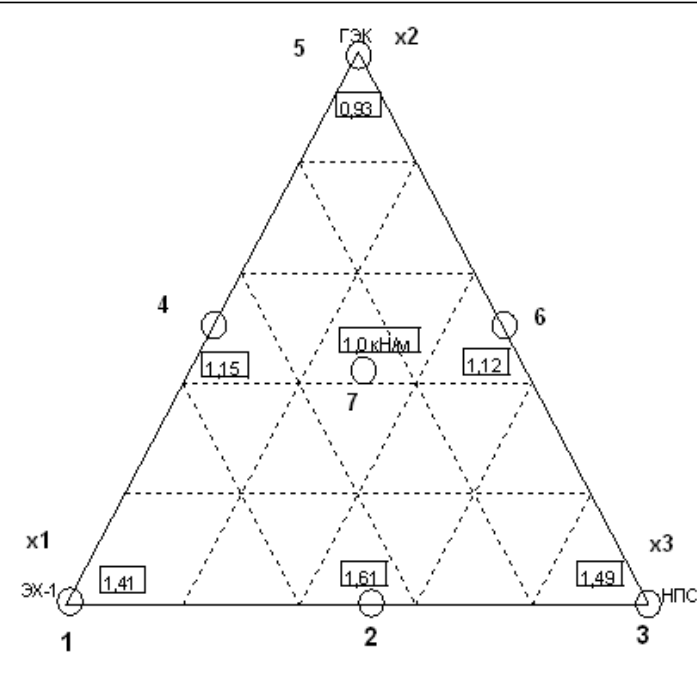

a)

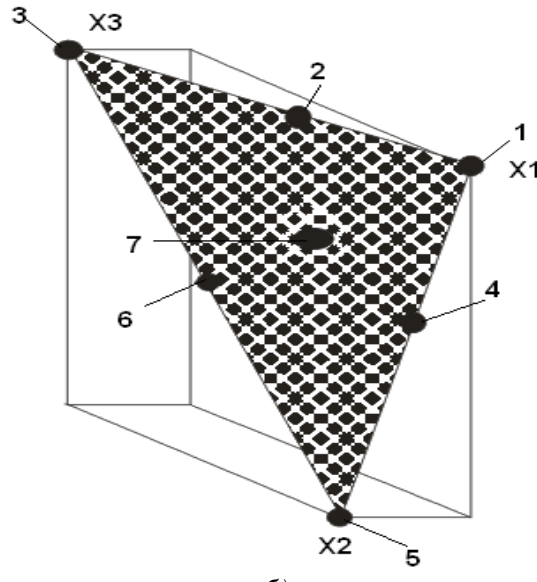

б)

Рис. 7. Графическая интерпретация расположения точек в факторном пространстве: а) - плоское изображение, б) - пространственное изображение

Fig. 7. Graphical interpretation of trend in points in a factor space: a) is a flat image, б) is a spatial image

План для неполной кубической модели запишем следующим образом:

\begin{tabular}{|c|c|c|c|c|c|c|c|}
\hline \multirow{2}{*}{$\begin{array}{c}\text { От- } \\
\text { клик }\end{array}$} & \multicolumn{3}{|c|}{ Координаты точек } & \multirow{2}{*}{$\begin{array}{c}\text { От- } \\
\text { клик }\end{array}$} & \multicolumn{3}{|c|}{ Координаты точек } \\
\hline & $x_{1}$ & $x_{2}$ & $x_{3}$ & & $x_{1}$ & $x_{2}$ & $x_{3}$ \\
\hline$y_{1}$ & 1 & 0 & 0 & $y_{12}$ & $1 / 2$ & $1 / 2$ & 0 \\
\hline$y_{2}$ & 0 & 1 & 0 & $y_{13}$ & $1 / 2$ & 0 & $1 / 2$ \\
\hline$y_{3}$ & 0 & 0 & 1 & $y_{23}$ & 0 & $1 / 2$ & $1 / 2$ \\
\hline & & & & $y_{123}$ & $1 / 3$ & $1 / 3$ & $1 / 3$ \\
\hline
\end{tabular}


Параметры неполной кубической модели вычисляются по следующим формулам:

$\beta_{1}=y_{1} ; \beta_{2}=y_{2} ; \beta_{3}=y_{3} ; \beta_{12}=4 y_{12}-2 y_{1}-2 y_{2} ;$

$\beta_{13}=4 y_{13}-2 y_{1}-2 y_{3} ; \beta_{23}=4 y_{23}-2 y_{2}-2 y_{3}$;

$\beta_{123}=27 y_{123}-12\left(y_{12}+y_{13}+y_{23}\right)+3\left(y_{1}+y_{2}+y_{3}\right)$.

На рисунке 8 представлена блок-схема алгоритма расчета параметров математической модели и координат точек, необходимых для построения диаграммы состав-свойство.

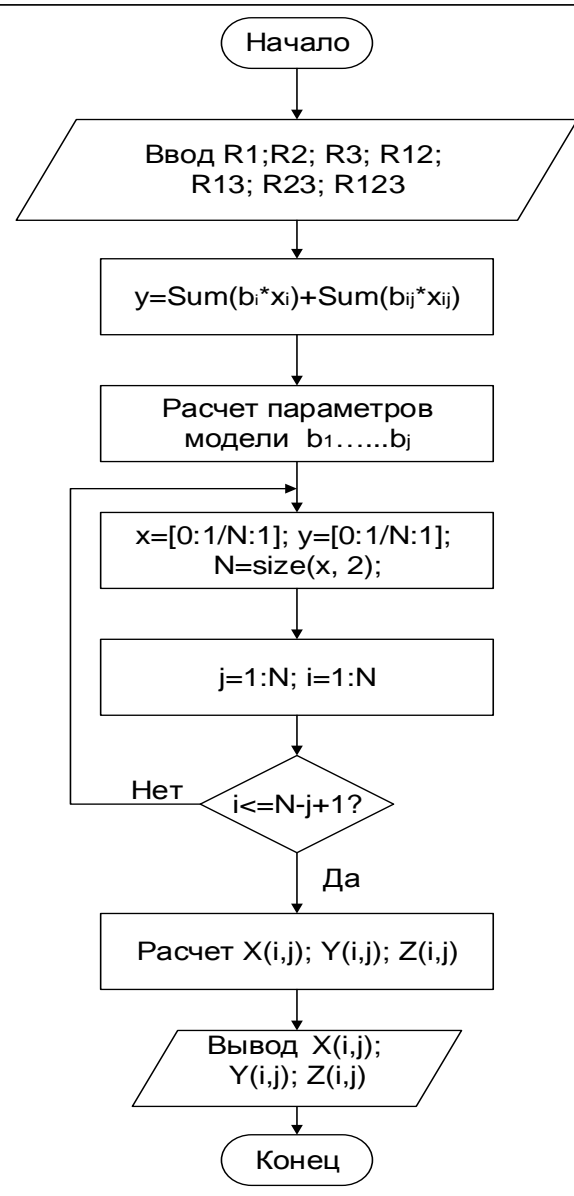

Рис. 8. Блок-схема алгоритма расчета параметров модели и построения диаграммы состав-свойство (R1-R123 - экспериментальные значения в точках, изображенных на рис. 7; y-математическая модель, $X, У, Z$ - расчетные значения точек, необходимые для построения диаграммы)

Fig. 8. A flowchart of algorithm for calculating model parameters and constructing a composition-property diagram $(R 1-R 123$ are experimental values at the points

in figure 7, $y$ is a mathematical model, $X, Y, Z$ are calculated values of the points necessary for constructing the diagram)

На основе разработанной модели были построены симплексные диаграммы состав-свойство, позволяющие оценить формирование прочности эластомерного композита.

Полученные в ходе выполнения действий данного алгоритма диаграммы состав-свойство представлены на рисунке 9. Данные графические зави- симости наглядно отображают влияние комбинации рецептурных и технологических факторов на формирование прочности соединения резины, определяемой степенью структурирования клеевого шва, учитывая формирование прочности во времени (через 24, 48 и 76 часов после получения соединения).

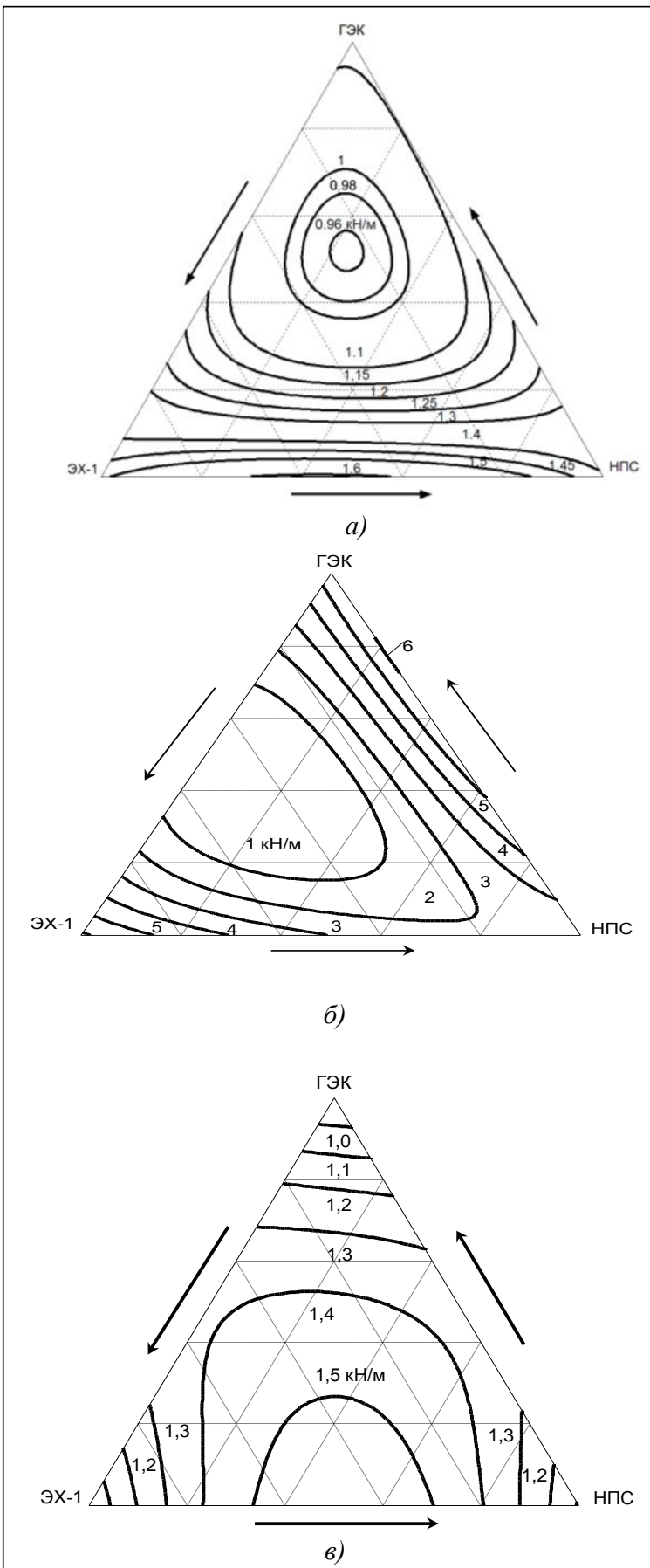

Рис. 9. Диаграмма состав-свойство для формирования прочности связи эластомерного композита: а) $\tau=24$ часа, б) $\tau=48$ часов, в) $\tau=72$ часа

Fig. 9. A composition-property diagram to form elastomeric composite bond strength: a) $\tau=24$ hours, б) $\tau=48$ hours, в) $\tau=72$ hours 


\section{Выводы}

Разработанная процессная модель позволяет структурировать алгоритмы контроля и управления химико-технологическими процессами смешения и структурирования многокомпонентных эластомерных композитов.

Авторы разработали блок-схемы алгоритмов управления процессами смешения и структурирования эластомерных композитов. Для визуализации разработанных моделей управления использованы программные продукты Table curve $2 \mathrm{~d} / 3 \mathrm{~d}$ (Systat Software). C их помощью на одном графике совмещены кривые степени структурирования, дифференциальные кривые скорости процесса, а также построены поверхности отклика, отражающие динамику изменения характеристик процесса структурирования при варьировании уровней факторов, имеющих рецептурно-технологический характер.

Построенные симплекс-модели для переменных оценивают влияние рецептурно-технологических факторов. Диаграммы состав-свойство построены на основе программного продукта Matlab 2010. Они позволяют найти параметры управления на основе анализа взаимного влияния уровней рецептурно-технологических факторов. Это дает возможность оператору процесса выбрать наиболее эффективный режим управления за счет комплексного анализа показателей качества процесса структурирования многокомпонентных эластомерных композитов.

\section{Литература}

1. Уральский М.Л., Горелик Р.А., Буканов А.М. Контроль и регулирование технологических свойств резиновых смесей. М.: Химия, $1983.128 \mathrm{c}$.

2. Сочнев А.Н. Автоматизированная система управления вулканизационными характеристиками резиновой смеси в производстве резинотехнических изделий: автореф. дис. ... канд. техн. наук. Саратов, 2008. 20 с.

3. Новаков И.А., Новопольцева О.М., Кракшин М.А. Ме- тоды оценки и регулирования пластоэластических и вулканизационных свойств эластомеров и композиций на их основе. М.: Химия, 2000. 240 с.

4. Кузнецов А.С., Корнюшко В.Ф., Гончаров И.А., Агаянц И.М. Информационная поддержка системы управления технологическим процессом структурирования эластомерных систем с применением реометрических кривых // Прикладная информатика. 2016. № 2. С. 5-12.

5. Кузнецов А.С., Корнюшко В.Ф. Математические модели реограмм состояния в программах Tablecurve $2 \mathrm{~d} / 3 \mathrm{~d}$ как основа интеллектуальной системы управления процессами структурирования многокомпонентных эластомерных композитов // Программные продукты и системы. 2017. Т. 30. № 4. С. 5-14.

6. Кузнецов А.С., Корнюшко В.Ф. Интеллектуальная система управления химико-технологическими процессами и структурирования многокомпонентных эластомерных композитов на основе продукционной модели // Тонкие химические технологии. 2017. № 5. С. 101-109.

7. Ахназарова С.Л., Кафаров В.В. Оптимизация эксперимента в химии и химической технологии. М.: Высш. шк., 1978. $319 \mathrm{c}$.

8. Рузинов Л.П. Статистические методы оптимизации химических процессов. М.: Химия, 1972. 200 с.

9. Рузинов Л.П., Слободчикова Р.И. Планирование эксперимента в химии и химической технологии. М.: Химия, 1980. $280 \mathrm{c}$.

10. Корнюшко В.Ф., Костров А.В., Породникова П.А. Подход к развитию системы управления тестированием программных средств // Программные продукты и системы. 2015. № 4. C. $126-132$.

11. Агаянц И.М. Азы статистики в мире химии: обработка экспериментальных данных. СПб: Изд-во НОТ, 2015. 614 с.

12. Гартман Т.Н., Клушин Д.В. Основы компьютерного моделирования химико-технологических процессов. М.: Академкнига, 2006. $416 \mathrm{c}$.

13. Анфилатов В.С., Емельянов А.А., Кукушкин А.А. Системный анализ в управлении. М.: Финансы и статистика, 2002. $368 \mathrm{c}$.

14. Дворецкий Д.С., Пешкова Е.В. Математическое моделирование и оптимизация процессов тонкого органического синтеза в условиях неопределенности // Вестн. ТГТУ. 2007. № 1. С. 119-129.

15. Тихомиров С.Г., Карманова О.В., Пятаков Ю.В., Маслов А.А. Программный комплекс для решения задач математического моделирования процесса изотермической вулканизации // Вестн. ВГУИТ. 2016. № 3. С. 93-99.

16. Осипов С.Ю., Осипов Ю.Р., Богданов Д.А., Ершов Е.В. Математическое моделирование и разработка системы автоматической корректировки режимов вулканизации эластомерных покрытий валов металлургических производств // Вестн. Череповец. гос. ун-та. 2017. № 3. С. 46-54.

\section{Algorithmic ware of data processing for elastomer composite structuring to solve a control problem}

A.S. Kuznechov ${ }^{1}$, Ph.D. (Engineering), Senior Lecturer, askuznetsov@mitht.ru

V.F. Kornyushko ${ }^{1}$, Dr.Sc. (Engineering), Professor, vfk256@mail.ru

${ }^{1}$ Moscow Technological University (MIREA), Moscow, 119454, Russian Federation

Abstract. Structuring is the most important stage of processing multicomponent elastomeric material into a finished product that is a product with a set of operational properties specified at the stage of recipe building. It is a combination of two 
processes: chemical interaction of various components in its composition, and the technological process of fixing the required properties and functions of the future product. Successful implementation of this final technological procedure requires strict control over compliance with a given sequence of all technological stages and preparatory operations that leads to production a semi-finished intermediate product. Improving the quality of the finished product is greatly facilitated by applying expresscontrol methods based on vibroreometry to assess the characteristics of raw materials, as well as the parameters of the semifinished and finished products.

The paper considers chemical-technological processes of mixing and structuring multicomponent elastomeric composites as components of a chemical-technological system. The authors propose algorithmic support of vibrereometry data processing to improve management efficiency of complex chemical-technological processes of mixing and structuring multicomponent elastomeric composites.

The paper describes the constructed process model for controlling the structuring of elastomeric composite systems. There are 4 groups of processes responsible for quality indicators of structuring. There are also block diagrams of control algorithms for complex chemical-technological processes of mixing and structuring of elastomeric systems. The authors show the methods of processing the main rheometric information using modern software products, as well as the techniques for visualizing rheometric data in Table curve $2 \mathrm{~d}$ and Table curve $3 \mathrm{~d}$.

Spatial images are constructed in the form of response surfaces for main recipe-technological factors and process quality indicators. There is also an algorithm for calculating coefficients of mathematical models. A set of composition-property diagrams visually characterizes the effect of changing levels of prescription and technological factors on the kinetics of the structuring process. It is shown that visualization of rheometric data using modern software products provides opportunities for more flexible and adaptive control of the process of structuring multicomponent elastomeric composites.

Keywords: algorithmic support, structuring process, structuring process control, elastomeric composite, rheometric data visualization.

\section{References}

1. Uralsky M.L., Gorelik R.A., Bukanov A.M. Control and Regulation of Technological Properties of Rubber Blends. Moscow, Khimiya Publ., 1983, 128 p.

2. Sochnev A.N. An Automatized Control System of Rubber Cure Characteristics in Rubber-Technical Products Production. PhD Thesis. Saratov, 2008, 20 p.

3. Novakov I.A., Volfson S.I., Novopoltseva O.M., Krakshin M.A. Rheological and Vulcanization Properties of Elastomeric Compositions. Moscow, Khimiya Publ., 2000, 240 p.

4. Kuznetsov A.S., Kornyushko V.F., Goncharov I.A., Agayants I.M. Information support of process structuring elastomeric systems control system using rheometer curves. J. of Applied Informatics. 2016, no. 2, pp. 5-12 (in Russ.).

5. Kuznetsov A.S., Kornyushko V.F. Mathematical models of rheograms of states in Table Curve 2d/3d programs as a basis of the intelligent system for managing structuring processes of multicomponent elastomer composites. Software \& Systems. 2017, vol. 30, no. 4, pp. 770-777 (in Russ.).

6. Kuznetsov A.S., Kornyushko V.F. Intelligent system for control of chemical-technological processes of structuring of multicomponent elastomer composites based on the production model. Fine Chemical Technologies. 2017, no. 5, pp. 88-96.

7. Akhnazarova C.L., Kafarov V.V. The Experiment Optimization in Chemistry and Chemical Technology. Moscow, Vyssh. Shkola Publ., 1978, 319 p.

8. Ruzinov L.P. Statistical Methods of Chemical Process Optimization. Moscow, Khimiya Publ., 1972, 200 p.

9. Ruzinov L.P., Slobodchikova R.I. The Experiment Planning in Chemistry and Chemical Technology. Moscow, Khimiya Publ., 1980, 280 p.

10. Kornyushko V.F., Kostrov A.V., Porodnikova P.A. An approach to software testing management system development. Software \& Systems. 2015, no. 4, pp. 126-132 (in Russ.).

11. Agayants I.M. The Basics of Statistics in the World of Chemistry: Processing Experimental Data. St. Petersburg, NOT Publ., 2015, 614 p.

12. Gartman T.N., Klushin D.V. Basics of Computer Modeling of Chemical and Technological Processes. Moscow, Akademkniga Publ., 2006, 416 p.

13. Anfilatov V.S., Emelyanov A.A., Kukushkin A.A. System Analysis in Management. Moscow, Finansy i statistika Publ., 2002,368 p.

14. Dvoretsky D.S., Peshkova E.V. Mathematic Modeling and optimization of the processes of fine organic synthesis in terms of uncertainty. Trans. of TSTU. 2007, no. 1, pp. 119-129 (in Russ.).

15. Tikhomirov S.G., Karmanova O.V., Pyatakov Yu.V., Maslov A.A. The software package for solving problems of mathematical modeling of isothermal curing process. Proc. of the Voronezh State Univ. of Engineering Technologies. 2016, no. 3, pp. 93-99 (in Russ.).

16. Osipov S.Yu., Osipov Yu.R., Bogdanov D.A., Ershov E.V. Mathematical modeling and development of automatic correction system for vulcanization regimes of elastomeric coatings for shafts of metallurgical industries. Cherepovets State Univ. Bulletin. 2017, no. 3, pp. 46-54 (in Russ.). 


\title{
Повыиение точности расчета систем автоматического управления с запаздыванием
}

\author{
B.3. Тхан 1, аспиранm, dungvietthan@gmail.com \\ Ю.Н. Дементьев 1, к.т.н., доиент, dementev@tрu.ru \\ B.И. Гончаров 1, д.m.н., npoppeccop, gvi@tpu.ru
}

1 Наииональный исследовательский Томский политехнический университет, 634050, г. Томск, Россия

В статье рассматриваются вопросы точности задач синтеза систем автоматического управления объектами с запаздыванием. Они охватывают традиционный подход на основе аппроксимации передаточной функции звена запаздывания его дробно-рациональным выражением, а также оригинальный путь, позволяющий сохранить точное описание звена запаздывания при решении задач синтеза регуляторов систем автоматического управления.

В работе выбран последний вариант, который базируется на привлечении частного случая преобразования Лапласа, обеспечивающего переход к описанию динамических систем в форме функций-изображений, имеющих вещественную переменную. Этот численный метод дает возможность получать дискретные модели динамических систем, сочетая преимущества численных методов и цифровых вычислительных средств.

На основе численного метода рассмотрены три актуальные задачи синтеза и исследования систем указанного класса. Первая из них связана с аппроксимацией звена запаздывания. Представлен сравнительный анализ подходов, базирующихся на отрезках ряда Тейлора, дроби Паде и численного метода. Выявлены преимущества последнего: более высокая точность и, главное, возможность перераспределения погрешности приближения в области малых/больших значений времени. В рамках второй задачи показана возможность формирования и решения уравнения синтеза систем автоматического управления без аппроксимации звена запаздывания, обеспечивая достижение потенциально возможной точности синтеза. Третья задача раскрывает возможности численного метода в оценивании точности синтеза систем автоматического управления и сравнения нескольких вариантов.

Предложен вариант оценивания, не требующий аппроксимации звена запаздывания. Результаты проиллюстрированы примерами расчетов.

Ключевые слова: объект с запаздыванием, синтез регуляторов, аппроксимация звена запаздывания, преобразования Лапласа, повышение точности САУ с запаздыванием.

Системы автоматического управления (САУ) объектами с запаздыванием составляют обширный класс индустриальных систем управления, что отражает постоянный интерес к ним в течение десятилетий. Их особенность состоит в наличии звена запаздывания, описываемого передаточной функцией $e^{-p \tau}$, которая не позволяет использовать классические методы синтеза и исследования систем управления. Для снятия препятствий обычно используется прием аппроксимации функции $e^{-p \tau}$ подходящим дробно-рациональным выражением, что позволяет привлекать стандартные методы расчета САУ [1-6].

Несмотря на очевидность и простоту этого пути, у него имеются негативные стороны. Во-первых, в исходном уравнении синтеза САУ $W_{\text {ж }}^{3}(p) \simeq W_{\mathrm{c}}^{3}(p)$, в котором передаточная функция $W_{\text {ж}}^{3}(p)$ описывает желаемую, эталонную систему, a $W_{\mathrm{c}}^{3}(p)$ - синтезируемую САУ, имеющую вид

$W_{\mathrm{c}}^{3}(p) \simeq \frac{W_{p}(p) W_{\text {нч }}(p) e^{-p \tau}}{1+W_{p}(p) W_{\text {нч }}(p) e^{-p \tau} k_{\mathrm{oc}}}$,

в случае замены составляющей $e^{-p \tau}$ конечномерным представлением появляется составляющая погрешности, определенная переходом от точного представления звена запаздывания к приближен- ному. Во-вторых, на этапе оценивания точности синтеза системы обычно стремятся получить ее переходную характеристику, которая позволяет найти прямые показатели качества. Однако здесь также приходится аппроксимировать звено запаздывания, так как иначе задача, за исключением простейших случаев, оказывается неразрешимой. В-третьих, для некоторых систем необходимо определять временные характеристики САУ с повышенной точностью при малых или больших значениях времени, что требует соответствующего инструмента при аппроксимации звена запаздывания.

Выделенные вопросы являются важными в практическом и теоретическом отношениях и потому являются предметом рассмотрения в настоящей работе. В рамках аналитических исследований получить приемлемые ответы на эти вопросы в общем случае невозможно, поэтому используется численный метод - вещчественный интерполяциионный метод (ВИМ) [7, 8].

\section{Предварительные замечания}

Для пояснения некоторых особенностей метода ВИМ приведем краткие сведения о нем. Метод базируется на вещественном интегральном преобразовании: 


$$
F(\delta)=\int_{0}^{\infty} f(t) e^{-\delta . t} d t, \delta \in[C, \infty), C \geq 0,
$$

которое ставит в соответствие оригиналу $f(t)$ изображение $F(\delta)$ в виде функции вещественной переменной $\delta$. Формулу прямого преобразования (2) можно рассматривать как частный случай прямого преобразования Лапласа при замене комплексной переменной $p=\delta+j \omega$ на вещественную $\delta \geq 0$. Еще один шаг, направленный на расширение возможностей метода, - переход от непрерывных функций $F(\delta)$ к их дискретным аналогам $F\left(\delta_{i}\right), i=1,2, \ldots, \eta$, с целью применения средств вычислительной техники и численных методов. Для этих целей в ВИМ введены численные характеристики $\left\{F\left(\delta_{i}\right)\right\}_{\eta}$, которые получают как совокупность значений функции $F(\delta)$ в узлах $\delta_{i}, i=1,2, \ldots, \eta$.

Основные достоинства непрерывных моделей $F(\delta)$ и их дискретных представлений $F\left(\delta_{i}\right), i=1,2$, ..., $\eta$, связаны, во-первых, с тем, что они описывают динамическую систему в области изображений, обеспечивая простоту действий над такими моделями по сравнению с функциями времени. Вовторых, аргумент $\delta$ является вещественным, что позволяет привлекать хорошо разработанные численные методы функций вещественных переменных. Модели вида $F\left(\delta_{i}\right), i=1,2, \ldots, \eta$, распространяются как на передаточные функции $W(p)$, базирующиеся на преобразовании Лапласа, так и на изображения сигналов $F(p)=L\{f(t)\}$, приводя, когда это нужно, к моделям $W(\delta)$ и $F(\delta)$.

Перейдем к рассмотрению выделенных ранее вопросов, начиная с наиболее значимого - аппроксимации передаточной функции звена запаздывания.

\section{Аппроксимация звена запаздывания}

В настоящее время используют два основных метода аппроксимации звена запаздывания, отличающихся простотой вычислений: разложение передаточной функции $e^{-p \tau}$ в ряд Тейлора и представление этой функции в виде дроби Паде [9]. Оба метода в своей основе используют степенной ряд Тейлора, а приближения имеют вид

$$
\begin{aligned}
e^{-\tau p} & =\frac{1}{1+\tau p+\frac{1}{2}(\tau p)^{2}+\frac{1}{6}(\tau p)^{3}+\ldots}, \\
e^{-\tau p} & =\frac{1-\frac{1}{2} \tau p+\frac{1}{12}(\tau p)^{2}+\ldots}{1+\frac{1}{2} \tau p+\frac{1}{12}(\tau p)^{2}+\ldots} .
\end{aligned}
$$

Сравнивая представленные выражения, можно отметить, что аппроксимационные возможности второго варианта должны быть выше, так как он имеет большее число варьируемых коэффициентов. На основе ВИМ также можно использовать аппроксимации, имеющие преимущества по числу коэффициентов. Для наглядного сравнения возможностей трех выделенных методов воспользуемся расчетным примером.

Для простоты примем запаздывание равным $1 \mathrm{c}$. Тогда передаточная функция звена будет иметь вид $W(p)=e^{-p}$. В качестве аппроксимирующего выражения примем распространенную функцию второго порядка. Результаты приближения принятой формой для ряда Тейлора и дроби Паде представлены соответственно выражениями

$$
e^{-p} \simeq \frac{1}{0.5 p^{2}+p+1} \text { и } e^{-p} \simeq \frac{0.083 p^{2}-0.5 p+1}{0.083 p^{2}+0.5 p+1} \text {. }
$$

Соответствующие переходные характеристики показаны на рисунке 1 . Их сравнение позволяет выделить достоинства и недостатки этих вариантов. Отрезок ряда Тейлора имеет хорошую точность при малых значениях времени, однако он проигрывает аппроксимации Паде при больших значениях времени. У последнего имеется несомненное достоинство - повышенная точность при $t>\tau$, однако заметен и недостаток, связанный с ненулевым начальным значением, определенным принятой структурой.

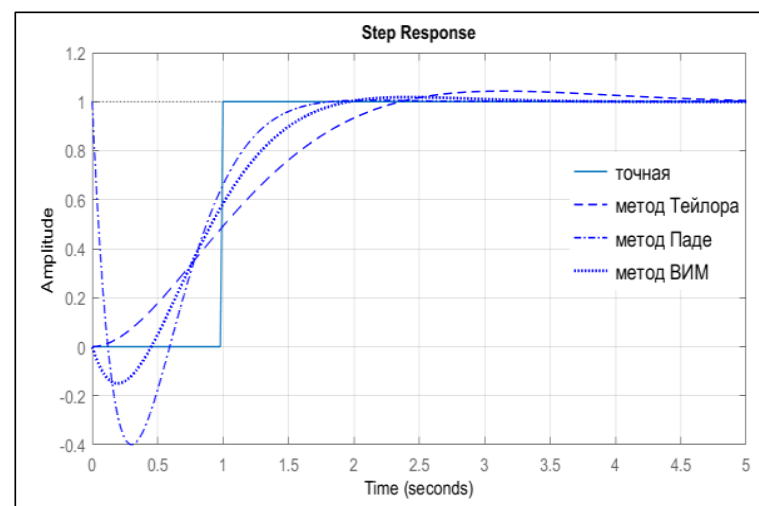

Рис. 1. Переходные характеристики звена запаздывания и аппроксимируюших выражений на основе ряда Тейлора, дроби Паде и ВИМ

Fig. 1. Transient characteristics of the time delay object and approximating expressions based on the Taylor series, Padé fraction and RIM

Перейдем к рассмотрению возможностей третьего метода - ВИМ. В качестве аппроксимирующей функции примем выражение

$$
W_{\text {пр. }}(p)=\frac{b_{1} p+b_{0}}{a_{2} p^{2}+a_{1} p+1},
$$

которое позволяет избежать ненулевого начального значения в области времени. Задача заключается в вычислении коэффициентов выбранной дроби. Представим ее решение достаточно подробно, настолько, чтобы была возможность проверки алгоритма и всех вычислений. Значение коэффициента $b_{0}$ найдется по установившемуся режиму: $b_{0}=1$. Для вычисления оставшихся трех коэффициентов воспользуемся численными расче- 
тами ВИМ. С этой целью заменим комплексную переменную $p=\delta+j \omega$ на вещественную $\delta \in[C, \infty]$, $C \geq 0$, и по вещественной функции $W(\delta)=e^{-\delta}$ найдем три узла интерполяции $\delta_{i}, i=1,2,3$, используя рекомендации из [7]. Получаем $\delta_{1}=0.1, \delta_{2}=0.2$, $\delta_{3}=0.3$, что позволяет найти численную характеристику $\left\{W\left(\delta_{i}\right)\right\}_{3}$, подставляя значения узлов в исходную функцию: $\left\{W\left(\delta_{i}\right)\right\}_{3}=\{0,9048 ; 0,8187$; $0,7408\}$. Это дает возможность сформировать систему уравнений вида $e^{-\delta_{i}}=\frac{b_{1} \delta_{i}+1}{a_{2} \delta_{i}^{2}+a_{1} \delta_{i}+1}, i=\overline{1,3}$, развернутая форма которой и ее решение приведены далее:

$$
\left\{\begin{array}{l}
0.9048=\frac{b_{1} \delta_{1}+1}{a_{2} \delta_{1}+a_{1} \delta_{1}+1} ; \\
0.8187=\frac{b_{1} \delta_{2}+1}{a_{2} \delta_{2}+a_{1} \delta_{2}+1} ; \Rightarrow\left\{\begin{array}{l}
b_{1}=-0.317 ; \\
a_{1}=0.184 ; \\
a_{2}=0.683 .
\end{array}\right. \\
0.7408=\frac{b_{1} \delta_{3}+1}{a_{2} \delta_{3}+a_{1} \delta_{3}+1} .
\end{array}\right.
$$

Приближенная передаточная функция звена запаздывания имеет вид $e^{-p} \simeq \frac{-0.317 p+1}{0.184 p^{2}+0.683 p+1}$, а ее переходная характеристика представлена на рисунке 1.

Из сопоставления временных характеристик можно сделать определенные выводы, позволяющие выбрать предпочтительный вариант аппроксимации при решении конкретных задач. Особенности двух первых методов в основном достаточно ясны, поэтому остановимся на возможностях ВИМ. Его привлекательность в том, что он позволяет перераспределять погрешность на участках малых и больших значений времени [10]. Условной границей между ними можно считать время, соответствующее величине запаздывания.

Для повышения точности в области малых или больших значений времени используется инструментальная переменная $\delta_{1}$, которая в обычных случаях определяет значения всех узлов интерполирования: $\delta_{i}=i \delta_{1}, i=1,2,3, \ldots$ [7].

Для демонстрации возможности коррекции точности по участкам приведем результаты приближения звена запаздывания прежней дробно-рациональной структурой с различными значениями переменной $\delta_{1}=0.05 ; 1.0 ; 1.5$ (см. рис. 2 ).

Из рисунка достаточно ясно видно, что в рамках ВИМ существует инструмент, который позволяет изменять погрешность приближения в области малых/больших значений времени, что важно, например, при исследовании систем повышенной точности. Механизм перераспределения погрешности по интересующему интервалу, например $[0 ; 2 \tau]$, следует непосредственно из соотношения (2), которое в обозначениях рассматриваемой задачи имеет вид

$$
W\left(\delta_{1}\right)=\delta_{1} \int_{0}^{\infty} h(t) e^{-\delta_{1} t} d t, \delta_{1}>0,
$$

где функция $h(t)$ - приближенная переходная характеристика. В этом интегральном соотношении функцию $e^{-\delta_{1} t}$ можно рассматривать в качестве весовой, которая позволяет изменять фильтрующие свойства. Например, при увеличении значения $\delta_{1}$ величина $W\left(\delta_{1}\right)$ будет определяться в основном начальной частью функции $h(t)$, что предопределяет снижение погрешности аппроксимации в области малых значений. Естественно, что погрешность при больших значениях времени будет возрастать вплоть до появления расходящегося процесса.

Справедливо и обратное - при уменьшении величины $\delta_{1}$ будет снижаться погрешность в области больших значений времени. Имеется и промежуточный вариант. Он ориентирован на повышение величины производной функции переходных характеристик в окрестности $t=\tau$, что в конечном итоге сказывается на точности приближения в указанной области. Но эта задача более сложная, так как требует неравномерного распределения узлов.

\section{Оценивание точности при решении задач синтеза}

Результаты синтеза САУ можно оценивать в комплексной, частотной и временной областях. Наиболее часто обращаются к функциям времени, обычно к переходным характеристикам, которые позволяют сравнивать по ним свойства эталонных и синтезированных систем, в том числе по их показателям качества. При этом задача сводится к обращению преобразования Лапласа $h_{\mathrm{c}}(p)=$ $=L^{-1}\left\{W_{\mathrm{c}}^{3}(p) / p\right\}$, которое является моделью синтезированной системы в форме изображения пере-

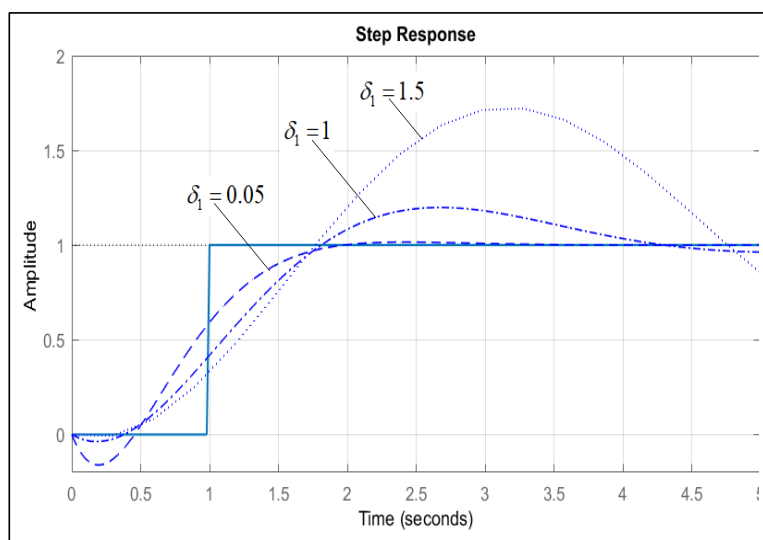

Рис. 2. Переходные характеристики аппроксимаций звена запаздывания по методу ВИМ при различных узлах интерполирования

Fig. 2. Transient characteristics of the time delay object approximations by the RIM method for various interpolation points 
ходной характеристики $h_{\mathrm{c}}(t)$. Однако этот путь в случае САУ с запаздыванием требует выполнения дополнительного этапа - замены выражения $e^{-\delta_{1} t}$ рациональной дробью, так как отсутствуют процедуры обратного преобразования изображений $W_{\mathrm{c}}^{3}(p) / p$, имеющих указанные особенности.

Сказанное свидетельствует о том, что при аппроксимационном пути получения оригинала $h_{\mathrm{c}}(t)$ по его изображению $W_{\mathrm{c}}^{3}(p) / p$ различие характеристик синтезированной $h_{\mathrm{c}}(t)$ и желаемой $h_{\text {ж }}(t)$ систем $\Delta h(t)=h_{ж}(t)-h_{\mathrm{c}}(t)$ будет содержать две составляющие: $\Delta h_{1}(t)+\Delta h_{2}(t)=\Delta h(t)$. Первая возникает из-за отсутствия точного решения уравнения синтеза. Вторая образуется как следствие этапа аппроксимации, что не позволяет в полной мере оценить точность решения синтеза по функции $\Delta h(t)$.

Для поиска путей уменьшения влияния составляющей $\Delta h_{2}(t)$ на общую величину $\Delta h(t)$ были проведены численные эксперименты, направленные на установление порядка аппроксимирующей функции $W_{\text {пр }}(p)=\frac{B_{m}(p)}{A_{n}(p)}$, при котором погрешность аппроксимации $\Delta h_{2}(t)$ будет значительно меньше интересующей нас ошибки $\Delta h_{1}(t)$. С этой целью для задачи синтеза САУ с желаемыми показателями перерегулирования и времени установления были получены переходные характеристики с различными вариантами дробей, аппроксимирующих звено запаздывания $e^{-3 p}$. Были исследованы дроби со следующими структурными параметрами: $m=0$, $n=1 ; m=1, n=2 ; m=2, n=3$. Для контроля точности сравнивались величины перерегулирования желаемой системы $\sigma_{ж}=5 \%$ и синтезированной $\sigma_{c}$, для чего использовалась оценка $\Delta \sigma=\sigma_{ж}-\sigma_{\mathrm{c}}$. Установлено, что уже при структуре $m=1, n=2$ достигнута приемлемо малая погрешность $\Delta h_{2}(t)$, так как оценка $\Delta \sigma$ оказалась равной $0,1 \%$. Этот результат свидетельствует о том, что для большинства практических задач аппроксимация звена запаздывания с параметрами $m=1, n=2$ позволяет оценивать точность синтеза САУ в области времени.

Рассмотренный вариант оценивания точности синтезированных САУ вполне приемлем для практики, однако следует иметь в виду, что он сохраняет в составе общей погрешности $\Delta h(t)$ составляющую $\Delta h_{2}(t)$, которая по сути является ошибкой вычислений. Для высокоточных систем могут потребоваться сопоставление и выбор одного из двух близких вариантов САУ. В этих случаях желательно полностью устранить влияние составляющей $\Delta h_{2}(t)$. Такой путь исследования точности может быть реализован на основе ВИМ. Рассмотрим эту возможность.

Одна из особенностей метода состоит в том, что он позволяет переходить к моделям вида $F(\delta)$ и $\left\{F\left(\delta_{i}\right)\right\}_{\eta}$, которые могут быть точными для передаточных функций, содержащих трансцендентные выражения, в том числе вида $e^{-p t}$ [7]. Это относится, в частности, к уравнению синтеза (1). Учитывая сказанное, положим, что задача синтеза решена, имеются вещественные передаточные функции желаемой $W_{ж}^{3}(\delta)$ и синтезированной системы $W_{\mathrm{c}}^{3}(\delta)$. Теперь можно найти погрешность синтеза в виде функции

$$
\Delta W^{3}(\delta)=W_{ж}^{3}(\delta)-W_{\mathrm{c}}^{3}(\delta) .
$$

График такой функции для конкретной задачи показан на рисунке 3. График демонстрирует области, в которых погрешность $\Delta W^{3}(\delta)$ мала либо, наоборот, велика. Эта особенность графического представления погрешности позволяет выделять области, имеющие большие отклонения, и намечать меры для их снижения за счет изменения значений узлов интерполирования. Напомним, что в ВИМ существует механизм, который позволяет изменять погрешность в области времени на начальном (или конечном) участке интервала $\left[0, t_{\mathrm{y}}\right]$ путем соответствующего смещения узлов $\delta_{i}, i=\overline{1, \eta}$.

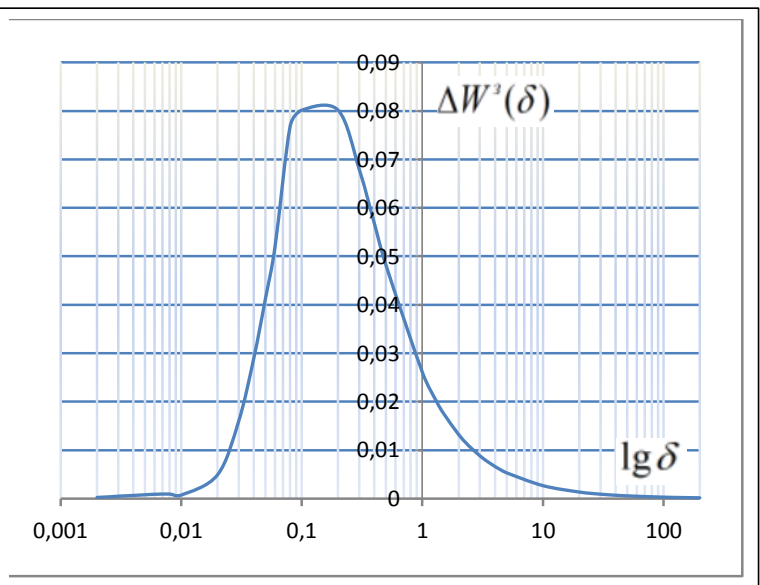

Рис. 3. График отклонения $\Delta W^{3}(\delta)$ синтезированной передаточной функции $W_{\mathrm{c}}^{3}(\delta)$ от желаемой $W_{ж}^{3}(\delta)$ замкнутой системы

Fig. 3. The graph of the deviation of the synthesized transfer function $W_{\mathrm{c}}^{3}(\delta)$ from the desired closed system $W_{\%}^{3}(\delta)$

Функция $\Delta W^{3}(\delta)$ может быть использована для получения численных оценок свойств САУ, например, в виде $\Delta W^{3}=\max _{\delta}\left|\Delta W^{3}(\delta)\right|$,

$$
\Delta W^{3}\left(\delta_{i}\right)=\int_{0}^{\infty} \Delta k^{3}(t) e^{-\delta_{i} t} d t, \delta_{i}>0 \text { и т.п. }
$$

Смысл таких оценок вытекает из взаимосвязи функций $\Delta W_{\mathrm{c}}^{3}(\delta)$ и $\Delta k^{3}(t)$, определенных соотношением

$$
\begin{aligned}
& \Delta W^{3}(\delta)=W_{\text {ж }}^{3}(\delta)-W_{\mathrm{c}}^{3}(\delta)= \\
& \left.=\int_{0}^{\infty} k_{\text {ж}}^{3}(t) e^{-\delta t} d t\right)-\int_{0}^{\infty} k_{\mathrm{c}}^{3}(t) e^{-\delta t} d t=\int_{0}^{\infty} \Delta k^{3}(t) e^{-\delta t} d t,
\end{aligned}
$$


в котором $k_{\text {ж }}^{3}(t)$ и $k_{\mathrm{c}}^{3}(t)$ - импульсные переходные характеристики.

И еще один вывод, который напрашивается при просмотре графика $\Delta W^{3}(\delta)$. Он связан с возможностью получения наилучшего равномерного приближения функции $W_{\mathrm{c}}^{3}(\delta)$ к $W_{\text {ж}}^{3}(\delta)$. Чебышев П.Л. доказал, что такие приближения достигаются, если, в частности, величины всех отклонений функции $\Delta W^{3}(\delta)$ (в обозначениях рассматриваемой задачи) равны между собой, а их знаки чередуются. Это явление, получившее название альтернанса Чебышева, в данном случае не соблюдается, что объясняется тем, что лучшее решение выбиралось по переходным характеристикам синтезированных САУ. Этот выбор можно формализовать, обеспечивая приближению к Чебышевскому альтернансу функции времени, например $\Delta k^{3}(t)$. Инструментом для этого может служить распределение узлов интерполирования [9]. Некоторые из изложенных сведений были использованы для формирования критерия робастности САУ с запаздыванием [11]. Он позволяет оценивать изменения параметров объекта управления, которые приводят к изменениям свойств САУ, в частности, перерегулирования.

\section{Заключение}

В работе рассмотрены вопросы оценивания точности синтеза систем управления с запаздыванием. Как результат можно выделить два основных вывода. Первый из них связан с аппроксимацией передаточной функции звена запаздывания. Он открывает новую возможность в аппроксимации звена запаздывания - перераспределение погрешности между участками малых и больших значений времени. Этот вывод важен еще и тем, что он распространяется на задачу исследования точности решения уравнения синтеза. Второй результат также связан с оценками точности синтезированных САУ. Он дает возможность сравнивать не- сколько вариантов синтеза по точным характеристикам без привлечения аппроксимации звена запаздывания.

Некоторые из изложенных сведений были использованы для формирования критерия робастности САУ с запаздыванием [8]. Он позволяет оценивать изменения параметров объекта управления, которые приводят к изменениям свойств САУ, в частности, перерегулирования.

Работа выполнена при поддержке профессора Нгуен Тхань Нги.

\section{Лuтература}

1. Денисенко В.В. Компьютерное управление технологическим процессом, экспериментом, оборудованием. М.: Горячая линия-Телеком, 2009. $608 \mathrm{c}$.

2. Громов Ю.Ю., Земской Н.А., Лагутин А.В., Иванова О.Г., Тютюнник В.М. Системы автоматического управления с запаздыванием. Тамбов: Изд-во Тамб. гос. техн. ун-та, 2007. $76 \mathrm{c}$.

3. Курганов В.В., Цавнин А.В. Управление объектом с запаздыванием // Автоматика и программная инженерия. 2015. № 2. C. $9-13$.

4. Лукас В.А. Теория автоматического управления. М.: Недра, 1990. 416 с.

5. Стопакевич А.А. Проектирование робастных регуляторов объектами с большим запаздыванием // Восточно-европейский журнал передовых технологий. 2016. Т. 1. № 2. С. 48-56.

6. Федосеев Б.Т. Об анализе САР со звеном задержки в контуре. URL: http://model.exponenta.ru/ (дата обращения: 28.03.2018).

7. Goncharov V.I., Aleksandrov I.A., Rudnicki V.A., Liepinsh A.V. Real Interpolation Method for Automatic Control Problem Solution. Saarbrucken, LAP LAMBERT Academic Publishing, 2014, $291 \mathrm{p}$.

8. Гончаров В.И. Вещественный интерполяционный метод синтеза систем автоматического управления. Томск: Изд-во ТПУ, 1995. $100 \mathrm{c}$.

9. Бейкер Дж., Грейвс-Моррис П. Аппроксимации Паде. М.: Мир, 1986. 502 c.

10. Goncharov V., Rudnicki V. Real interpolation method in automatic control systems self-adjustment problem // Systems Science, 2010, vol. 36, no. 3, pp. 35-37.

11. Белихмайер М.Я., Гончаров В.И. Синтез корректирующих устройств систем автоматического управления на основе равномерного приближения // Автоматика и телемеханика. 1997. № 5. C. 3-11.

\section{Improving the accuracy calculation of time delay automatic control}

V.D. Than ${ }^{1}$, Postgraduate Student, dungvietthan@gmail.com

Yu.N. Dementev ${ }^{1}$, Ph.D. (Engineering), Associate Professor, dementev@tpu.ru

V.I. Goncharov ${ }^{1}$, Dr.Sc. (Engineering), Professor, gvi@tpu.ru

${ }^{1}$ National Research Tomsk Polytechnic University, Tomsk, 634050, Russian Federation

Abstract. The article considers accuracy problems of synthesis automatic control systems (ACS) with time delay. The questions cover the traditional approach based on approximation of a delay element transfer function by a rational fractional 
expression, as well as the original way that allows keeping an accurate description of the delay element when solving the problems of ACS regulator synthesis.

The authors choose the last option, which is based on using a special case of the Laplace transform that provides a transition to the description of dynamical systems in the form of image functions with a real variable. This numerical method makes it possible to obtain discrete models of dynamic systems, combining the advantages of numerical methods and digital computing tools.

Based on a numerical method the authors consider three topical problems of synthesis and research of the indicated class systems. The first one is related to a delay element approximation. The paper gives a comparative analysis of the approaches based on segments of the Taylor series, Padé fractions and the numerical method. The advantages of the latter are: higher accuracy and, most importantly, it is possible to redistribute the approximation error in the region of small/large values of time.

Within the framework of the second problem the paper shows the possibility of forming and solving the synthesis equation for an automatic control system without approximation of a delay element ensuring the achievement of the potentially possible synthesis accuracy. The third problem reveals the possibilities of the numerical method in estimating the accuracy of automatic control system synthesis and the comparison of several options. The authors propose a variant of estimation that does not require the approximation of the delay element. A result is graphically illustrated and proved by numbers of examples.

Keywords: delay element, regulator synthesis, delay element approximation, Laplace transform, time delay ACS accuracy improvement.

Acknowledgements. The work has been supported by Professor Nguyễn Thanh Nghị.

\section{References}

1. Denisenko V.V. Computer Control of a Technical Process, an Experiment, Equipment. Moscow, Hotline-Telecom Publ., 2009, 608 p.

2. Gromov Yu.Yu., Zemsky N.A., Lagutin A.V., Ivanova O.G., Tyutyunnik V.M. Automatic Control Systems with Delay. Tambov, TSTU Publ., 2007, 76 p.

3. Kurganov V.V., Tsavnin A.V. Controlling an object with delay. Automation and Software Engineering. 2015, no. 2, pp. 9-13.

4. Lucas V.A. Theory of Automatic Control. Moscow, Nedra Publ., 1990, 416 p.

5. Stopakevich A.A. Designing robust regulators with objects with a long delay. East-European J. of Advanced Technologies. 2016, vol. 1, no. 2, pp. 48-56.

6. Fedoseev B.T. On the Analysis of ATS with a Link of Delay in the Circuit. Available at: http://model.exponenta.ru/ (accessed March 28, 2018).

7. Goncharov V.I., Aleksandrov I.A., Rudnicki V.A., Liepinsh A.V. Real Interpolation Method for Automatic Control Problem Solution. Saarbrucken, LAP LAMBERT Academic Publ., 2014, 291 p.

8. Goncharov V. Real Interpolation Method of Synthesis of Automatic Control Systems. Tomsk, TPU Publ., 1995,100 p.

9. Baker J., Graves-Morris P. Padé Approximations. Cambridge Univ. Press, 1996, 764 p. (Russ. ed.: Moscow, Mir Publ., 1986, 502 p.).

10. Goncharov V., Rudnicki V. Real interpolation method in automatic control systems self-adjustment problem. Systems Science. 2010, vol. 36, no. 3, pp. 35-37.

11. Belichmayer M.Ya., Goncharov V.I. Synthesis of correcting devices of automatic control systems based on uniform approximation. Automation and Remote Control. 1997, no. 5, pp. 3-11 (in Russ.)

\section{Примеры бибциографического описания статьи}

1. Тхан В.З., Дементьев Ю.Н., Гончаров В.И. Повышение точности расчета систем автоматического управцения с запаздыванием // Программные продукты и системы. 2018. Т. 31. № 3. С. 521-526. DOI: $10.15827 / 0236-235 X .123 .521-526$.

2. Than V.D., Dementev Yu.N., Goncharov V.I. Improving the accuracy calculation of time delay automatic control. Software \& Systems. 2018, vol. 31, no. 3, pp. 521-526 (in Russ.). DOI: 10.15827/0236235X.123.521-526. 


\title{
Облачная платформа IACPaaS для разработки оболочек интеллектуальных сервисов: состояние и перспективы развития
}

\author{
B.В. Грибова 1, д.т.н., старший научный сотрудник, зам. директора, gribova@iacp.dvo.ru \\ A.C. Клешев 1, д.фр.-м.н., профессор, главный научный сотрудник, kleschev@iacp.dvo.ru \\ Ф.M. Москаленко 1, к.т.н., старший научный сотрудник, philipmm@iacp.dvo.ru \\ B.A. Тимченко ${ }^{1}$, к.т.н., старший научный сотрудник, vadim@iacp.dvo.ru

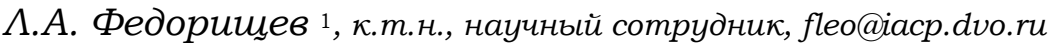 \\ E.A. Шалфреева 1, к.т.н., доиент, старший научный сотрудник, shalf@iacp.dvo.ru
}

${ }_{1}^{1}$ Институт автоматики и проиессов управления ДВО РАН, г. Владивосток, 690041, Россия

В работе описаны основные характеристики и функциональные возможности платформы облачных вычислений IACPaaS, которая поддерживает три модели предоставления облачных сервисов - PaaS, SaaS и DaaS. Платформа предназначена для разработки специализированных (то есть ориентированных на определенные предметные области и/или классы решаемых задач) оболочек интеллектуальных сервисов, а также прикладных интеллектуальных сервисов с использованием таких оболочек, которые при этом предоставляются и как облачные сервисы платформы. Создание (сопровождение) прикладных сервисов с помощью оболочки сводится к формированию (модификации) базы знаний с использованием предоставляемых этой оболочкой средств формирования баз знаний и связыванию ее с решателем задач. Решатель задач состоит из набора агентов - программных компонентов, взаимодействующих друг с другом посредством обмена сообщениями.

В специализированных оболочках при представлении знаний используется специфичное для предметной области концептуальное представление, определяемое онтологией той области, для которой создается оболочка. Такая проблемно-ориентированная модель (язык) представления знаний используется средством формирования баз знаний для генерации ориентированного на экспертов предметной области пользовательского интерфейса. В результате эксперты могут формировать и сопровождать базы знаний и данных в привычной для себя системе понятий (без посредников в лице инженеров-когнитологов или дополнительного обучения), не совершая ошибок в использовании языка представления знаний.

Платформа IACPaaS предоставляет базовую (универсальную) и множество специализированных технологий разработки оболочек прикладных интеллектуальных сервисов с использованием инструментальных средств поддержки этих технологий. Также предоставляется технология взаимодействия агентов решателей задач с внешним (не входящим в состав платформы IACPaaS) программным обеспечением. Она основана на стандартном механизме обработки http-запросов и возможности запуска исполняемых файлов внешнего программного обеспечения из программ (скриптов), расположенных на web-сервере.

Ключевые слова: оболочки экспертных систем, интеллектуальные системы, технология разработки интеллектуальных систем, облачная платформа, облачные вычисления, интеллектуальные сервисы, мультиагентные системьі.

Технологии облачных вычислений имеют сегодня широкое распространение. Рынок предоставляемых облачных решений и услуг достаточно разнообразен и предлагает как отдельные компоненты и услуги, так и широкий спектр комплексных решений, реализующих несколько моделей, - IaaS, PaaS, $\mathrm{SaaS}, \mathrm{DaaS}$ и др. Анализируя имеющиеся на рынке облачные инфраструктуры, предлагающие средства разработки различных приложений - модель PaaS [1-3], можно констатировать, что все они предназначены для решения широкого круга задач и содержат системы управления БД (MySQL, Redis, MongoDB, PostgreSQL, Memcached, Oracle и др.), a также средства разработки приложений на объектно-ориентированных и скриптовых языках программирования (Java, PHP, Python, Ruby, JavaScript, Node.js, Go, .NET и др.).

На сегодняшний день актуальной является задача поиска методов развития уровня $\mathrm{PaaS}$, позволяющих упростить создание сложных прикладных сервисов разных типов на основе масштабируемых облачных сред. Решению данной задачи посвящено достаточно большое количество проектов, и многие облачные платформы имеют специализированный инструментарий для поддержки разработки приложений разных типов. Типичным примером являются универсальные и специализированные инструменты разработки web-сайтов. В то же время большой класс задач, решение которых возможно лишь с помощью интеллектуальных систем (ИС), в архитектуре которых присутствует специализированный компонент - база знаний, не покрывается этими проектами. Общепризнано, что универсальные технологии либо полностью не применимы для создания ИС, либо значительно усложняют процесс их разработки и, прежде всего, сопровождения; вследствие этого жизнеспособность таких систем оказывается низкой [4].

Для снижения трудоемкости разработки и сопровождения ИС традиционно используются обо- 
лочки, каждая из которых предлагает разработчику систему управления базами знаний, основанную на некоторой модели представления знаний, и решатель задач, реализующий алгоритм обработки знаний и данных [4-7]. Создание (сопровождение) ИС с помощью оболочки сводится к формированию (модификации) базы знаний через систему управления базами знаний и связыванию ее с решателем задач. Разработка оболочек является отдельной и сложной проблемой; в настоящее время неизвестны облачные платформы, которые поддерживают их разработку.

Целью данной работы является описание облачной платформы IACPaaS, предназначенной для разработки оболочек интеллектуальных сервисов, ее основных принципов, архитектуры и функциональных возможностей.

\section{Основные принципы, положенные в основу платформы IACPaaS}

Платформа IACPaaS (далее - платформа) предназначена для разработки оболочек интеллектуальных сервисов по нескольким технологиям, состав которых является расширяемым, создания с помощью этих оболочек прикладных интеллектуальных сервисов, а также использования этих сервисов для решения задач.

Опишем общие принципы, положенные в основу платформы IACPaaS.

Поддерживаемые типы оболочек. Большинство оболочек, реализованных к настоящему времени, являются проблемно-независимыми. Их достоинство в универсальности - потенциальной возможности использования для создания ИС, предназначенных для решения широкого круга задач в различных предметных областях. Стремление разрабатывать именно проблемно-независимые оболочки с возможно более широкой областью применения связано и с высокой трудоемкостью их реализации. В то же время разработка и сопровождение ИС с помощью проблемно-независимой оболочки, не учитывающей специфику конкретной предметной области и задачи, часто оказываются трудоемкими и интеллектуально сложными.

Проблемно-ориентированные (или специализированные) оболочки, как правило, имеют более узкую область применения, чем проблемно-независимые. Однако создание и сопровождение ИС для задач и предметных областей, на которые ориентирована такая оболочка, имеют меньшую трудоемкость и интеллектуальную сложность, что делает такие ИС более жизнеспособными [8-10].

Платформа IACPaaS ориентирована на снижение трудоемкости разработки оболочек, прежде всего проблемно-ориентированных, что, в конечном счете, имеет целью повышение жизнеспособности интеллектуальных сервисов, создаваемых с помощью таких оболочек.
Модель представления знаний и данных. Системы управления базами знаний проблемно-независимых оболочек основаны на проблемно-независимых моделях представления знаний и данных - системах продукций (правил), фреймах, объектно-ориентированных моделях $[11,12]$. В системах продукций предметные и процедурные знания неразрывно связаны и имеют форму правил; в системах фреймов процедурные знания присоединяются к предметным, но имеют иное (процедурное) представление; в объектно-ориентированных моделях представляются только предметные знания и данные. Хотя практика показала, что системы управления базами знаний, основанные на проблемно-независимых моделях представления знаний и данных, позволяют формировать небольшие базы знаний в различных предметных областях, формирование и особенно сопровождение больших (компетентных) баз знаний - задача чрезмерной интеллектуальной сложности. Причина в том, что база знаний создается экспертами в соответствующей предметной области, а не специалистами в области инженерии знаний или программирования. Эксперту для формирования базы знаний и ее сопровождения необходимо, чтобы знания имели привычную для него форму и ему не приходилось бы преобразовывать знания в форму, навязываемую моделью представления знаний.

Система управления базами знаний проблемноориентированной оболочки основана на некоторой проблемно-ориентированной модели представления знаний и данных. В такой модели представляются только предметные знания и данные; она учитывает специфику организации знаний и данных в конкретной предметной области. Благодаря этим свойствам только системы управления базами знаний, основанные на проблемно-ориентированных моделях представления знаний, снижают интеллектуальную сложность формирования и сопровождения баз знаний до приемлемой. Вместе с тем класс таких моделей весьма широк; в качестве примеров можно указать модели представления медицинских знаний о диагностике и лечении [13], математических знаний и знаний о способах рассуждений при доказательстве теорем, знаний о компьютерных программах и их преобразованиях [14], знаний в области неорганической и органической химии [15], знаний о виртуальных мирах и сценах [16], знаний в области технической диагностики роботов [17].

Платформа IACPaaS предлагает разработчикам оболочек интеллектуальных сервисов универсальный проблемно-независимый метаязык для спецификации абстрактного синтаксиса моделей (языков) представления знаний [18]. Метаязык позволяет определить абстрактный синтаксис той модели (языка) представления знаний, которая учитывает организацию знаний и данных конкретной предметной области. 
Система управления базами знаний. Система IACPaaS основана на метаязыке для спецификации абстрактного синтаксиса моделей представления знаний. С помощью специального структурного редактора, входящего в состав IACPaaS [19], инженер знаний может определить абстрактный синтаксис необходимой модели представления знаний в форме грамматики, порождающей размеченные графы [20, 21], - семантические представления баз знаний и данных. Сама грамматика также имеет форму графа с единственной выделенной начальной вершиной (аксиомой). По этой грамматике эксперт с помощью структурного редактора может формировать и модифицировать базы знаний и данных. Структурный редактор генерирует для него полимодальный интерфейс - база знаний и данных (и их разные фрагменты) может представляться в виде размеченного квазидерева, графа, текста, таблицы.

Решатели задач. Разрабатываемые средствами платформы IACPaaS решатели задач имеют формальные параметры, каждый из которых состоит из имени формального параметра и грамматики, задающей абстрактный синтаксис модели представления знаний или данных, средствами которой представляются фактические параметры, соответствующие этому формальному [22]. Создание интеллектуального сервиса на основе оболочки состоит в формировании с помощью системы управления базами знаний необходимых баз знаний и данных - фактических параметров, соответствующих формальным параметрам решателя, и сборке из них и решателя интеллектуального сервиса. Решатели задач разрабатываются на основе агентного подхода, то есть решатель задач состоит из множества агентов, которые обмениваются сообщениями. Такой подход обеспечивает гибкость при создании решателей: решатель может «собираться» из агентов, разработанных ранее.

Использование внешних модулей для создания ИС. Тенденции развития программного обеспечения показывают, что во многих случаях (например, для реализации динамических экспертных систем) к ИС требуется подключение различных дополнительных модулей, реализованных на сторонних платформах. Платформа IACPaaS обеспечивает двусторонний обмен данными между решателями задач платформы IACPaaS и сторонними компонентами на других платформах.

Реализация совместной разработки ИС и их компонентов. Необходимость включения в процесс разработки оболочек и интеллектуальных сервисов специалистов разного профиля (инженеров знаний, экспертов предметной области, проектировщиков, программистов, дизайнеров интерфейса и др.) требует организации их совместной работы. Платформа обеспечивает возможность коллективной разработки оболочек и интеллектуальных сервисов через личные кабинеты разработчиков и механизмы управления процессом разработки.
Поддержка различных технологий создания оболочек. Инструментарий для разработки приложений на платформе IACPaaS можно разделить на два основных типа - универсальный и ориентированный на проблему либо задачу. Универсальный инструментарий позволяет создавать решатели задач любого типа, но процесс создания является более трудоемким по сравнению с использованием специализированного инструментария. Платформа поддерживает создание оболочек по нескольким технологиям: базовой, поддерживаемой универсальными средствами разработки, и специализированным, поддерживаемым специализированными средствами разработки. Набор технологий допускает расширение.

\section{Модель представления знаний и данных. Система управления базами знаний}

Обязательным компонентом любой оболочки ИС является система управления базами знаний. Если в универсальных оболочках базы знаний описываются на специализированных универсальных языках, поддерживающих известные модели представления знаний, то в проблемно-ориентированных оболочках при представлении знаний используется специфичное для предметной области концептуальное представление, определяемое онтологией той области, для которой создается оболочка.

Для спецификации абстрактного синтаксиса необходимой модели представления знаний используется универсальный метаязык, входящий в состав платформы. Сформированный с его помощью абстрактный синтаксис модели представления знаний - это пара $\langle G M, \sigma M>$, где $G M$ - граф понятий, в терминах которого формируются базы знаний и данных, возможно, содержащий циклы и петли, а $\sigma M$ - разметка этого графа. Граф $G M$ - это тройка $G M=<$ Vertices, Arcs, RootVertex $>$, где Vertices множество вершин графа, Arcs - множество дуг графа, RootVertex - корневая вершина графа (RootVertex $\in$ Vertices). Средства разметки $\sigma M$ включают в себя разметку вершин $\sigma V$ и разметку дуг $\sigma A$. Эта разметка позволяет при описании абстрактного синтаксиса необходимой модели представления знаний задать ограничения на структуру и содержание знаний или данных конкретной предметной области. Подробно метаязык описания моделей представления знаний рассмотрен в [18].

Базы знаний и данных, сформированные по описанной модели представления знаний, также являются парой $K B=<G I, \sigma I>$, где $G I-$ граф (сеть) понятий, $\sigma I$ - разметка этого графа. Граф $G I$ - это тройка GI =<IVertices, IArcs, IRootVertex>, компоненты которой представляют собой множество вершин (IVertices), дуг (IArcs) и корневую вершину (IRootVertex $\in$ IVertices). Средства разметки $\sigma I$, в 
отличие от $\sigma M$, включают в себя только разметку вершин, то есть $\sigma I \equiv \sigma V$. Каждая вершина графа информации отображается в пару $\sigma V=<S M, R M>$, где $S M$ - служебная метка, $R M$ - метка соответствия между моделью представления знаний (данных) и ее концептуальным представлением. Метка соответствия $R M$ - это имя понятия предметной области, которому соответствует либо имя понятия предметной области, заданное в концептуальной модели, либо некоторое имя, входящее в класс предметных областей, также заданный в этой концептуальной модели.

Cоответствие между базами знаний (данных) и их концептуальными представлениями задается следующим образом [23]. Каждой вершине в графе, представляющем базу знаний (данных), соответствует некоторая единственная вершина в ее концептуальной модели, называемая вершиной-прототипом (и каждой вершине в графе, представляющем концептуальную модель, соответствует некоторое множество вершин в базе знаний (данных)). Количество вершин в базе знаний (данных) определяется разметкой графа, представляющего его концептуальную модель. Проводя аналогию с программированием, можно заметить, что в предлагаемой модели, с одной стороны, вся информация представляется в едином унифицированном формате - в форме корневых иерархических орграфов, в чем можно усмотреть прямое сходство с функциональным программированием, в котором все данные представлены также унифицированно списками, с другой стороны, в традиционном программировании общепринятой практикой является разделение информации (входной, промежуточной и выходной) на множество разрозненных информационных единиц, соответствующих типам данных (программа имеет множество переменных различных типов). В связи с этим программист должен знать все неявные связи между переменными и выражать их через алгоритмы обработки. Предлагаемая модель основана на обратном принципе: количество орграфов невелико, они имеют более сложную структуру, но эта структура явно определяет связи между всеми информационными единицами.

Внутреннее представление баз знаний, порождаемых на основе концептуальной модели представления знаний, также имеет вид корневых иерархических орграфов (с возможными петлями и циклами). Терминальные вершины этих орграфов представляют объекты разных сортов: строки, целочисленные и вещественные константы и др. Иерархичность орграфа означает, что его вершина может быть либо простой (не имеющей внутренней структуры), либо некоторым другим орграфом (или его подграфом).

Для управления (формирования, модификации, отладки) баз знаний и данных платформа содержит специализированный редактор [19], который автоматически генерирует пользовательский интер- фейс по модели представления знаний. Для представления базы знаний (данных) в удобной для пользователей форме (модели представления) платформа имеет дополнительные средства генерации мультимодальных интерфейсов в форме графов, текстов и таблиц.

\section{Решатели задач}

Решатели задач разрабатываются на основе агентного подхода: решатель задач состоит из множества обменивающихся сообщениями агентов. Среди агентов решателя выделяются корневой (начинает работать первым), интерфейсный контроллер (обеспечивает сопряжение пользовательского интерфейса с решателем задач) и множество обрабатывающих агентов. Разработка кода агентов осуществляется на языке Java. Пользовательский web-интерфейс может быть создан несколькими способами: с использованием набора интерфейсных элементов, поддерживаемых специализированным интерфейсным агентом «Вид», а также средствами JavaScript и Flash. Разработка решателей задач подробно описана в [22].

Каждый решатель задач представляется корневым орграфом, который порожден по хранящейся в Фонде платформы метаинформации решателей задач (см. http://www.swsys.ru/uploaded/image/ 2018-3/2018-3-dop/11.jpg), интерпретируемой как абстрактный синтаксис языка спецификации решателей задач.

Агент декларативно представляется корневым орграфом, который порожден по хранящейся в Фонде платформы метаинформации агентов (см. http://www.swsys.ru/uploaded/image/2018-3/2018-3dop/12.jpg), интерпретируемой как абстрактный синтаксис языка спецификации агентов. Некоторые терминальные вершины сети, описывающей агента, представлены объектами сорта бинарные данные, содержащими как исходный, так и исполняемый код агента [24].

Каждый шаблон сообщений является метаинформацией, интерпретируемой как абстрактный синтаксис языка сообщений агентов. Некоторые терминальные вершины орграфа, описывающего шаблон сообщений, также могут быть представлены объектами сорта бинарные данные, содержащими методы создания и обработки сообщений [24].

Представление всех данных платформы в форме корневых иерархических орграфов обеспечивает универсальность их обработки с помощью единого программного интерфейса (API) для доступа к единицам хранения всех типов, а также единого инструментального сервиса платформы структурного редактора (для их формирования и сопровождения). Хранимые на платформе данные могут быть экспортированы во внешние форматы, количество которых расширяемо. 


\section{Использование внешних модулей для создания ИС}

Платформа поддерживает создание оболочек и сервисов на гетерогенных вычислительных архитектурах: одна часть компонентов сервиса может быть создана непосредственно на платформе IACPaaS (с использованием оболочек), другая часть - на сторонних платформах. При создании решателя задач оболочки также возможно его обращение к сторонним модулям на основе http-протокола. Для реализации механизма отправки httpзапросов из программных агентов платформы на внешние адреса был разработан агент-посредник. Агенты платформы взаимодействуют не напрямую с внешними модулями, а с агентом-посредником (посредством стандартного обмена сообщениями).

\section{Реализация совместной разработки ИС и их компонентов}

Каждому зарегистрированному пользователю платформы предоставляется виртуальное рабочее место - личный кабинет. Личные кабинеты представляют собой набор инструментов управления личными данными и сервисами пользователя.

Пользователи платформы разделяются на следующие типы: гость, зарегистрированный пользователь и служебный пользователь. Гостю доступна ограниченная функциональность, он может просмотреть содержимое Фонда платформы; зарегистрировавшись на платформе, он становится зарегистрированным пользователем, ему предоставляются личный кабинет и набор функциональных возможностей: запуск сервисов, создание оболочек сервисов по предлагаемым технологиям, создание сервисов с использованием оболочек, создание новых работ и технологий.

Зарегистрированные пользователи могут иметь дополнительные служебные роли: управляющий единицей хранения, администратор раздела, руководитель групповой разработки компонентов оболочки либо сервиса на ее основе. Руководитель группы определяет и приглашает участников созданной группы, распределяет роли, назначает сроки исполнения, а также формирует (передает) необходимые для выполнения работы ресурсы. Помимо перечисленных служебных ролей зарегистрированных пользователей, у платформы есть администратор, который отвечает за набор разделов Фонда платформы в целом, назначает администраторов разделов, удаляет пользователей, если они нарушают политику платформы.

\section{Поддержка различных технологий создания оболочек}

Пользователи могут разрабатывать оболочки ИС (возможно создание ИС с нуля, без использова- ния оболочек, что в общем случае значительно более трудоемко) в соответствии с работами, поддерживаемыми платформой, а также создавать новые работы. Под работой понимается набор инструментальных сервисов, с помощью которых можно создавать или модифицировать компоненты (определенного типа) разрабатываемой ИС или оболочки. Работа может быть простой или составной. Составная работа включает несколько этапов (шагов). Примером простой работы является создание базы знаний на основе ее концептуальной модели (пустой базы знаний). Пример составной работы - разработка агента, которая включает разработку шаблонов сообщений (этап пропускается, если все необходимые шаблоны сообщений содержатся в Фонде платформы) и декларативной части агента, генерацию заготовки кода агента на языке Java, его загрузку на платформу и интеграцию в декларативную спецификацию агента.

Компоненты ИС и оболочки создаются в соответствии с технологиями, доступными на платформе. Технология описывает работы по созданию оболочек (либо ИС) и частичный порядок выполнения этих работ. Технологии, поддерживаемые платформой, разделены на два класса: базовая технология и множество специализированных технологий.

Базовая технология позволяет создать ИС и оболочку для любого класса решаемых задач, при этом архитектура решателя допускает разные способы разбиения на агенты и их компоновки. Подробное описание технологии дано в [22, 24]. В настоящее время с использованием базовой технологии разработан ряд ИС и оболочек, а также инструментальных сервисов платформы, например, редактор графических сцен, интерпретатор виртуальных сред, оболочка для медицинской диагностики, сервис по диагностике острых конъюнктивитов и др.

Специализированные технологии ориентированы либо на конкретный класс задач, либо на определенную архитектуру решателя задач. В любом случае архитектура решателя задач такой оболочки или сервиса имеет заданный технологией состав компонентов. Количество специализированных технологий может расширяться пользователями платформы. Каждая технология поддерживается набором инструментальных сервисов и информационных ресурсов, необходимых для создания оболочки или сервиса. В настоящее время платформа поддерживает создание ИС и оболочек по двум специализированным технологиям: технологии разработки ИС и оболочек с интерактивными виртуальными средами и технологии разработки ИС и оболочек с агентами, присоединенными к метаинформации.

Специализированная технология разработки ИС и оболочек с интерактивными виртуальными средами предназначена для создания облачных 
сервисов с 3D-сценами. В соответствии с данной технологией оболочка содержит онтологию виртуальной сцены, по которой описывается 3D-сцена, причем описание сцены разделено на два этапа логическое и презентационное. Логическое описание формирует эксперт предметной области с помощью редактора информации, презентационное - дизайнер с помощью графического редактора, разработанного для поддержки данной технологии. Сформированное описание 3D-сцены подается на вход интерпретатору виртуального мира (решателю задач, разработанному для поддержки данной технологии), который затем автоматически генерирует 3D-сцену и обеспечивает управление ею в процессе работы пользователя с облачным сервисом. Более подробное описание технологии и реализованных сервисов дано в работе [16].

\section{Специилизированная} технология разработки сервисов и оболочек $c$ агентами, присоединенными $к$ метаинформации, удобна для использования в двух случаях: если результатом работы сервиса является некоторый выходной информационный ресурс, формирование которого по его концептуальной модели осуществляется методом «сверху-вниз»; если разработчик может декларативно (в виде информационного ресурса) описать решатель задач. В этом случае решатель задач - это специальный инструментальный сервис «расширяемый редактор информации», управляемый метаинформацией либо выходного информационного ресурса, либо управляющей структуры, к некоторым вершинам которой присоединены агенты, порождающие фрагменты выходного информационного ресурса (результата работы сервиса) или вы-

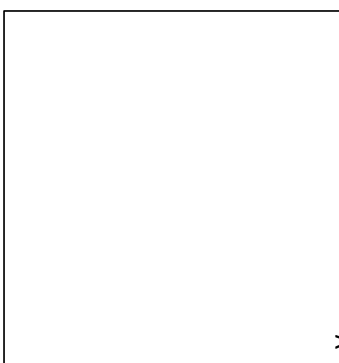

полняющие другие требуемые для работы сервиса преобразования. С помощью данной технологии разработана оболочка для исследований в области верификации интуитивных математических доказательств.

\section{Архитектура платформы}

Платформа IACPaaS поддерживает три модели предоставления сервисов - PaaS, SaaS и DaaS. Ha рисунке 1 справа представлена модель предоставляемых сервисов платформы IACPaaS, слева стандартные модели предоставления сервисов
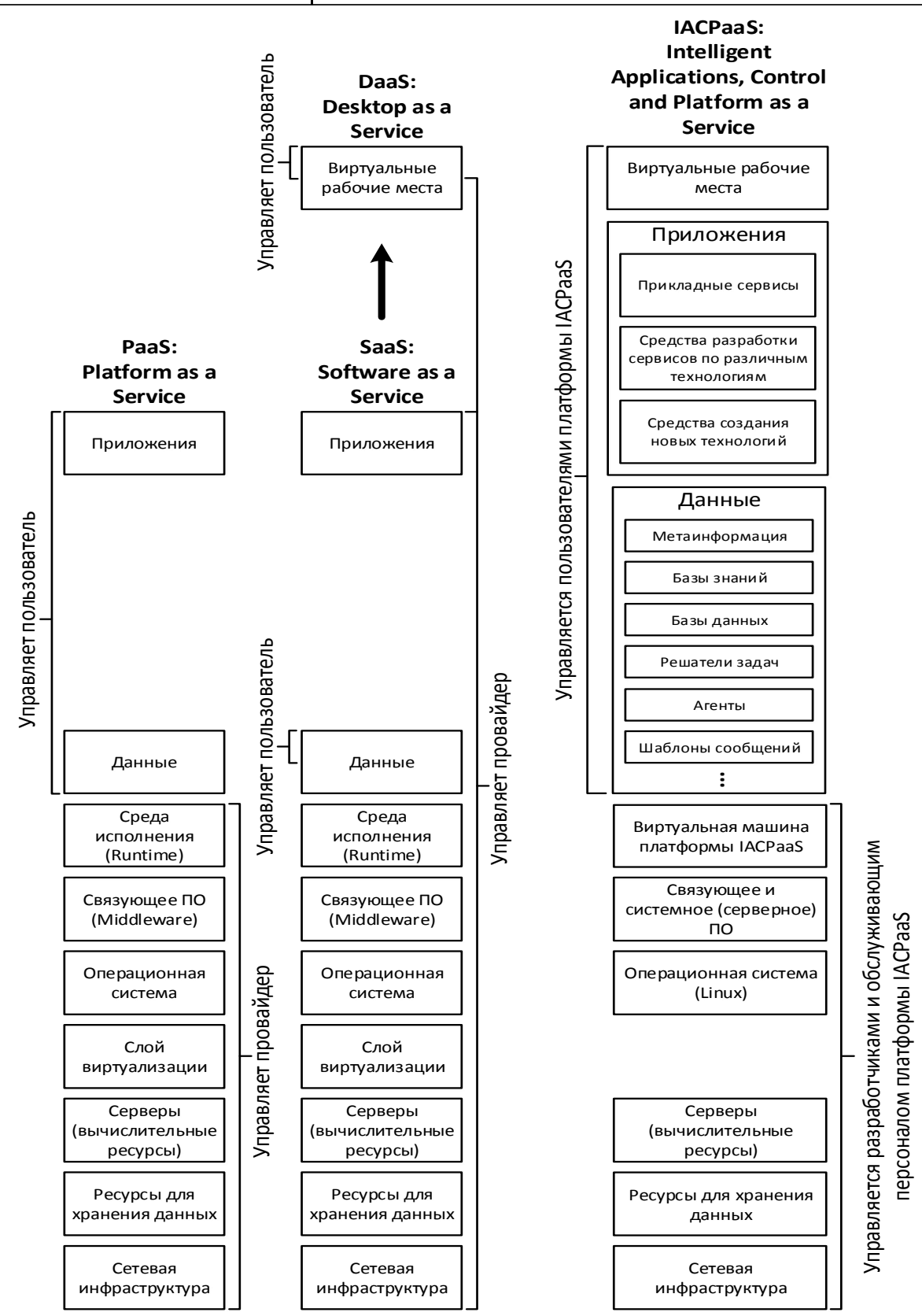

Рис. 1. Различные модели предоставления сервисов

Fig. 1. Different models of service delivery 
$\mathrm{PaaS}, \mathrm{SaaS}$ и DaaS в облачных платформах. Рисунок позволяет сравнить набор компонентов платформы IACPaaS и наборы компонентов в других облачных платформах в соответствии с реализованными в их рамках моделями предоставления сервисов.

Архитектуру платформы можно разделить на четыре логических уровня: системный уровень, уровень управления, сервисный уровень и библиотечный уровень (рис. 2).

1. Системный уровень (уровень Виртуальной машины). Виртуальная машина платформы IACPaaS состоит из процессора информационных ресурсов, процессора решателей задач и процессора пользовательского интерфейса. Каждый из перечисленных процессоров предназначен для поддержки соответствующих архитектурных компонентов облачных сервисов.

2. Библиотечный уровень (уровень Фонда платформы и Фонда пользователя). Фонд платформы и Фонд пользователя - это множество единиц хранения различных видов и уровней абстрак- ции (содержательно это хранимые базы данных и знаний, их концептуальные модели (метаинформация), решатели задач, агенты, шаблоны сообщений, модель абстрактного пользовательского интерфейса и т.п.).

3. Сервисный уровень. Данный уровень является совокупностью сервисов и оболочек интеллектуальных сервисов. Выделяются прикладные сервисы, создаваемые разработчиками для решения прикладных задач, а также оболочки и специализированные инструментальные сервисы, обеспечивающие поддержку соответствующих технологий разработки сервисов и оболочек, работ и необходимые для развития Фонда платформы.

4. Уровень управления. Данный уровень представлен базовым инструментальным сервисом Система управления, который предназначен для обеспечения контролируемого доступа к функциональным возможностям платформы IACPaaS и управления правами доступа на использование прикладных и инструментальных сервисов, разработанных на базе платформы.

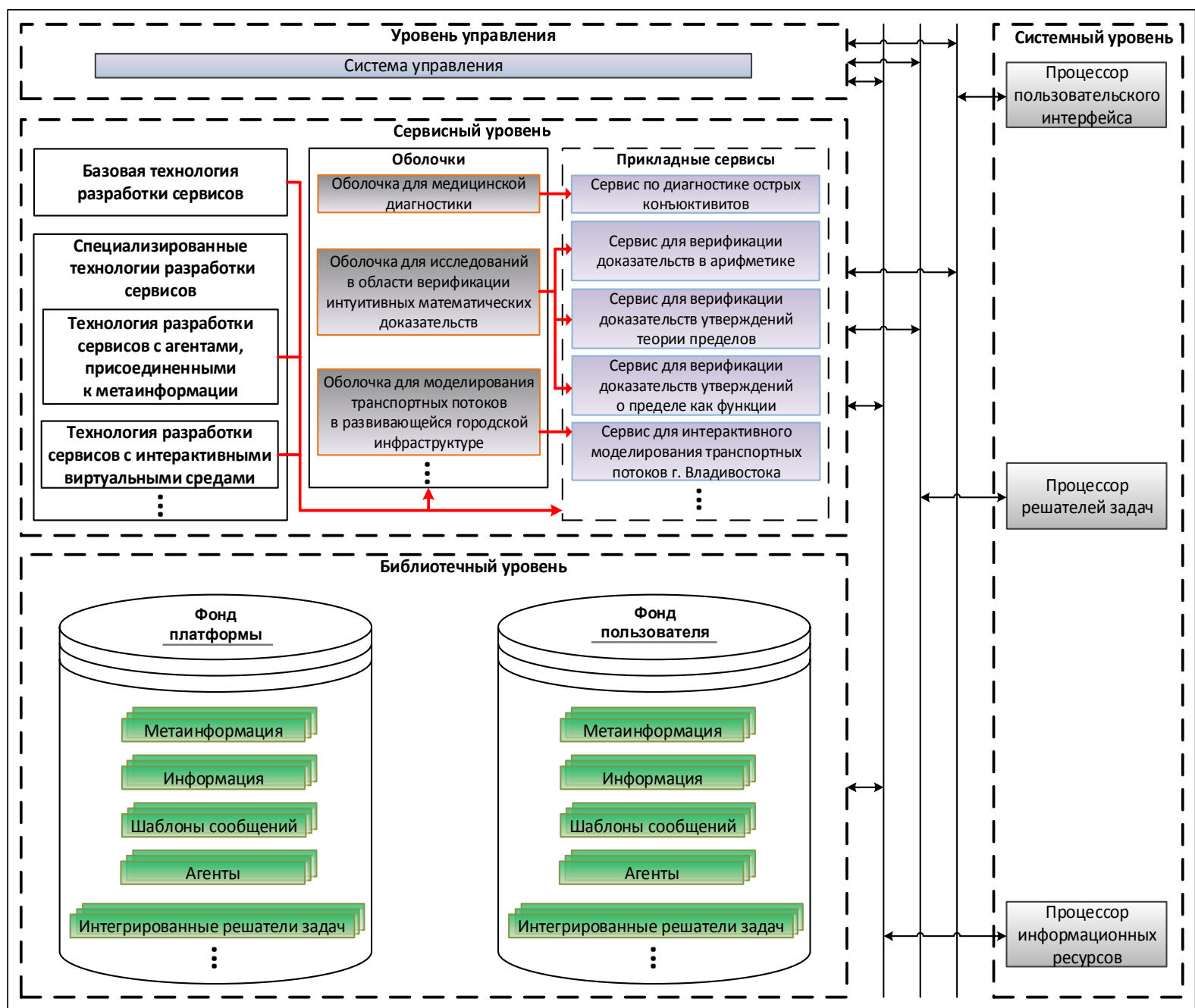

Pис. 2. Концептуальная четырехуровневая архитектура платформы IACPaаS

Fig. 2. A conceptual four-level architecture of the IACPaaS platform 


\section{Заключение}

В работе описаны основные характеристики и функциональные возможности облачной платформы IACPaaS, которые отличают ее от других платформ.

Платформа поддерживает создание специиалзированных оболочек интеллектуальных систем. Их основная особенность и отличие от проблемнонезависимых оболочек - ориентация на класс задач. С одной стороны, такие оболочки имеют более узкую по сравнению с проблемно-независимыми оболочками область применения, а с другой, они учитывают специфику предметной области и задачи. В связи с этим формирование баз знаний с использованием таких оболочек значительно упрощается, в процесс разработки могут быть включены эксперты предметной области, что соответствует современным требованиям к созданию интеллектуальных систем. Простота и понятность формирования баз знаний в таких типах оболочек, как отмечается в [8-10], значительно упрощают процесс разработки интеллектуальных систем и повышают их качество.

Платформа поддерживает создание оболочек ИС и сервисов по нескольким технологиям: базовой и специализированныл. В настоящее время реализована поддержка двух специализированных технологий: технологии разработки сервисов с интерактивными виртуальными средами и технологии создания сервисов с агентами, присоединенными к метаинформации. Каждая такая технология имеет свой набор инструментальных сервисов, упрощающих (по сравнению с базовой технологией) создание разрабатываемой оболочки или сервиса.

Платформа поддерживает создание новых специализированных технологий и работ, разработку необходимых для их поддержки инструментальных сервисов с использованием уже существующих технологий платформы.

Особенностью платформы является поддержка запуска и выполнения сервисов не только непосредственно на платформе, но и на сторонних вычислительных платформах, взаимодействие с приложениями которых возможно по протоколу http. Это обеспечивает гибкое создание оболочек и сервисов без ограничений на вычислительные мощности, используемые библиотеки, операционные системы и другие требования.

Решатели задач разрабатываются на основе агентного подхода, в соответствии с которым любой решатель - это множество агентов, обрабатывающих информационные ресурсы и обменивающихся между собой сообщениями.

Зарегистрированные пользователи платформы имеют личные кабинеты - виртуальные рабочие места, которые предоставляют им набор инструментов для управления данными и сервисами.
В настоящее время ведутся работы по расширению функциональных возможностей платформы, прежде всего по повышению уровня инструментальной поддержки различных технологий. Важными задачами являются усовершенствование методов и средств обеспечения безопасности платформы и защиты ее от некорректных действий пользователей, создание усовершенствованных методов единого программного интерфейса для доступа к единицам хранения Фонда и операций над информационными ресурсами.

Платформа поддерживает три модели облачных вычислений: PaaS, SaaS, DaaS.

Работа выполнена при частичной финансовой поддержке РФФИ (проекты №№ 16-07-00340 u 17-07-00299) и ПФИ ДВО РАН «Дальний Восток» (проект № 18-5-078)

\section{Лuтература}

1. Sun Le, Dong H., Khadeer Hussain F., Khadeer Hussain O., Chang E. Cloud service selection: State-of-the-art and future research directions. J. of Network and Computer Applications, 2014, vol. 45 , pp. 134-150.

2. CloudServiceMarket. A comprehensive overview of Cloud Computing services. URL: http:/www.cloudservicemarket.info/ default.aspx (дата обращения: 06.10.2017).

3. Zhang Qi, Cheng Lu, Boutaba R. Cloud computing: stateof-the-art and research challenges. J. of Internet Services and Applications, 2010, no. 1, pp. 7-18. DOI 10.1007/s13174-010-0007-6.

4. Рыбина Г.В. Интеллектуальные системы: от А до Я. Серия монографий. В 3-х книгах. Книга 3. Проблемно-специализированные интеллектуальные системы. Инструментальные средства построения интеллектуальных систем. М.: Научтехлитиздат, 2015. $180 \mathrm{c.}$

5. Kumar S., Prasad R. Importance of expert system shell in development of expert system. Intern. J. of Innovative Research \& Development, 2015 , vol. 4 , iss. 3, pp. 128-133.

6. Rajendra M. Sonar An enterprise intelligent system development and solution framework. Intern. J. of Applied Science, Engineering and Technology, 2007, vol. 4, no. 1, pp. 34-39.

7. Schalkoff R.J. Intelligent systems: principles, paradigms and pragmatics. Sudbury, Mass. Jones and Bartlett Publ., 2011, $758 \mathrm{p}$.

8. Артемьева И.Л. Специализированные оболочки интеллектуальных систем для сложно-структурированных предметных областей // 11-я Национ. конф. по искусств. интеллекту с междунар. участ. М.: ЛЕНАНД, 2008. Т. 1. С. 95-103.

9. Загорулько Ю.А., Боровикова О.И. Программная оболочка для построения многоязычных тезаурусов предметных областей, ориентированная на экспертов // КИИ-2012: тр. 13-й Национ. конф. по искусств. интеллекту с междунар. участ. Белгород: Изд-во БГТУ, 2012. Т. 4. С. 76-83.

10. Загорулько Ю.А. Семантическая технология разработки интеллектуальных систем, ориентированная на экспертов предметной области // Онтология проектирования. 2015. № 1. C. $30-46$.

11. Musen M. The protégé project: a look back and a look forward. Newsletter AI Matters, 2015, vol. 1, iss. 4, pp. 4-12. DOI: $10.1145 / 2757001.2757003$.

12. Осипов Г.С. Методы искусственного интеллекта. М.: Физмалит, 2015. 296 с.

13. Черняховская М.Ю. Формирование баз наблюдений на основе онтологии медицины // Информатика и системы управления. 2009. № 4. С. 198-200.

14. Князева М.А., Купневич О.А. Модель онтологии предметной области «Оптимизация последовательных программ». Определение расширения языка модели структурных программ 
терминами потокового анализа // НТИ: Сер. 2. 2005. № 4. C. $14-22$.

15. Артемьева И.Л., Рештаненко Н.В. Интеллектуальная система, основанная на многоуровневой онтологии химии // Программные продукты и системы. 2008. № 1. С. 84-87.

16. Грибова В.В., Федорищев Л.А. Визуализация виртуальных сред в облачных сервисах // Научная визуализация. 2016. T. 8. № 1. C. 133-145.

17. Inzartsev A., Pavin A., Kleschev A., Gribova V., and Eliseenko G. Application of artificial intelligence techniques for fault diagnostics of autonomous underwater vehicles. Proc. OCEANS 2016 MTS/IEEE Conference \&Exhibition, USA, Monterey, 2016. DOI: 10.1109/OCEANS.2016.7761098.

18. Gribova V.V., Kleshchev A.S., Moskalenko F.M., Timchenko V.A. A two-level model of information units with complex structure that correspond to the questioning metaphor. Automatic Documentation and Mathematical Linguistics, 2015, vol. 49, no. 5, pp. $172-181$.

19. Gribova V.V., Kleshchev A.S., Moskalenko F.M., Timchenko V.A. Implementation of a model of a metainformation-controlled editor of information units with a complex structure. Automatic Documentation and Mathematical Linguistics, 2016, vol. 50, no. 1 , pp. 14-25
20. Rozenberg G. (Ed.) Handbook of graph grammars and computing by graph transformation, vol. 1: Foundations. World Scientific Publ. Co. Pte. Ltd., 1997, 572 p.

21. Ehrig H., Engels G., Kreowski H.-J., Rozenberg G. (Eds.). Handbook of Graph Grammars and Computing by Graph Transformation, vol. 2: Applications, Languages and Tools. World Scientific, $1999,720 \mathrm{p}$.

22. Грибова В.В., Клещев А.С., Крылов Д.А., Москаленко Ф.М., Тимченко В.А., Шалфеева Е.А. Базовая технология разработки интеллектуальных сервисов на облачной платформе IACPaaS. Ч. 1: Разработка базы знаний и решателя задач // Программная инженерия. 2015. № 12. С. 3-11.

23. Gribova V.V., Kleshchev A.S., Moskalenko F.M., Timchenko V.A. A Model for generation of directed graphs of information by the directed graph of metainformation for a two-level model of information units with a complex structure. Automatic Documentation and Mathematical Linguistics, 2015, vol. 49, no. 6, pp. 221-231.

24. Грибова В.В., Клещев А.С., Крылов Д.А., Москаленко Ф.М., Тимченко В.А., Шалфеева Е.А. Базовая технология разработки интеллектуальных сервисов на облачной платформе 1ACPaaS. Ч. 2: Разработка агентов и шаблонов сообщений // Программная инженерия. 2016. Т. 7. № 1. С. 14-20.

\section{IACPaaS cloud platform for the development of intelligent service shells: current state and future evolution}

V.V. Gribova ${ }^{1}$,Dr.Sc. (Engineering), Senior Researcher, Deputy Director, gribova@iacp.dvo.ru

A.S. Kleschev ${ }^{1}$, Dr.Sc. (Physics and Mathematics), Professor, Chief Researcher, kleschev@iacp.dvo.ru

F.M. Moskalenko ${ }^{1}$, Ph.D. (Engineering), Senior Researcher, philipmm@iacp.dvo.ru

V.A. Timchenko ${ }^{1}$, Ph.D. (Engineering), Senior Researcher, vadim@iacp.dvo.ru

L.A. Fedorischev ${ }^{1}$, Ph.D. (Engineering), Research Associate, fleo@iacp.dvo.ru

E.A. Shalfeeva ${ }^{1}$, Ph.D. (Engineering), Associate Professor, Senior Researcher, shalf@iacp.dvo.ru

${ }^{1}$ Institute of Automation and Control Processes Far Eastern Branch of RAS, Vladivostok, 690041, Russian Federation

Abstract. The paper describes the main features and functional capabilities of the IACPaaS cloud platform. It provides three models of cloud service delivery: PaaS, SaaS and DaaS. The platform is intended for development of specialized (i.e., oriented to specific domains and/or classes of solved problems) intelligent service shells, as well as for development of applied intelligent services using such shells. Intelligent service shells are also presented as cloud services of the platform. Development (maintenance) of applied services using a shell is reduced to formation (modification) of a knowledge base using the tools provided by this shell and binding it with a problem solver. The problem solver consists of a set of agents that are software components interacting with each other by exchanging messages.

Specialized intelligent service shells use a domain-specific conceptual representation, which is defined by the ontology of the domain for which the shell is created, for knowledge representation. The knowledge base formation tool uses such problemoriented model (language) for knowledge representation to generate user interface oriented on domain experts. As a result, domain experts can form and maintain knowledge bases and databases within a familiar conceptual framework (without cognitive engineers as intermediaries or additional training) and make no mistakes in using the language for knowledge representation.

The IACPaaS platform provides a basic (universal) and a several specialized technologies for development of the applied intelligent service shells using tools that support these technologies. In addition, there is a technology of interaction between problem solver agents and external software (not included in the IACPaaS platform). It is based on the standard mechanism of HTTP request processing and the ability to run external software executable files from programs (scripts) located on a web server. 
Keywords: expert system shells, intelligent systems, intelligent system development technology, cloud platform, cloud computing, intelligent services, multi-agent services.

Acknowledgements. The work has been partially financially supported by the RFBR (projects no. 16-07-00340, 17-07-00299) and PFR FEB RAS “Far East” (project no. 18-5-078).

\section{References}

1. Sun Le, Dong H., Khadeer Hussain F., Khadeer Hussain O., Chang E. Cloud service selection: State-of-the-art and future research directions. J. of Network and Computer Applications. 2014, vol. 45, pp. 134-150.

2. CloudServiceMarket. A Comprehensive Overview of Cloud Computing Services. Available at: http://www.cloudservicemarket.info/default.aspx (accessed October 6, 2017).

3. Zhang Qi, Cheng Lu, Boutaba R. Cloud computing: state-of-the-art and research challenges. J. of Internet Services and Applications. 2010, no. 1, pp. 7-18. DOI 10.1007/s13174-010-0007-6.

4. Rybina G.V. Intelligent systems: from A to Z. Book 3. Problem-Specific Intelligent Systems. Instrumental Tools for Building Intelligent Systems. Moscow, Nauchtekhlitizdat Publ., 2015, $180 \mathrm{p}$.

5. Kumar S., Prasad R. Importance of expert system shell in development of expert system. Intern. J. of Innovative Research \& Development. 2015, vol. 4, iss. 3, pp. 128-133.

6. Rajendra M. Sonar an enterprise intelligent system development and solution framework. Intern. J. of Applied Science, Engineering and Technology. 2007, vol. 4, no. 1, pp. 34-39.

7. Schalkoff R.J. Intelligent Systems: Principles, Paradigms and Pragmatics. Sudbury, Mass. Jones and Bartlett Publ., 2011, 758 p.

8. Artemeva I.L. Specialized shells of intelligent systems for complex structured domains. Proc. 11th National Conf. on Artificial Intelligence with Intern. Participation. Moscow, LENAND Publ., 2008, vol. 1, pp. 95-103 (in Russ.).

9. Zagorulko Yu.A., Borovikova O.I. The software shell for building multilingual domain thesauri, focused on experts. Proc. 13th National Conf. on Artificial Intelligence with Intern. Participation (KII-2012). Belgorod, BGTU Publ., 2012, vol. 4, pp. 76-83 (in Russ.).

10. Zagorulko Yu.A. A semantic technology for the development of intelligent systems, focused on domain experts. Ontology of Designing. 2015, no. 1, pp. 30-46 (in Russ.).

11. Musen M. The protégé project: a look back and a look forward. Newsletter AI Matters. 2015, vol. 1, iss. 4, pp. 4-12. DOI: $10.1145 / 2757001.2757003$

12. Osipov G.S. Artificial Intelligence Methods. Moscow, Fizmalit Publ., 2015, 296 p.

13. Chernyakhovskaya M.Yu. Formation of observation databases based on the medicine ontology. Informatics and Management Systems. 2009, no. 4, pp. 198-200 (in Russ.).

14. Knyazeva M.A., Kupnevich O.A. An ontology model for "optimizing sequential programs". The definition of extensions for structural programs model language by terms of data flow analysis. Scientific and Technical Information. Ser. 2. Information Processes and Systems. 2005, no. 4, pp. 14-22 (in Russ.).

15. Artemeva I.L., Reshtanenko N.V. An intelligent system based on multilevel chemistry ontology. Software \& Systems. 2008, no. 1, pp. 84-87 (in Russ.).

16. Gribova V.V., Fedorishchev L.A. Visualization of virtual environments in cloud services. Scientific Visualisation. 2016, vol. 8, no. 1, pp. 133-145 (in Russ.).

17. Inzartsev A., Pavin A., Kleschev A., Gribova V., Eliseenko G. Application of artificial intelligence techniques for fault diagnostics of autonomous underwater vehicles. Proc. OCEANS 2016 MTS/IEEE Conf. \& Exhibition. Monterey, California, USA, 2016.

18. Gribova V.V., Kleshchev A.S., Moskalenko F.M., Timchenko V.A. A two-level model of information units with complex structure that correspond to the questioning metaphor. Automatic Documentation and Mathematical Linguistics. 2015, vol. 49, no. 5, pp. 172-181.

19. Gribova V.V., Kleshchev A.S., Moskalenko F.M., Timchenko V.A. Implementation of a model of a metainformationcontrolled editor of information units with a complex structure. Automatic Documentation and Mathematical Linguistics. 2016, vol. 50, no. 1, pp. 14-25.

20. Handbook of Graph Grammars and Computing by Graph Transformation. Vol. 1: Foundations. G. Rozenberg (Ed.). World Sci. Publ. Co. Pte. Ltd., 1997, 572 p.

21. Handbook of Graph Grammars and Computing by Graph Transformation. Vol. 2: Applications, Languages and Tools. H. Ehrig, G. Engels, H.-J. Kreowski, G. Rozenberg (Eds.). World Scientific, 1999, 720 p.

22. Gribova V.V., Kleshchev A.S., Krylov D.A., Moskalenko F.M., Timchenko V.A., Shalfeeva E.A. A basic technology for developing intelligent services using IACPaaS cloud platform. Part 1. Development of a knowledge base and problem solver. Software Engineering. 2015, no. 12, pp. 3-11 (in Russ.).

23. Gribova V.V., Kleshchev A.S., Moskalenko F.M., Timchenko V.A. A Model for generation of directed graphs of information by the directed graph of metainformation for a two-level model of information units with a complex structure. Automatic Documentation and Mathematical Linguistics. 2015, vol. 49, no. 6, pp. 221-231.

24. Gribova V.V., Kleshchev A.S., Krylov D.A., Moskalenko F.M., Timchenko V.A., Shalfeeva E.A. A base technology for development of intelligent services with the use of IACPaaS cloud platform. Part 2. A development of agents and message templates. Software Engineering. 2016, vol. 7, no. 1, pp. 14-20 (in Russ.). 
УДК 004.891.2

Дата подачи статьи: 25.04.18

DOI: $10.15827 / 0236-235 X .123 .537-542$

2018. Т. 31. № 3. С. 537-542

\title{
Повычение скорости логического вывода продукиионнъх экспертных систем путем использования аспектно-ориентированного подхода
}

\author{
A.A. Гончаров 1, аспиранm, andre_goncharov@hotmail.com \\ H.A. Семенов 1, д.m.н., npoфpeccop, is@tstu.tver.ru \\ 1 Тверской государственный технический университет, г. Тверь, 170026, Россия
}

Каждая экспертная система базируется на модели представления знаний. К наиболее общим моделям относятся продукционная модель, семантические сети и фреймы. Наиболее распространено применение продукционной модели.

В статье рассматривается актуальный недостаток продукционных систем, связанный с низкой эффективностью процесса логического вывода, по сравнению с другими моделями представления знаний.

Описан предлагаемый способ повышения эффективности процесса логического вывода в продукционных системах, основанный на использовании аспектно-ориентированного подхода.

Аспектно-ориентированный подход позволяет выявлять пересекающиеся функциональные элементы и обеспечивать их консолидацию в ходе создания архитектуры и реализации системы. Впервые представленный в 1997 году, данный подход популярен и в настоящее время.

В качестве примера приводится набор из продукционных правил экспертной системы выбора требований, предъявляемых к заданному уровню контроля в соответствии с требованиями руководящих документов. В данном наборе продукционных правил фактами являются значения уровней контроля, а в виде действий представлены требования, предъявляемые к выбранному уровню контроля.

Предложенный аспектно-ориентированный подход к организации продукционных систем позволил повысить скорость логического вывода в экспертных системах. Сокращение количества операций при поиске решения и избавление от перебора фактов и действий стало возможным благодаря выделению в аспекты пересекающихся фактов и действий из набора продукционных правил.

Ключевые слова: аспектно-ориентированное программирование, АОП, экспертная система, продукционное правило, искусственный интеллект.

Поиск аналогии решения интеллектуальных задач экспертами нашел свое отражение в экспертных системах (ЭС).

ЭС - направление исследований в области искусственного интеллекта по созданию вычислительных систем, умеющих принимать решения, схожие с решениями экспертов (высококвалифицированных специалистов) в заданной предметной области [1].

Результат интереса к ЭС, продиктованный их умением решать задачи интерпретации данных, диагностики, мониторинга, проектирования, прогнозирования, планирования и обучения, проявился в виде активного применения ЭС в различных отраслях промышленности. Насчитываются тысячи ЭС, успешно решающих задачи определенного узкого класса, и это позволяет говорить о том, что ЭС сейчас составляют мощную ветвь в индустрии программных средств [2].

Каждая ЭС базируется на модели представления знаний. К наиболее общим моделям относятся продукционная модель (или система, основанная на правилах), семантические сети и фреймы. В некоторых случаях прибегают к использованию нечетких правил и нейронных сетей.

Наиболее распространенной моделью представления знаний для ЭС является продукционная модель. Этому способствуют модульная организация, наличие средств объяснения и аналогии с познавательным процессом человека [3].
Одним из актуальных недостатков продукционных систем, согласно [4], является более низкая эффективность логического вывода по сравнению с другими моделями представления знаний. Это происходит из-за того, что значительная часть времени при логическом выводе затрачивается на непроизводительную проверку применимости правил.

Авторы статьи предлагают повысить эффективность процесса логического вывода в продукционных системах путем использования аспектно-ориентированного подхода.

\section{Продукционная модель представления знаний}

Впервые системы, основанные на продукционных правилах (production rule), были предложены в 1943 году Э. Постом.

Продукционные системы представляют знания о решении задач в виде правил продукции - выражений вида «Если [условие], то [действие]». К продукционным правилам применимы логические операции И, ИЛИ, НЕ.

В продукционном правиле антецедентом (Antecedent) называется условная часть, консеквентом (Consequent) - часть действия. Для сопоставления антецедентов и выполнения консеквентов предназначен интерпретатор правил.

В наиболее абстрактном виде БД продукционной системы схематично представлена на рисунке 1. 


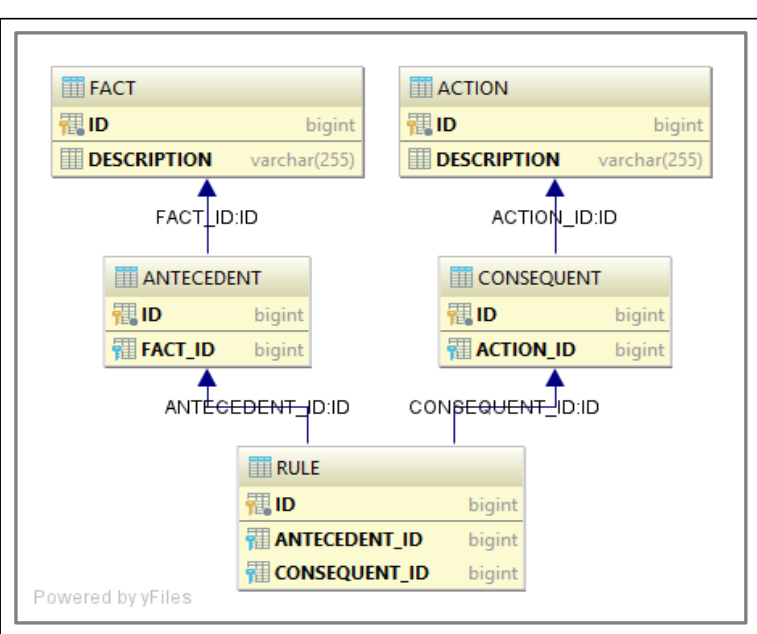

Рис. 1. БД продукиионной системы

Fig. 1. The production system database

На данной схеме набор правил (RULE) образует базу знаний продукционной системы, набор исходных фактов составляет базу фактов (FACT), набор действий представляется в виде базы действий (ACTION), факты составляют базу антецедентов (ANTECEDENT), а действия образуют базу консеквентов (CONSEQUENT).

Рассмотрим продукционную систему, применяемую в ЭС выбора требований, предъявляемых к заданному уровню контроля в соответствии с требованиями руководящих документов. Представим фрагмент набора продукционных правил:

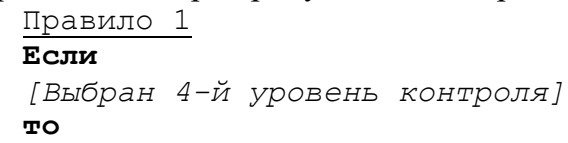

[Выполнить контроль состава и содержания документа Спецификация (ГОСТ 19.20278) ]

Правило 2

Если

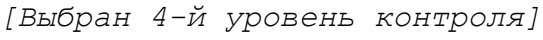
To

[Выполнить контроль состава и содержания документа Описание программы (ГОст 19.402-78)]

Правило 3

Если

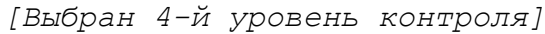
то

[Выполнить контроль состава и содержания документа Описание применения (ГОСТ 19.502-78)]

...

Правило 19

Если

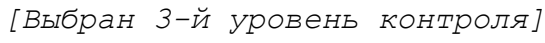

TO

[Выполнить контроль информационных объектов ]

Правило 20

Если

[Выбран 3-й уровень контроля]
TO

[Выполнить формирование перечня маршрутов выполнения функциональных объектов]

$\cdots$

Правило 39

Если

[Выбран 2-й уровень контроля]

TO

[Выполнить контроль выполнения Функциональных объектов ]

Правило 40

Если

[Выбран 2-ц̆ уровень контроля]

TO

[Выполнить сопоставление фактических маршрутов выполнения функциональных объектов и маршрутов, построенных в процессе проведения статического анализа]

...

Правило 57

Если

[Выбран 1-й уровень контроля]

TO

[Выполнить контроль выполнения функциональных объектов ]

Правило 58

\section{Если}

[Выбран 1-ц̆ уровень контроля]

TO

[Выполнить сопоставление фактических маршрутов выполнения функциональных объектов и маршрутов, построенных в процессе проведения статического анализа]

Правило 59

Если

[Выбран 1-й уровень контроля] To

[Оформить протокол испытаний]

В данном наборе продукционных правил фактом является значение выбранного уровня контроля. Требования, предъявляемые к выбранному уровню контроля, представлены в виде действий.

На рисунке 2 приведены значения скорости логического вывода в базе знаний ЭС из 59 правил до применения аспектно-ориентированного подхода (АО-подхода): в первом случае без объяснения решения, во втором - с объяснением решения. На оси $y$ отмечено время выполнения поиска решения в микросекундах, на оси $x$ отмечены номера проведенных тестов.

Для повышения эффективности процесса логического вывода в продукционных системах предлагается использовать АО-подход.

АО-подход - техника, позволяющая выявлять пересекающиеся (спутывающиеся) функциональные элементы и обеспечивать их консолидацию в ходе создания архитектуры и реализации системы. Под системой в данном случае понимается любая информационная система, через которую реализована некоторая предметная область в виде функций бизнес-логики.

Впервые данный подход был представлен в 1997 году Г. Кичалесом в работе [5]. 

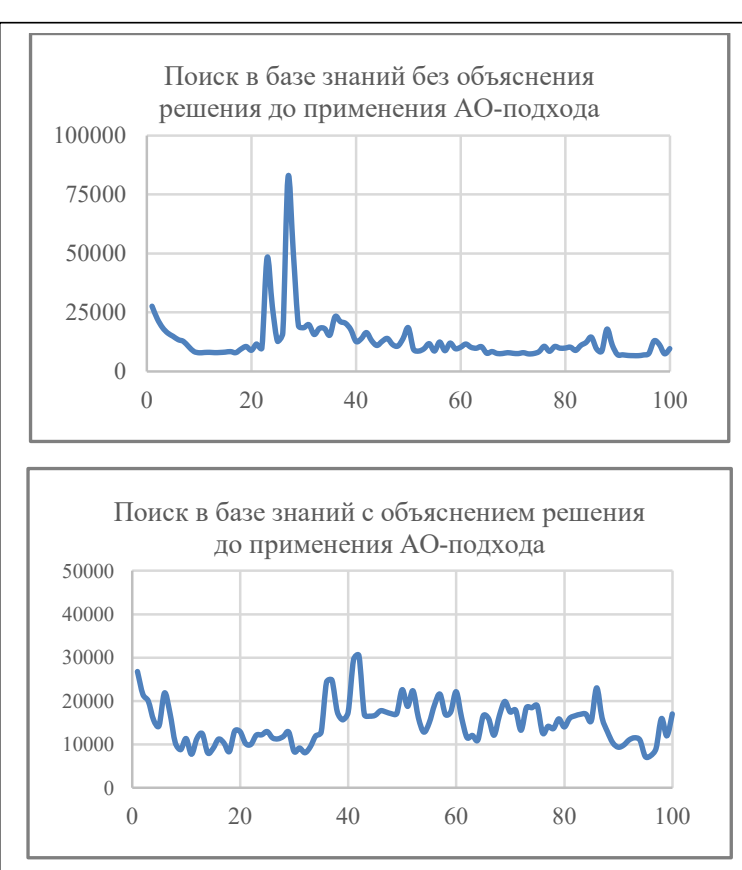

Рис. 2. Скорость поиска решения в базе знаний ЭС до АO-подхода

Fig. 2. The speed of finding solutions in the expert system knowledge base without AO approach

В настоящее время сформировался подход AOSD (Aspect-oriented software development) - комплексный АО-подход к сбору требований, построению архитектуры и дизайну систем [6]. Данный подход формируют:

- аспектно-ориентированная инженерия требований;

- аспектно-ориентированное управление бизнес-процессами;

- аспектно-ориентированная системная архитектура;

- аспектно-ориентированное моделирование и дизайн;

- аспектно-ориентированное программирование (АОП).

АОП - наиболее известная область применения АО-подхода. Согласно данным Google Trends, представленным на рисунке 3, популярность данной техники в последние 5 лет неизменно находится на самом высоком уровне.

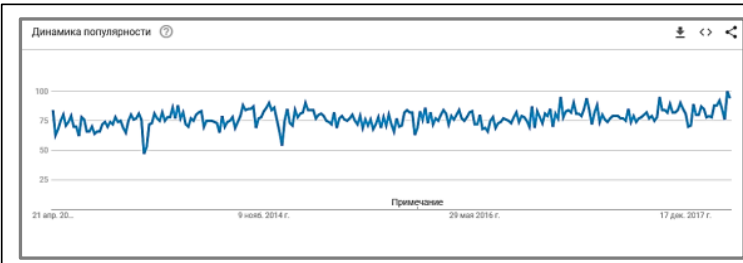

Рис. 3. Динамика популярности АОП за последние 5 лет согласно Google Trends

Fig. 3. Dynamics of $A O$ approach popularity over the last 5 years according to Google Trends
АО-подход как метод повышения эффективности процесса логического вывода в продукционных системах ранее не использовался.

При использовании АО-подхода в отдельные сущности, называемые аспектами, инкапсулируется сквозная функциональность.

Сквозная функциональность (Cross-cutting concern) - это функциональность, рассеянная по всему исходному коду ПО, систематически не зависящая от предметной области [7].

Для внедрения АО-подхода необходимо выполнить декомпозицию системы на модули, а затем с использованием концепций АО-подхода идентифицировать общность модулей, выделив пересечение сквозной функциональности в отдельные аспекты.

Основные концепции АО-подхода [8]:

- аспект (модульный элемент);

- совет (конструкция изменения поведения системы);

- точка соединения (точка вызова);

- срез (конструкция отбора точек соединения);

- цель;

- компоновщик (аспектный интегратор).

Взаимосвязь концепций АО-подхода в упрощенном виде представлена на рисунке 4.

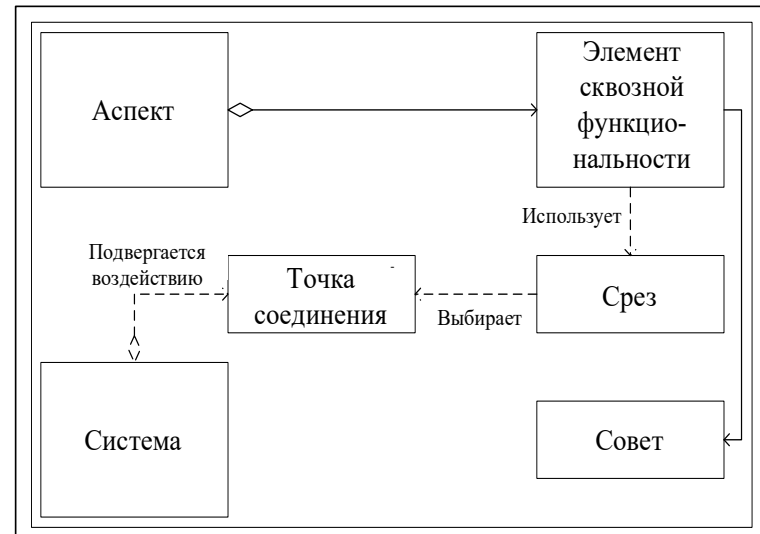

Рис. 4. Упрощенная схема АО-подхода

Fig. 4. A simplified AO approach scheme

Для связывания аспектов с системой предназначен компоновщик. Результатом связывания является целевой объект (цель). В общем случае целевой объект складывается из бизнес-логики системы и сквозной функциональности, представленной аспектом.

Совокупность правил вида Условие $\Rightarrow$ Действие, где Условие специфицирует разрез системы, а Действие задает фрагмент кода, активизируемый в системе при выполнении данного условия, по сути дела формирует аспект [9].

Рассмотрим АО-поход как метод повышения эффективности процесса логического вывода в продукционных системах. 


\section{Метод повышения эффективности процесса логического вывода в продукционных системах}

Пусть $F=\left\{f_{1}, f_{2}, \ldots, f_{n}\right\}-$ множество фактов в наборе правил ЭС, где $n \in N$ - общее количество фактов. Пусть $A=\left\{a_{1}, a_{2}, \ldots, a_{m}\right\}$ - множество действий в наборе правил ЭС, где $m \in N$ - общее количество действий. Каждый антецедент включает известный факт из БД ЭС, следовательно, Ant $\subseteq F$, где $A n t-$ множество антецедентов. Каждый консеквент включает известное действие из БД ЭС, следовательно, $C o n \subseteq A$, где Con - множество консеквентов. Правило можно представить парой $R_{k}=$ $=\left\langle a n t_{k} \in A n t, \operatorname{con}_{k} \in C o n\right\rangle$, где $k \in N$ - общее количество правил в базе знаний ЭС.

Аспектом (Aspect) Asp будем называть пересечение отдельных фактов в антецедентах или действий в консеквентах в наборе правил ЭС. Каждый аспект состоит из среза (Pointcut) фактов или действий. Тогда аспектом, являющимся описанием уровней контроля, будет $A s p_{F} \in F$, а аспектами, представляющими требования контроля состава и содержания документации, $-A s p_{A 1} \in A$, контроля исходного состояния ПО - $A s p_{A 2} \in A$, статического анализа исходных текстов программ $-A s p_{A 3} \in A$, динамического анализа исходных текстов программ - $A s p_{A 4} \in A$, требования к отчетности $A s p_{A 5} \in A$.

Заменив в антецеденте и консеквенте конкретный факт или действие выделенным аспектом, получаем представление антецедента в виде Ant $\in$ $\in A s p_{F}$, представление консеквента в виде Con $\subseteq\left\langle A s p_{A 1} \vee A s p_{A 2} \vee A s p_{A 3} \vee A s p_{A 4} \vee A s p_{A 5}\right\rangle$. При этом избавляемся от повторяющихся фактов и действий.

Выявленные пересечения фактов или действий в наборе правил образуют аспект. Множество фактов или действий, выделенных в аспект, образуют срез. Аспект внедряется в правило через антецедент или консеквент. Роль совета в данном подходе играют факт или действие, которые будут заменены элементом аспекта. Правило, в котором факт или действие будет заменено элементом аспекта, обозначается целью. Интерпретатор правил выполняет роль компоновщика.

Представим результат анализа составляющих продукционных систем и основных концепций АО-похода:

аспект - выявленные пересечения фактов или действий в наборе правил;

срез - множество фактов или действий, принадлежащих аспекту;

точка соединения - место внедрения элементов аспекта, представленное антецедентом или консеквентом;

совет - факт или действие, которые будут заменены элементом аспекта; цель - правило, в котором факт или действие будет заменено элементом аспекта;

компоновщик - интерпретатор правил.

Приведем фрагмент набора продукционных правил после применения АО-подхода:

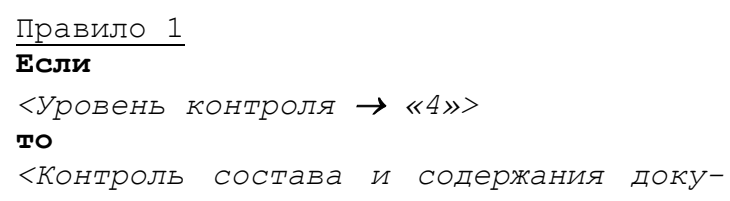
ментации $\rightarrow$ «Выполнить контроль состава и содержания документа Спецификация (ГОСТ 19.202-78)»>

Правило 2

Если

<Уровень контроля $\rightarrow$ «4»>

To

<Контроль состава и содержания документации $\rightarrow$ «Выполнить контроль состава и содержания документа Описание программы (ГОСТ 19.402-78)»>

\section{Правило 3 \\ сли}

$<$ Уровень контроля $\rightarrow$ « $4>$

то

<Контроль состава и содержания документации $\rightarrow$ «Выполнить контроль состава и содержания документа Описание применения (ГОСТ 19.502-78) »>

...

Правило 19

Если

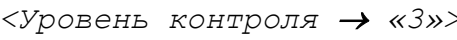

To

$<$ Статический анализ исходных текстов программ $\rightarrow$ «Выполнить контроль информационных объектов»>

Правило 20

Если

$<$ Уровень контроля $\rightarrow$ «3»>

To

$<$ статический анализ исходных текстов программ $\rightarrow$ «Выполнить формирование перечня маршрутов выполнения функциональных объектов»>

...

Правило 39

Если

$<$ Уровень контроля $\rightarrow$ «2»>

то

$<$ Динамический анализ исходных текстов программ $\rightarrow$ «Выполнить контроль выполнения функциональных объектов»>

Правило 40

Если

$<$ Хровень контроля $\rightarrow$ «2»>

то

<Динамический анализ исходных текстов программ $\rightarrow$ «Выполнить сопоставление фактических маршрутов выполнения функциональных объектов и маршрутов, построенных в процессе проведения статического анализа»> 
$\cdots$

Правило 57

Если

$<$ Хровень контроля $\rightarrow$ «1»>

TO

<Динамический анализ исходных текстов

программ $\rightarrow$ «Выполнить контроль выполнения функциональных объектов»>

Правило 58

Если

$<$ Уровень контроля $\rightarrow$ «I»>

TO

$<$ Динамический анализ исходных текстов программ $\rightarrow$ «выполнить сопоставление фактических маршрутов выполнения функциональных объектов и маршрутов, построенных в процессе проведения статического анализа»>

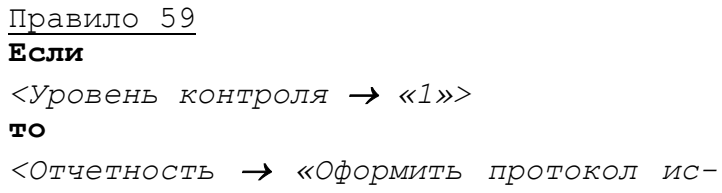

Внедрение АО-похода не требует переработки структуры базы знаний и БД ЭС. В целях совместимости предлагается использовать АО-поход в интерпретаторе правил.

На рисунке 5 приведены значения скорости логического вывода в базе знаний ЭС после применения АО-подхода.

Как видим, скорость логического вывода в базе знаний ЭС после применения АО-подхода в обоих случаях увеличилась. Выделение аспектов позволило избавиться от непроизводительной проверки применимости правил.

\section{Заключение}

Представленная множеством правил продукции ЭС организует знания в виде логической связки Факт (Посылка) $\Rightarrow$ Действие (Следствие). Умение ЭС решать различные задачи (интерпретация данных, диагностика, мониторинг, проектирование, прогнозирование, планирование и обучение) позволило применять ЭС в различных отраслях промышленности.

В статье был рассмотрен актуальный недостаток продукционных систем, который, согласно [4], выражается в более низкой эффективности процесса логического вывода по сравнению с другими моделями представления знаний.

Предложенный АО-подход в продукционных системах позволил повысить скорость логического вывода в ЭС, а выделение аспектов - сократить количество операций при поиске решения и избавиться от перебора фактов и действий, что привело к повышению скорости логического вывода.
Поиск в базе знаний без объяснения решения после применения АО-подхода

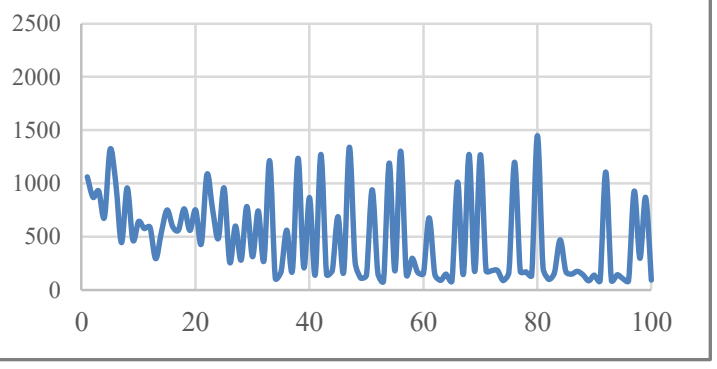

Поиск в базе знаний с объяснением решения после применения АО-подхода

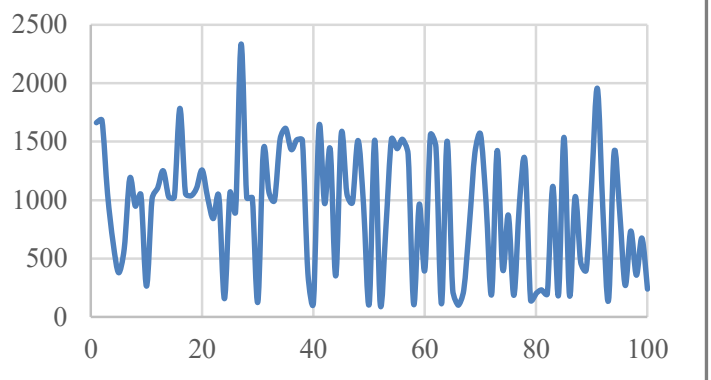

Рис. 5. Скорость поиска решения в базе знаний ЭС после АО-подхода

Fig. 5. The speed of finding solutions in the expert system knowledge base after $\mathrm{AO}$ approach

\section{Литература}

1. Минин А.Я. Информационные технологии в образовании. М.: Изд-во МПГУ, 2016. 148 с.

2. Корнеев И.К., Машурцев В.А. Информационные технологии в управлении. М.: ИНФРА-М, 2001. 158 с.

3. Джарратано Дж., Райли Г. Экспертные системы. Принципы разработки и программирование; [пер. с англ.]. М.: Вильямс, 2007. 1152 c.

4. Валетов В.А., Орлова А.А., Третьяков С.Д. Интеллектуальные технологии производства приборов и систем. СПб: Изд-во СПб ГУИТМО, 2008. 134 с.

5. Kiczales G., Lamping J., Mendhekar A., Maeda C., Lopes C., Loingtier J., Irwin J. Aspect-oriented programming. Proc. Europ. Conf. on Object-Oriented Programming (ECOOP), Jyvaskyla, Finland, 1997. URL: http://people.cs.ubc.ca/ gregor/papers/ kiczales-ECOOP1997-AOP.pdf (дата обращения: 23.04.2018).

6. Rashid A. Aspect-oriented software development in practice: tales from AOSD-Europe. 2010. URL: https://pdfs.seman ticscholar.org/08d0/1e2ebec9c9904376c92d092663c2e5467ed2.pdf (дата обращения: 15.04.2018).

7. Гончаров А.А., Семенов Н.А. Аспектно-ориентированное программирование в контексте решения вопросов повышения эффективности экономических показателей IT-проектов // Программные продукты и системы. 2016. № 3. С. 149-153.

8. Laddad R., Johnson R. AspectJ in action: enterprise AOP with spring applications. Manning Publ., 2009, 568 p.

9. Сафонов B.O. Aspect.NET - инструмент аспектно-ориентированного программирования для разработки надежных и безопасных программ // Компьютерные инструменты в образовании. 2007. № 5. С. 3-13. 


\title{
Improving logical inference speed of production expert systems using aspect-oriented approach
}

\author{
A.A. Goncharov ${ }^{1}$, Postgraduate Student, andre_goncharov@hotmail.com \\ N.A.Semenov ${ }^{1}$, Dr.Sc. (Engineering), Professor, is@tstu.tver.ru \\ ${ }^{1}$ Tver State Technical University, Tver, 170026, Russian Federation
}

Abstract. The reason for active applying of expert systems in various industries is their ability to solve problems of data interpretation, diagnosis, monitoring, design, forecasting, planning and training.

Each expert system is based on a knowledge representation model. A production model, semantic networks and frames are the most common models. The production model is the one used most frequently.

The paper considers the important shortage of production systems related to low efficiency of the logical inference process compared to other knowledge representation models.

The paper describes the proposed method of increasing the efficiency of the logical inference process in production systems based on applying an aspect-oriented approach.

The aspect-oriented approach allows identifying intersecting functional elements and providing their consolidation during architecture creation and system implementation. This approach was first introduced in 1997 and it remains popular at the present time.

As the example, the article provides a set of production rules of expert system for selecting the requirements for a given level of control according to the requirements of guidance document of undocumented features. In this case, the facts are presented in the form of values of control levels and actions are presented as requirements to the selected level of control.

The proposed aspect-oriented approach to organizing production systems provided an opportunity of increasing the speed of logical inference in expert systems. The separation of intersecting facts and actions from the set of production rules into aspects has made it possible to reduce the number of operations when searching for a solution and to eliminate exhaustive search for facts and actions.

Keywords: aspect-oriented programming, aspect-oriented approach, expert system, production rule, artificial intelligence.

\section{References}

1. Minin A.Ya. Information Technologies in Education. Moscow, MPGU Publ., 2016, 44 p.

2. Korneev I.K., Mashurtsev V.A. Informat Information Technologies in Management. Moscow, INFRA-M Publ., $2001,158 \mathrm{p}$.

3. Giarratano J.C., Riley G.D. Expert Systems: Principles and Programming. 4th ed. Course Technology Publ., 2004, 288 p. (Russ. ed.: Moscow, Williams Publ., 2007, 1152 p.).

4. Valetov V.A., Orlova A.A., Tretyakov S.D. Intellectual Technologies for the Production of Devices and Systems. St. Petersburg, SPb GUITMO Publ., 2008, 134 p.

5. Kiczales G., Lamping J., Mendhekar A., Maeda C., Lopes C., Loingtier J., Irwin J. Aspect-oriented programming. Proc. Europ. Conf. on Object-Oriented Programming (ECOOP). Jyvaskyla, Finland, 1997. Available at: http://people.cs.ubc.ca/ gregor/papers/kiczales-ECOOP1997-AOP.pdf (accessed April 23, 2018).

6. Rashid A. Aspect-Oriented Software Development in Practice: Tales From AOSD-Europe. 2010. Available at: https://pdfs.semanticscholar.org/08d0/1e2ebec9c9904376c92d092663c2e5467ed2.pdf (accessed April 15, 2018).

7. Goncharov A.A., Semenov N.A. Aspect-oriented programming as an approach to improve the efficiency of IT projects economic performance. Software \& Systems. 2016, no. 3, pp. 149-153.

8. Laddad R., Johnson R. AspectJ in Action: Enterprise AOP with Spring Applications. Manning Publ., 2009, $568 \mathrm{p}$.

9. Safonov V.O. Aspect.NET as an aspect-oriented programming tool for the development of reliable and safe programs. Computer Tools in Education. 2007, no. 5, pp. 3-13 (in Russ.). 


\title{
Нейросетевой метод обнаружения вредоносных программ на платформе Android
}

\author{
T.M. Татарникова 1, д.m.н., доиент, nрофессор, tm-tatarn@yandex.ru \\ A.M. Журавлев 1, магистрант, asn93@mail.ru \\ 1 Санкт-Петербургский государственный университет аэрокосмического приборостроения, \\ г. Санкт-Петербург, 190000, Россия
}

\begin{abstract}
Непрерывный рост числа вредоносных программ, нацеленных на операционную систему Android, делает актуальной задачу их обнаружения. Отсутствие централизованного механизма распространения приложений и недостаточная эффективность существующих решений усугубляют проблему.

Экспериментально показана недостаточная эффективность существующих механизмов обнаружения вредоносных программ операционной системы Android. Необходимость автоматизированного решения, позволяющего повысить вероятность обнаружения вредоносных программ операционной системы Android, в том числе ранее неизвестных, модифицированных и обфусцированных версий уже известных программ, определила цель исследования.

В работе применялись методы классификации нейронных сетей, статического анализа кода и анализа поведения программы в виртуальной среде. Новизна предлагаемого решения состоит в использовании классификационных признаков, полученных как статическим анализом кода, так и анализом поведения программы на виртуальном устройстве. Предложенный подход устраняет недостатки существующих решений рассматриваемой проблемы.

Экспериментально доказана способность предложенного решения обнаруживать вредоносные программы, не использовавшиеся в обучении нейронной сети, а также обфусцированные экземпляры.

Практическая значимость предлагаемого решения заключается в его применении для построения систем обнаружения вредоносных программ операционной системы Android, которую можно использовать в магазине приложений Android.
\end{abstract}

Ключевые слова: платформа Android, вредоносные программы, антивирусы, машинное обучение, нейронные сети, классификация, анализ программ.

Google Android в настоящее время занимает лидирующие позиции на рынке мобильных операционных систем (ОС) [1]. Постоянно растет и количество вредоносных программ на OC Android. Например, шпионская программа SMSVova, маскировавшаяся под системное обновление, была скачана свыше трех миллионов раз и оставалась незамеченной более двух лет. Мобильные вирусы способны шпионить за пользователями, использоваться для получения незаконных доходов, например, отправлять платные SMS или шифровать данные пользователя с целью вымогательства [2].

Помимо этих угроз, существуют и другие проблемы, связанные с недостаточной проверкой приложений, реализованных Google Play и другими магазинами, при скачивании которых пользователи устанавливают себе вредоносное ПО, замаскированное под игры и программы. Более того, пользователи с целью экономии часто прибегают к сторонним источникам программ для ОC Android, например торрентам, где приложения и вовсе могут не проверяться. Пользователи также подвергаются утечкам персональных данных, скрытым загрузкам на веб-сайтах и другим опасностям [3].

Меры противодействия скрытой установке вредоносного ПО могут быть различными. С увеличением разнообразия назначения и объемов данных популярными стали методы машинного обучения и непосредственно искусственные нейронные сети, которые, в частности, позволяют решать задачи распознавания образов, классификации и анализа скрытых закономерностей в данных [4].

Рассмотрим задачу обнаружения вредоносного ПО как задачу классификации, решение которой преследует цель повышения вероятности обнаружения вредоносных программ ОС Android.

\section{Анализ существующих механизмов обнаружения вредоносных программ}

В системе Android можно выделить два основных механизма обнаружения вредоносных программ: систему тестирования Google Bouncer и антивирусы.

Как правило, по умолчанию устройства под управлением OC Android не поддерживают установку приложений из неизвестных источников, к числу которых относятся приложения, не подписанные сертификатом Google. Если разработчик приложения получил сертификат, то оно может быть опубликовано в магазине Google Play Store. Перед публикацией приложение проходит проверку системой Google Bouncer, являющейся антивирусным функционалом Google. Проверка заключается в тестировании приложения на наличие вредоносного кода посредством облачного сервиса, то есть приложение устанавливается на виртуальную машину и проводится динамический анализ. При обнаружении подозрительной активности приложение не проходит верификацию и не публикуется, 
аккаунт разработчика при этом может быть заблокирован [5].

Другой подход к обнаружению вредоносных программ - использование антивирусов. Существующие для ОС Android антивирусы являются приложениями, а не компонентами ОС, что, собственно, и определяет их основной недостаток изоляцию антивирусов от других приложений, что позволяет проводить только статический анализ [6].

Дополнительно к существующим подходам стоит отметить наличие механизма разрешений, суть которого в том, что, во-первых, ни одно приложение OC Android по умолчанию не имеет разрешений на операции, способные повлиять на получение личных данных, ОС или другие приложения, а во-вторых, приложениям назначаются привилегии и только от пользователя зависит, давать ли доступ к данным тому или иному приложению.

B OC Android до 6-й версии все разрешения выдаются при установке. Пользователю выводится список доступных приложению разрешений, и для продолжения установки он должен подтвердить, что разрешает приложению использовать перечисленные компоненты системы. В новых версиях Android выделена группа особых разрешений, называемых опасными, которые будут запрашиваться непосредственно перед использованием, тем самым не позволяя программе скрыто производить нежелательные действия на устройстве. Все разрешения, используемые приложением, должны быть указаны в манифесте [7].

\section{Недостатки существующих механизмов защиты от вредоносных программ}

Основным недостатком динамического анализа, на котором реализована система Google Bouncer, является то, что спустя какое-то время после проведенного анализа приложение может вновь запускать вредоносную программу. Существует множество методов определения завершения анализа на виртуальном устройстве: всевозможные датчики, камера, микрофон, Wi-Fi модуль, которыми снабжены современные смартфоны. Они позволяют обойти процедуру динамического анализа. Также известны методики обнаружения гипервизора, которые могут быть применены вредоносной программой без обращения к каким-либо датчикам или данным мобильного устройства. Помимо общих недостатков, связанных непосредственно с динамическим анализом, к минусам подхода, основанного на системе тестирования Google Bouncer, можно отнести то, что обязательную проверку проходят лишь приложения, распространяемые через Google Play. Для проверки приложений из других источников необходимы включенная опция валидации сторонних приложений и подключение к сети Интернет.
Для оценки эффективности мобильных антивирусов был проведен эксперимент, заключающийся в следующем:

- для вредоносной программы из открытого источника был определен показатель ее выявления на сервисе Virustotal, который составил $41 \%$ из $56 \%$;

- программа декомпилировалась;

- в программу вносились различные изменения;

- программа заново компилировалась;

- на сервисе Virustotal оценивались новые показатели выявления.

Полученные результаты приведены в таблице 1. Эксперимент показал, что антивирусы не могут успешно обнаруживать программы, к коду которых была применена обфускация.

Показатели выявления измененной Таблица 1 вредоносной программы

Table 1

Indicators of detected malware change

\begin{tabular}{|l|c|}
\hline \multicolumn{1}{|c|}{ Внесенное изменение } & Показатель выявления, \% \\
\hline Программа без изменений & $41 / 56$ \\
\hline Переподпись приложения & $29 / 56$ \\
\hline $\begin{array}{l}\text { Переименование пакета } \\
\text { приложения }\end{array}$ & $23 / 56$ \\
\hline Изменения манифеста & $22 / 56$ \\
\hline Изменения ресурсов & $25 / 56$ \\
\hline $\begin{array}{l}\text { Шифрование строк } \\
\text { в байт-коде программы }\end{array}$ & $13 / 56$ \\
\hline $\begin{array}{l}\text { Переименование классов } \\
\text { в байт-коде }\end{array}$ & $21 / 56$ \\
\hline $\begin{array}{l}\text { Переименование классов, } \\
\text { методов и шифрование } \\
\text { строк в байт-коде } \\
\text { программы }\end{array}$ & $8 / 56$ \\
\hline
\end{tabular}

Недостаток антивирусов кроется в ограничениях статического анализа приложений, применение которого требует наличия сигнатур, то есть новые вредоносные программы, для которых сигнатуры еще не выпущены, не могут быть обнаружены. К тому же к коду вредоносной программы может быть применена обфускация для усложнения анализа [8].

Основной недостаток механизма разрешений состоит в большом количестве разрешений, которые пользователь должен прочесть при установке приложения, при этом угрозы того или иного разрешения не всегда очевидны. Только стандартных разрешений в ОС Android порядка 300. Не решает этих проблем и появившаяся в 6-й версии ОС Android функция динамически запрашиваемых разрешений. Для поддержки приложений, написанных ранее, разработчики ОС Android оставили возможность получать все необходимые разрешения 
при установке. Для этого нужно указать в манифесте, что программа разрабатывалась для версий Android, предшествующих 6-й.

\section{Предлагаемое решение}

Задачу обнаружения вредоносных программ OC Android можно рассматривать как задачу классификации, для решения которой привлекаются инструменты нейронной сети.

Bce приложения OC Android в рамках поставленной задачи разделим на два класса: безопасные и вредоносные. Для классификации необходимо выделить признаки, по которым можно определить принадлежность программы к одному из классов. В качестве классификационных признаков могут быть использованы действия, которые программа производит на устройстве, а для получения признаков приложения OC Android - манифест, байт-код приложения и динамический анализ.

Из манифеста приложения можно получить список разрешений приложения и список обрабатываемых широковещательных намерений.

По списку разрешений можно определить функции, которые программе разрешено выполнять на устройстве. Однако, как уже упоминалось ранее, список разрешений может быть очень большим, к тому же далеко необязательно использование приложением всех полученных разрешений. Из всего списка возможных разрешений необходимо выделить наиболее важные и более свойственные вредоносным программам. По списку обрабатываемых широковещательных намерений можно определить, какие события на устройстве отслеживает программа: подключение к Интернету, получение SMS-сообщения, входящий или исходящий вызов, включение устройства и другие. Получатели широковещательных намерений используются многими вредоносными приложениями, например, для перехвата SMS-сообщений, подтверждающих покупку с банковской карты, или для ожидания события подключения к Интернету для передачи украденных личных данных.

По байт-коду приложения можно определить, какие действия производит программа на устройстве. В качестве признаков, полученных из байткода, можно выделить вызовы к Android API и библиотекам ядра. Полученные в результате анализа байт-кода списки вызовов к API или библиотекам ядра достовернее списка разрешений, однако получение признаков из байт-кода может быть затруднено использованием динамической загрузки кода, механизмов рефлексии, обфускации. Динамическая загрузка кода позволяет скрыть почти весь функционал программы от анализа байт-кода, но сам факт того, что код приложения загружается из Интернета или зашифрованного файла, является подозрительным и может использоваться как признак для классификации.
Признаки могут быть получены и при динамическом анализе: при запуске исследуемой программы на реальном или виртуальном устройстве будут отслеживаться все действия программы, выполненные ею без участия пользователя.

Использование данных, полученных статическим и динамическим анализом одновременно, может устранить их недостатки, тем самым повысив вероятность обнаружения вредоносной программы. Таким образом, в сравнении с рассмотренными механизмами обнаружения вредоносных программ ОС Android предлагаемый подход имеет ряд преимуществ:

- способность обнаруживать ранее неизвестные вредоносные программы;

- отсутствие необходимости базы сигнатур;

- стойкость к обфускации.

Способность обнаруживать ранее неизвестные вредоносные программы достигается применением нейронных сетей, которые позволяют выявлять сложные зависимости между входными и выходными данными. При обучении на существующих программах нейронная сеть выявляет закономерности, свойственные приложениям каждого класса, и в результате способна верно определять, к какому из классов относится программа, отсутствующая в обучающей выборке.

Предлагаемый подход не требует сигнатур для анализа, поскольку все признаки, по которым классифицируются приложения, могут быть получены из приложения в результате проведенного анализа. Совместное применение статического и динамического анализа позволяет избавиться от некоторых их недостатков. Например, если вредоносная программа обнаружит, что ее анализируют, она может приостановить свою работу, не позволяя провести динамический анализ. Однако на работу статического анализатора такая способность программы не повлияет. Статический анализ может быть значительно затруднен обфускацией, но динамический анализ работает на уровень ниже в программном стеке OC Android и обнаруживает реальные действия программы, которые невозможно скрыть обфускацией. Стойкость к обфускации также обеспечивается способностью нейронной сети получать верные результаты на искаженных или неполных входных данных.

Для оценки эффективности предлагаемого подхода создана его программная реализация, представляющий собой статический и динамический анализатор, а также классификатор на основе нейронной сети.

Статический анализатор распаковывает пакет приложения, анализирует байт-код и манифест приложения. К байт-коду приложения применяется декомпиляция, а к манифесту - десериализация. Для декомпиляции была использована программа smali. 
Результатом работы статического анализатора являются списки

- функций Android API и библиотек ядра, которые могут быть вызваны из кода программы в процессе работы;

- разрешений приложения, которые запрашиваются при установке;

- широковещательных намерений, которые могут быть обработаны программой.

Динамический анализатор представляет собой модифицированную версию эмулятора OC Android - droidbox, который позволяет отслеживать вызовы к Android API [7]. Приложение может взаимодействовать с устройством только через Android API, поэтому все действия программы будут обнаружены. Проверяемая программа запускается на виртуальном устройстве и работает в течение 5 минут. Во время работы программы отслеживались следующие действия:

- отправка данных в сеть;

- операции чтения и записи файлов на устройстве;

- использование DexClassLoader;

- отправка и чтение SMS-сообщений;

- чтение сохраненных на устройстве контактов;

- совершение звонков;

- использование встроенного криптопровайдера;

В качестве классификатора использовалась нейронная сеть с архитектурой многослойный персептрон с двумя скрытыми слоями. Обучение производилось методом обратного распространения ошибки $[9,10]$. В качестве примеров приложений, относящихся к классу безопасных, были взяты 100 из 1000 самых популярных приложений из магазина Google Play. Программы, относящиеся к классу вредоносных, были получены из Android Malware Genome Project.

\section{Анализ результатов работы}

Для оценки работы предлагаемого решения были проанализированы существующие программы для ОC Android. Анализ проводился на 25 вредоносных и на 50 безопасных программах. Полученные результаты отражены в таблице 2 .

Таблий 2

Результаты анализа программ

Table 2

Results of program analysis

\begin{tabular}{|l|c|}
\hline \multicolumn{1}{|c|}{ Характеристика результата } & Количество \\
\hline Проанализировано программ & 75 \\
\hline Вредоносных программ & 25 \\
\hline Безопасных программ & 50 \\
\hline Верный результат классификации & 64 \\
\hline Ложноотрицательные результаты & 4 \\
\hline Ложноположительные результаты & 3 \\
\hline
\end{tabular}

В результате анализа было верно классифицировано 84 \% вредоносных программ. Следует отметить, что проанализированные программы не использовались в обучении сети. Таким образом, проведенный анализ подтверждает способность предлагаемого решения верно классифицировать ранее неизвестные программы.

Для оценки способности предлагаемого решения обнаруживать вредоносные программы, к которым была применена обфускация, проанализированы использовавшиеся в эксперименте с антивирусами измененные версии вредоносной программы. Все экземпляры были верно определены как вредоносные. Результаты анализа, представленные в таблице 3, показывают способность предлагаемого решения обнаруживать обфусцированные версии вредоносных программ.

Таблииа 3

\section{Результаты анализа измененной вредоносной программы}

Table 3

Results of the analysis of a changed malicious program

\begin{tabular}{|l|c|}
\hline \multicolumn{1}{|c|}{ Внесенное изменение } & Результат \\
\hline Программа без изменений & + \\
\hline Переподпись приложения & + \\
\hline Переименование пакета приложения & + \\
\hline Изменения манифеста & + \\
\hline Изменения ресурсов & + \\
\hline Шифрование строк в байт-коде & + \\
\hline Переименование классов в байт-коде & + \\
\hline $\begin{array}{l}\text { Переименование классов, методов } \\
\text { и шифрование строк в байт-коде }\end{array}$ & + \\
\hline
\end{tabular}

\section{Заключение}

Анализ информационных источников и проведенный эксперимент на программах, к коду которых была применена обфускация или у которых отсутствуют их сигнатуры, показал, что существующих механизмов обнаружения вредоносных программ ОC Android недостаточно.

Комплексное применение статического и динамического анализа программ ОС Android позволяет получить достаточное множество признаков, позволяющих с высокой долей вероятности безошибочно классифицировать исследуемые программы.

Задача классификации решена с применением аппарата нейронных сетей. Результаты показали, что все вредоносные программы, к байт-коду которых была применена обфускация, верно определены как вредоносные. Нейронная сеть верно классифицировала 84 \% новых вредоносных программ.

\section{Лuтература}

1. Worldwide smartphone forecast update. 2016-2020, December 2016. URL: http:/www.idc.com/getdoc.jsp?containerId=US42060116 (дата обращения: 27.01.2018).

2. Безопасность Android: взгляд внутрь. URL: http://www. securitylab.ru/blog/personal/Informacionnaya_bezopasnost_v_deta lyah/325122.php (дата обращения: 18.01.2018). 
3. Соглашение Google Play о распространении программных продуктов. URL: https://play.google.com/intl/ALL_ru/about/ developer-distribution-agreement.html (дата обращения: 22.01.2018),

4. Рутковская Д., Пилиньский М., Рутковский Л. Нейронные сети, генетические алгоритмы и нечеткие системы. М.: Горячая линия-Телеком, 2013. $384 \mathrm{c.}$

5. Using DroidBox for dynamic malware analysis. URL: https://hackmag.com/uncategorized/droidbox-for-dynamic-malware-analysis/ (дата обращения: 03.01.2018).

6. Android Platform Architecture. URL: https://developer.android.com/guide/platform/index.html (дата обращения: 25.01.2018).
7. Android App permissions explained. URL: http://www.androidauthority.com/android-app-permissions-explained-642452/ (дата обращения: 10.01.2018)

8. Татарникова Т.М. Защищенные корпоративные сети. Раздел: Задачи по защите информации. СПб: Изд-во РГГМУ, 2012. 113 c.

9. Татарникова Т.М. Задача синтеза комплексной системы защиты информации в ГИС // Ученые записки РГГМУ. 2013. № 30. C. 204-211.

10. Тархов Д.А. Нейросетевые модели и алгоритмы. М.: Радиотехника, 2014. 349 с.
Software \& Systems

DOI: $10.15827 / 0236-235 X .123 .543-547$
Received 29.01.18

2018, vol. 31, no. 3, pp. 543-547

\section{A neural network method for detecting malicious programs on the Android platform}

T.M. Tatarnikova ${ }^{1}$,Dr.Sc. (Engineering), Associate Professor, Professor,tm-tatarn@yandex.ru A.M.Zhuravlev ${ }^{1}$, Graduate Student, asn93@mail.ru

${ }^{1}$ St. Petersburg State University of Aerospace Instrumentation, St. Petersburg, 190000, Russian Federation

Abstract. Continuous growth in the number of malicious programs aimed at the Android operating system makes the problem of their detection very important. The lack of a centralized mechanism for distributing applications and effectiveness of existing solutions exacerbate the problem.

The paper demonstrates experimentally the lack of effectiveness of the existing mechanisms for detecting malicious programs in the Android operating system. The need for an automated solution that increases the probability of malicious program detection in the Android operating system including previously unknown modified and obfuscated versions of already known programs determined the purpose of the work.

The authors used the methods of neural network classification, static code analysis and analysis of program behavior in a virtual environment. The novelty of the proposed solution is the use of classification features obtained both by static code analysis and by analysis of program behavior on a virtual device. The proposed approach eliminates the shortcomings of existing solutions to the problem under consideration.

The ability of the proposed solution to detect malicious programs that were not used in neural network training, as well as obfuscated instances, has been experimentally proven.

The practical significance of the proposed solution is its use for building malware detection systems of the Android operating system, which can be applied in the Android application store.

Keywords: android platform, malware, antivirus, machine learning, neural networks, classification, program analysis.

\section{References}

1. Worldwide Smartphone Forecast Update. 2016-2020: December 2016. International Data Corporation (IDC). Available at: http://www.idc.com/getdoc.jsp?containerId=US42060116 (accessed January 27, 2018).

2. Android Security: Look Inside. Available at: http://www.securitylab.ru/blog/personal/Informacionnaya_bezopasnost_v_detalyah/325122.php (accessed January 18, 2018).

3. Google Play Software Distribution Agreement. Available at: https://play.google.com/intl/ALL_ru/about/developerdistribution-agreement.html (accessed January 22, 2018).

4. Rutkovskaya D., Pilinsky M., Rutkovsky L. Neural Networks, Genetic Algorithms and Fuzzy Systems. Moscow, Goryachaya liniya-Telekom Publ., 2013, 384 p.

5. Using DroidBox for Dynamic Malware Analysis. Available at: https:/hackmag.com/uncategorized/droidbox-for-dynamic-malware-analysis/ (accessed January 3, 2018).

6. Android Platform Architecture. Available at: https://developer.android.com/guide/platform/index.html (accessed January 25,2018 )

7. Android App Permissions Explained. Available at: http://www.androidauthority.com/android-app-permissions-explained-642452/ (accessed January 10, 2018).

8. Tatarnikova T.M. Protected Corporate Networks. Section: Information Security Tasks. St. Petersburg, RGGMU Publ., 2012, $113 \mathrm{p}$.

9. Tatarnikova T.M. The task of synthesizing an integrated information security system in GIS. Proc. of the Russian State Hydrometeorological Univ. 2013, no. 30, pp. 204-211 (in Russ.).

10. Tarkhov D.A. Neural Network Models and Algorithms. Moscow, Radiotekhnika Publ., 2014, 349 p. 


\title{
Автоматизированная система заииты доступности информации от атак внечним несанкиионированным трафиком в UNIX-подобных системах
}

\author{
E.B. Пальчевский 1, аспирант, tеelxp@inbox.ru \\ A.P. Халиков 1, к.фр.-м.н., доиенm, khalikov.albert.r@gmail.com
}

1 Уфимский государственный авиаиионный технический университет, г. Уфра, 450008, Россия

Данная статья посвящена разработке программного модуля для защиты доступности информации при массивных DoS- и DDoS-атаках. Разработанная система позволяет в автоматизированном режиме определять тип и вид атак внешним несанкционированным трафиком, а также отфильтровывать сетевые пакеты по заданному лимиту (от 10 тысяч до 7 миллионов в секунду) с последующим распределением нагрузки по физическим и логическим ядрам кластера.

На первом этапе разработки были проанализированы направленности DoS- и DDoS-атак, а также рассмотрены аналогичные решения системы защиты от DDoS-атак. Второй этап представляет собой техническую разработку автоматизированной системы защиты доступности информации AntiDDoS: показаны основной функционал и схема работы системы защиты от DDoS-атак. Основной функционал представлен следующими техническими данными: название функции, цель выполнения, условие работы и результат выполнения. Третьим этапом является апробация реализованной системы в течение десяти дней, результаты которой представлены в виде таблицы со среднесуточной нагрузкой на ресурсы ЭВМ.

Созданная система защиты доступности информации позволяет эффективно отфильтровывать сетевые пакеты в автоматизированном режиме, а также отправлять все данные в СУБД MySQL с последующим выводом информации в веб-интерфейс. Веб-часть является одной из управляющих частей разработанной системы. В ней реализована возможность управления системой с персональных компьютеров/серверов и мобильных устройств.

Разработанная автоматизированная система защиты доступности информации от атак внешним несанкционированным трафиком AntiDDoS показала высокую стабильность и надежность при фильтрации сетевых пакетов в больших и малых объемах. Средняя загруженность центрального процессора при DDoS-атаках принимает значение 6,64 \%, тогда как без использования данной системы нагрузка при DDoS-атаке может повышаться до 100 \%. Пониженная нагрузка является приемлемой и позволяет одновременно запускать сложные вычислительные операции без нарушения работоспособности системы.

Ключевые слова: DoS-атака, DDoS-атака, автоматизачия защиты, доступность информации, информационная безопасность, защита информации, AntiDDoS, несанкиионированный трафик, сетевые пакеты, внешний сетевой интерфейс, обработка трафика.

Несколько десятилетий одним из основных направлений в сфере информационной безопасности является защита от возрастания количества и сложности атак сетевыми пакетами [1-3]. Зачастую DDoS-атаки направлены на нарушение доступности ресурсов какой-либо системы, имеющей сетевую инфраструктуру по выходу во внешнюю глобальную сеть [4-7]. Доступность является важнейшим из трех основополагающих критериев наряду с целостностью и конфиденциальностью информационной безопасности объекта [8-11]. DDoS-атаки вызывают массовый отказ оборудования в области информационно-коммуникационных технологий [12-14]. Например, физические серверы Московской биржи в 2014 году; информационные ресурсы ПАО «Аэрофлот» в 2010 году, в том числе и на ряд организаций банковского сектора в 2014 году. Была отключена сеть банкоматов «Генбанка» (изза интенсивных DDoS-атак) 4-5 декабря 2016 года. Сайты группы ВТБ 5 декабря 2016 года также подверглись атакам типа DoS и DDoS, что нарушило их доступность. Из-за DDoS-атак произошли многочисленные сбои сервисов компании Dr.Web 27 января и Министерства здравоохранения России 12 февраля 2017 года. В целях сведения к минимуму исходных последствий DoS- и DDoS-атак их обнаружение и предотвращение особенно актуальны.

B настоящее время с DDoS-атаками справляются, как правило, при помощи аппаратно-программных средств. В качестве примера можно привести компании CloudFlare и OVH, которые применяют метод проксирования при защите своих клиентов. Но данный метод недостаточно эффективен из-за нестабильности при DDoS-атаках и проявляется в виде ложных блокировок к удаленному ресурсу.

Исследованиями в области защиты доступности информации и в моделировании DDoS-атак занимаются многие ученые, о чем свидетельствуют многочисленные публикации. Например, в [15] рассмотрены методы противодействия DDoS-aтaкам в SDN-сетях. Способы защиты от DDoS-атак проанализированы в [16]. В [17] смоделированы DDoS-атаки типа HTTP-flood и SLOWBODY (rudead-yet) с помощью средства имитационного моделирования CMO - GPSS WORLD. B [18] pacсмотрена возможность применения нейронных сетей для обнаружения атак внешним несанкционированным трафиком. Актуальные типы DDoSатак и методы защиты от них проанализированы 
в [19]. Авторы рассмотрели расширение профиля операционного риска в банках при возрастании DDoS-угроз [20]. B [21] описана методика защиты сети связи от DDoS-атак с помощью BGP FLOWSPEC. Работа [22] посвящена механизмам защиты от инфраструктурных DDoS-атак. B [23] авторы применили метод Хертса для определения сезонности сетевого трафика с целью раннего обнаружения DDoS-атак, а в [24] рассмотрено влияние DDoS-атак на финансово-экономические результаты деятельности компаний. Разработки нейросетевого метода обнаружения низкоинтенсивных атак типа «отказ в обслуживании» описаны в [25], а метода обнаружения DDoS-атак в [26].

Целью данной работы является реализация многофункциональной аппаратно-программной защиты от DDoS-атак с возможностью оптимизации сетевой нагрузки, а также снижения загруженности ресурсов физического сервера и вычислительного кластера.

\section{Аналогичные решения}

Системы фильтрации DoS- и DDoS-атак представляют собой комплекс принимаемых мер по их нейтрализации и защите доступности информации. B настоящее время системы защиты от DoS- и DDoS-атак подразделяются на три основные категории: проксирующие, стыковочные и программные.

1. Проксирующие системы фильтрации DoS- и DDoS-атак. Данное решение реализовано за счет отдельных физических серверов, работающих в ка- честве Proxy. Схема фильтрации представлена на рисунке 1.

Существенными недостатками данной системы являются повышение задержки (пинга), а также частые потери сетевых пакетов во время DoS- и DDoS-атак.

2. Стыковочные системы защиты от атак типа DoS и DDoS. Данное решение представляет собой реализацию физического сетевого стыка: протягиваются оптические волокна от серверов клиента до центра обработки данных компании, предоставляющей защиту от DoS- и DDoS-атак. Схема работы данной системы представлена на рисунке 2.

Недостатком данной системы является невозможность физического взаимодействия с центром обработки данных по защите от атак типа DoS и DDoS. Например, если компания по защите от DoSи DDoS-атак находится в Москве, а серверы клиента во Владивостоке, то физический стык будет неуместен из-за огромного расстояния между двумя сетевыми узлами.

3. Программные системы защиты от DDoSатак. Данные решения представляют собой стандартные межсетевые экраны, внедренные различными корпорациями в операционные системы. Схема работы стандартных фаерволов представлена на рисунке 3.

Существенными недостатками данных решений являются невозможность многопоточной обработки трафика, неспособность полной защиты физического сервера от огромного количества трафика, а также повышенная сетевая нагрузка (при DoS- и DDoS-атаках) на ресурсы ЭBM.

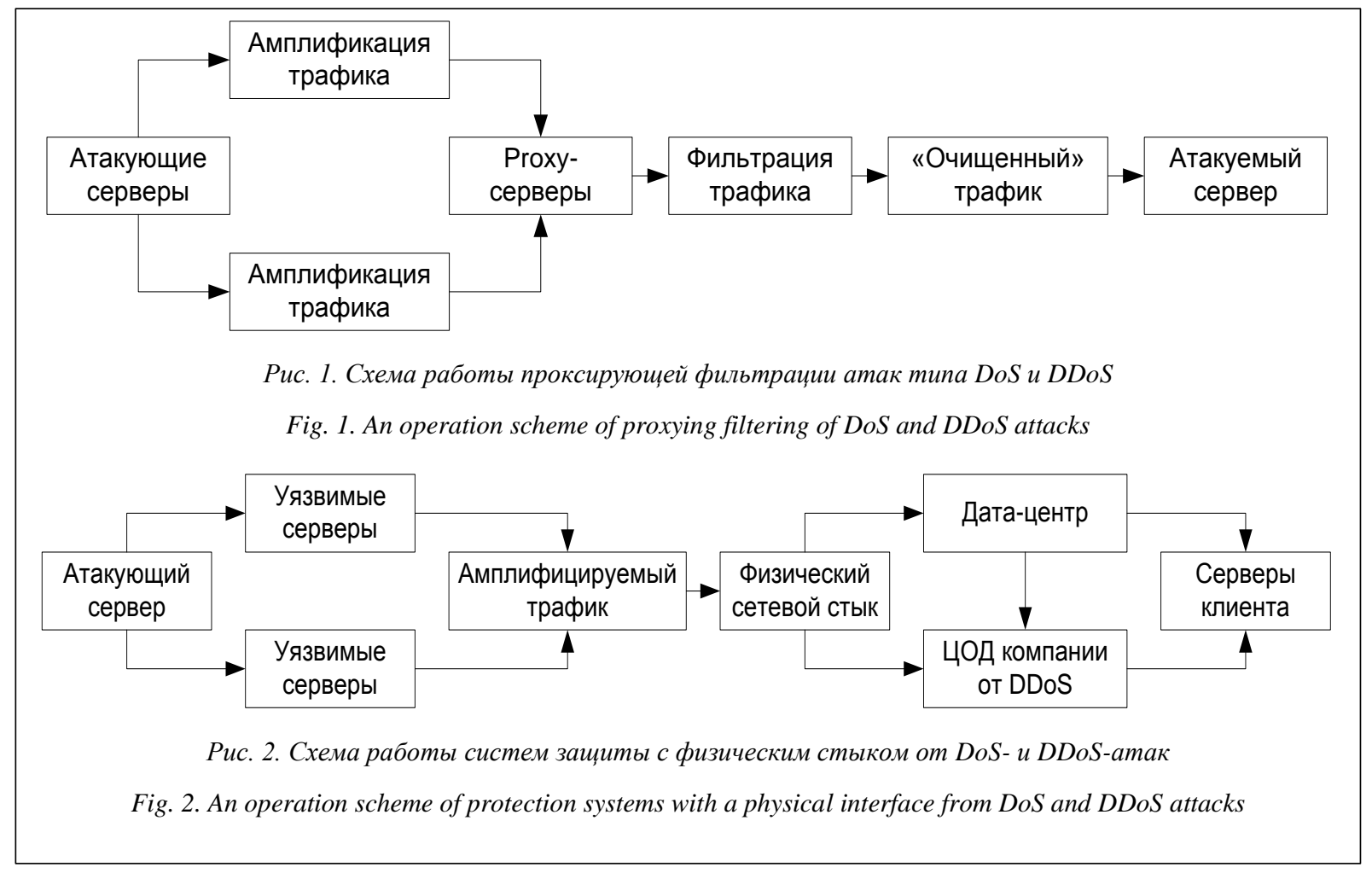




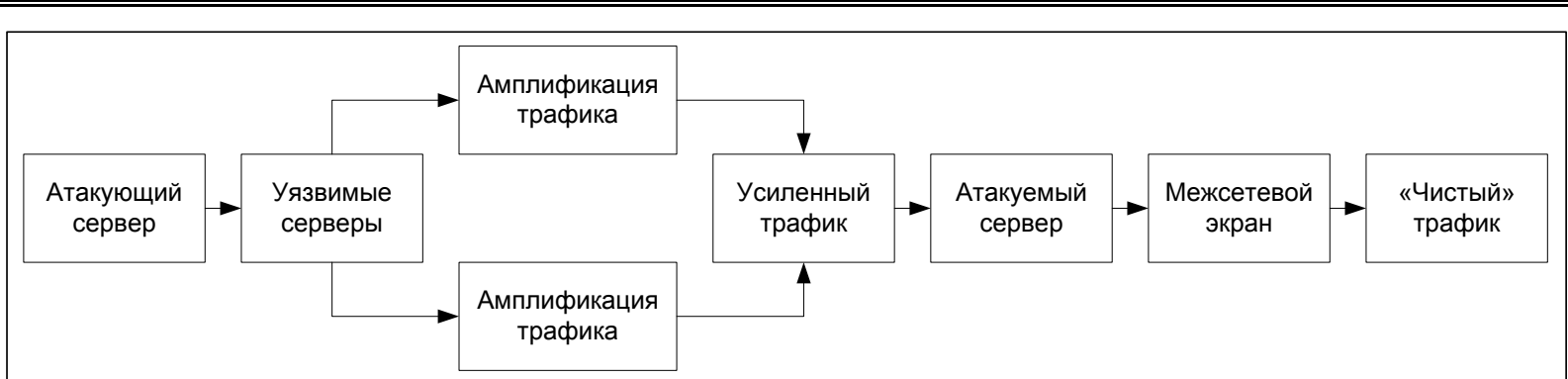

Рис. 3. Схема работы стандартных межсетевых экранов

Fig. 3. An operation scheme of standard firewalls

\section{Особенности разработанной системы}

Разработанная система представляет собой аппаратно-программный комплекс с возможностью фильтрации внешнего сетевого трафика. Основные преимущества разрабатываемого программного продукта:

- считывание трафика с внешнего сетевого интерфейса;

- автоматизированное добавление правил фильтрации;

- возможность добавления правил фильтрации от DDoS-атак через веб-интерфейс;

- вывод скорости внешнего сетевого интерфейса и количества сетевых пакетов в веб-часть;

- автоматизированный анализ внешнего сетевого трафика на наличие в нем отклонений от нормы;

- алгоритм для автоматизированного распределения правил фильтрации;

- модуль для определения вида и типа, а также фильтрации DoS- и DDoSатак в режиме реального времени с применением цепей Маркова.

Разработана многофункциональная система для отражения DoS- и DDoSатак в UNIX-подобных системах. Схема защиты от DoS- и DDoS-атак представлена на рисунке 4. ЭВМ атакующего распространяет алгоритм амплифицирования для поиска уязвимых серверов с целью увеличения мощности DDoSатаки. Далее головной сервер кластера принимает атаку и распределяет ее по физическим серверам. После запуска алгоритма на основе цепей Маркова осуществляются управление сетевой нагрузкой, распределение правил фильтрации сетевого трафика, а также автоматизированное определение типа DDoS-атаки. После отправки данных в ядро операционной системы происходят определение количества входящих сетевых пакетов, прием данных из системного ядра каждого сервера, а также определение (с внешнего сетевого интерфейса) скорости атаки. В конечном итоге все сводится к повышенной защите доступности информации.

Эффективным решением является использование в основе модуля цепей Маркова для защиты от DDoS-атак. Управление сетевой нагрузкой проис-

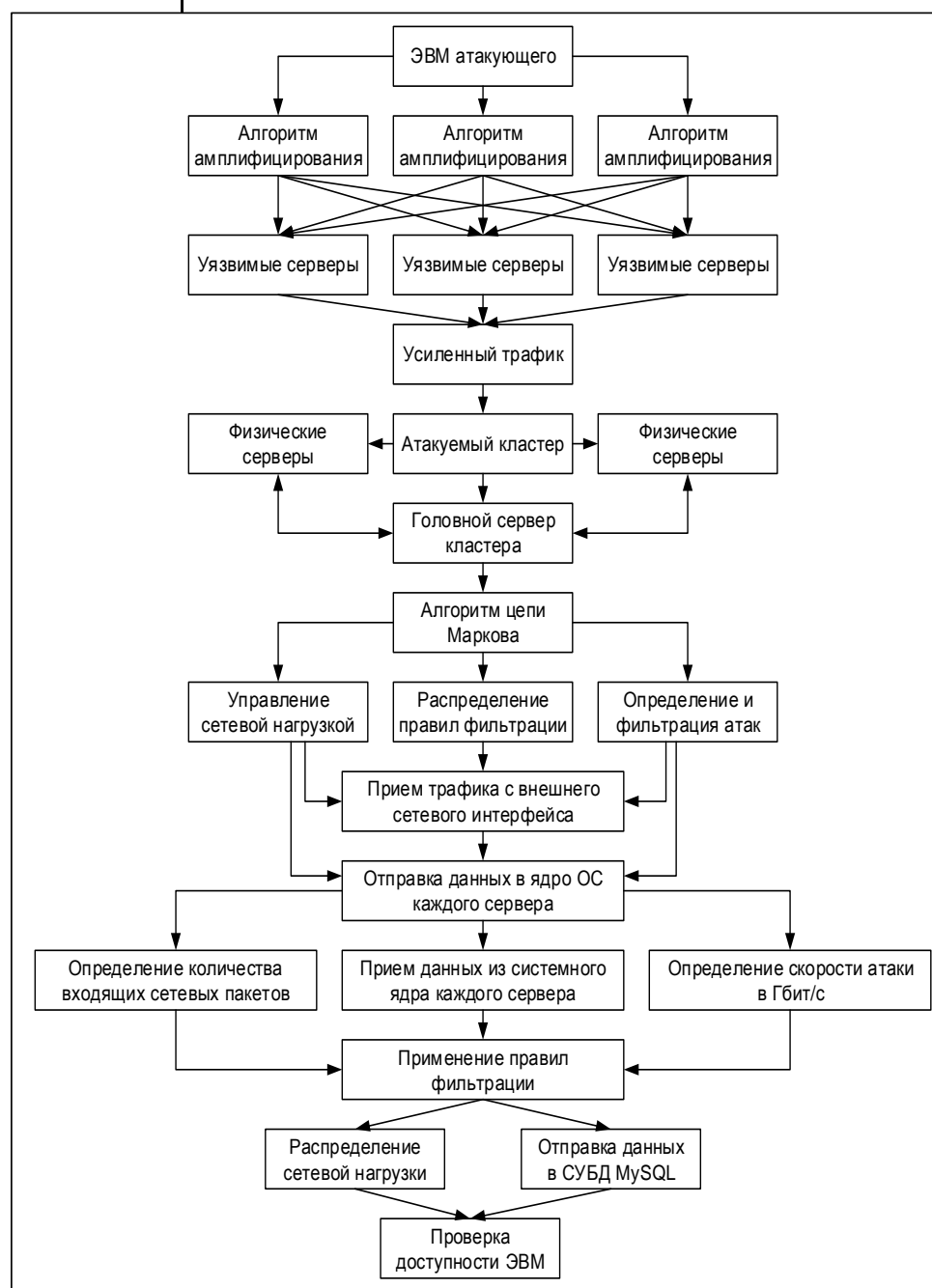

Рис. 4. Схема работы системы защитты доступности информачии

Fig. 4. An operation scheme of the information accessibility protection system 
ходит за счет обработки поступающих заявок (в режиме реального времени):

$$
\lambda=K * N, K=\frac{\frac{M}{J}}{\sum_{p=0}^{m}\left(\frac{M}{J}\right)^{K}},
$$

где $\lambda$ - управление сетевой нагрузкой; $K$ - количество ядер атакуемого сервера; $N$ - вероятность атаки в режиме реального времени; $M$ - общее количество ядер кластера; $J$ - текущая вычислительная нагрузка. Это необходимо для равномерного распределения сетевых пакетов по физическому серверу/кластеру с целью снижения загруженности ресурсов ЭВМ. Далее применяется распределение правил фильтрации с успешной вероятностью:

$$
P=\frac{N^{*} B}{M * J},
$$

где $P$ - распределение правил фильтрации с успешной вероятностью; $N$ - вероятность атаки в режиме реального времени; $B$ - вероятность успешной обработки трафика; $M$ - общее количество ядер кластера; $J$ - текущая вычислительная нагрузка. Это необходимо для фильтрации несанкционированного сетевого трафика. Также определяются виды и типы атак по содержимому сетевых пакетов:

$$
P_{v t}=\frac{S_{p}}{1-\frac{J_{p}}{M_{K}}},
$$

где $P_{v t}$ - вероятность определения вида и типа атак по содержимому сетевых пакетов; $S_{p}$ - анализ содержимого пакета; $J_{p}$ - возможные виды атак; $M_{k}-$ количество ядер в кластере. Фильтрация DoS- и DDoS-атак выполняется по всем физическим сер- верам кластера с равномерным распределением нагрузки по ядрам:

$$
T=\frac{\sum_{j=0}^{M} K^{*} H+(N * B)}{t_{h}+t_{\min }+t_{a v}+t_{\max }},
$$

где $T$ - вероятность успешной фильтрации DoS- и DDoS-атак; $K$ - количество ядер атакуемого сервера; $H$ - количество физических серверов в кластере; $N$ - вероятность атаки в режиме реального времени; $B$ - вероятность успешной обработки трафика; $t_{h}$ - время сбора данных о входящем сетевом пакете за последний час; $t_{\min }$ - минимальная продолжительность сетевой атаки за последний год; $t_{a v}-$ средняя продолжительность сетевой атаки за последний год; $t_{\max }$ - максимальная продолжительность сетевой атаки за последний год. Определение длительности DoS- и DDoS-атак необходимо для применения ограничительных лимитов по обработке внешнего сетевого трафика в правилах фильтрации. В целях более успешной фильтрации DoS и DDoS рассчитываются продолжительности атак за последний год.

Таким образом, разработанный программный модуль для защиты от DoS- и DDoS-атак позволяет качественно фильтровать внешний сетевой трафик.

\section{Основной функционал разработанной системы защиты доступности информации}

Система AntiDDoS является комплексным решением по фильтрации и отделению вредоносного сетевого трафика, направленного на переполнение канала и отказ в удаленном обслуживании. Основной функционал системы защиты от DoS- и DDoSатак представлен в таблице 1.

Функционал программного модуля со средней теоретической нагрузкой на CPU

Таблица 1

Functionality of a software module with an average theoretical load on the CPU

\begin{tabular}{|l|l|c|l|}
\hline \multicolumn{1}{|c|}{ Функция } & \multicolumn{1}{|c|}{ Цель функции } & $\begin{array}{l}\text { Теоретическая } \\
\text { нагрузка, \% }\end{array}$ & \multicolumn{1}{|c|}{ Результат } \\
\hline $\begin{array}{l}\text { Считывание трафика с внеш- } \\
\text { него сетевого интерфейса }\end{array}$ & $\begin{array}{l}\text { Вывод и отправка данных о входя- } \\
\text { щем и исходящем трафиках в СУБД } \\
\text { MуSQL }\end{array}$ & 0,06 & $\begin{array}{l}\text { Прием данных для «руч- } \\
\text { ного» анализа трафика }\end{array}$ \\
\hline $\begin{array}{l}\text { Автоматизированное добав- } \\
\text { ление правил фильтрации }\end{array}$ & $\begin{array}{l}\text { Добавление необходимых значений } \\
\text { для фильтрации вредоносного } \\
\text { трафика }\end{array}$ & 0,09 & $\begin{array}{l}\text { Добавление правил } \\
\text { фильтрации из БД }\end{array}$ \\
\hline $\begin{array}{l}\text { Вывод данных в веб-интер- } \\
\text { фейс }\end{array}$ & $\begin{array}{l}\text { Удобное администрирование } \\
\text { системы AntiDDoS }\end{array}$ & $\begin{array}{l}\text { Ситуационный анализ } \\
\text { системным администра- } \\
\text { тором }\end{array}$ \\
\hline $\begin{array}{l}\text { Распределение правил филь- } \\
\text { трации по видам и типам } \\
\text { атак }\end{array}$ & Автоматическая сортировка правил & 0,12 & $\begin{array}{l}\text { Более быстрое реагирова- } \\
\text { ние на DоS и DDоS }\end{array}$ \\
\hline $\begin{array}{l}\text { Автоматизированный анализ } \\
\text { сетевого трафика }\end{array}$ & Выявление DoS- и DDoS-атак & 0,15 & $\begin{array}{l}\text { Автоматизированный } \\
\text { анализ трафика на нали- } \\
\text { чие отклонений }\end{array}$ \\
\hline $\begin{array}{l}\text { Фильтрация DoS- и DDoS- } \\
\text { атак }\end{array}$ & Защита доступности информации & 0,35 & $\begin{array}{l}\text { Сохранение повышенной } \\
\text { доступности информации }\end{array}$ \\
\hline
\end{tabular}


Вышеприведенные фрагменты исходных кодов взаимосвязаны, так как после добавления правил фильтрации происходит их автоматизированный вывод в веб-интерфейс. Это позволит системному администратору отслеживать состояние системы фильтрации в режиме реального времени.

\section{Апробация реализованной системы}

После этапа разработки системы защиты от DDoS-атак необходимо провести апробацию (тестирование). Тестирование будет происходить в двух режимах: до атаки (обычный) и во время атаки (боевой). Для тестирования необходимы DDoSатаки, запуск которых производится из панелей типа Stresser. Данные панели представляют собой веб-систему управления ботнетом и, как правило, находятся в других странах. Соответственно, каждый день автоматически запускались интенсивные и массивные DDoS-атаки на каждый физический сервер кластера. Запуск DDoS-атак необходим для более тщательного тестирования разработанного модуля в течение десяти дней. Тестирование в течение десяти дней объясняется тем, что некоторые DDoS-атаки дают весомую нагрузку только после увеличения их мощности через определенный промежуток времени. Таким образом, мощность DDoS-атак возрастала и нагрузка на ресурсы ЭВМ постепенно увеличивалась. Сами значения загруженности физических ресурсов выводит в веб-интерфейс система.
Нагрузка на ЭВМ в обычном режиме представлена в таблице 2.

Средняя нагрузка (из данных таблицы 2) остается достаточно низкой и приравнивается к следующим значениям: центральный процессор $2,75 \%$; $S S D$-накопитель - $1,10 \%$; оперативная память - $0,14 \%$.

Загруженность (табл. 2) свидетельствует о малом потреблении физических ресурсов ЭВМ в режиме до атаки (обычный). Это предоставляет возможность использования остальных вычислительных мощностей под различные задачи.

Рассмотрим загруженность ресурсов ЭВМ при DoS- и DDoS-атаках различной интенсивности и мощности (табл. 3).

Средняя нагрузка при DoS- и DDoS-атаках (табл. 3) является достаточно низкой: центральный процессор - 6,64 \%; SSD-накопитель - 1,48 \%; оперативная память $-1,23 \%$.

Приведенные результаты свидетельствуют о достаточно низкой нагрузке в боевом режиме тестирования. Данная загруженность достигается за счет применения цепей Маркова для распределения нагрузки во время DoS- и DDoS-атак. Таким образом, разработанная система показывает высокую производительность, а также обеспечивает надежную защиту доступности информации.

Апробация разработанной системы для защиты от DDoS-атак производилась на следующем оборудовании: процессор - 2xIntel Xeon 5690 (24 потока); оперативная память - 32 Гб; винчестеры -

Таблииа 2

Потребление вычислительных мощностей ЭВМ в течение десяти дней

Table 2

Consumption of computing power for ten days

\begin{tabular}{|c|c|c|c|c|c|c|c|c|c|c|}
\hline \multirow{2}{*}{ Показатель } & \multicolumn{9}{|c|}{ День } & \multicolumn{1}{|c|}{$\mathbf{~}$} \\
\cline { 2 - 12 } & $\mathbf{1}$ & $\mathbf{2}$ & $\mathbf{3}$ & $\mathbf{4}$ & $\mathbf{5}$ & $\mathbf{6}$ & $\mathbf{7}$ & $\mathbf{8}$ & $\mathbf{9}$ & $\mathbf{1 0}$ \\
\hline $\mathrm{A}$ & 0,50 & 0,70 & 0,90 & 1,10 & 1,30 & 1,50 & 1,70 & 1,90 & 2,10 & 2,30 \\
\hline $\mathrm{B}$ & 0,11 & 0,20 & 0,25 & 0,36 & 0,42 & 0,56 & 0,70 & 0,84 & 0,96 & 1,00 \\
\hline $\mathrm{C}$ & 0,50 & 1,00 & 1,50 & 2,00 & 2,50 & 3,00 & 3,50 & 4,00 & 4,50 & 5,00 \\
\hline $\mathrm{D}$ & 0,01 & 0,02 & 0,03 & 0,04 & 0,05 & 0,06 & 0,07 & 0,08 & 0,09 & 0,10 \\
\hline $\mathrm{E}$ & 0,10 & 0,30 & 0,50 & 0,80 & 1,00 & 1,20 & 1,40 & 1,60 & 1,90 & 2,20 \\
\hline
\end{tabular}

Нагрузка на ресурсы ЭВМ при атаках DoS и DDoS в течение десяти дней

Таблица 3

Load on computer resources during DoS and DDoS attacks for ten days

\begin{tabular}{|c|c|c|c|c|c|c|c|c|c|c|}
\hline \multirow{2}{*}{ Показатель } & \multicolumn{9}{|c|}{ День } & \multicolumn{10}{c|}{ ( } & $\mathbf{2}$ & $\mathbf{2}$ & $\mathbf{3}$ & $\mathbf{4}$ & $\mathbf{5}$ & $\mathbf{6}$ & $\mathbf{7}$ & $\mathbf{8}$ & $\mathbf{9}$ & $\mathbf{1 0}$ \\
\hline & 1,00 & 2,00 & 3,00 & 4,00 & 5,00 & 6,00 & 7,00 & 8,00 & 9,00 & 9,90 \\
\hline $\mathrm{A}$ & 3,00 & 4,00 & 5,00 & 6,00 & 7,00 & 8,00 & 9,00 & 10,00 & 11,00 & 12,00 \\
\hline $\mathrm{B}$ & 1,80 & 2,45 & 3,13 & 5,76 & 6,10 & 7,06 & 8,65 & 9,34 & 10,23 & 11,90 \\
\hline $\mathrm{C}$ & 0,10 & 0,30 & 0,50 & 0,80 & 1,18 & 1,28 & 1,90 & 1,98 & 2,08 & 2,20 \\
\hline $\mathrm{D}$ & 0,18 & 0,45 & 0,65 & 0,97 & 1,14 & 1,79 & 2,01 & 2,25 & 2,41 & 3,00 \\
\hline $\mathrm{E}$ & &
\end{tabular}

Примечание. В таблицах 2 и 3 приняты следующие обозначения: А - количество входящего сетевого трафика, Гбит/с; В - количество входящих сетевых пакетов, млн. шт./с; С - нагрузка на CPU, \%; D - потребление ОЗУ, \%; E - нагрузка на SSD, \%. 
RAID 10 (Intel S3710 SSDSC2BA012T401 800 ГБ каждый); суммарный сетевой канал - 10 Гбит/с; операционная система - UBUNTU 16.04.2 LTS.

После этапа апробации системы защиты доступности информации произведено окончательное инсталлирование на вычислительный кластер (находится в одном из ЦОД г. Москвы) со следующими характеристиками: количество физических серверов - 30; процессор - Intel Xeon 5690 (CPU 60 , физических ядер - 360, количество потоков $720)$; общая оперативная память - 960 ГБ; винчестеры - RAID 10 (Intel S3710 SSDSC2BA012T401 800 ГБ каждый); внешний сетевой канал 20 Гбит/с.

\section{Сравнение с аналогами}

Сравним предлагаемое решение с аналогами. В качестве аналогов рассмотрим программный продукт от компании CloudFlare, представленный в виде метода проксирования внешнего сетевого трафика, и стандартные межсетевые экраны операционных систем Linux и Windows.

Данный анализ необходим для определения эффективности разработанной аппаратно-программной системы и выявления целесообразности использования AntiDDoS. Сравнение показано в таблице 4.

Средняя разница в нагрузке на центральный процессор между разработанной системой защиты от DDoS-атак и аналогичными решениями $-3,02$ раза. Среднее различие в задержке ответа (пинге) от сервера составляет 4,127 раза.

Предлагаемое решение существенно снижает загруженность центрального процессора (в 3,02 раза) по сравнению с аналогичными решениями. Данный результат достигается при помощи разработанных алгоритмов на основе цепей Маркова,

Сравнение полученных результатов с аналогами

Таблица 4

Comparison of the obtainesd results with analogues

Table 4

\begin{tabular}{|c|c|c|c|c|c|c|c|c|c|c|}
\hline \multirow{2}{*}{$\begin{array}{c}\text { Показа- } \\
\text { тель }\end{array}$} & \multicolumn{10}{|c|}{ День } \\
\hline & 1 & 2 & 3 & 4 & 5 & 6 & 7 & 8 & 9 & 10 \\
\hline A & 1,00 & 2,00 & 3,00 & 4,00 & 5,00 & 6,00 & 7,00 & 8,00 & 9,00 & 9,90 \\
\hline B & 3,00 & 4,00 & 5,00 & 6,00 & 7,00 & 8,00 & 9,00 & 10,00 & 11,00 & 12,00 \\
\hline $\mathrm{C}$ & 1,80 & 2,45 & 3,13 & 5,76 & 6,10 & 7,06 & 8,65 & 9,34 & 10,23 & 11,90 \\
\hline $\mathrm{D}$ & 2,00 & 3,00 & 4,00 & 6,00 & 7,24 & 8,34 & 9,78 & 10,56 & 11,77 & 14,39 \\
\hline$E$ & 6,76 & 9,98 & 14,54 & 18,97 & 21,76 & 24,79 & 28,99 & 32,72 & 36,44 & 42,00 \\
\hline$F$ & 7,88 & 10,00 & 18,56 & 21,98 & 24,76 & 29,00 & 32,09 & 36,88 & 42,00 & 47,13 \\
\hline $\mathrm{G}$ & 19,00 & 20,00 & 21,00 & 21,00 & 22,00 & 23,00 & 24,00 & 25,00 & 26,00 & 27,00 \\
\hline $\mathrm{H}$ & 50,00 & 70,00 & 90,00 & 120,00 & 130,00 & 140,00 & 150,00 & 160,00 & 170,00 & 180,00 \\
\hline I & 29,00 & 38,00 & 49,00 & 54,00 & 67,00 & 72,00 & 83,00 & 90,00 & 98,00 & 102,00 \\
\hline $\mathrm{J}$ & 36,00 & 47,00 & 55,00 & 78,00 & 89,00 & 100,00 & 110,00 & 140,00 & 150,00 & 160,00 \\
\hline $\mathrm{K}$ & 1,11 & 1,22 & 1,27 & 1,04 & 1,18 & 1,18 & 1,47 & 1,13 & 1,15 & 1,20 \\
\hline $\mathrm{L}$ & 3,75 & 4,07 & 4,64 & 3,29 & 3,56 & 3,51 & 3,35 & 3,50 & 3,56 & 3,52 \\
\hline M & 4,37 & 4,08 & 5,92 & 3,81 & 4,05 & 4,10 & 3,70 & 3,94 & 4,10 & 3,96 \\
\hline $\mathrm{N}$ & 1,52 & 1,90 & 2,33 & 2,57 & 3,04 & 3,13 & 3,45 & 3,60 & 3,76 & 3,77 \\
\hline $\mathrm{O}$ & 1,89 & 2,35 & 2,61 & 3,71 & 4,04 & 4,34 & 4,58 & 5,60 & 5,76 & 5,92 \\
\hline $\mathrm{P}$ & 2,63 & 3,50 & 4,28 & 5,71 & 5,90 & 6,08 & 6,25 & 6,40 & 6,53 & 6,66 \\
\hline
\end{tabular}

Примечание. В таблице приняты следующие обозначения: А - количество входящего сетевого трафика, Гбит/с; B - количество входящих сетевых пакетов, млн. шт./с; C - нагрузка на CPU разработанной системой защиты от DDoS-aтак, \%; D - нагрузка на CPU методом проксирования DDoS-атак, \%; E - нагрузка на CPU стандартным межсетевым экраном операционной системы Linux (UBUNTU 16.04.2 LTS), \%; F - нагрузка на CPU стандартным межсетевым экраном операционной системы Windows, \%; G - пинг (от Уфы до Москвы) при отражении DDoS-aтаки разработанной системой защиты доступности информации, мс; H - пинг (от Уфы до Москвы) при отражении DDoSатаки методом проксирования, мс; I - пинг (от Уфы до Москвы) при отражении DDoS-атаки межсетевым экраном операционной системы Linux (UBUNTU 16.04.2 LTS), мc; J - пинг при отражении DDoS-атаки межсетевым экраном операционной системы Windows, мc; K - разница в нагрузке между предлагаемым решением и методом проксирования, раз; L - разница в нагрузке между фаерволом Linux и предлагаемым решением, раз; M - разница в нагрузке между межсетевым экраном Windows и предлагаемым решением, раз; $\mathrm{N}$ - разница в задержке (пинге) между межсетевым экраном Linux и предлагаемым решением, мс; O - разница в пинге между межсетевым экраном Windows и предлагаемым решением, мс; $\mathrm{P}$ - разница в задержке между методом проксирования и разработанным решением, мс. 
а также невозможностью обработки больших объемов трафика стандартными методами операционных систем ЭВМ.

Разница в задержке (пинге) объясняется тем, что в операционных системах сетевой стек недостаточно оптимизирован для высоких сетевых нагрузок. Разработанная система решает данную проблему. Соответственно, пинг при использовании предложенного ПО в 4,127 раза меньше по сравнению с аналогами.

Таким образом, разработанная система защиты доступности информации показала повышенную производительность в рамках загруженности центрального процессора и пониженную задержку ответа от физического сервера. Это дает возможность более рационального использования ресурсов ЭВМ под различные цели. Также при низкой задержке ответа от ЭВМ более комфортно работать в пределах удаленного обслуживания физического сервера.

\section{Заключение}

В ходе проведенных исследований и разработок получены следующие результаты.

Разработана система защиты доступности информации AntiDDoS, способствующая усовершенствованию аппаратно-программной защиты от атак типа DoS и DDoS в пределах выделяемого канала.

Обоснована целесообразность применения системы защиты доступности информации на вычислительном кластере и отдельном физическом сервере. Разработана и предложена методика усовершенствования защиты от DoS- и DDoS-атак на ресурсах вычислительного кластера и отдельного физического сервера.

Проведена апробация разработанной системы защиты доступности информации AntiDDoS, peзультатами которой стали нагрузочные значения на ресурсы ЭВМ в двух режимах: до атаки (обычный) и во время атаки (боевой). Средняя нагрузка (при обычном режиме) на ресурсы физического сервера следующая: центральный процессор - 2,75 \%; твердотельный накопитель - 1,10\%; оперативная память $-0,14 \%$. Низкая загруженность ресурсов реализованной системой защиты доступности информации позволяет параллельно запускать другие ресурсоемкие процессы. Загруженность ресурсов ЭВМ в боевом режиме следующая: CPU (central processing unit) - 6,64 \%; SSD-накопитель - 1,48 \%; О3У (оперативная память) - 1,23 \%. Высокая производительность системы защиты доступности информации во время DoS- и DDoS-атак позволяет не только параллельно запускать ресурсоемкие процессы, но и предоставляет надежную защиту от перегрузки сетевой инфраструктуры внешним несанкционированным трафиком.

Таким образом, разработанная система защиты доступности информации показала высокую про- изводительность при интенсивных DoS- и DDoSатаках. Низкая загруженность ресурсов ЭВМ позволяет обеспечивать стабильную работу физического сервера и вычислительного кластера.

\section{Лuтература}

1. Палюх Б.В., Семенов Н.А., Бурдо Г.Б., Мельникова В.В. Автоматизированная система тестирования программных средств в скомпилированном виде // Программные продукты и системы. 2014. № 1. С. 123-128. DOI: 10.15827/0236-235X.027. $1.123-128$.

2. Пальчевский Е.В., Халиков А.Р. Автоматизированная система обработки данных в UNIX-подобных системах // Программные продукты и системы. 2017. Т. 30. № 2. С. 227-234. DOI: $10.15827 / 0236-235 X .030 .2 .227-234$.

3. Пальчевский Е.В., Халиков А.Р. Техника инструментирования кода и оптимизация кодовых строк при моделировании фазовых переходов на языке С++ // Тр. ИСП РАН. 2015. Т. 27. № 6. С. $87-96$.

4. Пальчевский Е.В., Халиков А.Р. Равномерное распределение нагрузки аппаратно-программного ядра в UNIX-системах // Тр. ИСП РАН. 2016. Т. 28. № 1. С. 93-102.

5. Верхний T.B., Гуц А.K. DDoS-атаки как дифференциальная игра // Математические структуры и моделирование. 2016. № 3. C. 184-188.

6. Рашевский Р.Б., Шабуров А.С. Практическое применение нейронных сетей для защиты информационно-управляющих систем критически важных объектов от DDoS-атак // Нейрокомпьютеры: разработка, применение. 2015. № 10. C. 16-20.

7. Zhang M., Liu X., Tang J., Kong H. Study on modeling and simulation of DDoS active defense. Xitong fangzhen xuebao. Zhongguo Xitong Fangzhen Xuehui Publ., 2014. vol. 26, no. 11, pp. 2698-2703.

8. Борисенко К.А., Бекенева Я.А., Шипилов Н.Н., Шоров А.В. Система имитационного моделирования для разработки и тестирования методов защиты от DDoS-атак с возможностью подключения реальных узлов // Изв. СПбГЭТУ «ЛЭТИ». 2015. Т. 6. С. 22-29.

9. Частикова В.А., Картамышев Д.А., Власов К.А. Нейросетевой метод защиты информации от DDoS-aтaк // Coвременные проблемы науки и образования. 2015. № 1-1. URL: http://science-education.ru/ru/article/view?id=18343 (дата обращения: 09.12.2017).

10. Бекенева Я.А. Анализ актуальных типов DDoS-атак и методов защиты от них // Изв. СПбГЭТУ «ЛЭТИ». 2016. Т. 1. C. 7-14.

11. Тарасов Я.В. Метод обнаружения низкоинтенсивных DDoS-атак на основе гибридной нейронной сети // Изв. ЮФУ: Технич. науки. 2014. № 8. С. 47-57.

12. Крылов В.В., Кравцов К.Н. Защита IP-подсетей от DDoS-атак и несанкционированного доступа методом псевдослучайной смены сетевых адресов // Вопросы защиты информации. 2014. № 3. С. 24-31.

13. Абрамов Е.С., Тарасов Я.В., Тумоян Е.П. Нейросетевой метод обнаружения низкоинтенсивных атак типа «отказ в обслуживании» // Изв. ЮФУ: Технич. науки. 2016. № 9. С. 58-71.

14. Соколова Э.С., Крылов В.В., Ляхманов Д.А., Капранов С.Н., Балашов Т.И. Разработка архитектуры кластера программно-конфигурируемой сети с централизованным управлением, устойчивого к воздействиям DDoS-атак // Информационно-измерительные и управляющие системы. 2015. Т. 13. № 3. C. $43-48$.

15. Федоришин Д.А. Методы противодействия DDOSатакам в SDN-сетях // Актуальные научные исследования в современном мире. 2016. № 5-3. С. 114-120.

16. Быков А.С., Перминов Г.В. Анализ способов защиты от DDoS-атак // Актуальные вопросы эксплуатации систем охраны и защищенных телекоммуникационных систем: сб. тр. Всерос. науч.-практич. конф. 2016. С. 105-106.

17. Бондаренко M.C. Моделирование DDOS-атак типа HTTP-flood И SLOWBODY (ru-dead-yet) с помощью средства 
имитационного моделирования CMO - GPSS WORLD // Вестн. Воронеж. ин-та высоких технологий. 2017. № 3. С. 13-17.

18. Пилюгина К.Н. Применение нейронных сетей с целью обнаружения вторжений // Современные научные исследования и инновации. 2016. № 2. С. 105-109.

19. Бекенева Я.А. Анализ актуальных типов DDOS-атак и методов защиты от них // Изв. СПбГЭТУ «ЛЭТИ». 2016. Т. 1. С. 7-14.

20. Ревенков П.В., Бердюгин А.А. Расширение профиля операционного риска в банках при возрастании DDoS-угроз // Вопросы кибербезопасности. 2017. № 3. С. 16-23.

21. Казаков Д.Б., Красов А.В., Лоханько Н.О., Подоляк Р.С. Методика защиты сети связи от DDoS-атак с помощью BGP FLOWSPEC // Актуальные проблемы инфотелекоммуникаций в науке и образовании: сб. науч. стат. V Междунар. науч.-технич. и науч.-методич. конф. СПб, 2016. С. 386-390.

22. Якубашко А.И. Механизмы защиты от инфраструктурных DDoS-атак // Актуальные проблемы современной науки в
21 веке: матер. XII Междунар. науч.-практич. конф. Махачкала, 2016. C. $51-52$

23. Терновой О.С., Жариков А.В., Шатохин А.С. Применение метода Хертса для определения сезонности сетевого трафика с целью раннего обнаружения DDoS-атак // Динамика систем, механизмов и машин. 2016. Т. 4. № 1. С. 57-61.

24. Дацко Т.Г., Алешина И.Ф. Влияние DDoS-атак на финансово-экономические результаты деятельности компаний // Научные исследования и разработки. Экономика. 2017. Т. 5. № 3. С. 51-58.

25. Абрамов Е.С., Тарасов Я.В., Тумоян Е.П. Нейросетевой метод обнаружения низкоинтенсивных атак типа «отказ в обслуживании» // Изв. ЮФУ: Технич. науки. 2016. № 9. С. 58-71.

26. Borisenko K., Rukavitsyn A., Shorov A., Gurtov A. Detecting the origin of DDOS-attacks in openstack cloud platform using data mining techniques. LNCS. Springer-Verlag GmbH, Heidelberg, 2016, vol. 9870, pp. 303-315.

\title{
An automated system of information accessibility protecting from attacks by unauthorized traffic in UNIX-like systems
}

\author{
E.V.Palchevsky ${ }^{1}$, Postgraduate Student, teelxp@inbox.ru \\ A.R. Khalikov ${ }^{1}$, Ph.D (Physics and Mathematics), Associate Professor, khalikov.albert.r@gmail.com
}

${ }^{1}$ Ufa State Aviation Technical University, Ufa, 450008, Russian Federation

Abstract. The paper is devoted to the development of a software module for protecting information accessibility during massive DoS and DDoS attacks. The developed system allows automatically determining a type and form of attacks by unauthorized traffic, and also filtering network packets by a specified limit (from 10 thousand to 7 million per second), with subsequent load distribution by physical and logical cluster cores.

At the first stage of development, DoS and DDoS attacks were analyzed, and similar solutions for a DDoS protection system were examined. The second stage is technical development of the automated system for protecting information accessibility AntiDDoS. The authors show basic functionality and the operation scheme of the DDoS attack protection system. The basic functionality is represented by the following technical data: the name of the function, the execution goal, the operating condition and the result of execution. The third stage is approbation of the implemented system within ten days. The results are presented in a table with an average daily load on computer resources.

The created information accessibility protection system allows effectively filtering network packets in an automated mode, as well as sending all data to the MySQL database, and then outputting information to the web interface. The web part is one of the control parts of the developed system. It implements the ability to manage the system from personal computers/servers and mobile devices.

The developed information accessibility protection system from AntiDDoS unauthorized traffic attacks has shown high stability and reliability when filtering network packets in large and small volumes. The average CPU load during DDoS attacks is $6.64 \%$. Whereas without using this system, the load during DDoS attack can increase to $100 \%$. Reduced load is acceptable and allows simultaneous running complex computational operations without disrupting the system.

Keywords: DoS attack, DDoS attack, protection automation, information accessibility, information security, AntiDDoS, unauthorized traffic, network packets, external network interface, traffic handling.

\section{References}

1. Palyukh B.V., Semenov N.A., Burdo G.B., Melnikova V.V. Automated system for testing software in a compiled form. Software \& Systems. 2017, vol. 27, no. 1, pp. 123-128 (in Russ.). DOI: 10.15827/0236-235X.027.1.123-128. 
2. Palchevsky E.V., Khalikov A.R. Automated data processing system in UNIX-like systems. Software \& Systems. 2017, vol. 30, no. 2, pp. 227-234 (in Russ.). DOI: 10.15827/0236-235X.030.2.227-234.

3. Palchevsky E.V., Khalikov A.R. The code instrumentation technique and optimization of code lines in modeling of phase transitions in C++. Proc. of ISP RAS. 2015, vol. 27, no. 6, pp. 87-96 (in Russ.).

4. Palchevsky E.V., Khalikov A.R. Uniform distribution of hardware-software kernel loading in UNIX-systems. Proc. of ISP RAS. 2016, vol. 28, no. 1, pp. 93-102 (in Russ.).

5. Verkhny T.V., Guts A.K. DDoS-attacks as differential game. Mathematical Structures and Simulation. Omsk, 2016, no. 3, pp. 184-188 (in Russ.).

6. Rashevsky R.B., Shaburov A.S. Practical application of neural networks for protection of management information systems of crucial objects from DDoS attacks. Neurocomputers: Development, Application. Moscow, 2015, no. 10, pp. 16-20 (in Russ.).

7. Zhang M., Liu X., Tang J., Kong H. Study on modeling and simulation of DDoS active defense. Xitong Fangzhen Xuebao. Zhongguo Xitong Fangzhen Xuehui Publ., 2014, vol. 26, no. 11, pp. 2698-2703.

8. Borisenko K.A., Bekeneva Ya.A., Shipilov N.N., Shorov A.V. The system of simulation modeling for development and testing DDoS attack protection methods with a possibility of connecting real nodes. Izvestiya SPbGETU "LETI". St. Petersburg, 2015, vol. 6, pp. 22-29 (in Russ.).

9. Chastikova V.A., Kartamyshev D.A., Vlasov K.A. A neural network method of information security from the DDoS attacks. Modern Problems of Science and Education. Penza, 2015, no. 1. Available at: .http://science-education.ru/ru/article/ view?id=18343 (accessed December 9, 2017).

10. Bekeneva Ya.A. The analysis of relevant types of DDoS attacks and protection methods. Izvestiya SPbGETU "LETI". St. Petersburg, 2016, vol. 1, pp. 7-14 (in Russ.).

11. Tarasov Ya.V. A method of detecting low-intensive DDoS attacks based on a hybrid neural network. Izvestiya SFedU. Engineering Sciences. Rostov-on-Don, 2014, no. 8, pp. 47-57 (in Russ.).

12. Krylov V.V., Kravtsov K.N. Protecting IP subnets from DDoS attacks and illegal access using the method of pseudorandom change of network addresses. Information Security Questions. Moscow, 2014, no. 3, pp. 24-31 (in Russ.).

13. Abramov E.S., Tarasov Ya.V., Tumoyan E.P. A neural network method of detecting low-intensive attacks like "service failure”. Izvestiya SFedU. Engineering Sciences. Rostov-on-Don, 2016, no. 9, pp. 58-71 (in Russ.).

14. Sokolova E.S., Krylov V.V., Lyakhmanov D.A., Kapranov S.N., Balashov T.I. Development of architecture of a program configured network cluster with centralized DDoS attack resistant management. Information and Control Systems. Moscow, 2015, vol. 13, no. 3, pp. 43-48 (in Russ.).

15. Fedorishin D.A. Methods of countering DDOS attacks in SDN-networks. Current Scientific Research in the Modern World. Institute for Social Transformation Publ., 2016, no. 5-3, pp. 114-120 (in Russ.).

16. Bykov A.S., Perminov G.V. Analysis of ways to protect from DDoS attacks. Topical Issues of Operating Security Systems and Secure Telecommunication Systems: Proc. All-Russ. Sci. and Pract. Conf. 2016, pp. 105-106 (in Russ.).

17. Bondarenko M.S. Modeling DDOS attacks like HTTP-flood and SLOWBODY (ru-dead-yet) using the simulation tool SMO - GPSS WORLD. VESTNIK of VIHT. Voronezh, 2017, no. 3, pp. 13-17 (in Russ.).

18. Pilyugina K.N. Application of neural networks to detect intrusion. Modern Scientific Research and Innovations. Moscow, 2016, no. 2, pp. 105-109 (in Russ.).

19. Bekeneva Ya.A. Analysis of current types of DDOS attacks and methods of protection. Izvestiya SPbGETU "LETI". St. Petersburg, 2016, vol. 1, pp. 7-14 (in Russ.).

20. Revenkov P.V., Berdyugin A.A. Expansion of the operational risk profile in banks with increasing DDoS threats. $C y-$ bersecurity Issues. Moscow, 2017, no. 3, pp. 16-23 (in Russ.).

21. Kazakov D.B., Krasov A.V., Lokanko N.O., Podolyak R.S. A method of protecting a communication network from DDOS attacks using BGP FLOWSPEC. Proc. 5th Intern. Sci.-Tech. and Sci.-Methodical Conf. "Pressing Problems of Information Telecommunications in Science and Education”. St. Petersburg, 2016, pp. 386-390 (in Russ.).

22. Yakubashko A.I. Mechanisms of protection from infrastructural DDoS attacks. Proc. 12th Intern. Sci. and Pract. Conf. "Pressing Problems of Modern Science in the 21st century". Makhachkala, 2016, pp. 51-52 (in Russ.)

23. Ternovoy O.S., Zharikov A.V., Shatokhin A.S. Application of the Herts method to determine the seasonality of network traffic for early detection of DDOS attacks. Dynamics of Systems, Mechanisms and Machines. Omsk, 2016, vol. 4, no. 1, pp. 57-61 (in Russ.).

24. Datsko T.G., Aleshina I.F. The impact of DDoS attacks on the financial and economic performance of companies. Scientific Research and Development. Economy. INFRA-M Publ., Moscow, 2017, vol. 5, no. 3, pp. 51-58 (in Russ.).

25. Abramov E.S., Tarasov Ya.V., Tumoyan E.P. A neural network method of detecting low-intensity attacks of the "service denial" type. Izvestiya SFedU. Technical Sciences. Rostov-on-Don, 2016, no. 9, pp. 58-71 (in Russ.).

26. Borisenko K., Rukavitsyn A., Shorov A., Gurtov A. Detecting the origin of DDOS-attacks in the openstack cloud platform using data mining techniques. Lecture Notes in Computer Science. Springer-Verlag GmbH Publ., Heidelberg, 2016, vol. 9870 , pp. 303-315. 
УДК 519.68

DOI: $10.15827 / 0236-235 X .123 .557-564$

Дата подачи статьи: 15.02 .18

\title{
Эфрфективность поэтапного применения средств защиты с пересечением областей обнаружения угроз
}

\author{
B.C. Коломойцев 1, аспирант, dek-s-kornis@yandex.ru \\ B.A. Богатырев 1, д.m.н., npodeccop, vladimir.bogatyrev@gmail.com
}

1 Санкт-Петербургский наииональный исследовательский университет информаиионных технологий, механики и оптики (Университет ИТМО), г. Санкт-Петербург, 197101, Россия

В работе исследованы возможности повышения эффективности схемы безопасного доступа «Прямое соединение» на основе выбора вариантов ее построения с учетом поэтапного применения различных средств защиты информации и их объединения в систему кластерной архитектуры, направленного на консолидацию ограниченных ресурсов защиты. Консолидация ресурсов защиты проводится с целью достижения максимальной защищенности при минимальных задержках и стоимости системы.

Предложены критерии эффективности систем защиты информации, ориентированные на повышение вероятности обнаружения угроз за минимальное время, с учетом его возможной ограниченности. Данные критерии учитывают среднее время пребывания запросов и вероятности обнаружения и устранения угроз системой защиты информации. Время обслуживания на каждом этапе предполагается распределенным по показательному закону.

Предложены модели оценки вероятности обнаружения угроз и задержек их поиска в зависимости от последовательности применения средств защиты информации в узлах. Модели учитывают пересекаемость множеств угроз, обнаруживаемых различными средствами защиты информации. Показана возможность реализации адаптивной стратегии последовательного применения средств защиты информации для предотвращения угроз информационной безопасности в зависимости от изменяемой интенсивности поступающих запросов. Рассмотрены варианты комплектации узлов полным или частичным набором имеющихся программных или аппаратно-программных средств защиты информации.

Ключевые слова: информационная безопасность, защита информации, схема доступа, несанкиионированный доступ, оиенка эффективности системы, системы массового обслуживания, вероятность обнаружения угроз, информачионные угрозы.

Обеспечение высокой надежности и информационной защищенности является одной из ключевых задач в современных системах обработки, хранения и передачи информации. Угрозы информационной безопасности (ИБ) могут иметь многообразные проявления, например, в виде вирусных атак, направленных на искажение или уничтожение обрабатываемых в вычислительной системе данных, или несанкционированного доступа к узлам вычислительной сети [1-4].

Актуальными представляются исследования влияния на эффективность вычислительной системы организации системы защиты информации (ЗИ) и схемы безопасного доступа (СБД), позволяющих безопасно взаимодействовать со всеми внешними и внутренними узлами инфокоммуникационной системы [5].

Проектирование системы ЗИ для сложных инфокоммуникационных систем требует модельноориентированного подхода, при котором предполагается оценка эффективности проектных решений по построению системы ЗИ рациональных проектных решений с их дальнейшей оптимизацией. Выбор и оптимизация проектных решений требуют формирования системы критериев эффективности системы ЗИ, включающей совокупность частных и комплексных критериев.

Цель работы - исследование возможностей повышения эффективности инфокоммуникационной системы, использующей СБД «Прямое соедине- ние», на основе выбора вариантов ее организации с учетом поэтапного применения различных средств ЗИ и их объединения в систему кластерной архитектуры, направленного на консолидацию ограниченных ресурсов защиты для достижения максимальной защищенности при минимальных задержках и стоимости системы.

\section{Объект исследования}

Рассматривается СБД «Прямое соединение» (а именно: ее частный случай - СБД «Связующий узел»), предполагающая совместное использование некоторого множества последовательно подключенных элементов (средств) защиты [5].

Будем считать, что система ЗИ содержит один или некоторое множество узлов, объединенных в кластер. Узлы кластера комплектуются некоторым множеством средств защиты, реализованных программно, аппаратно или аппаратно-программно. При комплектовании узлов аппаратными или аппаратно-программными средствами ЗИ возможно их последовательное, параллельное или конвейерное использование. Конструктивно узел может быть реализован в виде компьютера со встраиваемыми платами средств ЗИ. При этом стоимость узла пропорциональна числу включенных в его состав средств ЗИ. При программной реализации средств ЗИ узел содержит компьютер, укомплектованный набором программных средств ЗИ (СБД «Связую- 
щий узел». Инициализация функционирования средств ЗИ реализуется последовательно, причем задается различный порядок их использования. При программной реализации средств ЗИ стоимость узла в основном определяется стоимостью компьютера.

Типовая СБД «Прямое соединение» представлена на рисунке 1.

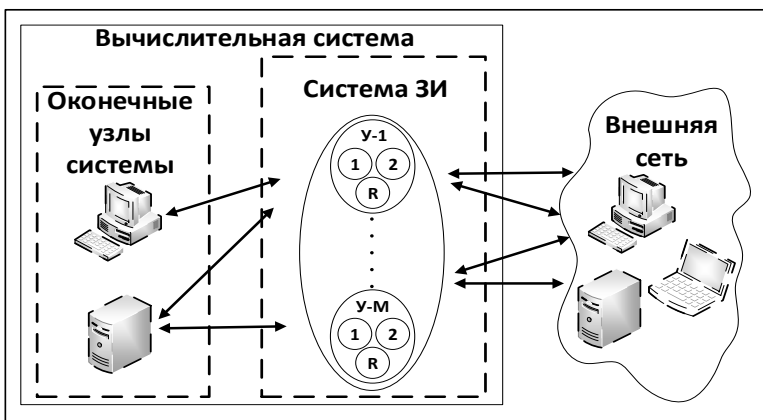

Рис. 1. Типовая СБД «Прямое соединение»

Fig. 1. A typical "Direct connection" PSA

Данная схема имеет три ключевые зоны:

- оконечные узлы вычислительной системы, содержащие встроенные персональные средства ЗИ;

- система ЗИ, представляющая набор средств ЗИ, встраиваемых в узлы и, возможно, объединяемых в кластер (кластер узлов ЗИ);

- внешняя инфокоммуникационная система объединяющая внешние (не подконтрольные системе) средства обработки, хранения и передачи данных.

В качестве базового решения рассмотрим систему ЗИ, реализуемую в виде вычислительного узла с некоторым набором программных средств защиты. Активизация работы используемых средств защиты осуществляется последовательно (поэтапно) с возможностью запуска в любом порядке. Каждый узел представим в виде одноканальной системы массового обслуживания (СМО) с общей бесконечной очередью и поэтапным выполнением запросов [6]. Процесс обслуживания запроса системой защиты, включающей $R$ этапов, представлен на рисунке 2.

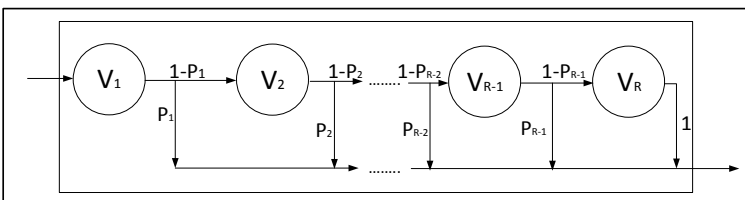

Рис. 2. Процесс обслужсивания запроса системой защитты, включаюший $R$ этапов: $V_{l}, \ldots, V_{R}-$ время обработки на этапах системы защиты; $P_{1}, \ldots, P_{R-1}-$ вероятность прохождения запросом $i$-го этапа системы защиты $, i=1, \ldots, R$

Fig. 2. The process of request maintenance by a security system that includes $R$-stages
После завершения очередного $i$-го этапа запрос либо с вероятностью $P_{i}$ немедленно покидает систему (средство обнаружило и устранило угрозу), либо с вероятностью $\left(1-P_{i}\right)$ поступает на следующий $(i+1)$-й этап обслуживания. После завершения обслуживания на этапе $R$ запрос покидает систему и начинается поэтапное выполнение следующего запроса из очереди. Время выполнения этапов будем считать распределенным по показательному закону [7].

\section{Критерии эффективности системы защиты}

К исследуемой системе защиты предъявляются требования высокой вероятности обнаружения отказов, малых задержек обнаружения угроз информационной безопасности и ограниченной (возможно, минимальной) стоимости системы зашиты.

Эффективность системы охарактеризуем некоторым набором частных и комплексных критериев (показателей). Набор критериев, характеризующих задержки поиска угроз, вероятность их обнаружения и надежность системы, по выполнению требуемых функций включает:

- среднее время обнаружения угрозы $(x)$;

- второй начальный момент $\left(x^{(2)}\right)$ распределения времени обнаружения угрозы;

- среднее время пребывания (ожидания) запросов $\left(T_{S}\right)$ в системе ЗИ во время поиска угроз;

- вероятность обнаружения и устранения угроз $i$-м элементом системы ЗИ $\left(P_{i}\right)$;

- вероятность обнаружения и устранения угроз системой ЗИ $\left(P_{S}\right)$;

- коэффициент готовности $\left(k_{\Gamma}\right)$;

- вероятность безотказной работы системы за время пребывания в ней запроса на обнаружение и устранение угрозы $\left(P\left(T_{S}\right)\right)$.

Рассмотрим комплексные показатели эффективности анализируемой системы.

Надежность системы ЗИ по обслуживанию запросов поиска угроз ИБ можно охарактеризовать по коэффициенту оперативной готовности $k_{\text {ог }}=$ $=k_{\Gamma} \cdot P\left(T_{S}\right)$, который является комплексным показателем и определяется вероятностью готовности системы ЗИ к обнаружению и устранению угроз в поступившем в систему запросе $\left(k_{\Gamma}\right)$ и безотказности задействованных при этом средств ЗИ за время пребывания запроса в системе ЗИ $\left(P\left(T_{S}\right)\right)$.

Задержку и вероятность обнаружения и устранения угроз системой ЗИ охарактеризуем по комплексному критерию - показатель эффективности системы ЗИ:

$$
Q_{s}=\frac{\left(T_{0}-T_{S}\right)}{T_{0}} P_{S},
$$

где $T_{0}$ - предельно допустимое время пребывания запроса в системе; $T_{S}$ - время пребывания запроса в системе; $P_{S}-$ вероятность обнаружения и устра- 
нения угроз системой ЗИ (степень защищенности вычислительной системы).

Предложенный критерий выражает нормированную среднюю экономию времени до обнаружения и устранения угрозы относительно предельно допустимого времени задержки, вносимой системой ЗИ. Критерий предполагает абсолютную надежность системы.

С учетом готовности системы ЗИ к решению задачи обнаружения угроз в произвольный момент времени критерий может быть модернизирован как

$$
Q_{s}=\frac{\left(T_{0}-T_{S}\right)}{T_{0}} k_{\mathrm{r}} P_{S},
$$

где $k_{\text {г }}$ - коэффициент готовности системы ЗИ (вероятность того, что в произвольный момент времени поступления запроса задачи поиска угроз система ЗИ работоспособна (готова к выполнению требуемой функции обнаружения и устранения угроз)).

Критерий может быть расширен с учетом не только готовности системы ЗИ в некоторый момент времени, но и вероятности безотказной работы системы в течение реализации процедуры обнаружения и устранения угроз:

$$
Q_{s}=\frac{\left(T_{0}-T_{S}\right)}{T_{0}} k_{\text {ог }} P_{S}=\frac{\left(T_{0}-T_{S}\right)}{T_{0}} k_{\mathrm{r}} P\left(T_{S}\right) P_{S},
$$

где $k_{\text {ог }}-$ коэффициент оперативной готовности; $P\left(T_{S}\right)$ - вероятность безотказной работы системы за время пребывания в ней запроса на обнаружение и устранение угрозы.

\section{Оценка задержек системы ЗИ}

СМО с поэтапным обслуживанием (рис. 2) является частным случаем СМО типа $M / G / 1$ [6]. Среднее время пребывания запроса в системе $T$ можно определить по формуле Полячика-Хинчина:

$$
T=\bar{x}+\frac{\lambda x^{(2)}}{2(1-\lambda \bar{x})},
$$

где $\bar{x}-$ среднее время обслуживания запроса; $x^{(2)}$ второй начальный момент; $\lambda$ - интенсивность входного потока [6].

Если СБД [8-13] включает $M$ систем, которые ведут обслуживание поступающих запросов, то интенсивность потока запросов, поступающих в каждую из $M$ систем, будет $\lambda / M$, а среднее время пребывания запросов в системе находиться как

$$
T_{S}=\bar{x}+\frac{\lambda x^{(2)}}{2(M-\lambda \bar{x})} .
$$

Определим первый и второй начальные моменты времени реализации $R$-этапной процедуры обнаружения и устранения угроз. Пусть время обслуживания каждого этапа - случайная величина, распределенная по показательному закону. В таком случае, используя распределение Кокса (в соответ- ствии с рисунком 2) [6], получаем преобразование Лапласа для плотности распределения вероятностей времени обслуживания в виде

$$
\begin{aligned}
& B(s)=\left(\frac{\mu_{1}}{s+\mu_{1}}\right) P_{1}+ \\
& +\left(\sum_{i=2}^{R-1} P_{i}\left(\prod_{j=1}^{I-1}\left(1-P_{j}\right)\right) \prod_{j=1}^{i}\left(\frac{\mu_{j}}{s+\mu_{j}}\right)+\right. \\
& +\prod_{i=1}^{R}\left(\frac{\mu_{i}}{s+\mu_{i}}\right)\left(\prod_{j=1}^{R-1}\left(1-P_{j}\right)\right),
\end{aligned}
$$

где $\mu_{i}$ и $P_{i}-$ интенсивность обслуживания и вероятность устранения угрозы на $i$-м этапе обслуживания; $R$ - количество этапов обслуживания (обнаружения и устранения угроз).

Для вычисления $n$-го начального момента случайной величины [6], воспользуемся следующей формулой: $\overline{X^{n}}=(-1)^{n} A^{*(n)}(0)$.

Первая производная $B(s)$ соответствует первому начальному моменту (математическому ожиданию) времени поэтапного поиска угрозы:

$$
x=\left.\frac{d B(s)}{d s}\right|_{s=0} .
$$

Вторая производная $B(s)$ соответствует второму начальному моменту распределения времени поэтапного поиска угрозы: $x^{(2)}=\left.\frac{d^{2} B(s)}{d s^{2}}\right|_{s=0}$

Для примера рассмотрим систему ЗИ вычислительной системы, включающей два элемента ЗИ $(R=2)$. В этом случае при двухэтапном обслуживании из формулы (6) получаем

$$
\begin{aligned}
& B^{\prime}(s)=\frac{\mu_{1} P_{1}}{\left(\mu_{1}+s\right)^{2}}+\frac{\mu_{1} \mu_{2}\left(1-P_{1}\right)}{\left(\mu_{1}+s\right)\left(\mu_{2}+s\right)^{2}}+ \\
& +\frac{\mu_{1} \mu_{2}\left(1-P_{1}\right)}{\left(\mu_{1}+s\right)^{2}\left(\mu_{2}+s\right)}, \\
& B^{\prime \prime}(s)=\frac{2 \cdot \mu_{1}}{\left(\mu_{1}+s\right)}\left(\frac{P_{1}}{\left(\mu_{1}+s\right)^{2}}+\frac{\mu_{2}\left(1-P_{1}\right)}{\left(\mu_{2}+s\right)^{3}}+\right. \\
& \left.+\frac{\mu_{2}\left(1-P_{1}\right)}{\left(\mu_{1}+s\right)\left(\mu_{2}+s\right)^{2}}+\frac{\mu_{2}\left(1-P_{1}\right)}{\left(\mu_{1}+s\right)^{2}\left(\mu_{2}+s\right)}\right) . \\
& \text { Отсюда } \\
& \bar{x}=V_{1} P_{1}+\left(1-P_{1}\right)\left(V_{1}+V_{2}\right) ; \\
& x^{(2)}=2\left(V_{1}^{2} P_{1}+V_{2}^{2}\left(1-P_{1}\right)+V_{1} V_{2}\left(1-P_{1}\right)+V_{1}^{2}\left(1-P_{1}\right)\right),
\end{aligned}
$$

где $V_{i}$ - среднее время обслуживания $i$-го средства ЗИ.

\section{Оценка вероятности обнаружения и устранения угроз}

Степень защищенности системы определим по вероятности обнаружения и устранения угрозы системой ЗИ [7].

Вероятность обнаружения угрозы после применения $r$ средств защиты при их независимости по 
областям обнаружения угроз можно определить как $P_{r}=1-\prod_{i=1}^{r}\left(1-p_{i}\right)$.

Определим вероятности совместного обнаружения и устранения угроз при пересекаемости множеств угроз, обнаруживаемых различными средствами ЗИ.

В общем виде пересечения множеств угроз ИБ для системы ЗИ, включающей три элемента, с указанием доли угроз ИБ, устраняемых каждым из элементов или группой элементов, показан диаграммой Венна на рисунке 3.

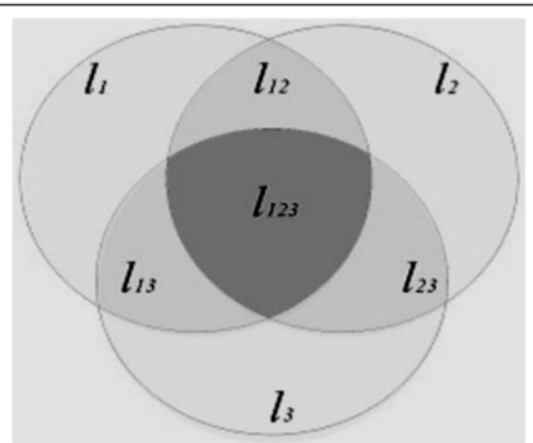

Рис. 3. Пересечения множеств угроз, устраняемых тремя средствами зашиты

Fig. 3. Crossings of sets of threats eliminated by three means of protection

Для характеристики зависимости обнаружения угроз используемыми средствами ЗИ определим:

- долю угроз от общего множества угроз ИБ, которые обнаруживаются и устраняются $i$-м элементом, $-L_{i}$;

- долю угроз от общего множества угроз ИБ, обнаруживаемых и устраняемых $i$-м элементом, применяемым в составе системы ЗИ, состоящей из $r$ элементов, $-l_{i}$;

- долю угроз от общего множества угроз ИБ, обнаруживаемых и устраняемых элементами $i, j$ (используя для этого отличные друг от друга методы и/или алгоритмы), применяемыми в составе системы ЗИ, состоящей из $r$ элементов, $-l_{i j}$;

- долю угроз от общего множества угроз ИБ, обнаруживаемых (и устраняемых) элементами $i, j$, $\ldots, m$ (используя для этого отличные друг от друга методы и/или алгоритмы), применяемыми в составе системы ЗИ, состоящей из $r$ элементов, $-l_{i j . . m}$;

- вероятность обнаружения системой ЗИ угроз ИБ, которым может быть подвержена вычислительная система, $-I_{S}$.

$$
L_{i}=\left|A_{i}\right| /|E| ; l_{i}=\frac{\left|A_{i} \backslash \bigcup_{\substack{j=1 \\ j \neq i}}^{r} A_{j}\right|}{|E|} ;
$$
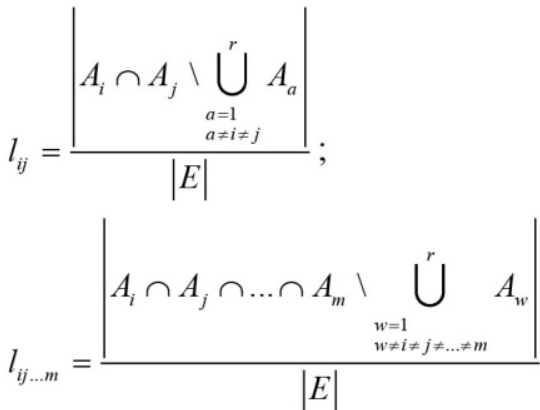

$I_{S}=|E| /|H|$,

где $|E|,|H|,\left|A_{i}\right|$ - кардинальные числа (число угроз) множеств, соответственно, $E, H, A_{i}$. При этом $H$ - с которыми необходимо бороться в рамках конкретной вычислительной системы; $E$ - множество угроз, которые способен обнаружить (и с некоторой вероятностью устранить) набор из $R$ средств (мер), использующихся в составе системы ЗИ; $A_{i}-$ множество угроз, которые способен обнаружить и устранить $i$-й элемент системы ЗИ.

Вероятность устранения и обнаружения угрозы $P_{S}$ при поэтапном применении средств защиты, вычислим как

$$
\begin{aligned}
& P_{S}=I_{S} W \sum_{i=1}^{R}\left(l_{i} p_{i}+\sum_{j=1}^{j<i} l_{j i} \cdot\left(1-\overline{p_{i}} \overline{p_{j}}\right)+\right. \\
& +\sum_{q=1}^{q<j}\left(l_{q j i} \cdot\left(1-\overline{p_{i}} \overline{p_{j}} \overline{p_{q}}\right)+\ldots+\right. \\
& \left.\ldots+\sum_{m=1}^{m<t}\left(l_{m t \ldots i} \cdot\left(1-\overline{p_{i}} \overline{p_{j}} \ldots \overline{p_{m}}\right)\right) \ldots\right),
\end{aligned}
$$

где $W=\lambda_{T} / \lambda$ - доля угроз ИБ в поступающем потоке запросов, здесь $\lambda_{T}$ и $\lambda$ - соответственно интенсивности входного потока угроз ИБ и общего потока запросов (в том числе с угрозами ИБ); $l_{i}-$ доля угроз ИБ от общего множества, определяемая только $i$-м элементом системы ЗИ, состоящей из $R$ элементов; $l_{i \ldots m}$ - доля угроз ИБ от общего множества угроз ИБ, обнаруживаемых и устраняемых элементами с $i, j$ по $m$, применяемыми в составе системы ЗИ, состоящей из нескольких элементов; $p_{i}-$ вероятность обнаружения угрозы $i$-м средством; $\overline{p_{j}}-$ вероятность, определяемая как $\overline{p_{j}}=1-p_{j}$; $i, j, \ldots, t$ - порядковые номера элементов системы ЗИ [7].

Используя (7), получим вероятность устранения угрозы $P_{i}$ на $i$-м этапе обслуживания [7]:

$$
\begin{aligned}
& P_{i}=I_{S} W \cdot\left(l_{i} p_{i}+\sum_{j=1}^{j<i}\left(l_{j i} \cdot\left(p_{i} \overline{p_{j}}\right)+\right.\right. \\
& \left.+\sum_{q=1}^{q<j}\left(\begin{array}{l}
l_{q j i} \cdot\left(p_{i} \overline{p_{j}} \overline{p_{q}}\right)+ \\
+\ldots+\sum_{m=1}^{m<t}\left(l_{m t \ldots i} \cdot\left(p_{i} \overline{p_{j}} \ldots \overline{p_{m}}\right)\right.
\end{array}\right)\right) \ldots .
\end{aligned}
$$


На основе (8) получим, что для системы, использующей два элемента защиты информации, $P_{1}=I_{S} W p_{1} L_{1}$, здесь $L_{1}=\left|A_{1}\right| /|E|$.

Используя (7), вероятность устранения и обнаружения угрозы системой $P_{S}$ вычислим как

$$
P_{S 2}=I_{S} W \cdot\left(p_{1} l_{1}+p_{2} l_{2}+l_{12} \cdot\left(1-\overline{p_{1}} \overline{p_{2}}\right)\right),
$$

здесь $l_{1}=L_{1}-l_{12.0} ; l_{2}=L_{2}-l_{12.0}$, где $l_{12.0}=$ $=\left|A_{1} \cap A_{2}\right| /|E|, L_{2}=\left|A_{2}\right| /|E|$.

\section{Обоснование выбора организации системы $3 И$}

В работах $[5,7]$ показано, что последовательное применение средств от слабых (быстрых и с малой областью обнаружения угроз) к наиболее сильным (имеющим большую область обнаружения угроз, но и затрачивающим большее количество времени на свою работу) дает лучшие результаты по среднему времени обнаружения угроз. Имея три средства ЗИ, можно выделить следующие варианты их последовательного применения: $(1,2,3) ;(1,2) ;(2$, 3); (1, 3); (1); (2); (3).

По формулам (3) и (4) получим, что для системы с последовательным применением трех средств ЗИ $(1,2,3)$ математическое ожидание и второй начальный момент среднего времени обслуживания будут равны

$$
\begin{aligned}
& \bar{x}=V_{1} P_{1}+\left(1-P_{1}\right) P_{2}\left(V_{1}+V_{2}\right)+ \\
& +\left(1-P_{1}\right)\left(1-P_{2}\right)\left(V_{1}+V_{2}+V_{3}\right), \\
& x^{(2)}=2\left(V_{1}^{2}\left(P_{1}+P_{2}\left(1-P_{1}\right)\right)+V_{2}^{2} P_{2}\left(1-P_{1}\right)+\right. \\
& \left.+V_{1} V_{2} P_{2}\left(1-P_{1}\right)+V_{3}^{2}\left(1-P_{1}\right)\left(1-P_{2}\right)\right)+ \\
& +\left(V_{1}^{2}+V_{1} V_{2}+V_{2}^{2}\right)\left(1-P_{1}\right)\left(1-P_{2}\right)+ \\
& +2 V_{3}\left(V_{1}+V_{2}\right)\left(1-P_{1}\right)\left(1-P_{2}\right) .
\end{aligned}
$$

Вероятность обнаружения и устранения угрозы системой при варианте $(1,2,3)$ получим как

$$
\begin{aligned}
& P_{S 3}=I_{S} W\left(p_{1} l_{1}+p_{2} l_{2}+p_{3} l_{3}+l_{12}\left(1-\overline{p_{1}} \overline{p_{2}}\right)+\right. \\
& +l_{23}\left(1-\overline{p_{2}} \overline{p_{3}}\right)+l_{13}\left(1-\overline{p_{1}} \overline{p_{3}}\right)+l_{123}\left(1-\overline{p_{1}} \overline{p_{2}} \overline{p_{3}}\right) .
\end{aligned}
$$

Вероятность обнаружения и предотвращения угрозы на первом и втором этапах контроля определяется как $P_{1}=I_{S} W p_{1} L_{1} ; \quad P_{2}=I_{S} W\left(p_{2}\left(L_{2}-l_{12}\right)+\right.$ $\left.\left.+l_{12}\left(1-p_{1}\right) p_{2}\right)\right)$.

Здесь $l_{1}=L_{1}-l_{12.0}-l_{13.0}+l_{123} ; l_{2}=L_{2}-l_{12.0}-l_{23.0}+$ $+l_{123} ; l_{3}=L_{3}-l_{13.0}-l_{23.0}+l_{123} ; l_{12}=L_{1}-l_{12.0}-l_{123}$; $l_{13}=l_{13.0}-l_{123} ; l_{23}=l_{23.0}-l_{123} ; l_{123}=l_{123.0}, L_{1}, L_{2}, L_{3}-$ доля угроз ИБ от общего множества, определяемых, соответственно, первым, вторым и третьим элементами системы ЗИ; $l_{12.0}=\left|A_{1} \cap A_{2}\right| /|E|, l_{23.0}=$ $=\left|A_{2} \cap A_{3}\right| /|E|, \quad l_{13.0}=\left|A_{1} \cap A_{3}\right| /|E|, \quad l_{123.0}=$ $=\left|A_{1} \cap A_{2} \cap A_{3}\right| /|E|-$ доля угроз ИБ от общего множества, определяемых, соответственно, первым и вторым, вторым и третьим, первым и третьим и первым, вторым и третьим элементами.

Для системы, использующей один элемент защиты, математическое ожидание и второй момент времени обнаружения угроз $\bar{x}=V_{1} P_{1} ; x^{(2)}=2 V_{1} P_{1}^{2}$.

Вероятность обнаружения и устранения угрозы на первом этапе обслуживания будет равна вероятности обнаружения и устранения угрозы системой и определяется как $P_{S 1}=P_{1}=I_{S} W p_{1} L_{1}$. Здесь $L_{1}=$ $=\left|A_{1}\right| /|E|$.

Для примера будем считать, что десятая часть поступающих в вычислительную систему данных вредоносны (представляют угрозу для системы) и могут быть обнаружены применяемыми в ней элементами ЗИ $(W=0.1)$, а также пусть $I_{S}=1$ (все применяемые средства в составе системы ЗИ покрывают все имеющиеся угрозы ИБ, направленные против рассматриваемой системы). Среднее время обслуживания каждым элементом системы ЗИ: $V_{1}=0.0025 \mathrm{c}$, $V_{2}=0.004 \mathrm{c}, V_{3}=0.0075$ с. Вероятность устранения угрозы ИБ каждым элементом системы ЗИ: $p_{1}=0.9$, $p_{2}=0.95, p_{3}=0.925$. Доли угроз ИБ от общего множества угроз ИБ, определяемых и устраняемых элементами системы ЗИ для рассматриваемых вариантов системы: $L_{1}=35 \%, L_{2}=50 \%, L_{3}=70 \%$, $l_{12.0}=15 \%, l_{13.0}=20 \%, l_{23.0}=30 \%, l_{123.0}=10 \%$. Допустимое время пребывания запроса в системе $T_{0}=0.2$ с. Стоимость каждого элемента защиты и ограничение на общую стоимость системы ЗИ $C_{0}=100$ y.e., $c_{1}=10$ y.e., $c_{2}=15$ y.e., $c_{3}=25$ y.e.

Эффективность системы ЗИ определим по комплексному критерию, учитывающему задержку и вероятность обнаружения и устранения угроз при последовательном применении средств ЗИ, вычисляемого по (1). Подставив в (1) формулы (5) и (7), получим показатель эффективности системы ЗИ, предполагая абсолютную надежность системы.

На рисунке 4 представлена зависимость эффективности системы ЗИ от интенсивности входного потока с различной комплектацией элементов ЗИ на вычислительном узле (4a) и систем, использующих разное количество элементов ЗИ при фиксированном количестве имеющихся в узле элементов защиты (4б).

Анализ зависимостей, представленных на графиках (рис. 4), показывает влияние состава и порядка последовательного применения средств ЗИ на эффективность системы ЗИ, а также существование границ эффективности применения вариантов комплектации и последовательности применения средств ЗИ.

При программной реализации средств ЗИ и их последовательной инициализации для обнаружения и устранения угроз возможна адаптивная стратегия предотвращения угроз ИБ в зависимости от измеряемой интенсивности поступающих запросов. При размещении в узлах защиты полного комплекта аппаратно-программных средств ЗИ становится потенциально реализуемой адаптация системы ЗИ к интенсивности поступающих запросов на основе оптимальной последовательности использования средств ЗИ. 


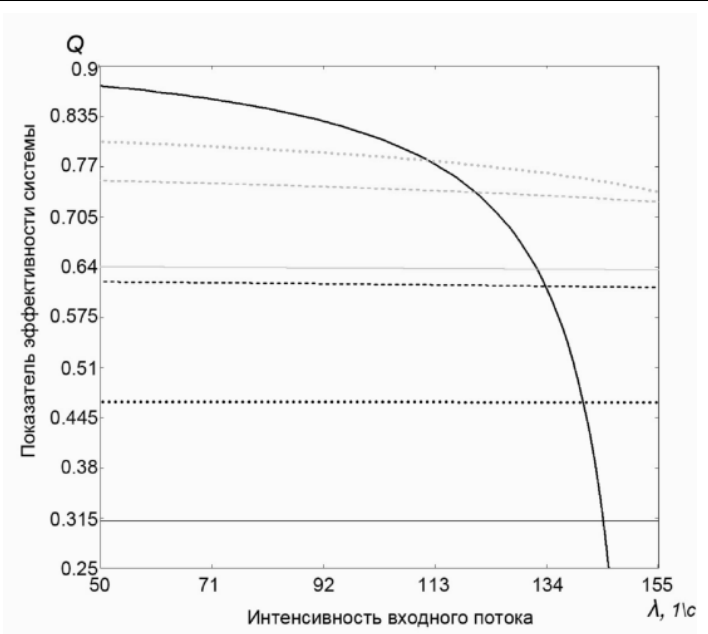

a)

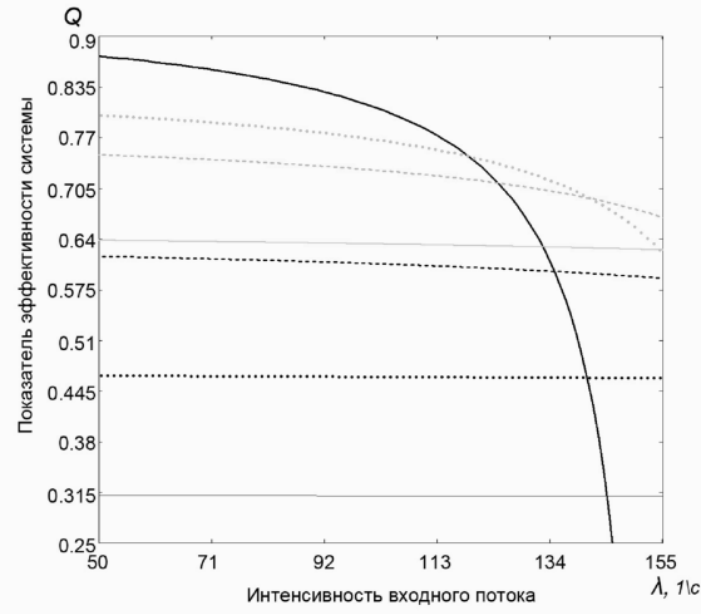

б)

Рис. 4. Зависимость эффективности системы ЗИ от интенсивности входного потока для систем с различным последовательным применением средств ЗИ. Вариант 1 - (1,2,3) (черная толстая линия); варианты 2-4-(1,2), (2,3), (1,3) (серая тонкая, штрихпунктирная, пунктирная линии, соответственно); варианты 5-7-(1), (2), (3) (серая тонкая, итрихпунктирная, пунктирная линии, соответственно)

Fig. 4. Dependence of information security system effectiveness on the intensity of the input flow for systems with different sequential use of means of information protection

При комплектации узлов защиты неполным набором реализуемых в виде аппаратно-программных средств ЗИ адаптивная настройка на оптимальную последовательность используемых средств ЗИ становится проблематичной. Целесообразность перекомпоновки (перекомплектации) узлов в зависимости от изменяющегося потока запросов требует дополнительных исследований, связанных с остановкой обслуживания при реконфигурации системы [14-17]. В случае неполной комплектации узлов аппаратно-программными средствами ЗИ при проектировании может решаться задача выбора оптимальной комплектации узлов средствами ЗИ и последовательности их применения, ориентируясь на ожидаемую (среднюю) интенсивность входного потока запросов, проверяемого на наличие угроз.

Повышение интенсивности входного потока нередко является следствием организации атаки на систему. Поэтому требуется установление минимальной конфигурации элементов ЗИ системы, которая будет способна обеспечить необходимый для системы уровень информационной защищенности при максимально возможном потоке запросов, формируемых при атаках [7, 18-23].

\section{Заключение}

Исследованы возможности повышения эффективности инфокоммуникационной системы, использующей СБД «Прямое соединение» при различных вариантах комплектации узлов средствами ЗИ и последовательности их применения при предотвращении угроз ИБ в зависимости от интенсивности входного потока запросов.

Предложены критерии эффективности систем ЗИ, ориентированные на повышение вероятности обнаружения угроз за минимальное время с учетом возможной ограниченности допустимых задержек запросов.

Предложены модели оценки вероятности обнаружения угроз и задержек их поиска в зависимости от последовательности применения средств ЗИ в узлах с учетом пересекаемости множеств угроз, обнаруживаемых различными средствами защиты.

Проанализированы возможность и целесообразность реализации адаптивной стратегии последовательного применения средств ЗИ для предотвращения угроз ИБ в зависимости от измеряемой интенсивности поступающих запросов при комплектации узлов полным набором программных или аппаратно-программных средств ЗИ.

\section{Литература}

1. Ellison R.J., Fisher D.A., Linger R.C., Lipson H.F., Longstaff T., Mead N.R. Survivable network systems: an emerging discipline. 1997. URL: http://www.cert.org $\mid$ research $\backslash 97$ tr013.pdf (дата обращения: 10.02.2018).

2. Korobeynikov A.G., Fedosovsky M.E., Maltseva N.K., Baranova O.V., Zharinov I.O., Gurjanov A.V., Zharinov O.O. Use of information technologies in design and production activities of instrument-making plants. Indian J. of Sc. and Tech., IET-2016, vol. 9 , no. 44 , pp. $1-8$.

3. Kopetz H. Real-time systems: design principles for distributed embedded applications. Springer, 2011, $396 \mathrm{p}$.

4. Советов Б.Я., Колбанев М.О., Татарникова Т.М. Технологии инфокоммуникации и их роль в обеспечении информационной безопасности // Геополитика и безопасность. 2014. № 1. C. $69-77$.

5. Коломойцев В.С. Выбор варианта построения многоуровневого защищенного доступа к внешней сети // Науч.-технич. вестн. информ. технологий, механики и оптики. 2016. T. 16. № 1. C. 115-121. 
6. Kleinrock L. Queueing system. Jogn Wiley \& Sons, Inc., 1975 , vol. $1,417 \mathrm{p}$

7. Коломойцев В.С., Богатырев В.А. Вероятностно-временные показатели при поэтапном применении средств защиты информации // Вестн. компьютер. и информ. технологий. 2017. № 11. C. 37-43. DOI: 10.14489/vkit.2017.11.pp. 037-043.

8. Sorin D. Fault tolerant computer architecture. Morgan \& Claypool, 2009, 103 p.

9. Кутузов О.И., Татарникова Т.М. Инфокоммуникационные сети. Моделирование и оценка вероятностно-временных характеристик. СПб: Изд-во ГУАП, 2015. 381 с.

10. Верзун Н.А., Колбанев М.О., Омельян А.В. Введение в инфокоммуникационные технологии и сети Future Networks. СПб: Изд-во СПбГЭУ, 2016. 51 с.

11. Верзун Н.А., Колбанев М.О., Татарникова Т.М. Технологическая платформа четвертой промышленной революции // Геополитика и безопасность. 2016. № 2. С. 73-78.

12. Богатырев В.А., Богатырев С.В. Резервированное обслуживание в кластерах с уничтожением неактуальных запросов // Вестн. компьютер. и информ. технологий. 2017. № 1 . C. $21-28$.

13. Богатырев В.А., Богатырев С.В. Критерии оптимальности многоустойчивых отказоустойчивых компьютерных систем // Науч.-технич. вестн. СПбГУ ИТМО. 2009. № 5. С. 92-98.

14. Колбанев М.О., Татарникова Т.М., Воробьев А.И. Оценка вероятностно-временных характеристик процесса предоставления информационно-справочных услуг // Изв. вузов: Приборостроение. 2014. Т. 57. № 9. С. 15-18.

15. Алиев Т.И., Муравьева-Витковская Л.А. Приоритетные стратегии управления трафиком в мультисервисных компьютерных сетях // Изв. вузов: Приборостроение. 2011. Т. 54. № 6. C. $44-48$.
16. Gatchin Y.A., Zharinov I.O., Korobeynikov A.G., Zharinov O.O. Theoretical estimation of Grassmann's transformation resolution in avionics color coding systems. Modern Applied Science, 2015, vol. 9, no. 5, pp. 197-210.

17. Korobeynikov A.G., Fedosovsky M.E., Gurjanov A.V., Zharinov I.O., Shukalov A.V. Development of conceptual modeling method to solve the tasks of computer-aided design of difficult technical complexes on the basis of category theory. Intern. J. of Applied Engineering Research, 2017, vol. 12, no. 6, pp. 1114-1122.

18. Гатчин Ю.А., Жаринов И.О., Коробейников А.Г. Математические модели оценки инфраструктуры системы защиты информации на предприятии // Науч.-технич. вестн. информ. технологий, механики и оптики. 2012. № 2. С. 92-95.

19. Щеглов К.А., Щеглов А.Ю. Метод реализации песочницы для потенциально опасных программ // Изв. вузов: Приборостроение. 2017. Т. 60. № 10. С. 940-944.

20. Kniga E., Zharinov I., Shukalov A., Nechaev V. Reliability evaluation of integrated modular avionics computational structures for different hardware configurations. Key Engineering Materials, 2016, vol. 685 , pp. 350-354. DOI: 10.4028/www.scientific.net/ KEM.685.350.

21. Колбанев М.О., Татарникова Т.М. Физические ресурсы информационных процессов и технологий // Науч.-технич. вестн. ИТМО. 2014. Т. 14. № 6. С. 113-123.

22. Nyrkov A.P., Goloskokov K.P., Koroleva E.A., Sokolov S.S., Zhilenkov A.A., Chernyi S.G. Mathematical models for solving problems of reliability maritime system. Lecture Notes in Electrical Engineering, 2018, vol. 442, pp. 387-394.

23. Nyrkov A.P., Sokolov S.S., Karpina A.S., Chernyakov A.V., Gaskarov V.D. Cluster-type models in the logistics industry. Intern. J. of Engineering and Technology (UAE), 2018, vol. 7 , no. 1 , pp. $39-43$.

\title{
The effectiveness of stage-by-stage use of securirty means crossing threat detection areas
}

\author{
V.S. Kolomoitsev ${ }^{1}$, Postgraduate Student, dek-s-kornis@yandex.ru \\ V.A. Bogatyrev ${ }^{1}$, D.Sc., Professor \\ ${ }^{1}$ The National Research University of Information Technologies, Mechanics and Optics, \\ St. Petersburg, 197101, Russian Federation
}

Abstract. The paper investigates the ways of improving the efficiency of a secure access scheme "direct connection". The scheme is based on choosing options for its construction, taking into account the phased use of various information security means and their integration into a cluster architecture system aimed at consolidating limited protection resources. Consolidation of protection resources is carried out in order to achieve maximum security with minimum delays and system costs.

The authors propose criteria for the effectiveness of information security systems aimed at increasing the probability of threat detection in the shortest time, taking into account its limitations. The proposed criteria take into account the average time of request stay in the system and the probability of threat detection and removal by an information security system. There is an assumption that the service time of each stage is a random value having exponential distribution.

The paper proposes models of estimating the probability of detection and elimination of threats and delays based on the sequence of application of information security means in the nodes. The models take into account intersections of sets of threats detected by various means of information security. The authors show the possibility of implementing an adaptive strategy of 
consistent application of information security means to prevent threats to information security depending on changing intensity of incoming requests. There are some options of bundling nodes by a complete or partial set of available software or hardwaresoftware means of information security.

Keywords: information protection, information security, access scheme, unauthorized access, system quality assessment, queueing system, probability of detecting threats, information threat.

\section{References}

1. Ellison R.J., Fisher D.A., Linger R.C., Lipson H.F., Longstaff T., Mead N.R. Survivable Network Systems: An Emerging Discipline. Software Engineering Institute. 1997. Available at: https://resources.sei.cmu.edu/asset_files/ technicalreport/1998_005_001_16598.pdf (accessed February 10,2018).

2. Korobeynikov A.G.G., Fedosovsky M.E., Maltseva N.K., Baranova O.V., Zharinov I.O., Gurjanov A.V., Zharinov O.O. Use of information technologies in design and production activities of instrument-making plants. Indian J. of Science and Technology. IET-2016, vol. 9, no. 44, pp. 1-8.

3. Kopetz H. Real-Time Systems: Design Principles for Distributed Embedded Applications. Springer Publ., 2011,396 p.

4. Sovetov B.Ya., Kolbanev M.O., Tatarnikova T.M. Technologies of infocommunication and their role in ensuring information security. Geopolitics and Security. 2014, no. 1, pp. $69-77$ (in Russ.).

5. Kolomoitsev V.S. Choice of option for implementation of the multilevel secure access to the external network. Sci. and Tech. J. of Information Technologies, Mechanics and Optics. 2016, vol. 16, no. 1, pp. 115-121 (in Russ.).

6. Kleinrock L. Queueing System. Vol. 1: Theory. J. Wiley \& Sons Publ., 1975, 417 p.

7. Kolomoitsev V.S., Bogatyrev V.A. Probabilistic and temporal indicators in the stage-by-stage use of information protection means. Herald of Computer and Information Technologies. 2017, no. 11, pp. 37-43 (in Russ.).

8. Sorin D. Fault Tolerant Computer Architecture. Morgan \& Claypool Publ., 2009, 103 p.

9. Kutuzov O.I., Tatarnikova T.M. Infocommunication Networks. Modeling and Estimation of Probability-Time Characteristics. St. Petersburg, SUAI Publ., 2015, 381 p.

10. Verzun N.A., Kolbanev M.O., Omelyan A.V. Introduction to Infocommunication Technologies and Future Networks. St. Petersburg, 2016, 51 p.

11. Verzun N.A., Kolbanev M.O., Tatarnikova T.M. A technological platform of the fourth industrial revolution. Geopolitics and Security. 2016, no. 2, pp. 73-78 (in Russ.).

12. Bogatyrev V.A., Bogatyrev S.V. Redundant maintenance in clusters with destruction of irrelevant requests. Herald of Computer and Information Technologies. 2017, no. 1, pp. 21-28 (in Russ.).

13. Bogatyrev V.A., Bogatyrev S.V. Optimality criteria of multistable fault-tolerant computer systems. Sci. and Tech. J. of Information Technologies, Mechanics and Optics. 2009, no. 5, pp. $92-98$ (in Russ.).

14. Kolbanev M.O., Tatarnikova T.M., Vorobev A.I. Assessment of probabilistic-temporal characteristics of the process of I\&R service rendering. J. of Instrument Engineering. 2014, vol. 57, no. 9, pp. 15-18 (in Russ.).

15. Aliev T.I., Muraveva-Vitkovskaya L.A. Priority-based strategies of traffic management in multiservice computer networks. J. of Instrument Engineering. 2011, vol. 54, no. 6, pp. 44-48 (in Russ.).

16. Gatchin Yu.A., Zharinov I.O., Korobeynikov A.G., Zharinov O.O. Theoretical estimation of Grassmann's transformation resolution in avionics color coding systems. Modern Applied Science. 2015, vol. 9, no. 5, pp. 197-210.

17. Korobeynikov A.G., Fedosovsky M.E., Gurjanov A.V., Zharinov I.O., Shukalov A.V. Development of conceptual modeling method to solve the tasks of computer-aided design of difficult technical complexes on the basis of category theory. Intern. J. of Applied Engineering Research. 2017, vol. 12, no. 6, pp. 1114-1122.

18. Gatchin Yu.A., Zharinov I.O., Korobeynikov A.G. Mathematical models of an estimation of an infrastructure of system of protection of the information at the enterprise. Sci. and Tech. J. of Information Technologies, Mechanics and Optics. 2012, no. 2, pp. 92-95 (in Russ.).

19. Shcheglov K.A., Shcheglov A.Yu. Implementation of sandbox method for potentially malicious applications. J. of Instrument Engineering. 2017, vol. 60, no. 10, pp. 940-944 (in Russ.).

20. Kniga E., Zharinov I., Shukalov A., Nechaev V. Reliability evaluation of integrated modular avionics computational structures for different hardware configurations. Key Engineering Materials. 2016, vol. 685, pp. 350-354.

21. Kolbanev M.O., Tatarnikova T.M. Physical resources of information processes and technologies. Sci. and Tech. J. of Information Technologies, Mechanics and Optics. 2014, vol. 14, no. 6, pp. 113-123 (in Russ.).

22. Nyrkov A.P., Goloskokov K.P., Koroleva E.A., Sokolov S.S., Zhilenkov A.A., Chernyi S.G. Mathematical models for solving problems of reliability maritime system. Lecture Notes in Electrical Engineering. 2018, vol. 442, pp. 387-394.

23. Nyrkov A.P., Sokolov S.S., Karpina A.S., Chernyakov A.V., Gaskarov V.D. Cluster-type models in the logistics industry. Intern. J. of Engineering and Technology (UAE). 2018, vol. 7, no. 1, pp. 39-43. 


\section{Алгоритм оиенки значения остаточных рисков угроз информационной безопасности с учетом разделения механизмов заициты на muпы}

\section{Д.А. Дерендяев 1, аспирант, оd@таil.ifmo.ru}

Ю.А. Гатчин 1, д.m.н., профресcop, od@mail.ifmo.ru

B.A. Безруков ${ }^{1}$, к.m.н., доиент, оd@mail.ifmo.ru

${ }_{1}$ Санкт-Петербургский наииональный исследовательский университет иноормаиионных технологий, механики и оптики (Университет ИТМО), г. Санкт-Петербург, 197101, Россия

На основе анализа современных подходов к оценке риска реализации угроз информационной безопасности можно сделать вывод, что большинство из них не рассматривают разделение механизмов защиты на типы, которое позволило бы более качественно проанализировать существующую систему защиты на предприятии.

Представленный алгоритм учитывает такое разделение и рассматривает каждый тип с упором на его особенности. Ввиду отсутствия четкого разграничения механизмов защиты предложено разделить их на две группы: технические и организационные. Для расчета остаточного риска учитываются дополнительные переменные, такие как вероятность корректной работы механизма защиты и вероятность преодоления механизма при реализации угрозы.

Для технических механизмов защиты необходимо учитывать вероятность перехода в неработоспособное состояние с течением времени. Рассматривая организационные меры, стоит принять во внимание истечение ее срока действия или изменение в связи с меняющимися условиями. Ввиду случайного характера таких процессов для определения их вероятностей используются математические аппараты скрытой марковской модели и случайных марковских процессов. Итоговый показатель остаточного риска определяется с помощью альтернативной математической модели, полученной на основе полного факторного эксперимента и позволяющей получить более корректные значения, рассматривая входные параметры на верхнем и нижнем уровнях.

В результате реализации алгоритма определяются значения остаточных рисков с учетом противодействия угрозе каждого из типов защитных мер, что дает возможность более четко определять недостатки системы защиты.

Ключевые слова: оценка остаточного риска, информачионная безопасность, типы механизмов защиты, скрытые марковские модели, случайные марковские прочессы.

Существует большое количество нормативных документов, регламентирующих процесс оценки рисков (BSI, BS7799, ISO/IEC 27001), и методик, которые включают в себя определение значений остаточного риска (CRAMM, Risk Watch, ГРИФ и др. [1-4]). Проанализировав существующие подходы, можно сделать вывод об отсутствии в большинстве случаев разделения механизмов защиты на типы при расчете значений остаточных рисков. Представленный алгоритм исключает этот недостаток и рассматривает каждый тип с учетом его индивидуальных особенностей.

Разработанный алгоритм включает в себя определение вероятности корректной работы каждого из типов механизмов защиты, а также для более корректного определения значения остаточных рисков рассчитывается вероятность преодоления механизма защиты при реализации угрозы. Так как вероятность этих событий носит случайный характер, для их определения используются математические аппараты скрытых марковских моделей (СММ) и случайных марковских процессов [5].

Все механизмы защиты разделены на две группы - технические и организационные.

\section{Определение вероятности корректной работы механизмов защиты}

Для каждого типа составляется ориентированный граф, на основании которого строится система уравнений Колмогорова и определяется значение вероятностей каждого состояния. При расчетах для технических механизмов защиты, как и для любого оборудования, необходимо учитывать вероятность перехода в неработоспособное состояние с течением времени. Пример графа для технических механизмов защиты представлен на рисунке 1.

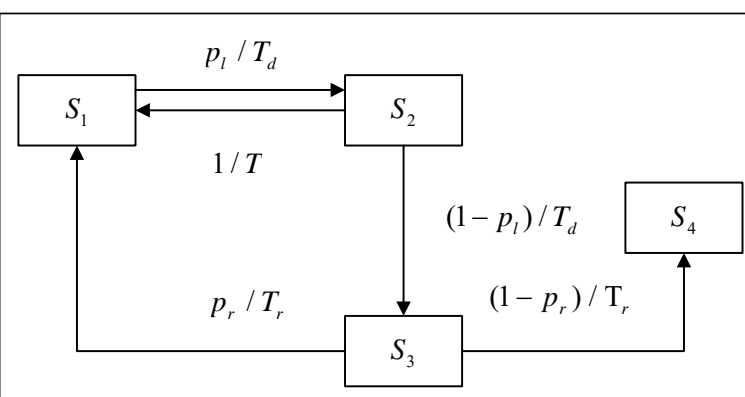

Рис. 1. Ориентированный граф состояний технических механизмов зашиты: $S_{1-}$ работоспособное состояние; $S_{2}-$ диагностика; $S_{3}-$ ремонт; $S_{4}$ - неработоспособное состояние механизма; $T$-среднее время до проведения диагностики; $T_{d}-$ среднее время диагностики; $T_{r}-$ среднее время ремонта; $p_{r}$ - вероятность успешного ремонта; $p_{l}$-вероятность корректного состояния механизма

Fig. 1. A oriented state graph of technical protection mechanisms 
На основе графа получим систему уравнений Колмогорова:

$$
\left\{\begin{array}{l}
P_{1}^{\prime}(t)=\frac{P_{2}(t)^{*} p_{l}}{T_{d}}+\frac{P_{3}(t)^{*} p_{r}}{T_{r}}-\frac{P_{1}(t)}{T} ; \\
P_{2}^{\prime}(t)=\frac{P_{1}(t)}{T}-\frac{P_{2}(t)}{T_{d}} ; \\
P_{3}^{\prime}(t)=\frac{\left(1-p_{l}\right)^{*} P_{2}(t)}{T_{d}}-\frac{P_{3}(t)}{T_{r}} ; \\
P_{4}^{\prime}(t)=\frac{\left(1-p_{r}\right)^{*} P_{3}(t)}{T_{r}} .
\end{array}\right.
$$

Рассматривая организационные механизмы защиты, необходимо учитывать истечение срока действия механизма и его изменения в связи с меняющимися условиями. Пример графа для организационных механизмов защиты представлен на рисунке 2.

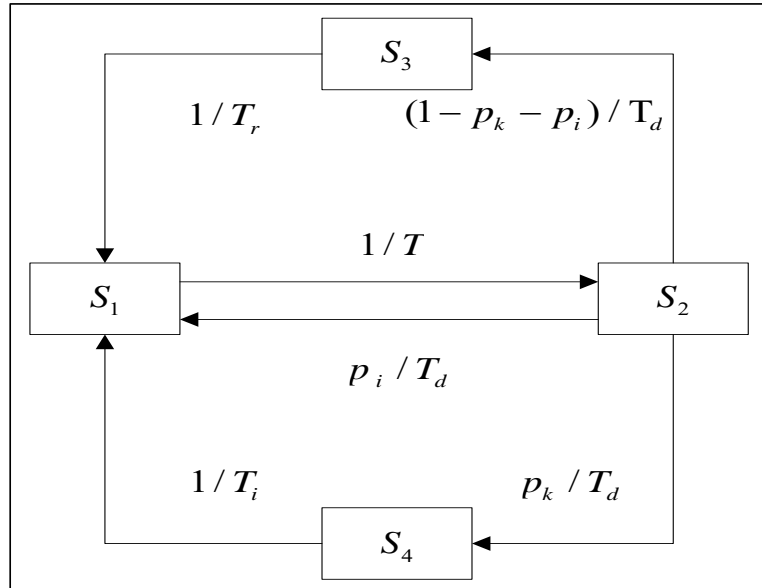

Рис. 2. Ориентированный граф работоспособного состояния организационных механизмов защиты: $S_{1}$ - работоспособное состояние; $S_{2}$ - диагностика; $S_{3}$ - обновление существующего механизма; $S_{4}-$ доработка механизма; $T$ - среднее время до проведения диагностики; $T_{d}$ - среднее время диагностики; $T_{r}-$ среднее время обновления существующего механизма; $T_{i}-$ среднее время доработки механизма; $p_{r}$ - вероятность корректного состояния механизма; $p_{l}$ - вероятность необходимости доработки механизма

Fig. 2. An oriented graph of the operational state of organizational protection mechanisms

Система уравнений Колмогорова на основе графа:

$$
\left\{\begin{array}{l}
P_{1}^{\prime}(t)=\frac{P_{2}(t) * p_{l}}{T_{d}}+\frac{P_{3}(t)}{T_{r}}+\frac{P_{4}(t)}{T_{i}}-\frac{P_{1}(t)}{T} ; \\
P_{2}^{\prime}(t)=\frac{P_{1}(t)}{T}-\frac{P_{2}(t)}{T_{d}} ; \\
P_{3}^{\prime}(t)=\frac{\left(1-p_{l}-p_{k}\right) * P_{2}(t)}{T_{d}}-\frac{P_{3}(t)}{T_{r}} ; \\
P_{4}^{\prime}(t)=\frac{p_{k}^{*} P_{2}(t)}{T_{d}}-\frac{P_{4}(t)}{T_{i}} .
\end{array}\right.
$$

\section{Определение вероятности преодоления механизма защиты конкретного типа}

Вероятность преодоления механизма защиты конкретного типа определяется с помощью СММ. В этом случае модель будет состоять из двух состояний, соответствующих вероятности преодоления технических или организационных мер (рис. 3).

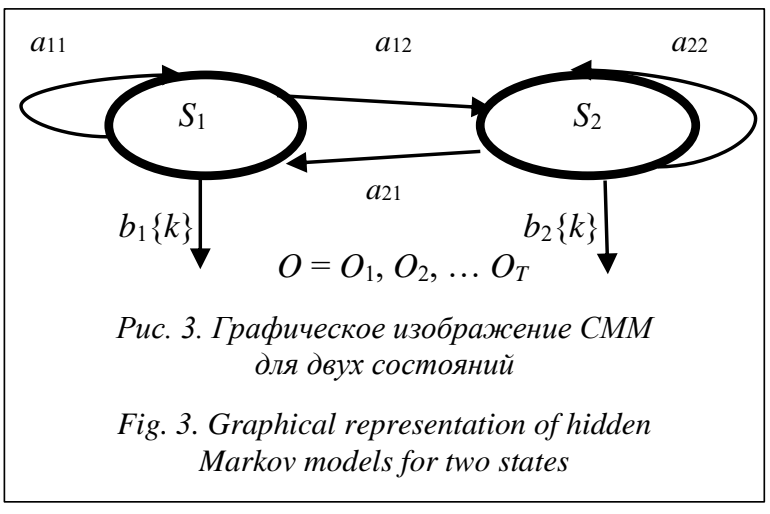

Модель включает в себя $S_{1} / S_{2}-$ состояние модели (преодоление технических/организационных мер защиты); $O=O_{1}, O_{2}, \ldots O_{T}$ - наблюдаемая последовательность, генерируемая моделью, соответствующая инцидентам информационной безопасности; $b_{j}\{k\}$ - вероятность того, что в определенный момент времени система, находящаяся в $j$-м состоянии, выдаст $k$-й символ; $a_{i j}-$ вероятность состояний системы и переходов между ними.

Изначальные характеристики модели определяются экспертным путем, для корректности которого в методе добавлены определение наиболее критичного фактора и расчет коэффициента его влияния [6-9]. При этом полученные факторы проходят проверку в соответствии с алгоритмом, представленным на рисунке 4.

Идея алгоритма заключается в определении коэффициентов математической модели остаточного риска от угрозы в целом, под действием наиболее критичного фактора и под действием остальных факторов. Сами коэффициенты рассчитываются с помощью математического аппарата полного факторного эксперимента [10]. Фактор проходит проверку в случае выполнения условия $a_{i}<a_{i_{c}}<a_{i_{o}}$, где $a_{i}-$ коэффициенты модели остаточного риска от угрозы в целом; $a_{i_{c}}-$ коэффициенты модели остаточного риска под действием наиболее критичного фактора; $a_{i_{o}}$ - коэффициенты модели остаточного риска под действием остальных факторов.

Для получения более точных значений вероятностей с помощью СММ необходимо решить задачу обучения, которая заключается в подстройке параметров модели, для получения значений вероятности наиболее соответствующих наблюдаемой последовательности. Для ее решения используется алгоритм Баума-Уэлча [5]. 


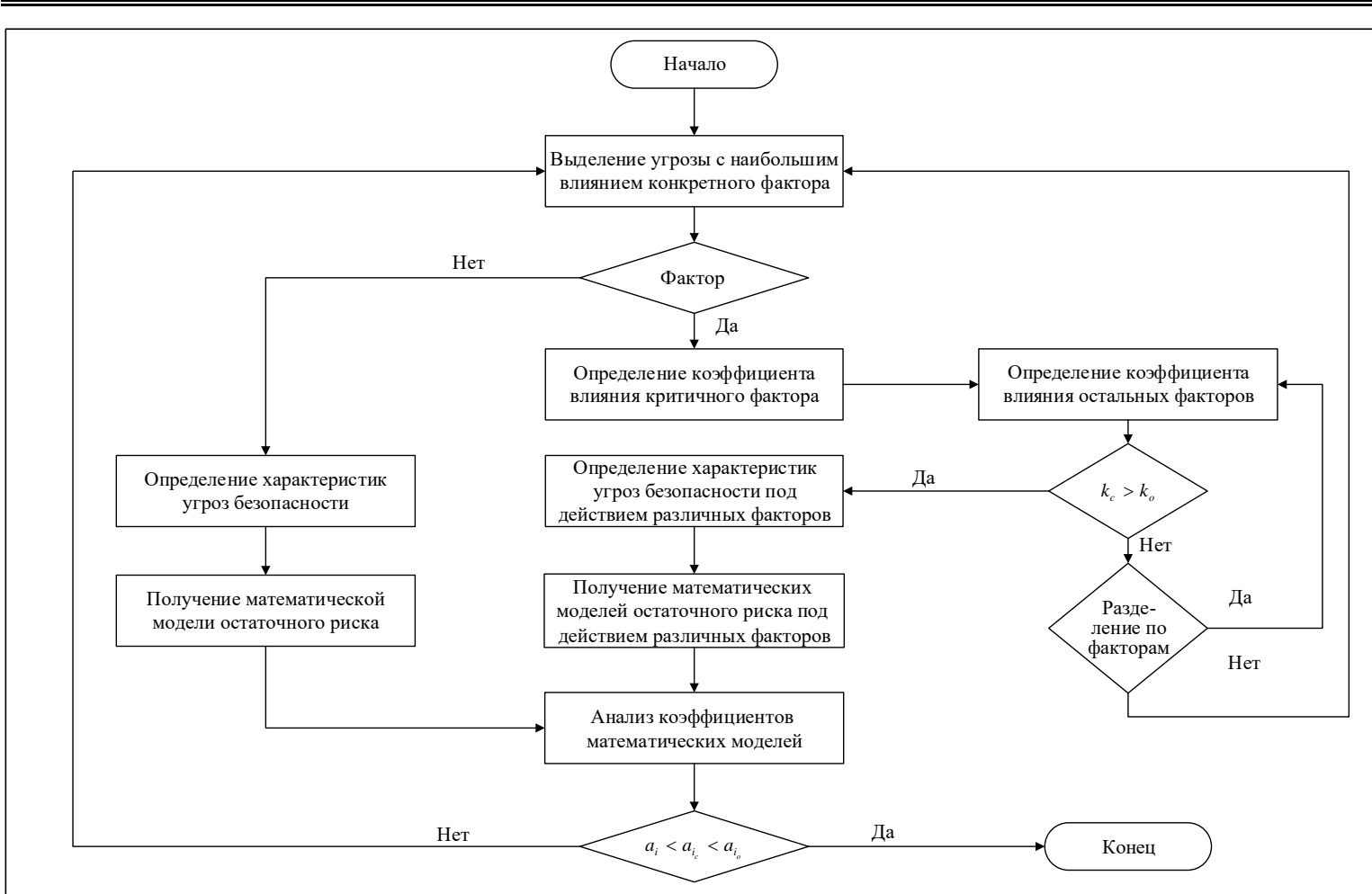

Рис. 4. Алгоритм проверки выбора наиболее критичного фактора

Fig. 4. Algorithm for checking the choice of the most critical factor

Переоценка параметров модели происходит по следующим формулам: $\bar{\pi}=\gamma_{t}(i), \overline{a_{i j}}=\frac{\sum_{t=1}^{T-1} \xi_{t}(i, j)}{\sum_{t=1}^{T-1} \gamma_{t}(i)}$, $\overline{\beta_{j}}(k)=\frac{\sum_{t=1}^{T} \gamma_{t}(j)}{\sum_{t=1}^{T} \gamma_{t}(j)}$, где $\xi_{t}(i, j)-v_{k}$ вероятность того, что при заданной последовательности наблюдений в моменты времени $t$ и $t+1$ система будет находиться в состояниях $S_{i}$ и $S_{j}$ соответственно; $\gamma_{t}(i)$ - вероятность пребывания модели в момент $t$ в состоянии $S_{i}$ при заданной последовательности наблюдений.

После определения необходимых параметров рассчитывается значение остаточного риска с помощью математической модели, полученной на основе полного факторного эксперимента, который позволяет учесть входные параметры на верхнем и нижнем уровнях, что дает возможность уменьшить вероятность ошибки экспертной оценки [11-14].

\section{Заключение}

Разработанный алгоритм позволяет определять значение остаточного риска для угроз информационной безопасности с учетом разделения механиз- мов защиты на типы, что в дальнейшем может помочь более качественно анализировать существующую систему защиты на предприятии и, возможно, позволит более качественно определять комплекс мер защиты конкретного типа при противодействии угрозам.

\section{Лuтература}

1. ISO/IEC 27001:2013. Information technology. Security techniques. Information security management systems. Requirements. ISO, 2013, $30 \mathrm{p}$.

2. BS 7799-2:2002. Information security management. Specification with guidance for use. BSI, 2002, $38 \mathrm{p}$.

3. BSI Standard 100-3. Risikoanalyse auf der Basis von IT-Grundschutz. BSI, 2008, 23 p.

4. Баранова Е.К. Методики анализа и оценки рисков информационной безопасности // Образовательные ресурсы и технологии. 2015. № 1. С. 73-79.

5. Rabiner $\mathrm{L}$. A tutorial on hidden markov models and selected applications in speech recognition. Proc. of IEEE, 1989. T. 77. № 2. C. $86-120$.

6. Дерендяев Д.А., Гатчин Ю.А., Безруков В.А. Математическая модель оценки коэффициента влияния отдельно взятого фактора на угрозы информационной безопасности // Кибернетика и программирование. 2016. № 5. С. 222-227.

7. Гатчин Ю.А., Жаринов И.О., Коробейников А.Г. Математические модели оценки инфраструктуры системы защиты информации на предприятии // Науч.-технич. вестн. информ. технологий, механики и оптики. 2012. № 2. С. 92-95.

8. Гришина Н.В. Организация комплексной системы защиты информации. М.: Гелиос АРВ, 2007. 256 с.

9. Berr J. Computer security's weak link: Humans. 2015. URL: http://www.cbsnews.com/news/the-human-element-and-computersecurity (дата обращения: 19.09.17).

10. Дерендяев Д.А., Безруков В.А. Алгоритм определения фактора, оказывающего наиболее критичное влияние на угрозы 
информационной безопасности // XVII Междунар. науч.-практич. конф.: сб. стат. М.: Интернаука, 2016. № 15. С. 97-102.

11. Дерендяев Д.А., Гатчин Ю.А., Безруков В.А. Алгоритм представления математической модели остаточного риска // Кибернетика и программирование. 2016. № 4. С. 81-85.

12. Goel S., Chen V. Information security risk analysis - a matrix-based approach. 2005. URL: http://www.albany.edu/ goel/ publications/goelchen2005.pdf (дата обращения: 19.09.17).

13. Lee M.C. Information security risk analysis methods and research trends: AHP and fuzzy comprehensive method. IJCSIT, 2014, vol. 6, no. 1. URL: http://www.airccse.org/journal/jcsit/6114ijcsit03. pdf (дата обращения: 19.09.17).

14. Варфоломеев А.А. Управление информационными рисками. М.: РУДН, 2008. 158 с.

\title{
An algorithm of information security residual risk assessment taking into account a protection mechanisms separation by types
}

\author{
D.A. Derendyaev ${ }^{1}$, Postgraduate Student, od@mail.ifmo.ru \\ Yu.A. Gatchin ${ }^{1}$, Dr.Sc. (Engineering), Professor, od@mail.ifmo.ru \\ V.A. Bezrukov ${ }^{1}$, Ph.D. (Engineering), Associate Professor, od@mail.ifmo.ru \\ ${ }^{1}$ The National Research University of Information Technologies, Mechanics and Optics, \\ St. Petersburg, 197101, Russian Federation
}

Abstract. Analyzing modern approaches to assessing the risk of information security threats, the authors conclude that most of these approaches do not consider protection mechanisms separation by types, which would allow a better analysis of the existing protection system in an enterprise.

The presented algorithm takes into account such separation and considers each type with an emphasis on its features. Due to the absence of clear separation of protection mechanisms, it is proposed to divide them into two groups: technical and organizational. To calculate residual risk, the authors taken into account additional variables, such as a possibility of the correct operation of the protection mechanism and the possibility of overcoming the mechanism in threat materializing.

Technical protection mechanisms reqiire taking into account the probability of transition to an inoperative state over time. Considering organizational measures, it is worth considering an expiration of its validity or its changing due to changing conditions. Such processes have random nature, therefore the mathematical apparatuses of the hidden Markov model and random Markov processes are used to determine their probabilities. The final indicator of residual risk is determined using an alternative mathematical model obtained after a full factorial experiment. This model allows obtaining more correct values as it considers input parameters at upper and lower levels.

As a result of the algorithm implementation, the values of residual risks are determined taking into account counteraction to the threat of each type of protective measures, which allows identifying the disadvantages of the protection system more precisely.

Keywords: residual risk assessment, information security, types of protection mechanisms, hidden Markov models, random Markov processes.

\section{References}

1. ISO/IEC 27001:2013. Information technology. Security techniques. Information security management systems. Requirements. 2013, $30 \mathrm{p}$.

2. BS 7799-2:2002. Information security management. Specification with guidance for use. BSI Publ., 2002, $38 \mathrm{p}$.

3. BSI Standard 100-3. Risikoanalyse auf der Basis von IT-Grundschutz. BSI Publ., 2008, 23 p.

4. Baranova E.K. Methods of analysis and assessment of information security risks. Educational Resources and Technologies. 2015, no. 1, pp. 73-79 (in Russ.).

5. Rabiner L. A tutorial on hidden markov models and selected applications in speech recognition. Proc. of IEEE. 1989, vol. 77 , no. 2, pp. 86-120

6. Derendyaev D.A., Gatchin Yu.A., Bezrukov V.A. A mathematical model for estimating the coefficient of an individual factor influence on information security threats. Cybernetics and Programming. 2016, no. 5, pp. 222-227 (in Russ.).

7. Gatchin Yu.A., Zharinov I.O., Korobeynikov A.G. Mathematical models of an estimation of an infrastructure of an information security system at the enterprise. Sci. and Tech. J. of Information Technologies, Mechanics and Optics. 2012, no. 2, pp. 92-95 (in Russ.).

8. Grishina N.V. Organization of a Comprehensive Information Security System. Moscow, Gelios ARV Publ., 2007, $256 \mathrm{p}$.

9. Berr J. Computer security's weak link: Humans. J. Berr. CBS News. 2015, no. 04. Available at: http://www.cbsnews. com/news/the-human-element-and-computer-security (accessed September 19, 2017).

10. Derendyaev D.A., Bezrukov V.A. An algorithm for determining the factor that has the most critical impact on information security threats. Proc. 17th Intern. Sci. and Pract. Conf. Moscow, Internauka Publ., 2016, no. 15, pp. 97-102 (in Russ.).

11. Derendyaev D.A., Gatchin Ya.A., Bezrukov V.A. An algorithm for representing the mathematical model of residual risk. Cybernetics and Programming. 2016, no. 4, pp. 81-85 (in Russ.)

12. Goel S., Chen V. Information Security Risk Analysis - a Matrix-Based Approach. 2005. Available at: http://www.albany.edu/ goel/publications/goelchen2005.pdf (accessed September 19, 2017).

13. Lee M.C. Information security risk analysis methods and research trends: AHP and fuzzy comprehensive method. IJCSIT. 2014, vol. 6, no. 1. Available at: http://www.airccse.org/journal/jcsit/6114ijcsit03.pdf (accessed September 19, 2017).

14. Varfolomeev A.A. Information Risk Management. Moscow, RUDN Publ., 2008, 158 p. 
УДК $004.89: 519.712 .2$

Дата подачи статьи: 04.06.18

DOI: $10.15827 / 0236-235 X .123 .569-580$

2018. Т. 31. № 3. С. 569-580

\title{
Разработка и программная реализация гибридного алгоритма решения оптимизаиионных задач автоматизированного проектирования
}

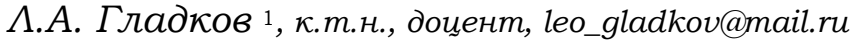 \\ C.Н. Мейба ${ }^{1}$, аспирант \\ В.Б. Тарасов 2, к.т.н., доиент, vbulbov@yаhоo.com
}

${ }_{1}$ Южный федеральный университет, г. Таганрог, 347928, Россия

2 Московский государственный технический университет им. Н.Э. Баумана,

г. Москва, 105005, Россия

В статье рассмотрен гибридный алгоритм решения сложных оптимизационных задач проектирования на примере решения задач размещения и трассировки элементов схем цифровой электронно-вычислительной аппаратуры. Приведена постановка задачи, выбраны ограничения области допустимых решений и сформулирован критерий оценки качества получаемых решений.

Предложен новый гибридный подход к решению рассматриваемой задачи на основе сочетания эволюционных методов поиска, математического аппарата нечеткой логики и возможностей параллельной организации вычислительного процесса, а также модифицированный оператор миграции для обмена информацией между популяциями решений в процессе выполнения параллельных вычислений. Разработана структура параллельного гибридного алгоритма.

Показана реализация модуля нечеткого управления на основе использования многослойной нейронной сети и функции Гаусса. Отмечены основные отличия предложенной структуры нейронной сети от традиционных нейронных сетей. Сформулированы основные принципы работы блока нечеткого управления. Подробно рассмотрены особенности программной реализации предложенного гибридного алгоритма. Сформулированы требования к архитектуре разрабатываемой программы с учетом необходимости поддержки свойств модульности и расширяемости приложения. Приведены примеры описания элемента печатной платы на основе существующих спецификаций. Описана структура интерфейса, представлены основные элементы графического интерфейса разработанного приложения.

Для оценки качества получаемых решений и процесса поиска решений в целом предложено использовать параметры, характеризующие динамику изменения среднего и лучшего значений целевой функции, а также разнообразие популяции.

Дано краткое описание проведенных вычислительных экспериментов, подтвердивших эффективность предложенного метода. Показаны зависимости вероятности выполнения генетических операторов от значений управляющих параметров.

Ключевые слова: вычислительный интеллект, гибридная система, биоинспирированные алгоритмы, проектирование, нейронные сети, гибридные методы, параллельные вычисления.

Подавляющее большинство оптимизационных задач, решаемых в процессе конструкторского этапа автоматизированного проектирования элементов электронно-вычислительной аппаратуры (ЭВА), требуют огромных затрат времени и вычислительных ресурсов. Это обусловлено необходимостью перебора огромного числа различных вариантов решений. При этом по своей вычислительной сложности задачи проектирования относятся к классу так называемых NP-полных задач, то есть задач, для которых не существует детерминированного полиномиального алгоритма.

Следовательно, для гарантированного нахождения наилучшего решения (глобального экстремума) в таких задачах требуется выполнить полный перебор, что в реальности не представляется возможным в силу их большой размерности [1-4]. Поэтому на практике для решения такого рода задач разрабатываются различные метаэвристические алгоритмы, позволяющие находить близкие к оптимальным (квазиоптимальные) решения.

Одним из подходов, позволяющих успешно решать задачу повышения эффективности и качества решения сложных оптимизационных задач большой размерности, является интеграция различных научных методов, характерных для таких направлений вычислительного интеллекта, как биоинспирированные алгоритмы, нечеткие вычисления, искусственные нейронные сети [5-8].

В научной литературе описано большое количество различных модификаций генетических алгоритмов для решения широкого круга задач конструкторского этапа проектирования [5-8]. Как правило, такие алгоритмы достаточно успешно справляются с задачей нахождения квазиоптимального решения за полиномиальное время. Однако большинство упомянутых выше алгоритмов имеют проблемы с преждевременной сходимостью процесса поиска. Также при организации генетических алгоритмов важно учитывать необходимость расширения области поиска, возможность организации поиска в различных удаленных друг от друга областях пространства допустимых решений.

В данной статье предлагается гибридный подход к решению рассматриваемых оптимизационных задач на основе интеграции таких подходов, 
как эволюционные алгоритмы поиска, искусственные нейронные сети, нечеткие модели управления параметрами алгоритма и механизмы распараллеливания вычислений для повышения эффективности организации процесса поиска [9-19].

\section{Постановка задачи}

К конструкторскому этапу проектирования ЭВА относятся задачи компоновки, размещения, трассировки, планирования, верификации. Наиболее сложными и ответственными с точки зрения качества будущих изделий являются задачи размещения и трассировки. Кроме того, эти задачи тесно связаны между собой, поскольку результат решения задачи размещения элементов является исходной информацией для задачи трассировки, а качество решения задачи размещения непосредственно влияет на сложность и качество задачи трассировки. Поэтому представляет практический интерес разработка интегрированных методов, позволяющих решать эти задачи в едином цикле с учетом взаимных ограничений и текущих результатов $[20,21]$.

Пусть задано множество элементов $E=\left\{e_{i} \mid i=\right.$ $=1, \ldots, N\}$, где $e_{i}$ - размещаемый элемент; $N$ - количество размещаемых элементов. Здесь $e_{i}=\left(l_{i}, h_{i}\right.$, $\left.T_{i}\right)$, где $l_{i}$ - длина элемента; $h_{i}$ - высота элемента; $T_{i}$ - список контактов элемента размещения, $T_{i}=\left\{t_{j}\right.$ $\mid j=1, \ldots, K\}$, где $t_{j}$ - контакт, $K$ - количество контактов элемента, причем $t_{j}=\left(x_{j}, y_{j}\right)$, где $x_{j}, y_{j}-$ координаты контакта относительно базовой точки элемента.

Множество соединяющих элементы цепей $U=$ $=\left\{u_{h} \mid h=1, \ldots, L\right\}$, где $u_{h}-$ цепь, $L-$ количество цепей; $u_{h}=\left\{\left(N e_{k}, N c_{k}\right) \mid k=1, \ldots, M\right\}, N e_{k}-$ номер элемента, $N c_{k}$ - номер контакта, $M$ - количество контактов, соединяемых цепью.

Необходимо найти вариант размещения элементов на монтажном пространстве: $V=\left\{\left(x_{i}, y_{i}\right) \mid\right.$ $i=1, \ldots, N\}$, где $\left(x_{i}, y_{i}\right)$ - координаты верхнего левого угла установочной площади элемента размещения $i$, такие, чтобы суммарная площадь перекрытия размещенных элементов была равна нулю, а сумма значений остальных критериев минимальна.

Для каждой цепи следует найти список позиций коммутационного поля, через которые она проходит: $W_{h}=\left\{\left(x_{q}, y_{q}\right) \mid i=1, \ldots, Q\right\}$, где $Q$ - количество позиций, через которые проходит $h$-я цепь.

\section{Описание алгоритма}

Кодирование пространства решений задачи. При кодировании решений множество позиций представляется в виде регулярной структуры (решетки). Каждая позиция $p_{i}$ имеет координаты $x_{i}, y_{i}$. Позиции нумеруются по возрастанию координаты $x_{i}$ в пределах строки слева направо, а строки, в свою очередь, упорядочиваются по возрастанию координаты $y_{i}$ сверху вниз.

Каждый элемент имеет базовую точку $O^{\delta}{ }_{i}$ и базовые оси координат $O_{i}^{\delta} X_{i}^{\delta}, O_{i}^{\delta} Y_{i}{ }_{i}$, относительно которых задается контурное описание элемента $e_{i}$. Базовой точкой является нижний левый угол элемента. Контурное описание имеет прямоугольную форму. Будем считать, что элемент $e_{i}$ назначен в позицию $p_{j}$, если его базовая точка $O^{\delta}{ }_{i}$ совмещена с точкой коммутационного поля, имеющей координаты $x_{j}, y_{j}$. Точки пересечения пунктирных линий соответствуют посадочным позициям на коммутационном поле (рис. 1).

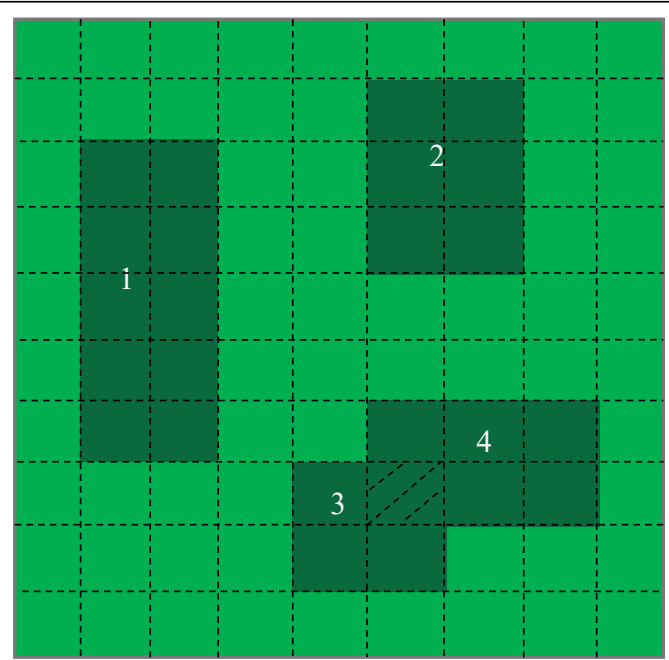

Рис. 1. Графическое отображение размещченных элементов

Fig. 1. Graphical display of placed elements

Каждое решение представляется в виде хромосомы $H_{i}$. Порядковый номер гена в хромосоме соответствует порядковому номеру размещаемого элемента. Значение гена соответствует номеру позиции на коммутационном поле. Число генов в хромосоме равно количеству размещаемых элементов.

Определение целевой функиии (ЦФ) задачи. При расчете значения ЦФ размещения вычисляются нормированная оценка суммы штрафа за перекрытие площадей размещаемых элементов, оценки длин межсоединений, показателя трассируемости, а также оценки тепловой и электромагнитной совместимости элементов: $F_{p}=k_{1} * S+k_{2} * L+$ $+k_{3} * T+k_{4} * J+k_{5} * Q$, где $S-$ суммарная площадь перекрытия элементов; $L$ - оценка длин межсоединений; $T$ - показатель трассируемости; $J$ - суммарное электромагнитное воздействие элементов друг на друга; $Q$ - суммарное тепловое воздействие элементов друг на друга; $k_{1}, k_{2}, k_{3}, k_{4}, k_{5}$ - коэффициенты, определяющие влияние каждой составляющей функции принадлежности на общую оценку.

Размер штрафа за перекрытие площадей размещаемых элементов зависит от суммарной площади пересечения всех элементов. При этом учитыва- 
ется минимально допустимое расстояние между элементами.

Площадь пересечения двух элементов вычисляется следующим образом:

$x_{11}=\max \left(\min \left(x_{1}, x_{2}+d\right), \min \left(x_{3}, x_{4}+d\right)\right) ;$

$x_{12}=\min \left(\max \left(x_{1}, x_{2}+d\right), \max \left(x_{3}, x_{4}+d\right)\right)$;

$y_{11}=\max \left(\min \left(y_{1}, y_{2}+d\right), \min \left(y_{3}, y_{4}+d\right)\right)$;

$y_{12}=\min \left(\max \left(y_{1}, y_{2}+d\right), \max \left(y_{3}, y_{4}+d\right)\right)$;

ЕСЛИ $\left(\left(x_{12}-x_{11}>=0\right)\right.$ И $\left.\left(y_{12}-y_{11}>=0\right)\right)$

ТО $R_{i j}=\left(x_{12}-x_{11}\right) *\left(y_{12}-\mathrm{y}_{11}\right)$ ИНАЧЕ $R_{i j}=0$,

где $x_{1}, y_{1}$ - координаты верхнего левого угла первого прямоугольника; $x_{2}, y_{2}-$ координаты нижнего правого угла первого прямоугольника; $x_{3}, y_{3}$ - координаты верхнего левого угла второго прямоугольника; $x_{4}, y_{4}-$ координаты нижнего правого угла второго прямоугольника; $d$ - минимально допустимое расстояние между элементами.

Для оценки длин межсоединений целесообразно использовать полупериметр описывающего прямоугольника цепи (рис. 2).

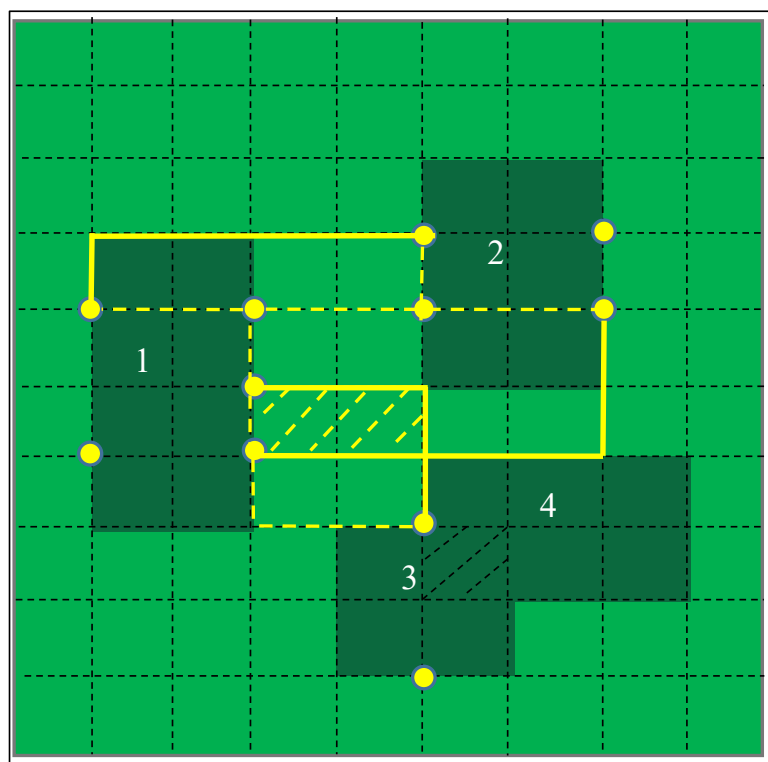

Рис. 2. Пример определения качества размещения

Fig. 2. The example of determining the quality of placement

При решении задачи трассировки показателем качества решения является доля (процент) непротрассированных соединений. Дополнительным критерием качества трассировки является суммарная площадь пересечения областей описывающих прямоугольников всех цепей (рис. 3).

Параллельный алгоритм биоинспирированного поиска. Для совместного решения задач размещения и трассировки используется параллельный многопопуляционный генетический алгоритм [15-19]. Он предполагает параллельное выполнение эволюционных процессов на нескольких популяциях. Для обмена особями используются островная и буферная модели параллельного генетического алгоритма.

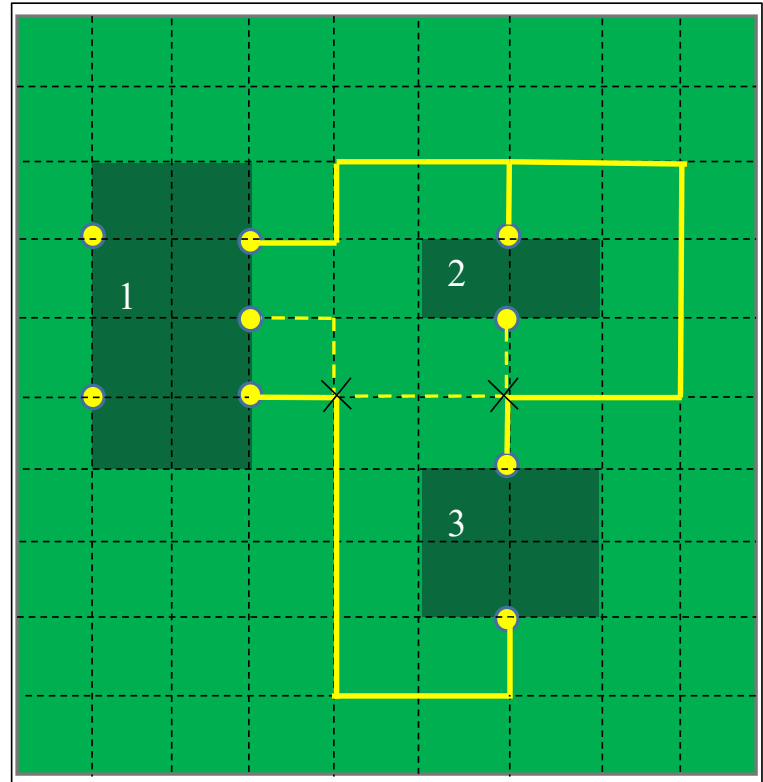

Рис. 3. Пример определения качества трассировки

Fig. 3. The example of determining the quality of trace

В островной модели синхронизация асинхронных процессов осуществляется в точках миграции. Оператор миграции применяется для обмена особями между популяциями. Отбор особей для миграции выполняется из некоторого количества хромосом популяции, имеющих наилучшее значение ЦФ размещения. Отбор осуществляется на основе оценки количества непротрассированных соединений. Для каждого варианта размещения, описываемого хромосомой, выполняется трассировка с помощью волнового алгоритма. Затем некоторое количество хромосом с наилучшим значением данного показателя копируется из одной популяции в другую. При этом из популяций удаляется такое же количество хромосом с наихудшим значением показателя. На рисунке 4 представлена схема модели параллельного генетического алгоритма, выполняемого на двух популяциях. На практике количество популяций может быть значительно больше.

В буферной модели обмен особями между популяциями осуществляется через общий промежуточный буфер хромосом. Обмен выполняется в точках миграции. К популяции, достигшей точки миграции, применяется оператор миграции.

Для трассировки используется волновой алгоритм. Работа алгоритма включает в себя три этапа: инициализацию, распространение волны и восстановление пути. Во время инициализации строится образ множества ячеек печатной платы, каждой ячейке приписываются атрибуты проходимости/непроходимости, запоминаются стартовая и финишная ячейки.

Далее от стартовой ячейки порождается шаг в соседнюю ячейку, при этом проверяется, проходима ли она и не является ли ранее помеченной в пути ячейкой. Для классификации соседних ячеек 


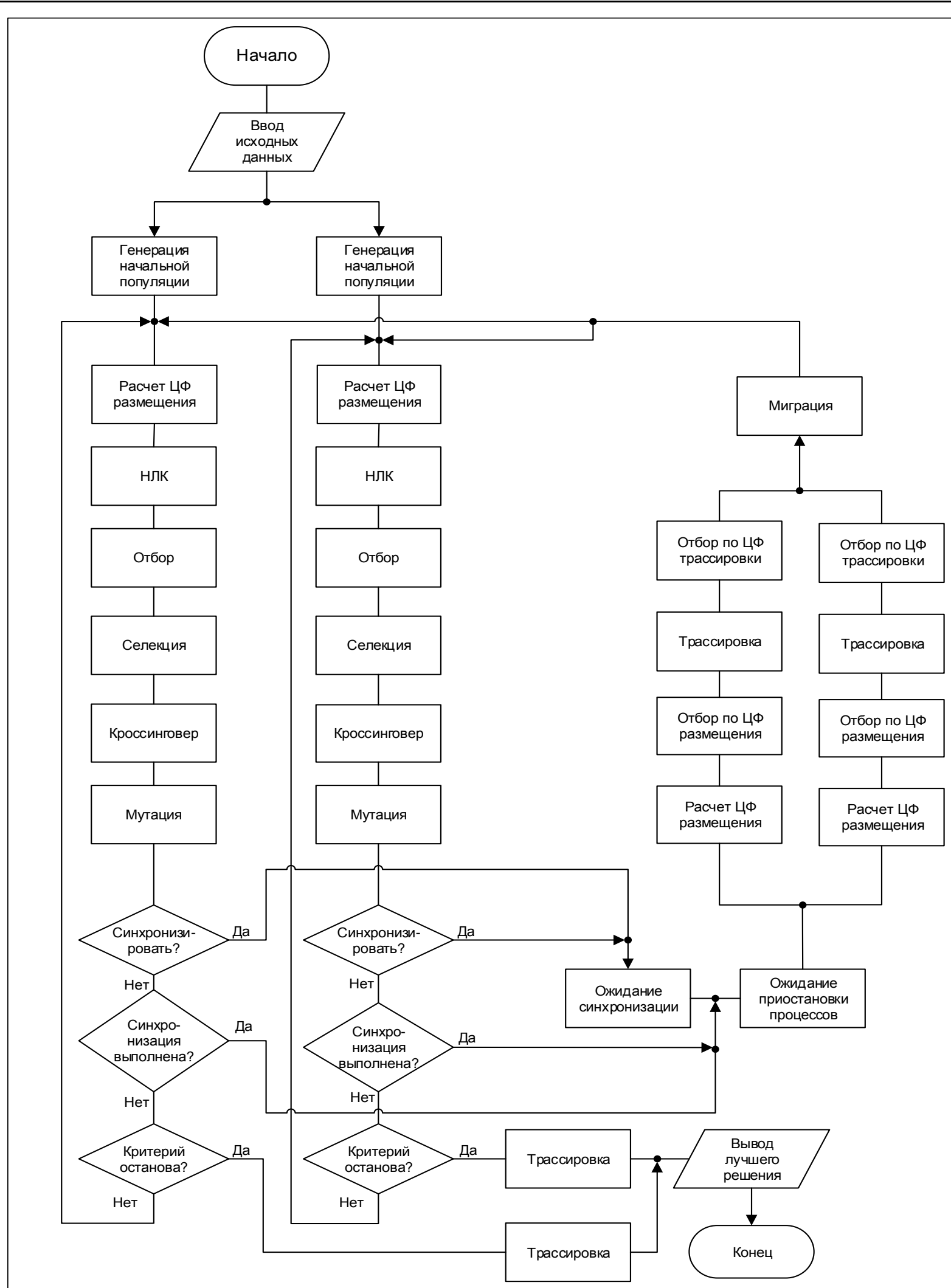

Рис. 4. Структурная схема островной модели алгоритма размещения

Fig. 4. A structural diagram of the allocation algorithm island model

используется окрестность фон Неймана. Соседними ячейками считаются 4 ячейки по вертикали и горизонтали. При выполнении условий проходи- мости и непринадлежности ее к ранее помеченным в пути ячейкам в атрибут ячейки записывается число, равное количеству шагов от стартовой 
ячейки, на первом шаге это будет 1. Каждая ячейка, помеченная числом шагов от стартовой ячейки, становится стартовой, и из нее порождаются очередные шаги в соседние ячейки. Очевидно, что при таком переборе будет найден путь от начальной ячейки к конечной либо очередной шаг из любой порожденной в пути ячейки будет невозможен. Структурная схема волнового алгоритма представлена на рисунке 5.

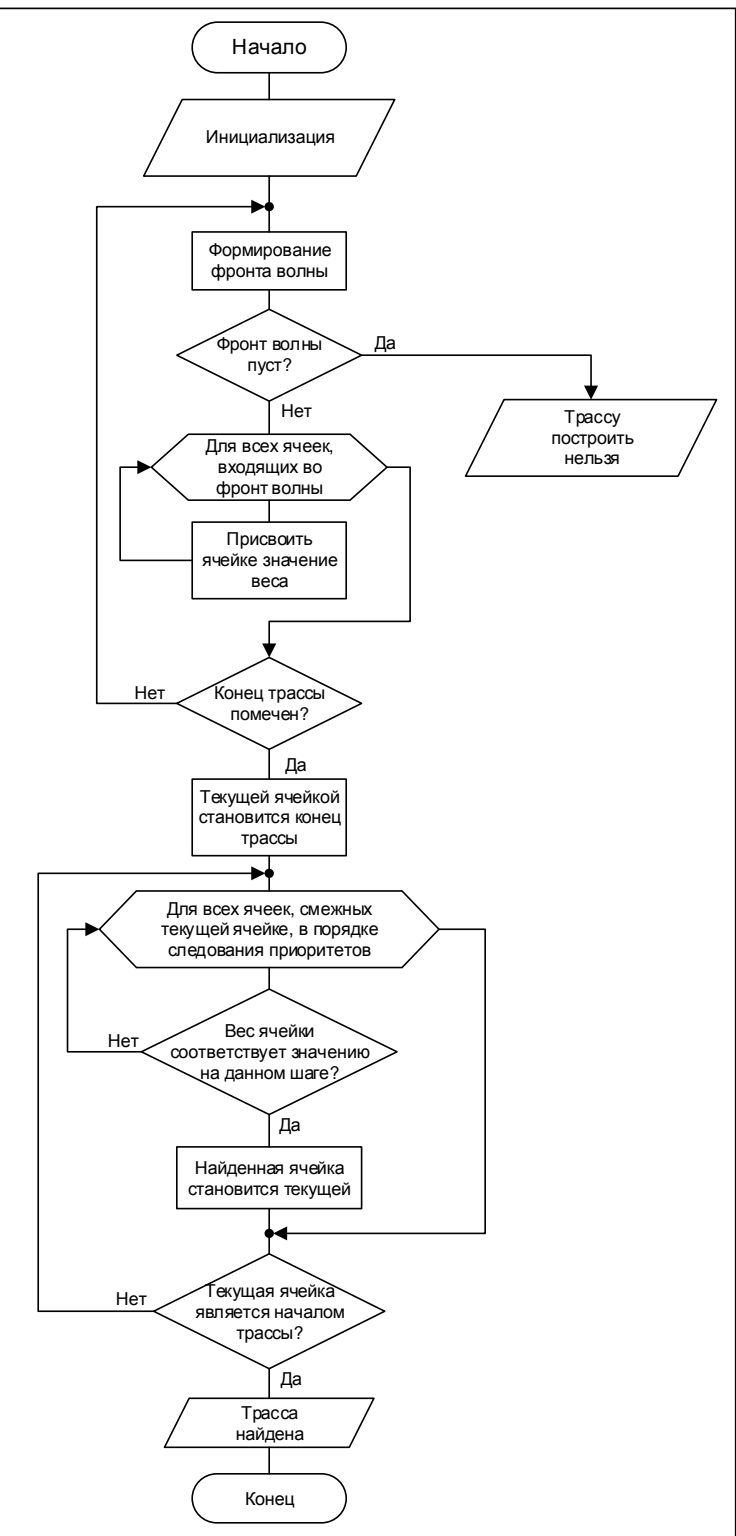

Рис. 5. Структурная схема волнового алгоритма трассировки

Fig. 5. A structural diagram of the wave trace algorithm

После выбора метода кодирования решений и задания критериев оценки качества получаемых решений построим биоинспирированный алгоритм поиска на основе модифицированных генетических операторов.

Для создания начальной популяции используется метод «дробовика». Он подразумевает случай- ный выбор альтернатив из всей области решений данной задачи [6]. После подсчета значений ЦФ для выбора решений применяется оператор селекции на основе метода «рулетки». Также в алгоритме используются модифицированные одноточечный оператор кроссинговера и многоточечный оператор мутации.

Развитие гибридных подходов и систем, основанных на интеграции различных научных направлений, дает основания полагать, что при организации параллельной структуры вычислений и построении схемы процесса эволюции весьма перспективным является использование принципов построения многоагентных систем [22, 23]. Методы и модели организации многоагентных систем и технологий в последнее время наиболее бурно развиваются. Активно прорабатываются вопросы, связанные с использованием интеллектуальных организаций агентов в различных отраслях науки и экономики, в том числе в проектировании, робототехнике, в военных целях.

Эволюционное моделирование и многоагентные методы тесно взаимосвязаны. С одной стороны, применение принципов эволюционного развития позволяет решать задачи адаптации многоагентных систем к изменениям внешней среды. С другой, эволюция может быть движущей силой в процессе развития МАС, являться механизмом для достижения поставленных целей и обеспечивать мотивацию.

Можно выделить некоторые параллели (соответствия) между базовыми понятиями эволюционного моделирования и теории многоагентных систем:

\begin{tabular}{|c|c|}
\hline $\begin{array}{c}\text { Эволюционное } \\
\text { моделирование }\end{array}$ & $\begin{array}{c}\text { Tеория многоагентных } \\
\text { систем }\end{array}$ \\
\hline Ген & Свойство агента \\
\hline Хромосома & Набор свойств \\
\hline Особь (решение) & Агент \\
\hline $\begin{array}{l}\text { Семья (2 родителя } \\
\text { и } 1 \text { потомок) }\end{array}$ & Коллектив агентов \\
\hline Популяция & $\begin{array}{l}\text { Эволюционирующая } \\
\text { многоагентная система }\end{array}$ \\
\hline
\end{tabular}

Также можно предположить, что принципы организации многоагентных систем могут быть успешно использованы для решения задачи распараллеливания вычислений.

Модуль нечеткого управления. Для повышения качества решений, получаемых биоинспирированным алгоритмом, в схему поиска включается нечеткий логический контроллер, регулирующий значения параметров основных эволюционных операторов. Таким образом, мы можем оценить текущее состояние процесса поиска и обеспечить возможность обратного управляющего воздействия на параметры генетического алгоритма с целью их оперативной коррекции $[9,11,12,24]$.

Для оценки текущего состояния популяции могут использоваться следующие величины $[13,14]$. 
1. Разнообразие генотипа популяции. Определяется по формуле $V G=\frac{\bar{d}-d_{\min }}{d_{\max }-d_{\min }}$, где $\bar{d}, d_{\max }$, $d_{\min }$ - среднее, максимальное и минимальное расстояния хромосом популяции от лучшей. Очевидно, что $V G \in[0,1]$.

2. Фенотип особи. Зависит от значения ее функции пригодности $V F \in[0,1]$. Разнообразие фенотипа определяется по одной из следующих формул: $V F=a b s\left(f_{\text {best }}-\bar{f}\right) / f_{\text {best }} ; V F=\frac{f_{\text {best }}}{f}$, где $f_{\text {best }}$, $\bar{f}$ - лучшее и среднее значения функции пригодности.

3. Скорость роста среднего значения функции пригодности по популяции $S A \in[0,1]$. Она позволяет судить о том, насколько быстро происходит развитие особей в популяции. Вычисляется по следующей формуле: $S A=\left(f_{\text {ave }}-f_{\text {avep }}\right) / f_{\text {ave }}$, где $f_{\text {ave }}$, $f_{\text {avep }}$ - среднее значение функции пригодности на текущей и предыдущей популяциях [14].

4. Изменение значения лучшей хромосомы в ходе эволюции: $\Delta f_{\text {best }_{k}}=\frac{f_{\text {best }_{i}}-f_{\text {best }_{i-k}}}{\Delta Y}$, где $f_{\text {best }_{i}}$, $f_{\text {best }_{i-k}}$ - лучшее значение функции пригодности на $i$-м и $(i-k)$-м поколениях; $\Delta Y$ - точность нахождения решения; $k$ - количество анализируемых поколений.

5. Среднее изменение значения функции пригодности популяции в ходе эволюции: $\Delta f_{\text {ave }_{k}}=\frac{f_{\text {ave }_{i}}-f_{\text {ave }_{i-k}}}{\Delta Y}$, где $f_{\text {ave }_{i}}, f_{\text {ave }_{i-k}}-$ среднее значение функции пригодности на $i$-м и $(i-k)$-м поколениях; $\Delta Y$ - точность нахождения решения; $k$ - количество анализируемых поколений.

Были выбраны следующие параметры для оценки эффективности эволюции:

$$
\begin{aligned}
& e_{1}(t)=\frac{f_{\text {ave }}(t)-f_{\text {best }}(t)}{f_{\text {ave }}(t)} ; \\
& e_{2}(t)=\frac{f_{\text {ave }}(t)-f_{\text {best }}(t)}{f_{\text {worst }}(t)-f_{\text {best }}(t)} ; \\
& e_{3}(t)=\frac{f_{\text {best }}(t)-f_{\text {best }}(t-1)}{f_{\text {best }}(t)} ; \\
& e_{4}(t)=\frac{f_{\text {ave }}(t)-f_{\text {ave }}(t-1)}{f_{\text {ave }}(t)},
\end{aligned}
$$

где $t$ - временной шаг; $f_{\text {best }}(t)$ - лучшее значение ЦФ на итерации $t ; f_{\text {best }}(t-1)$ - лучшее значение ЦФ на итерации $(t-1) ; f_{\text {worst }}(t)$ - худшее значение ЦФ на итерации $t$; $f_{\text {ave }}(t)$ - среднее значение ЦФ на итерации $t ; f_{\text {ave }}(t-1)$ - среднее значение ЦФ на итерации $(t-1)[13,14,25,26]$.

Переменные $e_{1}, e_{2}, e_{3}, e_{4}$ заданы на следующих интервалах: $e_{1} \in[0 ; 1] ; e_{2} \in[0 ; 1] ; e_{3} \in[-1 ; 1]$; $e_{4} \in[-1 ; 1]$.
Выходными параметрами являются вероятности выполнения кроссинговера, мутации и миграции соответственно - $P c(t), \Delta P m(t), \Delta P s(t)$ : $P c(t) \in[0 ; 1] ; P m(t) \in[0 ; 1] ; P s(t) \in[0 ; 1]$.

Для расчета выходных значений используется блок нечеткого управления, представленный ранее. В качестве входных переменных $\bar{x}_{i}$ будем использовать параметры $e_{i}$. Полученные значения $\bar{y}$ будут эквивалентны параметрам $\Delta P c, \Delta P m, P s(t)$. Для вычисления каждого из данных параметров будет использоваться отдельный модуль нечеткого управления.

Рассмотрим реализацию блока нечеткого управления, представленную двумя функциями, которые задают значения вероятности кроссинговера и мутации:

void GA::Population::set_d_ver_mut()\{

$\mathrm{kf}[0]=-0.5 ; \mathrm{kf}[1]=0 ; \mathrm{kf}[2]=0.5$;

$\mathrm{fp}[0] . \mathrm{x}=-50 ; \mathrm{fp}[0] . \mathrm{y}=30$;

$\mathrm{fp}[1] . \mathrm{x}=25 ; \mathrm{fp}[1] . \mathrm{y}=20$;

float $\mathrm{x}=\exp (-((\mathrm{e} 1-\mathrm{fp}[0] . \mathrm{x}) / \mathrm{fp}[0] . \mathrm{y}) *((\mathrm{e} 1-\mathrm{fp}[0] . \mathrm{x}) / \mathrm{fp}[0] . \mathrm{y}))$; float $y=\exp \left(-((e 2-f p[1] \cdot x) / f p[1] . y)^{*}((e 2-f p[1] . x) / f p[1] . y)\right)$;

float $\mathrm{s} 01=\mathrm{x} * \mathrm{y}$;

float $\mathrm{s} 1=\mathrm{x} * \mathrm{y} * \mathrm{kf}[0]$

$\mathrm{fp}[2] . \mathrm{x}=0 ; \mathrm{fp}[2] . \mathrm{y}=30$;

$\mathrm{fp}[3] . \mathrm{x}=50 ; \mathrm{fp}[3] \cdot \mathrm{y}=20$;

$\mathrm{x}=\exp (-((\mathrm{e} 1-\mathrm{fp}[2] \cdot \mathrm{x}) / \mathrm{fp}[2] \cdot \mathrm{y}) *((\mathrm{e} 1-\mathrm{fp}[2] \cdot \mathrm{x}) / \mathrm{fp}[2] \cdot \mathrm{y}))$; $y=\exp (-((e 2-f p[3] \cdot x) / f p[3] . y) *((e 2-f p[3] . x) / f p[3] . y))$;

float $\mathrm{s} 02=\mathrm{x} * \mathrm{y}$;

float $\mathrm{s} 2=\mathrm{x} * \mathrm{y} * \mathrm{kf}[1]$;

$\mathrm{fp}[4] . x=50 ; \mathrm{fp}[4] . \mathrm{y}=30$;

$\mathrm{fp}[5] . \mathrm{x}=75 ; \mathrm{fp}[5] . \mathrm{y}=20$;

$x=\exp (-((e 1-f p[4] \cdot x) / f p[4] \cdot y) *((e 1-f p[4] \cdot x) / f p[4] \cdot y))$;

$y=\exp (-((e 2-f p[5] \cdot x) / f p[5] \cdot y) *((e 2-f p[5] \cdot x) / f p[5] \cdot y)) ;$

float $\mathrm{s} 03=\mathrm{x} * \mathrm{y}$;

float $\mathrm{s} 3=\mathrm{x} * \mathrm{y} * \mathrm{kf}[2]$;

float $\mathrm{s} 0=\mathrm{s} 01+\mathrm{s} 02+\mathrm{s} 03$;

float $\mathrm{s}=\mathrm{s} 1+\mathrm{s} 2+\mathrm{s} 3$;

float $\mathrm{a}=\mathrm{s} / \mathrm{s} 0$;

ver_mut=ver_mut $+\mathrm{a}^{*} 100$;

\}

void GA::Population::set_d_ver_cross ()\{

$\mathrm{kf}[3]=-0.3 ; \mathrm{kf}[4]=0 ; \mathrm{kf}[5]=0.6$;

$\mathrm{fp}[6] . \mathrm{x}=-50 ; \mathrm{fp}[6] . \mathrm{y}=30$;

$\mathrm{fp}[7] . \mathrm{x}=25 ; \mathrm{fp}[7] . \mathrm{y}=20$;

float $\mathrm{x}=\exp (-((\mathrm{e} 1-\mathrm{fp}[6] \cdot \mathrm{x}) / \mathrm{fp}[6] \cdot \mathrm{y}) *((\mathrm{e} 1-\mathrm{fp}[6] \cdot \mathrm{x}) / \mathrm{fp}[6] \cdot \mathrm{y}))$; float $y=\exp (-((\mathrm{e} 2-\mathrm{fp}[7] . \mathrm{x}) / \mathrm{fp}[7] . y) *((\mathrm{e} 2-\mathrm{fp}[7] . \mathrm{x}) / \mathrm{fp}[7] . \mathrm{y}))$; float $\mathrm{s} 01=\mathrm{x} * \mathrm{y}$;

float $\mathrm{s} 1=\mathrm{x} * \mathrm{y} * \mathrm{kf}[3]$;

$\mathrm{fp}[8] \cdot \mathrm{x}=0 ; \mathrm{fp}[8] \cdot \mathrm{y}=30$;

$\mathrm{fp}[9] . x=50 ; \mathrm{fp}[9] . \mathrm{y}=20$;

$\mathrm{x}=\exp (-((\mathrm{e} 1-\mathrm{fp}[8] \cdot \mathrm{x}) / \mathrm{fp}[8] \cdot \mathrm{y}) *((\mathrm{e} 1-\mathrm{fp}[8] \cdot \mathrm{x}) / \mathrm{fp}[8] \cdot \mathrm{y}))$; $y=\exp \left(-((e 2-f p[9] \cdot x) / f p[9] \cdot y)^{*}((e 2-f p[9] \cdot x) / f p[9] . y)\right) ;$

float $\mathrm{s} 02=\mathrm{x} * \mathrm{y}$;

float s2 $=x^{*} y^{*} k f[4]$; 
$\mathrm{fp}[10] . \mathrm{x}=50 ; \mathrm{fp}[10] \cdot \mathrm{y}=30$;

$\mathrm{fp}[11] . \mathrm{x}=75 ; \mathrm{fp}[11] \cdot \mathrm{y}=20$;

$\mathrm{x}=\exp (-((\mathrm{e} 1-\mathrm{fp}[10] \cdot \mathrm{x}) / \mathrm{fp}[10] \cdot \mathrm{y}) *((\mathrm{e} 1-\mathrm{fp}[10] \cdot \mathrm{x}) / \mathrm{fp}[10] \cdot \mathrm{y}))$;

$y=\exp (-((e 2-f p[11] . x) / f p[11] . y) *((e 2-f p[11] . x) / f p[11] . y)) ;$

float $\mathrm{s} 03=\mathrm{x} * \mathrm{y}$;

float $\mathrm{s} 3=\mathrm{x} * \mathrm{y} * \mathrm{kf}[5]$;

float $\mathrm{s} 0=\mathrm{s} 01+\mathrm{s} 02+\mathrm{s} 03$

float $\mathrm{s}=\mathrm{s} 1+\mathrm{s} 2+\mathrm{s} 3$;

float $\mathrm{a}=\mathrm{s} / \mathrm{s} 0$;

ver_cross $=$ ver_cross $+\mathrm{a} * 100$;

\}

Завершающий этап в процессе проектирования модуля нечеткого управления - это определение формы представления нечетких множеств $A_{i}{ }^{k}, 1, \ldots$, $n ; k=1, \ldots, N$. Например, это может быть функция Гаусса $\mu_{A_{i}^{k}}(x)=\exp \left(-\left(\frac{x_{i}-\bar{x}_{i}^{k}}{\sigma_{i}^{k}}\right)\right)$, где параметры $\bar{x}_{i}^{k}$ и $\sigma_{i}{ }^{k}$ имеют физическую интерпретацию: $\bar{x}_{i}^{k}$ центр, а $\sigma_{i}^{k}-$ ширина гауссовской кривой.

Как будет показано далее, эти параметры могут модифицироваться в процессе обучения, что позволяет изменять положение и структуру нечетких множеств [25-27]. После объединения всех элементов функция для модуля нечеткого управления приобретает окончательный вид:

$$
\bar{y}=\frac{\sum_{k=}^{N} \bar{y}^{k}\left(\prod_{i=1}^{n} \exp \left(-\left(\frac{\bar{x}_{i}-\bar{x}_{i}^{k}}{\sigma_{i}^{k}}\right)^{2}\right)\right)}{\sum_{k=1}^{N}\left(\prod_{i=1}^{n} \exp \left(-\left(\frac{\bar{x}_{i}-\bar{x}_{i}^{k}}{\sigma_{i}^{k}}\right)^{2}\right)\right)} .
$$

Каждый элемент этой формулы можно задать в форме функционального блока (сумма, произведение, функция Гаусса), что после соответствующего объединения позволяет создать многослойную нейронную сеть. В рассматриваемом случае нейронная сеть будет содержать четыре слоя. Каждый элемент первого слоя реализует функцию принадлежности нечеткого множества $A_{i}{ }^{k}, 1, \ldots, n$; $k=1, \ldots, N$. В этот слой поступают входные сигналы $\bar{x}_{i}$, а на его выходе формируются значения функции принадлежности для этих сигналов. На выходе первого слоя формируются значения функции принадлежности нечетким множествам. Конфигурация связей второго слоя соответствует базе правил, а мультипликаторы - блоку вывода. Применение мультипликаторов в качестве узлов этого слоя обусловлено тем, что в нечетких операциях используется операция умножения. Количество элементов этого слоя равно количеству правил, хранимых в базе. Третий и четвертый слои реализуют функции блока дефаззификации [25-27].

Очевидно, что описанная структура представляет собой многослойную сеть, основанную на идее нечеткого вывода. В отличие от «чистых» нейронных сетей каждый слой в целом и отдельные составляющие его элементы, как и конфигурация связей, все параметры и веса, имеют физическую интерпретацию. Это свойство оказывается необычайно важным, поскольку знания не распределяются по сети, могут быть легко локализованы и при необходимости откорректированы экспертомнаблюдателем.

В работе блока нечеткого управления используются 6 функций принадлежности для множеств $A^{k}$ и 2 функции для множеств $B^{k}$. При этом $k_{f}[i]$ эквивалентны параметрам $y^{k}$ и интерпретируются как центры функций принадлежности нечетких множеств $B^{k} ; f_{p}[i] x$ и $f_{p}[i] y$ интерпретируются соответственно как центр и ширина функции Гаусса для оценки степени принадлежности входных данных $\bar{x}_{i}$, к соответствующим нечетким множествам $A_{i}^{k}$ и соответствуют параметрам $x_{i}^{k}$ и $\sigma_{i}{ }^{k}$ в модуле нечеткого управления; величина $a$ соответствует выходному значению модуля управления $\bar{y}$. В процессе работы блока вычисляются 24 функции принадлежности для множеств $A_{i}^{k}$ и 6 функций для множеств $B^{k}$.

\section{Программная реализация гибридного алгоритма}

Архитектура приложения. Приложение состоит из следующих модулей: алгоритмы размещения и трассировки, модуль нечеткого управления, синтаксический анализатор и графический интерфейс. Алгоритмы размещения и трассировки реализованы в виде обобщенных алгоритмов, которые могут обрабатывать различные входные данные. Алгоритм совместного решения задач размещения и трассировки реализован на основе обобщенного алгоритма размещения, для которого определен метод расчета целевой функции размещения. На вход алгоритма подаются данные о топологии печатной платы. Алгоритм трассировки является вспомогательным и используется для оценки получаемых вариантов размещения. Модуль нечеткого управления используется для динамической настройки генетического алгоритма. База правил модуля нечеткого управления считывается из файла. Синтаксический анализатор используется для считывания данных о топологии печатной платы из файла, а также для записи данных в файл. Разработанная архитектура позволяет дополнять систему новыми свойствами и моделями поведения.

Хранение данных. Для хранения данных о топологии печатной платы используется LEF/DEFспецификация. LEF (Library Exchange Format) - это спецификация для представления физической структуры интегральной схемы в формате ASCII. Она включает правила оформления и абстрактную информации об элементах. LEF применяется в сочетании с DEF (Design Exchange Format)-спецификацией, которая используется для представления полного размещения элементов интегральной схемы [28, 29]. 
Далее приведен пример описания элемента печатной платы при помощи LEF-спецификации:

MACRO ms00f80

PROPERTY LEF58 EDGETYPE "

EDGETYPE LEFT $\overline{2}$;

EDGETYPE RIGHT 2;

$"$;

CLASS CORE ;

ORIGIN 00 ;

SIZE 1.6 BY 2.0 ;

SYMMETRY X Y R90 ;

SITE core ;

PIN o DIRECTION OUTPUT ;

PORT

LAYER metal2 ;

RECT 0.050 .5000 .151 .500 ;

END

END o

PIN a DIRECTION INPUT ;

PORT

LAYER metal1 ;

RECT 1.050 .5001 .151 .500 ;

END

END a

END ms00f80

Приведем также пример описания размещения элементов на печатной плате, а также описания цепей при помощи DEF-спецификации:

COMPONENTS 6;

- g2278701 ms00f80

+ PLACED $(20,10)$

- g2278702 ms00f80

+ PLACED $(20,40)$

- g2278703 ms00f80

+ PLACED $(20,70)$

- g2278704 ms00f80

+ PLACED $(60,10)$

- g2278705 ms00f80

+ PLACED $(60,40)$;

- g2278706 ms00f80

+ PLACED $(60,70)$

END COMPONENTS

NETS 2;

- ternarymux ln49 unr9_z 9_(g2278701 a) (g2278705 o) (g2278703 a);

- ternarymux ln49_unr9 z 10_(g2278704 o) (g2278702 a) (g2278706 o);

Реализация алгоритма. Алгоритм размещения реализован классом CPlacingAlgorithm (см. http:// www.swsys.ru/uploaded/image/2018-3/2018-3-dop/2. jpg). Для выполнения алгоритма вызывается метод execute, который принимает указатель на класс CBoard, используемый для хранения топологии печатной платы. Результатом работы алгоритма является обработанная топология печатной платы с заданными позициями элементов и протрассированными соединениями. Параметры алгоритма устанавливаются с помощью метода setParams, который принимает структуру SParams, содержащую такие поля, как количество хромосом, количество итераций, вероятности кроссинговера и мутации, а также частота миграции. Генетические операторы устанавливаются при помощи указателей на абстрактные базовые классы, определяющие интерфейс операторов. Каждый указатель может соответствовать конкретной реализации оператора. Родительские и дочерние популяции хранятся в динамической памяти. Доступ к ним осуществляется с помощью векторов указателей. Промежуточный буфер хромосом также хранится в динамической памяти.

Алгоритм трассировки реализован классом CRoutingAlgorithm (см. http://www.swsys.ru/uploaded/image/2018-3/2018-3-dop/3.jpg). Для выполнения алгоритма вызывается метод execute, он принимает указатель на объект класса CBoard, в котором хранится топология печатной платы с размещенными элементами. Результатом работы алгоритма является обработанная топология печатной платы с протрассированными соединениями.

Алгоритм трассировки каждой цепи определяется конкретной реализацией базового класса CRoutingOperator. На текущем этапе разработки приложения используется только волновой алгоритм, реализованный в классе CWaveRoutingOperator.

Графический интерфейс. Для реализации графического интерфейса использовался фреймворк Qt 5.6. Qt представляет собой кроссплатформенный инструментарий разработки прикладного ПО, широко используемый для создания графических интерфейсов [30, 31]. Он написан на С++ и предоставляет мощные расширения этого языка. Включает в себя все основные классы, которые могут потребоваться при разработке ПО, начиная от элементов графического интерфейса и заканчивая классами для работы с сетью, БД и XML. B целом Qt является полностью объектно-ориентированным, легко расширяемым и поддерживающим технику компонентного программирования.

Рассмотрим основные элементы графического интерфейса разработанного приложения. Окно приложения состоит из меню, панели инструментов, рабочего пространства и текстового поля для вывода различной вспомогательной информации. Меню состоит из пунктов File и Help (рис. 6). Пункт меню File содержит подпункты Import и

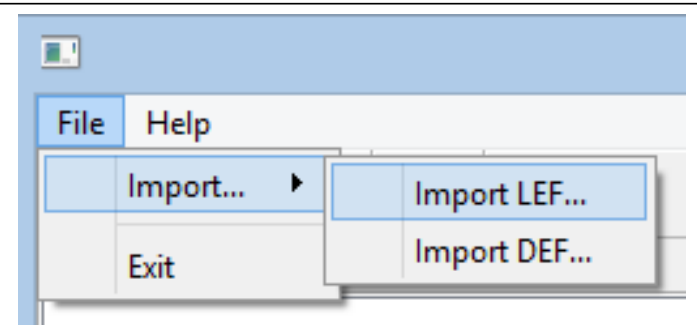

Puc. 6. Меню File

Fig. 6. File menu 
Exit. В пункте Import можно перейти к загрузке файлов, содержащих LEF- и DEF-спецификацию. Пункт Help содержит подпункты About и AboutQt, по нажатии на которые открываются окно с информацией о приложении и окно с информацией об используемой версии библиотеки Qt соответственно.

Панель инструментов содержит кнопку для загрузки конфигурации печатной платы по умолчанию, кнопки для запуска алгоритмов размещения, трассировки и обучения, а также кнопку настроек.

В окне настроек (рис. 7) можно задать параметры размещения элементов на печатной плате, такие как минимальное расстояние между элементами и шаг сетки размещения. Также можно установить параметры алгоритма: количество хромосом, количество итераций, первоначальные значения вероятностей кроссинговера и мутации, частоту и интенсивность миграции, количество потоков при вычислении целевых функций алгоритмов размещения и трассировки и количество потоков выполнения основного алгоритма.

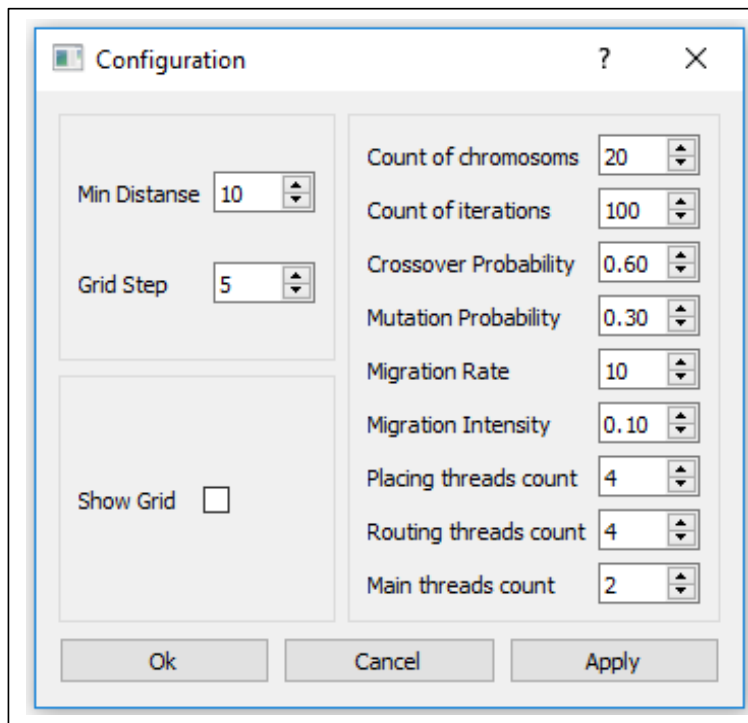

Рис. 7. Окно настроек

Fig. 7. Settings window

В рабочей области приложения осуществляется отрисовка текущего состояния печатной платы (см. http://www.swsys.ru/uploaded/image/2018-3/2018-3dop/4.jpg). Для отрисовки используется класс QGraphicsView. Для представления графических элементов используются классы, наследуемые от класса QGraphicsItem. Размещаемые элементы печатной платы представляются классом CGraphicComponent, соединения - классом CGraphic-Net, сетка размещения - классом CGraphicGrid. Bce графические элементы добавляются на сцену. Сцена является объектом класса QGraphicsScene. Сцена отрисовывается с помощью объекта класса QGraphicsView, которым можно манипулировать посредством матрицы преобразований. Реализована возможность масштабирования и вращения графического отображения печатной платы. При увеличении графического отображения можно изменять видимую область путем перетаскивания. Размещенные графические элементы также можно перетаскивать, тем самым корректируя полученное размещение [10].

Для отображения графиков используется расширение для фреймворка QT - QCustomPlot. Это виджет QT, который используется для построения графиков и визуализации данных. Он не имеет дополнительных зависимостей и хорошо документирован. Данная библиотека позволяет получать качественное визуальное отображение графиков и диаграмм, при этом обладает высокой производительностью, что позволяет использовать ее в системах реального времени [30, 31].

\section{Результаты вычислительных экспериментов}

Для анализа эффективности разрабатываемых алгоритмов используются графики изменения среднего и минимального значений целевой функции размещения. На каждой итерации рассчитываются средние значения целевой функции всех популяций, в которых запущен эволюционный процесс. Также используются графики среднего и минимального значений целевой функции трассировки, рассчитываемых в точках миграции.

Для анализа работы нечеткого логического регулятора (НЛР) используются графики изменения его входных и выходных параметров (см. http:// www.swsys.ru/uploaded/image/2018-3/2018-3-dop/5. jpg, http://www.swsys.ru/uploaded/image/2018-3/ 2018-3-dop/6.jpg, http://www.swsys.ru/uploaded/image/2018-3/2018-3-dop/7.jpg).

Эффективность работы регулятора можно повысить введением блока обучения на базе нейронной сети. Коэффициенты сети можно определять путем случайного или направленного поиска. В качестве инструмента направленного поиска можно использовать генетический алгоритм. В результате использования блока обучения были определены оптимальные параметры (см. http://www.swsys.ru/ uploaded/image/2018-3/2018-3-dop/8.jpg, http:// www.swsys.ru/uploaded/image/2018-3/2018-3-dop/9. jpg, http://www.swsys.ru/uploaded/image/2018-3/ 2018-3-dop/10.jpg и рис. 8).

По умолчанию заданы параметры НЛР, определяющие следующие функции принадлежности (рис. 8):

$$
\begin{aligned}
& \text { для } e_{1} \text { и } e_{2}: \mu_{\text {low }}=\exp \left(-\left(\frac{x_{i}}{0,3}\right)^{2}\right), \\
& \mu_{\text {ave }}=\exp \left(-\left(\frac{x_{i}-0.5}{0,3}\right)^{2}\right), \mu_{\text {high }}=\exp \left(-\left(\frac{x_{i}-1}{0,3}\right)^{2}\right) ;
\end{aligned}
$$




$$
\begin{gathered}
\text { для } e_{3} \text { и } e_{4}: \mu_{\text {low }}=\exp \left(-\left(\frac{x_{i}+1}{0,6}\right)^{2}\right), \\
\mu_{\text {ave }}=\exp \left(-\left(\frac{x_{i}}{0,6}\right)^{2}\right), \mu_{\text {high }}=\exp \left(-\left(\frac{x_{i}-1}{0,6}\right)^{2}\right) .
\end{gathered}
$$
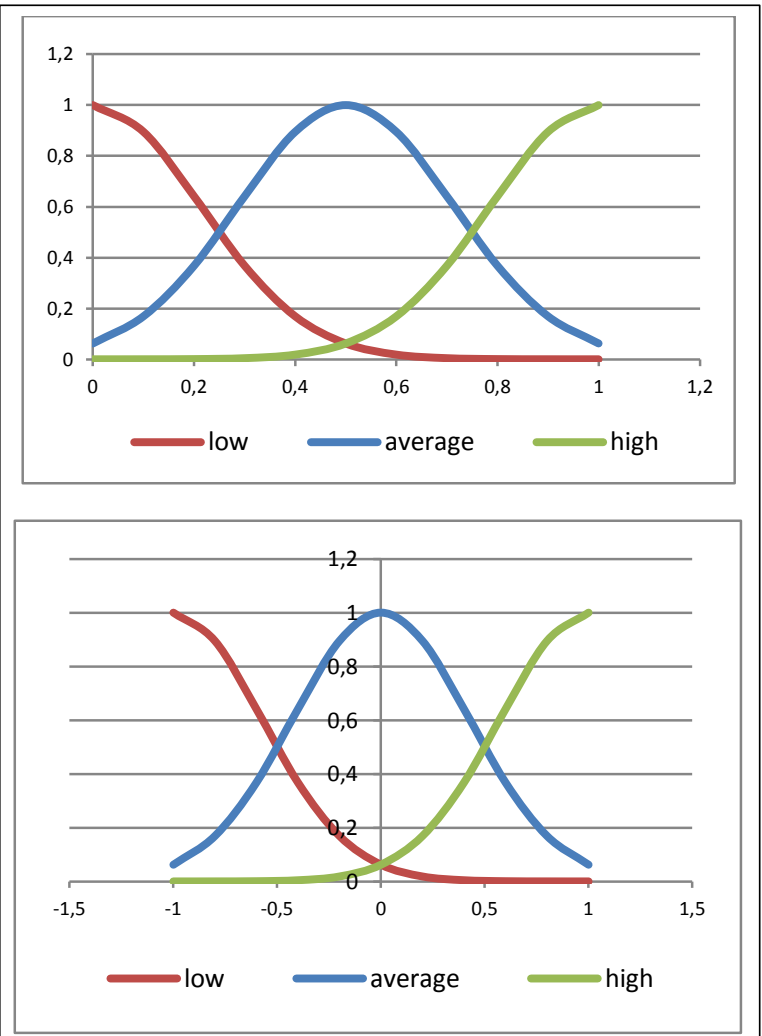

Рис. 8. Вид функиии принадлежности для параметров е $e_{1}-e_{4}$

Fig. 8. View of the membership function for the parameters $e_{1}-e_{4}$

Нечеткий лингвистический регулятор позволяет получить значение вероятностей кроссинговера и мутации на основе четырех входных переменных, которые характеризуют эволюционный процесс. При этом зависимость выходных значений от входных переменных определяется параметрами НЛР. Количество этих параметров зависит от количества входных переменных, функций принадлежности и параметров, которые определяют каждую функцию принадлежности.

Параметры НЛР, используемые при исследовании, были получены с помощью генетического алгоритма обучения. Обучение проводилось на основе статистической информации о зависимости параметров НЛР и эффективности алгоритма размещения. Эта информация собиралась в процессе обучения. После обучения НЛР показал достаточно высокую эффективность, при этом благодаря обучению были получены зависимости выхода от входа, которые практически невозможно задать на основе опыта эксперта. Были получены достаточно сложные зависимости, которые проблематично описать, оперируя лингвистическими переменными.

Проанализировав полученные данные, можно сделать вывод о том, что для получения наилучшего решения задач размещения и трассировки необходимо использовать четыре потока параллельного генетического алгоритма. Дальнейшее увеличение количества потоков негативно отражается на результате решения задач.

Работа выполнена при финансовой поддержке Российского фонда фундаментальных исследований, грант № 17-37-50076.

\section{Лumepamypa}

1. Alpert Ch.J., Dinesh P., Mehta D.P., Sapatnekar S.S. Handbook of algorithms for physical design automation. CRC Press, NY, USA, 2009.

2. Cohoon J.P., Karro J., Lienig J. Evolutionary algorithms for the physical design of VLSI circuit. In: Advances in Evolutionary Computing: Theory and Applications. A. Ghosh, S. Tsutsui (Eds.). Springer Verlag, London, 2003, pp. 683-712.

3. Норенков И.П. Основы автоматизированного проектирования. М.: Изд-во МГТУ им. Н.Э. Баумана, 2009. 434 с.

4. Shervani N. Algorithms for VLSI physical design automation. Kluwer Acad. Publ., Dordrecht, 1995. 538 p.

5. Гладков Л.А., Курейчик В.М., Курейчик В.В., Сороколетов П.В. Биоинспирированные методы в оптимизации. М.: Физматлит, 2009. 384 с.

6. Гладков Л.А., Курейчик В.В., Курейчик В.М. Генетические алгоритмы. М.: Физматлит, 2010. 368 с.

7. Гладков Л.А., Курейчик В.В., Курейчик В.М., Родзин С.И. Основы теории эволюционных вычислений: монография. Ростов н/Д.: Изд-во ЮФУ, 2010. 222 с.

8. Гладков Л.А. О некоторых подходах к построению гибридных интеллектуальных систем для решения графовых задач // Новости искусственного интеллекта. 2000. № 3. С. 71-90.

9. Michael A., Takagi H. Dynamic control of genetic algorithms using fuzzy logic techniques. Proc. $5^{\text {th }}$ Intern. Conf. on Genetic Algorithms. Morgan Kaufmann, 1993, pp. 76-83.

10. Im S.-M., Lee J-J. Adaptive crossover, mutation and selection using fuzzy system for genetic algorithms. Artificial Life and Robotics. 2008, vol. 13, no. 1, pp. 129-133.

11. Herrera F., Lozano M. Fuzzy adaptive genetic algorithms: design, taxonomy, and future directions. Soft Computing, 2003, vol. 7, pp. 545-562.

12. Herrera F., Lozano M. Adaptation of genetic algorithm parameters based on fuzzy logic controllers. In: Genetic algorithms and soft computing. F. Herrera, J.L. Verdegay (Eds.), PhysicaVerlag, Heidelberg, 1996, pp. 95-124.

13. Ярушкина Н.Г. Основы теории нечетких и гибридных систем. М.: Финансы и статистика, 2004. 320 с.

14. Батыршин И.З., Недосекин А.О., Стецко А.А., Тарасов В.Б. Нечеткие гибридные системы. Теория и практика; [под ред. Н.Г. Ярушкиной]. М.: Физматлит, 2007. 208 с.

15. King R.T.F.A., Radha B., Rughooputh H.C.S. A fuzzy logic controlled genetic algorithm for optimal electrical distribution network reconfiguration. Proc. 2004 IEEE Intern. Conf. on Networking, Sensing and Control, Taipei, Taiwan, 2004, pp. $577-582$

16. Rodriguez M.A., Escalante D.M., Peregrin A. Efficient distributed genetic algorithm for rule extraction. Applied Soft Computing, 2011, vol. 11, pp. 733-743.

17. Alba E., Tomassini M. Parallelism and evolutionary algorithms. IEEE T. Evolut. Comput., 2002, vol. 6, pp. 443-461.

18. Zhongyang X., Zhang Y., Zhang L., Niu S. A parallel 
classification algorithm based on hybrid genetic algorithm. Proc. $6^{\text {th }}$ World Congress on Intelligent Control and Automation, Dalian, China, 2006, pp. 3237-3240.

19. Кныш Д.С., Курейчик В.М. Параллельные генетические алгоритмы: Проблемы, обзор и состояние // Изв. РАН. Теория и системы управления. 2010. № 4. С. 72-82.

20. Гладков Л.А. Интегрированный алгоритм решения задач размещения и трассировки на основе нечетких генетических методов // Изв. ЮФУ. Технич. науки. 2011. № 7. С. 22-30.

21. Гладков Л.А. Гибридный генетический алгоритм решения задачи размещения элементов СБИС с учетом трассируемости соединений // Вестн. Ростов. гос. ун-та путей сообщения. 2011. № 3. C. 58-66.

22. Тарасов В.Б. От многоагентных систем к интеллектуальным организациям: философия, психология, информатика. М.: Эдиториал УРСС, 2002.

23. Гладков Л.А. Решение задач поиска и оптимизации решений на основе нечетких генетических алгоритмов и многоагентных подходов // Изв. ТРТУ. 2006. № 8. С. 83-88.

24. Пегат А. Нечеткое моделирование и управление. М.: БИНОМ. Лаборатория знаний, 2009.
25. Gladkov L.A., Gladkova N.V., Leiba S.N. Manufacturing scheduling problem based on fuzzy genetic algorithm. Proc. IEEE East-West Design \& Test Symposium (EWDTS'2014). Kiev, Ukraine, 2014, pp. 209-213.

26. Gladkov L.A., Gladkova N.V., Legebokov A.A. Organization of knowledge management based on hybrid intelligent methods. In: Software engineering in intelligent systems. Proc. 4th Comp. Sc. On-line Conf. 2015 (CSOC 2015), Springer, Switzerland, 2015, vol. 3, pp. 107-113.

27. Гладков Л.А., Гладкова Н.В., Лейба С.Н. Размещение элементов схем ЭВА на основе гибридных интеллектуальных методов // Изв. ЮФУ. Технич. науки. 2015. № 4. С. 25-36.

28. Гамма Э., Хелм Р., Джонсон Р., Влиссидес Д. Приемы объектно-ориентированного программирования. Паттерны проектирования. СПб: Питер, 2001. 368 с.

29. Макконел С. Совершенный код. СПб: Питер, 2005. $896 \mathrm{c}$

30. Qt Documentation. URL: http://doc.qt.io/qt-5/referenceoverview.html (дата обращения: 20.02.2018).

31. QCustomPlot. URL: http://qcustomplot.com/index.php/ introduction (дата обращения: 20.02.2018).

\title{
A hybrid algorithm for solving optimization problems of computer-aided design and its software implementation
}

\author{
L.A. Gladkov ${ }^{1}$, Ph.D. (Engineering), Associate Professor,leo_gladkov@mail.ru \\ S.N. Leyba ${ }^{1}$, Postgraduate Student \\ V.B. Tarasov ${ }^{2}$, Ph.D. (Engineering), Associate, vbulbov@yahoo.com \\ ${ }^{1}$ Southern Federal University, Taganrog, 347922, Russian Federation \\ ${ }^{2}$ Bauman Moscow State Technical University, Moscow, 105005, Russian Federation
}

Abstract. The article suggests a hybrid algorithm for solving complex design optimization problems. The work of the algorithm is examined using the example of solving the problems of placement and tracing elements of digital electronic computing equipment circuits. The paper gives a problem statement, limitations of the admissible solutions domain and formulates a criterion for estimating the quality of solutions.

The authors propose a new hybrid approach to solving this problem based on a combination of evolutionary search methods, the mathematical apparatus of fuzzy logic and the possibilities of parallel organization of the computational process. They also propose a modified migration operator to exchange information between solution populations in the process of performing parallel computations. The structure of the parallel hybrid algorithm is developed.

The paper proposes implementation of the fuzzy control module based on using a multilayer neural network and the Gaussian function. It also notes the main differences of the proposed structure of a neural network from "traditional" neural networks. The basic principles of the fuzzy control unit are formulated. The authors consider the features of software implementation of the proposed hybrid algorithm in detail. They also state the requirements to the architecture of the developed program taking into account the need to support the modularity and extensibility of the application. There are some examples of the description of a printed circuit board element based on existing specifications. The paper describes the interface structure and the main elements of the graphic interface of the developed application.

To assess the quality of the obtained solutions and the search for solutions in general, it was suggested to use parameters characterizing the dynamics of changes in the mean and the best values of the objective function, as well as the diversity of the population.

There is a brief description of the computational experiments that confirm the effectiveness of the proposed method. The paper shows dependencies of the probability of the performance of genetic operators on control parameter values.

Keywords: computational intelligence, hybrid system, bio-inspired algorithms, design, neural networks, hybrid methods, parallel computing. 
Acknowledgements. The work has been financially supported by the Russian Foundation for Basic Research, grant no. 17-37-50076.

\section{References}

1. Alpert Ch.J., Mehta D.P., Sapatnekar S.S. Handbook of Algorithms for Physical Design Automation. CRC Press, NY, USA, 2009.

2. Cohoon J.P., Karro J., Lienig J. Evolutionary algorithms for the physical design of VLSI circuits. Advances in Evolutionary Computing: Theory and Applications. A. Ghosh, S. Tsutsui (Eds.) Springer Verlag Publ., London, 2003, pp. 683-712.

3. Norenkov I.P. Fundamentals of Computer Aided Design. Moscow, Bauman MSTU Publ., 2010, 434 p.

4. Shervani N. Algorithms for VLSI Physical Design Automation. Kluwer Academy Publ., Dordrecht, 1995, $538 \mathrm{p}$.

5. Gladkov L.A., Kureychik V.M., Kureychik V.V., Sorokoletov P.V. Bioinspirated Methods in Optimization. Moscow, Fizmatlit Publ., 2009, 384 p.

6. Gladkov L.A., Kureychik V.V., Kureychik V.M. Genetic Algorithms. Moscow, Fizmatlit Publ., 2010, 368 p.

7. Gladkov L.A., Kureychik V.V., Kureychik V.M., Rodzin S.I. Fundamentals of the Theory of Evolutionary Computations. Monograph. Rostov-on-Don, SFedU Publ., 2010, 222 p.

8. Gladkov L.A. On some approaches to constructing hybrid intelligent systems for solving graph tasks. News of Artificial Intelligence. 2000, no. 3, pp. 71-90 (in Russ.).

9. Michael A., Takagi H. Dynamic control of genetic algorithms using fuzzy logic techniques. Proc. 5th Intern. Conf. on Genetic Algorithms. Morgan Kaufmann Publ., 1993, pp. 76-83.

10. Im S.-M., Lee J-J. Adaptive crossover, mutation and selection using fuzzy system for genetic algorithms. Artificial Life and Robotics. 2008, vol. 13, no. 1, pp. 129-133.

11. Herrera F., Lozano M. Fuzzy Adaptive Genetic Algorithms: design, taxonomy, and future directions. Soft Computing. 2003, vol. 7, pp. 545-562.

12. Herrera F., Lozano M. Adaptation of genetic algorithm parameters based on fuzzy logic controllers. Genetic Algorithms and Soft Computing. F. Herrera, J.L. Verdegay (Eds.). Physica-Verlag, Heidelberg Publ., 1996, pp. 95-124.

13. Yarushkina N.G. Fundamentals of the Theory of Fuzzy and Hybrid Systems. Moscow, Finansy i statistika Publ., 2004, $320 \mathrm{p}$.

14. Batyrshin I.Z., Nedosekin A.O., Stetsko A.A., Tarassov V.B. Fuzzy Hybrid Systems. Theory and Practice. N.G. Yarushkina (Ed.). Moscow, Fizmatlit Publ., 2007, 208 p.

15. King R.T.F.A., Radha B., Rughooputh H.C.S. A fuzzy logic controlled genetic algorithm for optimal electrical distribution network reconfiguration. Proc. 2004 IEEE Intern. Conf. on Networking, Sensing and Control. Taipei, Taiwan. 2004, pp. 577-582.

16. Rodriguez M.A., Escalante D.M., Peregrin A. Efficient distributed genetic algorithm for rule extraction. Applied Soft Computing. 2011, vol. 11, pp. 733-743.

17. Alba E., Tomassini M. Parallelism and evolutionary algorithms. IEEE T. Evolut. Comput. 2002, vol. 6. pp. $443-461$.

18. Zhongyang X., Zhang Y., Zhang L., Niu S. A parallel classification algorithm based on hybrid genetic algorithm. Proc. 6th World Congr. on Intelligent Control and Automation. Dalian, China. 2006, pp. 3237-3240.

19. Knysh D.S., Kureychik V.M. Parallel genetic algorithms: a survey and problem state of the art. J. of Computer and Systems Sciences Intern. 2010, vol. 49, iss. 4, pp. 579-589 (in Russ.).

20. Gladkov L.A. Integrated algorithm for solving allocation and tracing problems based on fuzzy genetic methods. Izvestiya SFedU. Engineering Sciences. Taganrog, 2011, no. 7, pp. 22-30 (in Russ.).

21. Gladkov L.A. Hybrid genetic algorithm for solving the problem of VLSI elements placement taking into account the traceability of connections. Vestnik RGUPS. Rostov-on-Don, 2011, no. 3, 2011, pp. 58-66 (in Russ.).

22. Tarasov V.B. From Multi-Agent Systems to Intellectual Organizations: Philosophy, Psychology, Informatics. Moscow, Editorial URSS Publ., 2002.

23. Gladkov L.A. Solving the problems of search and optimization of solutions based on fuzzy genetic algorithms and multi-agent approaches. Proc. of TRTU. Thematic Issue: Intelligent CAD. Taganrog, 2006, no. 8, pp. 83-88 (in Russ.).

24. Pegat A. Fuzzy Modeling and Control. Moscow, BINOM. Laboratoriya znany Publ., 2009.

25. Gladkov L.A., Gladkova N.V., Leiba S.N. Manufacturing scheduling problem based on fuzzy genetic algorithm. Proc. IEEE East-West Design \& Test Symp. (EWDTS'2014). Kiev, Ukraine, 2014, pp. 209-213.

26. Gladkov L.A., Gladkova N.V., Legebokov A.A. Organization of knowledge management based on hybrid intelligent methods. Software engineering in intelligent systems. Proc. 4th Computer Science On-line Conf. 2015 (CSOC 2015). Vol. 3: Software Engineering in Intelligent Systems. Springer Intern. Publ., Switzerland, 2015, pp. 107-113.

27. Gladkov L.A. Gladkova N.V., Leyba S.N. Placement of elements of EVA schemes based on hybrid intellectual methods. Izvestiya SFedU. Engineering Sciences. Thematic Issue: Intelligent CAD. Taganrog, 2015, no. 4, pp. 25-36 (in Russ.).

28. Gamma E., Helm R., Johnson R., Vlissides J. Design Patterns. Elements of Reusable Object-Oriented Software. Addison-Wesley Publ., 1994, 395 p. (Russ. ed.: St. Petersburg, Piter Publ., 2001).

29. McConnell S. Code Complete. Microsoft Press, 1993, 857 p. (Russ. ed.: St. Petersburg, Piter Publ., 2005).

30. Qt Documentation. Available at: http://doc.qt.io/qt-5/reference-overview.html (accessed February 20, 2018).

31. QCustomPlot. Available at: http://qcustomplot.com/index.php/introduction (accessed February 20, 2018). 
Система моделирования поведения групп робототехнических агентов с элементами соииальной организаиии Кворум

\author{
В.Э. Карпов 1,2, к.т.н., доиент, руководитель Отделения нейрокогнитивных наук \\ и интеллектуальных систем, karpov.ve@gmail.com \\ M.A. Ровбо 1, инженер-исследователь, rovbота@gmail.com \\ Е.Е. Овсянникова 1, инженер-исследователь, ееоvsуап@уапdeх.ru
}

1 Наииональный исследовательский иентр "Курчатовский институт" , г. Москва, 123182, Россия

2 Московский физико-технический институт (государственный университет), г. Долгопрудный, 141701, Россия

В работе описана архитектура среды многоагентного моделирования Кворум, разработанной для реализации конструктивных решений и алгоритмов индивидуального поведения агентов-роботов, а также для моделирования поведения больших групп роботов. Основной задачей системы является инструментальное обеспечение исследований в области применения методов социальной организации в групповой робототехнике.

Кворум - это прототип системы имитационного и агентного моделирования, которая должна адекватно абстрагировать сложность физической системы, обеспечивая удобные интерфейсы и библиотечные модули для моделирования групп мобильных роботов и отдельных внутренних структур агента. Она была построена как модульная, легко расширяемая система, ориентированная на моделирование систем с большим количеством агентов за счет упрощения физических и других эффектов, а также благодаря способности выполнять моделирование с использованием параллельных вычислений.

Показано, что предлагаемый метод моделирования подобных систем применим к широкому спектру задач из области групповой робототехники с элементами социальной структуры (а также роевой и групповой робототехники в целом). Некоторые особенности архитектуры и модели, используемые в Кворум, позволяют расширить ее в последующих итерациях для полной поддержки моделирования на параллельных вычислительных системах.

Одной из важных особенностей Кворум является ориентация на управление реальными робототехническими системами. Для этого система обеспечивает использование одинаковых интерфейсов управления как для вычислительной модели, так и для реальных роботов.

Система была апробирована на ряде характерных для групповой робототехники задач, особенно тех, которые используют механизмы социальной структуры, а также на группе лабораторных роботов разных типов, поддерживающих интерфейс системы моделирования Кворум.

Ключевые слова: агентное моделирование, моделирование социального поведения, групповая робототехника, имитационное моделирование, инструменты разработки, кластерные вычисления, биоподобные системы, эусоичиальность, робот, искусственная жизнь.

Важной задачей групповой робототехники является построение такой системы, которая давала бы новые качества и улучшенные характеристики за счет взаимодействия многих отдельных агентов, обладающих относительно простыми правилами. Основным методом исследования этих систем является агентное моделирование, для которого исследователи используют различные среды и библиотеки.

Одним из направлений исследований в области групповой робототехники является изучение биологических систем с целью применения принципов их организации для построения команды роботов, поскольку они демонстрируют множество желательных качеств, таких как устойчивость к внешним возмущениям, умение работать в неизвестных условиях и эффективность. Новым и перспективным направлением в этой области является подход, основанный на применении в групповой робототехнике моделей и методов социального поведения [1]. Далее искусственные группы, в которых применяются эти механизмы, будем называть группами с элементами социальной структуры. Со- ставляющими этих групп являются агенты. Под ними будут пониматься реальные или виртуальные объекты, вычислительные системы, которые существуют в некоторой сложной динамичной среде, могут воспринимать окружающую среду через датчики и автономно действовать на нее с помощью эффекторов на основе полученной информации [2], тем самым достигая комплекса целей или задач, для которых они были разработаны [3].

Для полноценного всестороннего изучения искусственных коллективов, строящихся по подобным принципам, важно наличие такой системы имитационного моделирования, которая предоставляет средства реализации основных элементов коллектива с социальной структурой, обеспечивает масштабируемость системы, возможность удобного ее расширения, поддержку сбора данных для последующего анализа. В обзоре [4] была показана необходимость и сформулированы требования к специализированной системе моделирования, пригодной для решения задач коллективной робототехники, ориентированных на создание социальных структур. Коротко остановимся на некоторых 
характерных системах моделирования, а также их особенностях в связи с рассматриваемой проблемой.

Gazebo - это программа и набор библиотек, позволяющих моделировать поведение роботов с учетом разнообразных физических эффектов [5]. Когда предоставляемых системой моделируемых законов оказывается недостаточно, ее возможности могут быть расширены с помощью доступных плагинов или путем написания новых плагинов: добавление инфракрасных дальномеров, видеокамеры или физических эффектов движения через жидкость. Однако Gazebo плохо подходит для моделирования систем с большим количеством агентов из-за довольно высокой вычислительной стоимости.

AnyLogic [6] и Repast [7] являются мощными инструментами для моделирования, однако относятся к категории универсальных средств (AnyLogic больше подходит для моделирования макросистем, в то время как Repast - для моделирования многоагентных систем, состоящих из элементов с двигательной активностью), что делает их плохо приспособленными для исследования роботизированных систем с элементами социальной структуры, так как не предоставляют никаких специальных библиотек для моделирования систем в этой области.

В отличие от систем, поддерживающих детальное моделирование физических процессов, или универсальных систем агентного и имитационного моделирования существуют библиотеки моделирования, предоставляющие набор средств, более подходящих для построения социальных систем. Примерами являются NetLogo [8], Myrmedrome [9] и AntMe! [10]. NetLogo, несмотря на мощь самого языка, обладает весьма ограниченной функциональностью для моделирования роботизированных систем с элементами социальной структуры, а две другие программы не являются библиотеками моделирования, а, скорее, иллюстрируют и имитируют некоторые элементы поведения муравьев. Таким образом, возникла необходимость в создании специализированной системы моделирования. Прототип такой системы, получившей название Кворум, представлен в данной работе.

В статье описываются архитектура и некоторые экспериментальные результаты, демонстрирующие возможности моделирования различных задач, с которыми сталкиваются исследователи в этой области. Несмотря на то, что этот прототип сам по себе не предназначен для моделирования больших систем с использованием распределенных вычислений, его архитектура и особенности дают возможность протестировать некоторые концепции на базовом уровне, что позволяет в дальнейшем построить на нем специализированную имитационную систему, использующую параллельные вычисления.

\section{Модели социального поведения}

Согласно подходу к построению искусственных коллективов с элементами социальной структуры, агенты должны реализовывать ряд механизмов, необходимых для формирования и эффективного функционирования социума, например, стремление держаться группой, контагиозное и агонистическое поведение, образование коалиций [1].

Согласно работе [4], специализированная система моделирования также должна в той или иной мере поддерживать создание моделей внутреннего и внешнего мира, понятие пространства, времени, среды, в которой взаимодействуют агенты, предоставлять возможность модульной реализации отдельных аспектов агента, стигмергию как передачу информации через изменение внешней среды (например, с помощью феромонов), уметь поддерживать модель из нескольких взаимодействующих коллективов в силу распространенности задач деления и слияния групп роботов [11]. Использование стандартных поведенческих модулей позволяет сосредоточиться на содержательной части изучаемой проблемы.

Таким образом, для реализации и исследования искусственных коллективов агентов на основе элементов социальных сообществ необходима система моделирования со следующими особенностями [4]:

- масштабируемость, возможность использования параллельных вычислительных систем;

- поддержка определенных особенностей агентных систем в целом и их реализация в виде библиотек: понятие агента, взаимодействие агентов, окружающая среда, законы взаимодействия с окружающей средой, пространством, временем;

- основные структуры и механизмы социального поведения: индивидуальные психические различия, дифференциация функций, локальное взаимодействие индивидов и языковая коммуникация, формирование коалиций и иерархической структуры;

- поддержка создания моделей внутреннего и внешнего мира агента;

- поддержка моделей с несколькими взаимодействующими (но отличными) группами агентов.

Разработанная система Кворум реализует ряд вышеперечисленных свойств системы моделирования в дополнение к масштабируемости для распределенной вычислительной системы. Поскольку Кворум является экспериментальным прототипом, то библиотеки элементов высокого уровня, например, для механизмов формирования коалиции, разработчик модели должен реализовывать самостоятельно, исходя из ограничений конкретной задачи, вместо использования готового модуля, однако расширяемость системы позволяет дополнить ее необходимой функциональностью в дальнейшем и 
предоставить такие базовые механизмы в составе ПО системы моделирования.

\section{Архитектура системы моделирования Кворум}

Система Кворум предназначена для моделирования поведения больших групп физических (робототехнических) агентов. Пользователь может выбрать несколько типов агентов и любое количество агентов в каждом типе. Каждый агент снабжен виртуальными датчиками, которые имитируют реальные датчики на роботах, такие как локаторы, суперлокаторы, датчики положения и т.д.

Кворум представляет собой программный инструмент, который имитирует роботов и их окружение. Данная система предназначена, в первую очередь, для мобильных роботов. Одной из ее особенностей является наличие интерфейсов, позволяющих управлять как виртуальными агентами, так и реальными техническими устройствами. Виртуальный агент - это агент без физического тела, например, используемый в компьютерном моделировании роботизированного агента. Конфигурация архитектуры для конкретной системы управления осуществляется в соответствующих пользовательских программных модулях. Например, конфигурация для архитектуры TMU определяется в модуле tmurobot.py (архитектура TMU реализует многопроцессорную расширяемую систему управления малых мобильных роботов).

В отличие от систем моделирования, позволяющих реализовывать различные физические эффекты, Кворум использует упрощенную физическую модель для экономии вычислительных ресурсов и ускорения разработки моделей агентов и среды. В частности, исходя из особенностей предметной области, 2D-модель мира была выбрана в качестве основы, в которой движение агентов и многие взаимодействия геометризированы. Например, работа ультразвуковых и инфракрасных радиолокаторов моделируется путем расчета лучей и оценки зоны видимости датчика. Такой подход позволяет моделировать большие группы агентов, сохраняя важные для области элементы и абстрагируя их физические детали.

Система моделирования работает под управлением OC Linux и использует платформу ROS [12], которая передает данные между системными модулями. Модули, скрипты, подсистемы приложений могут быть написаны на любом поддерживаемом ROS языке. Основным требованием является реализация интерфейсов через систему сообщений так называемые топики.

Система основана на двух модулях - KVO$R U M \_m$ и KVORUM_v, которые составляют еe ядро, а также на программах прикладного уровня. Модули ядра написаны на языке Python. Поскольку одной из основных задач ядра системы является моделирование поведения группы реальных технических объектов, интерфейс модулей ядра определяется таким образом, чтобы максимально абстрагировать управляющую программу от объекта управления.

Абстракция управляющей программы от объекта управления (виртуального или реального робота, или группы роботов) осуществляется посредством взаимодействия компонентов ядра и пользовательского приложения, а именно путем обмена сообщениями (рис. 1).

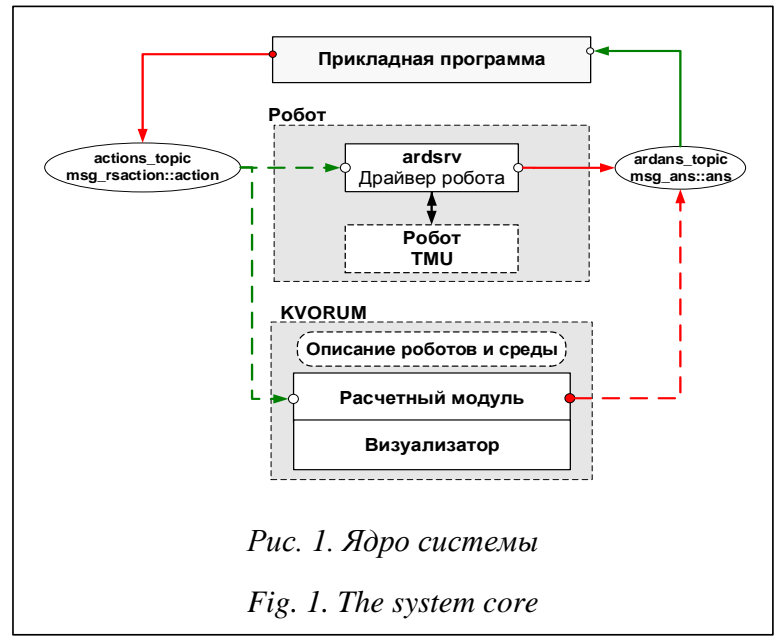

Симуляция Кворум состоит из ядра (расчетный модуль, визуализатор, описание робота и окружающей среды), модели роботов и прикладных программ. Ядро системы взаимодействует с имитационной моделью робота и программы через топики ввод (action_topic) и вывод (ardans_topic). Модель робота состоит из узла управления и логической модели робота TMU (один из используемых в лаборатории типов робота, определяющий протокол связи с ним). Прикладные программы создаются пользователем в зависимости от имеющейся задачи.

На рисунке 2 представлен пример организации модулей системы моделирования Кворум для трех разных управляющих алгоритмов. Программа Demo считывает конфигурационную информацию из файлов описания карты, среды и агентов и реализует логику агента в единственном модуле demo.py. На примере алгоритма SwHunt показано, как алгоритм управления группой агентов может пользоваться сторонним описанием агентов, в том числе включающих специфичные для робота элементы. tmusrv и temper вместе позволяют построить более сложную логику агента с модулями, peaлизующими механизм эмоций. Аналогично идее, использованной в системе ARGoS [13], все эти модули управления пользуются одним и тем же интерфейсом ardans_topic и actions_topic, связывающим их с ядром системы моделирования (kvorum_m, kvorum_v) или же с драйвером реальных роботов Ardsrv. 


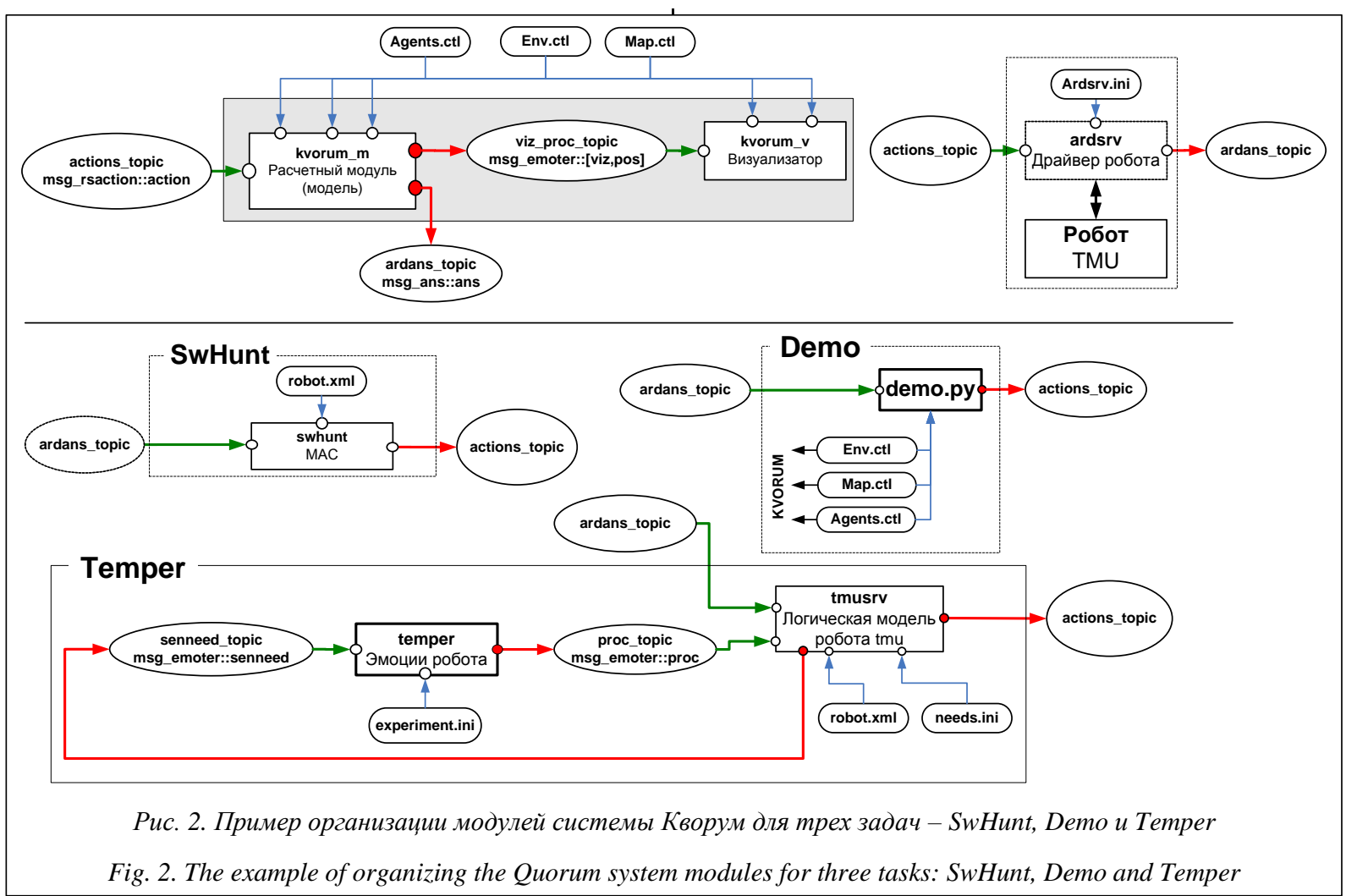

Такая архитектура имеет важное свойство переносимости кода элементов модели между симулятором и реальными роботами. В частности, роботы серий YARP-2 и YARP-3 (рис. 3),

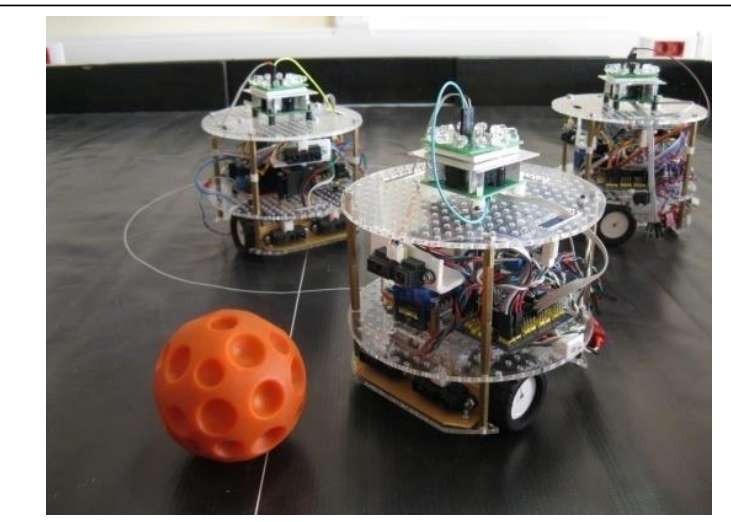

a)

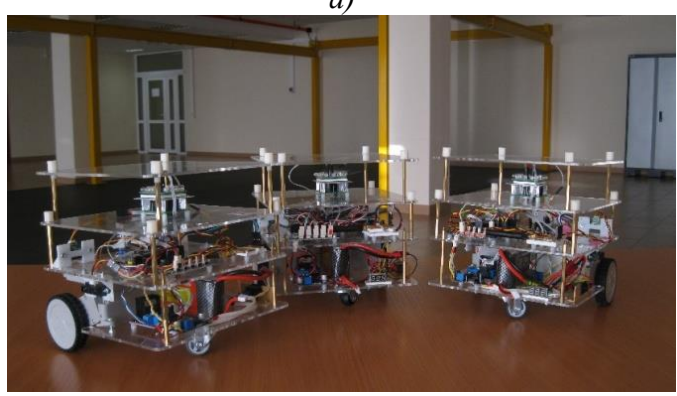

б)

Puc. 3. Роботы серии YARP-1 (a) и YARP-2 (б)

Fig. 3. Robots of YARP-1 (a) and YARP-2 (б) series разработанные в лаборатории робототехники НИЦ «Курчатовский институт», имеют архитектуру TMU и поэтому работают по аналогичной схеме управления.

Система Кворум основана на двухмерном представлении пространства. Это удобное упрощение, так как многие задачи групповой робототехники рассматриваются в контексте наземных мобильных роботов. Разделение этого пространства на отдельные элементы, например ячейки, позволяет дополнительно сократить количество необходимых вычислений, запрашивая и обрабатывая только те объекты, которые находятся в соответствующих ячейках. Подобное разбиение позволяет сократить объем информации, передаваемой между узлами системы распределенных вычислений, например, похожая схема используется в Repast HPC [14]. Использование только непрерывных координат привело бы к необходимости поиска среди большого количества объектов для сравнения их координат с данными ограничениями. В то же время, несмотря на деление на ячейки, непрерывные координаты остаются параметрами объектов и позволяют не ухудшать точность при моделировании смещения и оценке расстояний между объектами.

При работе с дискретной сеткой работа датчиков, таких как дальномеры, моделируется особым образом. Рассмотрим ультразвуковой дальномер. Для получения измерения от робота строится луч в том направлении, в котором осуществляет поиск дальномер. Ограничим длину луча некоторым максимальным значением. Клетки, которые он пере- 
сек, отмечены с использованием алгоритма Брезенхэма. Выбираем все объекты, расположенные в этих ячейках, из памяти системы. Если они удовлетворяют условиям, проверяемым датчиком (в данном случае они должны отражать ультразвуковой сигнал), то возвращается наименьшее расстояние из вычисленных. Стоит отметить, что вместо луча можно построить конус и выделить все клетки, пересекаемые им. Таким образом, подобный подход дает некоторую гибкость в описании работы датчиков.

Среда, в которой живут агенты, представляет собой множество слоев, каждый из которых отвечает за представление определенного физического или логического знака. Это означает, что каждая точка пространства $(x, y)$ описывается определенным вектором. Система представляет среду обитания в виде многомерного массива с размерами $[x, y$, level $]$. Например, интерпретация слоев (значения уровня) в зависимости от задачи может выглядеть так:

0 (LEVEL_LIGHT) - освещенность;

1 (LEVEL_COLOR) - цвет поверхности;

2 (LEVEL_IR) - эфир (инфракрасный сигнал);

3 (LEVEL_GROUND) - уровень поверхности;

$4\left(L E V E L \_O N B O A R D\right)$ - бортовой датчик (виртуальный уровень) и т.п.

Имена слоев определяются в словаре системы.

Такая организация данных позволяет разделить различные характеристики между различными областями памяти и выделить независимость псевдофизических характеристик среды. В дополнение к более структурированному представлению о мире подобное разделение имеет определенные технические преимущества: разные датчики, как правило, работают с различными характеристиками мира, и поэтому в разных слоях измерения и действия могут выполняться параллельно в отдельных потоках. Это также в значительной степени унифицирует операции, позволяя аналогичным функциям обрабатывать различные характеристики.

На рисунке 4 показано представление поля в виде слоев. Каждый датчик имеет свой слой, содержащий информацию о существующих агентах и объектах на нем. При создании датчиков можно изменять значения слоя. Оси координат представлены декартовой системой. Координаты точки всегда положительные, углы лежат в первом квартале

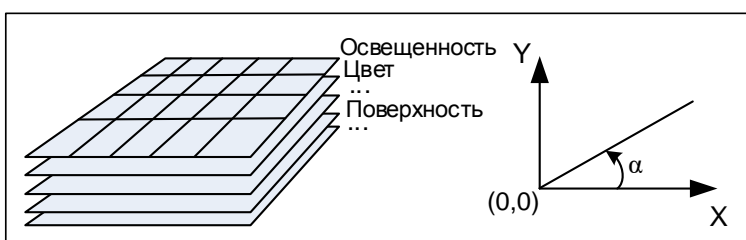

Рис. 4. Представление поля модели в виде слоев

Fig. 4. Representation of a model field as layers и отсчитываются против часовой стрелки от горизонтали (оси X).

Основными типами датчиков являются точечный детектор, дальномер, локатор и суперлокатор.

Дальномер возвращает расстояние до объекта, найденного на слое LEVEL_GROUND.

Локатор - датчик, способный регистрировать окружающие объекты в определенном секторе, возвращая результаты как вектор значений. В зависимости от типа локатора вектор возвращаемых значений может содержать или расстояние до обнаруженных объектов на данном слое, или значения обнаруженных объектов.

Суперлокатор - локатор, возвращаемые значения которого представляют собой вектор из пар вида (значение сигнала, расстояние). Это позволяет определять не только расстояния до объектов, но и сами объекты. Как и для локатора, необходимо определить соответствие угла и индекса в массиве показаний.

Модуль расчета отвечает за пошаговое моделирование состояния системы и обеспечивает интерфейс между агентами и запросами пользователей: получение данных от датчика агента, настройку скорости движения агента вперед и назад, удаление, инициализацию агентов, рендеринг и инициализацию системы моделирования. Модуль визуализации представляет карту и агентов на экране.

Чтобы перенести систему управления на реальных роботов, необходимо выполнить дополнительную настройку и использовать специфичный для робота узел, обеспечивающий необходимый интерфейс. Такой узел называется Ardsrv. Он переводит унифицированные команды, передаваемые через actions_topic, в сигналы, воспринимаемые роботом. В случае YARP-2 и YARP-3 эти команды переводятся в соответствующий формат и передаются по беспроводной связи бортовым компьютерам, выполняющим их. Ответ, поступающий от роботов на узел Ardsrv, переводится обратно в унифицированный формат и передается в систему управления чеpeз ardans_topic. Таким образом, модули системы моделирования заменяются модулем драйвера робота, а топики коммуникации остаются неизменными вместе с остальной частью системы.

\section{Описание конфигурации}

Для работы пользовательских приложений и модулей ядра необходимо иметь описание виртуальной среды, поля и агентов. Эти описания представлены в виде файлов - программ, написанных на языке Python.

Описание среды (Env.ctl) вынесено в отдельный файл в силу специфики инициализации управляющих структур системы. Будучи центральной глобальной структурой как для пользовательской программы, так и для компонент ядра, конструктор 
класса «Среда» TEnv требует отдельной предварительной инициализации.

Файл, описывающий среду, в которой находится робот, представляет собой фрагмент программы на языке Python, интерпретируемой при инициализации экземпляра класса TEnv («Сpeда») - глобальной переменной Env.

В файле конфигурации определяются размер рабочего окна визуализации $\left(M A X \_S C R \_X\right.$ и $\left.M A X \_S C R \_Y\right)$, размер виртуального поля (DIM_X и $\left.D I M \_Y\right)$, топология поля (признак топологии тора UseTorusRegime).

Если значение параметра UseTorusRegime равно True, это означает «склейку» сторон поля, то есть образование поверхности типа тор. В противном случае среда будет представлять собой прямоугольную область заданного размера, ограниченную по периметру препятствиями. Скрипт выполняется во время инициализации экземпляра класса и является фрагментом конструктора.

Описание карты, на которой будут находиться роботы, представляет собой программу (скрипт). В этом скрипте осуществляется работа с глобальной переменной Env, обозначающей среду, в которой обитают агенты.

Она состоит из множества слоев, каждый из которых отвечает за представление того или иного физического или логического признака: каждая точка пространства $(x, y)$ описывается некоторым вектором.

Система представляет среду обитания в виде трехмерного массива с измерениями $[x, y$, level $]$. Слои (LEVEL_LIGHT, LEVEL_COLOR и т.д.) были описаны выше.

Создание агента. Файл Agents.ctl содержит описание агентов. Процесс создания агентов включает в себя следующие шаги: создание экземпляра агента, определение параметров агента, регистрация агента в системе.

Необходимо создать экземпляр класса TAgent (описан в pylib/agents.py). Для этого вызывается соответствующий конструктор TAgent(cid, cpos, cshape, cenv, csize).

Здесь cid - идентификатор агента (число); $\operatorname{cpos}$ - начальные координаты агента $([x, y, a])$, где $a$ - угол ориентации робота относительно оси абсцисс $X$; cshape - имя формы (turtle, elefant, ...); $c e n v$ - указатель на среду (экземпляр класса TEnv), в которой работает агент (обычно это глобальная переменная Env); csize - размер фигуры (масштабный коэффициент относительно исходного размера изображения агента).

При этом углы в системе задаются в градусах. Нормализация значений происходит автоматически, поэтому пользователю нет необходимости приводить эти значения к тому или иному диапазону.

Система поддерживает несколько видов датчиков, различаемых по характеру возвращаемых зна- чений (вектор или скаляр), а также типу сигнала и принципу действия.

Датчики представлены классом TSensor модуля pylib/agent.py.

Тип датчика:

- gdic.ST_USONIC - аналог ультразвукового дальномера, возвращает величину, пропорциональную расстоянию до объекта;

- gdic.ST_SHARP - аналог инфракрасного дальномера, возвращающего величину, равную разности между радиусом действия датчика и расстоянием до объекта;

- gdic.ST_DETECTOR - детектор; возвращает значение поля соответствующего слоя;

- gdic.ST_CONST - фиктивный датчик; возвращает постоянное значение, применяется для эмуляции считывания внутренних параметров робота (например, напряжения питания).

Тип возвращаемого значения:

- gdic.RST_SCALAR - скалярная величина;

- gdic.RST_VECTOR - вектор значений;

- gdic.RST_SUPER_VECTOR - вектор пар значений вида [расстояние, значение_сигнала].

На рисунке 5 представлена окружность, на которой изображено деление обзора суперлокатора на сектора. Для определения местоположения объекта в секторе берутся граничные значения сектора и далее осуществляется проход по этому сектору (по элементам массива) для нахождения детектированных локатором значений.

Детектирование множественных сигналов. Предположим, что агенту необходимо зарегистрировать и проанализировать множество источников сигналов. Например, принять и обработать сигналы от окружающих его роботов, то есть определить, какие источники находятся вокруг, их местоположение, тип генерируемого сигнала.

Очевидно, что для этого нецелесообразно использовать обычные датчики, которые регистрируют значение первого попавшегося сигнала.

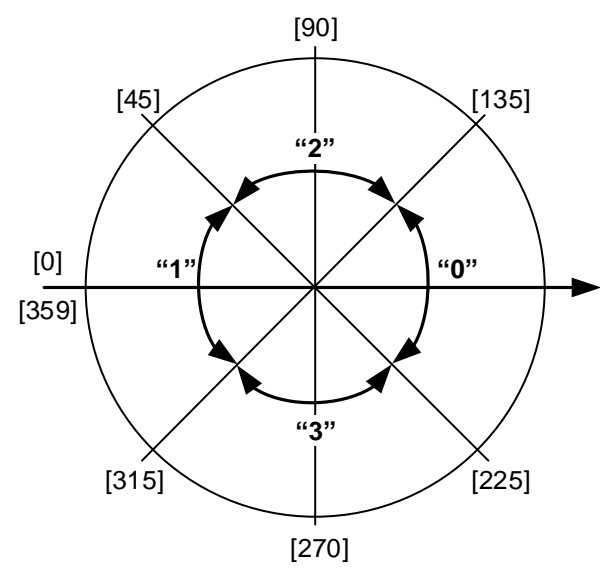

Рис. 5. Угль суперлокатора

Fig. 5. The superlocation corners 
Для таких задач удобнее использовать локатор. При этом тип локатора - детектор (gdic.ST_DETECTOR). В этом случае система определит значение сигнала и его азимут (по индексу в векторе). Если же, помимо значения сигнала и азимута, нас интересует и расстояние до источника, то вместо локатора предпочтительнее использовать суперлокатор. Вектор возвращаемых суперлокатором значений, как уже говорилось выше, представляет собой пары вида (значение_сигнала, расстояние). Итак, когда нужно различать агентов, рекомендуется использовать суперлокатор, который зарегистрирует вокруг агента все что возможно.

\section{Эксперименты и тестовые задачи}

Опишем использование системы Кворум с группировкой реальных роботов и приведем примеры моделирования некоторых характерных задач.

Управление группой роботов. Интерфейс системы моделирования, позволяющий использование кода системы управления как в симуляции, так и на реальных роботах, был апробирован на группе из нескольких роботов YARP. Для передачи сигналов с управляющего устройства группе роботов использовалось устройство радиосвязи. В силу определенных особенностей канала связи пропускная способность была весьма ограниченной и количество пакетов, отправляемых роботам, необходимо было регулировать, а также равномерно распределять ресурсы между ними. Для этого был создан диспетчер сообщений, принимающий сообщения, предназначенные общему командному каналу, от всех роботов и организующий их в очередь, при этом управляя скоростью и очередностью пересылки сообщений для распределения пропускной способности в равных долях между всеми участниками (рис. 6).

Новые сообщения, получаемые по callback, помещаются в очередь ожидания, по одной очереди на каждого робота. Тип таких очередей FIFO (firstin-first-out), они фиксированного размера. Старые сообщения выбрасываются из очереди, когда она переполняется. Для обработки сообщений, находящихся в очередях ожидания, в программе по таймеру вызывается обработчик, каждый вызов которого обрабатывает и посылает не более одного сообщения из очередей. Частота вызова этого обработчика обратна пропускной способности канала, что гарантирует соответствие пропускной способности выходного канала.

Функция обработки и отправки сообщения по мере вызовов последовательно проходит по всем очередям, посылая из них по одному сообщению: $R_{1}-R_{2}-\ldots-R_{N}-R_{l}$. Здесь $R_{i}-$ сообщение $i$-го робота. При появлении сообщений от нового робота динамически создается другая очередь, и порядок отсылки сообщений может временно нарушиться.

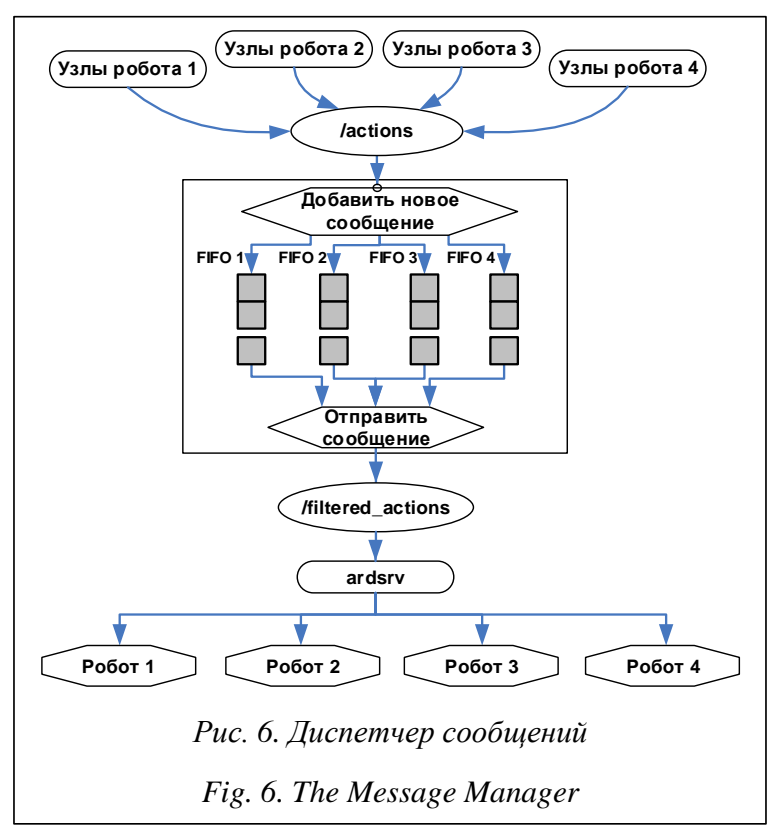

Если в просматриваемой очереди не осталось сообщений, то она пропускается и проверяется следующая очередь. Система предназначена для работы на основе топиков ROS [12] (/actions, /filtered_actions).

Эксперименты показали работоспособность предложенной архитектуры системы: реальные роботы управлялись той же программой, что и их виртуальные модели в симуляции без модификаций управляющего кода.

Коммуникация. Один из важных элементов построения групповых роботизированных систем это языковое взаимодействие роботов [1]. Важным элементом являются символические структуры, на основе которых также можно строить системы управления, реализующие некоторые базовые механизмы систем с социальной структурой (например, подражательное или контагиозное поведение), что иллюстрируется работой [15]. Особенностью задачи является моделирование связи между агентами, в частности, с использованием элементов языковой коммуникации.

В Кворум связи между агентами определены явно следующим образом: агенты снабжены как источниками сигналов, так и соответствующими приемниками. Связь осуществляется путем интерпретации генерируемых сигналов. Коммуникационные возможности применялись в работе [16], где группа агентов использовала их для координации усилий в задаче стайной охоты (см. http:/www. swsys.ru/uploaded/image/2018-3/2018-3-dop/18.jpg).

В рассмотренной задаче выбирается лидер группы, а затем группа разделяется на роли, определяющие, с какой стороны агенты-охотники будут атаковать жертву.

Следование пути по визуальным ориентирам. В работе [17] предложен метод построения пути вдоль визуальных ориентиров мобильным роботом. Эта задача относится к категории моделирова- 
ния внутреннего представления внешнего мира в агенте.

Описание маршрута в указанной работе основано на пространственных связях, а результаты подтверждены проведением имитационных экспериментов с использованием системы моделирования Кворум. Робот-разведчик использует алгоритм случайного блуждания, чтобы найти объект заданного цвета на полигоне $n \times m$ ячеек, по пути формируя описание маршрута. После достижения цели описание переносится на второго робота, который повторяет маршрут, следуя полученным ориентирам (рис. 7).

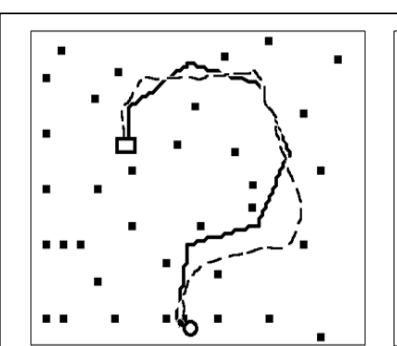

a)

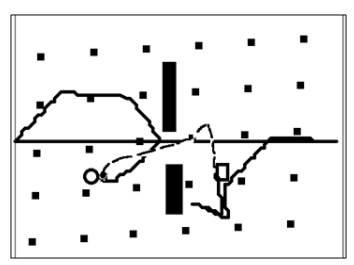

B)

Обозначения:

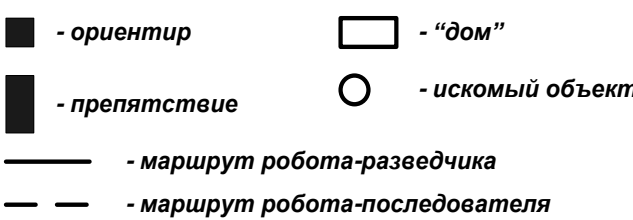

Рис. 7. Следование робота вдоль маршрута, обнаруженного другим роботом

Fig. 7. The robot going along the route detected by another robot

Поддержание энергетической автономности группы роботов. Одной из проблем коллективной робототехники является энергетическая независимость команды. В то же время можно рассматривать как задачу выполнения целевой функции одновременно с поддержанием необходимого энергетического уровня агентов, так и задачу сбора энергии из различных источников. Пример постановки задачи приведен в работе [18], где сформулирована многокритериальная оценка целей робота. Особенностью задачи с точки зрения системы моделирования является динамическая природа взаимодействий агентов и мира: сбор различных ресурсов, изменение параметров робота (энергетического уровня), генерация энергии в центральном гнезде. В этой модели агенты взаимодействуют через стигмергию в виде направленных феромонов [19]. Индивидуальное параметрическое регулирование поведения используется, чтобы управлять деятельностью группы. Оно реализуется путем назначения двух ролей и переключения между ними. Каждая роль соответствует различным характеристикам, в частности, способности переносить различное количество пищи и времени, по истечении которого агент возвращается в гнездо, если пища не была собрана. Механизм, используемый в этой работе, является по существу стохастическим автоматом с двумя состояниями $\varphi_{1}$ и $\varphi_{2} \mathrm{c}$ соответствующими стратегиями переключения ролей, которые определяются с помощью специальных матриц для возвращения с пищей, и для возврата без еды, где используются параметры вероятности переключения роли разведчика на роль собирателя и наоборот.

В работе [18] рассматривается проблема поддержания достаточного уровня энергии для функционирования группы с необходимостью использования нескольких ресурсов и централизованного генератора энергии. На тестовой карте размещено несколько объектов: источники ресурсов и базовая станция. Базовая станция определяет потребности в ресурсах и сообщает о них агентам, которые находятся поблизости. Агенты активируются и начинают искать ресурсы, извлекать их и доставлять до базы. Агент может собирать только один ресурс за один цикл работы. Каждый агент имеет ограниченный запас энергии, который он использует во время поиска. Если запас иссякает до того, как агент достигнет базы, он умирает (деактивируется). База играет роль зарядной станции коллектива, вырабатывающей энергию из ресурсов, добытых агентами (рис. 8). Используется модель принятия решения на основе оптимизации по Парето. Агенты оценивают обнаруженные источники пищи по следующим факторам: сколько времени проводился поиск; насколько острой была потребность в этом типе ресурса в гнезде; каким был его целевой pecypc.

Влияние факторов определяется коэффициентами в формуле. В общем виде целевая функция строится следующим образом: $f_{e}=c_{t} f_{t}(t)+$ $+c_{n} f_{n}(n, s)+c_{g} f_{g}(s, g)$, где $c_{t}, c_{n}$ и $c_{g}$ являются коэффициентами влияния соответствующих факторов, при этом $c_{t}+c_{n}+c_{g}=1$.

На рисунке 8 представлены 4 различных типа ресурсов, обозначенных цветными квадратами. Квадрат в центре, выделяющийся среди других по цвету, является базой, где агенты хранят собранные ресурсы. Маленькие черепахи обозначают роботов.

Модель системы была протестирована с помощью Кворум. Вычислительный эксперимент позволил оценить динамику количества роботов в команде по различным параметрам системы управления (по «характерам» агентов). 


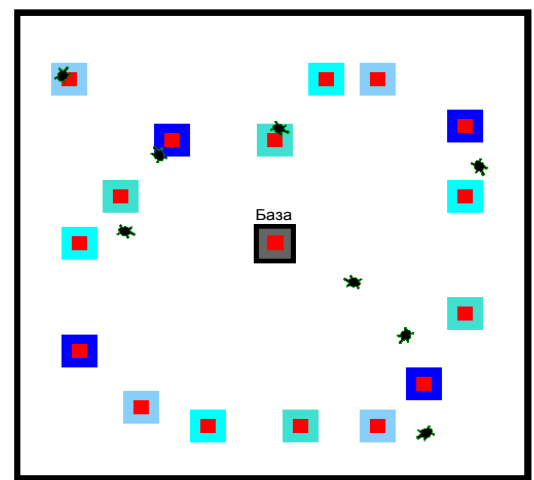

Рис. 8. Гомогенная группа агентов, собирающая различные ресурсы для базы

Fig. 8. A homogeneous group of agents that collects various resources for a database

\section{Заключение}

Разработан и апробирован прототип системы моделирования Кворум на некоторых репрезентативных задачах групповой робототехники, подтвердивший жизнеспособность предложенных концепций и моделей, которые станут основой специализированной системы моделирования коллективной робототехники с использованием параллельных вычислений. Еще одним важным свойством предлагаемой и реализованной архитектуры является переносимость кода элементов модели между симулятором и реальными роботами. Это позволяет развернуть тот же управляющий код, который был протестирован в моделировании, в реальных системах, откуда следует более четкая интерпретация результатов, полученных с помощью такой системы моделирования. Эта возможность была проверена на реальных роботах и прототипе симулятора.

Разработанный прототип удовлетворяет следующим функциональным требованиям:

- в архитектуру заложены масштабируемость, возможность моделирования с применением вычислительных кластеров;

- поддержка определенного функционала, свойственного агентным системам, и его предоставление в виде библиотек: агент, взаимодействие между агентами, среда, законы взаимодействия со средой, пространство, время;

- реализация некоторых базовых механизмов социального поведения и структур и поддержка дополнения и расширения соответствующих механизмов (индивидуальные психические различия, дифференциация функций и т.п.);

- поддержка модели из нескольких взаимодействующих коллективов.

Следующий шаг в развитии системы - полная поддержка параллельных вычислительных систем и тестирование на кластере компьютеров. Ожидается, что потенциальное увеличение скорости вы- числений позволит моделировать большие группы (десятки тысяч) локально взаимодействующих агентов в режиме реального времени, сохраняя при этом адекватное представление моделируемого мира.

Работа выполнена при частичной финансовой поддержке грантов РНФ № 16-11-00018, РФФИ № 16-29-04412 oфu_м.

\section{Литература}

1. Карпов В.Э. Модели социального поведения в групповой робототехнике // Управление большими системами. 2016. № 59. C. $165-232$.

2. Russell S.J. and Norvig P. Artificial intelligence: a modern approach, 3rd ed., Prentice Hall, 2010, 1152 p.

3. Maes P. Artificial life meets entertainment: lifelike autonomous agents. Commun. ACM, 1995, vol. 38, no. 11, pp. 108-114.

4. Ровбо М.А., Овсянникова Е.Е., Чумаченко А.А. Обзор средств имитационного моделирования коллективов роботов с элементами социальной организации // Программные продукты и системы. 2017. Т. 30. № 3. С. 425-434.

5. Koenig N. and Howard A. Design and use paradigms for gazebo, an open-source multi-robot simulator, Proc. 2004 IEEE/RSJ Int. Conf. Intell. Robot. Syst. (IEEE Cat. No. 04CH37566), 2004, vol. 3, pp. 2149-2154.

6. Borshchev A. The Big book of simulation modeling: multimethod modeling with AnyLogic 6. Amazon Digital Services LLC, 2015, $614 \mathrm{p}$.

7. Argonne National Laboratory: Repast Simphony, 2016. URL: http://repast.sourceforge.net/repast simphony.php\# (дата обращения: 10.01.2018)

8. Wilensky U. NetLogo ants model. Center for Connected Learning and Computer-Based Modeling, 1997. URL: http://ccl. northwestern.edu/netlogo/models/Ants (дата обращения: 10.01.2018).

9. Cacace S., Cristiani E. and D'Eustacchio D. Myrmedrome: simulating the life of an ant colony. In Imagine Math 2: between culture and mathematics, M. Emmer (Ed.), Springer Milan, 2013, pp. 201-210.

10. Wendel T. AntMe. 2014. URL: https://service.antme.net/ (дата обращения: 10.01.2018).

11. Воробьев В.В. Алгоритм кластеризации коллектива роботов // Беспилотные транспортные средства с элементами искусственного интеллекта (БТС-ИИ-2016): сб. тр. III Всерос. науч.-практич. семинара. М.: Перо, 2016. С. 50-59.

12. Koubaa A. Robot operating system (ROS), Springer, Cham, 2017, vol. 707, no. 2,665 p.

13. Pinciroli C., Trianni V., O’Grady R., Pini G., Brutschy A., Brambilla M., Mathews N., Ferrante E., Di Caro G.A., Ducatelle F., Stirling T., Gutiérrez Á., Gambardella L.M., and Dorigo M. ARGoS: a modular, multi-engine simulator for heterogeneous swarm robotics. Proc. IEEE Int. Conf. Intell. Robot. Syst., 2011, pp. 5027-5034.

14. Collier N. and North M. Parallel agent-based simulation with Repast for High Performance Computing. Simulation, 2013, $22 \mathrm{p}$.

15. Карпов В.Э. Сенсорная модель подражательного поведения роботов // OSTIS-2016: матер. VI Междунар. науч.-технич. конф. Минск: Изд-во БГУИР, 2016. С. 471-476.

16. Karpov V. and Karpova I. Leader election algorithms for static swarms. Biol. Inspired Cogn. Archit., 2015, vol. 12, pp. 54-64.

17. Карпова И.П. К вопросу о представлении маршрута мобильного робота на основе визуальных ориентиров // Мехатроника. Автоматизация. Управление. 2017. Т. 18. № 2. С. 81-89.

18. Ровбо М.А., Малышев А.А. Комплекс для изучения энергетически автономных коллективов роботов // Открытое образование. 2017. № 2. С. 68-77.

19. Boissard E., Degond P., and Motsch S. Trail formation based on directed pheromone deposition, J. Math. Biol., 2013, 35 p., vol. 66, iss. 6, pp. 1267-1301. URL: https://link.springer.com/ article/10.1007\%2Fs00285-012-0529-6 (дата обращения: 10.01.2018). 


\section{Kvorum - the system for modeling the behavior of robotic agent groups with elements of social organization}

V.E. Karpov 1, 2, PhD., associate professor, Head of the Department of Neurocognitive Sciences and Intelligence Systems, karpov.ve@gmail.com

M.A. Rovbo ${ }^{1}$, Research-Engineer, rovboma@gmail.com

E.E.Ovsyannikova ${ }^{1}$, Research-Engineer, eeovsyan@yandex.ru

${ }^{1}$ National Research Center «Kurchatov Institute», Moscow, 123182, Russian Federation

${ }^{2}$ Moscow Institute of Physics and Technology (State University), Moscow Region, Dolgoprudny, 141701, Russian Federation

Abstract. The paper describes the Kvorum architecture, which is a multi-agent modeling environment designed to develop constructive solutions and algorithms of robot agents' individual behavior, as well as for modeling behavior of large groups of robots. The main objective of the system is to provide tools for research in applying social organization methods in group robotics.

Kvorum is a prototype simulation and agent modeling system that abstracts the complexity of a physical system and provides convenient interfaces and library modules for modeling groups of mobile robots and internal structures of individual agents. It was built as a modular, easily extensible system focused on modeling systems with a large number of agents by simplifying physical and other effects, and also by the ability to perform simulations using parallel computations.

It is shown that the proposed method for modeling such systems is applicable to a wide range of problems from the field of group robotics with social structure elements (as well as for common robotics and group robotics problems in general). Some features of architecture and models in Kvorum allow it to be expanded in subsequent iterations to fully support simulation on parallel computing systems.

One of the important Kvorum features is the focus on controlling real robotic systems. For this purpose the system provides the same control control interfaces of both computational models and real robots.

The system was tested on some specific problems of group robotics, in particular those that use social structure mechanisms, as well as on a group of laboratory robots of different types that support the simulation system interface.

Keywords: agent modeling, social behavior modeling, group robotics, simulation tools, development tools, cluster computing, bioinspired systems, eusociality, robot, artificial life.

Acknowledgements. This work has been partially supported by RNF grants no. 16-11-00018, RFBR no. 16-29-04412 ofi_m.

\section{References}

1. Karpov V.E. Models of social behavior in group robotics. Managing Big Systems. 2016, no. 59, pp. 165-232 (in Russ.).

2. Russell S.J., Norvig P. Artificial Intelligence: A Modern Approach. 3rd ed. Prentice Hall Publ., 2010, 1152 p.

3. Maes P. Artificial life meets entertainment: lifelike autonomous agents. Commun. ACM. 1995, vol. 38, no. 11, pp. 108-114.

4. Rovbo M.A., Ovsyannikova E.E., Chumachenko A.A. Review of simulation modeling tools for obot groups with social organization elements. Software \& Systems. 2017, no. 3, pp. 425-434 (in Russ.).

5. Koenig N., Howard A. Design and use paradigms for gazebo, an open-source multi-robot simulator. 2004 IEEE/RSJ Int. Conf. Intell. Robot. Syst. (IEEE Cat. no. 04CH37566). 2004, vol. 3, pp. 2149-2154.

6. Borshchev A. The Big Book of Simulation Modeling: Multimethod Modeling with AnyLogic 6. Amazon Digital Services LLC, 2015, $614 \mathrm{p}$

7. Repast Simphony. Argonne National Laboratory. 2016. Available at: http://repast.sourceforge.net/repast_simphony.php\# (accessed January 10, 2018).

8. Wilensky U. NetLogo Ants Model. Center for Connected Learning and Computer-Based Modeling, Northwestern Univ., 1997. Available at: http://ccl.northwestern.edu/netlogo/models/Ants (accessed January 10, 2018).

9. Cacace S., Cristiani E., D'Eustacchio D. Myrmedrome: Simulating the life of an ant colony. Imagine Math 2: Between Culture and Mathematics. M. Emmer (Ed.). Milano, Springer Milan Publ., 2013, pp. 201-210.

10. Wendel T. AntMe. 2014. Available at: https://service.antme.net/ (accessed January 10, 2018).

11. Vorobev V.V. Algorithm for robot team clustering. Proc. 3rd All-Russ. Sci.-Pract. Workshop "Unmanned Vehicles with the Elements of Artificial Intelligence" (BTS-II-2016). Moscow, Pero Publ., 2016, pp. 50-59 (in Russ.).

12. Koubaa A. Robot Operating System (ROS). Springer Publ., Cham, 2017, vol. 707, no. 2, 655 p.

13. Pinciroli C., Trianni V., O'Grady R., Pini G., Brutschy A., Brambilla M., Mathews N., Ferrante E., Di Caro G.A., Ducatelle F., Stirling T., Gutiérrez Á., Gambardella L.M., Dorigo M. ARGoS: A modular, multi-engine simulator for heterogeneous swarm robotics. IEEE Int. Conf. Intell. Robot. Syst. 2011, pp. 5027-5034.

14. Collier N., North M. Parallel agent-based simulation with repast for high performance computing. Simulation. 2013, no. 89 , pp. $1215-1235$.

15. Karpov V.E. Sensory model of robots imitative behavior. Proc. 6th Intern. Sci. and Tech. Conf. "Open Semantic Technologies for Intelligent Systems" (OSTIS-2016). Minsk, BGUIR, 2016, pp. 471-476 (in Russ.).

16. Karpov V., Karpova I. Leader election algorithms for static swarms. Biol. Inspired Cogn. Archit. 2015, vol. 12, pp. 54-64.

17. Karpova I.P. About the problem of representing the route of a mobile robot based on visual landmarks. Mechatronics. Automation. Control. 2017, vol. 18, no. 2, pp. 81-89 (in Russ.).

18. Rovbo M.A., Malyshev A.A. Complex for studying energetically autonomous collectives of robots. Open Education. 2017, no. 2, pp. 68-77 (in Russ.).

19. Boissard E., Degond P., Motsch S. Trail formation based on directed pheromone deposition. J. Math. Biol. 2013, vol. 66, iss. 6, pp. 1267-1301. Available at: https://link.springer.com/article/10.1007\%2Fs00285-012-0529-6 (accessed January 10,2018$)$. 


\title{
Алгоритмическая неразрешимость проблемы первопорядковой
} определимости формул логики ветвяшегося времени

\author{
М.Н. Рыцбаков 1, 2, 3, к.ф.-м.н., доиент, научный сотрудник, инженер-программист, \\ m_rybakov@mail.ru \\ 1.A. Чагрова ${ }^{1}$, к.ф.-м.н., доиенm, chagrovy@mail.ru \\ 1 Тверской государственный университет, г. Тверь, 170100, Россия \\ 2 Университет Витватерсранда, г. Йоханнесбург, 2001, Южная Африка \\ ${ }^{3}$ НИИ "Центрпрограмисистем", г. Тверь, 170024, Россия
}

В качестве формального средства, описывающего свойства различных структур (в том числе структур вычислений), обычно используют язык логики предикатов. Этот язык, с одной стороны, понятен и удобен, а с другой, многие вопросы, важные с прикладной точки зрения, для него алгоритмически неразрешимы, то есть не могут быть решены программно.

Сейчас существует много альтернативных языков, позволяющих описывать вычисления и их свойства, при этом, в отличие от языка логики предикатов, аналогичные вопросы для них алгоритмически разрешимы. В работе рассматривается один из таких языков - язык логики ветвящегося времени CTL. Он используется для верификации программ, так как содержит средства для описания свойств программных вычислений, в частности, свойств бинарного отношения, возникающего в реляционной семантике Крипке.

В работе исследуется возможность алгоритмического нахождения формул языка первого порядка, которые задают те же классы шкал Крипке, что и формулы языка логики CTL. Известно, что для интуицинистских формул проблема их первопорядковой определимости алгоритмически неразрешима. Показано, как, используя перевод Гёделя интуиционистских формул в модальные, а затем перевод получившихся модальных формул в формулы языка логики CTL, свести проблему первопорядковой определимости интуиционистских формул на шкалах Крипке к проблеме первопопорядковой определимости CTL-формул на шкалах Крипке. В качестве следствия такого сведения получена алгоритмическая неразрешимость соответствующей проблемы для CTL.

В заключении обсуждаются возможные модификации приведенной конструкции с целью распространения полученного результата на фрагменты языка логики CTL, а также алгоритмическая разрешимость проблемы CTLопределимости формул первого порядка.

Ключевые слова: модели вычислений, логика ветвящегося времени, первопорядковая определимость.

Язык логики ветвящегося времени CTL (computational tree logic) - удобное и эффективное средство для описания свойств различных сложных вычислительных систем, в том числе с целью их последующей верификации $[1,2]$. Его существенным отличием от хорошо известного и широко используемого языка логики предикатов QCL является то, что важные для прикладного аспекта задачи общезначимости и выполнимости CTL-формул разрешимы [3], в то время как для проблем тождественной истинности и выполнимости формул языка логики QCL разрешающей процедуры не существует в принципе [4].

Оба языка позволяют описывать свойства (серийного) бинарного отношения: свойства отношения достижимости в шкалах Крипке для CTL, с одной стороны, могут быть описаны с помощью модальностей языка CTL, а с другой - с помощью формул языка логики предикатов, содержащих предикатную букву $R$ для отношения достижимости, $R^{*}$ для его рефлексивно-транзитивного замыкания, а также символ равенства. Многие условия, выражаемые на одном из этих языков, могут быть выражены и на другом. Таковыми являются, например, условия рефлексивности, симметричности и транзитивности отношения достижимости, а также многие другие. Но, скажем, условие ирре- флексивности не может быть выражено средствами языка логики CTL, а в языке логики QCL выражается формулой $\forall x \neg(x R x)$. И наоборот: например, условие, выраженное формулой Маккинси $A X \neg A X \neg p \rightarrow \neg A X \neg A X p$, не может быть выражено никакой формулой языка логики QCL.

В связи с этим возникают, как минимум, два вопроса. Первый: как по формуле одного из этих языков установить, существует ли ее эквивалент во втором языке? Второй: если такой эквивалент существует, то как его найти?

Частично ответы на эти вопросы известны. Так, для мономодального языка имеется класс так называемых формул Салквиста [5-7], а для предикатного - так называемых формул Крахта $[8,9]$. Между этими классами установлено соответствие, связывающее каждую формулу одного из них с ее эквивалентом в другом. Но ни формулы Салквиста, ни формулы Крахта не описывают все условия, выражаемые на языках логик CTL и QCL. Отметим, что недавно получены обобщения формул Салквиста и формул Крахта [10-13], а также ряд результатов, касающихся взаимосвязи между определимостью различных условий и запросами $[14,15]$.

В данной работе рассматривается ситуация без ограничений, то есть для полных языков, а не для специальных их фрагментов типа формул Салкви- 
ста, формул Крахта или их обобщений. При этом показано, что, хотя язык логики QCL алгоритмически более выразителен, чем язык CTL, тем не менее, не существует алгоритма, который по произвольной формуле языка CTL давал бы ответ на вопрос, существует ли эквивалент этой формулы в языке QCL. Чтобы показать это, будем использовать фундаментальные результаты из [16], полученные для интуиционистской логики Int и еe модального напарника S4, который, как будет показано, встроен в CTL. Приводимые здесь результаты не являются неожиданными для специалистов по теории соответствий (Correspondence Theory), но могут оказаться интересными тем, кто не знаком с этой теорией, но пользуется средствами языка логики CTL для верификации программ.

\section{Синтаксис и семантика}

Коротко напомним, как устроены языки логик CTL, S4 и Int, а также одна из возможных их семантик (см. более детально $[1,2,6])$.

Каждый из этих языков содержит счетное множество пропозициональных переменных, логические связки $\wedge$ (конъюнкция), $\vee$ (дизъюнкция), $\rightarrow$ (импликация), ᄀ (отрицание), логические константы $\perp$ (ложь) и Т (истина), а также скобки. При этом язык логики $\mathrm{S} 4$ содержит дополнительно модальность $\square$, а язык CTL - модальности $A X, E X$, $A F, E F, A G, E G, A U, E U$. Модальность $\square$ позволяет строить формулы вида $\square \varphi$, читаемые как «необходимо $\varphi$ ». Модальности языка логики CTL являются составными, при этом первые шесть - одноместные, они позволяют строить формулы вида $A X \varphi$, $E X \varphi, A F \varphi, E F \varphi, A G \varphi$ и $E G \varphi$, а две последние двухместные, они позволяют строить формулы вида $(\varphi A U \psi)$ и $(\varphi E U \psi)$. Каждая из этих модальностей состоит из двух частей: первая $-A$ или $E$, вторая $-X, F, G$ или $U$. Части $A$ и $E$ называются кванторами пути и соответствуют выражениям «для каждого пути верно, что...» $(A-$ от all) и «существует такой путь, что...» ( $E-$ от exists). Части $X$, $F, G$ и $U$ называются кванторами состояний и соответствуют выражениям «в следующем состоянии данного пути...» $(X-$ от next $)$, «в некотором состоянии данного пути...» $(F-$ от future $)$, «в каждом состоянии данного пути...» $(G-$ от globally) и «в состояниях данного пути справедливо..., пока не станет справедливо...» (U - от until). Так, $E G \varphi$ означает, что «существует путь, в каждом состоянии которого верно $\varphi$ », а формула $(\varphi E U \psi)-$ что «существует путь, в состояниях которого верно $\varphi$, пока не станет верным $\psi »$.

Для оценки истинности формул каждого из языков будем использовать семантику С. Крипке. Шкала Крипке - это набор $\mathcal{F}=\langle W, R\rangle$, где $W$ - непустое множество, а $R$ - бинарное отношение на $W$. Элементы $W$ принято называть точками, состояниями или мирами, а отношение $R$ - отношением достижимости. Если выполнено условие $x R y$, то говорим, что из точки $x$ достижима точка $y$. В случае CTL дополнительно требуется, чтобы отношение достижимости в шкалах было серийным (серийность $R$ выражается следующей формулой логики предикатов: $\forall x \exists y(x R y))$. В случае $\mathrm{S} 4$ отношение достижимости должно быть рефлексивным (то есть $\forall x(x R x)$ ) и транзитивным (то есть $\forall x \forall y \forall z(x R y \wedge y R z \rightarrow x R z))$, а в случае Int - peфлексивным, транзитивным и антисимметричным (то есть $\forall x \forall y(x R y \wedge y R x \rightarrow x=y)$ ). Оценкой в шкале $\mathcal{F}=\langle W, R\rangle$ называется функция $v$, которая каждой пропозициональной переменной $p$ сопоставляет некоторое подмножество $v(p)$ множества $W$. Содержательно условие $x \in v(p)$ означает, что переменная $p$ истинна в точке $x$. При этом в случае интуиционистской логики дополнительно требуется наследственность оценки, то есть следующее условие: если $x \in v(p)$ и $x R y$, то $y \in v(p)$. Модель Крипке - это набор $\mathcal{M}=\langle W, R, v\rangle$, где $\langle W, R\rangle-$ шкала Крипке, а $v$ - оценка в этой шкале.

Путем в шкале $\mathcal{F}=\langle W, R\rangle$ называется бесконечная последовательность $\pi=\left(\pi_{0}, \pi_{1}, \pi_{2}, \pi_{3}, \ldots\right)$ состояний (необязательно различных), в которой для каждого $k$ выполнено условие $\pi_{k} R \pi_{k+1}$; при этом $\pi_{0}$ называется началом пути $\pi$. Заметим, что в случае серийности отношения $R$ каждое состояние является началом хотя бы одного пути.

Для модели $\mathcal{M}=\langle W, R, v\rangle$, точки $x \in W$ и CTLформулы $\varphi$ определим отношение истинности $\mathcal{M}, x \vDash \varphi$ (читается: в точке $x$ модели $\mathcal{M}$ истинна формула $\varphi$ ). Оно определяется классически для $\wedge$, $\mathrm{V}, \rightarrow, \neg, \perp$ и $\mathrm{T}$, а для модальностей - в соответствии с вкладываемым в них смыслом:

- $\mathcal{M}, x \vDash A X \varphi$, если для каждого пути $\pi$, начинающегося в $x$, верно, что $\mathcal{M}, \pi_{1} \vDash \varphi$;

- $\mathcal{M}, x \vDash A F \varphi$, если в каждом пути $\pi$, начинающемся в $x$, существует такое состояние $\pi_{k}$, что $\mathcal{M}, \pi_{k} \vDash \varphi$;

- $\mathcal{M}, x \vDash A G \varphi$, если в каждом пути $\pi$, начинающемся в $x$, для каждого состояния $\pi_{k}$ верно, что $\mathcal{M}, \pi_{k} \vDash \varphi$;

- $\mathcal{M}, x \vDash \varphi A U \psi$, если в каждом пути $\pi$, начинающемся в $x$, существует состояние $\pi_{k}$, для которого $\mathcal{M}, \pi_{k} \vDash \psi$, при этом для каждого $m$, строго меньшего $k$, верно, что $\mathcal{M}, \pi_{m} \vDash \varphi$;

- $\mathcal{M}, x \vDash E X \varphi$, если существует такой начинающийся в $x$ путь $\pi$, что $\mathcal{M}, \pi_{1} \vDash \varphi$;

- $\mathcal{M}, x \vDash E F \varphi$, если существует такой начинающийся в $x$ пути $\pi$, для некоторого состояния $\pi_{k}$ которого верно, что $\mathcal{M}, \pi_{k} \vDash \varphi$;

- $\mathcal{M}, x \vDash E G \varphi$, если существует такой начинающийся в $x$ путь $\pi$, для каждого состояния $\pi_{k}$ которого верно, что $\mathcal{M}, \pi_{k} \vDash \varphi$;

- $\mathcal{M}, x \vDash \varphi E U \psi$, если в некотором начинающемся в $x$ пути $\pi$ существует состояние $\pi_{k}$, для которого $\mathcal{M}, \pi_{k} \vDash \psi$, при этом для каждого $m$, строго меньшего $k$, верно, что $\mathcal{M}, \pi_{m} \vDash \varphi$. 
Формула $\varphi$ истинна в модели, если $\varphi$ истинна в каждом состоянии этой модели. Формула $\varphi$ истинна в шкале, если $\varphi$ истинна в каждой модели, определенной на этой шкале.

Для случая S4-формул аналогичное определение требует следующей корректировки:

- $\mathcal{M}, x \vDash \square \varphi$, если для каждого $y \in W$, достижимого из $x$ по $R$, верно, что $\mathcal{M}, y \vDash \varphi$.

Для случая интуиционистских формул ситуация иная. Определение истинности для переменных, а также для логических связок $\wedge, \vee, \perp$ и $\mathrm{T}$ внешне не отличается от классического случая, а истинность связок $\rightarrow$ и $\neg$ определяется иначе:

- $\mathcal{M}, x \vDash \varphi \rightarrow \psi$, если для каждого $y \in W$, достижимого из $x$ по $R$, из условия $\mathcal{M}, y \vDash \varphi$ следует, что $\mathcal{M}, y \vDash \psi$;

- $\mathcal{M}, x \vDash \neg \varphi$, если для каждого $y \in W$, достижимого из $x$ по $R$, неверно, что $\mathcal{M}, y \vDash \varphi$.

Пусть $\mathrm{C}_{\mathrm{S}}, \mathrm{C}_{\mathrm{R}}, \mathrm{C}_{\mathrm{T}}$ и $\mathrm{C}_{\mathrm{A}}$ - классы всех серийных, всех рефлексивных, всех транзитивных и всех антисимметричных шкал. Пусть также $\mathrm{C}_{\mathrm{RT}}=\mathrm{C}_{\mathrm{R}} \cap \mathrm{C}_{\mathrm{T}}$ и $\mathrm{C}_{\mathrm{RTA}}=\mathrm{C}_{\mathrm{RT}} \cap \mathrm{C}_{\mathrm{A}}$. Определим логики CTL, S4 и Int как множества формул в соответствующих языках, истинных во всех шкалах из $\mathrm{C}_{\mathrm{S}}, \mathrm{C}_{\mathrm{RT}}$ и $\mathrm{C}_{\mathrm{RTA}}$ (при подходящем определении отношения истинности), соответственно. Каждая формула $\varphi$ задает некоторый класс шкал, в которых она истинна, являющийся подклассом $\mathrm{C}_{\mathrm{S}}, \mathrm{C}_{\mathrm{RT}}$ или $\mathrm{C}_{\mathrm{RTA}}$ в зависимости от того, в языке какой логики определена $\varphi$; обозначим этот класс посредством С $(\varphi)$.

\section{Погружения S4 в CTL и Int в S4}

Опишем некоторые связи между языками логик CTL, S4 и Int, позволяющие в ряде случаев задавать классы шкал Крипке формулами одного из этих языков, если известно, как можно это сделать в другом.

Заметим, что S4-формулы моделируются CTLформулами. Определение истинности формулы $A X \varphi$ можно переписать в эквивалентном виде следующим образом: $\mathcal{M}, x \vDash A X \varphi$ тогда и только тогда, когда для каждого $y \in W$, достижимого из $x$ по $R$, верно, что $\mathcal{M}, y \vDash \varphi$. Такая формулировка по своей форме в точности соответствует определению истинности формулы вида $\square \varphi$. Но имеется существенное отличие: в случае шкал для CTL отношение достижимости является серийным, а в случае шкал для S4 - рефлексивным и транзитивным. Из рефлексивности бинарного отношения следует его серийность, но из серийности не следуют ни рефлексивность, ни транзитивность. Тем не менее, можно ввести в рассмотрение отношение $R^{*}$, определив его как рефлексивно-транзитивное замыкание отношения $R$. В случае шкал логики $\mathrm{S} 4$ получаем, что $R^{*}=R$ и определение истинности для формулы $\square \varphi$ не изменится при замене в нем $R$ на $R^{*}$. А в случае CTL при замене $R$ на $R^{*}$ в приведенном определении истинности формулы $A X \varphi$ полу- чим определение истинности формулы $A G \varphi$ : $\mathcal{M}, x \vDash A G \varphi$ тогда и только тогда, когда для каждого $y \in W$, достижимого из $x$ по $R^{*}$, верно, что $\mathcal{M}, y \vDash \varphi$. Так происходит из-за того, что достижимость по $R^{*}$ как раз и дает все точки всех путей, выходящих из данной точки, то есть соответствует модальности $A G$.

Это наблюдение позволяет сделать следующий вывод. Пусть $f$ - функция, которая заменяет в произвольной S4-формуле $\varphi$ каждое вхождение символа $\square$ вхождением модальности $A G$. Для каждой шкалы $\mathcal{F}=\langle W, R\rangle$ определим шкалу $\mathcal{F}^{*}$, положив $\mathcal{F}^{*}=\left\langle W, R^{*}\right\rangle$; тогда, если $\mathcal{F} \in \mathrm{C}_{\mathrm{S}}$, то $\mathcal{F}^{*} \in \mathrm{C}_{\mathrm{RT}}$. Справедливо следующее утверждение.

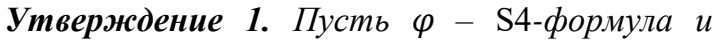

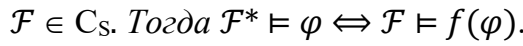

Замечание 1. В частности, это означает, что $\varphi \in \mathrm{S} 4 \Leftrightarrow f(\varphi) \in \mathrm{CTL}$.

Следствие 1. Для всякой S4-формуль $\varphi$ имеет место равенство $\mathrm{C}(\varphi)=\mathrm{C}(f(\varphi)) \cap \mathrm{C}_{\mathrm{RT}}$.

Таким образом, если известен класс шкал, задающий $f(\varphi)$ в классе $\mathrm{C}_{\mathrm{S}}$, то известен и класс шкал, задающий $\varphi$ в классе $\mathrm{C}_{\mathrm{RT}}$.

Покажем, как моделировать интуиционистские формулы S4-формулами. Для этих целей можно использовать перевод Гёделя $t$, который действует так: он ставит модальность $\square$ перед каждой пропозициональной переменной, логической константой, отрицанием и импликацией [6]. Например, $t(\neg p \wedge q \rightarrow \perp)=\square(\square \neg \square p \wedge \square q \rightarrow \square \perp)$.

Для перевода Гёделя верно следующее [6]: $\varphi \in$ Int $\Leftrightarrow t(\varphi) \in \mathrm{S} 4$. Рассмотрим, как связаны классы шкал, определяемые формулами $\varphi$ и $t(\varphi)$. Пусть $\mathcal{F}=\langle W, R\rangle$ - шкала логики $\mathrm{S} 4$, то есть $\mathcal{F} \in \mathrm{C}_{\mathrm{RT}}$. Разобьем множество $W$ на классы эквивалентности по отношению $R$, где класс $[x]$, порожденный точкой $x$, определяется обычно: $[x]=$ $=\{y \in W: x R y$ и $y R x\}$. Класс $[x]$ называют сгусmком, или кластером. Пусть $W^{\#}$ - множество получившихся сгустков в шкале $\mathcal{F}$, а $R^{\#}$ - отношение достижимости на $W^{\#}$, определяемое следующим образом: $[x] R^{\#}[y]$, если $x R y$. Пусть $\mathcal{F}^{\#}=\left\langle W^{\#}, R^{\#}\right\rangle$. Если $\mathcal{F} \in \mathrm{C}_{\mathrm{RTA}}$, то шкала $\mathcal{F}^{\#}$ изоморфна шкале $\mathcal{F}$, поскольку в этом случае $[x]=\{x\}$. В случае, когда $\mathcal{F} \in \mathrm{C}_{\mathrm{RT}}$ (в частности, и если $\mathcal{F} \in \mathrm{C}_{\text {RTA }}$ ), получаем, что $\mathcal{F}^{\#} \in \mathrm{C}_{\mathrm{RTA}}$, причем единственным отличием шкалы $\mathcal{F}^{\#}$ от шкалы $\mathcal{F}$ будет то, что каждый сгусток «схлопнется» в одну точку. Из-за условия наследственности оценки интуиционистские формулы не могут различить точки из одного сгустка, а потому не могут этого сделать и их образы при переводе Гёделя. Таким образом, справедливо следующее утверждение.

Утверждение 2. Пусть $\varphi-$ интуиционистская формула и $\mathcal{F} \in \mathrm{C}_{\mathrm{RT}}$. Тогда $\mathcal{F}^{\#} \vDash \varphi \Leftrightarrow \mathcal{F} \vDash t(\varphi)$.

Следствие 2. Для всякой интуиционистской формуль $\varphi$ имеет место следующее равенство: $\mathrm{C}(\varphi)=\mathrm{C}(t(\varphi)) \cap \mathrm{C}_{\mathrm{RTA}}$ 
Из следствий 1 и 2 получаем результат, описывающий связь между интуиционистским языком и языком логики CTL.

Следствие 3. Для всякой интуиционистской формуль $\varphi$ имеет место равенство $\mathrm{C}(\varphi)=$ $=\mathrm{C}(f(t(\varphi))) \cap \mathrm{C}_{\mathrm{RTA}}$.

\section{Логика предикатов и шкалы Крипке}

Обратимся к языку первого порядка, то есть к языку логики предикатов QCL. Рассмотрим не весь язык логики предикатов, а только ту его часть, которая позволяет описывать свойства отношения достижимости в моделях Крипке. Будем считать, что в языке логики предикатов имеются счетное множество предметных переменных, бинарная предикатная буква $R$, соответствующая отношению достижимости в шкалах Крипке, символ равенства =, а также логические связки, кванторы по предметным переменным и технические символы (скобки). Тогда каждую шкалу Крипке $\mathcal{F}=\langle W, R\rangle$ можно понимать как модель описанного фрагмента языка логики QCL, в результате чего для предикатной формулы $\Phi$ получаем естественное определение отношения истинности в шкале $\mathcal{F}$; если $\Phi$ истинна в $\mathcal{F}$, то пишем $\mathcal{F} \vDash \Phi$. Так, например, если $\Phi=\forall x(x R x)$, то $\mathcal{F} \vDash \Phi$ тогда и только тогда, когда отношение достижимости в $\mathcal{F}$ рефлексивно. Далее под формулами языка логики предикатов будем понимать только замкнуmые формулы, то есть не содержащие свободных переменных. Пусть С $(\Phi)$ - класс шкал, в которых истинна формула $\Phi$.

В случае семантики CTL для описания свойств отношения достижимости $R$ наряду с символами $R$ и $=$ целесообразно использовать также символ $R^{*}$, соответствующий рефлексивно-транзитивному замыканию отношения $R$. Тогда выразительные свойства предикатного языка существенно повышаются: проблема истинности формул становится не только алгоритмически неразрешимой, но и рекурсивно неперечислимой. Для предикатной формулы $Ф$ в языке с символами $=, R$ и $R^{*}$ класс шкал, в которых истинна $\Phi$, также будем обозначать $\mathrm{C}(\Phi)$.

Здесь будет важным следующее.

Утверждение 3. Пусть $\Phi-$ формула в языке с символами $=, R$ и $R^{*}$, причем $\mathrm{C}(\Phi) \subseteq \mathrm{C}_{\mathrm{RT}}$. Тогда существует такая формула $\Psi$ в языке с символами $R$ $u=$, чmо $\mathrm{C}(\Phi)=\mathrm{C}(\Psi)$.

Доказательство. Поскольку $\mathrm{C}(\Phi) \subseteq \mathrm{C}_{\mathrm{RT}}$, формула $\Phi$ определяет в шкалах отношение $R$, являющееся рефлексивно-транзитивным. Следовательно, его рефлексивно-транзитивное замыкание совпадает с ним самим, то есть $R^{*}=R$. Таким образом, в качестве $\Psi$ можно взять формулу, получающуюся из $\Phi$ заменой каждого вхождения символа $R^{*}$ на $R$.

Утверждение доказано.

\section{Определимость классов шкал формулами}

Класс шкал С называется определимым формулами языка логики $L$, если существует такая фор- мула $\varphi$ языка логики $L$, что выполняется равенство $\mathrm{C}=\mathrm{C}(\varphi)$. Например, $\mathrm{C}_{\mathrm{S}}=\mathrm{C}(\forall x \exists y(x R y))$, то есть $\mathrm{C}_{\mathrm{S}}$ является определимым предикатными формулами, или, как принято говорить, первопорядково определимым. Поскольку условия рефлексивности, транзитивности и антисимметричности также описываются предикатными формулами, то классы шкал $\mathrm{C}_{\mathrm{R}}, \mathrm{C}_{\mathrm{T}}$ и $\mathrm{C}_{\mathrm{A}}$ тоже первопорядково определимы. Именно, пусть $\operatorname{ref}_{\mathrm{QCL}}, \operatorname{tr}_{\mathrm{QCL}}$ и аsym $\mathrm{QCL}-$ это формулы $\forall x(x R x), \forall x \forall y \forall z(x R y \wedge y R z \rightarrow x R z)$ и $\forall x \forall y(x R y \wedge y R x \rightarrow x=y)$, соответственно; тогда $\mathrm{C}_{\mathrm{R}}=\mathrm{C}\left(\mathrm{ref}_{\mathrm{QCL}}\right), \mathrm{C}_{\mathrm{T}}=\mathrm{C}\left(\operatorname{tr}_{\mathrm{QCL}}\right), \mathrm{C}_{\mathrm{A}}=\mathrm{C}\left(\operatorname{asym}_{\mathrm{QCL}}\right)$. Условия рефлексивности и транзитивности можно описать и CTL-формулами: взяв $\operatorname{ref}_{\mathrm{CTL}}=A X p \rightarrow p$ и $\operatorname{tr}_{\mathrm{CTL}}=A X p \rightarrow A X A X p$, получим, что $\mathrm{C}_{\mathrm{R}}=\mathrm{C}\left(\operatorname{ref}_{\mathrm{CTL}}\right)$ и $\mathrm{C}_{\mathrm{T}}=\mathrm{C}\left(\operatorname{tr}_{\mathrm{CTL}}\right)$.

Сделаем следующее наблюдение.

Утверждение 4. Пусть классы $\mathrm{C}_{1}$ и $\mathrm{C}_{2}$ определимы формулами языка одной из логик Int, S4, CTL или QCL. Тогда класс $\mathrm{C}_{1} \cap \mathrm{C}_{2}$ тоже является определимым формулами языка этой же логики.

Доказательство. Достаточно заметить: если $\mathrm{C}_{1}$ определяется формулой $\varphi_{1}$, a $\mathrm{C}_{2}-$ формулой $\varphi_{2}$, то $\mathrm{C}_{1} \cap \mathrm{C}_{2}$ определяется формулой $\varphi_{1} \wedge \varphi_{2}$.

Утверждение доказано.

Отметим, что для операции объединения аналогичное утверждение тоже выполняется, а для дополнения ситуация иная. В предикатном случае, если $\Phi$ задает некоторый класс шкал, $\neg \Phi$ задает его дополнение. В случае же логик Int, S4 и CTL это не так. Например, в CTL условие рефлексивности описывается формулой $\operatorname{ref}_{\mathrm{CTL}}$, условие транзитивности - формулой $\operatorname{tr}_{\mathrm{C}}$, условие симметричности формулой sym $_{\mathrm{CTL}}=p \rightarrow A X \neg A X \neg p$, при этом условия нерефлексивности, нетранзитивности, несимметричности (и антисимметричности) формулами языка CTL описать невозможно. Так, отрицание формулы $\operatorname{ref}_{\mathrm{CTL}}=A X p \rightarrow p$, задающей условие peфлексивности в шкалах, можно опровергнуть в любой шкале логики CTL, в том числе в нерефлексивной: достаточно взять оценку, при которой переменная $p$ истинна в каждой точке шкалы, и тогда формула $\mathrm{ref}_{\mathrm{CTL}}$ станет истинной в каждой точке получившейся модели, a $\neg \mathrm{ref}_{\mathrm{CTL}}-$ ложной. Таким образом, $\neg \mathrm{ref}_{\mathrm{CTL}}$ не задает условие нерефлексивности (формула $\neg \mathrm{ref}_{\mathrm{CTL}}$ вообще определяет пустой класс шкал логики CTL). Ситуация с остальными указанными формулами аналогична.

\section{Точные формулировки вопросов}

Теперь можно дать точные формулировки вопросов, о которых шла речь в начале статьи.

Вопрос 1. Существует ли алгоритм, который по произвольной CTL-формуле $\varphi$ дает ответ на вопрос о том, существует ли такая предикатная формула $\Phi$, что $\mathrm{C}(\varphi)=\mathrm{C}(\Phi)$ ?

Вопрос 2. Существует ли алгоритм, который по произвольной CTL-формуле $\varphi$ строит такую 
предикатную формулу $\Phi$, что $\mathrm{C}(\varphi)=\mathrm{C}(\Phi)$, а в случае ее отсутствия сообщает об этом?

Вопрос 3. Существует ли алгоритм, который по произвольной предикатной формуле Ф дает ответ на вопрос о том, существует ли такая CTLформула $\varphi$, что $\mathrm{C}(\varphi)=\mathrm{C}(\Phi)$ ?

Вопрос 4. Существует ли алгоритм, который по произвольной предикатной формуле Ф строит такую CTL-формулу $\varphi$, что $\mathrm{C}(\varphi)=\mathrm{C}(\Phi)$, а в случае ее отсутствия сообщает об этом?

Конечно, вопросы связаны между собой. Если ответ на вопрос 2 положителен, то и ответ на вопрос 1 положителен; соответственно, отрицательный ответ на вопрос 1 приводит к отрицательному ответу на вопрос 2 . То же относится и к вопросам 3 и 4. Покажем, как из известных результатов о связи между Int и QCL получить ответ на вопросы 1 и 2; в отношении же вопросов 3 и 4 ограничимся формулировкой гипотезы.

Формулу $\varphi$ языка логики $L$ будем называть первопорядково определимой, если класс $\mathrm{C}(\varphi)$ определим с помощью формул языка логики предикатов, то есть если существует такая предикатная формула $\Phi$, что $\mathrm{C}(\varphi)=\mathrm{C}(\Phi)$. Под проблемой первопорядковой определимости формул языка логики $L$ будем понимать следующую задачу: по произвольной $L$-формуле $\varphi$ выяснить, является ли $\varphi$ первопорядково определимой. Для краткости первопорядково определимые формулы будем называть ППО-формулами.

Известен следующий результат для Int и QCL, доказанный в [16]: проблема первопорядковой определимости интуиционистских формул алгоритмически неразрешима, то есть не существует алгоритма, решающего эту задачу. Покажем, как из этого результата и сделанных выше наблюдений следует аналогичный результат для языков CTL и QCL.

\section{Неразрешимость первопорядковой определимости CTL-формул}

Пусть функция $g$ определена для каждой интуиционистской формулы $\varphi$ следующим образом: $g(\varphi)=f(t(\varphi)) \wedge \operatorname{ref}_{\mathrm{CTL}} \wedge \operatorname{tr}_{\mathrm{CTL}}$

Утверждение 5. Пусть $\varphi$-интуиционистская формула. Тогда $\mathrm{C}(\varphi)=\mathrm{C}(g(\varphi)) \cap \mathrm{C}_{\mathrm{A}}$.

Доказательство. Согласно следствию 3, имеем $\mathrm{C}(\varphi)=\mathrm{C}(f(t(\varphi))) \cap \mathrm{C}_{\mathrm{RTA}}$. По утверждению 4, $\mathrm{C}(g(\varphi))=\mathrm{C}(f(t(\varphi))) \cap \mathrm{C}\left(\operatorname{ref}_{\mathrm{CTL}}\right) \cap \mathrm{C}\left(\operatorname{tr}_{\mathrm{CTL}}\right)$. Поскольку $\mathrm{C}_{\mathrm{R}}=\mathrm{C}\left(\operatorname{ref}_{\mathrm{CTL}}\right)$ и $\mathrm{C}_{\mathrm{T}}=\mathrm{C}\left(\operatorname{tr}_{\mathrm{CTL}}\right)$, получаем, что $\mathrm{C}(g(\varphi))=\mathrm{C}(f(t(\varphi))) \cap \mathrm{C}_{\mathrm{R}} \cap \mathrm{C}_{\mathrm{T}}$, следовательно, $\mathrm{C}(g(\varphi)) \cap \mathrm{C}_{\mathrm{A}}=\mathrm{C}(f(t(\varphi))) \cap \mathrm{C}_{\mathrm{R}} \cap \mathrm{C}_{\mathrm{T}} \cap \mathrm{C}_{\mathrm{A}}$, то есть $\mathrm{C}(g(\varphi)) \cap \mathrm{C}_{\mathrm{A}}=\mathrm{C}(f(t(\varphi))) \cap \mathrm{C}_{\mathrm{RTA}}$. В итоге получаем $\mathrm{C}(\varphi)=\mathrm{C}(g(\varphi)) \cap \mathrm{C}_{\mathrm{A}}$, что и требовалось.

Утверждение доказано.

Следствие 4. Пусть $\varphi$ - интуиционистская формула. Тогда, если $g(\varphi)-$ ППО-формула, то $\varphi-$ тоже ППО-формула.

Доказательство. Пусть $\Phi$ - формула языка логики предикатов, для которой выполнено равен- ство $\mathrm{C}(g(\varphi))=\mathrm{C}(\Phi)$. Согласно утверждению 5, $\mathrm{C}(\varphi)=\mathrm{C}(g(\varphi)) \cap \mathrm{C}_{\mathrm{A}}$. Класс $\mathrm{C}_{\mathrm{A}}$ первопорядково определим, и тогда из утверждения 4 получаем, что класс $\mathrm{C}(\Phi) \cap \mathrm{C}_{\mathrm{A}}$ тоже первопорядково определим. Поскольку он равен С $(\varphi)$, заключаем, что $\varphi-$ ППОформула.

Следствие доказано.

Следствие 5. Пусть $\varphi$ - интуиционистская формула. Тогда, если $\varphi-$ ППО-формула, то $g(\varphi)-$ тоже ППО-формула.

Доказательство. Пусть $\Phi$ - формула логики предикатов, для которой $\mathrm{C}(\varphi)=\mathrm{C}(\Phi)$. Тогда, согласно утверждению $5, \mathrm{C}(\varphi)=\mathrm{C}(g(\varphi)) \cap \mathrm{C}_{\mathrm{A}}$, отсюда получаем $\mathrm{C}(\Phi)=\mathrm{C}(g(\varphi)) \cap \mathrm{C}_{\mathrm{A}}$. Шкалы класса $\mathrm{C}(\varphi)$ являются рефлексивными, транзитивными и антисимметричными, поэтому формула $\Phi$ должна, в частности, требовать выполнения каждого из этих условий. Формула $g(\varphi)$ требует выполнения рефлексивности и транзитивности, но, вообще говоря, не антисимметричности.

Пусть $\mathcal{F}=\langle W, R\rangle-$ некоторая шкала из класса $\mathrm{C}(g(\varphi))$. Поскольку $\mathrm{C}(g(\varphi))=\mathrm{C}(f(t(\varphi))) \cap \mathrm{C}_{\mathrm{RT}}$, получаем, что $\mathcal{F} \in \mathrm{C}(f(t(\varphi)))$ и $\mathcal{F} \in \mathrm{C}_{\mathrm{RT}}$. Из условия $\mathcal{F} \in \mathrm{C}_{\mathrm{RT}}$ следует, что $R^{*}=R$, а значит, $\mathcal{F}^{*}=\mathcal{F}$. Из того, что $\mathcal{F}^{*} \in \mathrm{C}(f(t(\varphi)))$, по утверждению 1 получаем, что $\mathcal{F} \in \mathrm{C}(t(\varphi))$. Кроме того, из условия $\mathcal{F} \in \mathrm{C}_{\mathrm{RT}}$ следует, что $\mathcal{F}^{\#} \in \mathrm{C}_{\mathrm{RTA}}$. Но тогда, по утверждению $2, \mathcal{F}^{\#} \in \mathrm{C}(\varphi)$. Шкала $\mathcal{F}$ отличается от $\mathcal{F}^{\#}$ лишь тем, что каждый сгусток в $\mathcal{F}$ заменяется в $\mathcal{F}^{\#}$ одной точкой. Пусть теперь $\mathcal{F}_{1} \in \mathrm{C}(\varphi)$. Тогда из сделанного наблюдения вытекает следующее: если $\mathcal{F}$ - такая шкала, что $\mathcal{F}^{\#}$ изоморфна шкале $\mathcal{F}_{1}$, то $\mathcal{F} \in \mathrm{C}(g(\varphi))$. Следовательно, для описания шкал из класса $\mathrm{C}(g(\varphi))$ достаточно в формуле $\Phi$ понимать переменные не как точки, а как сгустки. Заменим в $\Phi$ каждую подформулу вида $x R y$ на формулу $\forall u \forall v(x R u \wedge u R x \wedge y R v \wedge v R y \rightarrow u R v)$, где $u$ и $v-$ некоторые не входящие в $\Phi$ переменные; получившуюся предикатную формулу обозначим $\Phi^{\#}$. Суть сделанной замены в том, что условие достижимости точки $y$ из точки $x$ заменяется на условие достижимость любой точки $v \in[y]$ из любой точки $u \in[x]$. Тогда $\mathrm{C}\left(\Phi^{\#}\right)=\mathrm{C}(g(\varphi))$, а значит, $g(\varphi)-$ ППО-формула.

Следствие доказано.

Следующее утверждение вытекает из следствий 4 и 5.

Следствие 6. Для любой интуиционистской формуль $\varphi$ справедлива следующая эквивалентность: $\varphi$ - ППО-формула тогда и только тогда, когда $g(\varphi)-$ ППО-формула. боты.

Теперь можно доказать основной результат ра-

Теорема. Проблема первопорядковой определимости CTL-формул алгоритмически неразрешима.

Доказательство. Предположим, что это не так, то есть существует алгоритм $\mathcal{A}$, который по любой CTL-формуле $\varphi$ находит ответ на вопрос о том, су- 
ществует ли такая предикатная формула $\Phi$, для которой выполнено равенство $\mathrm{C}(\varphi)=\mathrm{C}(\Phi)$. Покажем, что в этом случае проблема первопорядковой определимости интуиционистских формул тоже должна быть алгоритмически разрешима, что противоречит упомянутому выше результату из [16].

Пусть $\varphi-$ произвольная интуиционистская формула. Применим алгоритм $\mathcal{A}$ к CTL-формуле $g(\varphi)$. Если результат работы $\mathcal{A}$ на $\varphi$ будет положительным, то, согласно следствию $6, \varphi$ является ППО-формулой; если же результат будет отрицательным, то, снова по следствию $6, \varphi$ не является ППО-формулой. Таким образом, с помощью преобразования $g$ и алгоритма $\mathcal{A}$ можно решить проблему первопорядковой определимости интуиционистских формул, а это противоречит результату из [16]. Значит, такого алгоритма $\mathcal{A}$ не существует.

Теорема доказана.

\section{Заключение}

При формулировке понятия первопорядковой определимости был установлен запрет на использование для описания классов шкал буквы $R^{*}$, соответствующей рефлексивно-транзитивному замыканию отношения достижимости в шкалах Крипке. Поэтому выясним, изменится ли что-нибудь, если разрешить использовать $R^{*}$ для описания классов шкал. Такое расширение языка представляется естественным, поскольку при описании вычислений бывает важно не только то, что происходит на следующем шаге вычисления (этому соответствует $R)$, но и то, что может произойти когда-либо (этому соответствует $R^{*}$ ). Проблема определимости CTLформул в таком обогащенном языке тоже будет алгоритмически неразрешимой. Достаточно заметить, что преобразование $g$ строит формулу $g(\varphi)$, требующую от отношения достижимости, чтобы оно было рефлексивным и транзитивным. Тогда, согласно утверждению 3 , если существует такая формула $\Phi$ в языке с $R^{*}$, что $\mathrm{C}(\Phi)=\mathrm{C}(g(\varphi))$, то существует и формула $\Psi$ в языке без $R^{*}$, для которой выполняется равенство $\mathrm{C}(\Psi)=\mathrm{C}(g(\varphi))$.

Следующий уместный вопрос: какова ситуация с первопорядковой определимостью естественных фрагментов языка CTL, в частности, таких, в которых не будет модальности $A G$ ? Во-первых, заметим, что $A G$ можно промоделировать, используя $E U$ : формула $A G \varphi$ эквивалентна в CTL формуле $\neg E F \neg \varphi$, при этом $E F \varphi$ эквивалентна в CTL формуле ТEU $\varphi$. Во-вторых, в приведенных выше рассуждениях можно вообще обойтись без модальности $A G$ и использовать только $A X$. Для этого в определении функции $f$ надо заменить $A G$ на $A X$. Причем для полученной модификации $f$ уже не будет выполняться аналог утверждения 1; если же добавить конъюнктивные члены $\operatorname{ref}_{\mathrm{CTL}}$ и $\operatorname{tr}_{\mathrm{C} L}$, то аналог утверждения 1 будет справедлив.

Итак, согласно доказанной теореме, ответ на вопросы 1 и 2 отрицателен, причем даже для до- вольно простых фрагментов языка логики CTL. Что касается вопросов 3 и 4, то ответ на них не получить так же просто, как это было сделано для решения вопросов 1 и 2 (хотя известно, что проблема определимости предикатных формул интуиционистскими алгоритмически неразрешима): в приведенном доказательстве авторы, по сути, лишь воспользовались тем, что интуиционистские связки можно промоделировать средствами CTL, но как сделать обратное - непонятно, поскольку язык логики CTL является более богатым по своим выразительным возможностям и подходящий перевод CTL-формул в интуиционистские неизвестен (и, видимо, невозможен). Таким образом, вопросы 3 и 4 требуют отдельного исследования и иных методов решения. Тем не менее, сформулируем предположение.

Гипотеза. Проблема CTL-определимости формул логики предикатов алгоритмически неразрешима.

Работа выполнена при поддержке РФФИ, гранты №№ 16-07-01272, 17-03-00818-ОГН и 18-011-00869.

\section{Литература}

1. Кларк Э.М., Грамберг О., Пелед Д. Верификация моделей программ: Model checking. М.: Изд-во МЦНМО, 2002, 416 с.

2. Карпов Ю.Г. Model checking: Верификация параллельных и распределенных программных систем. СПб: БХВ-Петербург, 2010, $560 \mathrm{c.}$.

3. Emerson E.A., Halpern J.Y. Decision procedures and expressiveness in the temporal logic of branching time. J. of Comp. and Syst. Sc., 1985, vol. 30, no. 1, pp. 1-24. DOI: http://dx.doi.org/ 10.1016/0022-0000(85)90001-7.

4. Булос Дж., Джеффри Р. Вычислимость и логика. М.: Мир, 1994, 396 с.

5. Blackburn P., de Rijke M., Venema Y. Modal logic. Cambridge Univ. Press, 2002.

6. Chagrov A.V., Zakharyaschev M.V. Modal logic. Oxford Univ. Press, 1997.

7. Sahlqvist H.. Completeness and correspondence in the first and second order semantics for modal logic. Proc. 3rd Scandinavian Logic Symposium, Amsterdam, North-Holland, 1975, pp. 110-143. DOI: http://dx.doi.org/10.1016/S0049-237X(08)70728-6.

8. Kracht M. How completeness and correspondence theory got married. In: M. de Rijke (Ed.), Diamonds and Defaults, 1993, pp. 175-214. DOI: http://dx.doi.org/10.1007/978-94-015-8242-1 7.

9. Kracht M.. Tools and techniques in modal logic. Studies in Logic and the Foundations of Mathematics, Elsevier, 1999, vol. 142, 559 p.

10. Balbiani P., Kikot S. Sahlqvist theorems for precontact logics. Advances in Modal Logic, 2012, vol. 9, pp. 55-70.

11. Kikot S. A new generalization of Sahlqvist theorem. In Algebraic and Topological Methods in Non-classical Logics II, Univ. de Barcelona, 2005, pp. 40-41.

12. Kikot S. An extension of Kracht's theorem to generalized Sahlqvist formulas. J. of Applied Non-Classical Logic, 2009, vol. 19, no. 2, pp. 227-251. DOI: http://dx.doi.org/10.3166/jancl.19.227-251.

13. Kikot S. Semantic characterization of Kracht's formulas. Advances in Modal Logic. 2010, vol. 8, pp. 218-234.

14. Kikot S., Tsarkov D., Zakharyaschev M., Zolin E.. Query Answering via Modal Definability with FaCT++. In Proc. of DL, 2013.

15. Kikot S., Zolin E. Modal definability of first-order formulas with free variables and query answering. J. of Applied Logic, 2013, vol. 11, pp. 190-216. DOI: http://dx.doi.org/10.1016/j.jal.2013.03.007.

16. Chagrova L.A. An undecidable problem correspondence theory. J. of Symbolic Logic, 1991, vol. 56, iss. 4, pp. 1261-1272. DOI: http://dx.doi.org/10.2307/2275473.

17. Мендельсон Э. Введение в математическую логику. М.: Наука, 1976, 320 c. 


\section{Algorithmic undecidability of the problem of first-order correspondence of computational tree logic formulas}

M.N. Rybakov ${ }^{1,2,3}$, Ph.D. (Physics and Mathematics), Associate Professor, Research Fellow, Software Engineer, m_rybakov@mail.ru

L.A. Chagrova ${ }^{1}$, Ph.D. (Physics and Mathematics), Associate Professor, chagrovy@mail.ru

${ }^{1}$ Tver State University, Tver, 170100, Russian Federation

${ }^{2}$ University of the Witwatersrand, Johannesburg, 2001, South Africa

${ }^{3} R \& D$ Institute Centerprogramsystem, Tver, 170024, Russian Federation

Abstract. It is common to use the first-order language as a formal tool for describing properties of various (computational) structures. On the one hand, this language is well understood and easy to use; on the other, many questions that are important from the applications point of view related to this language are algorithmically undecidable, i.e., cannot be answered using a computer program.

These days, there exist various alternative languages that can be used for describing computational processes and their properties, for which the corresponding questions are, in contrast to the first-order language, algorithmically decidable. In this paper, we consider one of such languages, - the language of the Computational Tree Logic (CTL). It is commonly used for program verification as it is capable of describing properties of computational processes, - in particular, properties of the binary relation used in the Kripke semantics.

The authors investigate the possibility of finding algorithmically first-order formulas defining the same classes of Kripke frames as the formulas of the language of CTL. It is well known the problem of finding first-order correspondents of propositional intuitionistic formulas is algorithmically undecidable. The authors reduce - using the Gödel translation of intuitionistic formulas into modal ones, and subsequently a translation of resultant modal formulas into CTL-formulas - the first-order correspondence problem for propositional intuitionistic formulas to the first-order correspondence problem for CTL-formulas on Kripke frames. As a result of this reduction, they prove that the first-order correspondence problem for CTL-formulas is algorithmically undecidable.

In the conclusion, the authors discuss some possible modifications of their construction for fragments of the language of CTL as well as algorithmic decidability of the CTL correspondence problem for first-order formulas.

Keywords: computational models, computational tree logic, first-order definability.

Acknowledgements. The work has been supported by RFBR, projects no. 16-07-01272, 17-03-00818, and 18-011-00869.

\section{References}

1. Clarke E.M., Grumberg O., Peled D. Model Checking. MIT Press, 1999, 314 p.

2. Karpov Yu.G. Model Checking: Vefification of Parallel and Distributive Software Systems. St. Petersburg, BHVPeterburg Publ., 2010, 560 p.

3. Emerson E.A., Halpern J.Y. Decision procedures and expressiveness in the temporal logic of branching time. J. of Comp. and Syst. Sciences. 1985, vol. 30, no. 1, pp. 1-24.

4. Boolos G.S., Jeffrey R.C. Computability and Logic. 3rd ed. Cambrige Univ. Press, 1989.

5. Blackburn P., de Rijke M., Venema Y. Modal logic. Cambridge Univ. Press, 2002.

6. Chagrov A.V., Zakharyaschev M.V. Modal Logic. Oxford Univ. Press, 1997.

7. Sahlqvist H. Completeness and correspondence in the first and second order semantics for modal logic. Proc. 3rd Scandinavian Logic Symp. Amsterdam, North-Holland, 1975, pp. 110-143.

8. Kracht M. How completeness and correspondence theory got married. Diamonds and Defaults. M. de Rijke (Ed.). 1993, pp. 175-214

9. Kracht M. Tools and Techniques in Modal Logic. Studies in Logic and the Foundations of Mathematics. Elsevier Publ., 1999, $142 \mathrm{p}$.

10. Balbiani P., Kikot S. Sahlqvist theorems for precontact logics. Advances in Modal Logic. 2012, vol. 9, pp. 55-70.

11. Kikot S. A new generalization of Sahlqvist theorem. Algebraic and Topological Methods in Non-classical Logics II. Barcelona, 2005, pp. 40-41.

12. Kikot S. An extension of Kracht's theorem to generalized Sahlqvist formulas. J. of Applied Non-Classical Logic. 2009, vol. 19 , no. 2, pp. 227-251.

13. Kikot S. Semantic characterization of Kracht's formulas. Advances in Modal Logic, 2010, vol. 8, pp. $218-234$.

14. Kikot S., Tsarkov D., Zakharyaschev M., Zolin E. Query Answering via Modal Definability with FaCT++: First Blood. Proc. of DL. 2013.

15. Kikot S., Zolin E. Modal definability of first-order formulas with free variables and query answering. J. of Applied Logic. vol. 11, 2013, pp. 190-216.

16. Chagrova L.A. An undecidable problem correspondence theory. J. of Symbolic Logic. 1991, vol. 56, iss. 4, pp. 1261-1272.

17. Mendelson E. Introduction to Mathematical Logic. Van Nostrand Reinhold Inc. Publ., 1964, 300 p. 
УДК 519.171 .4

DOI: 10.15827/0236-235X.123.598-604

Дата подачи статьи: 26.03.18

\title{
Модель группировки радиоэлектронных систем для оченки временных показателей надежности
}

\author{
С.В. Игнатьев ${ }^{1}$, д.т.н., профессор, начальник кафедры
}

Ю.А. Плакса ${ }^{1}$, к.т.н., доиент

А.В. Красников ${ }^{1}$, к.т.н., доиент

A.В. Дрожжжин 1, адъюнкт, drozhzhin-1991@mail.ru

1 Ярославское высшее военное училище противовоздушной обороны, кафедра автоматики и вычислительных средств, г. Ярославль, 150001, Россия

Эффективное применение комплексов специального назначения, основу которых составляют радиоэлектронные системы, предполагает выбор оптимальных методов эксплуатации, организации и проведения технического обслуживания, войскового ремонта и снабжения комплексов запасными инструментами и принадлежностями с целью обеспечения высокой степени готовности этих комплексов к применению по предназначению. Для этого создана система технической эксплуатации, эффективность функционирования которой зависит от взаимного расположения радиоэлектронных систем на местности.

Основные положения работы связаны с построением модели группировки радиоэлектронных систем, которая является основой для разработки инструментальной среды, с учетом пространственного расположения элементов группировки и временных соотношений между ними.

Построение модели группировки выполняется в два этапа. Первый этапа заключается в построении модели транспортной сети местности, которая представляет собой совокупность графа и матрицы достижимости. Такое представление позволяет получить все возможные маршруты между элементами транспортной сети. На втором этапе осуществляется описание группировки радиоэлектронных систем путем выделения на графе транспортной сети вершин особого типа, в которых размещаются элементы группировки радиоэлектронных систем. Далее производится построение пространственно-временной модели группировки радиоэлектронных систем, представляющей собой совокупность графа и подматриц достижимостей, где каждому маршруту между элементами группировки ставится в соответствие временной показатель (время движения по маршруту).

Пространственно-временная модель группировки, программно реализованная на языке С\#, позволяет рассчитать временные показатели надежности с учетом влияния различных факторов и оценить степень их влияния на коэффициент готовности.

Ключевые слова: группировка радиоэлектронных систем, пространственно-временная модель, транспортная сеть местности, граф, матрица достижимости, временная система маршрутов.

Актуальность поддержания сложных радиоэлектронных систем (РЭС) на заданном уровне надежности не вызывает сомнений. Для этого создана система технической эксплуатаџии (СТЭ), которая, в свою очередь, включает системы технического обслуживания, диагностирования и материально-технического обеспечения [1]. Функционирование первых двух систем направлено на увеличение времени наработки РЭС до отказа $\left(T_{\mathrm{O}}\right)$ и уменьшение их времени восстановления $\left(T_{\mathrm{B}}\right)$ соответственно.

На сегодняшний день исследования ведутся по каждой системе, причем в разных направлениях [2-6]. В основу таких исследований положены математические модели, учитывающие влияние различных параметров этих систем на надежность РЭС. Кроме того, они проводились при определенных ограничениях, одним из которых является допущение того, что РЭС полностью укомплектованы требуемыми материально-техническими ресурсами (МТР) и последние не оказывают никакого воздействия на $T_{\mathrm{O}}$ и $T_{\mathrm{B}}$. Такой подход не позволяет в полной мере оценить эффективность функционирования СТЭ при обеспечении заданного уровня надежности группировки РЭС, что приводит к необходимости более глубокого исследования процесса восстановления РЭС.

Опыт эксплуатации показывает, что эффективность функционирования СТЭ будет зависеть от ряда факторов. Прежде всего это взаимное расположение на местности элементов группировки РЭС, что определяет пространственную топологию группировки (так называемый пространственный параметр). Кроме того, в процессе эксплуатации возникает ряд задач [7]: доставка запасных частей, инструментов и принадлежностей, горюче-смазочных материалов, прибытие специалиста для ремонта и т.д. Их решение характеризуется временными показателями, которые, в свою очередь, являются составляющими времени восстановления: $T_{\mathrm{B}}=t_{\mathrm{K}}+t_{\mathrm{p}}+t_{\text {подг. }}+t_{\text {пер. }}+t_{\text {дост. }}+t_{\text {адм. }}$, где $t_{\mathrm{K}}-$ время поиска и локализации отказавшего элемента; $t_{\mathrm{p}}$ время устранения отказа; $t_{\text {подг. }}-$ время подготовки к включению; $t_{\text {пер. }}$ - время перерывов обслуживающего персонала; $t_{\text {дост. }}-$ время доставки исправного элемента; $t_{\text {адм. }}-$ время прибытия специалиста для ремонта [1]. Как правило, решение последних двух задач осуществляется с использованием транспортной сети местности (ТСМ), на которой расположена группировка РЭС. 


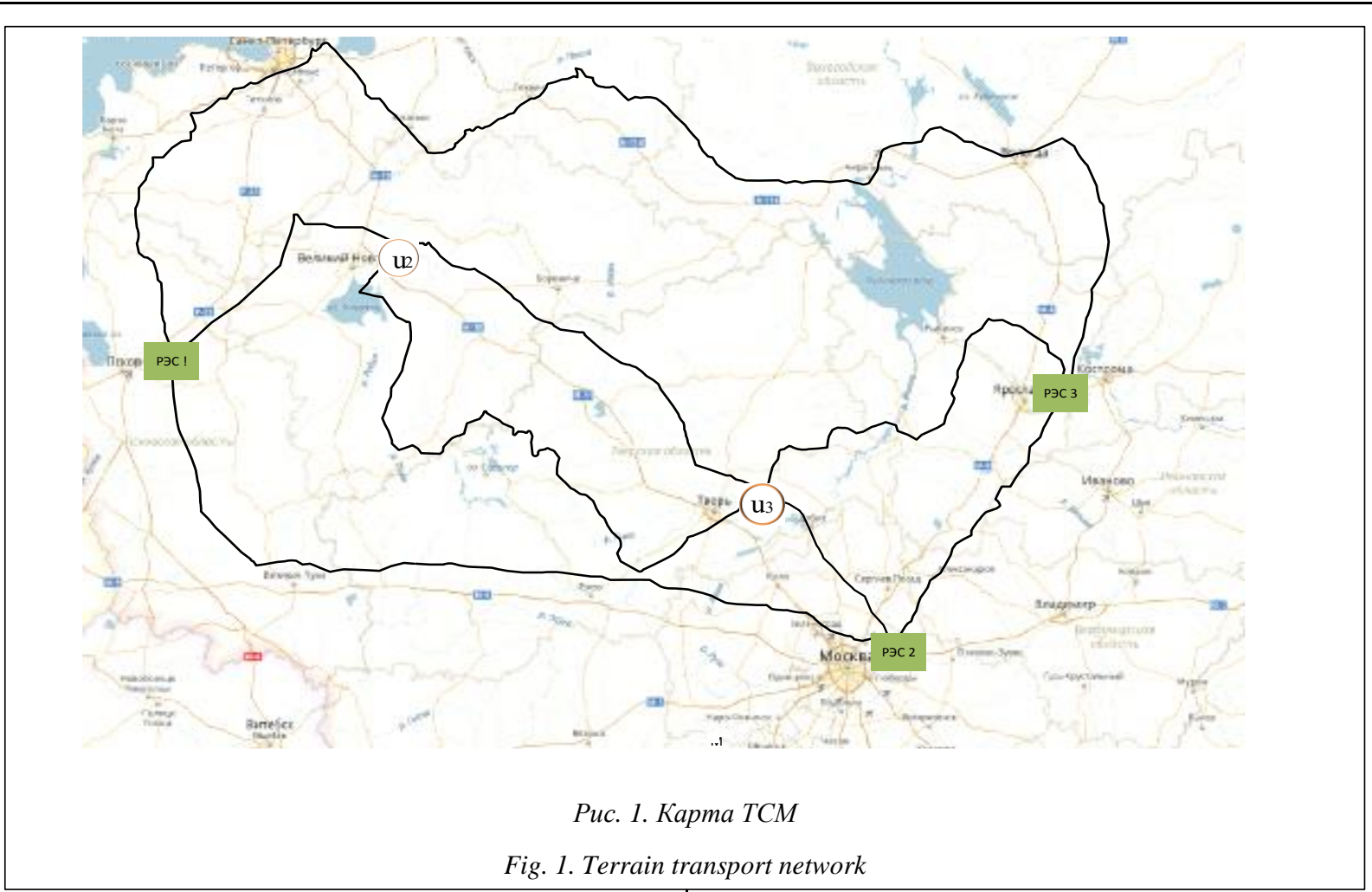

Учитывая это, время восстановления элемента группировки можно представить как $T_{\mathrm{B}}=T_{\text {Эг }}+T_{\mathrm{TC}}$, где $T_{\ni г}=t_{\mathrm{K}}+t_{\mathrm{p}}+t_{\text {подг. }}+t_{\text {пер. }}-$ время выполнения операций в элементе группировки; $T_{\mathrm{TC}}=t_{\text {дост. }}+$ $+t_{\text {адм. }}-$ время выполнения операций с использованием транспортной сети (ТС).

В этом случае расстояние $s$ между узлами ТСМ, в которых размещаются элементы группировки РЭС, и средняя скорость движения $v$ будут определять $T_{\mathrm{TC}}$ (так называемый временной параметр).

Для комплексного учета возможных ситуаций и проведения дальнейших исследований с оценкой показателей надежности, связанных с временными параметрами (коэффициент готовности, коэффициент технического использования, время восстановления), необходимо построить модель группировки РЭС, учитывающую пространственное положение ее элементов и временные соотношения между ними, которую будем называть пространственно-временной моделью группировки РЭС.

С учетом того, что группировка РЭС располагается на местности (на ТС), построение данной модели целесообразно осуществить в два этапа.

Первый этап предполагает построение модели TCM, на которой размещается группировка РЭС. На втором этапе производится описание группировки РЭС на модели ТСМ путем размещения в ее узлах элементов группировки.

\section{Первый этап (построение модели ТСМ)}

Рассмотрим абстрактный пример. Пусть имеется некая ТСМ, на которой размещается группировка РЭС (рис. 1).
Для ее формализации осуществим переход от концептуальной модели (разнотипных элементов, описанных в терминах предметной области) к ее математическому описанию (формальным однотипным). Очевидно, что наиболее просто это осуществимо с использованием теории графов [8].

Представим узловые пункты ТС (населенные пункты, элементы РЭС, пункты перегрузки груза и смены транспорта, развилки дорог и т.д.) вершинами (узлами) графа, а пути сообщения между этими пунктами (наземные, воздушные, водные) ребрами графа.

В результате получим мультиграф ТС (рис. 2): $G_{\Pi}=<U, R>$, где $U=\left\{u_{i} \mid i=1,2, \ldots, 5\right\}$ - множество вершин графа; $R=\left\{r_{k} \mid k=1,2, \ldots, 8\right\}$ - множество ребер графа [4].

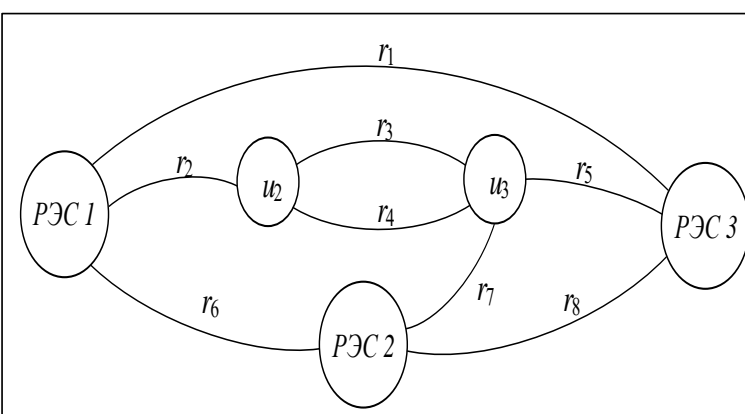

Рис. 2. Неориентированный мультиграф ТС

Fig. 2. Transport network undirected multigraph

В общем случае $G_{\Pi}=<U, R>$, где $U=\left\{u_{i} \mid i=1\right.$, $2, \ldots, I\}, I-$ количество вершин графа; $R=\left\{r_{k} \mid\right.$ $k=1,2, \ldots, K\}, K-$ количество ребер графа. 
Каждая вершина графа $G_{M}$ (рис. 3) нагружается кортежем

$$
e_{i}=\left[t_{i}, c_{i}\right],
$$

где $t_{i}-$ время выполнения определенных действий (время задержки) в $i$-м узле ТС (например: дозаправка транспортного средства (ТСp), оформление необходимых документов, перегрузка материальных ресурсов из одного ТСр в другое и т.д.), которые необходимо выполнить, чтобы продолжить дальнейшее движение; $c_{i}-$ стоимость выполнения этих действий в $i$-м узле ТС.

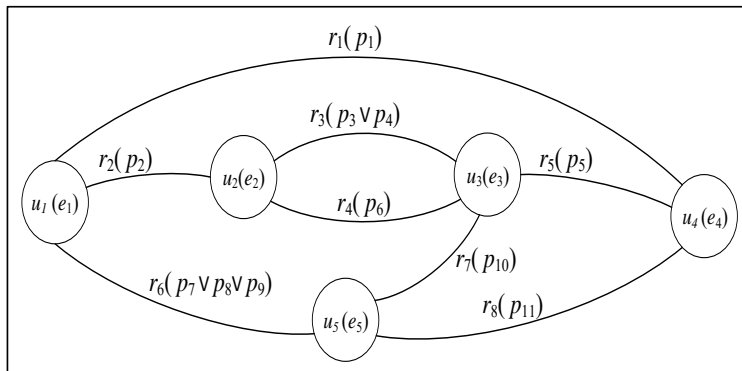

Puc. 3. Граф МTC

Fig. 3. Graph of transport route network

Ребра графа $G_{M}$ нагружены кортежем

$$
p=\left[r_{k}, s_{k}, \theta_{n}, v_{k}\left(\theta_{n}\right), g_{k}, c_{k}\left(\theta_{n}\right)\right],
$$

где $r_{k}$ - обозначение участка пути ТС (ребра графа); $s_{k}$ - протяженность участка пути ТС; $\theta_{n}-$ тип ТСp, движущегося по участку пути ТС; $v_{k}\left(\theta_{n}\right)-$ скорость $\mathrm{TCp}$, движущегося по участку пути ТС; $g_{k}-$ коэффициент изменения скорости ТСp; $c_{k}\left(\theta_{n}\right)-$ стоимость перевозки конкретным типом ТСр за единицу пути.

Исходя из вышеизложенного, в общем виде граф маршрутов ТС [8,9] опишется выражением

$G_{\mathrm{m}}=\langle(U, E) ;(R, P)\rangle$,

$U=\left\{u_{1}, u_{2}, \ldots, u_{i}, \ldots, u_{I}\right\}$,

$E=\left\{e_{1}, e_{2}, \ldots, e_{i}, \ldots e_{I}\right\}$,

$R=\left\{r_{1}, r_{2}, \ldots, r_{k}, \ldots, r_{K}\right\}$,

$P=\left\{p_{1}, p_{2}, \ldots, p_{l}, \ldots, p_{L}\right\}$

$e_{i}=\left[t_{i}, c_{i}\right], p_{l}=\left[r_{k}, s_{k}, \theta_{n}, v_{k}\left(\theta_{n}\right), g_{k}, c_{k}\left(\theta_{n}\right)\right]$,

$\theta_{n} \in \Theta, n=1,2, \ldots, N$.

Веса вершин и ребер графа (рис. 3) могут выступать в качестве их идентификаторов. Поэтому $G_{\mathrm{M}}$ опишем матрицей смежности взвешенного графа [9-11] (весовой матрицей смежности) $S\left(G_{\mathrm{M}}\right)=\left[s_{i j}\right]_{I \times I}$ вида

$$
s_{i j}=\left\{\begin{array}{l}
p_{l}, \text { если ребро } r_{k} \in R, \\
0, \text { если ребро } r_{k} \notin R .
\end{array}\right.
$$

В результате весовая матрица смежности $S\left(G_{\mathrm{M}}\right)$ для рассматриваемого графа будет иметь следующий вид:

$S\left(G_{\mathrm{u}}\right)=$\begin{tabular}{|c|c|c|c|c||}
\hline & $p_{2}$ & & $p_{1}$ & $\left(p_{7} \vee p_{8} \vee p_{9}\right)$ \\
\hline$p_{2}$ & & $\left(p_{3} \vee p_{4} \vee p_{6}\right)$ & & \\
\hline & $\left(p_{3} \vee p_{4} \vee p_{6}\right)$ & & $p_{5}$ & $p_{10}$ \\
\hline$p_{1}$ & & $p_{5}$ & & $p_{11}$ \\
\hline$\left(p_{7} \vee p_{8} \vee p_{9}\right)$ & & $p_{10}$ & $p_{11}$ & \\
\hline
\end{tabular}

Для получения возможных маршрутов между $i$-й и $j$-й вершинами графа $G_{M}-m_{i j}$, где $i=\overline{1,5}$, $j=\overline{1,5}$ и $i \neq j$, находится матрица достижимости:

$$
\begin{aligned}
& D(G)=\sum_{n=1}^{d(G)}[S(G)]^{n}= \\
& =S(G)+S(G)^{2}+\ldots S(G)^{n}+\ldots+S(G)^{d(G)},
\end{aligned}
$$

где $d(G)$ - диаметр графа $G_{\mathrm{M}}$.

При этом операцию умножения при возведении матрицы смежности в степень необходимо рассматривать как конкатенацию, а операцию сложения - как дизъюнкцию и учитывать только простые маршруты, в которых отсутствуют повторения вершин графа между начальным $e_{i}$ и конечным $e_{j}$ узлами маршрута: $e_{i} \neq \ldots \neq e_{q} \neq \ldots e_{j}$, то есть каждая вершина в одном маршруте должна встречаться один раз.

В общем виде

$$
\begin{aligned}
& D\left(G_{M}\right)=\bigvee_{n=1}^{d(G)}\left[S\left(G_{M}\right)\right]^{n}= \\
& =S\left(G_{M}\right) \vee S\left(G_{M}\right)^{2} \vee \ldots \vee S\left(G_{M}\right)^{n} \vee \ldots \vee S\left(G_{M}\right)^{d(G)} .
\end{aligned}
$$

Так, например, в соответствии с выражением (7) маршруты между узлами $e_{1}$ и $e_{2}$ опишутся следующим выражением:

$$
\begin{aligned}
& m_{1,2}=e_{1} p_{2} e_{2} \vee e_{1} p_{1} e_{4} p_{5} e_{3}\left(p_{3} \vee p_{4} \vee p_{6}\right) e_{2} \vee \\
& \vee e_{1}\left(p_{7} \vee p_{8} \vee p_{9}\right) e_{5} p_{10} e_{3}\left(p_{3} \vee p_{4} \vee p_{6}\right) e_{2} \vee \\
& \vee e_{1}\left(p_{7} \vee p_{8} \vee p_{9}\right) e_{5} p_{11} e_{4} p_{5} e_{3}\left(p_{3} \vee p_{4} \vee p_{6}\right) e_{2} \vee \\
& \vee e_{1} p_{1} e_{4} p_{11} e_{5} p_{10} e_{3}\left(p_{3} \vee p_{4} \vee p_{6}\right) e_{2} .
\end{aligned}
$$

Тогда с учетом примера (8) представим матрицу достижимости:

$$
D\left(G_{\mathrm{M}}\right)=\left\|\begin{array}{||l|l|l|l|l}
\hline & m_{1,2} & m_{1,3} & m_{1,4} & m_{1,5} \\
\hline m_{2,1} & & m_{2,3} & m_{2,4} & m_{2,5} \\
\hline m_{3,1} & m_{3,2} & & m_{3,4} & m_{3,5} \\
\hline m_{4,1} & m_{4,2} & m_{4,3} & & m_{4,5} \\
\hline m_{5,1} & m_{5,2} & m_{5,3} & m_{5,4} & \\
\hline
\end{array}\right\| .
$$

Содержимое ячеек матрицы (9) полностью определяет систему маршрутов ТС $[4,9]$.

В общем виде модель ТС запишется как $G_{\mathrm{м}}=\langle(U, E) ;(R, P)\rangle, U=\left\{u_{1}, u_{2}, \ldots, u_{i}, \ldots, u_{I}\right\}$, $E=\left\{e_{1}, e_{2}, \ldots, e_{i}, \ldots e_{I}\right\}, R=\left\{r_{1}, r_{2}, \ldots, r_{k}, \ldots, r_{K}\right\}$, $P=\left\{p_{1}, p_{2}, \ldots, p_{l}, \ldots, p_{L}\right\}$,

$e_{i}=\left[t_{i}, c_{i}\right], p_{l}=\left[r_{k}, s_{k}, \theta_{n}, v_{k}\left(\theta_{n}\right), g_{k}, c_{k}\left(\theta_{n}\right)\right]$, $\theta_{n} \in \Theta$. 


$$
D\left(G_{\mathrm{M}}\right)=\left\{\begin{array}{l}
m_{i, j}=\bigvee_{h}\left(e_{i} p_{x_{h}} e_{a_{h}} \ldots p_{y_{h}} \ldots e_{b_{h}} p_{z_{h}} e_{j}\right)_{h} ; \\
h=1,2, \ldots H_{i j} ; \\
\forall h: e_{i} \neq e_{a_{h}} \neq \ldots \neq e_{b_{h}} \neq e_{j} ; \\
e_{i}, e_{a_{h}}, e_{b_{h}}, e_{j} \in E ; \\
p_{x_{h}}, p_{y_{h}} \in P ; i=1,2, \ldots, I ; j=1,2, \ldots, I ; \\
\vdots \\
m_{i, j}=\bigvee_{h}\left(e_{i} p_{x_{h}} e_{a_{h}} \ldots \vee \ldots e_{b_{h}} p_{y_{h}} e_{j}\right)_{h} ; \\
h=1,2, \ldots ; \\
\forall h: e_{i} \neq e_{a_{h}} \neq \ldots \neq e_{b_{h}} \neq e_{j} ; e_{i}, e_{a_{h}}, e_{b_{h}}, e_{j} \in E ; \\
p_{x_{h}}, p_{y_{h}} \in P ; j=1,2, \ldots, I ; i=1,2, \ldots, I ; i \neq j .
\end{array}\right.
$$

В соответствии с выражением (10) количество маршрутов между начальным $e_{i}$ и конечным $e_{j}$ узлами ТС $H_{i j}$ будет равно количеству слагаемых по операции дизъюнкции.

\section{Второй этап (описание группировки РЭС на ТСМ)}

Для описания группировки РЭС выделим из рассматриваемого графа ТС вершины особого типа, в которых размещаются элементы группировки РЭС, и объединим их в множество $E^{\prime}: E^{\prime} \subseteq E$. Пусть для рассматриваемого графа ТС (рис. 2) это вершины $e_{1}, e_{4}, e_{5}: E^{\prime}=e_{1}, e_{4}, e_{5}$. В результате получим граф группировки РЭС (рис. 4).

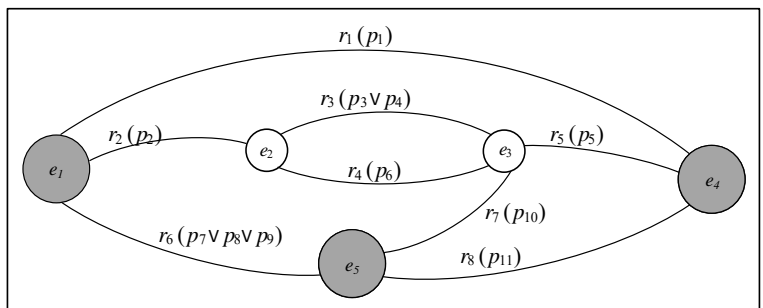

Рис. 4. Граф группировки РЭС

Fig. 4. Graph of radio-electronic system nest

Особенностью данных вершин является то, что попарное сочетание вершин множества образуют начало и конец маршрутов ТС. Другие вершины графа (рис. 4) не могут выступать в качестве начала и окончания маршрутов.

Матрица достижимости $D^{\prime}\left(G_{\mathrm{M}}\right)$ для вершин графа из множества $E^{\prime}$ получается из $D\left(G_{\mathrm{M}}\right)$ путем вычисления соответствующих строк и столбцов:

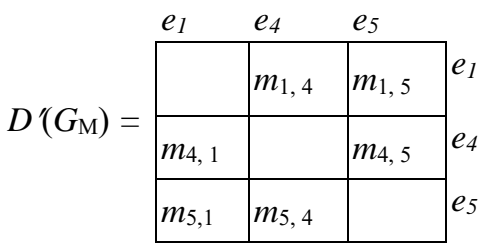

Следует отметить, что полученная подматрица является симметричной. Учтем сделанные ранее замечания (вес вершины (ребра) при движении в прямом и обратном направлениях одинаковый).
Для уменьшения количества вычислений будем использовать только те ячейки преобразованной матрицы достижимости, которые находятся выше (ниже) главной диагонали. Тогда система маршрутов между элементами группировки для рассматриваемого примера примет вид

$$
\begin{aligned}
& \mid \begin{array}{l}
m_{1}=e_{1} p_{1} e_{4} \\
m_{2}=e_{1} p_{7} e_{5} p_{11} e_{4} ;
\end{array} \\
& m_{3}=e_{1} p_{8} e_{5} p_{11} e_{4} ; \\
& m_{4}=e_{1} p_{9} e_{5} p_{11} e_{4} ; \\
& m_{5}=e_{1} p_{2} e_{2} p_{3} e_{3} p_{5} e_{4} ; \\
& m_{6}=e_{1} p_{2} e_{2} p_{4} e_{3} p_{5} e_{4} ; \\
& m_{1,4}=\left\{m_{7}=e_{1} p_{2} e_{2} p_{6} e_{3} p_{5} e_{4} ;\right. \\
& m_{8}=e_{1} p_{7} e_{5} p_{10} e_{3} p_{5} e_{4} ; \\
& m_{9}=e_{1} p_{8} e_{5} p_{10} e_{3} p_{5} e_{4} ; \\
& m_{10}=e_{1} p_{9} e_{5} p_{10} e_{3} p_{5} e_{4} ; \\
& m_{11}=e_{1} p_{2} e_{2} p_{3} e_{3} p_{10} e_{5} p_{11} e_{4} \text {; } \\
& m_{12}=e_{1} p_{2} e_{2} p_{4} e_{3} p_{10} e_{5} p_{11} e_{4} \text {; } \\
& m_{13}=e_{1} p_{2} e_{2} p_{6} e_{3} p_{10} e_{5} p_{11} e_{4} \text {. } \\
& \left\{\begin{array}{l}
m_{1}=e_{1} p_{7} e_{5} ; \\
m_{2}=e_{1} p_{8} e_{5} ;
\end{array}\right. \\
& m_{3}=e_{1} p_{9} e_{5} ; \\
& m_{4}=e_{1} p_{1} e_{4} p_{11} e_{5} ; \\
& m_{1,5}=\left\{\begin{array}{l}
m_{5}=e_{1} p_{2} e_{2} p_{3} e_{3} p_{10} e_{5} ; \\
m_{6}=e_{1} p_{2} e_{2} p_{4} e_{3} p_{10} e_{5} ;
\end{array} ;\right. \\
& m_{7}=e_{1} p_{2} e_{2} p_{6} e_{3} p_{10} e_{5} ; \\
& m_{8}=e_{1} p_{1} e_{4} p_{5} e_{3} p_{10} e_{5} ; \\
& m_{9}=e_{1} p_{2} e_{2} p_{3} e_{3} p_{5} e_{4} p_{11} e_{5} ; \\
& m_{10}=e_{1} p_{2} e_{2} p_{4} e_{3} p_{5} e_{4} p_{11} e_{5} ; \\
& m_{11}=e_{1} p_{2} e_{2} p_{6} e_{3} p_{5} e_{4} p_{11} e_{5} \\
& m_{1}=e_{4} p_{11} e_{5} \text {; } \\
& m_{2}=e_{4} p_{1} e_{1} p_{7} e_{5} ; \\
& m_{3}=e_{4} p_{1} e_{1} p_{8} e_{5} ; \\
& m_{4}=e_{4} p_{1} e_{1} p_{9} e_{5} ; \\
& m_{5}=e_{4} p_{5} e_{3} p_{10} e_{5} ; \\
& m_{6}=e_{4} p_{5} e_{3} p_{3} e_{2} p_{2} e_{1} p_{7} e_{5} \\
& m_{7}=e_{4} p_{5} e_{3} p_{3} e_{2} p_{2} e_{1} p_{8} e_{5} \\
& m_{4,5}=\left\{\begin{array}{l}
m_{8}=e_{4} p_{5} e_{3} p_{3} e_{2} p_{2} e_{1} p_{9} e_{5} ; \\
m_{9}=e_{4} p_{5} e_{3} p_{4} e_{2} p_{2} e_{1} p_{7} e_{5} ;
\end{array}\right. \\
& m_{10}=e_{4} p_{5} e_{3} p_{4} e_{2} p_{2} e_{1} p_{8} e_{5} ; \\
& m_{11}=e_{4} p_{5} e_{3} p_{4} e_{2} p_{2} e_{1} p_{9} e_{5} ; \\
& m_{12}=e_{4} p_{5} e_{3} p_{6} e_{2} p_{2} e_{1} p_{7} e_{5} ; \\
& m_{13}=e_{4} p_{5} e_{3} p_{6} e_{2} p_{2} e_{1} p_{8} e_{5} ; \\
& m_{14}=e_{4} p_{5} e_{3} p_{6} e_{2} p_{2} e_{1} p_{9} e_{5} ; \\
& m_{15}=e_{4} p_{1} e_{1} p_{2} e_{2} p_{3} e_{3} p_{10} e_{5} ; \\
& m_{16}=e_{4} p_{1} e_{1} p_{2} e_{2} p_{4} e_{3} p_{10} e_{5} ; \\
& m_{17}=e_{4} p_{1} e_{1} p_{2} e_{2} p_{6} e_{3} p_{10} e_{5}
\end{aligned}
$$

Для дальнейшего решения задачи преобразованную матрицу достижимости представим в виде набора подматриц достижимостей, в ячейках которых между вершинами $e_{i}$ и $e_{j}$ записывается только 
один $h$-й маршрут $m_{i j}^{h}$, где $h-$ номер маршрута в системе $m_{i j}$. Например, для рассматриваемого примера одна из набора подматриц достижимости будет иметь вид

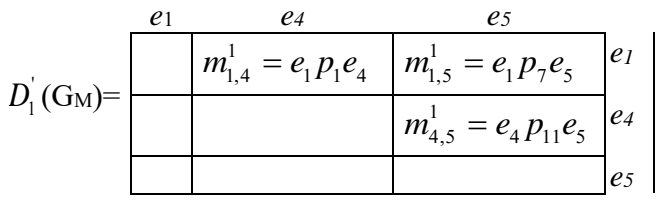

Из выражения (12) видно, что между вершинами $e_{1}$ и $e_{4}$ существуют 13 маршрутов, то есть $H_{1,4}=13$. Аналогично $H_{1,5}=11, H_{4,5}=17$. Тогда общее количество маршрутов между элементами группировки может быть вычислено как $H=H_{1,5}+$ $+H_{4,5}=41$.

В общем виде выражение для определения всех маршрутов между элементами группировки представим в виде

$$
H=\sum_{H_{i j}} \sum_{h} m_{i j}^{h} .
$$

Учитывая, что в одной ячейке подматрицы достижимости записывается один маршрут и выбор маршрута является (может быть) произвольным (осуществляется в произвольном порядке), количество подматриц достижимости $D^{\prime}\left(G_{\mathrm{M}}\right)$ для рассматриваемого примера определяется как число сочетаний из общего количества маршрутов по количеству элементов группировки: $Z=\frac{41 !}{(41-3) ! 3 !}=10660$ и в общем виде представлено как

$$
Z=C_{e^{\prime}}^{H},
$$

где $e^{\prime}-$ количество вершин особого типа (элементов группировки).

Для рассматриваемого примера набор подматриц достижимости представим в матричной форме:

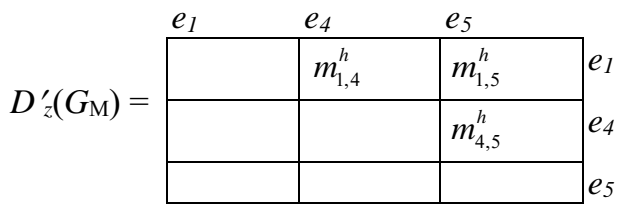

или в виде системы

$$
D_{z}^{\prime}\left(G_{\mathrm{M}}\right)=\left\{\begin{array}{l}
m_{i j}=\left(e_{i} p_{x_{h}} e_{a_{h}} \ldots p_{y_{h}} \ldots e_{b_{h}} p_{z_{h}} e_{j}\right)_{h} ; \\
h=1,2, \ldots H_{i j} ; \forall h: e_{i} \neq e_{a_{h}} \neq \ldots \neq e_{b_{h}} \neq e_{j} ; \\
e_{i}, e_{j} \in E^{\prime} \mid E^{\prime} \subseteq E ; \\
p_{x_{h}}, p_{y_{h}} \in P ; i=1,2, \ldots, I ; j=1,2, \ldots, I ; \\
\vdots \\
m_{i j}=\left(e_{i} p_{x_{h}} e_{a_{h}} \ldots \vee \ldots e_{b_{h}} p_{y_{h}} e_{j}\right)_{h} ; \\
h=1,2, \ldots H_{i j} ; \forall h: e_{i} \neq e_{a_{h}} \neq \ldots \neq e_{b_{h}} \neq e_{j} ; \\
e_{i}, e_{j} \in E^{\prime} \mid E^{\prime} \subseteq E ; \\
p_{x_{h}}, p_{y_{h}} \in P ; i=1,2, \ldots, I ; j=1,2, \ldots, I ; \\
z \in Z, Z=C_{e^{\prime}}^{H}, \\
H=\sum_{H_{i j}} \sum_{h} m_{i j}, e \in E^{\prime} \mid E^{\prime} \subseteq E .
\end{array}\right.
$$

Для каждого $h$-го маршрута системы рассчитывается $\mathrm{T}_{\mathrm{Tc}}$. Необходимые данные для этого содержатся в весах графа $e$ и $p$. Время движения на $n$-м типе ТС $\theta_{n}$ на $k$-м участке маршрута будет определяться как $t_{\text {движ. }}^{k}=\frac{S_{k}}{v_{k}\left(\theta_{n}\right) g_{k}}$, а время задержки в $i$-м узле маршрута - временем $t_{i}$.

Тогда общее время выполнения операций на всем маршруте ТС найдем как сумму соответствующих величин исходя из количества участков на этом маршруте и количества узлов, входящих в этот маршрут.

Например, для маршрута $m_{1}$ между вершинами $e_{1}$ и $e_{4}$ (см. (13)) получим следующее значение времени $\mathrm{T}_{\mathrm{TC}}$ :

$$
T_{T C_{1,4}}^{1}=t_{1}+\frac{s_{1}}{v_{1}\left(\theta_{1}\right) g_{1}}+t_{4}=t_{1}+t_{\text {дбиж }}^{1}+t_{4} .
$$

Учитывая описание маршрута выражением (20), систему маршрутов на примере выражения (12) можно представить временной системой марирутов:

$$
\begin{aligned}
& T_{m c 1}=t_{1}+t_{\text {движ. }}^{1}+t_{4} \text {; } \\
& T_{m c 2}=t_{1}+t_{\text {движ. }}^{7}+t_{5}+t_{\text {движ. }}^{11}+t_{4} \text {; } \\
& T_{\text {mс3 }}=t_{1}+t_{\text {движ. }}^{8}+t_{5}+t_{\text {движ. }}^{11}+t_{4} \text {; } \\
& T_{\text {mс4 }}=t_{1}+t_{\text {движ. }}^{9}+t_{5}+t_{\text {движ. }}^{11}+t_{4} \text {; } \\
& T_{m c 5}=t_{1}+t_{\text {движ. }}^{2}+t_{2}+t_{\text {движ. }}^{3}+t_{3}+t_{\text {движ. }}^{5}+t_{4} \text {; } \\
& T_{m c 6}=t_{1}+t_{\text {движ. }}^{2}+t_{2}+t_{\text {движ. }}^{4}+t_{3}+t_{\text {движ. }}^{5}+t_{4} \text {; } \\
& T_{T C_{1,4}}=\left\{T_{m c 7}=t_{1}+t_{\text {движ. }}^{2}+t_{2}+t_{\text {движ. }}^{6}+t_{3}+t_{\text {движ. }}^{5}+t_{4} ;\right. \\
& T_{m c 8}=t_{1}+t_{\text {движ. }}^{7}+t_{5}+t_{\text {движ. }}^{10}+t_{3}+t_{\text {движ. }}^{5}+t_{4} \text {; } \\
& T_{\text {mс9 }}=t_{1}+t_{\text {движ. }}^{8}+t_{5}+t_{\text {двик. }}^{10}+t_{3}+t_{\text {движ. }}^{5}+t_{4} \text {; } \\
& T_{m с 10}=t_{1}+t_{\text {движ. }}^{9}+t_{5}+t_{\text {движ. }}^{10}+t_{3}+t_{\text {движ. }}^{5}+t_{4} \text {; } \\
& T_{m с 11}=t_{1}+t_{\text {движ. }}^{2}+t_{2}+t_{\text {движ. }}^{3}+t_{3}+t_{\text {двнж. }}^{10}+t_{5}+t_{\text {движ. }}^{11}+t_{4} \text {; } \\
& T_{\text {mс12 }}=t_{1}+t_{\text {двик. }}^{2}+t_{2}+t_{\text {движ. }}^{4}+t_{3}+t_{\text {движ. }}^{10}+t_{5}+t_{\text {двик. }}^{11}+t_{4} \text {; } \\
& T_{m c 13}=t_{1}+t_{\text {движ. }}^{2}+t_{2}+t_{\text {движ. }}^{6}+t_{3}+t_{\text {движ. }}^{10}+t_{5}+t_{\text {движ. }}^{11}+t_{4} .
\end{aligned}
$$

В общем виде $T_{\mathrm{TC}}$ между вершинами $e_{i}$ и $e_{j}$ на $h$-м маршруте запишется как

$$
T_{T C_{i, j}}^{h}=\sum_{i} t_{i}+\sum_{k} \frac{S_{k}}{v_{k}\left(\theta_{n}\right) g_{k}}=\sum_{i} t_{i}+\sum_{k} t_{\text {движ. }}^{k} .
$$

В итоге получим пространственно-временную модель группировки РЭС $H$, представляющую собой совокупность графа (3) и подматриц достижимостей (19), где каждому $h$-му маршруту между вершинами $e_{i}$ и $e_{j}$ ставится в соответствие время $T_{\mathrm{TC}}$ на этом маршруте.

В общем виде пространственно-временная модель группировки РЭС запишется как $H=G_{M}$, $D_{z}^{\prime \prime}\left(G_{M}\right)$, где

$$
\begin{aligned}
& G_{\mathrm{M}}=\langle(U, E) ;(R, P)\rangle, U=\left\{u_{1}, u_{2}, \ldots, u_{i}, \ldots, u_{I}\right\}, \\
& E=\left\{e_{1}, e_{2}, \ldots, e_{i}, \ldots e_{I}\right\}, R=\left\{r_{1}, r_{2}, \ldots, r_{k}, \ldots, r_{K}\right\}, \\
& P=\left\{p_{1}, p_{2}, \ldots, p_{l}, \ldots, p_{L}\right\}, \\
& e_{i}=\left[t_{i}, c_{i}\right], p_{l}=,\left[r_{k}, s_{k}, \theta_{n}, v_{k}\left(\theta_{n}\right), g_{k}, c_{k}\left(\theta_{n}\right)\right], \\
& \theta_{n} \in \Theta ;
\end{aligned}
$$




$$
D_{z}^{\prime \prime}(G \mathrm{M})=\left\{\begin{array}{l}
m_{i j}=\left(e_{i} p_{x_{h}} e_{a_{h}} \ldots p_{y_{h}} \ldots e_{b_{h}} p_{z_{h}} e_{j}\right)_{h}, \\
T_{T C_{i, j}}^{h}=\sum_{i} t_{i}+\sum_{k} t_{\text {движ. }}^{k} ; \\
h=1,2, \ldots H_{i j} ; \forall h: e_{i} \neq e_{a_{h}} \neq \ldots \neq e_{b_{h}} \neq e_{j} ; \\
e_{i}, e_{j} \in E^{\prime} \mid E^{\prime} \subseteq E ; \\
p_{x_{h}}, p_{y_{h}} \in P ; i=1,2, \ldots, I ; j=1,2, \ldots, I ; \\
\vdots \\
m_{i j}=\left(e_{i} p_{x_{h}} e_{a_{h}} \ldots \vee \ldots e_{b_{h}} p_{y_{h}} e_{j}\right)_{h}, \\
T_{T C_{i, j}}^{h}=\sum_{i} t_{i}+\sum_{k} t_{\text {движ. }}^{k} ; \\
h=1,2, \ldots H_{i j} ; \forall h: e_{i} \neq e_{a_{h}} \neq \ldots \neq e_{b_{h}} \neq e_{j} ; \\
e_{i}, e_{j} \in E^{\prime} \mid E^{\prime} \subseteq E ; \\
p_{x_{h}}, p_{y_{h}} \in P ; i=1,2, \ldots, I ; j=1,2, \ldots, I ; \\
z \in Z, Z=C_{e^{\prime}}^{H}, H=\sum_{H_{i j}} \sum_{h} m_{i j}, e \in E^{\prime} \mid E^{\prime} \subseteq E .
\end{array}\right.
$$

Модель программно реализована на языке программирования С\# (получены свид. о рег. прогр. для ЭВМ № 2015661720 и № 2017616840). Интерфейс представлен на рисунках (см. рис. 5 и http:// www.swsys.ru/uploaded/image/2018-3/2018-3-dop/ 13.jpg, http://www.swsys.ru/uploaded/image/20183/2018-3-dop/14.jpg, http://www.swsys.ru/uploaded/ image/2018-3/2018-3-dop/15.jpg).

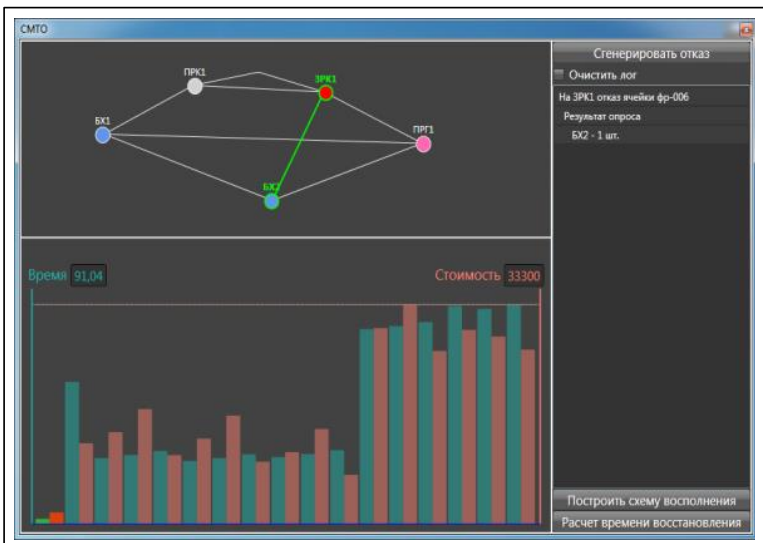

Рис. 5. Пример работы программы по расчету времени и стоимости движения

Fig. 5. The example of program operation in calculating movement time and cost
Использование данного программного продукта позволяет рассчитывать временные показатели надежности группировки РЭС и проводить исследования с учетом влияния на них следующих факторов: расположение элементов группировки на местности, расстояние между элементами группировки, тип используемого транспорта, скорость движения, условия, в которых осуществляется движение, время выполнения работ.

\section{Литература}

1. Анисимов О.В., Беляков Р.А., Игнатьев С.В., Каменский И.Е., Мещеряков В.Д., Приступюк А.И., Тихонов В.Б., Черваков В.О. Основы эксплуатации радиотехнических систем. Ярославль: Изд-во Филиала ВКА им. А.Ф. Можайского, 2015. $200 \mathrm{c}$.

2. Давыдов П.С. Техническая диагностика радиоэлектронных систем. М.: Радио и связь, 1988. 256 с.

3. Дорохов А.Н., Керножицкий В.А., Миронов А.Н., Шестопалова О.Л. Обеспечение надежности сложных технических систем. СПб: Лань, 2016. 352 с.

4. Анисимов О.В., Осипов А.А., Харитонов А.В., Беляков Р.А. Техническое обслуживание зенитного ракетного вооружения в системе ВКО // Вестн. ВУНЦ ВВС. 2012. Вып. 15. Ч. 1. C. $34-38$

5. Анисимов О.В., Попов Т.А. Метод информационной поддержки процесса диагностирования сложных технических комплексов на основе паттернов элементов электрических схем радиоэлектронной аппаратуры // Теоретические и прикладные проблемы развития и совершенствования автоматизированных систем управления военного назначения: сб. тез. II Всерос. науч.-технич. конф. СПб: 2015. С. 16-17.

6. Анисимов О.В., Курчидис В.А., Приветень А.С. Дескриптивная модель радиоэлектронной аппаратуры на основе онтологий для автоматизации информационной поддержки обслуживающего персонала при диагностировании сложных технических комплексов // Наукоемкие технологии в космических исследованиях Земли. 2016. Т. 8. № 3. С. 72-77.

7. Медведев В.М., Мищенко В.И., Солоха Н.Г. Развитие концепции эксплуатации изделий // Вестн. ОГУ. 2008. № 85. C. $149-157$.

8. Черкесов Г.Н. Оценка надежности систем с учетом ЗИП. СПб: БХВ-Петербург, 2012. 480 с.

9. Игнатьев С.В., Тихонов В.Б., Красников А.В., Осипов А.А. Пространственно-временная модель транспортной сети системы материально-технического обеспечения эксплуатации группировки радиоэлектронных средств // Программные продукты и системы. 2017. № 3. С. 510-517.

10. Оре О. Теория графов. М.: Наука, 1980. 336 с.

11. Горбатов В.А., Горбатов А.В., Горбатова М.В. Дискретная математика. М.: Астрель, 2003. 447 с.

12. Кристофидес Н. Теория графов. Алгоритмический подход. М.: Мир, 1978. 432 с.
Software \& Systems

DOI: $10.15827 / 0236-235 X .123 .598-604$
Received 26.03.18

2018, vol. 31 , no. 3 , pp. 598-604

\section{A nested model of radio-electronic systems for estimation of temporary reliability}

S.V. Ignatev ${ }^{1}$, Dr.Sc. (Engineering), Professor, Head of Chair

Yu.A. Plaksa ${ }^{1}$, Ph.D. (Engineering), Associate Professor

A.V. Krasnikov ${ }^{1}$, Ph.D. (Engineering), Associate Professor

A.V.Drozhin ${ }^{1}$, adjunct,drozhzhin-1991@mail.ru

${ }^{1}$ Yaroslavl Higher Military Air Defense College, Yaroslavl, 150001, Russian Federation

Abstract. The effective intended application of special-purpose complexes based on radio-electronic systems involves a proper choice of optimal exploitation methods, as well as organization of maintenance, first line repair and supply of the sys- 
tems with replacement tools and supplies to provide high readiness of the systems for using as intended. For this purpose, there is a system of maintenance with the operating effectiveness depending on the relative position of the radio-electronic systems in a terrain.

The essence of the article implies the construction of a nested model of radio-electronic systems designed to develop environment tools allowing to estimate temporary reliability characteristics of the nested radio-electronic systems as well as to undertake the study taking into account a relative position of nest elements and temporary correlation between them.

The construction of the nest model has two stages. The first one is the construction of a terrain transport network representing a combination of a graph and a reachability matrix. The approach allows obtaining all possible routes between transport network elements. The second stage includes a description of radio-electronic nest systems by highlighting special type apexes in the transportation network, which include nest radio-electronic systems elements. Then there goes the construction of a spatial and temporary nested model of radio-electronic systems that represens the combination of a graph and reachability submatrixes with each route being relevant of temporary features (the route movement time).

The spatial and temporary nested model is implemented in C\#. It allows calculating temporal reliability indicators taking into account the influence of various factors and estimating the degree of their influence on the availability factor.

Keywords: radio-electronic nested systems, spatial and temporary model, terrain transport network, graph, attainability matrix, temporary route system.

\section{References}

1. Anisimov O.V., Belyakov R.A., Ignatev S.V., Kamensky I.E., Meshcheryakov V.D., Pristupyuk A.I., Tikhonov V.B., Chervakov V.O. Operation Basics of Radio Engineering Systems. Yaroslavl, 2015, 200 p.

2. Davydov P.S. Technical Diagnostics of Radio Electronic Systems. Moscow, Radio i svyaz Publ., 1998, 256 p.

3. Dorokhov A.N., Kernozhitsky V.A., Mironov A.N., Shestopalova O.L. Ensuring the Reliability of Complex Technical Systems. 2nd ed., St. Petersburg, Lan Publ., 2016, 352 p.

4. Anisimov O.V., Osipov A.A., Kharitonov A.V., Belyakov R.A. Maintenance of surface-to-air missile weapons in the aerospace defense system. Bulletin of Air Force Academy. 2012, iss. 15, part 1, pp. 34-38 (in Russ.).

5. Anisimov O.V., Popov T.A. The method of informational support of diagnosing complex technical complexes based on the patterns of elements of radioelectronic equipment electrical circuits. Proc. 2nd All-Russ. Sci. and Techn. Conf. "Theoretical and Applied Problems of Development and Improvement of Military Automated Control Systems". St. Petersburg, 2015, pp. 16-17 (in Russ.).

6. Anisimov O.V., Kurchidis V.A., Priveten A.S. A descriptive model of radio electronic equipment based on ontologies for automation of maintenance personnel information support in diagnosing complex technical complexes. High Tech in Earth Space Research. 2016, vol. 8, no. 3, pp. 72-77 (in Russ.).

7. Medvedev V.M., Mishchenko V.I., Solokha N.G. Development of the concept of product operation. Vestnik of OSU. 2008, no. 85, pp. 149-157 (in Russ.).

8. Cherkesov G.N. Evaluation of System Reliability with Regard to Spare Parts. St. Petersburg, BHV-Peterburg Publ., $2012,480 \mathrm{p}$.

9. Ignatev S.V., Tikhonov V.B., Krasnikov A.V., Osipov A.A. A spatio-temporal model of a material and technical resources traffic network of a radio-electronic facilities group exploitation. Software \& Systems. 2017, iss. 3, pp. $510-516$ (in Russ.).

10. Ore O. Theory of Graphs. American Mathematical Society Publ., 1962, 284 p. (Rus. ed.: Moscow, Nauka Publ., 1980, 336 p.).

11. Gorbatov V.A., Gorbatov A.V., Gorbatova M.V. Discrete Mathematics. Moscow, Astrel Publ., 2003, 447 p

12. Christofides N. Graph Theory: An Algorithmic Approach. Academic Press, 1975, 415 p. (Rus. ed.: Moscow, Mir Publ., 1978, 432 p.).

\section{Примеры бибциографического описания статьи}

1. Игнатьев С.В., Пцакса Ю.А., Красников А.В., Дрожжин А.В. Модель группировки радиоэлектронных систем дия оценки временных показателей надежности // Программные продукты и системы. 2018. T. 31. № 3. C. 598-604. DOI: 10.15827/0236-235X.123.598-604.

2. Ignatev S.V., Plaksa Yu.A., Krasnikov A.V., Drozhin A.V. A nested model of radio-electronic systems for estimation of temporary reliability. Software \& Systems. 2018, vol. 31, no. 3, pp. 598-604 (in Russ.). DOI: $10.15827 / 0236-235 X .123 .598-604$. 
УДК 004.4

DOI: $10.15827 / 0236-235 X .123 .605-613$

\title{
F-Ranking: компьютерная система для ранжирования нечетких иисел
}

\author{
A.B. Радаев 1, магистрант, rad.yyhh@yandex.ru \\ A.B. Коробов 1, аспирант, alexander.korobov.1993@gmail.com \\ Б.И. Яuало 1, д.m.H., npoфpeccop, yatsalo@gmail.com
}

1 Обнинский институт атомной энергетики - филиал "Наиионального исследовательского ядерного университета "МИФИ", г. Обнинск, 249040, Россия

Во многих областях своей деятельности человек сталкивается с неопределенностями, одним из способов учета и анализа которых является использование нечетких множеств, нечеткой логики и нечетких чисел в частности. Использование нечетких чисел в рамках анализа решений неизбежно ведет к задачам их сравнения и ранжирования.

Большинство существующих систем, использующих нечеткие числа, несмотря на разнообразие методов ранжирования, применяют в своей работе лишь методы дефаззификации. Однако замена нечеткого числа одним действительным числом (как и замена плотности распределения вероятностей соответствующим математическим ожиданием) неизбежно ведет к сужению и потере информации, содержащейся в исходном нечетком числе.

В работе представлена оригинальная компьютерная система F-Ranking для ранжирования нечетких чисел различного типа: в качестве входных могут использоваться треугольные, трапециевидные и кусочно-линейные (в том числе кусочно-непрерывные сверху) нечеткие числа, а также синглтоны. В системе реализованы три метода ранжирования нечетких чисел, основанных на дефаззификации (методы центра тяжести, медианы и интеграла средних значений альфа-срезов), а также два метода ранжирования, основанные на оценке нечеткой приемлемости рангов (Fuzzy Rank Acceptability Analysis) с использованием двух (Юаня и интегрального) нечетких отношений предпочтения. Для последних двух методов доступны также нечеткая мера предпочтения одного нечеткого числа над другим и нечеткие индексы приемлемости рангов (Fuzzy Rank Acceptability Indexes).

В статье дано краткое описание алгоритмов указанных методов. Проведен обзор существующих систем, которые в той или иной степени могут быть использованы для ранжирования нечетких чисел. Представлены структура системы F-Ranking, входные и выходные формы для рассматриваемых методов ранжирования. Приведены примеры ранжирования нечетких чисел с использованием реализованных методов, иллюстрирующие как отличительные особенности самих методов, так и возможности всей системы F-Ranking в целом.

Ключевые слова: нечеткое множество, нечеткое число, ранжирование нечетких чисел, методы дефаззификачии, методы попарного сравнения, нечеткая система.

Одной из особенностей человеческого интеллекта является возможность принимать решения в условиях неполной информации и неопределенности. Теория вероятностей и теория нечетких множеств представляют в настоящее время основные методологические направления для учета и анализа неопределенностей самой различной природы. На сегодняшний день нечеткие множества находят применение в самых разных научно-технических и социально-экономических областях человеческой деятельности $[1,2]$.

Нечеткие числа представляют собой важное и востребованное направление в рамках теории нечетких множеств [3-5]. При этом ранжирование нечетких чисел является одной из ключевых проблем теории нечетких множеств [6]. В отличие от действительных чисел нечеткие числа не имеют естественного способа (очевидного и/или основанного на применении интуитивно понятных аксиом) их сравнения и ранжирования. В настоящее время существует более 40 методов ранжирования нечетких чисел $[3,4]$. В данной работе реализованы три метода ранжирования с использованием дефаззификации нечетких чисел, а также два метода ранжирования на основе попарного сравнения с применением нечетких отношений предпочтения.

\section{Базовые понятия теории нечетких множеств} и нечетких чисел

Нечеткое множество (см. [5, 7]) представляет собой расширение классического понятия множества, в котором функция принадлежности элемента множеству может принимать любые значения в интервале [0, 1].

Определение 1. Нечеткое число (fuzzy number) $Z$ представляет собой выпуклое, нормальное и ограниченное нечеткое множество, определенное на множестве действительных чисел $\mathbb{R}$, с непрерывной или кусочно-непрерывной сверху функцией принадлежности $\mu_{z}(x) \in[0,1]$ (см. $\left.[5,7]\right)$.

Таким образом, предполагается наличие действительных чисел $c_{1}, c_{2}, c_{1} \leq c_{2}$, таких, что

$Z=\left\{\left(x, \mu_{z}(x)\right): \mu_{z}(x)>0, x \in\left(c_{1}, c_{2}\right)\right.$,

$\left.\mu_{z}(x)=0, x \notin\left[c_{1}, c_{2}\right]\right\}$.

Всюду далее $\mathbb{F}$ представляет множество нечетких чисел согласно определению 1.

Замечание 1. Если $c_{1}=c_{2}=c, Z=c$ является синглтоном (singleton) и $\mu_{z}(c)=1$.

Замечание 2. Строго говоря, условие $\mu_{z}\left(c_{1}\right)=$ $=\mu_{z}\left(c_{2}\right)=0$ не является необходимым и часто используется для удобства, подчеркивая тем самым 
наиболее используемый в приложениях вид нечетких чисел.

Определение 2. $\alpha$-срез ( $\alpha$-cut) нечеткого числа $Z, \alpha \in(0,1]$, представляет собой четкое множество: $Z_{\alpha}=\left[A_{\alpha}, B_{\alpha}\right]=\left\{x \in \mathbb{R} \mid \mu_{Z}(x) \geq \alpha\right\}$ (см. [5, 7]).

Для $\alpha=0$ положим $\left[A_{0}, B_{0}\right]=\left[c_{1}, c_{2}\right]$ (здесь $c_{1}$, $c_{2}$ - граничные значения согласно (1)), тогда нечеткое число $Z$ может быть идентифицировано с множеством $\alpha$-срезов:

$$
Z=\left\{\left[A_{\alpha}, B_{\alpha}\right]\right\}, \alpha \in[0,1] \text {. }
$$

Определение 3. Нечеткое отношение предпочтения (fuzzy preference relation) представляет собой бинарное отношение $R=\left(\left(Z_{i}, Z_{j}\right), \mu_{R}\left(Z_{i}, Z_{j}\right)\right)$, в котором нечеткая мера $\mu_{R}\left(Z_{i}, Z_{j}\right)$ отражает степень предпочтения нечеткого числа $Z_{i}$ над $Z_{j}$.

Определение 4. Пусть $R$ - нечеткое отношение предпочтения на $\mathbb{F} \times \mathbb{F}$, тогда для любых нечетких чисел $Z_{i}, Z_{j} \in \mathbb{F}$ их нечеткое ранжирование определяется следующим образом [8]:

$$
\begin{aligned}
& Z_{i} \succeq Z_{j}, \text { если } \mu_{R}\left(Z_{i}, Z_{j}\right) \geq 0.5 ; \\
& Z_{i} \succ Z_{j}, \text { если } \mu_{R}\left(Z_{i}, Z_{j}\right)>0.5 ; \\
& Z_{i} \sim Z_{j}, \text { если } \mu_{R}\left(Z_{i}, Z_{j}\right)=0.5 .
\end{aligned}
$$

\section{Ранжирование нечетких чисел}

Методы ранжирования нечетких чисел можно разделить на три основные группы $[3,4]$ :

- методы дефаззификации;

- методы, основанные на оценке расстояния до эталонного множества;

- методы попарного сравнения.

В данной работе рассматриваются методы дефаззификации и попарного сравнения, представляющие собой наиболее востребованные методы ранжирования нечетких чисел.

Метод дефаззификации основан на представлении нечеткого числа $A$ соответствующим методу четким (crisp) значением, заменяющим исходное нечеткое число в последующих оценках. В данной работе используются три метода дефаззификации: метод иентра тяжести (Centroid Index или метод Ягера $\left.Y_{1}\right)$, метод медианы $\left(m_{A}\right)$ и метод интеграла средних значений $\alpha$-срезов (метод Ягера $Y_{2}$ ) [3].

Метод ицентра тяжести. Для нечеткого числа $A$, определенного на отрезке $\left[c_{1}, c_{2}\right]$ (см. определение 1 ), дефаззификация по методу центра тяжести происходит согласно следующей формуле [3, 9]:

$$
C I(A)=\frac{\int_{c_{1}}^{c_{2}} x \mu_{A}(x) d x}{\int_{c_{1}}^{c_{2}} \mu_{A}(x) d x},
$$

где $C I(A)$ представляет собой центроид-индекс. Аналогом $C I(A)$ является математическое ожидание случайной величины, заданной с плотностью распределения вероятностей $\mu_{A}(x) / \mathrm{S}$, где $S=\int_{c_{1}}^{c_{2}} \mu_{A}(x) d x$ (площадь под кривой функции принадлежности) $[3,10]$.
Метод медианы. Медианным значением $m_{A}$ нечеткого множества $A$, определенного на $\left[c_{1}, c_{2}\right]$, называется такое число, для которого справедливо выражение [11]:

$$
\int_{c_{1}}^{m_{A}} \mu_{A}(x) d x=\int_{m_{A}}^{c_{2}} \mu_{A}(x) d x .
$$

Геометрически медиана представляет собой такую точку на оси абсцисс, что проведенный через нее перпендикуляр делит площадь плоской фигуры, ограниченной функцией принадлежности нечеткого множества, на две равные части.

Метод интеграла средних значений $\alpha$-срезов. Для нечеткого числа $Z$, представленного согласно (2), по методу Ягера $Y_{2}$ вычисляется следующий интеграл [3]:

$$
Y_{2}(Z)=\int_{0}^{1} M(Z) d \alpha,
$$

где $M(Z)$ - среднее значение $\alpha$-среза $\left[A_{\alpha}, B_{\alpha}\right]$ : $M(Z)=\left(A_{\alpha}+B_{\alpha}\right) / 2$.

Методы попарного сравнения. В рамках системы ранжирования F-Ranking реализованы два метода попарного сравнения, основанные на нечетком анализе приемлемости рангов (Fuzzy Rank Acceptability Analysis, FRAA) с применением интегрального нечеткого отношения предпочтения $F R A A_{I}[8]$, а также нечеткого отношения предпочтения Юаня $[4,8]-F R A A_{Y}$.

Интегральное отношение предпочтения $R_{I}=$ $=\left(Z_{i}, Z_{j}, \mu_{I}\left(Z_{i}, Z_{j}\right)\right)$ основывается на вычислении площади $S_{I}\left(Z_{i j}\right)$ под функцией принадлежности нечеткого числа $Z_{i j}=Z_{i}-Z_{j}=\left\{\left[A_{\alpha}, B_{\alpha}\right]\right\}$, а также площади $S_{I}^{+}\left(Z_{i j}\right)$ под положительной частью $(x \geq 0)$ данной функции принадлежности:

$$
S_{I}^{+}\left(Z_{i j}\right)=\int_{0}^{1}\left(B_{\alpha} \theta\left(B_{\alpha}\right)-A_{\alpha} \theta\left(A_{\alpha}\right)\right) d \alpha,
$$

где $\theta(x)$ - функция Хэвисайда: $\theta(x)=\{1, x \geq 0 ; 0$, $x<0\}$.

Степень предпочтения $Z_{i}$ над $Z_{j}$ вычисляется по формуле

$$
\mu_{I}\left(Z_{i}, Z_{j}\right)=S_{I}^{+}\left(Z_{i j}\right) / S_{I}\left(Z_{i j}\right), S_{I}\left(Z_{i j}\right)>0
$$

(для четких/crisp чисел $Z_{i}, Z_{j}, S_{I}\left(Z_{i j}\right)=0$, для этого случая формула (8) имеет соответствующую естественную модификацию $[8,12])$.

Для отношения предпочтения Юаня степень предпочтения $Z_{i}$ над $Z_{j}, \mu_{Y}\left(Z_{i}, Z_{j}\right)$, также вычисляется по формуле (8) (с заменой нижнего индекса $I$ на $Y$ ), однако $S_{Y}^{+}$интерпретируется в этом случае как расстояние от положительной части нечеткого числа $Z_{i j}=Z_{i}-Z_{j}=\left\{\left[A_{\alpha}, B_{\alpha}\right]\right\}$ до оси ОҮ и вычисляется по формуле

$$
S_{Y}^{+}\left(Z_{i j}\right)=\int_{0}^{1}\left(B_{\alpha} \theta\left(B_{\alpha}\right)+A_{\alpha} \theta\left(A_{\alpha}\right)\right) d \alpha,
$$

при этом

$$
S_{Y}\left(Z_{i j}\right)=S_{Y}^{+}\left(Z_{i j}\right)+S_{Y}^{+}\left(Z_{j i}\right) .
$$

Нечеткий анализ приемлемости рангов (FRAA; Fuzzy Rank Acceptability Analysis). Рассмотренные выше нечеткие отношения предпочтения использу- 
ются в нечетком анализе приемлемости ранга для ранжирования нечетких чисел $[8,12]$. Метод FRAA базируется на оценке индексов нечеткой приемлемости рангов (Fuzzy Rank Acceptability Indices, FRAIs). Для оценки FRAIs используется модель оценки нечеткой меры утверждения/события ранга (FRS, Fuzzy Rank Statement) $F_{i k}[8]: F_{i k}=\left(Z_{i}, k\right)=\left\{Z_{i}\right.$ имеет ранг $k\}, i, k=1, \ldots, n$.

Нечеткий индекс приемлемости ранга (FRAI) $\mu(i, k)$ определяется как нечеткая мера утверждения (нечеткого логического выражения) $F_{i k}: \mu(i, k)=$ $=\mu_{R}\left(F_{i k}\right)$ для заданного отношения предпочтения $R$ (детальное изложение свойств метода FRAA представлено в [12]). Для нечетких чисел $Z_{i}, i=1, \ldots, n$, и нечеткого отношения предпочтения $R$ нечеткое число $Z_{m}$ имеет $F R A A_{R}$ ранг $k \in\{1, \ldots, n\}, r\left(Z_{m}\right)=k$, если $Z_{m}$ имеет максимальный нечеткий индекс приемлемости для ранга $k$ :

$\mu_{R}(m, k)=\max _{\mathrm{i}=1, \ldots, \mathrm{n}} \mu_{R}(i, k), 1 \leq m, k \leq n$.

Свойства FRAA-ранжирования на основе отношений предпочтения $R_{I}\left(F R A A_{I}\right)$ и $R_{Y}\left(F R A A_{Y}\right)$ исследованы в [12].

\section{Существующие системы ранжирования нечетких чисел}

На сегодняшний день существуют различные программные комплексы/системы, использующие нечеткие числа, в которых применяются методы сравнения и ранжирования нечетких чисел. Несмотря на разнообразие алгоритмов ранжирования, в указанных нечетких системах в основном применяются методы дефаззификации. При этом существует лишь несколько систем, непосредственно предназначенных для ранжирования нечетких чисел.

Fuzzy Logic Designer (www.mathworks.com/help/ fuzzy/fuzzylogicdesigner-app.html). Реализованы логические операции над нечеткими множествами со следующими функциями принадлежности: треугольная, трапециевидная, колоколообразная, Гаусса, z-образная и s-образная. Имеется возможность производить ранжирование методами дефаззификации (центр тяжести, среднее максимума, наименьшее максимума, наибольшее максимума); экспорт в систему MATLAB. Программа является платной, доступна демонстрационная 30-дневная версия.

fuzzyTECH (www.fuzzytech.com). Предназначена для решения различных задач нечеткого моделирования; в системе реализованы следующие методы дефаззификации: центр максимума, центр минимума, центр тяжести, среднее максимума.

FUZDYNm. В данной системе реализованы следующие методы: Ченга, Кауфманна и Гупта, Ли и Вонга, Джейна, Дубоиса и Прайда, входящие в две группы методов ранжирования (дефаззификации и попарного сравнения), при этом входными величинами могут быть только треугольные и трапецие- видные нечеткие числа. В [13] представлены входные и выходные формы программы.

\section{Приложение F-Ranking}

Созданная система F-Ranking является настольным приложением, разработанным на языке программирования Java (что делает приложение кроссплатформенным, для запуска требуется наличие Java Runtime Environment (JRE) v. 1.8), и может применяться для решения широкого круга задач с использованием нечетких чисел. В приложении реализованы следующие методы ранжирования нечетких чисел на основе дефаззификации и попарного сравнения: метод центра тяжести, метод медианы, метод интеграла средних значений $\alpha$-срезов, а также методы $F R A A_{I}$ и $F R A A_{Y}$, основанные, соответственно, на нечетких отношениях предпочтения $R_{I}$ (интегральное отношение предпочтения) и $R_{Y}$ (отношение предпочтения Юаня), которые также реализованы в системе (см. http://www. swsys.ru/uploaded/image/2018-3/2018-3-dop/28.jpg, http://www.swsys.ru/uploaded/image/2018-3/2018-3dop/29.jpg и табл. 1). Отношения предпочтения $R_{I}$ и $R_{Y}$ используют в своей основе нечеткую меру (степень) предпочтения числа $Z_{i}$ над $Z_{j}: \mu_{Y}\left(Z_{i}, Z_{j}\right)$ и $\mu_{I}\left(Z_{i}, Z_{j}\right)$. В то же время в системе F-Ranking фактически реализованы также методы ранжирования, основанные на отношениях предпочтения $R_{Y}$ и $R_{I}$ на основе использования мер предпочтения $\mu_{Y}\left(Z_{i}\right.$, $\left.Z_{j}\right)$ и $\mu_{I}\left(Z_{i}, Z_{j}\right)$. В [12] доказано, что ранжирования заданного множества нечетких чисел по методам $F R A A_{Y}$ и $R_{Y}$ совпадают; однако FRA $A_{Y}$-ранжирование в отличие от ранжирования на основе отношения предпочтения $R_{Y}$ дает дополнительную информацию о мере того, что нечеткое число $Z_{k}$ имеет соответствующий ранг $m$. Показано также (см. [12], табл. 1), что ранжирование $R_{I}$ не является транзитивным.

UML-диаграмма классов, реализующих методы ранжирования нечетких чисел, представлена на рисунке (см. http://www.swsys.ru/uploaded/image/ 2018-3/2018-3-dop/26.jpg).

При работе с программой пользователь задает нечеткие числа, выбирает методы ранжирования и проводит ранжирование заданного множества или подмножества нечетких чисел (рис. 1).

В программе реализованы следующие типы нечетких чисел (по функции принадлежности): синглтоны, треугольные, трапециевидные и кусочнолинейные нечеткие числа (cм. http://www.swsys.ru/ uploaded/image/2018-3/2018-3-dop/27.jpg).

Нечеткие числа с нелинейной функцией принадлежности $\mu_{z}(x)$ могут быть аппроксимированы кусочно-линейной функцией с достаточной для практического применения точностью.

Ранжирование нечетких чисел может проводиться по всем или по нескольким выбранным (из списка реализованных) методам ранжирования. 


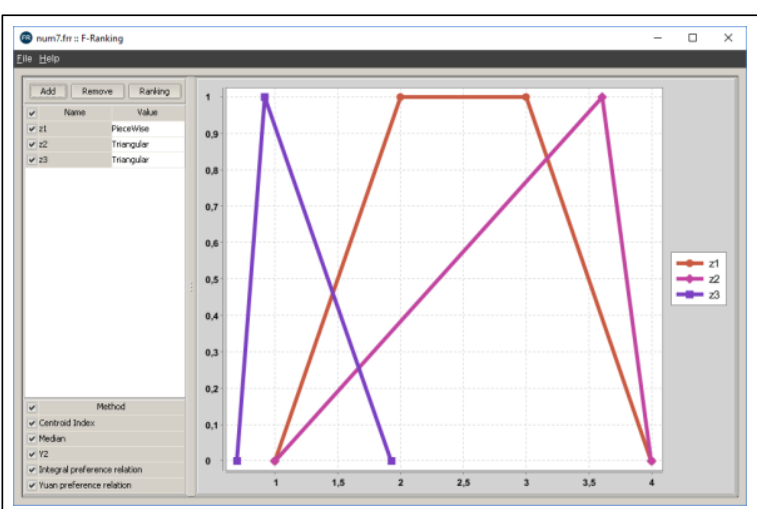

Рис. 1. Главное окно приложения

Fig. 1. The main window of application

Окно результатов ранжирования состоит из нескольких вкладок и позволяет сравнить полученные результаты по нескольким методам.

На первой вкладке (рис. 2) отображаются результаты ранжирования по всем выбранным методам с указанием соответствующего методу ранжирования значения: для методов дефаззификации это значения, полученные в результате дефаззификации исходных чисел, а для методов $F R A A_{I}$ и $F R A A_{Y}$ - максимальная, согласно $F R A A$-ранжированию, нечеткая мера (степень/мера уверенности), что число принадлежит данному рангу.

\begin{tabular}{|c|c|c|c|c|c|}
\hline \multicolumn{6}{|c|}{ FR Ranking result } \\
\hline All methods & FRAIs-I & $\mu_{I}\left(z_{i}, z_{j}\right)$ & FRAIs-Y $Y$ & $\mu_{Y}\left(z_{i}, z_{j}\right)$ & \\
\hline Ranki'Method & Centroid Index & Median & Y2 & FRAA I & FRAA Y \\
\hline 1 & $22(2.869)$ & $22(2.977)$ & $22(3.053)$ & $22(0.643)$ & $22(0.654)$ \\
\hline 2 & $21(2.5)$ & $z 1(2.5)$ & $21(2.5)$ & $21(0.643)$ & $z 1(0.654)$ \\
\hline 3 & $23(1.183)$ & $23(1.142)$ & $23(1.117)$ & $23(0.918)$ & $23(0.933)$ \\
\hline
\end{tabular}

Рис. 2. Результать ранжирования нечетких чисел $Z_{1}, Z_{2} u Z_{3}$

Fig. 2. FNs $Z_{1}, Z_{2}$, and $Z_{3}$ ranking results

Для методов попарного сравнения можно также получить значения нечетких индексов приемлемости FRAIs в виде таблицы и графика (рис. 3). Например, при использовании интегрального отношения предпочтения $R_{I}$ нечеткое число $Z_{2}$ принадлежит рангу 1 с мерой уверенности 0.643 $-\mu_{I}(2,1)=0.643$, рангу 2 с мерой $0.357-\mu_{I}(2,2)=$ $=0.357$ и рангу 3 с мерой $0.057-\mu_{I}(2,3)=0.057$.

Кроме того, для всестороннего анализа полученных результатов по методам попарного сравнения $R_{Y}$ и $R_{I}$ существует возможность рассмотреть значения меры превосходства $\mu_{R}\left(Z_{i}, Z_{j}\right)$ одного числа над другими (см. http://www.swsys.ru/uploaded/image/2018-3/2018-3-dop/28.jpg).

В программе доступны русский и английский языки (переключение: File>Language). Настройка параметров программы (количество знаков после точки и т.д.) производится в меню File > Settings. Кроме того, имеется возможность сохранить вве-

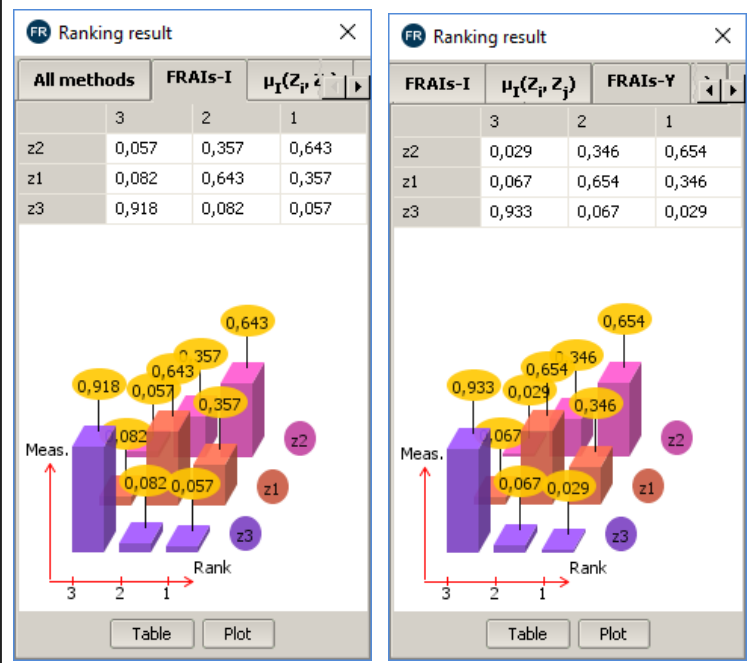

Рис. 3. Нечеткие индексы приемлемости FRAIs-I u FRAIs-Y

Fig. 3. Fuzzy Rank Acceptability Indices FRAIs-I and FRAIs-Y

денные нечеткие числа для их повторного использования. Для отображения нечетких чисел на правой панели (рис. 1) используется свободная библиотека jFreeChart.

\section{Примеры использования системы F-Ranking}

Представим ряд примеров, иллюстрирующих работу созданной системы с использованием нечетких чисел с функциями принадлежности треугольной, трапециевидной и кусочно-линейной формы и всеми методами ранжирования, реализованными в системе.

Пример 1. Рассмотрим три множества $\left(S_{1}, S_{2}, S_{3}\right)$ треугольных нечетких чисел (рис. 4), визуальное/ интуитивное ранжирование которых невозможно:

$S_{1}: Z_{1}=(11,13.95,16.91)$,

$Z_{2}=(13.9,13.95,14), Z_{3}=(10,14.95,16.29)$;

$S_{2}: Z_{1}=(11,13.95,16.91)$

$Z_{2}=(13.9,13.95,14), Z_{3}=(10,14.95,16.3)$;

$S_{3}: Z_{1}=(11,13.95,16.9)$,

$Z_{2}=(13.9,13.95,14), Z_{3}=(10,14.95,16.3)$.

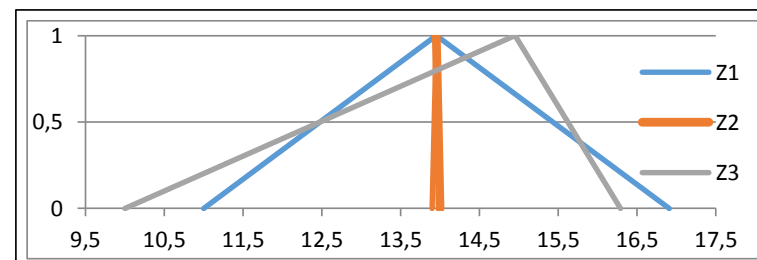

Pис. 4. Нечеткие числа $Z_{1}, Z_{2}, Z_{3}$ из множества $S_{1}$

Fig. 4. Fuzzy numbers $Z_{1}, Z_{2}, Z_{3}$ of the set $S_{1}$

C использованием системы F-Ranking (см. http://www.swsys.ru/uploaded/image/2018-3/2018-3dop/29.jpg) результаты ранжирования указанных 
нечетких чисел по всем методам, представленным в системе, приведены в таблице 1.

По результатам, представленным в таблице 1 , можно видеть, что интегральное отношение предпочтения не является транзитивным.

В таблице 2 приведено ранжирование рассмотренных выше нечетких чисел с указанием соответствующего методу дефаззификации (Centroid Index, Median, $Y_{2}$ ) значения; для методов FRAAI и $F R A A_{Y}$ указана максимальная мера принадлежности данному рангу. Можно видеть, что для методов центра тяжести и медианы порядок рангов совпадает, а метод Ү2 (метод интеграла средних значений $\alpha$-срезов) имеет такой же порядок рангов, как и методы попарного сравнения. Кроме того, ранжирование указанных нечетких чисел по методам $F R A A_{I}$ и $F R A A_{Y}$ совпадает для чисел из множеств $S_{1}$ и $S_{2}$ и отличается для множества $S_{3}$. При этом показано также, что $F R A A_{I}$ - ранжирование, основанное на нетранзитивном отношении предпочтения $R_{I}$, обладает свойством множественности рангов.

Необходимо отметить, что модели нетранзитивных отношений, имеющих место в реальном мире, привлекают внимание исследователей $[14,15]$. Нечеткое отношение предпочтения $R_{I}$, являющееся одним из наиболее интуитивно понятных среди имеющихся отношений предпочтения, а также основанный на концепции нечеткой приемлемости метод ранжирования $F R A A_{I}$ являются одной из немногих моделей исследования иррациональных/нетранзитивных порядков. Отметим также, что обобщенный метод ранжирования $F R A A_{I}$ является транзитивным [12].
Пример 2. Рассмотрим множество нечетких чисел $S_{4}(A, B$ - трапециевидные, $C$ - треугольное) (рис. 5):

$$
\begin{aligned}
& S_{4}: A=(1,2,5,7), B=(2,3,5,5.2), \\
& C=(5,6,7) .
\end{aligned}
$$

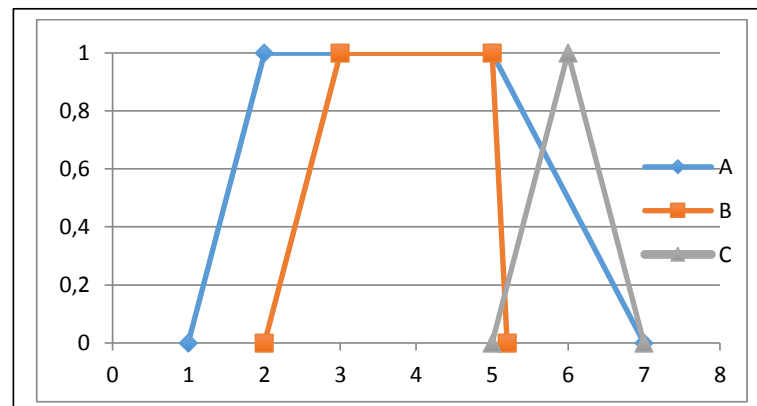

Рис. 5. Нечеткие числа A, B, С из множества $S_{4}$

Fig. 5. Fuzzy numbers $A, B$, $C$ of the set $S_{4}$

С помощью системы F-Ranking было проведено ранжирование нечетких чисел $A, B$ из множества $S_{4}$ (15) по методу центра тяжести, в результате были получены значения $C I(A)=3.778, C I(B)=3.785$ coответственно. Из этого следует:

$B \succ A$.

Рассмотрим множество $S_{5}$ (рис. 6) трапециевидных нечетких чисел, полученных в результате сложения чисел из множества $S_{4}(15)$ :

$S_{5}: A+C=(6,8,11,14)$,

$B+C=(7,9,11,12.2)$.

По методу центра тяжести нечеткие числа $A+C, B+C$ из множества $S_{5}(17)$ имеют значения

Таблииа 1

Ранжирование (сравнение) нечетких чисел $Z_{1}, Z_{2}, Z_{3}$ из множеств $S_{1}, S_{2}, S_{3}(12-14)$ по методам дефаззификации (Centroid Index, Median, $Y_{2}$ ) и методам попарного сравнения $R_{I}$ и $R_{Y}$

Ranking of fuzzy numbers $Z_{1}, Z_{2}, Z_{3}$ of the sets $S_{1}, S_{2}, S_{3}(12-14)$ by defuzzification methods

Table 1 (Centroid Index, Median, $Y_{2}$ ) and pairwise comparison methods $R_{I}$ and $R_{Y}$

\begin{tabular}{|c|c|c|c|c|c|}
\hline Множество & Centroid Index & Median & $\boldsymbol{Y}_{\mathbf{2}}$ & $\boldsymbol{R}_{\boldsymbol{I}}$ & $\boldsymbol{R}_{\boldsymbol{Y}}$ \\
\hline$S_{1}$ & $\mathrm{Z}_{1}>\mathrm{Z}_{2}>\mathrm{Z}_{3}$ & $\mathrm{Z}_{1}>\mathrm{Z}_{2}>\mathrm{Z}_{3}$ & $\mathrm{Z}_{3}>\mathrm{Z}_{1}>\mathrm{Z}_{2}$ & $\mathrm{Z}_{1}>\mathrm{Z}_{2}, \mathrm{Z}_{2}>\mathrm{Z}_{3}, \mathrm{Z}_{3}>\mathrm{Z}_{1}$ & $\mathrm{Z}_{3}>\mathrm{Z}_{1}>\mathrm{Z}_{2}$ \\
\hline$S_{2}$ & $\mathrm{Z}_{1}>\mathrm{Z}_{2}>\mathrm{Z}_{3}$ & $\mathrm{Z}_{1}>\mathrm{Z}_{2}>\mathrm{Z}_{3}$ & $\mathrm{Z}_{3}>\mathrm{Z}_{1}>\mathrm{Z}_{2}$ & $\mathrm{Z}_{1}>\mathrm{Z}_{2}, \mathrm{Z}_{2} \sim \mathrm{Z}_{3}, \mathrm{Z}_{3}>\mathrm{Z}_{1}$ & $\mathrm{Z}_{3}>\mathrm{Z}_{1}>\mathrm{Z}_{2}$ \\
\hline$S_{3}$ & $\mathrm{Z}_{1}>\mathrm{Z}_{2}>\mathrm{Z}_{3}$ & $\mathrm{Z}_{1}>\mathrm{Z}_{2}>\mathrm{Z}_{3}$ & $\mathrm{Z}_{3}>\mathrm{Z}_{1}>\mathrm{Z}_{2}$ & $\mathrm{Z}_{1} \sim \mathrm{Z}_{2}, \mathrm{Z}_{2} \sim \mathrm{Z}_{3}, \mathrm{Z}_{3}>\mathrm{Z}_{1}$ & $\mathrm{Z}_{3}>\mathrm{Z}_{1} \sim \mathrm{Z}_{2}$ \\
\hline
\end{tabular}

Таблица 2

Ранги нечетких чисел $Z_{1}, Z_{2}, Z_{3}$ из множеств $S_{1}, S_{2}, S_{3}(12-14)$ по всем методам, реализованным в системе F-Ranking

Ranks of fuzzy numbers $Z_{1}, Z_{2}$, and $Z_{3}$ of the sets $S_{1}, S_{2}, S_{3}(12-14)$ by all methods implemented in F-Ranking

\begin{tabular}{|c|c|c|c|c|c|c|}
\hline Множество & Ранги & Centroid Index & Median & $\boldsymbol{Y}_{\mathbf{2}}$ & $\boldsymbol{F R A A} \boldsymbol{I}_{\boldsymbol{I}}$ & $\boldsymbol{F R A A _ { \boldsymbol { Y } }}$ \\
\hline \multirow{3}{*}{$\mathrm{S}_{1}$} & 1 & $\mathrm{Z}_{1}(13.953)$ & $\mathrm{Z}_{1}(13.953)$ & $\mathrm{Z}_{3}(14.047)$ & $\mathrm{Z}_{3}(0.499)$ & $\mathrm{Z}_{3}(0.515)$ \\
\cline { 2 - 7 } & 2 & $\mathrm{Z}_{2}(13.95)$ & $\mathrm{Z}_{2}(13.95)$ & $\mathrm{Z}_{1}(13.953)$ & $\mathrm{Z}_{1}(0.501)$ & $\mathrm{Z}_{1}(0.501)$ \\
\cline { 2 - 7 } & 3 & $\mathrm{Z}_{3}(13.747)$ & $\mathrm{Z}_{3}(13.946)$ & $\mathrm{Z}_{2}(13.95)$ & $\mathrm{Z}_{2}(0.499)$ & $\mathrm{Z}_{2}(0.501)$ \\
\hline \multirow{3}{*}{$\mathrm{S}_{2}$} & 1 & $\mathrm{Z}_{1}(13.953)$ & $\mathrm{Z}_{1}(13.953)$ & $\mathrm{Z}_{3}(14.05)$ & $\mathrm{Z}_{3}(0.5)$ & $\mathrm{Z}_{3}(0.516)$ \\
\cline { 2 - 7 } & 2 & $\mathrm{Z}_{2}(13.95)$ & $\mathrm{Z}_{2}(13.95)$ & $\mathrm{Z}_{1}(13.953)$ & $\mathrm{Z}_{1}(0.501)$ & $\mathrm{Z}_{1}(0.501)$ \\
\cline { 2 - 7 } & 3 & $\mathrm{Z}_{3}(13.75)$ & $\mathrm{Z}_{3}(13.949)$ & $\mathrm{Z}_{2}(13.95)$ & $\mathrm{Z}_{2}(0.5)$ & $\mathrm{Z}_{2}(0.501)$ \\
\hline \multirow{3}{*}{$\mathrm{S}_{3}$} & 1 & $\mathrm{Z}_{1}(13.95)$ & $\mathrm{Z}_{1}(13.95)$ & $\mathrm{Z}_{3}(14.05)$ & $\mathrm{Z}_{2}(0.5), \mathrm{Z}_{3}(0.5)$ & $\mathrm{Z}_{3}(0.516)$ \\
\cline { 2 - 7 } & 2 & $\mathrm{Z}_{2}(13.95)$ & $\mathrm{Z}_{2}(13.95)$ & $\mathrm{Z}_{1}(13.95)$ & $\mathrm{Z}_{1}(0.5), \mathrm{Z}_{2}(0.5), \mathrm{Z}_{3}(0.5)$ & $\mathrm{Z}_{1}(0.5), \mathrm{Z}_{2}(0.5)$ \\
\cline { 2 - 7 } & 3 & $\mathrm{Z}_{3}(13.75)$ & $\mathrm{Z}_{3}(13.949)$ & $\mathrm{Z}_{2}(13.95)$ & $\mathrm{Z}_{1}(0.5), \mathrm{Z}_{2}(0.5)$ & $\mathrm{Z}_{1}(0.5), \mathrm{Z}_{2}(0.5)$ \\
\hline
\end{tabular}


9.788 и 9.77 соответственно. Из этого следует: $A+C \succ B+C$.

Таким образом, из (16) и (18) следует, что для метода центра тяжести $A \succeq B \nRightarrow A+C \succeq B+C$ [3].

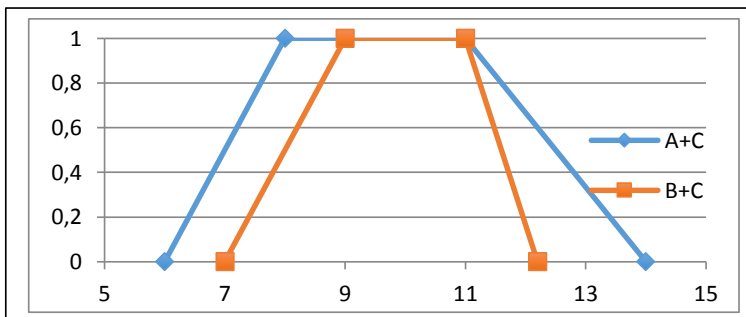

Рис. 6. Нечеткие числа $A+C, B+C$ из множества $S_{5}$

Fig. 6. Fuzzy numbers $A+C, B+C$ of the set $S_{5}$

Пример 3. Рассмотрим множество кусочно-линейных нечетких чисел $S_{6}$ (рис. 7):

$$
\begin{gathered}
A= \begin{cases}0, \text { если } & x<1, \\
1, \text { если } & 1 \leq x \leq 1, \\
0.05, \text { если } & 2<x \leq 15, \\
0, \text { если } & x>15,\end{cases} \\
B= \begin{cases}0, \text { если } & x<2.5, \\
1, \text { если } & 2.5 \leq x \leq 5, \\
0, \text { если } & x>5,\end{cases} \\
C= \begin{cases}0, \text { если } & x<1, \\
1, \text { если } & 1 \leq x \leq 3, \\
0.3, \text { если } & 2<x \leq 10, \\
0, \text { если } & x>10 .\end{cases}
\end{gathered}
$$

По методу центра тяжести нечеткие числа $A$ и $B$ из множества $S_{6}(19)$ имеют значения $C I(A)=4.258$, $C I(B)=3.75$ соответственно. Из этого следует

$A \succ B$.

Рассмотрим множество $S_{7}$ (рис. 8) кусочно-линейных нечетких чисел $A+C, B+C$ :

$$
\begin{gathered}
A+C= \begin{cases}0, \text { если } & x<2, \\
1, \text { если } & 2 \leq x \leq 5, \\
0.3, \text { если } & 5<x \leq 12, \\
0.05, \text { если } & 12<x \leq 25, \\
0, \text { если } & x>25,\end{cases} \\
B+C= \begin{cases}0, \text { если } & x<3.5, \\
1, \text { если } & 3.5 \leq x \leq 8, \\
0.3, \text { если } & 8<x \leq 15, \\
0, \text { если } & x>15 .\end{cases}
\end{gathered}
$$

По методу центра тяжести нечеткие числа $A+C$, $B+C$ из множества $S_{7}(21)$ имеют значения 7.022 , 7.58 соответственно. Из этого следует

$$
B+C \succ A+C \text {. }
$$

Таким образом, из (20) и (22) следует, что для метода центра тяжести и заданных нечетких чисел $A, B, C$ с кусочно-линейной функцией принадлежности $A \succeq B \nRightarrow A+C \succeq B+C$ [3].
Пример 4. Рассмотрим множество треугольных нечетких чисел $S_{8}$ (рис. 9):

$$
\begin{aligned}
& S_{8}: Z_{1}=(0,2.3,4), Z_{2}=(0.2,1.55,4.5), \\
& W=(0.043,0.1735,0.304) .
\end{aligned}
$$

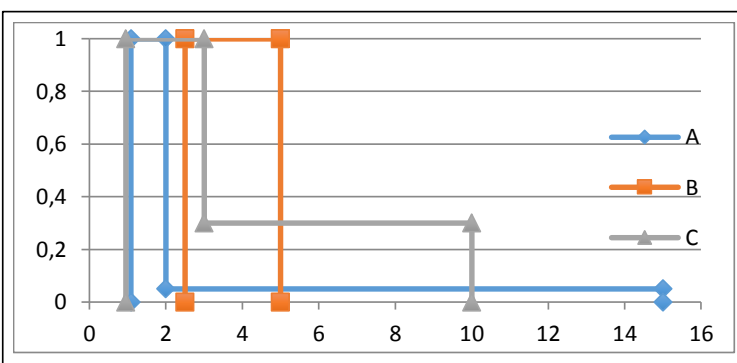

Рис. 7. Нечеткие числа A, B, С из множества $S_{6}$ Fig. 7. Fuzzy numbers $A, B, C$ of the set $S_{6}$

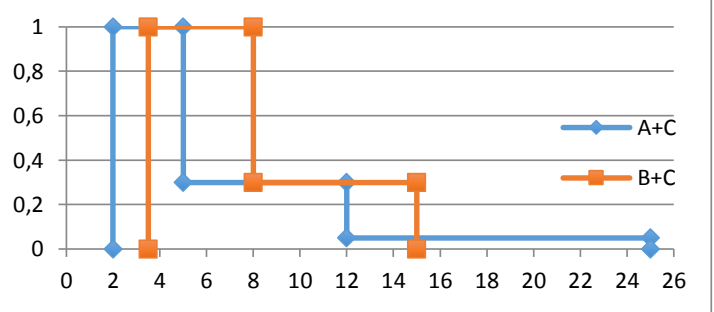

Pис. 8. Нечеткие числа $A+C, B+C$ из множества $S$ Fig. 8. Fuzzy numbers $A+C, B+C$ of set $S_{7}$

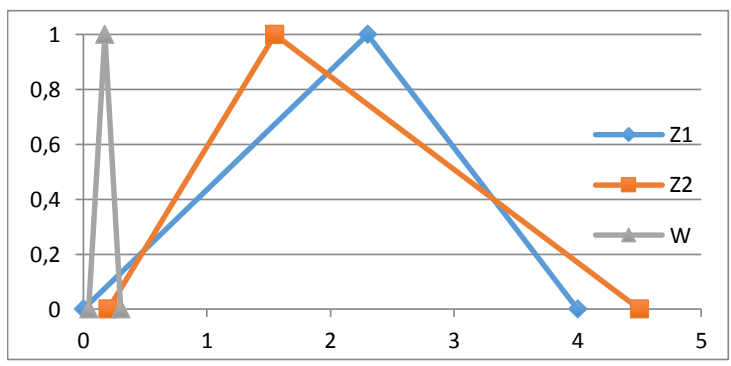

Pис. 9. Нечеткие числа $Z_{1}, Z_{2} u W$ из множества $S_{8}$ Fig. 9. Fuzzy numbers $Z_{1}, Z_{2}$, and $W$ of the set $S_{8}$

По методу центра тяжести нечеткие числа $Z_{1}$ и $Z_{2}$ из множества $S_{8}(23)$ имеют значения 2.1 и 2.083 соответственно. Из этого следует

$$
Z_{1} \succ Z_{2} \text {. }
$$

В отличие от двух предыдущих примеров, исследующих сложения исходных множеств, рассмотрим множество чисел $S_{9}$ (рис. 10$)$, полученных в результате перемножения чисел из множества $S_{8}(23)$ :

$S_{9}: Z_{1} \times W, Z_{2} \times W$.

По методу центра тяжести нечеткие числа $Z_{1} \times W$ и $Z_{2} \times W$ из множества $S_{9}(25)$ имеют значения 0.494 и 0.506 соответственно. Из этого следует

$$
Z_{2} \times W \succ Z_{1} \times W \text {. }
$$

Таким образом (так же, как и в случае сложения в примерах 2, 3), из (24) и (26) следует, что для метода центра тяжести (и положительного нечеткого числа $W) Z_{1} \succeq Z_{2} \nRightarrow Z_{1} \times W \succeq Z_{2} \times W$. 
Пример 5. Рассмотрим множество треугольных нечетких чисел $S_{10}$ (рис. 11):

$S_{10}: Z_{1}=(1,1.2,8.2), Z_{2}=(1,4,4.5)$,

$W=(0.043,0.1735,1.3)$.

По аналогии с предыдущим примером перемножим числа из (27), в результате получим нечеткие числа множества $S_{11}$ (рис. 12):

$S_{11}: Z_{1} \times W, Z_{2} \times W$.

Ранжирование методом Юаня чисел из множеств $S_{10}(27)$ и $S_{11}(28)$ приводит к следующим результатам: $\mu\left(Z_{2}, Z_{1}\right)=0.577, \mu\left(Z_{1} \times W, Z_{2} \times W\right)=$ $=0.556$. Из этого следует, что для метода Юаня $Z_{2} \succeq Z_{1} \nRightarrow Z_{2} \times W \succeq Z_{1} \times W$.

Анализируя данный пример, можно отметить, что порядок ранжирования нарушается не только для метода центра тяжести, но и для других методов ранжирования.

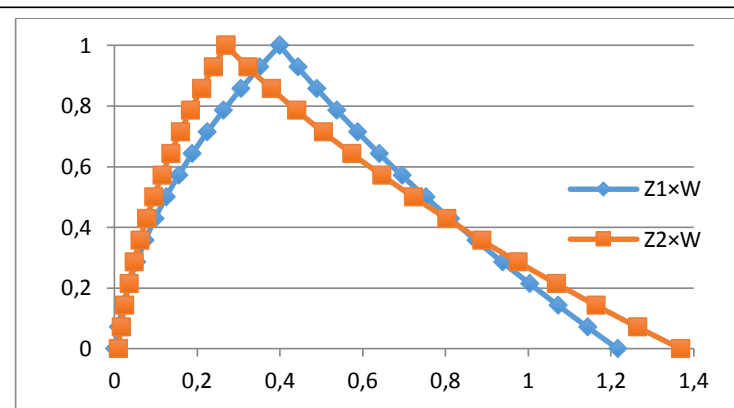

Pис. 10. Нечеткие числа $Z_{1} \times W, Z_{2} \times W$ из множества $S_{9}$

Fig. 10. Fuzzy numbers $Z_{1} \times W$ and $Z_{2} \times W$ of the set $S_{9}$

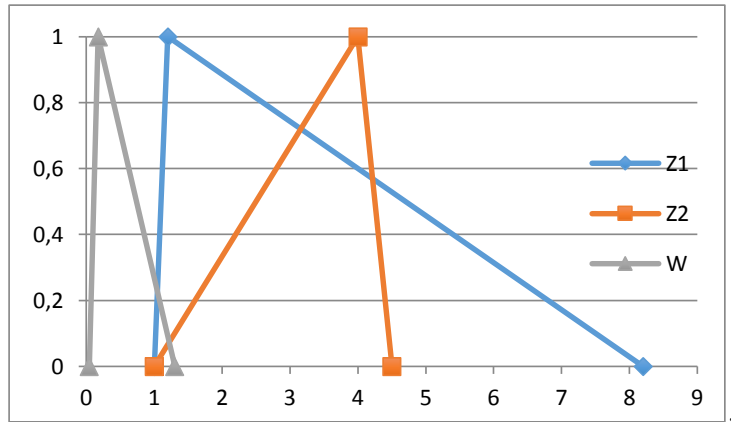

Рис. 11. Нечеткие числа $Z_{1}, Z_{2}, W$ из множества $S_{10}$ Fig. 11. Fuzzy numbers $Z_{1}, Z_{2}$ and $W$ of the set $S_{10}$

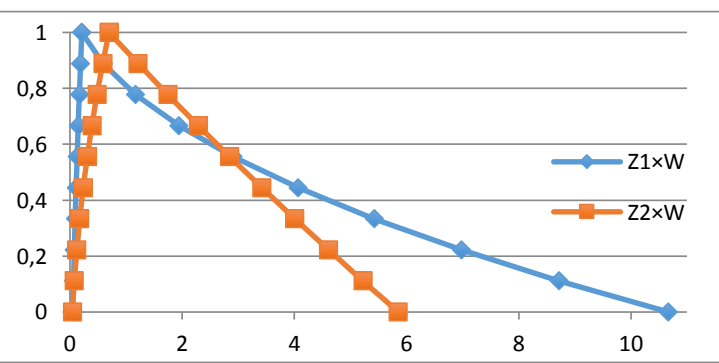

Рис. 12. Нечеткие числа $Z_{1} \times W, Z_{2} \times W$ из множества $S_{11}$

Fig. 12. Fuzzy numbers $Z_{1} \times W, Z_{2} \times W$ of the set $S_{11}$
В примере 5 вычисления производятся с десятью альфа-срезами. Для проверки корректности работы приложения F-Ranking нечеткие числа из множества $S_{10}$ (27) были перемножены с разбиением на 20 альфа-срезов. После ранжирования были получены следующие результаты (для наглядности значения приведены с 7 знаками после десятичной точки): 10 альфа-срезов: $\mu\left(Z_{2}, Z_{1}\right)=$ $=0.5774372, \mu\left(Z_{1} \times W, Z_{2} \times W\right)=0.5557413$, 20 альфа-срезов: $\mu\left(Z_{2}, Z_{1}\right)=0.5774372, \mu\left(Z_{1} \times W\right.$, $\left.Z_{2} \times W\right)=0.5550221$. Для сравнения: при 30 альфасрезах $\mu\left(Z_{1} \times W, Z_{2} \times W\right)=0.5549033$, то есть различие с аналогичным значением для 20 альфа-срезов составляет около $10^{-4}$.

Таким образом, можно говорить о корректности работы приложения F-Ranking; при этом количество альфа-срезов можно варьировать в зависимости от требований к точности выходных результатов.

\section{Заключение}

Система F-Ranking предоставляет широкие возможности для сравнения и ранжирования нечетких чисел. Она является особенно востребованной в случаях, когда визуальное/интуитивное ранжирование нечетких чисел невозможно (пример 1). Кроме того, система эффективна для проведения научных исследований (примеры 2-5). Наличие в программе сразу нескольких методов ранжирования: центра тяжести, медианы, интеграла средних значений $\alpha$-срезов, а также метода Юаня и интегрального метода, в том числе дополнительных инструментов анализа при использовании двух последних методов, позволяет получить более полное представление о ранжируемых числах. Указанные характеристики делают систему F-Ranking удобным инструментом при решении широкого спектра научно-прикладных задач с использованием нечетких чисел. Программа спроектирована с учетом возможности добавления в нее других методов ранжирования. Разработанные программные библиотеки для ранжирования нечетких чисел используются в методах нечеткого многокритериального анализа решений для ранжирования альтернатив в условиях неопределенности.

\section{Лumepamypa}

1. Hatagar S., Halase S. Three input-one output fuzzy logic control of washing machine. Intern. J. of Sc. Research Eng. \& Technology (IJSRET), 2015, vol. 4, pp. 57-62.

2. Samuel E.K. Fuzzy logic and its practical use in mass transit systems. 2005. URL: http://skisko.blogspot.com/2005/06/fuzzylogic-and-its-practical-use-in.html (дата обращения: 26.12.2017).

3. Wang X., Kerre E. E. Reasonable properties for the ordering of fuzzy quantities (I). Fuzzy Sets and Systems, 2001, vol. 118, no. 3 , pp. $375-385$.

4. Wang X., Kerre E.E. Reasonable properties for the ordering of fuzzy quantities (II). Fuzzy Sets and Systems, 2001, vol. 118, no. 3, pp. 387-405

5. Lee K.H. First course on fuzzy theory and applications. Springer Science \& Business Media, 2006, vol. 27, 341 p.

6. Matarazzo B., Munda G. New approaches for the compare- 
son of L-R fuzzy numbers: a theoretical and operational analysis. Fuzzy Sets and Systems, 2001, vol. 118, no. 3, pp. 407-418.

7. Hanss M. Applied Fuzzy Arithmetic An Introduction with Engineering Applications. Springer-Verlag Berlin Heidelberg, 2005, $261 \mathrm{p}$.

8. Yatsalo B., Korobov A., Martínez L. Fuzzy multi-criteria acceptability analysis: A new approach to multi-criteria decision analysis under fuzzy environment. Expert Systems With Applications, 2017, vol. 84, pp. 262-271.

9. Allahviranloo T., Saneifard R. Defuzzification method for ranking fuzzy numbers based on center of gravity. Iranian J. of Fuzzy Systems, 2012, vol. 9, no. 6, pp. 57-67.

10. Ротштейн А.П., Штовба С.Д. Влияние методов дефаззификации на скорость настройки нечеткой модели // Кибернетика и системный анализ. 2002. № 5. С. 169-176.
11. Saneifard R., Saneifard R. The median value of fuzzy numbers and its applications in decision making. J. of Fuzzy Set Valued Analysis, 2012, vol. 2012, pp. 1-9.

12. Yatsalo B., Martinez L. Fuzzy rank acceptability analysis: a confidence measure of ranking fuzzy numbers. Proc. IEEE Transactions on Fuzzy Systems, 2018. DOI: https://doi.org/10.1109/TFUZZ. 2018.2838063

13. Kahraman C., Bozdağ C.E. Fuzzy investment analysis using capital budgeting and dynamic programming techniques. Computational Intelligence in Economics and Finance. Springer Berlin Heidelberg, 2004, pp. 93-128.

14. Klimenko A.Y. Intransitivity in theory and in the real world. Entropy, 2015, vol. 17, no. 6, pp. 4364-4412.

15. Fishburn P.C. Nontransitive preferences in decision theory. J. of Risk and Uncertainty, 1991, vol. 4, no. 2, pp. 113-134.

\section{F-Ranking: a computer system for ranking fuzzy numbers}

A.V. Radaev ${ }^{1}$, M.S. Graduate Student, rad.yyhh@yandex.ru

A.V. Korobov ${ }^{1}$, Postgraduate Student, alexander.korobov.1993@gmail.com

B.I. Yatsalo ${ }^{1}$, Dr.Sc. (Engineering), Professor, yatsalo@gmail.com

${ }^{1}$ Obninsk Institute for Nuclear Power Engineering of the National Research Nuclear University "MIPhI", Obninsk, 249040, Russian Federation

Abstract. In many areas of human activities, people face uncertainties. One of the ways of handling and analyzing uncertainties is using fuzzy sets including fuzzy logic and fuzzy numbers. The use of fuzzy numbers within decision analysis inevitably leads to the problems of their comparison and ranking.

Despite the variety of ranking methods, the majority of the existing systems with fuzzy numbers use only defuzzification methods. However, the replacement of a fuzzy number by one real number (like the replacement of the probability distribution density by the corresponding mathematical expectation) inevitably leads to narrowing and loss of information in the original fuzzy number.

The paper presents an original computer system F-Ranking for ranking different fuzzy numbers. The system allows using fuzzy numbers with singletons, triangular, trapezoidal and piecewise (including sectionally continuous from above) fuzzy numbers as input data. F-Ranking system includes six methods for ranking fuzzy numbers based on defuzzification: three defuzzification based ranking methods (a centroid index, median, and an integral of alpha-cut mean values) along with two ranking methods based on pairwise comparison (Fuzzy Rank Acceptability Analysis) using Integral and Yuan's fuzzy preference relations. For the last two methods, a preference fuzzy measure of one fuzzy number over another as well as Fuzzy Rank Acceptability Indexes are available.

The paper briefly describes the algorithms of the mentioned methods. The authors make a review of existing systems, which can be used for ranking fuzzy numbers. There is the structure of F-Ranking system with input/output forms and examples of ranking fuzzy numbers using different methods. These examples show the features of the ranking methods under consideration as well as the possibilities of F-Ranking system in general.

Keywords: fuzzy number, fuzzy set, ranking fuzzy numbers, defuzzification methods, pairwise comparison methods, fuzzy system.

\section{References}

1. Hatagar S., Halase S.V. Three input-one output fuzzy logic control of washing machine. Intern. J. of Scientific Research Engineering \& Technology (IJSRET). 2015, vol. 4, pp. 57-62.

2. Samuel E.K. Fuzzy Logic and its Practical use in Mass Transit Systems. 2005. Available at: http://skisko.blogspot.com/2005/06/fuzzy-logic-and-its-practical-use-in.html (accessed December 26, 2017). 
3. Wang X., Kerre E.E. Reasonable properties for the ordering of fuzzy quantities (I). Fuzzy Sets and Systems. 2001, vol. 118 , no. 3 , pp. $375-385$.

4. Wang X., Kerre E.E. Reasonable properties for the ordering of fuzzy quantities (II). Fuzzy Sets and Systems. 2001, vol. 118 , no. 3, pp. 387-405.

5. Lee K.H. First Course on Fuzzy Theory and Applications. Springer-Verlag Berlin Heidelberg Publ., 2006, vol. 27, $341 \mathrm{p}$.

6. Matarazzo B., Munda G. New approaches for the comparison of L-R fuzzy numbers: a theoretical and operational analysis. Fuzzy Sets and Systems. 2001, no. 118, pp. 407-418.

7. Hanss M. Applied Fuzzy Arithmetic: an Introduction with Engineering Applications. Springer-Verlag Berlin Heidelberg Publ., 2005, 261 p.

8. Yatsalo B., Korobov A., Martínez L. Fuzzy multi-criteria acceptability analysis: A new approach to multi-criteria decision analysis under fuzzy environment. Expert Systems with Applications. 2017, no. 84, pp. 262-271.

9. Allahviranloo T., Saneifard R. Defuzzification method for ranking fuzzy numbers based on center of gravity. Iranian J. of Fuzzy Systems. 2012, no. 9, pp. 57-67.

10. Rotshteyn A.P., Shtovba S.D. The influence of defuzzification methods on fuzzy model tuning speed. Cybernetics and Systems Analysis. 2002, no. 1, pp. 169-176.

11. Saneifard R., Saneifard R. The median value of fuzzy numbers and its applications in decision making. J. of Fuzzy Set Valued Analysis. 2012, vol. 2012, pp. 1-9.

12. Yatsalo B., Martinez L. Fuzzy rank acceptability analysis: A confidence measure of ranking fuzzy numbers. IEEE Trans. on Fuzzy Systems. 2018.

13. Kahraman C., Bozdağ C.E. Fuzzy investment analysis using capital budgeting and dynamic programming techniques. Computational Intelligence in Economics and Finance. Springer Berlin Heidelberg Publ., 2004, pp. 93-128.

14. Klimenko A.Y. Intransitivity in theory and in the real world. Entropy. 2015, no. 17, pp. 4364-4412.

15. Fishburn P.C. Nontransitive preferences in decision theory. J. of Risk and Uncertainty. 1991, no. 4, pp. 113-134.

\section{Примеры бибциографического описания статьи}

1. Радаев А.В., Коробов А.В., Яцало Б.И. F-Ranking: компьютерная система дмя ранжирования нечётких чисел // Программные продукты и системы. 2018. Т. 31. № 3. С. 605-613. DOI: $10.15827 / 0236-235 X .123 .605-613$.

2. Radaev A.V., Korobov A.V. F-Ranking: a computer system for ranking fuzzy numbers. Software \& Systems. 2018, vol. 31, no. 3, pp. 605-613 (in Russ.). DOI: 10.15827/0236-235X.123.605-613. 
Входной язык системы автоматизированного проектирования поковок muna валов

С.И. Канюков 1, к.т.н., старший научный сотрудник, ksi@imach.uran.ru

A.В. Коновалов 1, д.m.н., профессор, зав. лабораторией, avk@imach.uran.ru

О.Ю. Муйземнек 1, к.т.н., старший научный сотрудник, оlga@imach.uran.ru

1 Институт машиноведения Уральского отделения РАН, г. Екатеринбург, 620049, Россия

В Институте машиноведения УрО РАН разработана система автоматизированного проектирования технологических процессов ковки валов на прессах. В состав лингвистического обеспечения системы включен специализированный входной язык, предназначенный для ввода исходной информации и оперативных корректировок пользователями промежуточных и окончательных результатов проектирования поковок.

Ввод исходной информации может быть осуществлен в двух вариантах: ввод информации о новой детали, чтение и корректировка (при необходимости) информации о детали (или поковке), уже имеющейся в БД. Фрагмент входного языка системы, предназначенный для ввода информации о новой детали, предусматривает заполнение трех зон соответствующего меню, которые содержат общую информацию о детали, информацию о геометрии детали и задание на проектирование. Последнее включает перечень задач, которые необходимо решить в процессе автоматизированного проектирования поковки.

Автоматизированное проектирование поковки предусматривает назначение припусков на термообработку и механическую обработку, добавление различных проб для проведения механических испытаний и макроконтроля, назначение кузнечных напусков, определение технических требований и заканчивается моделированием рабочего чертежа заготовки, состоящего из семи графических зон. Фрагмент входного языка, предназначенный для корректировки рабочего чертежа заготовки, позволяет выбрать формат чертежа А3 или A4, изменять размеры графических зон с масштабированием геометрических объектов и перемещением их в поле чертежа, корректировать числовые и текстовые значения параметров поковки внутри зон через выпадающие меню, управлять видимостью зон.

Описанный в статье входной язык системы автоматизированного проектирования технологических процессов для автоматизированного проектирования поковок обеспечивает удобный ввод исходной информации о детали, гарантирует получение рабочих чертежей заготовок, пригодных для запуска в производственный процесс, и существенно облегчает адаптацию системы к условиям разных предприятий.

Ключевые слова: САПР, ковка, вал, проектирование поковки, лингвистическое обеспечение, входной язык.

Одним из способов повышения производительности кузнечного производства является применение систем автоматизированного проектирования (САПР) технологических процессов (ТП), позволяющих существенно сократить время на разработку и повысить качество проектных решений. Опыт создания САПР ТП в рассматриваемой области описан в работах [1-3].

Однако, несмотря на развитие вычислительной техники, языков и методов программирования, работы по автоматизации проектирования технологии кузнечного производства и по внедрению соответствующих САПР ТП в производство до сих пор не получили широкого развития. Особенно это касается технологии свободной ковки. Это объясняется тем, что автоматизация проектирования технологии свободной ковки является сложным и достаточно трудоемким процессом. Сложность заключается прежде всего в том, что эта предметная область слабо формализована, общие правила проектирования технологии ковки носят ориентировочный характер, технологические инструкции предприятий зачастую неоднозначны и даже противоречивы, большое значение при проектировании имеет опыт технологов. Поэтому, несмотря на естественное стремление сократить долю участия человека в процессе автоматизированного проек- тирования, разработчики соответствующих САПР вынуждены закладывать в систему «приближенные» алгоритмы и программы решения технологических задач и, как следствие, предоставлять пользователям возможность исправлять результаты проектирования в режиме графического диалога.

В настоящее время в Институте машиноведения УрО РАН (г. Екатеринбург) разработана САПР технологии ковки валов на прессах (САПР «ТЕХНОЛОГ»), в которой реализованы следующие функции:

- ввод исходной информации о детали;

- проектирование поковки;

- проектирование технологического процесса ковки;

- запись информации о спроектированных объектах в БД и ее чтение;

- оформление результатов проектирования в виде конструкторской и технологической документации (рабочий чертеж заготовки, технологическая карта ковки).

На всех этапах, начиная с ввода исходной информации и заканчивая оформлением результатов проектирования, предусмотрена возможность изменения пользователем решений, предлагаемых системой. Для этого разработаны специальные средства лингвистического обеспечения САПР. 
Как известно [4-7], под лингвистическим обеспечением подразумевается совокупность языков, используемых в процессе разработки и эксплуатации САПР. В состав таких языков обычно включают языки программирования, управления и проектирования.

Языки программирования необходимы для создания ПО при разработке САПР. Языки управления служат для управления ЭВМ и периферийными устройствами. Языки проектирования ориентированы на пользователей-проектировщиков и предназначены для эксплуатации САПР. Эта группа языков делится на входные (являются средством взаимодействия конечного пользователя с САПР), внутренние (служат для представления информации, передаваемой между различными подсистемами САПР и ЭВМ), выходные (обеспечивают оформление результатов проектирования в текстовом или графическом виде).

Вопросы взаимодействия пользователя с программными системами, создания собственного входного языка ввода начальной информации и разработки дружелюбных, интуитивно-понятных человеку интерфейсов программных продуктов рассмотрены в работах [8-12]. Обзор существующих шаблонов проектирования, используемых разработчиками ПО для создания пользовательского интерфейса, приведен в [13]. Методика построения прототипа пользовательского интерфейса с использованием теории нечетких множеств и экспертной оценки, повышающего объективность и оперативность принятия решений разработчиками программного продукта, описана в [14]. Применение агентного подхода для построения диалоговой системы рассмотрено в [15]. В работе [16] описана методика построения интеллектуальной САПР шнековых экструдеров, основанная на интеграции подсистем, а также рассматриваются вопросы построения пользовательского интерфейса системы. В работах $[17,18]$ показан пример интерфейса САПР штампов холодной листовой штамповки.

$\mathrm{B}$ настоящей статье приводится описание составной части входного языка САПР «ТЕХНОЛОГ», используемого при автоматизированном проектировании поковок и предназначенного для ввода исходной информации о детали и корректировки результатов проектирования.

\section{Ввод исходной информации}

Ввод исходной информации о детали может быть осуществлен в двух вариантах:

- ввод информации о новой детали;

- чтение и корректировка (при необходимости) информации о детали, имеющейся в БД.

Фрагмент входного языка САПР «ТЕХНОЛОГ», предназначенный для ввода информации о новой детали, предусматривает заполнение трех зон соответствующего меню: общая информация о детали, геометрия детали, задание на проектирование (рис. 1).

Зона общей информации о детали (рис. 1, слева) включает следующие сведения:

- номер и наименование детали;

- марка материала;

- группа поковки;

- категория прочности (КП);

- нормативная документация (НД) на поковку;

- степень ответственности (ответственная: деталь типа ротора, судового вала, баллера руля или обычная).

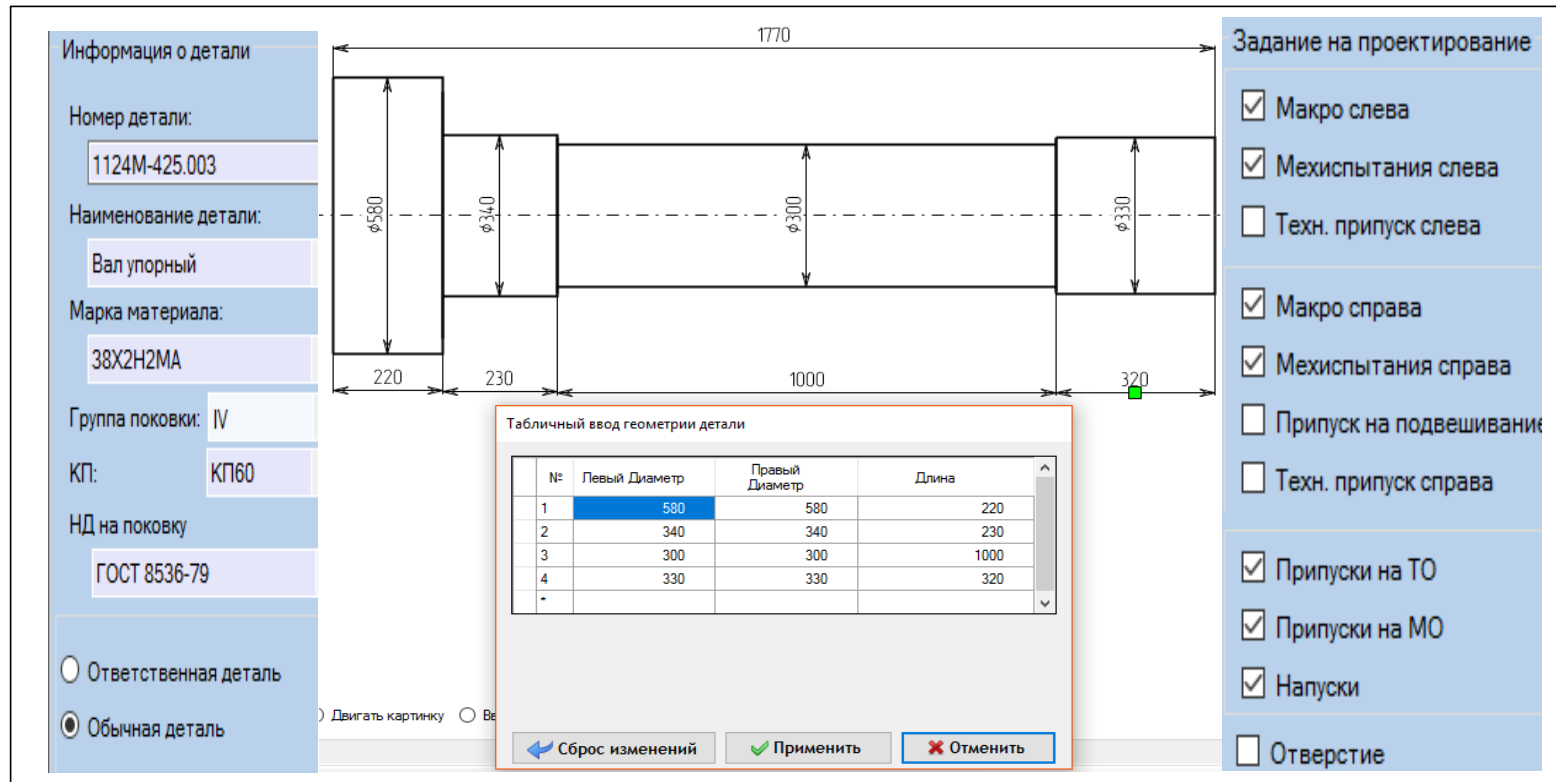

Рис. 1. Меню для ввода информачии о новой детали

Fig. 1. Menu for inputting information on a new forged part 
Номер, наименование и степень ответственности детали заполняются пользователем вручную. Выбор марки материала, группы поковки, категории прочности и нормативной документации осуществляется через выпадающие меню (см. http:// www.swsys.ru/uploaded/image/2018-3/2018-3-dop/ 16.jpg) БД системы.

Зона геометрии детали (рис. 1, в центре) представляет собой эскиз этой детали с размерами. Для облегчения ввода и корректировки геометрической информации о новой детали разработан специальный графический редактор [19], позволяющий вручную вводить и изменять размеры ступеней, объединять ступени с одинаковым диаметром в одну, разделять ступень на две, меняя при этом диаметры и длины полученных ступеней и т.д.

Зона задания на проектирование (рис. 1, справа) включает перечень задач, которые необходимо решить в процессе автоматизированного проектирования поковки. Так, например, для детали «Вал упорный» задание на проектирование предусматривает назначение проб для проведения макроконтроля и механических испытаний (слева и справа), припусков на термообработку и механическую обработку и кузнечных напусков.

Если же деталь «Вал упорный» уже имеется в БД (рис. 2, деталь № 5) и пользователь решил поработать с ней, он может прочитать ее из базы, сделав двойной клик мышкой на выбранной детали (например, «Вал упорный»).

\begin{tabular}{|c|c|c|c|c|}
\hline $\begin{array}{l}\text { № } \\
B D\end{array}$ & ДЕТАЛЬ № & Наименование детали & Марка стали & Отв \\
\hline 1 & ЭТ-8909-01 & Вал ротора & 35ХНЗМФАР & Отв \\
\hline 2 & $11442-425-015$ & Вал промежуточный & $38 \times 2 \mathrm{H} 2 \mathrm{BA}$ & Отв \\
\hline 3 & $1144-425-006$ & Заготовка промвала & $38 \times 2 \mathrm{H} 2 \mathrm{MA}$ & Нет \\
\hline 4 & 501598.07 & Муфта стяжная & $38 \times 2 \mathrm{H} 2 \mathrm{MA}$ & Нет \\
\hline 5 & $1124 \mathrm{M}-425.003$ & Вал упорный & $38 \times 2 \mathrm{H} 2 \mathrm{MA}$ & Нет \\
\hline
\end{tabular}

Рис. 2. Фрагмент базы данных САПР «ТЕХНОЛОГ»

Fig. 2. A part of database of a computer-aided system "TEKHNOLOG"

\section{Проектирование поковки}

Процесс автоматизированного проектирования поковки в САПР «ТЕХНОЛОГ» в общем случае предусматривает выполнение следующих этапов (если это не противоречит заданию на проектирование):

- назначение припусков на термообработку;

- назначение проб для проведения макроконтроля (слева и справа);

- назначение проб для проведения механических испытаний (слева и справа);

- назначение дополнительных технологических припусков (слева и справа);

- назначение припуска на подвешивание поковки при термообработке (справа);
- назначение припусков на механическую обработку;

- назначение кузнечных напусков на участки поковки, которые не могут быть выполнены на используемом кузнечном оборудовании.

На всех этапах, начиная с назначения припусков на термообработку и заканчивая назначением кузнечных напусков, предусмотрена возможность изменения пользователем решений, предлагаемых системой.

Задание на проектирование может быть выполнено либо сразу все, либо по шагам. Например, peзультат решения задач назначения припусков на термообработку и проб для проведения макроконтроля и механических испытаний для детали «Вал упорный» представлен на рисунке 3.

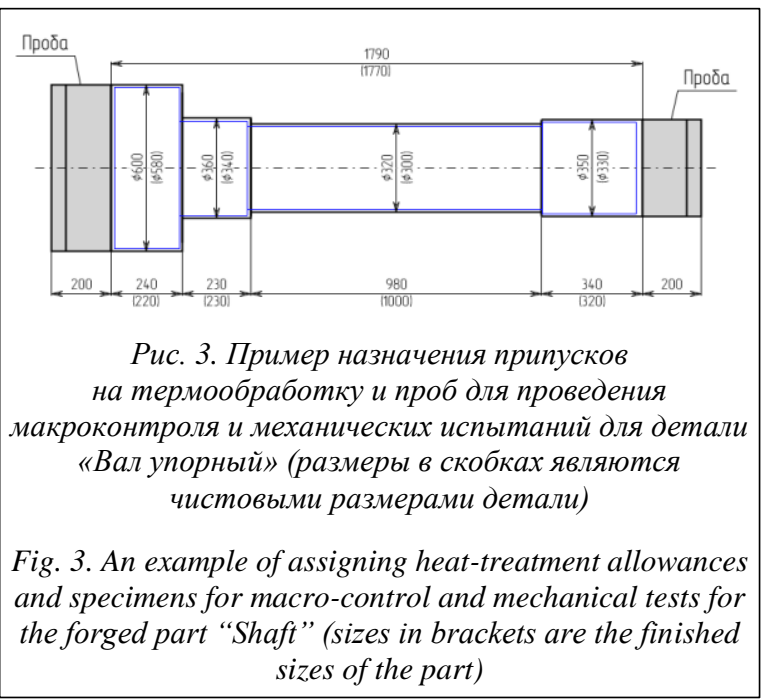

Рабочий чертеж заготовки для детали «Вал упорный», полученный в процессе выполнения задания на проектирование (рис. 1) в автоматическом режиме, представлен на рисунке 4 .

Как видно из рисунка 4, на рабочем чертеже заготовки можно выделить семь основных зон:

- зона 1 «Эскиз поковки» (слева вверху);

- зона 2 «Технические требования» (справа вверху);

- зоны 3 и 4 «Эскизы вырезки образцов для механических испытаний и требуемые значения механических свойств» (в центре);

- зоны 5 и 6 «Эскизы разрезки дисков для макроконтроля» (слева внизу);

- зона 7 «Штамп».

Входной язык, предназначенный для корректировки рабочего чертежа заготовки, позволяет изменять размеры зон (с проведением масштабирования геометрических объектов) и перемещать их в поле чертежа (зоны 1-6), корректировать числовые и текстовые значения параметров внутри зон (1-7) через выпадающие меню и перемещать эти значения (кроме зоны 7), управлять видимостью зон $3-6$, утвердить и записать рабочий эскиз заготовки в БД, перейти к проектированию технологической 


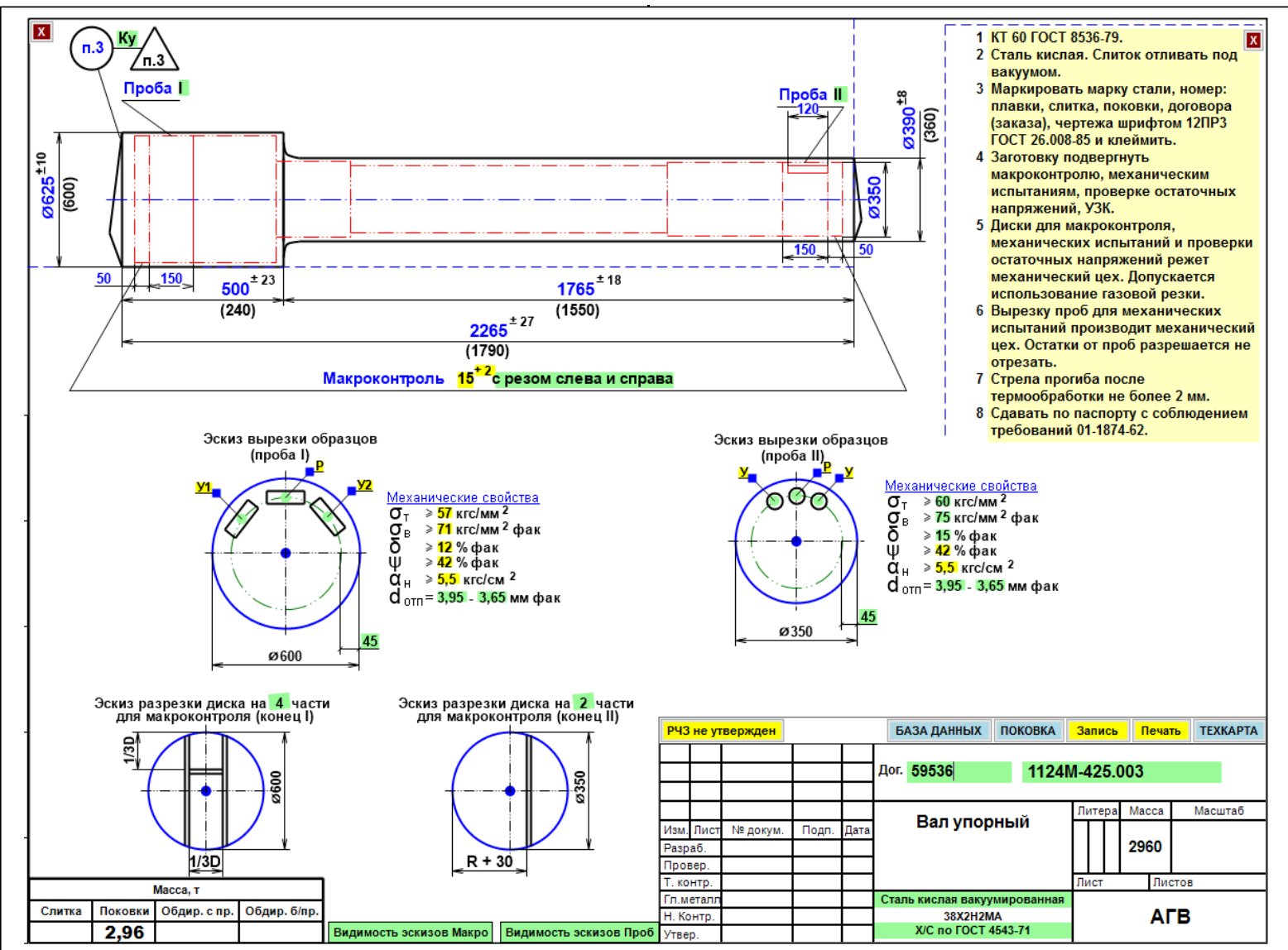

Рис. 4. Рабочий чертеж заготовки для детали «Вал упорный»

Fig. 4. A working drawing of a workpiece for the forged part "Shaft"

карты ковки, вернуться к поковке или к БД (зона 7).

Примеры выпадающих меню для изменения значений параметров рабочего чертежа заготовки приведены на рисунке 5 .

Изменение толщины дисков для макроконтроля (рис. 5а) производится путем ввода нужного значения (например, 35) либо выбора одного из крайних значений (10 или 50). Корректировка уточняющей надписи о разрезке макродисков слева и справа (рис. 5б) осуществляется методом выбора из предлагаемого списка. При выборе уточняющей надписи, например, «с резом слева», на рабочем чертеже заготовки будет показан только один эскиз разрезки диска для макроконтроля (конец I).

Входной язык для изменения схем вырезки образцов для механических испытаний позволяет вводить образцы нужного типа (рис. 5в), заменять или исключать уже введенные образцы (рис. 5г).

Корректировка частей разрезки дисков для макроконтроля производится путем выбора из возможных вариантов (рис. 5д), после чего эскиз разрезки диска заменяется в соответствии с выбранным вариантом (рис. 5e).

Возможности входного языка, связанные с изменением размеров зон рабочего чертежа заго- товки для детали «Вал упорный» (рис. 4) и перемещением графических элементов этого чертежа, проиллюстрированы на рисунке (см. http://www. swsys.ru/uploaded/image/2018-3/2018-3-dop/17.jpg).

\section{Заключение}

Сложность и слабая формализация рассматриваемой предметной области не позволяют полностью исключить участие человека в процессе автоматизированного проектирования. Для реализации такой возможности в составе средств лингвистического обеспечения САПР «ТЕХНОЛОГ» разработан входной язык, позволяющий вносить оперативные изменения в решения системы. Описанный в настоящей статье входной язык САПР «ТЕХНОЛОГ» для автоматизированного проектирования поковок не только обеспечивает удобный ввод исходной информации о детали, но и предоставляет пользователям широкие возможности для внесения корректировок в результаты проектирования, что, в свою очередь, гарантирует получение рабочих чертежей заготовок, пригодных для запуска в производственный процесс, и существенно облегчает внедрение системы на различных предприятиях. 


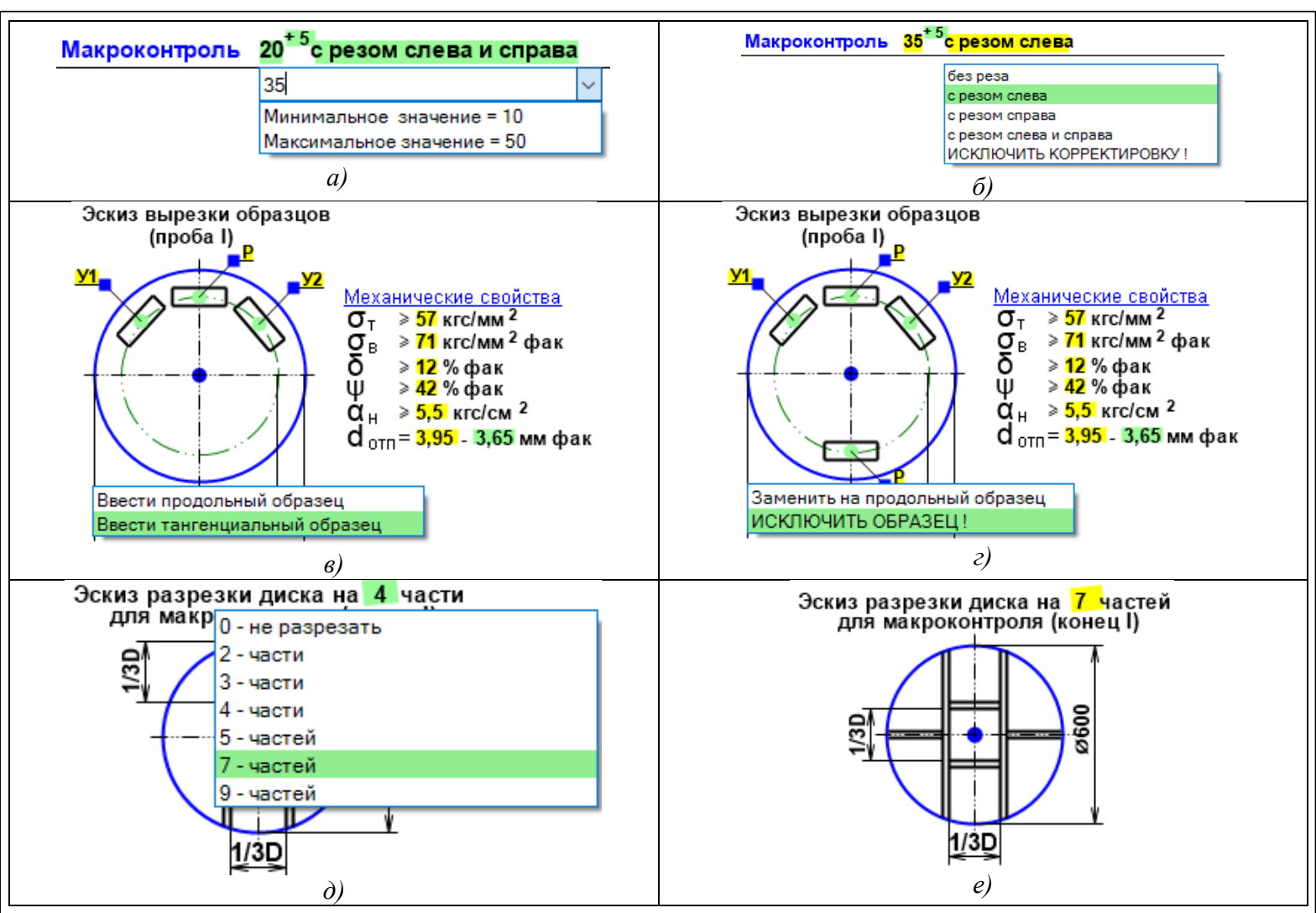

Рис. 5. Примеры выпадаюших меню для изменения значений параметров

Fig. 5. Examples of drop-down menus for adjusting design parameters

Работа выполнена по программе Уральского отделения РАН, проект № 18-1-1-13.

\section{Литература}

1. Трубин В.Н., Макаров В.И., Орлов С.Н., Шипицин А.А., Трубин Ю.В., Лебедев В.А. Система управления качеством проектирования технологических процессов ковки. М.: Машиностроение, 1984. 184 с.

2. Коновалов А.В., Арзамасцев С.В., Шалягин С.Д., Муйземнек О.Ю., Гагарин П.Ю. Интеллектуальная САПР технологических процессов ковки валов на молотах // Заготовительные производства в машиностроении. 2010. № 1. С. 20-23.

3. Возмищев Н.Е. Опыт разработки и внедрения САПР ТП заготовительного производства // Автоматизированное проектирование в машиностроении. 2015. № 3. С. 43-45.

4. Митрофанов В.Г. Диалоговые САПР технологических процессов; [под. ред. Ю.М. Соломенцева]. М.: Машиностроение, 2000.229 c.

5. Гаврилова Т.А., Хорошевский В.Ф. Базы знаний интеллектуальных систем. СПб: Питер, 2001. 384 с.

6. Акулович Л.М., Шелег В.К. Основы автоматизированного проектирования технологических процессов в машиностроении. Минск: Новое знание; М.: Инфра-М, 2012. 488 с.

7. Bimba A.T., Idris N., Al-Hunaiyyan A., Mahmud R.B., Abdelaziz A., Khan S., Chang V., Towards knowledge modeling and manipulation technologies: a survey. Intern. J. of Information Management, 2016, vol. 36, iss. 6, pp. 857-871.

8. Lau H.C.W., Lee C.K.M., Jiang B., Hui I.K., Pun K.F. Development of a computer-integrated system to support CAD to CAPP. Intern. J. of Advanced Manufacturing Technology, 2005, vol. 26, pp. 1032-1042

9. Грибова В.В., Черкезишвили Н.Н. Развитие онтологического подхода для автоматизации разработки пользовательских интерфейсов с динамическими данными // Информационные технологии. 2010. № 10. С. 54-58.
10. Грибова В.В., Клещев А.С. Процессы управления интеллектуальными системами // Онтология проектирования. 2011. № 1. C. 22-31.

11. Ali K., Emad A.N., Abdulrahman A.-A., Osama A., Syed H.M. Feature-based design approach for integrated $\mathrm{CAD}$ and computeraided inspection planning. Intern. Jo. of Advanced Manufacturing Technology, 2015, vol. 76, pp. 2159-2183.

12. Бессмертный И.А., Посевкин Р.В. Естественно-языковой пользовательский интерфейс диалоговой системы // Программные продукты и системы. 2016. № 3. С. 5-9.

13. Mayvan B.B., Rasoolzadegan A., Yazdi Z.G. The state of the art on design patterns: A systematic mapping of the literature. J. of Systems and Software, 2017, vol. 125, pp. 93-118.

14. Зубкова Т.М., Наточая Е.Н. Проектирование интерфейса программного обеспечения с использованием элементов искусственного интеллекта // Программные продукты и системы. 2017. № 1. С. 5-11.

15. Eisman E.M., Navarro M., Castro J.L., A multi-agent conversational system with heterogeneous data sources access. Expert Systems with Applications, 2016, vol. 53, pp. 172-191.

16. Зубкова Т.М., Мустюков Н.А., Токарева М.А. Построение архитектуры САПР одношнековых экструдеров с применением элементов искусственного интеллекта // Программные продукты и системы. 2016. № 4. С. 176-182.

17. Ковалев В.Г., Рыбаков А.В. Автоматизация проектирования технологических процессов листовой штамповки. Ч. 1. Основы создания САПР // Заготовительные производства в машиностроении. 2007. № 4. С. 30-33.

18. Xie S.Q., Xu X. Step-compliant process planning system for compound sheet metal machining. Intern. J. of Production Research, 2008, vol. 46, pp. 25-50.

19. Муйземнек О.Ю., Коновалов А.В., Арзамасцев С.В. Стратегия взаимодействия агентов графического редактора САПР технологических процессов ковки // Программные продукты и системы. 2015. № 3. С. 192-198. 


\section{Input language of a computer-aided system for shaft forging}

S.I. Kanyukov ${ }^{1}$, Ph.D. (Engineering), Senior Researcher, ksi@imach.uran.ru

A.V. Konovalov ${ }^{1}$, Dr.Sc. (Engineering),Professor, Head of Laboratory, avk@imach.uran.ru

O.Yu. Muyzemnek ${ }^{1}$, Ph.D. (Engineering), Senior Researcher, olga@imach.uran.ru

${ }^{1}$ Institute of Engineering Science of the Ural Branch of the RAS, Ekaterinburg, 620049, Russian Federation

Abstract. A computer-aided system for shaft press forging design has been created at the Institute of Engineering Science, Ural Branch of the Russian Academy of Sciences. The linguistic support of this system includes a specialized input language for input of initial information and operational adjustments of intermediate and finished results of forging design by users.

The input of initial information can be done by two ways: inputting information of a new forged part or reading and adjusting (if necessary) information of a forged part (or a forging), which is already available in a database. The input language part responsible for inputting information of a new forged part provides filling three zones of a corresponding menu. These zones contain general information on the forged part, on the forged part geometry and a design plan. The latter includes a list of tasks to be done in the computer-aided design of forging.

Computer-aided design of forging includes the assignment of machining and heat-treatment allowances, addition of various specimens for mechanical testing and macro-control, assignment of forging overlaps, a definition of technical requirements and a simulation of a workpiece working drawing, which consists of seven graphic zones. The input language part responsible for adjusting the workpiece working drawing allows selecting a drawing format (A3 or A4), changing the size of graphic areas with scaling geometric objects and moving them within the drawing field, adjusting numerical and text values of forging parameters inside zones by drop-down menus, controlling the visibility of zones.

The described input language of the computer-aided technological design system provides convenient input of initial information about forged parts, ensures obtaining workpiece working drawings suitable for production processes, and greatly facilitates system adaptation to different enterprise conditions.

Keywords: computer-aided design, forging, shaft, design of forgings, linguistic basis, input language.

Acknowledgements. The work has been done according to the program of the Ural Branch of the Russian Academy of Sciences, project no. 18-1-1-13.

\section{References}

1. Trubin V.N., Makarov V.I., Orlov S.N., Shipitsin A.A., Trubin Yu.V., Lebedev V.A. Quality Management System for Forging Process Design. Moscow, Mashinostroenie Publ., 1984, 184 p.

2. Konovalov A.V., Arzamastsev S.V., Shalyagin S.D., Muyzemnek O.Yu., Gagarin P.Yu. Intellectual CAD for technological processes of forging shafts on hammers. Blank Production in Mechanical Engineering. 2010, no. 1, pp. $20-23$ (in Russ.).

3. Vozmishchev N.E. Experience in the development and introduction of CAD software for blank production. Automated Design in Mechanical Engineering. 2015, no. 3, pp. 43-45 (in Russ.).

4. Mitrofanov V.G. Interactive CAD of Technological Processes. Yu.M. Solomentsev (Ed.). 2nd ed., Moscow, Mashinostroenie Publ., 2000, 229 p.

5. Gavrilova T.A., Khoroshevsky V.F. Intelligent Systems Knowledge Bases. St. Petersburg, Piter Publ., 2001, 384 p.

6. Akulovich L.M., Sheleg V.K. Fundamentals of Computer-Aided Design of Technological Processes in Mechanical Engineering. Minsk, Novoe znanie Publ., Moscow, Infra-M Publ., 2012, 488 p.

7. Bimba A.T., Idris N., Al-Hunaiyyan A., Mahmud R.B., Abdelaziz A., Khan S., Chang V. Towards knowledge modeling and manipulation technologies: a survey. Intern. J. of Information Management. 2016, vol. 36, iss. 6, pp. 857-871.

8. Lau H.C.W., Lee C.K.M., Jiang B., Hui I.K., Pun K.F. Development of a computer-integrated system to support CAD to CAPP. Intern. J. of Advanced Manufacturing Technology. 2005, vol. 26, pp. 1032-1042.

9. Gribova V.V., Cherkezishvili N.N. Development of the ontological approach for automating development of user interfaces with dynamic data. Information Technologies. 2010, no. 10, pp. 54-58 (in Russ.).

10. Gribova V.V., Kleshchev A.S. Intellectual system management processes. Ontology of Designing. 2011, no. 1, pp. 22-31 (in Russ.).

11. Ali K., Emad A.N., Abdulrahman A.-A., Osama A., Syed H.M. Feature-based design approach for integrated CAD and computer-aided inspection planning. Intern. J. of Advanced Manufacturing Technology. 2015, vol. 76, pp. 2159-2183.

12. Bessmertny I.A., Posevkin R.V. Natural language user interface of a dialogue system. Software \& Systems. 2016, no. 3, pp. $5-9$ (in Russ.)

13. Mayvan B.B., Rasoolzadegan A., Yazdi Z.G. The state of the art on design patterns: A systematic mapping of the literature. J. of Systems and Software. 2017, vol. 125, pp. 93-118.

14. Zubkova T.M., Natochaya E.N. Software interface design using elements of artificial intelligence. Software \& Systems. 2017, no. 1, pp. 5-11 (in Russ.).

15. Eisman E.M., Navarro M., Castro J.L. A multi-agent conversational system with heterogeneous data sources access. Expert Systems with Applications, 2016, vol. 53, pp. 172-191.

16. Zubkova T.M., Mustyukov N.A., Tokareva M.A. Single screw extruder engineering with artificial intelligence elements. Software \& Systems. 2016, no. 4, pp. 176-182 (in Russ.)

17. Kovalev V.G., Rybakov A.V. Automation of designing of sheet punching technological processes. Part 1. Fundamentals of CAD creation. Blank Production in Mechanical Engineering. 2007, no. 4, pp. 30-33 (in Russ.)

18. Xie S.Q., Xu X. Step-compliant process planning system for compound sheet metal machining. Intern. J. of Production Research. 2008, vol. 46, pp. 25-50.

19. Muyzemnek O.Yu., Konovalov A.V., Arzamastsev S.V. The strategy of agent interaction in graphic editor of forging CAPP. Software \& Systems. 2015, no. 3, pp. 192-198 (in Russ.) 
Система статистического анализа и контроля стабильности вибраuий гидроагрегаma

\author{
B.Н. Клячкин 1, д.m.н., nрофрессор, v_kl@mail.ru \\ Ю.Е. Кувайскова ${ }^{1}$, к.т.н., доиент \\ А.В. Иванова ${ }^{1}$, аспирант
}

1 Ульяновский государственный технический университет, кафедра прикладной математики и информатики, г. Ульяновск, 432027, Россия

Система вибромониторинга гидроагрегата включает показания распределенной сети интеллектуальных датчиков относительной и абсолютной вибраций, а также датчиков измерения скорости вращения вала. Эти датчики предназначены для работы в составе системы управления гидроагрегатом. Датчики объединяются в единую локальную сеть для передачи данных о параметрах вибраций в систему управления.

В режиме работы в сети при условии стационарной работы агрегата для оценки стабильности вибраций могут быть использованы алгоритмы многомерного статистического контроля, аналогичные применяемым при контроле многопараметрических технологических процессов. Такой подход обеспечивает раннее выявление нарушений процесса статистическими методами и своевременное принятие управляющих воздействий.

На основе проведенного исследования и анализа результатов вибромониторинга гидроагрегата на Краснополянской ГЭС разработана программная система, обеспечивающая контроль стабильности вибраций. Система включает три подсистемы: для визуализации и группировки показателей, для контроля независимых и коррелированных групп показателей по критериям стабильности среднего уровня и для рассеяния соответствующих процессов. Для контроля независимых показателей используются карты Шухарта для средних значений и стандартных отклонений. При контроле коррелированных показателей применяются карты Хотеллинга для мониторинга среднего уровня процесса и карта обобщенной дисперсии для мониторинга многомерного рассеяния.

Система позволяет своевременно выявлять возможные нарушения и обеспечивает предотвращение выхода контролируемых показателей за пределы допустимых значений.

Ключевые слова: вибрачии, статистический контроль, карта Хотеллинга, обобщенная дисперсия, диагностика нарушений.

Аварийные ситуации на гидроагрегатах могут привести к перебоям в производстве электроэнергии и нанести вред персоналу и окружающей среде. Причиной подобных происшествий часто являются вибрации. Одно из направлений повышения эффективности управления гидроагрегатом и исключения таких ситуаций связано с возможностью раннего предупреждения о предполагаемой аварии путем прогнозирования состояния агрегата по множеству его характеристик, в частности, по вибрациям.

Система вибромониторинга гидроагрегата включает контролируемые характеристики - показания распределенной сети интеллектуальных датчиков относительной и абсолютной вибраций, а также датчиков измерения скорости вращения вала [1]. Эти датчики предназначены для работы в составе системы управления гидроагрегатом. Датчики объединяются в единую локальную сеть для передачи данных о параметрах вибраций в систему управления.

Характеристики вибраций в различных зонах гидроагрегата могут быть взаимосвязаны и образуют систему временных рядов. Можно построить соответствующие математические модели как в режиме запуска агрегата, так и в режиме работы в сети. На базе этих моделей возможны прогнозирование изменений характеристик агрегата и обнаружение нарушений процесса до того, как контроли- руемые параметры превысили предельные значения $[2,3]$.

В режиме работы в сети при условии стационарной работы агрегата для оценки стабильности процесса могут быть использованы алгоритмы многомерного статистического контроля, аналогичные применяемым при контроле многопараметрических технологических процессов $[4,5]$. Такой подход обеспечивает раннее выявление нарушений процесса статистическими методами и своевременное принятие управляющих воздействий.

\section{Постановка задачи}

Для обработки информации и разработки методики анализа и контроля стабильности вибраций использовались результаты записи показателей в системе управления гидроагрегатом на Краснополянской ГЭС (Краснодарский край) в режиме работы в сети, при котором контролируемые показатели должны быть стабильными. Проводился мониторинг биения валов и вибраций гидроагрегата с периодичностью два измерения в секунду. Процесс определяется десятью показателями: $X_{1}-X_{2}-$ вибрации нижнего генераторного подшипника верхнего бьефа и на правом берегу; $X_{3}-X_{4}$ - соответствующие вибрации верхнего генераторного подшипника; $X_{5}-X_{6}-$ бой вала гидротурбины, нижний бьеф и правый берег соответственно; $X_{7}-X_{8}-$ бой 
вала гидрогенератора; $X_{9}-X_{10}-$ вибрации крышки гидротурбины.

На рисунке 1 показана схема системы управления гидроагрегатом. Данные по вибрациям от гидроагрегата поступают через стойку виброконтроля на сервер сбора данных и в виде дискретного сигнала в режиме реального времени на стойку управления гидроагрегатом, с помощью которой изменяется нагрузка или происходит останов агрегата.

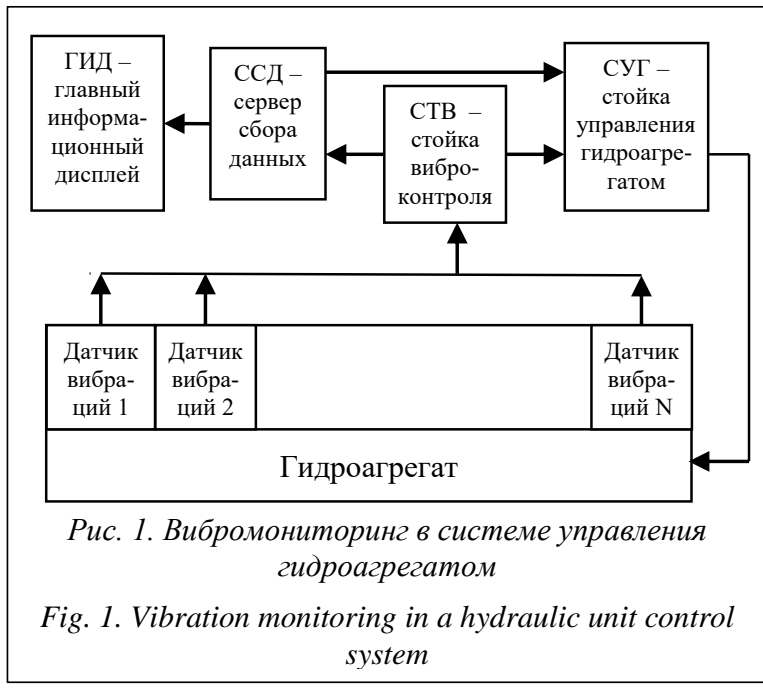

Для выявления участков установившейся (стационарной) работы гидроагрегата вибрации усреднялись по времени и визуализировались. На рисунке 2 в качестве примера показаны вибрации при усреднении данных по 10 сек. Начальная часть участка стабильной работы (25-30 усредненных данных) используется для оценки характеристик процесса: среднего уровня, рассеяния, корреляций, положения контрольных границ.

Статистический контроль многопараметрического процесса предполагает выделение из множества контролируемых показателей групп коррелированных параметров: для них необходимо применение многомерных методов, основанных на алгоритме Хотеллинга [5, 6]. Кроме того, статистический контроль ориентирован на нормально распределенные данные, однако, имея в виду большой объем измерений и усреднение данных, в условиях

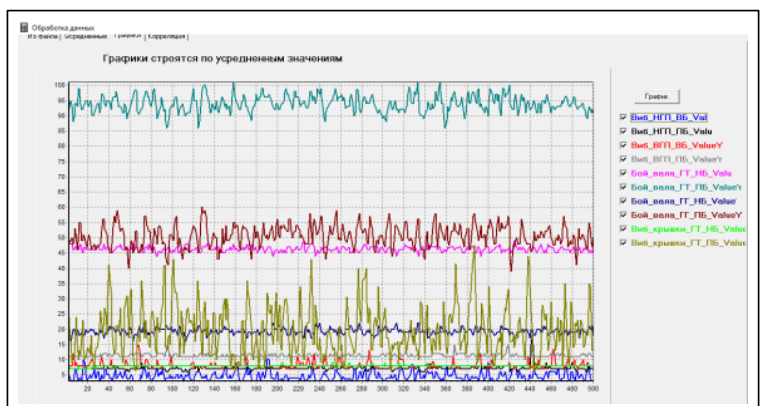

Рис. 2. Графики контролируемых вибрачий

Fig. 2. Charts of controlled vibrations рассматриваемой задачи это обстоятельство может не учитываться.

\section{Предварительный анализ данных}

Для анализа взаимосвязей между контролируемыми показателями строилась корреляционная матрица и проверялась значимость корреляций по критерию Стьюдента. Корреляционная матрица показана на рисунке 3, значимые корреляции выделены жирным шрифтом. Имеют место значимая отрицательная корреляция $r=-0,81$ между показателями $X_{5}$ и $X_{7}$ (боем валов гидрогенератора и гидротурбины на нижнем бьефе) и положительная корреляция $r=0,61$ между $X_{6}$ и $X_{8}$ (аналогичными показателями на правом берегу). Следует отметить, что корреляции зависят от того, как проводится усреднение данных (на рисунке приведены данные при усреднении по 10 сек.).

\begin{tabular}{|c|c|c|c|c|c|c|c|c|c|c|}
\hline \multirow[b]{2}{*}{$X_{1}$} & $X_{1}$ & $X_{2}$ & $X_{3}$ & $X_{4}$ & $X_{5}$ & $X_{6}$ & $X_{7}$ & $X_{8}$ & $X_{9}$ & $X_{10}$ \\
\hline & 1 & & & & & & & & & \\
\hline$X_{2}$ & $-0,01$ & 1 & & & & & & & & \\
\hline$X_{3}$ & $-0,14$ & $-0,03$ & 1 & & & & & & & \\
\hline$X_{4}$ & $-0,18$ & $-0,01$ & 0,10 & 1 & & & & & & \\
\hline$X_{5}$ & $-0,01$ & $-0,02$ & 0,15 & $-0,17$ & 1 & & & & & \\
\hline$X_{6}$ & 0,03 & 0,38 & $-0,02$ & 0,10 & 0,12 & 1 & & & & \\
\hline$X_{7}$ & $-0,07$ & 0,10 & $-0,20$ & 0,35 & $-0,81$ & \begin{tabular}{|l|}
$-0,07$ \\
\end{tabular} & 1 & & & \\
\hline$X_{8}$ & 0,03 & 0,44 & $-0,12$ & 0,22 & $-0,13$ & 0,61 & 0,31 & 1 & & \\
\hline$X_{9}$ & $-0,06$ & 0,14 & 0,05 & 0,18 & $-0,24$ & 0,09 & 0,31 & 0,20 & 1 & \\
\hline$X_{10}$ & $-0,01$ & 0,04 & $-0,08$ & 0,18 & $-0,10$ & 0,05 & 0,22 & 0,09 & 0,21 & 1 \\
\hline & & & Аеле & $\begin{array}{l}\text { oppe } \\
\text { bl } 3 н \text {. }\end{array}$ & цицио & $\begin{array}{l}\text { нная } \\
\text { е ко }\end{array}$ & $\begin{array}{l}\text { nат, } \\
\text { реля }\end{array}$ & & & \\
\hline & & Fig. & $\begin{array}{l}\text { A c } \\
\text { corre }\end{array}$ & $\begin{array}{l}\text { rela } \\
\text { ition }\end{array}$ & $\begin{array}{l}\text { tion } n \\
\text { s are }\end{array}$ & $\begin{array}{l}\text { atrix } \\
\text { highl }\end{array}$ & $\begin{array}{l}\text { (sign } \\
\text { ghted }\end{array}$ & fican & & \\
\hline
\end{tabular}

Анализ корреляционной матрицы показывает, что контролируемые показатели можно разделить на две группы.

1. Независимые показатели $X_{1}-X_{4}$ и $X_{9}-X_{10}$. Для контроля этих шести показателей могут быть использованы стандартные карты Шухарта для средних значений и стандартных отклонений.

2. Попарно коррелированные показатели $X_{5}-X_{7}, X_{6}-X_{8}$. Эти две пары показателей следует контролировать по стабильности среднего уровня с использованием карт Хотеллинга, а по контролю рассеяния - карт обобщенной дисперсии.

\section{Статистический контроль независимых показателей}

Контрольные карты Шухарта для показателя $X_{1}$ (вибрации нижнего генераторного подшипника верхнего бьефа), построенные в системе Statistica на этапе анализа для 30 выборок [7], показаны на рисунке 4. Видно, что процесс стабилен: нет выходов контролируемых значений за границы ни на одной из карт. Полученные значения среднего уровня процесса, среднего размаха и контрольных границ могут быть использованы для дальнейшего мони- 


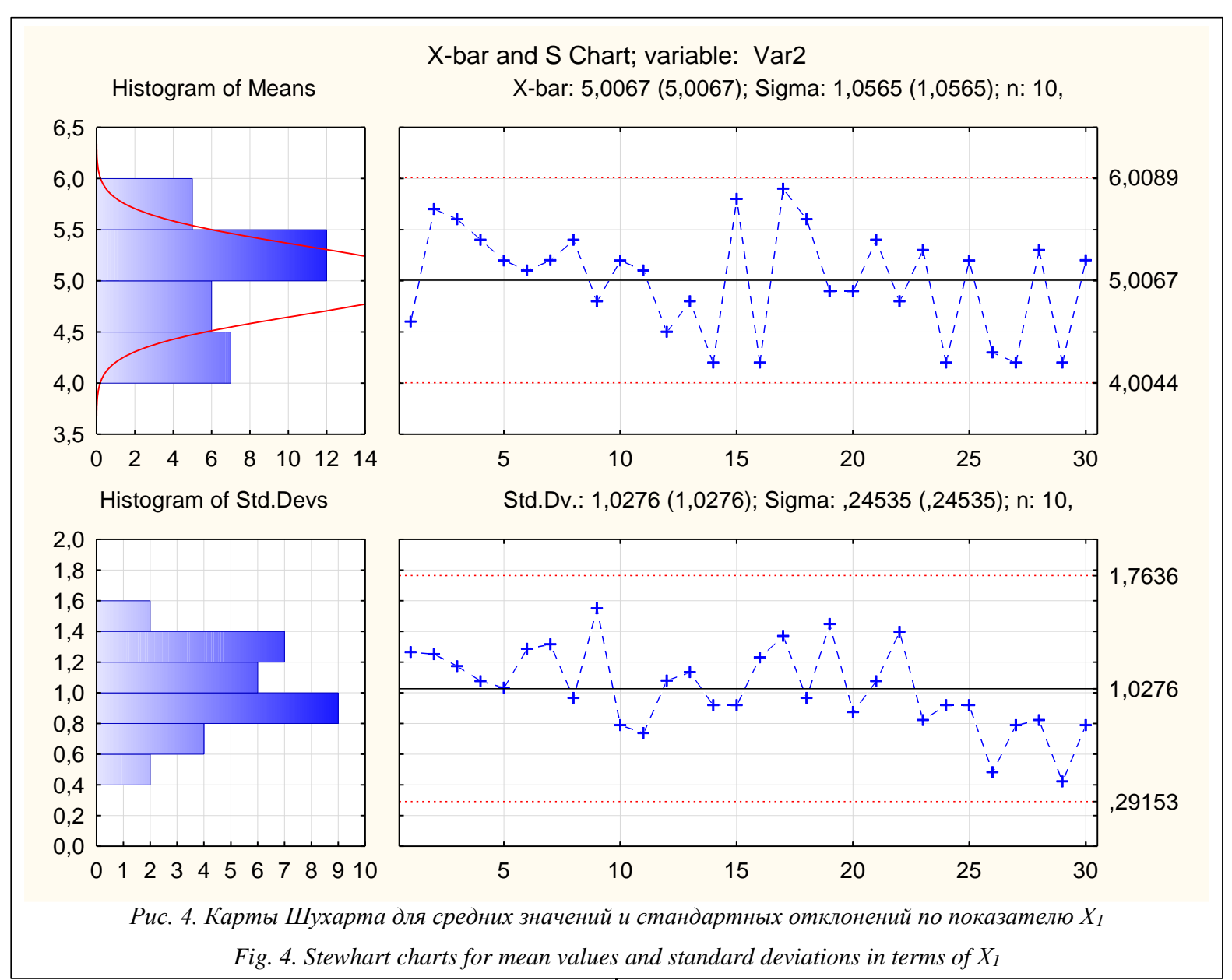

торинга процесса по этому показателю. Подобные карты были построены и для других независимых показателей.

При мониторинге процесса для оценки стабильности вибраций, кроме выходов точек за границы соответствующих доверительных интервалов, использовались и другие критерии, связанные с наличием так называемых неслучайных структур: наличие 9 точек подряд по одну сторону от центральной линии, 6 возрастающих или убывающих точек подряд (тренд), 14 попеременно возрастающих и убывающих точек и других [4].

\section{Многомерный контроль среднего уровня процесса}

Статистический контроль коррелированных показателей, как и независимых, может проводиться по среднему уровню вибраций и их рассеянию. Для контроля среднего уровня многопараметрического процесса используется алгоритм Хотеллинга, а многомерное рассеяние характеризуется обобщенной дисперсией - определителем ковариационной матрицы $[6,8]$.

На этапе анализа процесса в условиях его стабильности по результатам исследования 30 выборок для каждой группы коррелированных показателей (в рассматриваемом процессе таких групп две: $X_{5}-X_{7}$ и $\left.X_{6}-X_{8}\right)$ оцениваются следующие показатели:

$$
\begin{aligned}
& \text { - вектор средних } \mu_{0}=\left(\mu_{1}, \ldots, \mu_{p}\right)^{T}, \\
& \mu_{j}=\frac{1}{m n} \sum_{t=1}^{m} \sum_{i=1}^{n} x_{i j t},
\end{aligned}
$$

где $p$ - количество контролируемых показателей; $m$ - количество выборок; $n$ - объем выборки; $x_{i j t}$ - результат $i$-го наблюдения по $j$-му показателю в $t$-й выборке;

- ковариационная матрица, компоненты которой $s_{j k}=\frac{1}{m(n-1)} \sum_{t=1}^{m} \sum_{i=1}^{n}\left(x_{i j t}-\mu_{j}\right)\left(x_{i k t}-\mu_{k}\right)$,

$$
j, k=1, \ldots, p
$$

(определитель этой матрицы используется как оценка целевой обобщенной дисперсии $\left|\Sigma_{0}\right|$ );

- контрольные границы для карт Хотеллинга и обобщенной дисперсии.

Положение контрольной границы карты Хотеллинга определяется формулой

$$
T_{k p}^{2}=\frac{p(m-1)(n-1)}{m n-m-p+1} F_{1-\alpha}(p, m n-m-p+1),
$$

где $F_{1-\alpha}\left(k_{1}, k_{2}\right)$ - квантиль $F$-распределения Фишера с числами степеней свободы в числителе $k_{1}$, в знаменателе $-k_{2}$ порядка $1-\alpha, \alpha-$ значение уровня значимости (вероятность ложной тревоги). 
Верхняя и нижняя контрольные границы карты обобщенной дисперсии:

$$
\left.\begin{array}{l}
U C L \\
L C L
\end{array}\right\}=\left|\Sigma_{0}\right|\left(b_{1} \pm 3 \sqrt{b_{2}}\right) \text {. }
$$

Коэффициенты $b_{1}$ и $b_{2}$ вычисляются по формулам:

$$
\begin{gathered}
b_{1}=\frac{1}{(n-1)^{p}} \prod_{j=1}^{p}(n-j) \\
b_{2}=\frac{1}{(n-1)^{p}} \prod_{j=1}^{p}(n-j)\left[\prod_{k=1}^{p}(n-k+2)-\prod_{k=1}^{p}(n-k)\right] .
\end{gathered}
$$

Если значение на нижней границе окажется меньше нуля, она принимается равной нулю.

Найденные характеристики используются при последующем мониторинге вибраций. На рисунке 5 показана карта Хотеллинга при мониторинге группы показателей $X_{5}-X_{7}$ : на данном этапе наблюдений имеет место выброс за контрольную границу в выборке 13.

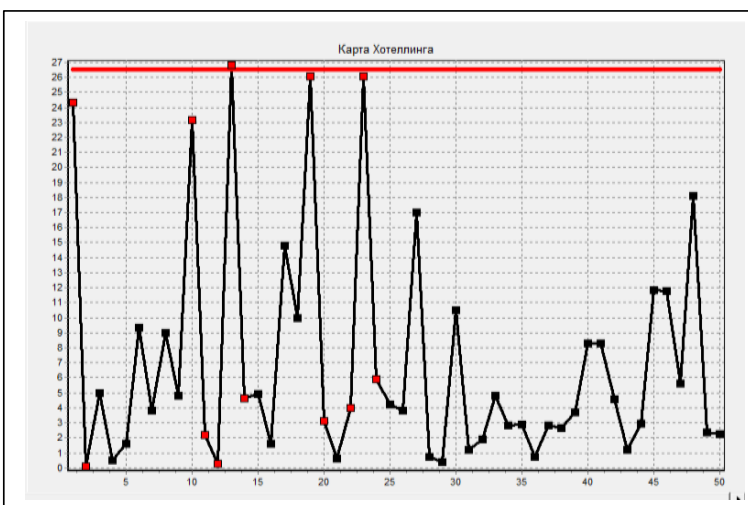

Рис. 5. Карта Хотеллинга при мониторинге группы показателей $X_{5}-X_{7}$

Fig. 5. Hotelling chart in monitoring a group of $X_{5}-X_{7}$ indicators

Возможные нарушения процесса анализировались также на наличие неслучайных структур (тренд, цикличность, приближение к оси абсцисс или контрольной границе, резкие скачки), а также с использованием предупреждающей границы [9]. Были выявлены резкие скачки в выборках 1-2, $10-11,12-13-14,19-20$ и 22-23-24, свидетельствующие о возможном нарушении процесса.

Заметим, что эти скачки, как и выход точки за контрольную границу, свидетельствуют о нарушении статистической стабильности среднего уровня процесса по группе показателей $X_{5}-X_{7}$, но не о выходе соответствующих характеристик за пределы допустимых значений. Принятие необходимых мер управленческого воздействия обеспечит стабилизацию процесса.

Одновременно проводился и мониторинг многомерного рассеяния по этим же группам показате- лей. На рисунке 6 показана карта обобщенной дисперсии, полученная для той же группы показателей $X_{5}-X_{7}$ в то же время, что и карта Хотеллинга (рис. 5). Эта карта свидетельствует о стабильности процесса по критерию многомерного рассеяния.

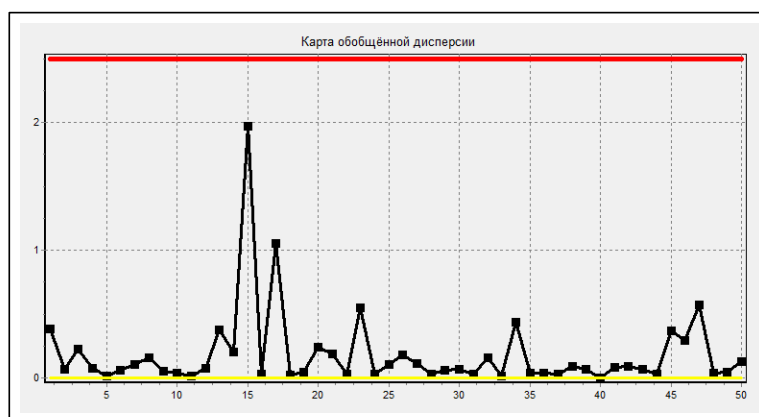

Рис. 6. Карта обобщенной дисперсии при мониторинге группы показателей $X_{5}-X_{7}$

Fig. 6. Chart of generalized variance in monitoring a group of $X_{5}-X_{7}$ indicators

\section{Структура системы статистического анализа и контроля стабильности вибраций гидроагрегата}

Система (структурная схема представлена на рисунке 7) предназначена для анализа и контроля вибраций гидроагрегата при его стационарной работе в сети с целью своевременного выявления нарушений стабильности и предотвращения выхода вибраций за допустимые границы. Система включает три программы.

Программа для предварительного анализа показаний интеллектуальных датчиков контроля вибраций дает возможность усреднить и визуализировать показания, оценить коррелированность между показаниями различных датчиков и разделить их на группы независимых и коррелированных с целью дальнейшего статистического контроля. Интерфейс программы на этапе усреднения данных (cм. http://www.swsys.ru/uploaded/image/2018-3/ 2018-3-dop/19.jpg), графики вибраций (рис. 2) построены в этой же программе.

Программа контроля стабильности вибраций по независимым показателям предназначена для анализа и мониторинга процесса с использованием карт Шухарта для средних значений и стандартных отклонений. На этапе анализа по представленной выборке результатов наблюдений оцениваются среднее значение и среднее стандартное отклонение, определяется положение центральных линий и контрольных границ на картах, которые в дальнейшем используются при мониторинге процесса. На этапе мониторинга также выявляются неслучайные структуры, появление которых может свидетельствовать о нарушении стабильности процесса. 


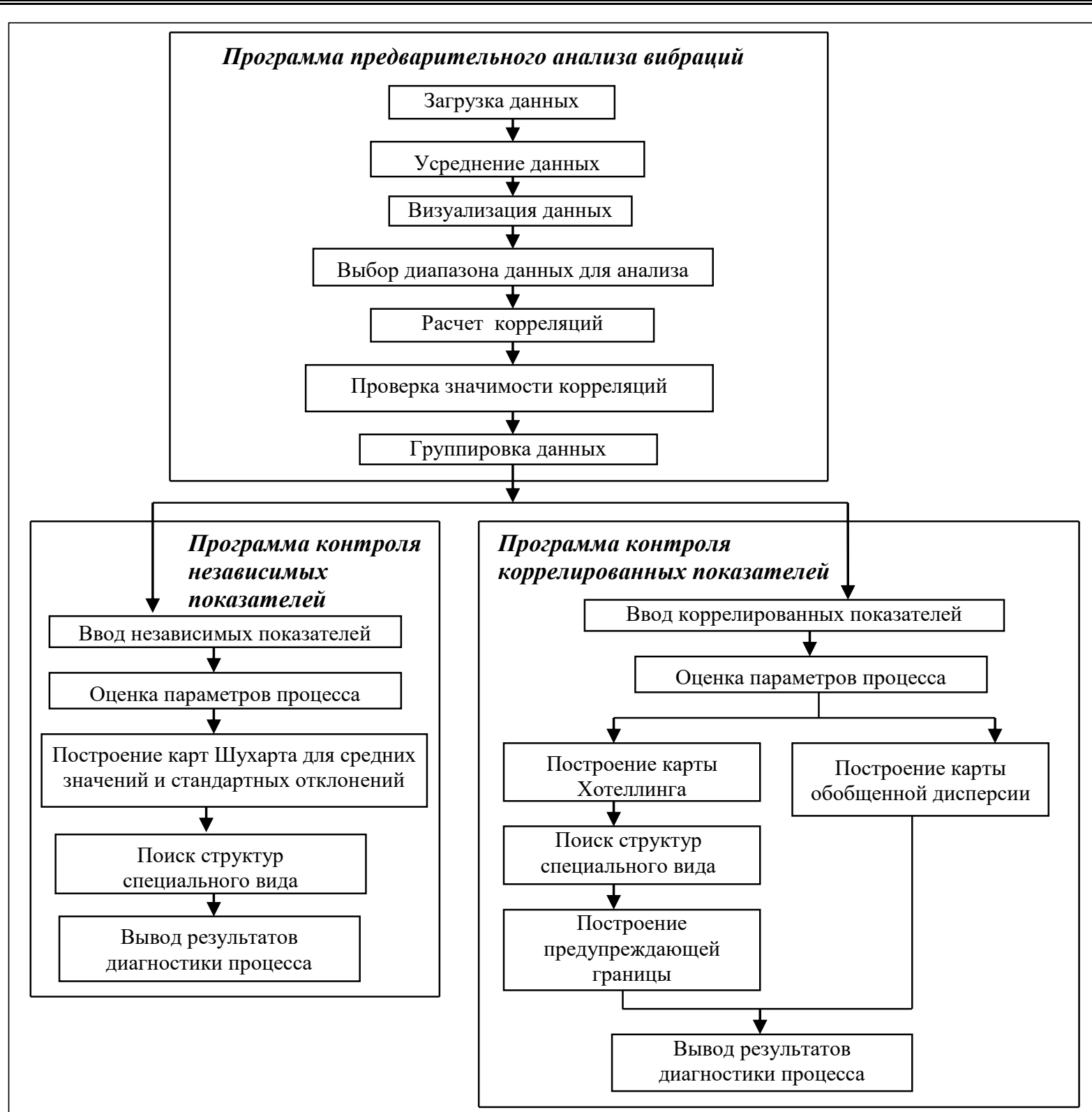

Рис. 7. Структурная схема системы

Fig. 7. A block diagram of the system

Программа контроля стабильности вибраций по коррелированным показателям предназначена для анализа и мониторинга с применением карты Хотеллинга для среднего уровня многомерного процесса и карты обобщенной дисперсии. При этом на этапе анализа оцениваются соответствующие характеристики по формулам (1)-(6), используемые при мониторинге коррелированных показателей. При мониторинге процесса также выявляются структуры специального вида, кроме того, используется предупреждающая граница для выявления нарушений по карте Хотеллинга [9]. Интерфейс программы на этапах выбора параметров и расчетов по алгоритмам Хотеллинга и обобщенной дисперсии представлен на рисунках (см. http://www. swsys.ru/uploaded/image/2018-3/2018-3-dop/20.jpg, http://www.swsys.ru/uploaded/image/2018-3/2018-3- dop/21.jpg), а построенные в программе контрольные карты - на рисунках 5 и 6.

Особенности разработанной программы по сравнению с существующими состоят, во-первых, в комплексном подходе к мониторингу стабильности вибраций гидроагрегата (от предварительного анализа данных до заключения о наличии или отсутствии нарушения стабильности). Во-вторых, программа дает возможность оперативной обработки файлов электронных таблиц, в которых сохраняется информация датчиков контроля вибраций (просмотр усредненных данных, группировка данных). Наконец, программа контроля стабильности вибраций по коррелированным показателям разработана на основе ранее предложенной системы [9] с существенным дополнением: предварительные исследования показали, что аварийные си- 
туации, связанные с нестабильностью вибраций, чаще определяются не изменением среднего уровня вибраций, а увеличением их разброса, поэтому необходим контроль рассеяния по обобщенной дисперсии.

\section{Заключение}

На основе проведенного исследования и анализа результатов вибромониторинга гидроагрегата на Краснополянской ГЭС разработана программная система, обеспечивающая контроль стабильности вибраций. Система включает три подсистемы: для визуализации и группировки показателей, а также контроля независимых и коррелированных групп показателей по критериям стабильности среднего уровня и рассеяния соответствующих процессов. Система позволяет своевременно выявить возможные нарушения и обеспечить предотвращение выхода контролируемых показателей за пределы допустимых значений.

Работа выполнена при поддержке гранта РФФИ № 16-48-732002.

\section{Лuтература}

1. Владиславлев Л.А. Вибрация гидроагрегатов гидроэлектрических станций. М.: Энергия, 1972. 153 с.

2. Клячкин В.Н., Кувайскова Ю.Е., Алешина А.А. Моделирование вибраций гидроагрегата на основе адаптивных динамических регрессий // Автоматизация. Современные технологии. 2014. № 1. С. 30-34

3. Кувайскова Ю.Е., Алешина А.А. Повышение эффективности системы управления техническими объектами при использовании адаптивного динамического регрессионного моделирования временных рядов // Автоматизация процессов управления. 2013. № 4. С. 77-83.

4. Уилер Д., Чамберс Д. Статистическое управление процессами. Оптимизация бизнеса с использованием контрольных карт Шухарта. М.: Альпина Бизнес Букс, 2009. 409 с.

5. Ryan T.P. Statistical methods for quality improvement. NY, John Wiley and Sons, 2011, 687 p.

6. Montgomery D.C. Introduction to statistical quality control. NY, John Wiley and Sons, 2009, $754 \mathrm{p}$.

7. Боровиков B. STATISTICA: искусство анализа данных. Для профессионалов. СПб: Питер, 2001. 656 с.

8. Bersimis S., Psarakis S., Panaretos J. Multivariate statistical process control charts: an overview. Quality and Reliability Eng. Intern., 2007, vol. 23, pp. 517-543.

9. Клячкин В.Н., Кравцов Ю.А. Обнаружение нарушений при многомерном статистическом контроле технологического процесса // Программные продукты и системы. 2016. № 3. C. $192-197$.
Software \& Systems

DOI: $10.15827 / 0236-235 X .123 .620-625$
Received 20.11 .17

2018 , vol. 31 , no. 3 , pp. $620-625$

\section{The system of statistical analysis and control of hydraulic unit vibration stability}

V.N. Klyachkin ${ }^{1}$, Dr.Sc. (Engineering), Professor, v_kl@mail.ru

Yu.E. Kuvayskova ${ }^{1}$, Ph.D. (Engineering), Associate Professor

A.V. Ivanova ${ }^{1}$, Postgraduate Student

${ }^{1}$ Ulyanovsk State Technical University, Ulyanovsk, 432027, Russian Federation

Abstract. The system of vibration monitoring of a hydraulic unit includes indications of a distributed network of relative and absolute vibration intelligent sensors, as well as sensors for measuring the shaft rotation speed. These sensors are designed to work as a part of the hydraulic unit control system. The sensors are combined into one local network to transfer data on vibration parameters to the control system.

The network operation mode during stationary operation of the unit can use multivariate statistical control algorithms in order to estimate vibration stability. These algorithms are similar to those used for controlling multiparameter technological processes. Such approach ensures early detection of process abnormalities using statistical methods and timely taking of control actions.

Based on the conducted research and result analysis of vibration monitoring of the hydroelectric unit in the Krasnopolanskaya hydroelectric power station, there is a developed software system that provides monitoring of the vibration stability. The system includes three subsystems: for visualization and grouping indicators, as well as for monitoring independent and correlated groups of indicators by stability criteria of the average level and the scattering the corresponding processes. In order to control independent indicators, the authors use Shewhart charts for mean values and standard deviations. When controlling correlated indicators, Hotelling charts are used to monitor the mean process level and a generalized variance chart for monitoring multidimensional scattering.

The system ensures timely detection of possible abnormalities and prevents overranging of controlled indicators.

Keywords: vibration, statistical control, Hotelling chart, generalized variance, diagnosis of violation.

Acknowledgements. Work has been supported by the Russian Foundation for Basic Research, grant no. 16-48-732002.

\section{References}

1. Vladislavlev L.A. Vibration of hydroelectric units in hydroelectric stations. Moscow, Energiya Publ., 1972, $153 \mathrm{p}$

2. Klyachkin V.N., Kuvayskova Yu.E., Aleshina A.A. Modeling of vibrations of a hydrounit on the basis of adaptive dynamic regressions. Automation. Modern Technologies. 2014, no. 1, pp. 30-34 (in Russ.)

3. Kuvayskova Yu.E., Aleshina A.A. Increasing the efficiency of technical object control system with the use of adaptive dynamic regression modeling of the time series. Automation of Control Processes. 2013, no. 4, pp. 77-83 (in Russ.).

4. Wheeler D.J., Chambers D.S. Understanding Statistical Process Control. SPC Press, 1992, 406 p. (Russ. ed.: Moscow, AlpinaBiznesBuks Publ., 2009, 409 p.).

5. Ryan T.P. Statistical Methods for Quality Improvement. NY, John Wiley and Sons Publ., 2011, 687 p.

6. Montgomery D.C. Introduction to Statistical Quality Control. NY, John Wiley and Sons, 2009, 754 p.

7. Borovikov V. STATISTICA: the Art of Data Analysis. For Professionals. St. Petersburg, Piter Publ., 2001, 656 p.

8. Bersimis S., Psarakis S., Panaretos J. Multivariate Statistical Process Control Charts: An Overview. Quality and reliability Engeneering Intern. 2007, vol. 23, pp. 517-543.

9. Klyachkin V.N., Kravtsov Yu.A. Irregularities in multivariate statistical control of a technological process. Software \& Systems. 2016, no. 3, pp. 192-197 (in Russ.). 


\section{Моделирование нанопористых структур кремний-резориинол-формальдегиднъх аэрогелей}

И.В. Мебедев ${ }^{1}$, аспирант, chemcom@muctr.ru

А.Ю. Tыцтышников 1, магистрант, chemcom@muctr.ru

С.И. Иванов 1, к.m.н., chemcom@muctr.ru

H.В. Менъшутина 1, д.т.н., профессор, chemсот@тистr.ru

1 Российский химико-технологический университет им. Д.И. Менделеева, г. Москва, 125480, Россия

Данная работа посвящена исследованию и моделированию структуры кремний-резорцинол-формальдегидных аэрогелей. Были проведены экспериментальные исследования получения гибридных кремний-резорцинол-формальдегидных аэрогелей, в основе которых варьирование условий их получения (соотношение реагентов, количество растворителя и т.д.).

В качестве структурных характеристик были выбраны следующие параметры: удельная площадь поверхности и распределение пор по размерам. Генерация структур, соответствующих реальным, открывает возможности для моделирования различных свойств аэрогелей in silico, что, в свою очередь, позволяет экономить ресурсы на проведении дорогостоящих экспериментов.

В ходе выполнения работы изучены существующие методы генерации пористых структур кремний-резорцинолформальдегидных аэрогелей. Для моделирования структур таких аэрогелей выбран метод Diffusion-Limited Cluster Aggregation (DLCA). Были проведены вычислительные эксперименты по генерации модельных структур и их сравнение с экспериментальными по выбранным критериям (распределение пор по размерам и удельная площадь поверхности).

Результаты, полученные в процессе вычислительных экспериментов, показали хорошую сходимость между экспериментальными и моделируемыми структурами гибридных кремний-резорцинол-формальдегидных аэрогелей. Для реализации данного метода был разработан алгоритм, написанный на языке программирования С\# в среде разработки Microsoft Visual Studio. Для функционирования созданного ПО необходимы операционная система Microsoft Windows 7 и выше и не менее 2 Гб ОЗУ.

В статье приведены результаты вычислительных экспериментов и алгоритм генерации структур кремний-резорцинол-формальдегидных аэрогелей. Разработанное ПО позволяет получать реальные структуры кремний-резорцинолформальдегидных аэрогелей с заданными структурными характеристиками.

Ключевые слова: моделирование, структура, аэрогель, ограниченная диффузией кластер-кластерная агрегация, кремний-резориинол-формальдегидные аэрогели.

Аэрогели - новое поколение высокопористых наноструктурированных материалов с низкой плотностью $\left(0,003-0,15\right.$ кг/м $\left.\mathbf{m}^{3}\right)$ и большой площадью удельной поверхности (500-1000 м²/г) [1]. Рассматриваемые в данной статье кремний-резорцинол-формальдегидные аэрогели применяются в качестве сорбентов и теплоизоляционных материалов [2]. Кроме того, с помощью процесса пиролиза из данных аэрогелей можно получить кремний-углеродные аэрогели. Внутренняя структура кремний-резорцинол-формальдегидных аэрогелей напрямую зависит от условий их получения (соотношение реагентов, тип и количество катализатора, количество растворителя и т.д.) [1-3]. Варьирование этих параметров позволяет получать аэрогели с различной структурой и характеристиками.

Данная работа посвящена моделированию структуры кремний-резорцинол-формальдегидных аэрогелей. Компьютерная модель структуры аэрогеля позволяет рассчитывать различные свойства, например, теплопроводность, механическую прочность, не прибегая к дорогостоящим экспериментам, тем самым сокращая время и затраты на проведение экспериментов. Для выполнения поставленной цели (адекватная модель структур кремний-резорцинол-формальдегидных аэрогелей) необходимо решить следующие задачи: изучение экспериментальных данных по получению исследуемых аэрогелей; выбор модели и ее адаптация под конкретную задачу; проведение численного эксперимента для проверки адекватности модели.

\section{Экспериментальные данные}

Процесс получения аэрогелей, как правило, включает в себя две основные стадии: формирование геля в среде соответствующего растворителя посредством золь-гель-процесса и процесс сушки в среде сверхкритического флюида [4].

Рассматриваемые в данной работе кремний-резорцинол-формальдегидные аэрогели получают путем раздельного формирования золей. Согласно данной методике, золи с органической и неорганической составляющими готовят по отдельности, а затем смешивают. Растворителем в обоих случаях выступает этанол. В результате в объединенном растворе происходит одновременное формирование структуры как из органической, так и из неорганической составляющих. Далее происходит замена растворителя (этанола) на изопропанол. После этого гели сушат в сверхкритическом диоксиде углерода для удаления изопропанола. 
На рисунке 1 представлена структура получившегося кремний-резорцинол-формальдегидного аэрогеля.

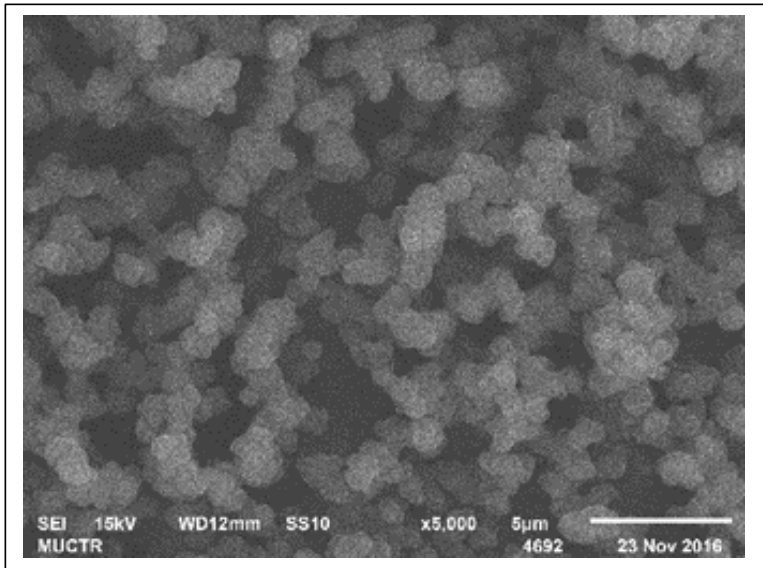

Рис. 1. Сканирующая электронная микроскопия кремний-резорцинол-формальдегидного аэрогеля

Fig. 1. SEM of a silica-resorcinol-formaldehyde aerogel

Ключевыми параметрами, характеризующими внутреннюю структуру аэрогеля, являются площадь удельной поверхности и распределение пор по размерам.

По классификации пор Международного союза по теоретической и прикладной химии (IUPAC), каждый интервал размеров (диаметров) пор имеет характерные для него адсорбционные свойства. Так, выделяют микропоры (поры с диаметром < 2 нм), мезопоры (поры с диаметром от 2 до 50 нм) и макропоры (поры с диаметром >50 нм) [5].

Согласно этой классификации, аэрогель имеет мезопористую структуру, то есть его структура содержит поры диаметром 2-50 нм. Как видно из изображения, структура аэрогеля состоит из четко различимых шарообразных кластеров, которые, в свою очередь, состоят из элементарных структурообразующих частиц - глобул. Размер и распределение мезопор обусловлены размером кластеров [6]. Таким образом, размер кластеров и их количество напрямую влияют на структуру аэрогеля.

\section{Выбор модели и ее адаптация под конкретную задачу}

Аэрогель имеет мезопористую структуру, поэтому наибольший интерес для рассматриваемой задачи представляют методы, которые позволяют моделировать структуру кремний-резорцинолформальдегидных аэрогелей на мезоуровне. Среди них предпочтительными являются методы МонтеКарло, так как они способны с достаточно высокой точностью моделировать структуры аэрогелей, но при этом не очень требовательны к вычислительным ресурсам [7]. Среди них для моделирования коллоидных систем (например аэрогелей) наиболее часто применяются методы агрегации кластер- кластер, такие как ограниченная диффузией кластер-кластерная агрегация (diffusion-limited cluster aggregation, DLCA) и др. [7, 8].

В качестве исходного метода был выбран метод DLCA как хорошо описывающий структуру аэрогелей $[9,10]$. Идея метода состоит в том, что хаотично двигающиеся частицы аэрогеля, размещенные на поле, агрегируют сначала в более крупные кластеры, а затем в единую структуру.

Для реализации данного метода была разработана клеточно-автоматная модель. Выбор этой модели обусловлен возможностью адаптировать ее для аэрогелей различной природы при относительно низких требованиях к вычислительным ресурсам $[10,11]$.

Как было сказано, структуру аэрогеля на мезоуровне формируют шарообразные кластеры, состоящие из глобул. Поэтому в предлагаемой адаптации модели DLCA в качестве начальных частиц, размещаемых на поле, были выбраны шарообразные кластеры, размер которых может варьироваться в зависимости от условий гелирования [11].

Разработанная модель имеет следующие допущения:

- в начале процесса есть только шарообразные кластеры, которые затем агрегируют в единую структуру;

- шарообразные кластеры представлены в виде шара/круга вещества для трехмерного и двухмерного случаев соответственно; размер кластеров подбирается эмпирически;

- шарообразные кластеры движутся хаотично, имитируя броуновское движение; при этом они не испытывают влияния никаких внешних сил;

- каждый шарообразный кластер образован либо органической, либо неорганической составляющей.

На рисунке 2 представлена блок-схема разработанной модели.

Входными параметрами модели являются пористость генерируемого образца и соотношение органической и неорганической составляющих. Диаметры шарообразных кластеров подбираются эмпирически для каждого образца, поэтому они также являются входными параметрами модели.

Моделирование структуры происходит на поле заданного размера, которое делится на равные ячейки, образуя сетку. Считается, что ячейки сетки однородные, то есть каждая из них может иметь только одно из возможных состояний в каждый момент времени (неорганика, органика, пустота).

Шарообразные кластеры размещаются на поле так, чтобы не перекрывать друг друга. Случайным образом задается начальный вектор скорости для каждого кластера. Затем они начинают двигаться и агрегировать друг с другом в более крупные кластеры и в итоге в единую структуру.

Алгоритм выполняется до тех пор, пока все кластеры не образуют единую структуру (то есть пока 


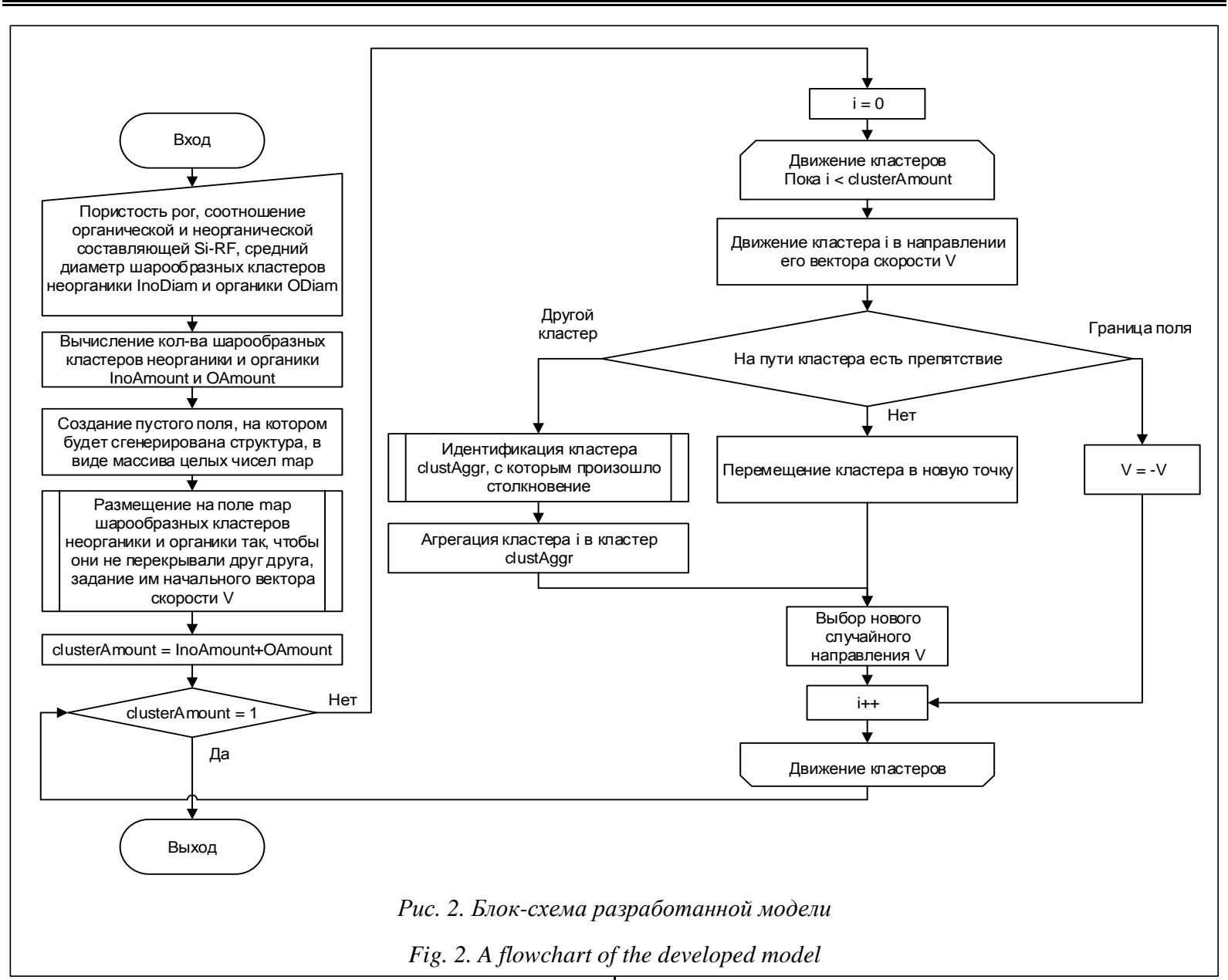

на поле не останется один кластер, содержащий в себе все остальные). Выходным параметром модели является двухмерная или трехмерная сетка.

На рисунке 3 представлена полученная с помощью модифицированной модели DLCA структура (двухмерный случай). Модель позволяет получить и трехмерную структуру образца. Была получена структура размером $1000 \times 1000$ нм, что на скани-

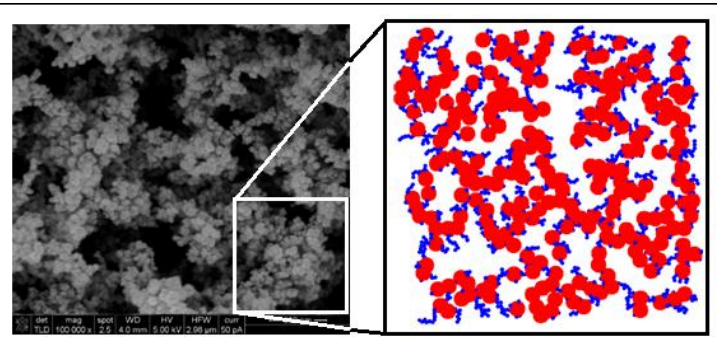

Рис. 3. Сканирующая электронная микроскопия структуры кремний-резориинол-формальдегидного аэрогеля (слева), модельная структура кремний-

резориинол-формальдегидного аэрогеля

для двухмерного случая (синий - неорганика, красный-органика) (справа)

Fig. 3. Silica-Resorcinol-Formaldehyde aerogel structure SEM (on the left), $2 D$ silica-resorcinol-formaldehyde aerogel structure model (blue is an inorganic part, red is an organic part) (on the right) рующей электронной микроскопии соответствует показанному участку. В данном примере размеры глобул неорганической части составляют 5 нм, а органической -41 нм.

\section{Проведение численного эксперимента для проверки адекватности модели}

Разработанная модель была использована для проведения численного эксперимента на реальных образцах кремний-резорцинол-формальдегидных аэрогелей. В качестве критерия адекватности полученных структур было выбрано распределение пор по размерам. Расчетные значения для указанного параметра получены с использованием алгоритмов, описанных в [12].

Экспериментальные данные исследуемых образцов представлены в таблице.

Экспериментальные данные одной из серий исследуемых образцов

Experimental data of one of the study sample series

\begin{tabular}{|l|c|c|c|c|}
\hline \multirow{2}{*}{\multicolumn{1}{|c|}{ Показатель }} & \multicolumn{4}{|c|}{ Образец } \\
\cline { 2 - 5 } & $\mathbf{1}$ & $\mathbf{2}$ & $\mathbf{3}$ & $\mathbf{4}$ \\
\hline Масса резорцинола, г & 0,31 & 0,39 & 0,46 & 0,55 \\
\hline Масса формальдегида, г & 0,9 & 1,16 & 1,35 & 1,62 \\
\hline Масса АЭАПТМС, г & 0,62 & 0,79 & 0,93 & 1,11 \\
\hline Масса ТЭОС, г & 0,76 & 0,97 & 1,13 & 1,36 \\
\hline Масса этанола, г & 8,04 & 7,76 & 7,04 & 6,72 \\
\hline
\end{tabular}


В образцах данной серии от первого к последнему уменьшалось соотношение растворителя (этанола) к другим реагентам. Все остальные соотношения оставались без изменений. Аминоэтиламинопропилтриметоксисилан (АЭАПТМС) и тетраэтоксисилан (ТЭОС) используются совместно для получения неорганической (кремниевой) части.

На рисунке 4 представлены модельные структуры кремний-резорцинол-формальдегидных аэрогелей, соответствующих образцам 1-4 таблицы. В данных структурах размер шарообразных кластеров кремния не менялся и был равен 5 нм. Пористость находилась в пределах 45-55 \%. Варьируемым параметром был диаметр шарообразных кластеров органической составляющей. Их итоговые диаметры принимают значения 17, 19, 37 и 41 нм для образцов 1-4 соответственно.

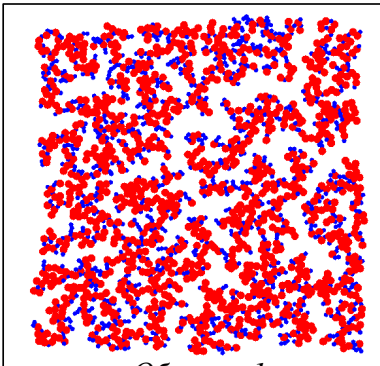

Образеи 1

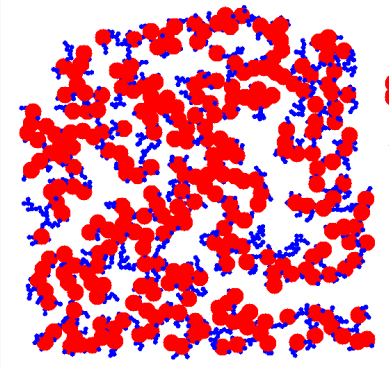

Образеи 3

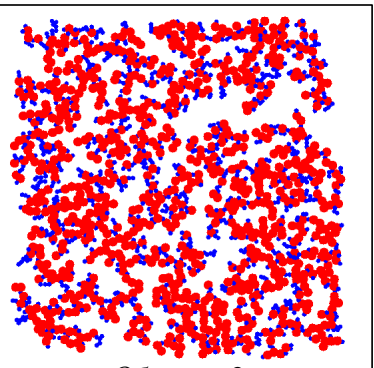

Образеи 2

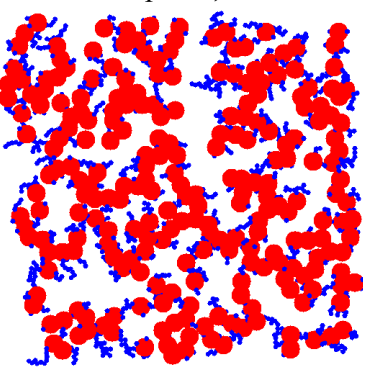

Образеи 4
Рис. 4. Модельные структуры кремний-резоричнол-формальдегидных аэрогелей (синий-неорганика, красный-органика)

Fig. 4. Silica-resorcinol-formaldehyde aerogel model structures (blue is an inorganic part, red is an organic part)

Распределение пор по размерам для экспериментальных образцов было получено с помощью азотной порометрии. Для определения распределения мезопор по размеру применяется метод Баррета-Джойнера-Халенды. Его суть заключается в следующем: образец помещается в адсорбат (азот) при заданном относительном давлении. При таком давлении заполняется часть пор. При повышении относительного давления заполняются все более крупные поры. Используя эти данные, можно построить кривую зависимости объема азота, который заполнил образец, от относительного давления. В дальнейшем полученную кривую можно преобразовать в зависимость объема азота, который заполнил образец, от диаметра пор. Такая кривая называется накопительной (интегральной) кривой распределения пор по размерам. Она выражает зависимость общего объема пор от их диаметра. Чтобы избежать влияния случайных погрешностей, по интегральной кривой строят дифференциальную кривую распределения пор по размерам с помощью графического дифференцирования. На дифференциальной кривой по оси абсцисс отложен диаметр пор, а по оси ординат - относительное изменение объема пор на единицу изменения диаметра пор. Дифференциальные кривые распределения пор по размерам экспериментальных и смоделированных структур приведены на рисунках (см. http://www.swsys.ru/uploaded/image/2018-3/2018-3dop/24.jpg, http://www.swsys.ru/uploaded/image/ 2018-3/2018-3-dop/25.jpg).

Для каждой пары кривых был рассчитан коэффициент различия $\left(f_{1}\right)$. Он показывает процент ошибки между двумя кривыми по всем точкам диаметра и рассчитывается по формуле

$$
f_{1}=\frac{\sum_{j=1}^{n}\left|d V(d) / d(d)_{\text {эксп., } j}-d V(d) / d(d)_{\text {мод., }, j}\right|}{\sum_{j=1}^{n} d V(d) / d(d)_{\text {эксп., } j}} \times 100 \%,
$$

где $n$ - число точек диаметра пор; $d V(d) / d(d)_{\text {эксп., }, \text { и }}$

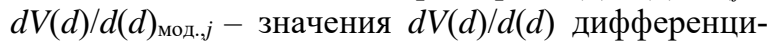
альной кривой распределения пор по размерам на диаметре пор $j$.

Коэффициент различия равен нулю, если кривые идентичны, и возрастает с увеличением различия двух кривых. Представим значения коэффициента различия для расчетных и экспериментальных кривых: для образца 1 он составляет $22 \%$, для 2 $24 \%$, для $3-18 \%$, для $4-20 \%$.

Как видно, коэффициент различия не превышает $25 \%$. Конечная структура аэрогеля имеет во многом случайный характер, поэтому различие ниже $25 \%$ означает допустимое соответствие экспериментальных и расчетных кривых. В дальнейшем точность моделирования будет повышаться.

Как видно из представленных кривых распределения пор по размерам, модельные структуры соответствуют экспериментальным. Таким образом, полученные структуры могут в дальнейшем использоваться как для прогнозирования свойств кремний-резорцинол-формальдегидных аэрогелей, так и для моделирования структуры кремний-углеродных аэрогелей на их основе.

\section{Выводы}

В ходе работы была разработана модель генерации структуры кремний-резорцинол-формальдегидных аэрогелей. Модель реализована на языке C\# в среде MS VisualStudio и апробирована на 100 образцах. Модельные структуры соответствуют 
экспериментальным образцам. Будет проведена модификация модели для учета кинетики структурообразования кремний-резорцинол-формальдегидных аэрогелей.

В дальнейшем планируется разработка модели процесса пиролиза, что позволит получать модель структуры кремний-углеродного аэрогеля из модели структуры кремний-резорцинол-формальдегидного аэрогеля.

Разработанные алгоритмы будут объединены в единый программный комплекс, который позволит моделировать структуры кремний-резорцинолформальдегидных и кремний-углеродных аэрогелей, оценивать их площадь удельной поверхности и распределение пор по размерам, а также прогнозировать свойства полученных структур.

Работа выполнена при финансовой поддержке Министерства образования и науки РФ в рамках соглашения № 114.583.21.0014. Уникальный идентификатор прикладных научных исследований (проекта) RFMEFI58316X0014.

\section{Лumepamypa}

1. Smirnova I., Gurikov P. Aerogel production: Current status, research directions, and future opportunities. The J. of Supercritical Fluids, 2017, vol. 134, pp. 228-233..

2. Berthon-Fabry S., Hildenbrand C., Ilbizian P., Jones E., Tavera S. Evaluation of lightweight and flexible insulating aerogel blankets based on Resorcinol-Formaldehyde-Silica for space applications. European Polymer J., 2017, vol. 93, pp. 403-416.

3. Schwan M., Tannert R., Ratke L. New soft and spongy resorcinol-formaldehyde aerogels. The J. of Supercritical Fluids, 2016, vol. 107, pp. 201-208.

4. Смирнов Б.М. Аэрогели // Успехи физических наук. 1987. T. 152. № 5. C. $133-157$.

5. Волкова А.В. Исследование структуры углеродных нанотрубок и оксидных наноматериалов, имеющих поры с осевой симметрией, с использованием адсорбции азота: дис. ... канд. хим. наук. М.: Изд-во МИЭТ, 2015. С. 21-28.

6. Fung A.W.P., Reynolds G.A.M., Wang Z.H., Dresselhaus M.S., Dresselhaus G., Pekala R.W. Relationship between particle size and magnetoresistance in carbon aerogels prepared under different catalyst conditions. J. of Non-Crystalline Solids. 1995, vol. 186, pp. 200-208.

7. Markutsya S. Modeling and simulation of nanoparticle aggregation in colloidal systems. Ph.D Thesis, Iowa State Univ., USA, 2010, $183 \mathrm{p}$.

8. Тыртышников А.Ю., Лебедев И.В., Иванов С.И., Меньшутина Н.B. Сравнение алгоритмов DLA и RLA при моделировании пористых структур // Программные продукты и системы. 2017. T. 30. № 4. C. 758-764

9. Lin M.Y., Lindsay H.M., Weitz D.A., Ball R.C., Klein R., Meakin P. Universality in colloid aggregation. Nature, 1989, vol. 339 , no. 6223 , pp. 360-362.

10. Rinewalt J., Noles W., Comer J. Modeling of particle aggregation processes. SCSCCC, 1992, pp. 58-65.

11. Aegerter M., Leventis N., Koebel M.M. (Ed.). Aerogels handbook. Springer, 2011, $956 \mathrm{p}$.

12. Колнооченко А.В. Моделирование структур аэрогелей и массопереноса в них с применением высокопроизводительных вычислений: дис. ... канд. физ.-мат. наук. М.: НИЯУ МИФИ, 2013. С. 78-91.

\section{Modeling nanoporous structures of silica-resorcinol-formaldehyde aerogels}

I.V. Lebedev ${ }^{1}$, Postgraduate Student, chemcom@muctr.ru

A.Yu.Tyrtyshnikov ${ }^{1}$, Graduate Student, chemcom@muctr.ru

S.I. Ivanov ${ }^{1}$, Ph.D (Engineering), chemcom@muctr.ru

N.V.Menshutina ${ }^{1}$, Dr.Sc. (Engineering), Professor, chemcom@muctr.ru

${ }^{1}$ D. Mendeleev University of Chemical Technology of Russia, 125480, Moscow, Russian Federation

Abstract. The paper is dedicated to investigating and modeling the structure of silica-resorcinol-formaldehyde aerogels. It considers experimental research on production of hybrid silica-resorcinol-formaldehyde aerogels based on the varying conditions for their production (reagent ratio, amount of solvent, etc.).

The structural characteristics were the following parameters: a specific surface area and pore size distribution. The generation of structures corresponding to the real ones makes it possible to model various properties of aerogels in silico, which in turn saves resources when carrying out costly experiments.

The authors have studied the existing methods of generating porous structures of silicon-resorcinol-formaldehyde aerogels. To model such aerogel structures, they have chosen the Diffusion-Limited Cluster Aggregation (DLCA) method. The paper considers the conducted computational experiments for generating model structures and compares them with experimental ones according to the selected criteria (pore size distribution and specific surface area).

The results of a number of computational experiments showed good convergence between experimental and simulated structures of hybrid silicon-resorcinol-formaldehyde aerogels. To implement this method, a C\# algorithm was developed in the Microsoft Visual Studio development environment. The created software requires the Microsoft Windows 7 operating system and above and at least 2 GB of RAM. 
The paper presents the results of computational experiments and the algorithm for generating silica-resorcinol-formaldehyde aerogel structures. The developed software allows obtaining real structures of silica-resorcinol-formaldehyde aerogels with given structural characteristics.

Keywords: modelling, structure, aerogel, diffusion-limited cluster aggregation, silica-resorcinol-formaldehyde aerogels.

Acknowledgements. The work has been financially supported by the Ministry of Education and Science of the Russian Federation within the framework of the agreement no. 114.583.21.0014. A unique applied research identifier (project) is RFMEFI58316X0014.

\section{References}

1. Smirnova I., Gurikov P. Aerogel production: Current status, research directions, and future opportunities. J. of Supercritical Fluids. 2018, vol. 134, pp. 228-233.

2. Berthon-Fabry S., Hildenbrand C., Ilbizian P., Jones E., Tavera S. Evaluation of lightweight and flexible insulating aerogel blankets based on Resorcinol-Formaldehyde-Silica for space applications. European Polymer J. 2017, vol. 93, pp. 403-416.

3. Schwan M., Tannert R., Ratke L. New soft and spongy resorcinol-formaldehyde aerogels. J. of Supercritical Fluids. 2016, vol. 107, pp. 201-208.

4. Smirnov B.M. Aerogels. Physics-Uspekhi. 1987, vol. 152, no. 5, pp. 133-157 (in Russ.).

5. Volkova A.V. Investigation of the Structure of Carbon Nanotubes and Oxide Nanomaterials with Axial Symmetry Pores Using Nitrogen Adsorption. PhD Thesis, MIET Publ., 2015, pp. 21-28 (in Russ.).

6. Fung A.W.P., Reynolds G.A.M., Wang Z.H., Dresselhaus M.S., Dresselhaus G., Pekala R.W. Relationship between particle size and magnetoresistance in carbon aerogels prepared under different catalyst conditions. J. of Non-Crystalline Solids. 1995, vol. 186, pp. 200-208.

7. Markutsya S. Modeling and Simulation of Nanoparticle Aggregation in Colloidal Systems. PhD Thesis, Iowa State Univ., USA, 2010, 183 p.

8. Tyrtyshnikov A.Yu., Lebedev I.V., Ivanov S.I., Menshutina N.V. Comparison of DLA and RLA porous structure modelling algorithms. Software and Systems. 2017, vol. 30, no. 4, pp 758-764 (in Russ.).

9. Lin M.Y., Lindsay H.M., Weitz D.A., Ball R.C., Klein R., Meakin P. Universality in colloid aggregation. Nature. 1989, vol. 339 , no. 6223 , pp. $360-362$.

10. Rinewalt J., Noles W., Comer J. Modeling of particle aggregation processes. SCSCCC. 1992, pp. 58-65.

11. Aegerter M., Leventis N., Koebel M. M. (Ed.). Aerogels Handbook. Springer Science \& Business Media Publ., 2011.

12. Kolnoochenko A.V. Modelling Aerogel Structures and Mass Transfer in them Using High-Performance Computing. Ph.D. Thesis, MEPhI Publ., 2013, pp. 78-91 (in Russ.).

\section{Примеры бибциографического описания статьи}

1. Аебедев И.В., Тыртышников А.Ю., Иванов С.И., Меньшутина Н.В. Моделирование нанопористых структур кремний-резорцинол-формальдегидных аэрогелей // Программные продукты и системы. 2018. т. 31. № 3. C. 626-631. DOI: 10.15827/0236-235X.123.626-631.

2. Lebedev I.V., Tyrtyshnikov A.Yu., Ivanov S.I., Menshutina N.V. Modelling nanoporous structures of silica-resorcinol-formaldehyde aerogels. Software \& Systems. 2018, vol. 31, no. 3, pp. 626-631 (in Russ.). DOI: 10.15827/0236-235X.123.626-631. 


\section{Моделирование транспортных потоков в среде AnyLogic}

Я.И. Шамлиикий ${ }^{1}$, к.т.н., доиент кафедры информаиионно-управляющих систем, 2538357@таil.ru A.C. Oxота 1, магистрант, okhota.sanya@mail.ru

С.Н. Мироненко ${ }^{1}$, аспирант

${ }_{1}$ Сибирский государственный университет науки и технологий им. академика М.Ф. Решетнева, 2. Красноярск, 660037, Россия

В статье предложена методика моделирования транспортных потоков в среде моделирования.

Была поставлена цель смоделировать участок дорожной сети г. Красноярска, для достижения которой необходимо решить две задачи: собрать данные по интенсивности транспортного потока на участке и разработать имитационную модель перекрестка. Для их решения выбрана среда моделирования AnyLogic.

При проведения эксперимента по моделированию необходимы входные параметры, в данной ситуации - интенсивность прибытия транспортных средств и распределение автомобилей по направлению.

Разработанная имитационная модель состоит из элементов дорожной сети, системы генерации агентов модели, блоков логики движения транспортных средств, элементов управления параметрами модели, модуля сбора статистики параметров агентов. В режиме исполнения модели отображается анимация, представляющая собой двухмерный план моделируемой системы с движущимися по ней транспортными средствами. Также есть функционал для переключения между двухмерным и трехмерным планами системы. В статистических данных учитываются время прохождения автомобилем участка дорожной сети, а также общая пропускная способность перекрестка.

Методика проведения эксперимента представляет собой предварительную настройку имитационной модели на среднюю пропускную способность перекрестка (обычно этот момент наступает после того, как количество автомобилей, вышедших из модели с помощью компонента Sink, достигнет значения 20 тыс. и более), далее, изменяя время работы светофоров, запускается поочередно имитационная модель. По окончании серии прогонов выполняется расчет разности средних задержек жесткого и адаптивного регулирования, строятся графики, делаются выводы.

В результате получается имитационная модель с методикой проведения эксперимента, которая может быть полезна при определении максимальной пропускной способности транспортных пересечений, планировании дорожной инфраструктуры и т.д.

Ключевые слова: АСУДД, AnyLogic, моделирование, имитационная модель, испытания.

В настоящее время остро стоит проблема управления транспортными потоками, особенно в больших городах. Увеличение количества как личных, так и общественных транспортных средств (ТC) привело к перегруженности городских дорог, многочасовым пробкам, затруднению движения пешеходов, увеличению количества аварий и т.д. Объектом в системе управления дорожным движением является транспортный поток, состоящий из технических средств (автомобилей, мотоциклов, автобусов и т.д.).

Компьютерное моделирование становится распространенным средством анализа сложных систем. Современный рынок внедрения и сопровождения технологических систем часто требует разработки систем поддержки принятия стратегических и оперативных решений на основе имитационных моделей. Так, низкоуровневое имитационное моделирование все чаще применяется при принятии решений о проектировании и реорганизации транспортных систем $[1,2]$.

В качестве платформы создания имитационной модели была выбрана среда моделирования AnyLogic 6.9.0 University (версия для образовательных учреждений).

Разработанная имитационная модель (см. рисунок) содержит следующие структурные элементы:

- четырехстороннее пересечение с примыкающими с каждой стороны дорогами;
- разделительная полоса, разделяющая каждую дорогу на две проезжие части по три полосы в каждом направлении;

- система генерации агентов модели - ТС двух типов: легковой автомобиль и грузовой автомобиль грузоподъемностью от 2 до 6 тонн;

- четыре блока логики движения ТС (по одному на каждое направление);

- модели элементов световой сигнализации светофоры типа Т.1.л;

- диаграмма состояний, моделирующая логику переключения сигналов светофоров, основанную на двухкольцевой фазировке;

- модуль системной динамики, моделирующий работу контроллера локального пересечения;

- блок управляющих параметров модели;

- элементы управления параметрами модели;

- модуль чтения параметров цикла жесткого регулирования из внешнего файла MSExcel;

- модуль сбора статистики параметров агентов;

- гистограмма распределения задержки ТС, показывающая также среднее время задержки всех ТС на протяжении эксперимента [3-9].

Созданная на базе AnyLogic 6.9.0 имитационная модель может быть использована для поддержки принятия решений и охватывает все этапы проведения исследований с помощью имитационного моделирования. 


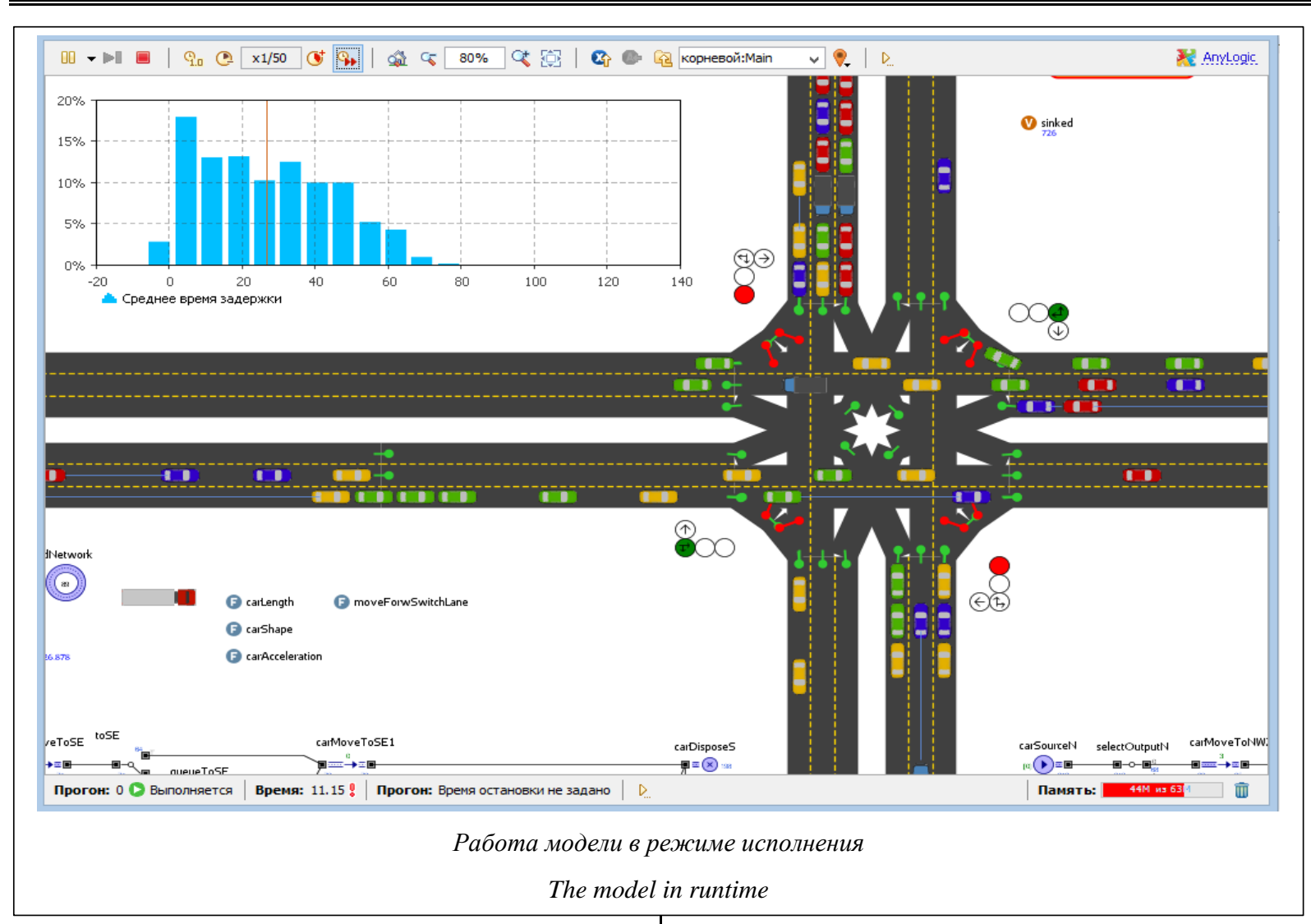

Для проведения исследований алгоритма была разработана методика проведения эксперимента.

Входящие параметры модели:

- интенсивность прибытия ТС северного $I_{N}$, восточного $I_{E}$, южного $I_{S}$ и западного $I_{W}$ подходов, авт./мин.;

- распределение автомобилей по направлениям (налево, прямо, направо) для каждого подхода, \%:

для северного $-p_{N}^{\text {лев. }}, p_{N}^{\text {прям. }}, p_{N}^{\text {прав.; }}$

для восточного $-p_{E}^{\text {лев. }}, p_{E}^{\text {прям. }}, p_{E}^{\text {прав.; }}$

для южного $-p_{S}^{\text {лев. }}, p_{S}^{\text {прям. }}, p_{S}^{\text {прав.; }}$

для западного $-p_{W}^{\text {лев. }}, p_{W}^{\text {прям. }}, p_{W}^{\text {прав. }}$.

Порядок проведения испытаний следующий.

1. Вначале составляется программа испытаний, базирующаяся на различных комбинациях последовательных изменений входящих параметров модели.

2. Далее для каждого испытания производится расчет длительностей основных тактов по общепринятому алгоритму Вебстера для жестких алгоритмов.

2.1. Рассчитывается поток насыщения:

$$
M=P \cdot n \cdot \frac{\left(I_{D} \cdot p_{D}{ }^{\text {прям. }}+I_{D} \cdot p_{D}{ }^{\text {лев. }}+I_{D} \cdot{p_{D}}^{\text {прав. }}\right)}{\left(I_{D} \cdot{p_{D}}^{\text {прям. }}+1,75 \cdot I_{D} \cdot p_{D}{ }^{\text {лев. }}+1,25 \cdot I_{D} \cdot p_{D}{ }^{\text {прав. }}\right)},(1)
$$

где $P$ - пропускная способность полосы движения, ед./ч; $n$ - число полос, открытых для движения; $I_{D}-$ интенсивность движения на рассматриваемом подходе к пересечению, прив.ед./час; $p_{\mathrm{D}}{ }^{\text {прям. }}, p_{\mathrm{D}}{ }^{\text {лев. }}$
$p_{\mathrm{D}}{ }^{\text {прав. }}-$ доли автомобилей, проезжающих в указанном направлении, \%.

2.2. Вычисляется фазовый коэффициент:

$y=I D / M$.

В каждой фазе выбирается подход или выделенное направление с максимальным фазовым коэффициентом, то есть наиболее загруженный. Он и является лимитирующим.

2.3. Выполняется расчет переходных тактов $t$.

В общем случае переходные интервалы не следует назначать длительностью менее 3 с. Если найденное значение $t^{\prime}$ не превышает $4 \mathrm{c}$, то переходный интервал состоит из одного такта (желтый сигнал). При $t^{\prime}=5, \ldots, 8$ с переходный интервал должен быть составлен из двух вспомогательных тактов (желтый и одновременно красный сигналы включаются в момент выключения желтого). Для упрощения расчетов принимаем длительность переходных интервалов $t^{\prime}=3 \mathrm{c}$.

2.4. Рассчитывается длительность цикла регулирования:

$$
T=\frac{(1,5 \cdot L+5)}{1-\sum y_{i}},
$$

где $L$ - сумма всех вспомогательных тактов, с; $y_{i}-$ фазовые коэффициенты.

2.5. Вычисляется длительность основных тактов:

$$
t_{i}=y_{i} \cdot \frac{T-L}{T-1,5 \cdot L-5} \cdot T .
$$


3. Полученные значения длительностей основных тактов сводятся в отдельный файл MSExcel (см. таблицу).

Длительность основных тактов

Duration of the main measures

\begin{tabular}{|c|c|c|c|c|c|c|c|c|c|}
\hline \multirow{3}{*}{$\begin{array}{c}\text { № ис- } \\
\text { Пыта- } \\
\text { ния }\end{array}$} & & \multicolumn{8}{|c|}{ Такты } \\
\hline & C-Ю & $\mathbf{K}+\boldsymbol{W}$ & $\mathbf{K}+3 \boldsymbol{л}$ & $\mathbf{K}+\boldsymbol{W}$ & 3 & Ж & $\mathbf{K}$ & $\mathbf{K}$ & $\mathbf{K}$ \\
\hline & 3-B & Ж & $\mathbf{K}$ & $\mathbf{K}$ & $\mathbf{K}$ & $\mathbf{K}+\boldsymbol{\Psi}$ & $\mathbf{K}+3$. & $\mathbf{K}+Ж$ & 3 \\
\hline 1 & & 3 & 8 & 3 & 17 & 3 & 8 & 3 & 17 \\
\hline 2 & & 3 & 12 & 3 & 18 & 3 & 12 & 3 & 18 \\
\hline 3 & & 3 & 16 & 3 & 19 & 3 & 16 & 3 & 19 \\
\hline$\ldots$ & & $\ldots$ & $\ldots$ & $\ldots$ & $\ldots$ & $\ldots$ & $\ldots$ & $\ldots$ & $\ldots$ \\
\hline$n$ & & 3 & $t_{n 1}$ & 3 & $t_{n 2}$ & 3 & $t_{n 3}$ & 3 & $t_{n 4}$ \\
\hline
\end{tabular}

4. Производится запуск модели, и в режиме исполнения выставляются значения входящих параметров в соответствии с номером эксперимента, а также режим работы модели «Жесткая логика» и номер логики жесткого управления.

5. После выставления параметров выставляется максимальная скорость выполнения и фиксируется момент, когда среднее время задержки примет стабильное состояние (обычно этот момент наступает после того, как количество автомобилей, вышедших из модели с помощью компонента Sink, достигнет значения 20 и более тысяч). При достижении стабильного состояния среднего времени задержки производятся снятие его значения и запись в соответствующую ячейку листа обработки экспериментальных данных. Затем выполняется выход из режима исполнения модели.

6. Осуществляется повторный запуск модели, в режиме исполнения выставляются значения входящих параметров в соответствии с номером эксперимента, выставляется режим работы модели «Адаптивная логика», выставляется максимальная длительность зеленого сигнала, равная максимальному значению длительности основных тактов для алгоритма жесткого регулирования, экипажное время выставляется равным 4 с.

7. После выставления параметров выставляется максимальная скорость выполнения и фиксируется момент, когда среднее время задержки примет стабильное состояние (обычно этот момент наступает после того, как количество автомобилей, вышедших из модели с помощью компонента Sink, достигнет значения 30 и более тысяч). При достижении стабильного состояния среднего времени задержки производятся снятие его значения и запись в соответствующую ячейку листа обработки экспериментальных данных. Затем выполняется выход из режима исполнения модели.

8. Снова повторяются этапы 6 и 7 с той лишь разницей, что при первом повторе максимальная длительность зеленого сигнала устанавливается на 2 с больше, во втором - на 2 с меньше и на третьем - на 5 с меньше.

9. Испытания повторяются для каждого номера эксперимента (этапы 4-8). Таким образом, полное исследование работы модели состоит из 150 прогонов.

10. По окончании серии прогонов выполняется расчет разности средних задержек жесткого и адаптивного регулирования, строятся графики, делаются выводы.

Указанная методика моделирования может быть полезна при определении максимальной пропускной способности транспортных пересечений, планировании дорожной инфраструктуры и т.д.

\section{Литература}

1. Левашев А.Г., Михайлов А.Ю. Основные параметры оценки пропускной способности регулируемых пересечений // ВИНИТИ. 2004. № 3. С. 14-19.

2. Малыханов А.А., Черненко В.Е. Среда низкоуровневого имитационного моделирования транспортных систем // Автоматизация в промышленности. 2010. № 1. С. 34-37.

3. Traffic control in oversaturated street networks. NCRHP report, 1978, no. 194, 152 p.

4. Highway Capacity Manual. TRB, Washington, DC, 2000, $1134 \mathrm{p}$.

5. Teply S. Canadian Capacity Guide for signalized intersection. Committee Canadian Capacity Guide for Signalized Intersections, $1995,117 \mathrm{p}$.

6. Врубель Ю.А. Исследования в дорожном движении. Минск: Изд-во БНТУ, 2007. 178 с.

7. Кременец Ю.А. Технические средства организации дорожного движения. М.: Академкнига, 2005. 279 с.

8. Mn/DOT Traffic Signal Timing Coordination Manual. Minnesota Department of Transportation, 2011, $184 \mathrm{p}$

9. Datta T.K. Innovations in Traffic Signal Systems. Advanced Traffic Signal Systems, Wayne State Univ., Detroit, Mich, 2003, pp. 23-25.
Software \& Systems

DOI: $10.15827 / 0236-235 X .123 .632-635$
Received 23.01.18

2018, vol. 31, no. 3, pp. 632-635

\section{Modeling traffic flows in AnyLogic}

Ya.I. Shamlicky ${ }^{1}$, Ph.D. (Engineering), Associate Professor of the Information management systems department, 2538357@mail.ru A.S.Okhota 1, Graduate Student, okhota.sanya@mail.ru S.N. Mironenko ${ }^{1}$, Postgraduate Student

${ }^{1}$ Academician M.F. Reshetnev Siberian State University of Science and Technology, Krasnoyarsk, 660037, Russian Federation

Abstract. The article proposes a technique for modeling traffic flows in a simulation environment

The goal was to simulate a section of the road network in Krasnoyarsk. The goal included the following tasks: to gather data on the traffic flow intensity at a site, to develop a simulation model of an intersection. The authors have chosen the AnyLogic modeling environment to solve the problems. 
The simulation experiment requires the input parameters. I this case, they are the intensity of vehicles arrival and the distribution of vehicles by a direction.

The developed simulation model has the following structural elements: road network elements, model agent generation system, vehicle traffic logic blocks, model parameters control elements, and an agent statistics gathering module. The model execution mode allows displaying animation, which is a two-dimensional plan of the simulated system with moving vehicles. In addition, there is a functional for switching between a two-dimensional and three-dimensional system plan. The statistical data take into account the time a vehicle passes a road network segment, as well as the total intersection traffic capacity.

The procedure of performing the experiment is a preliminary tuning of a simulation model to the average traffic capacity of the intersection (this usually occurs after a number of vehicles exiting the model using the Sink component reaches 20 or more thousands). Then while changing the time of the traffic lights, the simulation model is started alternately. After finishing a series of runs, follows the calculation of the difference in the mean delay of hard and adaptive regulation, construction of the graphs, and making the conclusions.

As a result, we get a simulation model with an experimental technique that can be useful in determining the maximum traffic capacity at traffic intersections, planning road infrastructure, etc.

Keywords: ATCS, AnyLogic, simulation, simulation model, tests.

\section{References}

1. Levashev A.G., Mikhaylov A.Yu. Basic parameters for estimating the throughput of controlled intersections. VINITI. 2004, no. 3, pp. 14-19 (in Russ.).

2. Malykhanov A.A., Chernenko V.E. Medium of low-level simulation of transport systems. Automation in Industry. Moscow, 2010, no. 1, pp. 34-37 (in Russ.).

3. Traffic Control in Oversaturated Street Networks. NCRHP report. 1978, no. 194, 152 p.

4. Highway Capacity Manual. TRB, Washington, DC, 2000, 1134 p.

5. Teply S. Canadian Capacity Guide for Signalized Intersection. Committee Canadian Capacity Guide for Signalized Intersections, 2nd ed. 1995, 117 p.

6. Vrubel Yu.A. Research in Road Traffic. Minsk, BNTU Publ., 2007, 178 p.

7. Kremenets Yu.A. Technical means to organize road traffic. Moscow, Akademkniga Publ., 2005, 279 p.

8. Mn/DOT Traffic Signal Timing Coordination Manual. Minnesota Department of Transportation. 2011, $184 \mathrm{p}$.

9. Datta T.K. Innovations in Traffic Signal Systems. Advanced Traffic Signal Systems. Wayne State Univ., Detroit, Mich, 2003, pp. 23-25.

\section{Примеры бибциографического описания статьи}

1. Шамлицкий Я.И., Охота А.С., Мироненко С.Н. Моделирование транспортных потоков в среде AnyLogic // Программные продукты и системы. 2018. T. 31. № 3. C. 632-635. DOI: 10.15827/0236235X.123.632-635.

2. Shamlicky Ya.I., Okhota A.S., Mironenko S.N. Modeling traffic flows in AnyLogic. Software \& Systems. 2018, vol. 31, no. 3, pp. 632-635 (in Russ.). DOI: 10.15827/0236-235X.123.632-635. 


\title{
Програмиа расиета настроек регуляторов
} методом расииренных частотных характеристик

\author{
Б.И. Марголис ${ }^{1}$, д.т.н., зав. кафедрой автоматизаиии технологических проиессов, \\ borismargolis@yandex.ru \\ Г.A. Мансур ${ }^{1}$, acnupaнm,gubran_ali@mail.ru \\ 1 Тверской государственный технический университет, г. Тверь, 170026, Россия
}

В статье рассмотрена постановка задачи расчета настроек типовых общепромышленных регуляторов в системах автоматического управления технологическими объектами. Показана возможность применения критерия устойчивости Найквиста для расширенных частотных характеристик систем. Сформулирована задача обеспечения необходимого качества переходного процесса в замкнутой системе за счет обеспечения заданной степени колебательности. Получено условие заданной колебательности системы, обеспечивающее нахождение настроек регулятора на линии равного затухания. Рассмотрена расширенная частотная характеристика ПИД-регулятора для случая введения в нее составляющей в виде реального дифференцирующего звена. Получены формулы для нахождения настроек ПИДрегулятора с использованием расширенных частотных характеристик в виде параметрических зависимостей. Приведены соотношения, получающиеся из общих формул для ПИ- и ПД-регуляторов.

На основе предложенного метода в среде MatLab разработана программа, позволяющая рассчитать оптимальные настройки регулятора по критерию минимального отклонения времени переходного процесса и перерегулирования от заданных значений. Приведены результаты расчета настроек ПИД-регулятора для контрольного примера и полученные линии равного затухания.

Показаны наилучшие по критерию качества переходные процессы для каждой из линий равного затухания и оптимальный процесс, удовлетворяющий требуемым характеристикам качества. Показаны недостатки метода расширенных частотных характеристик в предложенной постановке. Рассмотрены возможности альтернативной постановки задачи синтеза настроек регуляторов и применение предложенных методов для нахождения настроек регуляторов в многоконтурных системах автоматического управления технологическими объектами.

Ключевые слова: система автоматического управления, объект, регулятор, расчет настроек, расширенная частотная характеристика, переходный процесс, степень колебательности, линия равного затухания, программа расчета, оптимальные настройки, перерегулирование, критерий качества.

При автоматизации технологических процессов важную роль играет определение настроек регуляторов. Наибольшее применение находят одноконтурные замкнутые системы автоматического регулирования (САР) с типовыми линейными законами регулирования. В разомкнутой цепи такой системы находятся последовательно соединенные регулятор и объект регулирования с передаточными функциями $W(p)$ и $W_{p}(p)$ соответственно [1]. В отличие от большинства существующих методов расчета настроек регуляторов [2-4], в которых показателем качества являются интегральные критерии, метод расширенных частотных характеристик (РЧХ) обеспечивает определение множества настроек регулятора (линии равного затухания (ЛР3)), обеспечивающих заданную степень колебательности $m$ переходного процесса замкнутой системы [5].

Согласно критерию Найквиста $[5,6]$, для расширенной частотной характеристики (РЧХ) [7] условием заданной колебательности в замкнутой САР является прохождение расширенной амплитудно-фазовой характеристики (АФХ) разомкнутой системы через точку $(-1, j \cdot 0)$.

Обозначая расширенные частотные характеристики объекта и регулятора через $W(m, \omega)$ и $W_{p}(m$, $\omega)$, получим вышеуказанное условие в виде

$$
\begin{aligned}
& W_{\text {раз. }}(m, \omega)=W_{\text {раз. }}((j-m) \omega)=W(m, \omega) W_{p}(m, \omega)=-1, \\
& \text { откуда } W_{p}(m, \omega)=-1 / W_{p}(m, \omega) .
\end{aligned}
$$

Находя значения расширенной частотной передаточной функции объекта $W(m, \omega)$ и подставляя их в формулу (1), получим значения РЧХ регулятора $W_{p}(m, \omega)$. Пусть действительная часть РЧХ регулятора $-R(\omega)$, а мнимая часть $-I(\omega)$, тогда

$W_{p}(m, \omega)=-1 / W(m, \omega)=R(\omega)+j I(\omega)$.

Подставляя в (2) выражения для РЧХ объекта регулирования и регулятора и разрешая систему относительно настроечных параметров регулятора, можно получить уравнение ЛРЗ в параметрическом виде, где параметром является частота $\omega$. Произведем вывод расчетных соотношений ЛРЗ для случая типового общепромышленного ПИДрегулятора, рассматривая остальные законы регулирования как частный случай ПИД-закона. В отличие от приведенных в $[6,7]$ соотношений для описания дифференциальной составляющей ПИДрегулятора используется не идеальное, а реальное дифференцирующее звено [6]. Запишем РЧХ ПИДрегулятора:

$$
W_{p}(m, \omega)=K_{1}+\frac{K_{0}}{(j-m) \omega}+\frac{K_{2}(j-m) \omega}{T_{\phi}(j-m) \omega+1} .
$$

Избавляясь от комплексности в знаменателе второй и третьей частей уравнения, получим: 


$$
\begin{aligned}
& W_{p}(m, \omega)=K_{1}-\frac{m K_{0}}{\left(m^{2}+1\right) \omega}+ \\
& +\frac{K_{2} m \omega\left[T_{\phi} \omega(m+1)-1\right]}{\left(1-T_{\phi} m \omega\right)^{2}+T_{\phi}^{2} \omega^{2}}+ \\
& +j\left[\frac{K_{2} \omega}{\left(1-T_{\phi} m \omega\right)^{2}+T_{\phi}^{2} \omega^{2}}-\frac{K_{0}}{\left(m^{2}+1\right) \omega}\right] .
\end{aligned}
$$

Приравнивая действительную часть выражения (4) к $R(\omega)$, а мнимую к $I(\omega)$ и решая систему этих двух уравнений относительно пропорциональной $K_{1}$ и интегральной $K_{0}$ настроек, получим уравнения ЛР3 для системы с ПИД-регулятором в виде

$$
\left\{\begin{array}{l}
K_{1}=R(\omega)-m I(\omega)+\frac{K_{2} m \omega\left[2-T_{\phi} \omega(m+1)\right]}{\left(1-T_{\phi} m \omega\right)^{2}+T_{\phi}^{2} \omega^{2}}, \\
K_{0}=-I(w)\left(m^{2}+1\right) \omega+\frac{K_{2}\left(m^{2}+1\right) \omega^{2}}{\left(1-T_{\phi} m \omega\right)^{2}+T_{\phi}^{2} \omega^{2}} .
\end{array}\right.
$$

При $K_{2}=0$ получим уравнения ЛРЗ для системы с ПИ-регулятором. Подставляя в (5) $K_{0}=0$, получим уравнения ЛРЗ для системы с ПД-регулятором:

$$
\left\{\begin{array}{l}
K_{1}=R(\omega)+m I(\omega)\left[1-T_{\phi} \omega(m+1)\right], \\
K_{2}=I(\omega)\left[\left(1-T_{\phi} m \omega\right)^{2}+T_{\phi}^{2} \omega^{2}\right] / \omega .
\end{array}\right.
$$

Приведем текст программы для нахождения настроек регуляторов методом РЧХ $[8,9]$ в среде Matlab:

\section{clear \\ close all}

clc

$W=t f\left(\left[\begin{array}{lll}3 & 3\end{array},\left[\begin{array}{lll}1 & 2 & 2\end{array}\right]\right)\right.$

$m=0.3 \%$ степень колебательности

$w=[0.1: 0.1: 7] ; \%$ диапазон частот

$t z=4 ; \%$ желаемое время регулирования

sigz=32; \% желаемое перегулирование

Tf=0; \% постоянная времени фильтра

[num,den] =tfdata $\left(W,{ }^{\prime} v^{\prime}\right)$;

$r=\operatorname{roots}($ den $)$;

Wreg=-polyval(den, $(j-m) * w) . / p o l y v a l(n u m,(j-m) * w) ; \%$ P лятора

$R=\operatorname{real}($ Wreg); \% действительная часть $Р Ч Х$ регулятора

I=imag(Wreg); \% мнимая часть РЧХ регулятора

$K 2=\left[\begin{array}{lllllll}0 & 0.2 & 0.4 & 0.6 & 1 & 2 & 5\end{array}\right]$

$n=$ length $(K 2)$;

for $i=1: n \%$ по настройкам $K 2$

znam $=\left(1-T f^{*} m^{*} w\right) . \wedge 2+\left(T f^{*} w\right) . \wedge 2$;

$K 1=R-m * I+m * K 2(i) * w . *\left(2-T f^{*}(m+1) * w\right) . / z n a m$

$K O=-\left(m^{\wedge} 2+1\right) * I . * w+\left(\left(m^{\wedge} 2+1\right) * K 2(i) * w . * w\right) . /$ znam;

kp=0; K1_plus=[]; K0_plus=[]; \% положсительные

настройки

for $j=1$ :length $(K 1)$

if $(K 1(j)>0) \& \&(K 0(j)>0) \& \&\left(K 0(j) * K 2(i) / K 1(j)^{\wedge} 2<=0.25\right)$

$k p=k p+1$;

$K 1 \_p l u s(k p)=K 1(j) ; K 0 \_p l u s(k p)=K O(j)$;

end;

end;

if (length $\left(K 1 \_\right.$plus $\left.)>0\right)$

figure(1)

plot(K1 plus, KO plus, 'm')

grid on; title('График ЛР3 KO=f(K1)'); $x$ label('K1(\omega)');

ylabel('KO( \omega)');

hold on krit=[];

for $k=1: k p$

$W P I D=t f\left(\left[K 2(i)+T f^{*} K 1 \_p l u s(k) K 1 \_p l u s(k)+T f^{*} K 0 \_p l u s(k)\right.\right.$

KO_plus $(k)],[$ Tf 10$]$ )

Wzam =feedback $\left(W^{*} W P I D, 1,-1\right)$;

$\operatorname{krit}(k)=\operatorname{Jkrit}(W z a m, t z, \operatorname{sigz}, m)$;

end;

$[\mathrm{J} \min , \mathrm{kmin}]=\min (\mathrm{krit})$;

K1_min $=K 1 \_p l u s($ kmin $)$;

KO_min $=K 0 \_$plus $(\mathrm{kmin})$;

K1_opt $(i)=K 1 \_m i n$;

KO_opt $(i)=K 0 \_$min;

Jopt $(i)=J$ min;

Wreg_opt $=t f\left(\left[K 2(i)+T f^{*} K 1 \_\right.\right.$min $K 1 \_m i n+T f^{*} K 0 \_$min

KO_min],[Tf 10$])$

plot(K1 min, KO min,'--rs', 'MarkerEdgeColor', 'k','Marker-

FaceColor',' 'g','MarkerSize',8)

Wzam_opt=feedback $\left(W^{*}\right.$ Wreg_opt $\left., 1,-1\right)$;

$[y, t]=$ step $($ Wzam_opt $)$;

figure(2)

$\operatorname{plot}\left(t, y,{ }^{\prime} b{ }^{\prime}\right)$

grid on; title('График переходного процесса замкнутой системы');

xlabel(' $t$ '); ylabel $\left(' y(t)^{\prime}\right)$; hold on

chars=Quality $($ Wzam_opt $)$; chars_opt $(i)=$ chars;

end:

end;

[Jbest,kbest] $=\min ($ Jopt $)$

K1_best=K1_opt (kbest); K0_best=K0_opt (kbest);

$K 2 \_$best $=K 2$ (kbest);

Wreg best $=t f\left(\left[K 2\right.\right.$ best $+T f^{*} K 1$ best $K 1$ best $+T f^{*} K 0$ best

KO_best],[Tf 10$]$ )

figure (1)

inf=strcat $($ K1=',num2str(K1_best, '\%0.1f'),'

$K 0={ }^{\prime}$, num $2 \operatorname{str}\left(K 0 \_b e s t,{ }^{\prime} \% 0.1 f^{\prime}\right), \ldots$

'; K2=',num2str(K2_best, $\left.\left.{ }^{\prime} \% 0.1 f^{\prime}\right)\right)$;

text $\left(1.05^{*} K 1 \_\right.$best,KO_best, [ Vontsize $\{10\}$ ',inf], 'BackgroundCol-

or', $\left.\left.^{\prime}, 7.9 .7\right]\right)$;

figure(2)

Wzam_best=feedback $\left(W^{*}\right.$ Wreg_best $\left., 1,-1\right)$;

$[y, t]=\operatorname{step}($ Wzam_best $)$;

plot $\left(t, y,{ }^{\prime} r^{\prime}\right)$

inf $=$ strcat $\left(\backslash\right.$ sigma $={ }^{\prime}$, num 2 str $\left(\right.$ chars_opt $($ kbest $\left.) . p e r e r e g,{ }^{\prime} \% 0.1 f^{\prime}\right),{ }^{\prime} \%$;

$t={ }^{\prime}, \ldots$

num2str(chars_opt(kbest).tproc, '\%0.1 $\left.f^{\prime}\right),{ }^{\prime} c ; m={ }^{\prime}$

num 2 str(chars opt(kbest).m, '\%0.2f')),

text $\left(0.6^{*}\right.$ t(end),0.1,[Vontsize\{12\}',inf], 'BackgroundColor', [.7 .9 .7]);

Семейство ЛРЗ для приведенных в программе значений $K_{2}$ представлено на рисунке 1 .

При расчете использована колебательная передаточная функция объекта регулирования $W(p)=$ $=3 /\left(p^{2}+2 p+2\right)$.

Для выбора оптимальных настроек регулятора используется критерий, характеризующий минимальное отклонение перерегулирования $\sigma$, времени $t_{p}$ и степени колебательности $m$ переходного процесса замкнутой системы с регулятором от их заданных значений, соответственно $\sigma_{\text {зад., }} t_{\text {зад. }}$ и $m_{\text {зад.: }}$ :

$$
J=\frac{\left|\sigma-\sigma_{\text {зад. }}\right|}{\sigma_{\text {зад. }}}+\frac{\left|t_{p}-t_{\text {зад. }}\right|}{t_{\text {зад. }}}+\frac{\left|m-m_{\text {зад. }}\right|}{m_{\text {зад. }}} .
$$

Текст функции Jkrit для расчета критерия оптимальности:

function $J=J k r i t(W z a m, t z$, sigz,m)

chars $=$ Quality $($ Wzam $)$;

$J=a b s($ chars.tproc- $t z) / t z+a b s$ (chars.perereg-

sigz)/sigz+abs(chars.m-m)/m; 


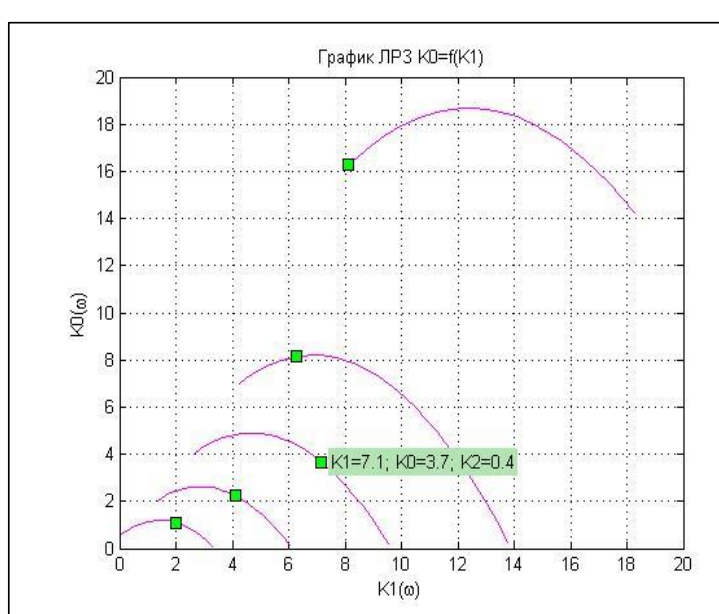

Рис. 1. Семейство ЛРЗ при выборе ПИД-регулятора

Fig. 1. The equal damping line family when choosing PID controller

Определение характеристик качества chars производится с помощью функции Quality, текст которой выглядит следующим образом:

function chars=Quality (sysw)

$\left[\right.$ numw, denw] $=t$ fdata $\left(\right.$ sysw, ' $\left.v^{\prime}\right)$;

chars.numw $=$ numw; chars. den $w=$ denw;

$[y, t]=\operatorname{step}($ sysw $)$;

chars. $y=y$; chars. $t=t$;

$\max y=\max (y) ; n p=$ length $(y) ; y y s t=y(n p)$;

if yyst $<=1 . E-3$ chars.perereg $=1 . E 6$;

else chars.perereg $=($ maxy-yyst $) / y y s t * 100 ;$ end;

chars.tproc $=t(n p)$;

$p=$ pole (sysw);

chars.roots $=p$;

$r e=\operatorname{real}(p) ; \operatorname{im}=\operatorname{imag}(p)$;

re_im $=a b s($ nonzeros $(\operatorname{diag}(i m \sim=0) * r e) . /$ nonzeros $(\mathrm{im}))$;

if isempty(re_im) chars. $m=1 . E 6$;

else chars.m=min(re_im); end;

На рисунке 2 показаны наилучшие по критерию (7) переходные процессы для каждой из линий равного затухания и оптимальный процесс, удовлетворяющий требуемым характеристикам качества.

Недостатком приведенного метода РЧХ является сведение пространственной задачи нахождения настроек ПИД-регулятора $K_{1}, K_{0}, K_{2}$ к решению двухмерной задачи в области параметров $K_{1}, K_{0}$ при фиксированных значениях $K_{2}$. В связи с этим в качестве дальнейшего развития метода РЧХ можно предложить переход от набора параметров $\left(K_{1}, K_{0}\right.$, $\left.K_{2}\right)$ к набору $\left(K_{1}, T_{\text {д }} / T_{u}, T_{u}\right)$, где $T_{u}=K_{1} / K_{0}$ и $T_{\text {д }}=K_{2} / K_{1}$ - постоянные времени, соответственно интегрирования и дифференцирования. Кроме того, метод работает некорректно, если желаемая степень колебательности системы $m$ больше степени колебательности объекта $m_{\text {об. }}$

Полученные результаты расчета настроек регуляторов можно использовать для оптимального

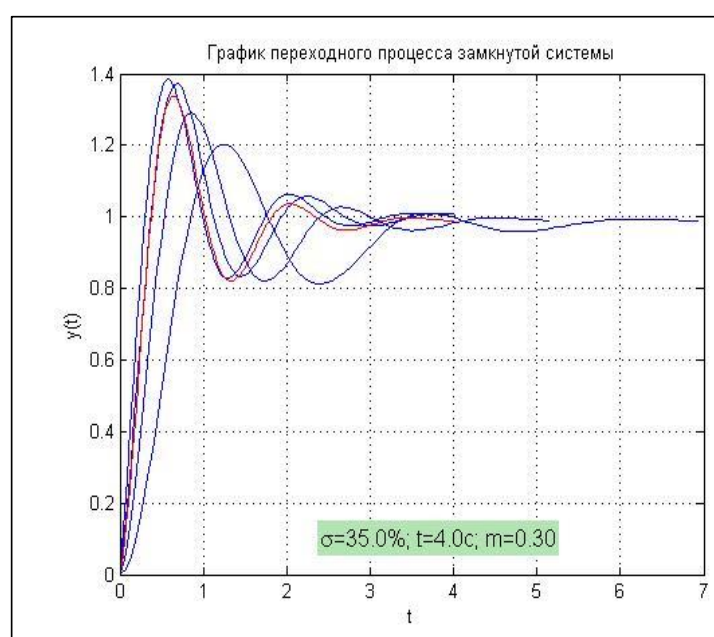

Рис. 2. Семейство переходных проиессов для настроек ПИД-регуляторов

Fig. 2. The transient process family for PID controller settings

управления объектами в технологических процесcax, а также распространить на многоконтурные системы управления [10].

Наличие в Matlab возможностей удобной работы с массивами и графического вывода данных позволяет эффективно использовать эту среду программирования для решения задач нахождения оптимальных настроек регуляторов.

\section{Лuтература}

1. Иванов В.А., Медведев В.С., Чемоданов Б.К., Ющенко А.С. Математические основы теории автоматического управления. М.: Изд-во МГТУ им. Н.Э. Баумана, 2006. Т. 1. 551 с.

2. Писарев А.В., Новиков С.И. Сравнительные исследования расчетных методов определения параметров настроек промышленных ПИД-регуляторов // Энергетика и теплотехника: Сб. науч. тр. 2007. Вып. 11. С. 191-200.

3. Денисенко В. ПИД-регуляторы: вопросы реализации. Ч. 2 // Современные технологии автоматизации. 2008. № 1. C. $86-97$.

4. Смирнов Н.И., Сабанин В.Р., Репин А.И. Структурная и параметрическая оптимизация каскадных САР с использованием эволюционных алгоритмов // Автоматизация и IT в энергетике. 2010. № 5. С. 26-34.

5. Ротач В.Я. Теория автоматического управления. М.: Изд-во МЭИ, 2005. 396 с.

6. Марголис Б.И. Компьютерные методы анализа и синтеза систем автоматического регулирования в среде Matlab. Тверь: Изд-во ТГТУ, 2015. 92 с.

7. Токарев В.В., Ягубов 3.Х., Приезжаев А.Б., Скабкин Н.Г. Расчет оптимальных параметров промышленных автоматических систем регулирования. Ухта: Изд-во УГТУ, 2003. $84 \mathrm{c}$.

8. Лазарев Ю. Моделирование процессов и систем в MATLAВ. СПб: Питер, 2005. 512 с.

9. Дьяконов В.П. MATLAB 7.*/ R2006/ R2007: самоучитель. М.: ДМК Пресс, 2008. 768 с.

10. Марголис Б.И., Мешков И.С. Синтез регуляторов в каскадных системах автоматического управления // Вестн. ТвГТУ. 2016. Вып. 29. № 1. С. 74-79. 


\section{A program for calculation of controller settings by the method of advanced frequency characteristics}

B.I. Margolis ${ }^{1}$, Dr.Sc. (Engineering) Head of Chair Automation of technological processes, borismargolis@yandex.ru G.A.Mansour ${ }^{1}$, Graduate Student, gubran_ali@mail.ru

${ }^{1}$ Tver State Technical University, Tver, 170026, Russian Federation

Abstract. The paper considers the problem of calculating settings of typical general industrial controllers in automatic control systems for technological objects. It shows the possibility of applying the Nyquist stability criterion for extended system frequency characteristics. It also formulates the problem of ensuring the necessary quality of a transient process in a closed system due to the provision of the given degree of oscillation. The obtained condition for the given system oscillation ensures that the controller settings are located on the equal damping line. The paper considers the extended frequency characteristic of the PID controller for the case when a component is introduced into it as a real differentiating element. The authors have obtained the formulas for finding PID controller settings using extended frequency characteristics in the form of parametric dependencies. There are also relations obtained from general formulas for PI and PD controllers.

A program developed in MatLab based on the proposed method allows calculating optimal controller settings by the criterion of minimum deviation of transient time and overshoot from the set values. There are also the results of calculating PID controller settings for a control example and the obtained equal damping lines.

The paper presents the best transient processes for each of the equal damping lines and the optimal process satisfying the required quality characteristics. It also shows the disadvantages of the method of extended frequency characteristics in the proposed formulation. The paper considered the possibilities of alternative formulation of the problem of synthesizing controller settings and the application of the proposed methods for finding controller settings in multi-loop systems for automatic control of technological objects.

Keywords: automatic control system, object, controller, calculation of settings, extended frequency response, transient response, oscillation degree, equal damping line, calculation program, optimal settings, overshoot, quality criteria.

\section{References}

1. Ivanov V.A., Medvedev V.S., Chemodanov B.K., Yushchenko A.S. Mathematical Foundations of the Theory of Automatic Control. Moscow, Bauman MSTU Publ., 2006, vol. 1, 551 p.

2. Pisarev A.V., Novikov S.I. Comparative studies of calculation methods for determining the parameters of industrial PID controllers. Proc. "Power and Heat Engineering”. 2007, iss. 11, pp. 191-200 (in Russ.).

3. Denisenko V. PID controllers: implementation issues. Part 2. Modern Automation Technologies. 2008, no. 1, pp. 86-97 (in Russ.).

4. Smirnov N.I., Sabanin V.R., Repin A.I. Structural and parametric optimization of cascaded ATS using evolutionary algorithms. Automation and IT in Power Engineering. 2010, no. 5, pp. $26-34$ (in Russ.).

5. Rotach V.Ya. Theory of Automatic Control. Moscow, MPEI Publ., 2005, 396 p

6. Margolis B.I. Computer Methods of Analysis and Synthesis of Automatic Control Systems in Matlab. Tver, TGTU Publ., 2015, 92 p.

7. Tokarev V.V., Yagubov Z.Kh., Priezzhaev A.B., Skabkin N.G. Calculation of Optimal Parameters of Industrial Automatic Control Systems. Ukhta, USTU Publ., 2003, 84 p.

8. Lazarev Yu. Modeling Processes and Systems in MATLAB. St.-Petersburg, Piter Publ., 2005, 512 p.

9. Dyakonov V.P. MATLAB 7.*/ R2006/ R2007: Teach Yourself. Moscow, DMK Press, 2008, 768 p.

10. Margolis B.I., Meshkov I.S. Synthesis of Controllers in Cascade Control Systems. Bulletin of TSTU. 2016, iss. 29, no. 1, pp. 74-79 (in Russ.). 
Мультиагентное моделирование процессов распространения массовых эпидемий с использованием суперкомпъютеров

\author{
C.Ю. Аапшина 1, начальник научно-организаиионного отдела, lapshina@jscс.ru \\ 1 Межведомственный суперкомпьютерный иентр РАН - филиал ФНЦ НИИСИ РАН, \\ 2. Москва, 119334, Россия
}

В статье рассматривается возможность использования современных суперкомпьютеров при решении ресурсоемких задач мультиагентного моделирования процессов распространения массовых эпидемий на основе теории роста перколяционных кластеров.

Мультиагентная перколяционная модель в задачах определения карантинных зон при распространении эпидемий предполагает формирование решетки взаимодействия представителей популяции, моделирование среды распространения заболевания, сбор информации о численности населения, реализацию параллельного алгоритма многократной маркировки перколяционных кластеров с механизмом линковки меток, визуализацию полученных результатов.

Описываются усовершенствованный для применения на многопроцессорной системе вариант алгоритма многократной маркировки перколяционных кластеров Хошена-Копельмана, а также действующий прототип его реализации, разработанный в МСЦ РАН. Данный алгоритм может быть использован в любой области в качестве инструмента дифференцирования кластеров решетки большого размера, так как ему на вход подаются данные в не зависимом от приложения формате.

Демонстрируется возможность выявления зависимостей латентных периодов распространения эпидемий от вероятности инфицирования агрегатов популяционных представителей и формирования пороговых значений перехода локальных эпидемий в крупномасштабные пандемии. Задав латентный период, вероятность инфицирования и очаг заражения, можно определить круг городов, где можно ожидать инфицирование. Эта информация используется для определения радиуса карантинной зоны. Если в некотором городе обнаружен очаг заболевания и латентный период уже закончился, то с помощью данного инструмента определяется зона, которую нужно изолировать от внешнего мира.

В работе приводятся оценки времени выполнения алгоритма многократной маркировки перколяционных кластеров Хошена-Копельмана при различных значениях входных параметров на двух высокопроизводительных вычислительных системах, установленных в МСЦ РАН, - МВС-100К и МВС-10П.

Ключевые слова: мультиагентное моделирование, теория перколяции, перколяционный кластер, распространение эпидемий, высокопроизводительные вычислительные системы.

В практике компьютерного моделирования поведения сложных систем часто проявляется феномен скачкообразного и лавинообразного изменения характеристик поведения системы под воздействием плавных изменений одного или нескольких ключевых параметров. Так, при исследовании распространения массовых эпидемий относительно малые изменения значений одного или нескольких параметров (например, вероятности инфицирования) могут привести к скачкообразному изменению поведения всей системы (заболевание локального характера становится широкомасштабным). Одним из интересных и эффективных инструментов исследования подобных ситуаций является метод построения и анализа роста перколяционных кластеров.

Теория перколяции достаточно подробно описывает процессы на виртуальных решетках, по отношению к ним доказан ряд строгих утверждений. Для реализации широкомасштабных приложений подобных процессов эффективно используются возможности современных суперкомпьютерных технологий. Что, в свою очередь, требует разработки соответствующих моделей компьютерной имитации, в том числе мультиагентных [1-3], а также специализированных алгоритмов распараллеливания $[4,5]$.
Агентный подход в разработке имитационных моделей применяется во всех случаях, когда именно индивидуальное поведение объектов является существенным в системе, а интегральные характеристики и динамика всей системы выводятся из этих особенностей. Под агентом понимается некая сущность, которая обладает активностью, автономным поведением, может принимать решения в соответствии с определенными правилами, взаимодействовать с окружением и другими агентами, а также изменяться (эволюционировать) [6-8]. Агентные модели используются для исследования децентрализованных систем, динамика функционирования которых определяется не глобальными правилами и законами, а наоборот, эти глобальные правила и законы являются результатами индивидуальной активности агента или группы агентов. Цель агентной модели - получить представление об этих глобальных правилах, исходя из предположений об индивидуальном, частном поведении ее активных объектов и взаимодействии этих объектов в системе.

При создании агентной модели логика поведения агентов и их взаимодействие не всегда могут быть выражены чисто графическими средствами, часто приходится использовать программный код. Обычно для этих целей применяется язык Java. 
С применением положений теории перколяции в МСЦ РАН - филиале ФНЦ НИИСИ РАН был разработан действующий прототип реализации алгоритма многократной маркировки перколяционных кластеров (ММПК) Хошэна-Копельмана [9] на языке Си с использованием библиотеки MPI. Он позволяет выделить связные подграфы (кластеры) некоторого графа (решетки), а также выяснить, к какому кластеру относится тот или иной узел решетки. Алгоритм был адаптирован для применения на многопроцессорной системе. Данный вариант алгоритма совпадает с однопроцессорным вариантом за одним исключением: вместо прохода по всей решетке каждый процессор активизирует действия алгоритма ММК только на выделенной ему группе узлов с последующим обменом информацией между процессорами.

Разработанный прототип был использован для исследования возникновения и распространения широкомасштабных эпидемий. Для формирования анализируемой решетки использовались общедоступные демографические данные о численности населения городов всего мира и некоторые предположения об интенсивности и характере взаимодействия между людьми. Для получения сведений о численности населения городов был разработан алгоритм обработки и анализа карт плотности населения (реализация на языке јаva). Сами карты были позаимствованы у Google при помощи Google Maps API, а для удобства восприятия результатов имитационных экспериментов были разработаны соответствующие средства визуализации.

\section{Принципиальная схема действующего прототипа}

Действующий прототип реализации алгоритма многократной маркировки перколяционных кластеров Хошэна-Копельмана, разработанный в МСЦ РАН, состоит из этапов, представленных на рисунке 1.

При помощи алгоритма сбора информации о численности населения (обработчик карт МарManager) были получены данные о городах мира и сохранены в БД в формате «номер города, численность населения, широта, долгота». БД городов содержит информацию о 56976 городах с общей численностью населения 6114628510 человек.

С помощью алгоритма формирования решетки взаимодействия представителей популяции (построитель графа GridBuilder) была создана исходная решетка (реализация на јаva) и сохранена в трех файлах: решетка grid размера 475 Мб и 2 файла edges 1 и edges 2 - ребра общим размером 429 Мб. Для каждого значения входного изменяемого параметра вероятности заражения при контакте с больным (параметр $p=0,01-1,00$ с шагом 0,01) исходной решетки в оперативной памяти формируется анализируемая решетка.
Далее проводилась разбивка графа соседних городов на связанные подмножества алгоритмом Хошена-Копельмана (маркировка кластеров Load). Для каждой анализируемой решетки запускался алгоритм ММК. Работу алгоритма можно разделить на три этапа.

Эman. 1. Инициализация: первый процесс загружает решетку в оперативную память из файла, преобразует ее по входным параметрам, распределяет узлы в группы по процессам и отсылает им. Остальные процессы ждут получения своей группы узлов. Получив такую группу, процессы выделяют из них подгруппу внешне связанных узлов, то есть узлов, связанных с узлами из групп других процессов. Для каждого узла своей группы задаются начальные значения меток в соответствии с абсолютным (в рамках всей решетки) номером узла. Каждый процесс создает группу внешних уз-

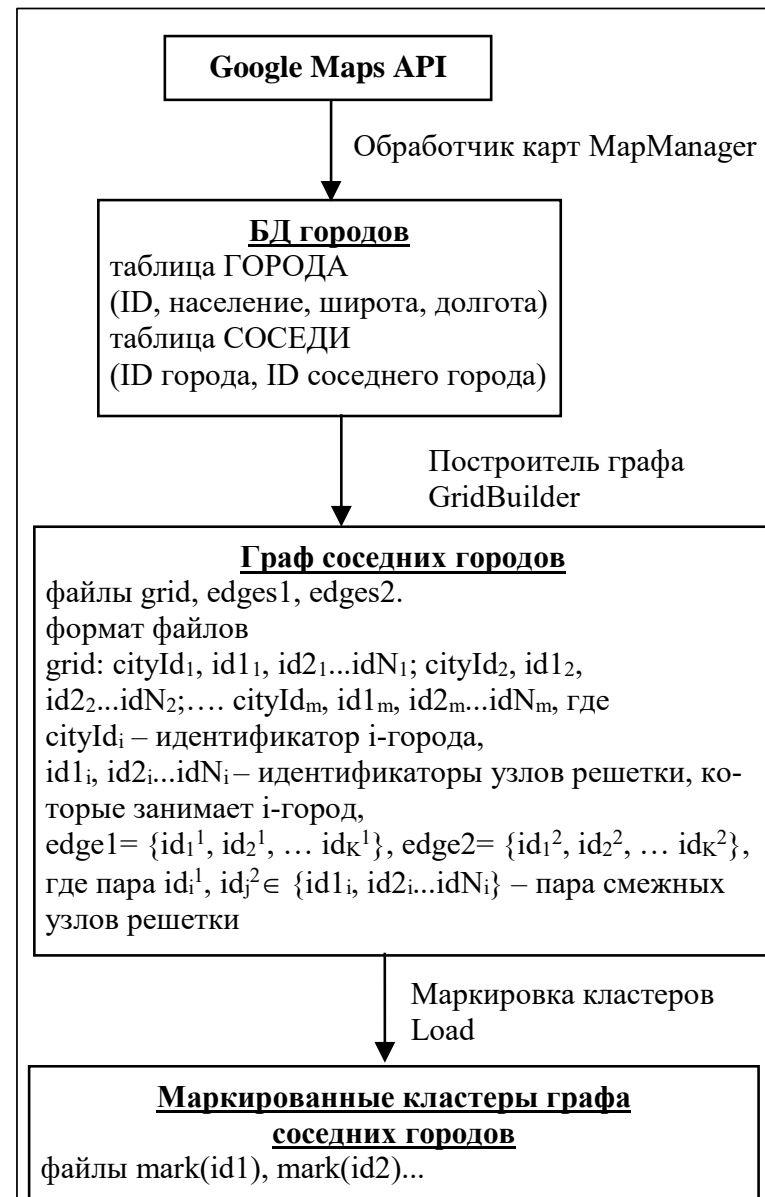

Преобразователь кластеров GridTransformer

Визуализация результатов по выбранному городу

файлы .html c javaScript кодом для Google Maps API

Pис. 1. Схема действующего прототипа

Fig. 1. The scheme of the working prototype 
лов, связанных с узлами своей группы, и инициализирует их метками связанных узлов своей группы.

Эman 2. Работа собственно алгоритма. Каждый процесс запускает алгоритм ММК на своей группе узлов.

Эman 3. Обмен информацией. Происходит в несколько шагов до тех пор, пока после очередного обмена метки узлов всех процессов не перестанут изменяться. Обмен информацией можно разделить на три шага. Первый шаг - каждый процесс посылает значения меток узлов из подгруппы внешне связанных узлов тем процессам, с которыми эти узлы связаны. Второй шаг - каждый процесс принимает значения меток от процессов, имеющих узлы, связанные с узлами данного. Эти значения присваиваются меткам узлов из группы внешних узлов. Если хоть одна из меток узлов из внешней группы была изменена, процесс должен повторить обмен информацией. Все метки узлов своей группы, равные замененным меткам внешней группы, должны быть также заменены. Третий шаг - отправка сообщения первому процессу о том, должен или нет данный процесс повторить обмен информацией с другими процессами. Первый процесс получает от всех процессов подобную информацию. Если все процессы не нуждаются в повторном обмене, первый процесс рассылает всем остальным сигнал о завершении работы всего алгоритма и начинает процедуру сбора данных по меткам их узлов. Если же хоть один процесс прислал сообщение, что ему необходимо продолжить обмен, всем процессам придется повторить процедуру обмена информацией.

В качестве результата маркировки кластеров был получен массив кластерных меток (с индексами от 1 до 100). Размер каждого сохраненного массива составляет около 24 Мб.

Программа маркировки кластеров Load запускалась в Межведомственном суперкомпьютерном центре на суперкомпьютере МВС-100К с общим количеством процессорных ядер 13004 на 48264 процессорах. Среднее время выполнения программы с входным параметром $p$ от 0,01 до 1 с шагом в 0,01 при постоянных значениях $t=1,3,5,10$, $15,20,25,30$ дней составило около 10 минут для каждого значения $t[10]$.

На суперкомпьютере МBC-10П с общим количеством процессорных ядер 28704 среднее время выполнения этой программы составило около 5 минут.

На следующем этапе проводился имитационный эксперимент с определенным городом (преобразователь кластеров GridTransformer). Визуализация полученных результатов в модели проводится с помощью Google Maps Api (реализация на java).

Выбирался город - очаг заражения, задавалось количество зараженных узлов в этом городе, и для данных $p$ и $t$ загружался вычисленный ранее массив кластерных меток. После определения меток зараженных узлов выбранного города проводился последовательный обход меток всех узлов из загруженного массива. Если метка являлась потенциально зараженной, то город, в который входил узел с данной меткой, также объявлялся потенциально зараженным. Таким образом формировался список потенциально зараженных городов. Этот список coxранялся в виде JavaScript-команд Google Maps API в html-файле. В зависимости от численности населения зараженный город помечался красным кругом определенного размера. Для визуализации результатов html-файл запускался в браузере.

\section{Результаты моделирования попыток предсказания распространения массовых эпидемий}

На рисунке 2 демонстрируется результат проведения численного эксперимента при размещении очага заражения в г. Токио, который является ближайшим крупным населенным пунктом к возможным местам вскрытия и расконсервации захоронений бактериологических отходов (под воздействием тектонических разломов, резкого потеп-

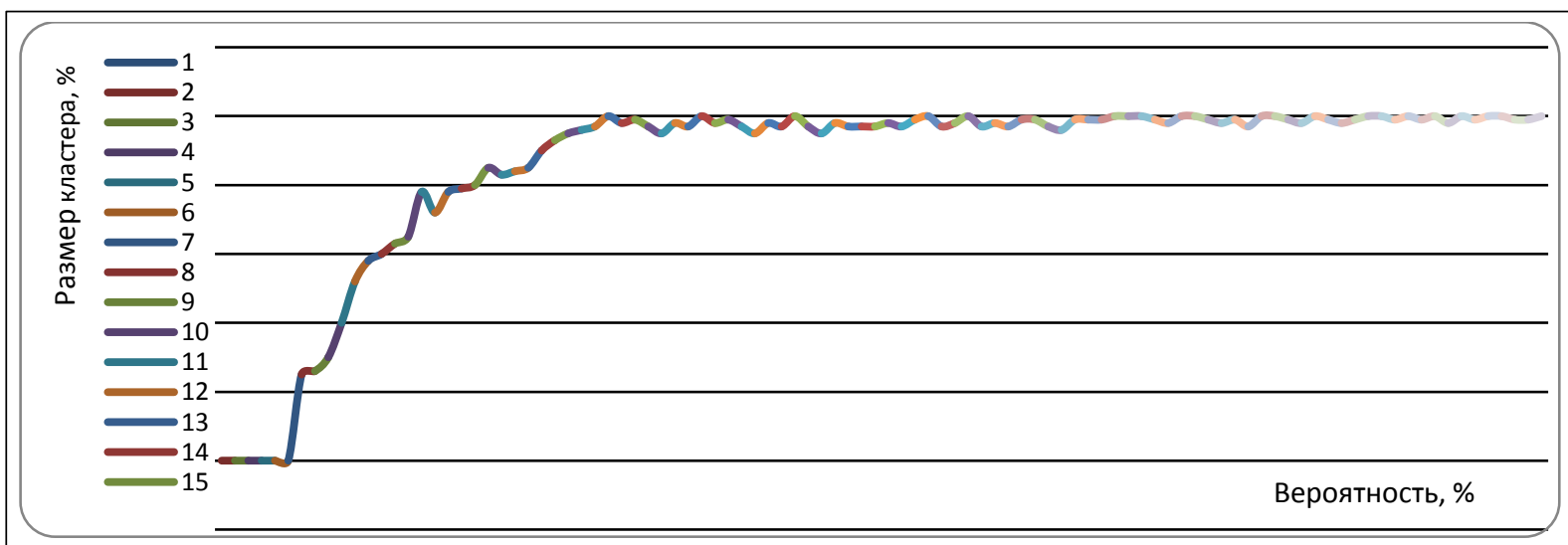

Рис. 2. Вероятность инфицирования в районе г. Токио

Fig. 2. The chance of infection in Tokyo's district 
ления, террористических актов, промышленных аварий и т.д.).

Как видно, максимальная вероятность инфицирования в районе Токио достигает $\sim 0.3$, то есть уже при вероятности инфицирования 0.3 эпидемия за счет высокой плотности населения в регионе может превратиться в широкомасштабную пандемию.

На рисунке 3 продемонстрированы результаты имитационных экспериментов при возникновении очага заражения в районе г. Токио.

В период с 5-го по 7-й день виден резкий скачок размера потенциально зараженного кластера и эпидемия имеет все шансы распространиться по миру.

Проводились численные эксперименты и с размещением очага заражения в городах России. На рисунке 4 продемонстрированы результаты имитационных экспериментов при возникновении очага заражения в районе г. Иваново. Результаты показывают, что даже при более высокой вероятности инфицирования и более длительном периоде, чем в Токио, эпидемия в стадию пандемии не переходит.

Расчеты проводились в Межведомственном суперкомпьютерном центре Российской академии наук на высокопроизводительных вычислительных системах МВC-100К и МВС-10П.
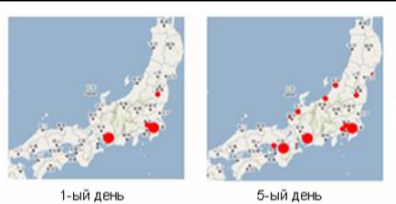

жалььныи счаг инфицирования = 100 уалов

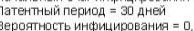

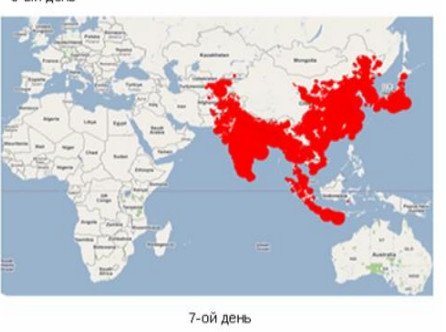

Рис. 3. Очаг заражения в районе г. Токио на 1-й, 5-й и 7-й день развития эпидемии

Fig. 3. The site of infection in Tokyo's district on the 1st, 5th and 7 th day of epidemic development

Работа выполнена в МСЦ РАН в рамках государственного задания по теме «Разработка архитектур, системных решений и методов для создания вычислительных комплексов и распределенных сред мультипетафлопсного диапазона производительности, в том числе нетрадиционных архитектур микропрочессоров» (№ 0065-2018-0409).

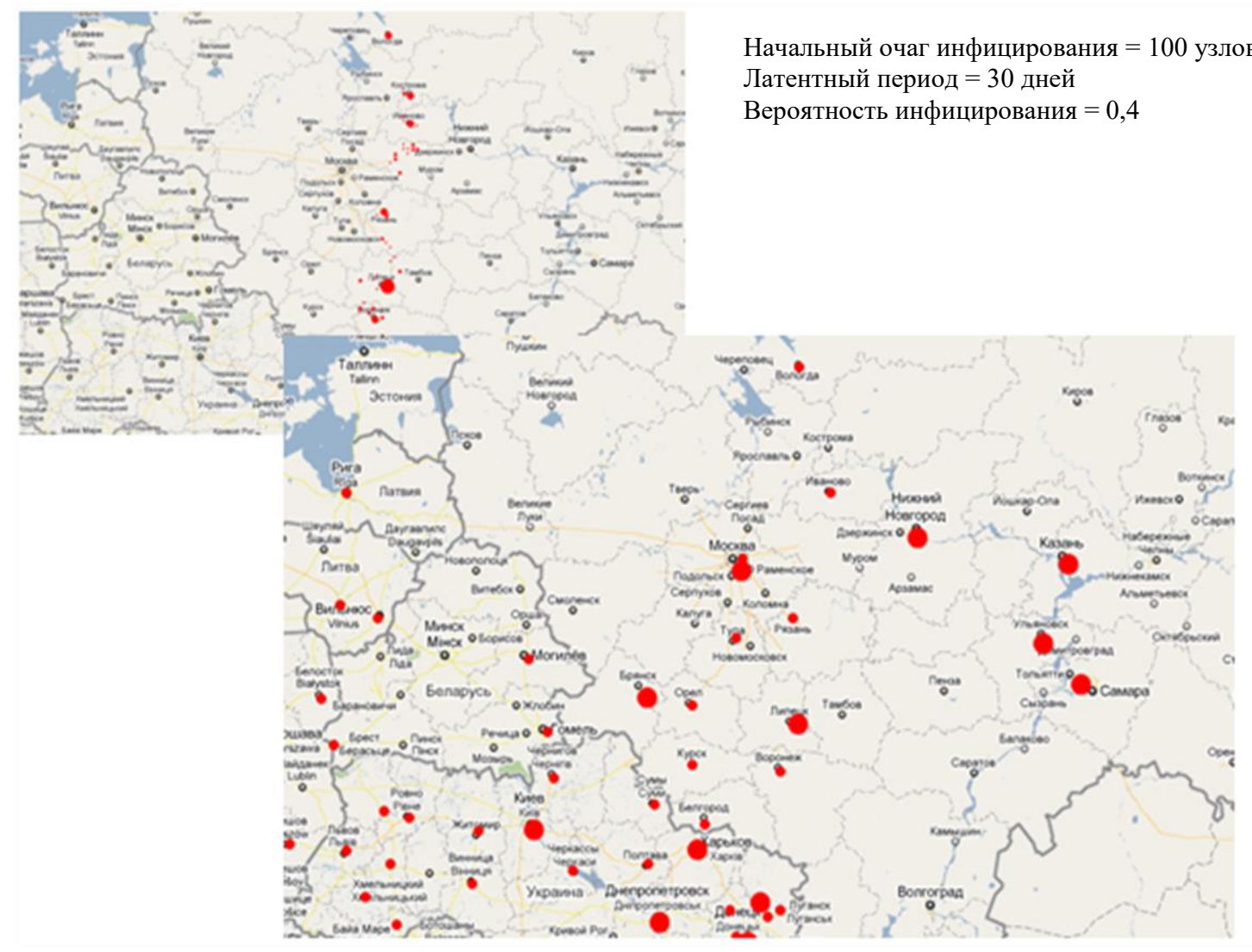

Рис. 4. Очаг заражения в районе г. Иваново на 5-й и 20-й день развития эпидемии

Fig. 4. The site of infection in Ivanovo's district on the $5^{\text {th }}$ and 20 th day of epidemic development 


\section{Литература}

1. Калихман Р.С., Шебеко Ю.А. Моделирование роста перколяционных кластеров на компьютерах с сильно выраженной параллельной архитектурой // Вычислительные технологии: сб. науч. тр. СО РАН. 1995. Т. 4. № 10. 344 с.

2. Кондратьев М.А., Ивановский Р.И., Цыбалова Л.М. Применение агентного подхода к имитационному моделированию процесса распространения заболевания // Науч.-технич. ведомости СПбГУ. 2010. Т. 2. № 2. С. 189-195.

3. Тарасевич Ю.Ю. Перколяция: теория, приложения, алгоритмы. М.: УРСС, 2002. 64 с.

4. Korneev V., Semenov D., Kiselev A., Shabanov B., Telegin P. Multiagent distributed Grid scheduler. Proc. Federated Conf. on Comp. Sc. and Inform. Syst., 2011, pp. 577-580.

5. Телегин П.Н. Настройка выполнения параллельных про- грамм // Программные продукты и системы. 2012. № 4. С. 25-30.

6. Карпов Ю.Г. Имитационное моделирование систем. Введение в моделирование с AnyLogic 5. СПб: БХВ-Петербург. 2005. $400 \mathrm{c}$.

7. Утакаева И.Х. Имитационное моделирование распространения эпидемий на основе агентного подхода // Науч. журн. КубГАУ. 2016. № 121. URL: http://ej.kubagro.ru/2016/07/pdf/ 85.pdf (дата обращения: 04.03.2018).

8. Боев Б.В. Прогнозно-аналитические модели эпидемий. M., 2005. $10 \mathrm{c}$.

9. Лапшина С.Ю. Высокопроизводительные вычисления в практике моделирования роста перколяционных кластеров // Программные продукты и системы. 2011. № 4. С. 75-79.

10. Клинов М.С., Лапшина С.Ю., Телегин П.Н., Шабанов Б.М. Особенности использования многоядерных процессоров в научных вычислениях // Вестн. УГАТУ. 2012. Т. 16. № 6. С. 25-31.

\title{
Multi-agent simulation of epidemics' distribution on supercomputers
}

\author{
S.Yu. Lapshina ${ }^{1}$, Head of the Scientific-organizational Department, lapshina@jscc.ru
}

${ }^{1}$ Joint Supercomputer Center of RAS, Moscow, 119991, Russian Federation

Abstract. The paper considers the possibility of using modern supercomputers to solve resource-intensive problems of multi-agent simulation of the advance of mass epidemics based on the percolating cluster growth theory.

In the problems of determining quarantine zones in advance of epidemics a multi-agent percolation model supposes the formation of an interaction grid of population representatives, modeling of a disease distribution medium, the collection of information on the population size, the implementation of a parallel algorithm for multiple marking of percolating clusters with a tagging mechanism, and result visualization.

The article describes an improved variant of the algorithm of multiple marking of Hoshen-Kopelman percolation clusters for a multiprocessor system, as well as a working prototype of its implementation developed at the JSCC RAS (Branch of SRISA). This algorithm can be used in any area as a tool for differentiating large-size lattice clusters, since it has the input in a format that is independent of the application.

The paper demonstrates the possibility of revealing the dependencies of latent periods of epidemic spread on the probability of infecting aggregates of population representatives and the formation of threshold values for the transition of local epidemics into large-scale pandemics. After setting a latent period, the chance and the source of infection one can determine the range of cities where infection can be expected. This information is used to determine the radius of a quarantine zone. If a hotbed of disease is found in some city and the latent period has already ended, then this tool might help to determine a zone to be isolated from the outside world.

The article also provides estimates of the execution time of the multiple-labeling algorithm for Hoshen-Kopelman percolating clusters for different values of input parameters in two high-performance computing systems installed in the MSC RAS - MVS-100K and MVS-10P.

Keywords: multi-agent simulation, theory of percolation, percolating cluster, advance of an epidemic, high-performance computing systems.

Acknowledgements. The work has been done in the Joint Supercomputer Center of RAS within the framework of the state assignment "Development of architectures, system solutions and methods for creating computational complexes and distributed environments of the multipetaflop performance range including non-traditional microprocessor architectures" (no. 0065-2018-0409).

\section{References}

1. Kalikhman R.S., Shebeko Yu.A. Modeling the growth of percolating clusters on computers with a strongly pronounced parallel architecture. Computational Technologies: Proc. SB RAS. 1995, vol. 4, no. 10, 344 p. (in Russ.).

2. Kondratev M.A., Ivanovsky R.I., Tsybalova L.M. Application of the agent approach to the simulation of the spread of the disease. Sci. and Tech. Reports of the Peter the Great St. Petersburg Polytechnic Univ. 2010. vol. 2, no. 2, pp. 189-195 (in Russ.).

3. Tarasevich Yu.Yu. Percolation: Theory, Applications, Algorithms. Moscow, URSS Publ., 2002, 64 p.

4. Korneev V., Semenov D., Kiselev A., Shabanov B., Telegin P. Multiagent Distributed Grid Scheduler. Proc. of the Federated Conf on Computer Science and Information Systems. 2011, pp. 577-580.

5. Telegin P.N. Configuring the Execution of Parallel Programs. Software \& Systems. 2012, no. 4, pp. 25-30 (in Russ.). $400 \mathrm{p}$.

6. Karpov Yu.G. System Simulation. Introduction to Modeling with AnyLogic 5. St. Petersburg, BHV-Peterburg Publ., 2005,

7. Utakaeva I.Kh. Simulation modeling of distribution of epidemics on the basis of agent approach. Scientific J. of KubSAU. 2016, no. 121. Available at: http://ej.kubagro.ru/2016/07/pdf/85.pdf (accessed March 4, 2018).

8. Boev B.V. Predictive-Analytical Models of Epidemics. Moscow, 2005, $10 \mathrm{p}$.

9. Lapshina S.Yu. High-performance computing in the practice of modeling the growth of percolating clusters. Software \& Systems. 2011, no. 4, pp. 75-79 (in Russ.).

10. Klinov M.S., Lapshina S.Yu., Telegin P.N., Shabanov B.M. Features of Using Multi-Core Processors in Scientific Computing. Bulletin of USATU. 2012, vol. 16, no. 6, pp. 25-31 (in Russ.). 


\section{СОДЕРЖ АН И}

Ефремов И.А., Мамросенко К.А., Решетников В.Н.

Методы разработки драйверов графической подсистемы.

Генов А.А., Русаков К.Д., Моисеев А.А., Осипов В.В.

Исследование сжатия растровых изображений с использованием искусственных нейронных сетей

Мадера А.Г., Кандалов П.И.

Принципы построения программного комплекса для теплового проектирования

электронных систем.

Родителев А.В., Гиацинтов А.М.

Высокоуровневая архитектура тренажерно-обучающих систем сложных

технических комплексов

Пранов Б.М.

Адекватные междисциплинарные модели в прогнозировании

временных рядов статистических данных

Усманов З.Д.

Моделирование восприятия мозгом анаграммно искаженного текста

\section{Лисецкий Ю.М.}

Модели сопровождения информационных систем предприятия

по этапам жизненного цикла

Баранов А.В., Молоканов В.В., Телегин П.Н., Тихомиров А.И.

Применение метода английского аукциона при планировании заданий

с абсолютными приоритетами в распределенной вычислительной системе

Галатенко В.А., Дзабраев М.Д., Костюхин К.А.

Выбор пакетного менеджера для многоверсионных приложений 469

\section{Масальский H.B.}

Температурная модель распределения потенциала в неравномерно легированных нанотранзисторах со структурой кремний на изоляторе

Афанаскин И.В., Королев А.В., Юдин В.А.

Использование метода математического моделирования для оценки влияния

смачиваемости пород на нефтеотдачу на примере внутрипластового горения

Островский Э.Я., Румянцев С.В., Фадеев В.А.

Развитие алгоритма спонтанного структурирования цифровых изображений природных комплексов

Афранаскин И.В., Вольпин С.Г., Ломакина О.В., Штейнберг Ю.М.

Интерпретация межскважинных исследований карбонатных коллекторов

методом двух режимов с помощью численных моделей.

Болодурина И.П., Парфенов Д.И.

Подходы к идентификации сетевых потоков и организации маршрутов трафика

в виртуальном центре обработки данных на базе нейронной сети

Кузнецов А.С., Корнюшко В.Ф.

Алгоритмическое обеспечение обработки данных процесса структурирования эластомерного композита с целью решения задачи управления

Тхан В.З., Дементьев Ю.Н., Гончаров В.И.

Повышение точности расчета систем автоматического управления с запаздыванием 
Грибова В.В., Клещев А.С., Москаленко Ф.М., Тимченко В.А., Федорищев Л.А., Шалфеева Е.A.

Облачная платформа IACPaaS для разработки оболочек интеллектуальных сервисов: состояние и перспективы развития

Гончаров А.А., Семенов Н.A.

Повышение скорости логического вывода продукционных экспертных систем путем использования аспектно-ориентированного подхода

Татарникова Т.М., Журавлев А.М.

Нейросетевой метод обнаружения вредоносных программ на платформе Android

Пальчевский Е.В., Халиков А.P.

Автоматизированная система защиты доступности информации от атак

внешним несанкционированным трафиком в UNIX-подобных системах

Коломойцев В.С., Богатырев В.A.

Эффрективность поэтапного применения средств защиты с пересечением

областей обнаружения угроз.

Дерендяев Д.А., Гатчин Ю.А., Безруков В.А.

Алгоритм оценки значения остаточных рисков угроз информационной безопасности

с учетом разделения механизмов защиты на типы

Гладков Л.А., Лейба С.Н., Тарасов В.Б.

Разработка и программная реализация гибридного алгоритма решения

оптимизационных задач автоматизированного проектирования

Карпов В.Э., Ровбо М.А., Овсянникова Е.E.

Система моделирования поведения групп робототехнических агентов

с элементами социальной организации Кворум .

Рыбаков М.Н., Чагрова Л.А.

Алгоритмическая неразрешимость проблемы первопорядковой определимости формул логики ветвящегося времени

Игнатьев С.В., Плакса Ю.А., Красников А.В., Дрожжин А.В.

Модель группировки радиоэлектронных систем для оценки временных

показателей надежности

Радаев А.В., Коробов А.В., Яцало Б.И.

F-Ranking: компьютерная система для ранжирования нечетких чисел

Канюков С.И., Коновалов А.В., Муйземнек О.Ю.

Входной язык системы автоматизированного проектирования поковок типа валов

Клячкин В.Н., Кувайскова Ю.Е., Иванова А.В.

Система статистического анализа и контроля стабильности вибраций гидроагрегата

Лебедев И.В., Тыртышников А.Ю., Иванов С.И., Меньшутина Н.В.

Моделирование нанопористых структур кремний-резорцинол-фрормальдегидных

аэрогелей

Шамлицкий Я.И., Охота А.С., Мироненко С.Н.

Моделирование транспортных потоков в среде AnyLogic

Марголис Б.И., Мансур Г.А.

Программа расчета настроек регуляторов методом расширенных частотных характеристик ..... 636

Лапшина С.Ю.

Мультиагентное моделирование процессов распространения массовых эпидемий

с использованием суперкомпьютеров 


\section{O N T E N T}

Efremov I.A., Mamrosenko K.A., Reshetnikov V.N.

Methods of developing graphics subsystem drivers.

Genov A.A., Rusakov K.D., Moiseev A.A., Osipov V.V.

Research on compression of raster images using artificial neural networks

Madera A.G., Kandalov P.I.

Principles of software construction for electronic system thermal design

Roditelev A.V., Giatsintov A.M.

High-level architecture of training simulation systems of complex technical systems.

Pranov B.M.

Adequate interdisciplinary models in forecasting time series of statistical data

Usmanov Z.D.

Modeling brain activity recognizing anagrammatically distorted words 448

Lisetskiy Yu.M.

Models of enterprise information system support in lifecycle stages.

Baranov A.V., Molokanov V.V., Telegin P.N., Tikhomirov A.I.

The English auction method for job scheduling with absolute priorities

in a distributed computing system.

Galatenko V.A., Dzabraev M.D., Kostyukhin K.A.

A package manager for multiversion applications 469

Masalsky N.V.

Temperature model of potential distribution for non-uniform doping nanotransistors

with the silicon-on-insulator structure.....

Afanaskin I.V., Korolev A.V., Yudin V.A.

A mathematical model approach for evaluation of oil recovery changes caused by wettability during in-situ combustion

Ostrovsky E. Ya., Rumyantsev S.V., Fadeev V.A.

Development of the spontaneous structuring algorithm of natural complex digital images 495

Afanaskin I.V., Volpin S.G., Lomakina O.V., Shteynberg Yu.M.

Carbonate reservoirs crosswell survey interpretation by a two-rate test using numerical models. 500

Bolodurina I.P., Parfenov D.I.

The approaches to identification of network flows and organization of traffic routes

in a virtual data center based on a neural network.

Kuznechov A.S., Kornyushko V.F.

Algorithmic ware of data processing for elastomer composite structuring

to solve a control problem

Than V.D., Dementev Yu.N., Goncharov V.I.

Improving the accuracy calculation of time delay automatic control

Gribova V.V., Kleschev A.S., Moskalenko F.M., Timchenko V.A., Fedorischev L.A., Shalfeeva E.A.

IACPaaS cloud platform for the development of intelligent service shells: current state and future evolution 
Goncharov A.A., Semenov N.A.

Improving logical inference speed of production expert systems

using aspect-oriented approach .

Tatarnikova T.M., Zhuravlev A.M.

A neural network method for detecting malicious programs on the Android platform

Palchevsky E.V., Khalikov A.R.

An automated system of information accessibility protecting from attacks by unauthorized traffic

in UNIX-like systems

Kolomoitsev V.S., Bogatyrev V.A.

The effectiveness of stage-by-stage use of securirty means crossing threat detection areas

Derendyaev D.A., Gatchin Yu.A., Bezrukov V.A.

An algorithm of information security residual risk assessment taking into account

a protection mechanisms separation by types

Gladkov L.A., Leyba S.N., Tarasov V.B.

A hybrid algorithm for solving optimization problems of computer-aided design

and its software implementation.

Karpov V.E., Rovbo M.A., Ovsyannikova E.E.

Kvorum - the system for modeling the behavior of robotic agent groups

with elements of social organization.

Rybakov M.N., Chagrova L.A.

Algorithmic undecidability of the problem of first-order correspondence

of computational tree logic formulas

Ignatev S.V., Plaksa Yu.A., Krasnikov A.V., Drozhin A.V.

A nested model of radio-electronic systems for estimation of temporary reliability

Radaev A.V., Korobov A.V., Yatsalo B.I.

F-Ranking: a computer system for ranking fuzzy numbers

Kanyukov S.I., Konovalov A.V., Muyzemnek O.Yu.

Input language of a computer-aided system for shaft forging

Klyachkin V.N., Kuvayskova Yu.E., Ivanova A.V.

The system of statistical analysis and control of hydraulic unit vibration stability.....

Lebedev I.V., Tyrtyshnikov A.Yu., Ivanov S.I., Menshutina N.V.

Modeling nanoporous structures of silica-resorcinol-formaldehyde aerogels.

Shamlicky Ya.I., Okhota A.S., Mironenko S.N.

Modeling traffic flows in AnyLogic.

Margolis B.I., Mansour G.A.

A program for calculation of controller settings by the method

of advanced frequency characteristics

Lapshina S.Yu.

Multi-agent simulation of epidemics' distribution on supercomputers. 
Brumaruna nagnucmeale

Международный журнал

«Программные продукты и системы»

распространяется по подписке

в странах СНГ и за их пределами.

В Каталоге подписных изданий

Агентства «Роспечать» индекс журнала

70799

Телебоон (482-2) 39-91-49

Факс (482-2) 39-91-00

WWW.sWSYS.ru

red@cps.tver.ru 